\title{
STATE OF THE CLIMATE IN 2011
}

Special Supplement to the

Bulletin of the American Meteorological Society Vol. 93, No. 7, July 2012
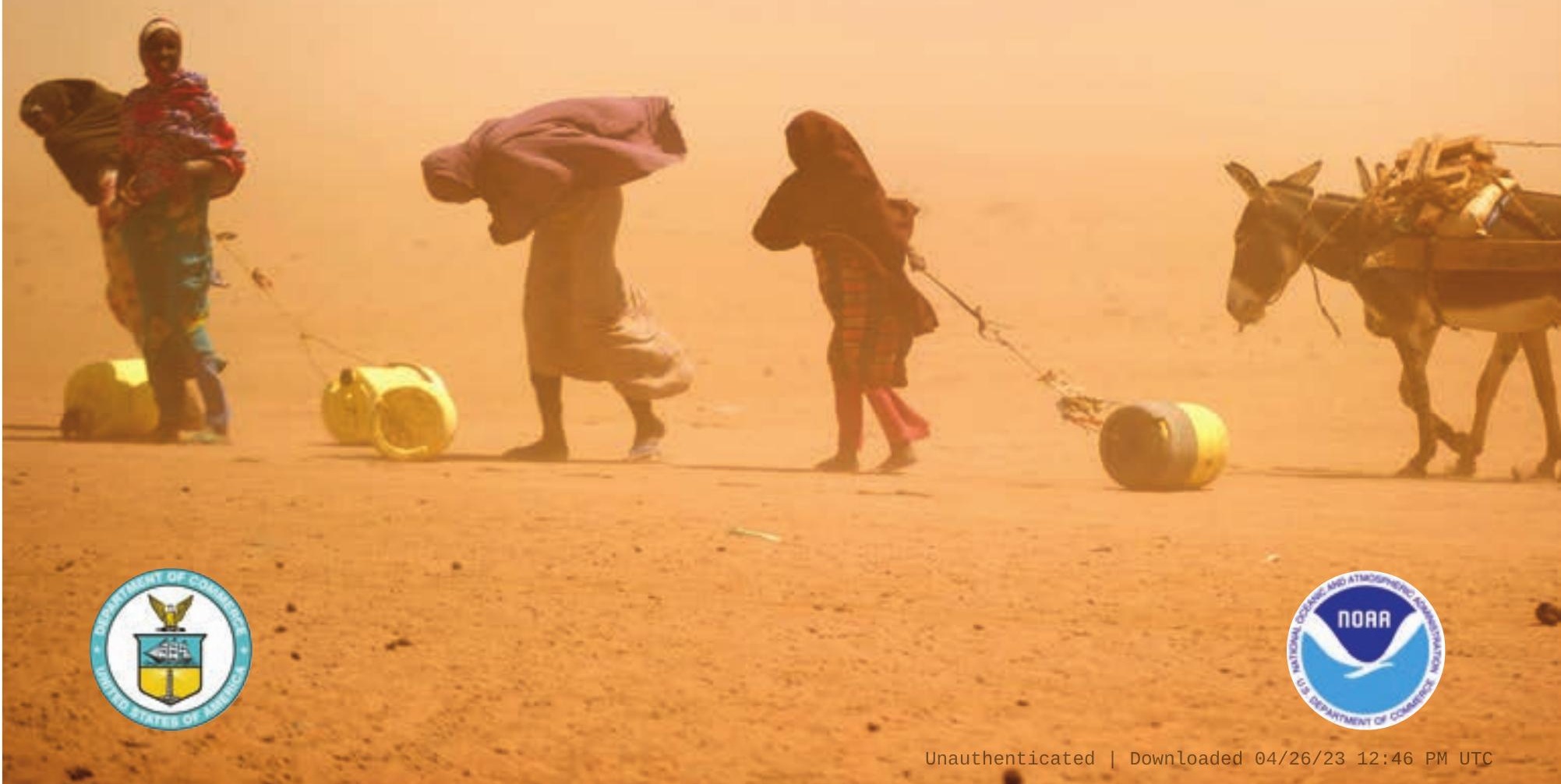


\title{
STATE OF THE CLIMATE IN 2011
}

\section{Editors}

\author{
Jessica Blunden \\ Derek S. Arndt
}

\section{Associate Editors}

Howard J. Diamond
A. Johannes Dolman
Ryan L. Fogt
Margarita C. Gregg
Bradley D. Hall

\author{
Martin O. Jeffries \\ Michele L. Newlin \\ James A. Renwick \\ Jacqueline A. Richter-Menge \\ Ahira Sánchez-Lugo
}

Ted A. Scambos

Wassila M. Thiaw

Peter W. Thorne

Scott J. Weaver

Kate M. Willett 
Copies of this report can be downloaded from doi: 10.I175/2012BAMSStateoftheClimate.I and http://www.ncdc.noaa. gov/bams-state-of-the-climate/

This report was printed on $85 \%-100 \%$ post-consumer recycled paper.

Cover credits:

Front: (Jakob Dall Photography — Wajir, Kenya, July 20II

Back: ( Jonathan Wood/Getty Images — Rockhampton, Queensland, Australia, January 20II

Citing the complete report:

Blunden, J., and D. S. Arndt, Eds., 2012: State of the Climate in 20II. Bull. Amer. Meteor. Soc., 93 (7), SI-S264.

Citing a chapter (example):

Gregg, M. C., and M. L. Newlin, Eds., 2012: Global oceans [in "State of the Climate in 20II”]. Bull. Amer. Meteor. Soc., 93 (7), S57-S92.

Citing a section (example):

Johnson, G. C., and J. M. Lyman, 2012: [Global oceans] Sea surface salinity [in "State of the Climate in 20II”]. Bull. Amer. Meteor. Soc., 93 (7), S68-S69. 


\section{EDITOR \& AUTHOR AFFILIATIONS (ALPHABETICAL BY NAME)}

Achberger, C., Earth Sciences Centre, University of Gothenburg, Gothenburg, Sweden

Ackerman, Steven A., CIMSS University of Wisconsin Madison, Madison, Wisconsin

Ahmed, Farid H., Direction de la Météo Nationale Comorienne, Comores

Albanil-Encarnación, Adelina, National Meteorological Service of Mexico, Mexico

Alfaro, Eric J., Center for Geophysical Research and School of Physics, University of Costa Rica, San Jose, Costa Rica

Allan, Rob, Met Office Hadley Centre, Exeter, United Kingdom

Alves, Lincoln M., Centro de Ciencias do Sistema Terrestre (CCST), Instituto Nacional de Pesquisas Espaciais (INPE), Cachoeira Paulista, Sao Paulo, Brazil

Amador, Jorge A., Center for Geophysical Research and School of Physics, University of Costa Rica, San Jose, Costa Rica

Ambenje, Peter, Kenya Meteorological Department (KMD), Nairobi, Kenya

Antoine, M. David, Laboratoire d'Océanographie de Villefranche, Villefranche-sur-Mer, France

Antonov, John, NOAA/NESDIS National Oceanographic Data Center, Silver Spring, Maryland

Arévalo, Juan, Instituto Nacional de Meteorología e Hidrología de Venezuela (INAMEH), Caracas, Venezuela

Arndt, Derek S., NOAA/NESDIS National Climatic Data Center, Asheville, North Carolina

Ashik, I., Arctic and Antarctic Research Institute, St. Petersburg, Russia

Atheru, Zachary, IGAD Climate Prediction and Applications Centre (ICPAC), Nairobi, Kenya

Baccini, Alessandro, The Woods Hole Research Center, Falmouth, Massachusetts

Baez, Julian, DMH-DINAC/CTA-UCA, Asunción, Paraguay

Banzon, Viva, NOAA/NESDIS National Climatic Data Center, Asheville, North Carolina

Baringer, Molly O., NOAA/OAR Atlantic Oceanographic and Meteorological Laboratory, Miami, Florida

Barreira, Sandra, Argentine Naval Hydrographic Service, Buenos Aires, Argentina

Barriopedro, D. E., Centro de Geofísica da Universidade de Lisboa, Lisbon, Portugal

Bates, John J., NOAA/NESDIS National Climatic Data Center, Asheville, North Carolina

Becker, Andreas, Global Precipitation Climatology Centre, Duetscher Wetterdienst, Offenbach am Main, Germany

Behrenfeld, Michael J., Oregon State University, Oregon

Bell, Gerald D., NOAA/NWS Climate Prediction Center, Camp Springs, Maryland
Benedetti, Angela, European Centre for Medium-Range Weather Forecasts, Reading, United Kingdom

Bernhard, Germar, Biospherical Instruments, San Diego, California

Berrisford, Paul, NCAS Climate, European Centre for Medium Range Weather Forecasts, Reading, United Kingdom

Berry, David I., National Oceanography Centre, Southampton, United Kingdom

Beszczynska-Moeller, A., Alfred Wegener Institute, Bremerhaven, Germany

Bhatt, U. S., Geophysical Institute, University of Alaska Fairbanks, Fairbanks, Alaska

Bidegain, Mario, Unidad de Ciencias de la Atmósfera, Universidad de la República, Uruguay

Bieniek, P., Geophysical Institute, University of Alaska Fairbanks, Fairbanks, Alaska

Birkett, Charon, Earth System Science Interdisciplinary Research Center, University of Maryland at College Park, College Park, Maryland

Bissolli, Peter, Deutscher Wetterdienst (German Meteorological Service, DWD), Offenbach, Germany; and WMO RA VI Regional Climate Centre on Climate Monitoring, Offenbach, Germany

Blake, Eric S., NOAA/NWS National Hurricane Center, Miami, Florida

Blunden, Jessica, ERT Inc., NOAA/NESDIS National Climatic Data Center, Asheville, North Carolina

Boudet-Rouco, Dagne, Institute of Meteorology of Cuba, Havana, Cuba

Box, Jason E., Byrd Polar Research Center, The Ohio State University, Columbus, Ohio

Boyer, Tim, NOAA/NESDIS National Oceanographic Data Center, Silver Spring, Maryland

Braathen, Geir O., WMO Atmospheric Environment Research Division, Geneva, Switzerland

Brackenridge, G. Robert, CSDMS, INSTAAR, University of Colorado, Boulder, Colorado

Brohan, Philip, Met Office Hadley Centre, Exeter, United Kingdom

Bromwich, David H., Byrd Polar Research Center, The Ohio State University, Columbus, Ohio

Brown, Laura, Interdisciplinary Centre on Climate Change and Department of Geography \& Environmental Management, University of Waterloo, Waterloo, Ontario, Canada

Brown, R., Climate Research Division, Environment Canada, Montreal, Quebec, Canada

Bruhwiler, Lori, NOAA/Earth System Research Laboratory, Boulder, Colorado 
Bulygina, O. N., Russian Institute for Hydrometeorological Information, Obninsk, Russia

Burrows, John, University of Bremen, Bremen, Germany

Calderón, Blanca, Center for Geophysical Research, University of Costa Rica, San Jose, Costa Rica

Camargo, Suzana J., Lamont-Doherty Earth Observatory, Columbia University, Palisades, New York

Cappellen, John, Danish Meteorological Institute, Copenhagen, Denmark

Carmack, E., Institute of Ocean Sciences, Sidney, British Columbia, Canada

Carrasco, Gualberto, Servicio Nacional de Meteorología e Hidrología de Bolivia (SENAMHI), La Paz, Bolivia

Chambers, Don P., College of Marine Science, University of South Florida, St. Petersburg, Florida

Christiansen, Hanne H., Geology Department, University Centre in Svalbard, UNIS, Norway; and Department of Geosciences, University of Oslo, Oslo, Norway

Christy, John, University of Alabama in Huntsville, Huntsville, Alabama

Chung, D., Institute for Photogrammetry and Remote Sensing, Vienna University of Technology, Vienna, Austria

Ciais, P., Laboratoire des Sciences du Climat et de l'Environnement (LSCE), CEA-CNR-UVSQ, Gif-sur-Yvette, France

Coehlo, Caio A. S., CPTEC/INPE, Center for Weather Forecasts and Climate Studies, Cachoeira Paulista, Brasil

Colwell, Steve, British Antarctic Survey, Cambridge, United Kingdom

Comiso, J., Cryospheric Sciences Branch, NASA Goddard Space Flight Center, Greenbelt, Maryland

Cretaux, Jean-Francois, Laboratoire d'Études en Géophysique et Océanographie Spatiales, Toulouse, France

Crouch, Jake, NOAA/NESDIS National Climatic Data Center, Asheville, North Carolina

Cunningham, Stuart A., National Oceanography Centre, Southampton, United Kingdom

De Jeu, Richard A. M., Earth and Climate Cluster, Department of Earth Sciences, Faculty of Earth and Life Sciences, VU University Amsterdam, Amsterdam, Netherlands

Demircan, M., Turkish State Meteorological Service, Ankara, Turkey

Derksen, C., Climate Research Division, Environment Canada, Toronto, Ontario, Canada

Diamond, Howard J., NOAA/NESDIS National Climatic Data Center, Silver Spring, Maryland

Dlugokencky, Ed J., NOAA/Earth System Research Laboratory, Boulder, Colorado

Dohan, Kathleen, Earth and Space Research, Seattle, Washington
Dolman, A. Johannes, Department of Earth Sciences, Faculty of Earth and Life Science, VU University Amsterdam, Amsterdam, Netherlands

Dorigo, Wouter A., Institute for Photogrammetry and Remote Sensing, Vienna University of Technology, Vienna, Austria

Drozdov, D. S., Earth Cryosphere Institute, Tumen, Russia

Duguay, Claude, Interdisciplinary Centre on Climate Change and Department of Geography \& Environmental Management, University of Waterloo, Waterloo, Ontario, Canada

Dutton, Ellsworth, NOAA/Earth System Research Laboratory, Boulder, Colorado

Dutton, Geoff S., Cooperative Institute for Research in Environmental Sciences, University of Colorado, Boulder, Colorado

Elkins, James W., NOAA/Earth System Research Laboratory, Boulder, Colorado

Epstein, H. E., Department of Environmental Sciences, University of Virginia, Charlottesville, Virginia

Famiglietti, James S., UC Center for Hydrologic Modeling, Earth System Science, Civil and Environmental Engineering, University of California, Irvine, California

Fanton d'Andon, Odile Hembise, ACRI-ST, France

Feely, Richard A., NOAA/OAR Pacific Marine Environmental Laboratory, Seattle, Washington

Fekete, Balázs M., CUNY Environmental CrossRoads Initiative, The City College of New York at CUNY, New York

Fenimore, Chris, NOAA/NESDIS National Climatic Data Center, Asheville, North Carolina

Fernández-Prieto, D., European Space Agency, ESRIN, Frascati, Italy

Fields, Erik, University of California, Santa Barbara, Santa Barbara, California

Fioletov, Vitali, Environment Canada, Toronto, Ontario, Canada

Fogt, Ryan L., Department of Geography, Ohio University, Athens, Ohio

Folland, Chris, Met Office Hadley Centre, Exeter, United Kingdom

Foster, Michael J., CIMSS University of Wisconsin Madison, Madison, Wisconsin

Frajka-Williams, Eleanor, National Oceanography Centre, Southampton, United Kingdom

Franz, Bryan A., NASA Goddard Space Flight Center, Greenbelt, Maryland

Frey, Karen, Graduate School of Geography, Clark University, Worcester, Massachusetts

Frith, Stacey H., NASA Goddard Space Flight Center, Greenbelt, Maryland

Frolov, I., Arctic and Antarctic Research Institute, St. Petersburg, Russia 
Frost, G. V., Department of Environmental Sciences, University of Virginia, Charlottesville, Virginia

Ganter, Catherine, Bureau of Meteorology, Melbourne, Australia

Garzoli, Silvia, NOAA/OAR Atlantic Oceanographic and Meteorological Laboratory, Miami, Florida

Gitau, Wilson, Department of Meteorology, University of Nairobi, Kenya

Gleason, Karin L., NOAA/NESDIS/National Climatic Data Center, Asheville, North Carolina

Gobron, Nadine, Climate Risk Management Unit, Institute for Environment and Sustainability (IES), European Commission Joint Research Centre, Ispra, Italy

Goldenberg, Stanley B., NOAA/OAR Atlantic Oceanographic and Meteorological Laboratory, Miami, Florida

Goni, Gustavo, NOAA/OAR Atlantic Oceanographic and Meteorological Laboratory, Miami, Florida

González-García, Idelmis, Institute of Meteorology of Cuba, Havana, Cuba

González-Rodríguez, Nivaldo, Institute of Meteorology of Cuba, Havana, Cuba

Good, Simon A., Met Office Hadley Centre, Exeter, United Kingdom

Goryl, Philippe, European Space Agency, Italy

Gottschalck, Jonathan, NOAA/NWS Climate Prediction Center, Camp Springs, Maryland

Gouveia, C. M., Centro de Geofísica da Universidade de Lisboa, Lisbon, Portugal

Gregg, Margarita C., NOAA/NESDIS National Oceanographic Data Center, Silver Spring, Maryland

Griffiths, Georgina M., NIWA, Auckland, New Zealand

Grigoryan, Valentina, Climate Research Division, Armstatehydromet, Armenia

Grooß, Jens-Uwe, Forschungszentrum Jülich, Jülich, Germany

Guard, Chip, Weather Forecast Office, Guam

Guglielmin, Mauro, Insubria University, Varese, Italy

Hall, Bradley D., NOAA/OAR Earth System Research Laboratory, Boulder, Colorado

Halpert, Michael S., NOAA/NWS Climate Prediction Center, Camp Springs, Maryland

Heidinger, Andrew K., NOAA/NESDIS University of Wisconsin Madison, Madison, Wisconsin

Heikkilä, Anu, Finnish Meteorological Institute, Helsinki, Finland

Heim, Richard R., Jr., NOAA/NESDIS National Climatic Data Center, Asheville, North Carolina

Hennon, Paula A., Cooperative Institute for Climate and Satellites, North Carolina State University; and NOAA/NESDIS National Climatic Data Center, Asheville, North Carolina

Hidalgo, Hugo G., Center for Geophysical Research and School of Physics, University of Costa Rica, San Jose, Costa Rica
Hilburn, Kyle, Remote Sensing Systems, Santa Rosa, California Ho, Shu-peng (Ben), UCAR COSMIC, Boulder, Colorado

Hobbs, Will R., Scripps Institution of Oceanography, University of California, San Diego, La Jolla, California

Holgate, Simon, The Permanent Service for Mean Sea Level, National Oceanography Centre, Liverpool, United Kingdom

Hook, Simon J., Jet Propulsion Laboratory, California Institute of Technology, Pasadena, California

Hovsepyan, Anahit, Climate Research Division, Armstatehydromet, Armenia

Hu, Zeng-Zhen, NOAA/NWS Climate Prediction Center, Camp Springs, Maryland

Hugony, Sebastien, MeteoFrance, French Polynesia

Hurst, Dale F., Cooperative Institute for Research in Environmental Sciences, University of Colorado Boulder/NOAA, Boulder, Colorado

Ingvaldsen, R., Institute of Marine Research, Bergen, Norway

Itoh, M., Japan Agency for Marine-Earth Science and Technology, Tokyo, Japan

Jaimes, Ena, Servicio Nacional de Meteorología e Hidrología de Perú (SENAMHI), Lima, Perú

Jeffries, Martin, Geophysical Institute, University of Alaska Fairbanks, Fairbanks, Alaska

Johns, William E., Rosenstiel School of Marine and Atmospheric Science, Miami, Florida

Johnsen, Bjørn, Norwegian Radiation Protection Authority, Østerås, Norway

Johnson, Bryan, NOAA Earth System Research Laboratory, Global Monitoring Division, and University of Colorado, Boulder, Colorado

Johnson, Gregory C., NOAA/OAR Pacific Marine Environmental Laboratory, Seattle, Washington

Jones, L. T., European Centre for Medium-Range Weather Forecasts, Reading, United Kingdom

Jumaux, Guillaume, Météo France, Réunion

Kabidi, Khadija, Direction de la Météorologie Nationale du Maroc, Rabat, Morocco

Kaiser, Johannes W., European Centre for Medium-Range Weather Forecasts, Reading, United Kingdom

Kang, Kyun-Kuk, Interdisciplinary Centre on Climate Change and Department of Geography \& Environmental Management, University of Waterloo, Waterloo, Ontario, Canada

Kanzow, Torsten O., Helmholtz-Centre for Ocean Research Kiel (GEOMAR), Kiel, Germany

Kao, Hsun-Ying, Earth \& Space Research, Seattle, Washington

Keller, Linda M., Department of Atmospheric and Oceanic Sciences, University of Wisconsin-Madison, Madison, Wisconsin

Kendon, Mike, Met Office, Exeter, Devon, United Kingdom 
Kennedy, John J., Met Office Hadley Centre, Exeter, United Kingdom

Kervankıran, Sefer, Turkish State Meteorological Service, Ankara, Turkey

Key, J., NOAA/NESDIS Center for Satellite Applications and Research, Madison, Wisconsin

Khatiwala, Samar, Lamont-Doherty Earth Observatory, Columbia University, Palisades, New York

Kholodov, A. L., Geophysical Institute, University of Alaska Fairbanks, Fairbanks, Alaska

Khoshkam, M., Islamic Republic of Iranian Meteorological Organization (IRIMO), Tehran, Iran

Kikuchi, T., Japan Agency for Marine-Earth Science and Technology, Tokyo, Japan

Kimberlain, Todd B., NOAA/NWS Climate Prediction Center, Camp Springs, Maryland

King, Darren, National Institute of Water and Atmospheric Research Ltd., Auckland, New Zealand

Knaff, John A., NOAA/NESDIS Center for Satellite Applications and Research, Fort Collins, Colorado

Korshunova, Natalia N., All-Russian Research Institute of Hydrometeorological Information - World Data Center, Obninsk, Russia

Koskela, Tapani, Finnish Meteorological Institute, Helsinki, Finland

Kratz, David P., NASA Langley Research Center, Hampton, Virginia

Krishfield, R., Woods Hole Oceanographic Institution, Woods Hole, Massachusetts

Kruger, Andries, South African Weather Service, Pretoria, South Africa

Kruk, Michael C., ERT Corp., NOAA/NESDIS National Climatic Data Center, Asheville, North Carolina

Kumar, Arun, NOAA/NWS Climate Prediction Center, Camp Springs, Maryland

Lagerloef, Gary, Earth \& Space Research, Seattle, Washington

Lakkala, Kaisa, Finnish Meteorological Institute, Arctic Research Centre, Sodankylä, Finland

Lammers, Richard B., Institute for the Study of Earth, Oceans, and Space, University of New Hampshire, Durham, New Hampshire

Lander, Mark A., University of Guam, Mangilao, Guam

Landsea, Chris W., NOAA/NWS National Hurricane Center, Miami, Florida

Lankhorst, Matthias, Jet Propulsion Laboratory, California Institute of Technology, Pasadena, California

Lapinel-Pedroso, Braulio, Institute of Meteorology of Cuba, Havana, Cuba
Lazzara, Matthew A., Space Science and Engineering Center, University of Wisconsin-Madison, Madison, Wisconsin

LeDuc, Sharon, IEDRO, Deale, Maryland

Lefale, Penehuro, Meteorological Service of New Zealand Ltd (MetService), Wellington, New Zealand

León, Gloria, Instituto de Hidrología de Meteorología y Estudios Ambientales de Colombia (IDEAM), Bogotá, Colombia

León-Lee, Antonia, Institute of Meteorology of Cuba, Havana, Cuba

Leuliette, Eric, NOAA/NESDIS Laboratory for Satellite Altimetry, Silver Spring, Maryland

Levitus, Sydney, NOAA/NESDIS National Oceanographic Data Center, Silver Spring, Maryland

L'Heureux, Michelle, NOAA/NWS Climate Prediction Center, Camp Springs, Maryland

Lin, I-I, National Taiwan University, Taipei, Taiwan

Liu, Hongxing, Department of Geography, University of Cincinnati, Cincinnati, Ohio

Liu, Y., Cooperative Institute of Meteorological Satellite Studies, University of Wisconsin, Madison, Wisconsin

Liu, Yanju, Climate Center, China Meteorological Administration, Beijing, China

Liu, Yi, School of Civil and Environmental Engineering, University of New South Wales, Sydney, Australia

Lobato-Sánchez, Rene, National Meteorological Service of Mexico, Mexico

Locarnini, Ricardo, NOAA/NESDIS National Oceanographic Data Center, Silver Spring, Maryland

Loeb, Norman G., NASA Langley Research Center, Hampton, Virginia

Loeng, H., Institute of Marine Research, Bergen, Norway

Long, Craig S., NOAA National Center for Environmental Prediction, Camp Springs, Maryland

Lorrey, Andrew M., National Institute of Water and Atmospheric Research, Ltd., Auckland, New Zealand

Lumpkin, Rick, NOAA/OAR Atlantic Oceanographic and Meteorological Laboratory, Miami, Florida

Lund Myhre, Cathrine, Norwegian Institute for Air Research, Kjeller, Norway

Luo, Jing-Jia, Centre for Australian Weather and Climate Research, Melbourne, Australia

Lyman, John M., NOAA/OAR Pacific Marine Environmental Laboratory, Seattle, Washington; and Joint Institute Marine and Atmospheric Research, University of Hawaii, Honolulu, Hawaii

MacCallum, Stuart, University of Edinburgh, Edinburgh, United Kingdom

Macdonald, Alison M., Woods Hole Oceanographic Institution, Woods Hole, Massachusetts 
Maddux, Brent C., AOS/CIMSS University of Wisconsin Madison, Madison, Wisconsin; and KNMI (Royal Netherlands Meteorological Institute) De Bilt, Netherlands

Manney, Gloria, Jet Propulsion Laboratory, California Institute of Technology, Pasadena, California; and New Mexico Institute of Mining and Technology, Socorro, New Mexico

Marchenko, S. S., Geophysical Institute, University of Alaska Fairbanks, Fairbanks, Alaska

Marengo, José A., Centro de Ciencias do Sistema Terrestre (CCST), Instituto Nacional de Pesquisas Espaciais (INPE), Cachoeira Paulista, Sao Paulo, Brazil

Maritorena, Stephane, University of California, Santa Barbara, Santa Barbara, California

Marotzke, Jochem, Max-Planck-Institut für Meteorologie, Hamburg, Germany

Marra, John J., NOAA/NESDIS National Climatic Data Center, Honolulu, Hawaii

Martínez-Güingla, Rodney, Centro Internacional para la Investigación del Fenómeno El Niño (CIIFEN), Guayaquil, Ecuador

Martínez-Sánchez, Odalys, NOAA National Weather Service, San Juan, Puerto Rico

Maslanik, J., Aerospace and Engineering Sciences, University of Colorado, Boulder, Colorado

Massom, Robert A., Australian Antarctic Division, Kingston, Tasmania, Australia; Antarctic Climate and Ecosystems Cooperative Research Center (ACE CRC), University of Tasmania, Tasmania, Australia

Mathis, Jeremy T., School of Fisheries and Ocean Sciences, University of Alaska Fairbanks, Fairbanks, Alaska

McBride, Charlotte, South African Weather Service, Pretoria, South Africa

McClain, Charles R., NASA Goddard Space Flight Center, Greenbelt, Maryland

McGrath, Daniel, Cooperative Institute for Research in Environmental Studies, University of Colorado-Boulder, Boulder, Colorado

McGree, Simon, Australian Bureau of Meteorology, Melbourne, Australia

McLaughlin, F., Institute of Ocean Sciences, Sidney, British Columbia, Canada

McVicar, Tim R., CSIRO Land and Water, Canberra, Australia

Mears, Carl, Remote Sensing Systems, Santa Rosa, California

Meier, W., National Snow and Ice Data Center, Cooperative Institute for Research in Environmental Sciences, University of Colorado, Boulder, Colorado

Meinen, Christopher S., NOAA/OAR Atlantic Oceanographic and Meteorological Laboratory, Miami, Florida

Menéndez, Melisa, Environmental Hydraulic Institute, Universidad de Cantabria, Santander, Spain
Merchant, Chris, University of Edinburgh, Edinburgh, United Kingdom

Merrifield, Mark A., Joint Institute Marine and Atmospheric Research, University of Hawaii, Honolulu, Hawaii

Miller, Laury, NOAA/NESDIS Laboratory for Satellite Altimetry, Silver Spring, Maryland

Mitchum, Gary T., College of Marine Science, University of South Florida, St. Petersburg, Florida

Montzka, Stephen A., NOAA/Earth System Research Laboratory, Boulder, Colorado

Moore, Sue, NOAA/National Marine Fisheries Service, Office of Science and Technology, Seattle, Washington

Mora, Natalie P., Center for Geophysical Research, University of Costa Rica, San Jose, Costa Rica

Morcrette, Jean-Jacques, European Centre for Medium-Range Weather Forecasts, Reading, United Kingdom

Mote, Thomas, Department of Geography, University of Georgia, Athens, Georgia

Mühle, Jens, Scripps Institution of Oceanography, University of California San Diego, La Jolla, California

Mullan, A. Brett, National Institute of Water and Atmospheric Research, Ltd., Wellington, New Zealand

Müller, Rolf, Forschungszentrum Jülich, Jülich, Germany

Myhre, Cathrine, Norwegian Institute for Air Research, Kjeller, Norway

Nash, Eric R., Science Systems and Applications Inc., NASA Goddard Space Flight Center, Greenbelt, Maryland

Nerem, R. Steven, Department of Aerospace Engineering Sciences, University of Colorado, Boulder, Colorado

Newlin, Michele L., NOAA/NESDIS National Oceanographic Data Center, Silver Spring, Maryland

Newman, Paul A., NASA Goddard Space Flight Center, Laboratory for Atmospheres, Greenbelt, Maryland

Ngari, Arona, Cook Islands Meteorological Service, Rarotonga, Cook Islands

Nishino, S., Japan Agency for Marine-Earth Science and Technology, Tokyo, Japan

Njau, Leonard N., African Centre of Meteorological Applications for Development (ACMAD), Niamey, Niger

Noetzli, Jeannette, University of Zürich, Zürich, Switzerland

Oberman, N. G., MIREKO, Syktivkar, Russia

Obregón, Andre, Deutscher Wetterdienst (German Meteorological Service, DWD), Offenbach, Germany; and WMO RA VI Regional Climate Centre on Climate Monitoring, Offenbach, Germany

Ogallo, Laban, IGAD Climate Prediction and Applications Centre (ICPAC), Nairobi, Kenya

Oludhe, Christopher, Department of Meteorology, University of Nairobi, Nairobi, Kenya

Overland, J., NOAA/OAR Pacific Marine Environmental Laboratory, Seattle, Washington 
Oyunjargal, Lamjav, Institute of Meteorology and Hydrology, National Agency for Meteorology, Hydrology and Environmental Monitoring, Ulaanbaatar, Mongolia

Parinussa, R. M., Earth and Climate Cluster, Department of Earth Sciences, Faculty of Earth and Life Sciences, VU University Amsterdam, Amsterdam, Netherlands

Park, Geun-Ha, NOAA/OAR Atlantic Oceanographic and Meteorological Laboratory, Miami, Florida

Parker, David E., Met Office Hadley Centre, Exeter, United Kingdom

Pasch, Richard J., NOAA/NWS National Hurricane Center, Miami, Florida

Pascual-Ramírez, Reynaldo, National Meteorological Service of Mexico, Mexico

Pelto, Mauri S., Nichols College, Dudley, Massachusetts

Penalba, Olga, Departamento Ciencias de la Atmósfera y los Océanos, Facultad de Ciencias Exactas y Naturales, Universidad de Buenos Aires, Buenos Aires, Argentina

Pérez-Suárez, Ramón, Institute of Meteorology of Cuba, Havana, Cuba

Perovich, D., ERDC - Cold Regions Research and Engineering Laboratory, Hanover, New Hampshire

Pezza, Alexandre B., Melbourne University, Melbourne, Australia

Phillips, Dave, Environment Canada, Toronto, Canada

Pickart, R., Woods Hole Oceanographic Institution, Woods Hole, Massachusetts

Pinty, Bernard, Climate Risk Management Unit, IES, EC Joint Research Centre, Ispra, Italy

Pinzon, J., Biospheric Science Branch, NASA Goddard Space Flight Center, Greenbelt, Maryland

Pitts, Michael C., NASA Langley Research Center, Hampton, Virginia

Pour, Homa Kheyrollah, Interdisciplinary Centre on Climate Change and Department of Geography \& Environmental Management, University of Waterloo, Waterloo, Ontario, Canada

Prior, John , Met Office, Exeter, Devon, United Kingdom

Privette, Jeff L., NOAA/NESDIS National Climatic Data Center, Asheville, North Carolina

Proshutinsky, A., Woods Hole Oceanographic Institution, Woods Hole, Massachusetts

Quegan, Shaun, Centre for Terrestrial Climate Dynamics, University of Sheffield, Sheffield, United Kingdom

Quintana, Juan, Dirección Meteorológica de Chile, Chile

Rabe, B., Alfred Wegener Institute, Bremerhaven, Germany

Rahimzadeh, Fatemeh, Atmospheric Science and Meteorological Research Center (ASMERC), Tehran, Iran

Rajeevan, M, National Atmospheric Research Laboratory, Gadanki, India
Rayner, Darren, National Oceanography Centre, Southampton, United Kingdom

Rayner, Nick A., Met Office Hadley Centre, Exeter, United Kingdom

Raynolds, M. K., Institute of Arctic Biology, University of Alaska Fairbanks, Fairbanks, Alaska

Razuvaev, Vyacheslav N., All-Russian Research Institute of Hydrometeorological Information, Obninsk, Russia

Reagan, James, NOAA/NESDIS National Oceanographic Data Center, Silver Spring, Maryland

Reid, Phillip, Australian Bureau of Meteorology Centre for Australian Weather and Climate Research, Tasmania, Australia

Renwick, James A., National Institute of Water and Atmospheric Research, Ltd., Wellington, New Zealand

Revadekar, J., Indian Institute of Tropical Meteorology, Pune, India

Rex, Markus, Alfred Wegener Institute for Polar and Marine Research, Potsdam, Germany

Richter-Menge, J., ERDC - Cold Regions Research and Engineering Laboratory, Hanover, New Hampshire

Rivera, Ingrid L., Center for Geophysical Research, University of Costa Rica, San Jose, Costa Rica

Robinson, David A., Rutgers University, Piscataway, New Jersey

Rodell, Matthew, Hydrospheric and Biospheric Sciences Laboratory, NASA Goddard Space Flight Center, Greenbelt, Maryland

Roderick, Michael L., Research School of Earth Sciences and Research School of Biology, The Australian National University, Canberra, Australia

Romanovsky, Vladimir E., Geophysical Institute, University of Alaska Fairbanks, Fairbanks, Alaska

Ronchail, Josyane, University of Paris, Paris, France

Rosenlof, Karen H., NOAA/Earth System Research Laboratory, Boulder, Colorado

Rudels, B., Finnish Institute of Marine Research, Helsinki, Finland

Sabine, Christopher L., NOAA/OAR Pacific Marine Environmental Laboratory, Seattle, Washington

Sánchez-Lugo, Ahira, NOAA/NESDIS National Climatic Data Center, Asheville, North Carolina

Santee, Michelle L., NASA Jet Propulsion Laboratory, Pasadena, California

Sawaengphokhai, P., Science Systems Applications, Inc., Hampton, Virginia

Sayouri, Amal, Direction de la Météorologie Nationale du Maroc, Rabat, Morocco

Scambos, Ted A., National Snow and Ice Data Center, University of Colorado-Boulder, Boulder, Colorado

Schauer, U., Alfred Wegener Institute, Bremerhaven, Germany 
Schemm, Jae, NOAA/NWS Climate Prediction Center, Camp Springs, Maryland

Schmid, Claudia, NOAA/OAR Atlantic Oceanographic and Meteorological Laboratory, Miami, Florida

Schreck, Carl, Cooperative Institute for Climate and Satellites, North Carolina State University, Asheville, North Carolina

Semiletov, Igor, International Arctic Research Center, University of Alaska Fairbanks, Fairbanks, Alaska

Send, Uwe, Scripps Institution of Oceanography, University of California, San Diego, La Jolla, California

Sensoy, Serhat, Turkish State Meteorological Service, Kalaba, Ankara, Turkey

Shakhova, Natalia, International Arctic Research Center, University of Alaska Fairbanks, Fairbanks, Alaska

Sharp, M., Department of Earth and Atmospheric Sciences, University of Alberta, Edmonton, Alberta, Canada

Shiklomanov, Nicolai I., Department of Geography, George Washington University, Washington, DC

Shimada, K., Tokyo University of Marine Science and Technology, Tokyo, Japan

Shin, J., Korea Meteorological Administration, Seoul, Republic of Korea

Siegel, David A., University of California, Santa Barbara, Santa Barbara, California

Simmons, Adrian, European Centre for Medium Range Weather Forecasts, Reading, United Kingdom

Skansi, Maria, Servicio Meteorológico Nacional, Buenos Aires, Argentina

Smith, Sharon L., Geological Survey of Canada, Natural Resources Canada, Ottawa, Ontario, Canada

Smith, Thomas M., NOAA/NESDIS Center for Satellite Applications and Research, Silver Spring, Maryland; and Cooperative Institute for Climate and Satellites, University of Maryland, College Park, Maryland

Sokolov, V., Arctic and Antarctic Research Institute, St. Petersburg, Russia

Spence, Jacqueline, Meteorological Service, Jamaica

Srivastava, A. K., India Meteorological Department, Pune, India

Stackhouse, Paul W., Jr., NASA Langley Research Center, Hampton, Virginia

Stammerjohn, Sharon, Institute of Arctic and Alpine Research, University of Colorado-Boulder, Boulder, Colorado

Steele, M., Applied Physics Laboratory, University of Washington, Seattle, Washington

Steffen, Konrad, Cooperative Institute for Research in Environmental Studies, University of Colorado-Boulder, Boulder, Colorado

Steinbrecht, Wolfgang, DWD (German Weather Service), Hohenpeissenberg, Germany
Stephenson, Tannecia, Department of Physics, University of the West Indies, Jamaica

Stolarski, Richard S., Johns Hopkins University, Baltimore, Maryland

Sweet, William, NOAA/NOS Center for Operational Oceanographic Products and Services, Honolulu, Hawaii

Takahashi, Taro, Lamont-Doherty Earth Observatory, Columbia University, Palisades, New York

Taylor, Michael A., Department of Physics, University of the West Indies, Jamaica

Tedesco, Marco, City College of New York, New York, New York

Thépaut, Jean-Noël, European Centre for Medium Range Weather Forecasts, Reading, United Kingdom

Thiaw, Wassila M., NOAA/NWS Climate Prediction Center, National Centers for Environmental Prediction, Camp Springs, Maryland

Thompson, Philip, Joint Institute Marine and Atmospheric Research, University of Hawaii, Honolulu, Hawaii

Thorne, Peter W., Cooperative Institute for Climate and Satellites, NCSU/NOAA NCDC, Asheville, North Carolina

Timmermans, M.-L., Yale University, New Haven, Connecticut

Tobin, Skie, Bureau of Meteorology, Melbourne, Australia

Toole, J., Woods Hole Oceanographic Institution, Woods Hole, Massachusetts

Trachte, Katja, LCRS, Philipps-Universität Marburg, Germany

Trewin, Blair C., Australian Bureau of Meteorology, Melbourne, Australia

Trigo, Ricardo M., Centro de Geofísica da Universidade de Lisboa, Lisbon, Portugal

Trotman, Adrian, Caribbean Institute of Meteorology and Hydrology, Barbados

Tucker, C. J., Biospheric Science Branch, NASA Goddard Space Flight Center, Greenbelt, Maryland

Ulupınar, Yusuf, Turkish State Meteorological Service, Ankara, Turkey

Van de Wal, Roderik S. W., Institute for Marine and Atmospheric Research Utrecht, Utrecht University, Utrecht, Netherlands

van der Werf, G. R., Department of Earth Sciences, Faculty of Earth and Life Sciences, VU University Amsterdam, Netherlands

Vautard, Robert, Laboratoire des Sciences du Climat et de l'Environnement (LSCE), CEA-CNR-UVSQ, Gif-surYvette, France 
Votaw, Gary, NOAA National Weather Service, San Juan, Puerto Rico

Wagner, Wolfgang W., Institute for Photogrammetry and Remote Sensing, Vienna University of Technology, Vienna, Austria

Wahr, John, Department of Physics and Cooperative Institute for Research in Environmental Sciences, University of Colorado, Boulder, Colorado

Walker, D. A., Institute of Arctic Biology, University of Alaska Fairbanks, Fairbanks, Alaska

Walsh, J., International Arctic Research Center, University of Alaska Fairbanks, Fairbanks, Alaska

Wang, Chunzai, NOAA/OAR Atlantic Oceanographic and Meteorological Laboratory, Miami, Florida

Wang, Junhong, Earth Observing Laboratory, NCAR, Boulder, Colorado

Wang, Lei, Department of Geography and Anthropology, Louisiana State University, Baton Rouge, Louisiana

Wang, Menghua, NOAA/NESDIS Center for Satellite Applications and Research, Camp Springs, Maryland

Wang, Sheng-Hung, Byrd Polar Research Center, The Ohio State University, Columbus, Ohio

Wanninkhof, Rik, NOAA/OAR Atlantic Oceanographic and Meteorological Laboratory, Miami, Florida

Weaver, Scott, NOAA/NWS Climate Prediction Center, Camp Springs, Maryland

Weber, Mark, University of Bremen, Bremen, Germany

Weingartner, T., School of Fisheries and Ocean Sciences, University of Alaska Fairbanks, Fairbanks Alaska

Weller, Robert A., Woods Hole Oceanographic Institution, Woods Hole, Massachusetts

Wentz, Frank, Remote Sensing Systems, Santa Rosa, California

Whitewood, Robert, Environment Canada, Toronto, Canada

Wilber, Anne C., Science Systems Applications, Inc., Hampton, Virginia

Willett, Kate M., Met Office Hadley Centre, Exeter, United Kingdom

Williams, W., Institute of Ocean Sciences, Sidney, British Columbia, Canada

Willis, Joshua K., Jet Propulsion Laboratory, California Institute of Technology, Pasadena, California

Wilson, R. Chris, Jet Propulsion Laboratory, California Institute of Technology, Pasadena, California

Wolken, G., Alaska Division of Geological \& Geophysical Surveys, Fairbanks, Alaska

Wong, Takmeng, NASA Langley Research Center, Hampton, Virginia

Woodgate, R., Applied Physics Laboratory, University of Washington, Seattle Washington
Wovrosh, Alex J., Department of Geography, Ohio University, Athens, Ohio

Xue, Yan, NOAA/NWS Climate Prediction Center, Camp Springs, Maryland

Yamada, Ryuji, Climate Prediction Division, Japan Meteorological Agency, Japan

Yamamoto-Kawai, M., Tokyo University of Marine Science and Technology, Tokyo, Japan

Yoder, James A., Woods Hole Oceanographic Institution, Woods Hole, Massachusetts

Yu, Lisan, Woods Hole Oceanographic Institution, Woods Hole, Massachusetts

Yueh, Simon, Jet Propulsion Laboratory, Pasadena, California

Zhang, Liangying, Earth Observing Laboratory, NCAR, Boulder, Colorado

Zhang, Peiqun, National Climate Centre, CMA, Beijing, China

Zhao, Lin, Cold and Arid Regions Environmental and Engineering Research Institute, Lanzhou, China

Zhou, Xinjia, UCAR COSMIC, Boulder, Colorado

Zimmermann, S., Institute of Ocean Sciences, Sidney, British Columbia, Canada

Zubair, Lafeer, International Research Institute for Climate and Society, Palisades, New York

\section{EDITORIAL AND PRODUCTION TEAM}

Hyatt, Glenn M., Lead Graphics Production, NOAA/NESDIS National Climatic Data Center, Asheville, North Carolina

Misch, Deborah J., Graphics Support, The Baldwin Group, Inc., NOAA/NESDIS National Climatic Data Center, Asheville, North Carolina

Riddle, Deborah, Graphics Support, NOAA/NESDIS National Climatic Data Center, Asheville, North Carolina

Sprain, Mara, Editorial Assistant, The Baldwin Group, Inc., NOAA/NESDIS National Climatic Data Center, Asheville, North Carolina

Veasey, Sara W., Graphic Production, NOAA/NESDIS National Climatic Data Center, Asheville, North Carolina 


\section{TABLE OF CONTENTS}

List of authors and affiliations.

Abstract

I. INTRODUCTION

2. GLOBAL CLIMATE

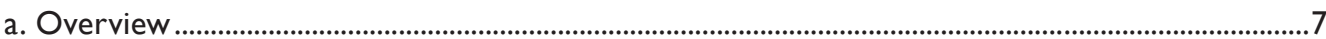

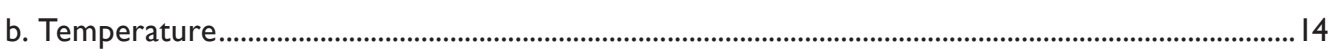

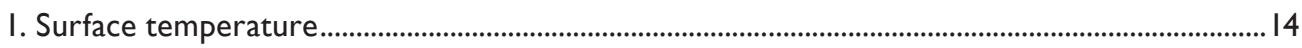

2. Lower tropospheric temperature..................................................................................... 15

3. Lower stratospheric temperature ............................................................................................... 16

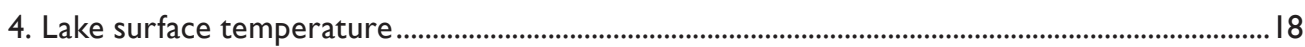

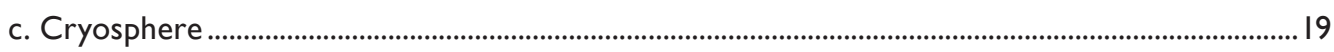

I. Pemafrost thermal state ......................................................................................................... 19

2. Northern Hemisphere continental snow cover extent.................................................................2I

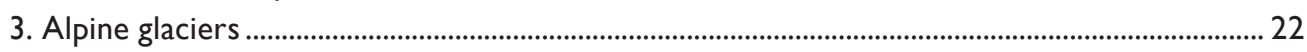

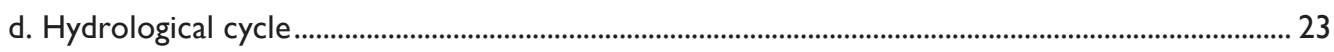

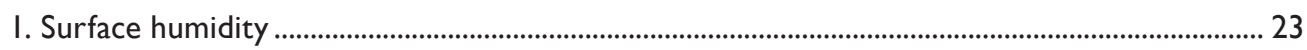

2. Total column water vapor ..................................................................................................... 25

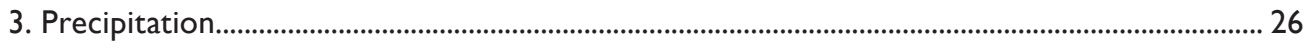

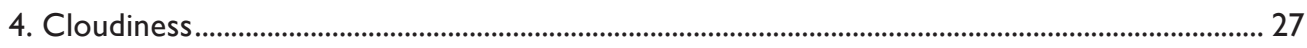

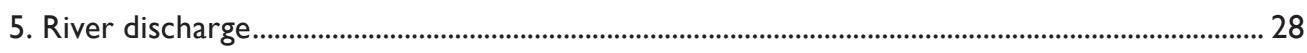

6. Groundwater and terrestrial water storage............................................................................. 29

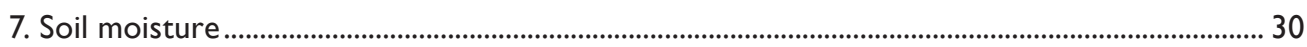

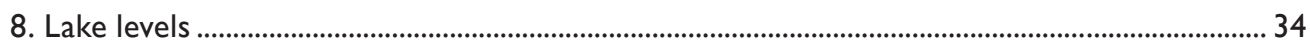

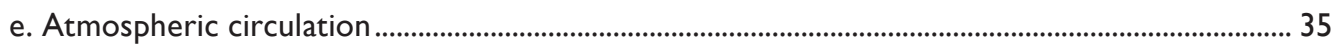

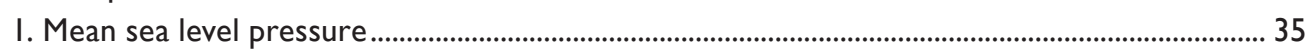

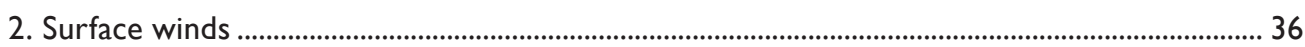

f. Earth radiation budget at the top-of-atmosphere ............................................................................ 38

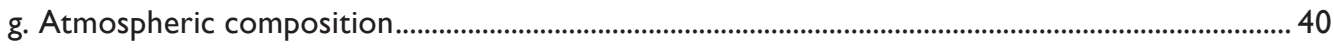

I. Atmospheric chemical composition .......................................................................................... 40

2. Aerosols

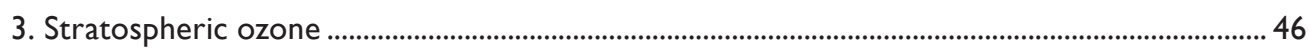

4. Stratospheric water vapor ......................................................................................................... 48

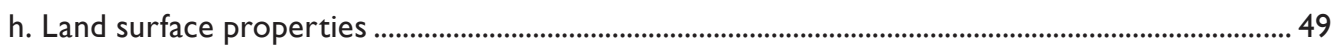

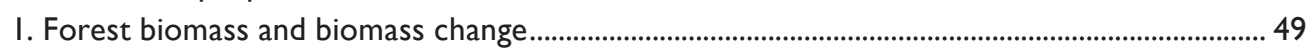

2. Land surface albedo................................................................................................................5

3. Terrestrial vegetation dynamics - fraction of absorbed photosynthetically active radiation. 53

4. Biomass burning................................................................................................................................. 54

3. GLOBAL OCEANS

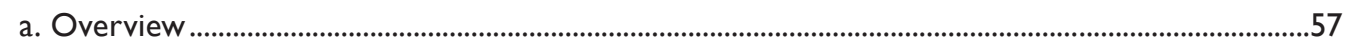

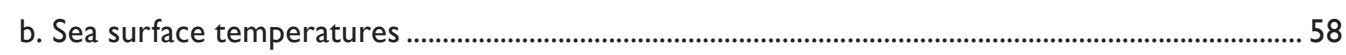

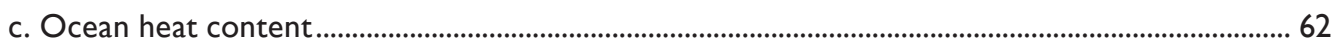

d. Global ocean heat fluxes ........................................................................................................................ 65

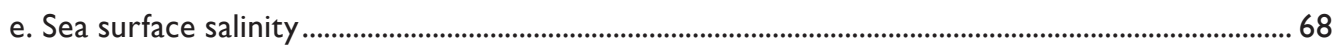

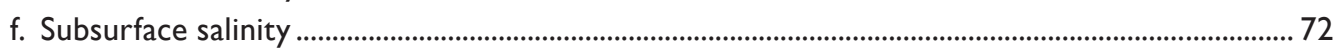

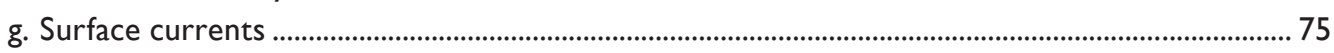

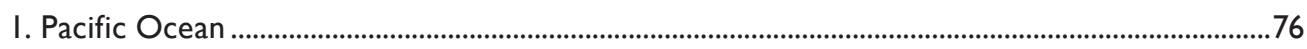

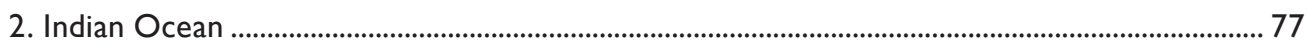

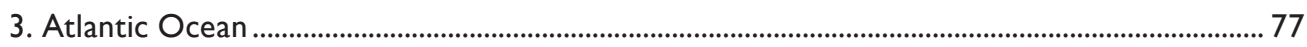


h. Meridional overturning circulation observations in the subtropical North Atlantic.................... 78

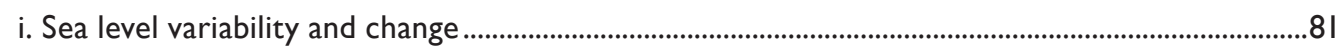

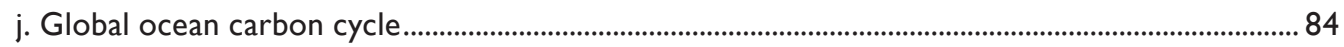

I. Air-sea carbon dioxide fluxes....................................................................................................... 84

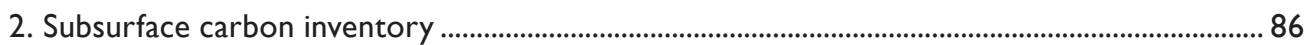

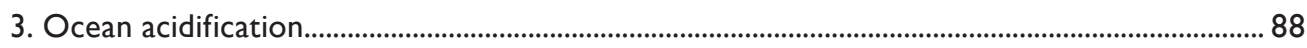

4. Global ocean phytoplankton .............................................................................................................. 89

4. TROPICS

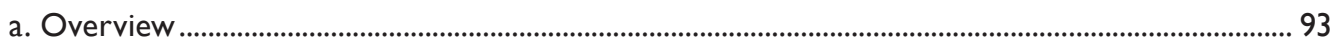

b. ENSO and the tropical Pacific ......................................................................................................... 93

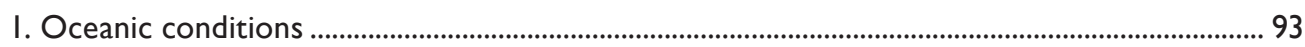

2. Atmospheric circulation: Tropics..................................................................................................... 95

3. Atmospheric circulation: Extratropics ....................................................................................... 96

4. ENSO temperature and precipitation impacts......................................................................... 97

c. Tropical intraseasonal activity.......................................................................................................... 97

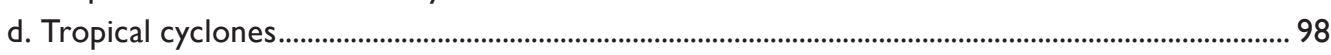

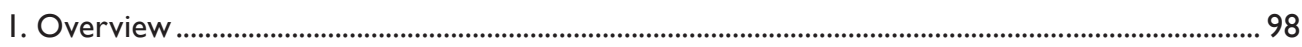

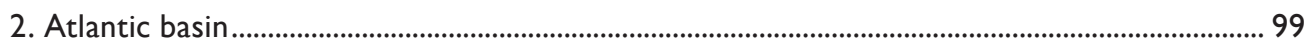

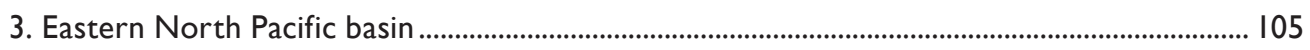

4. Western North Pacific basin........................................................................................................ 107

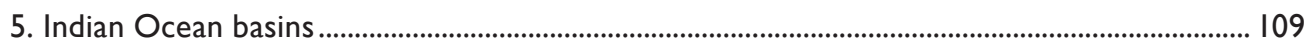

6. Southwest Pacific basin ........................................................................................................ 112

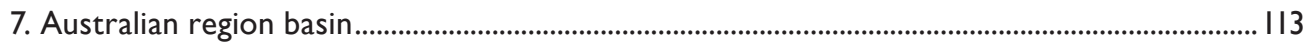

e. Tropical cyclone heat potential ................................................................................................ 114

f. Intertropical convergence zones ...................................................................................................... 116

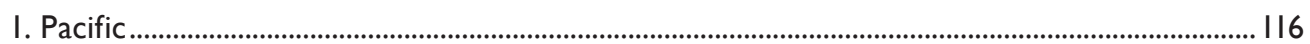

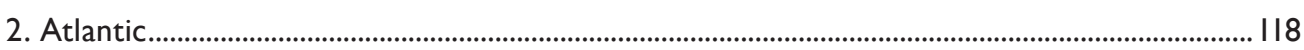

g. Atlantic multidecadal oscillation .......................................................................................... 119

h. Indian Ocean dipole...................................................................................................................... 122

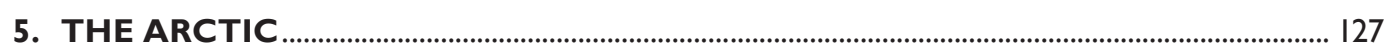

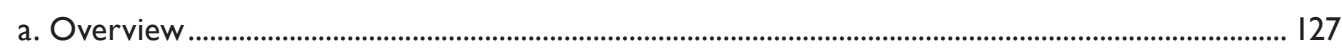

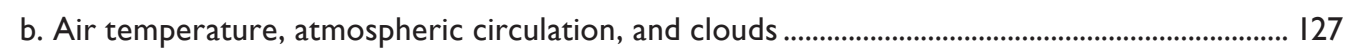

c. Ozone and UV radiation ................................................................................................................ 129

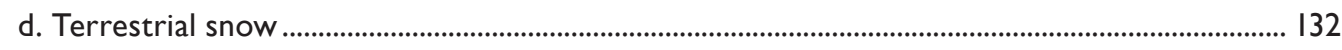

e. Glaciers and ice caps (outside Greenland) .............................................................................. 133

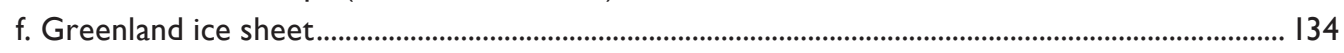

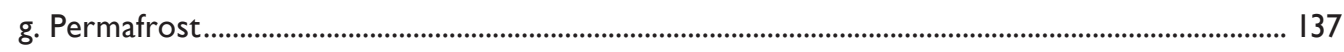

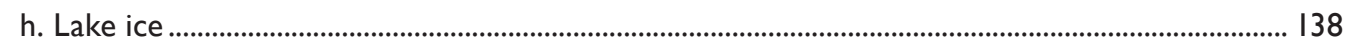

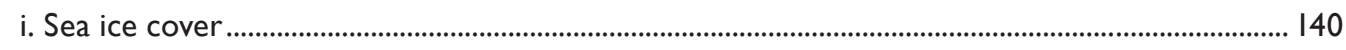

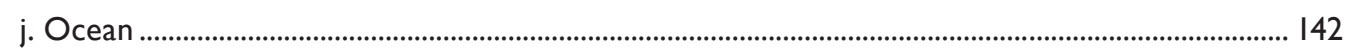

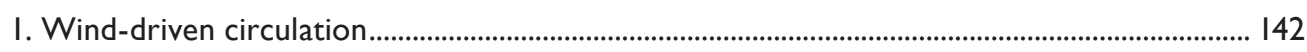

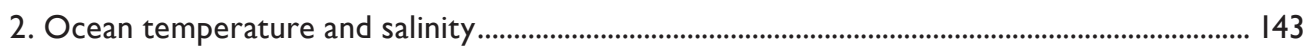

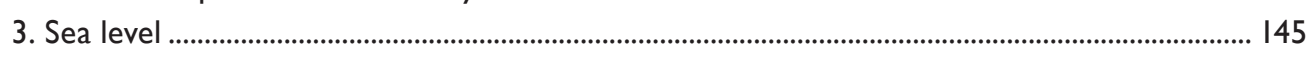

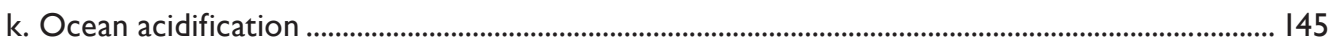

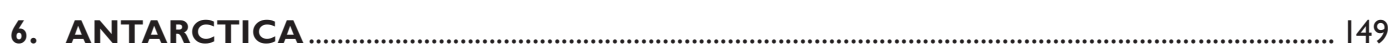

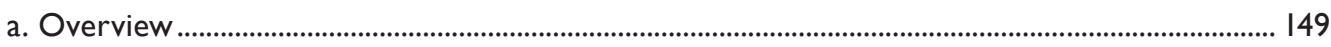

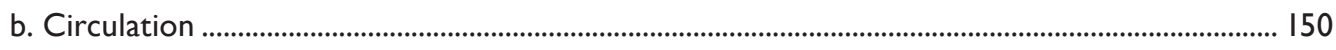


c. Surface manned and automatic weather station observations ........................................................ I5I

d. Net precipitation (P-E) ...................................................................................................................... 154

e. 2010/II Seasonal melt extent and duration ..................................................................................... 156

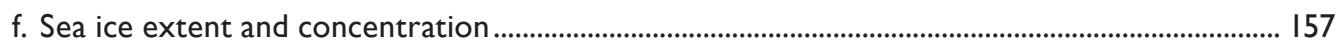

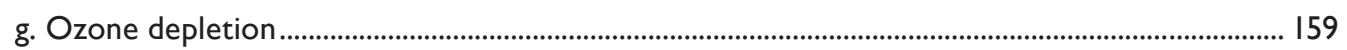

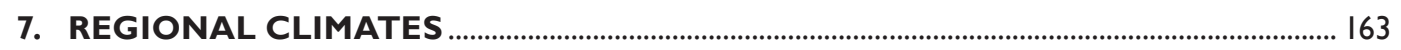

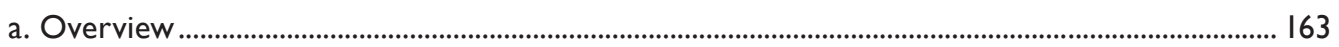

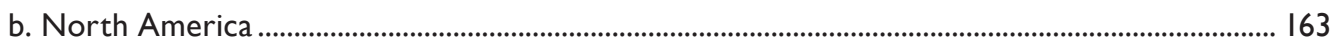

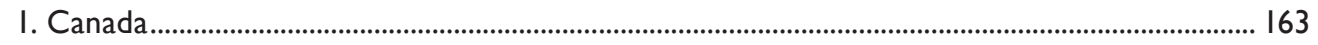

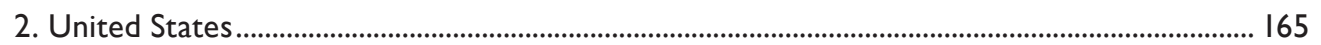

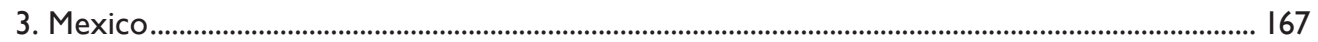

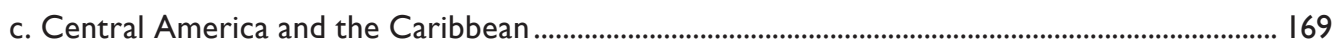

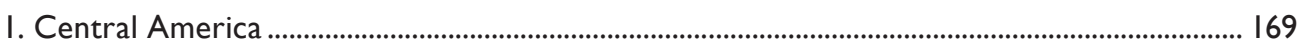

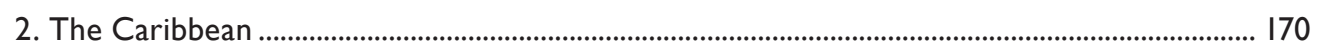

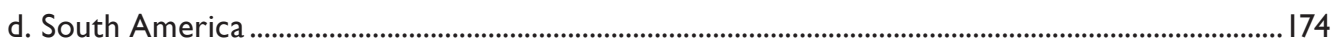

I. Northern South America and the tropical Andes.................................................................... 174

2. Tropical South America east of the Andes ................................................................................... 175

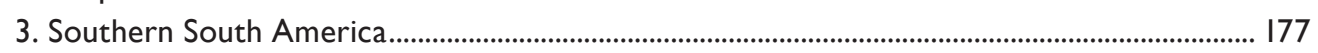

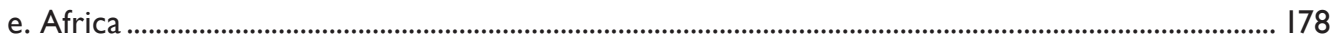

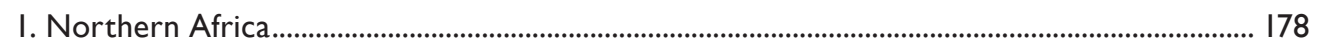

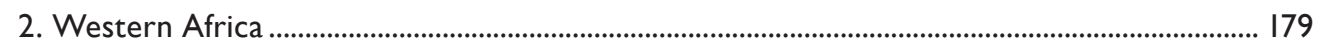

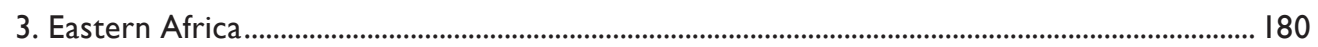

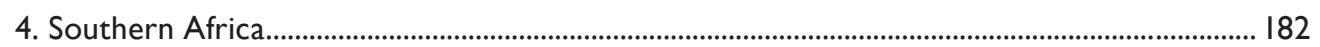

5. Western Indian Ocean countries............................................................................................. 184

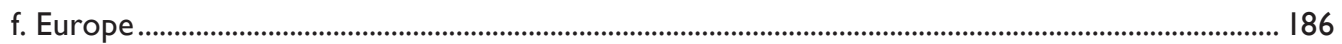

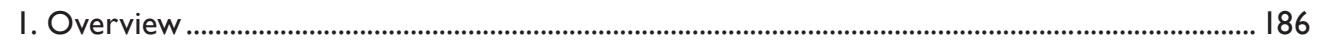

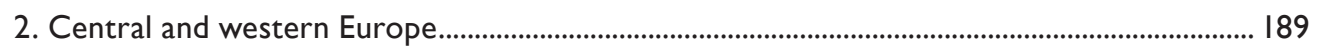

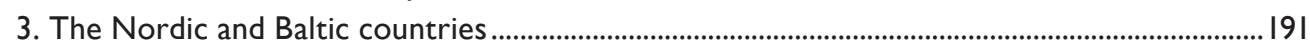

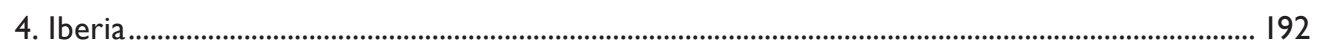

5. Mediterranean, Italian, and Balkan Peninsulas............................................................................ 193

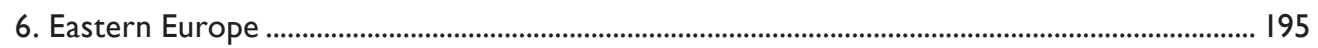

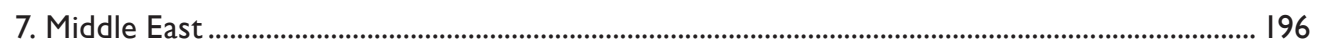

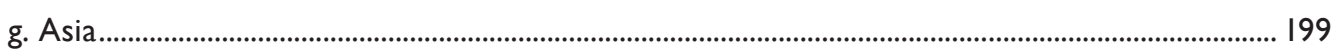

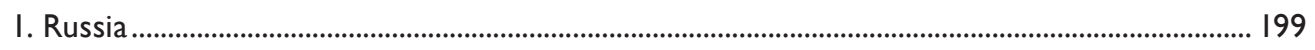

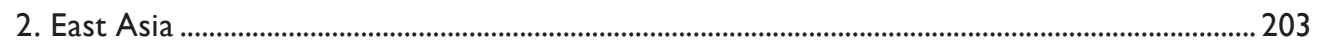

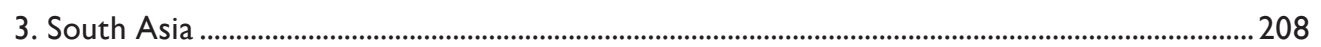

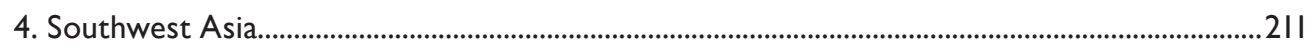

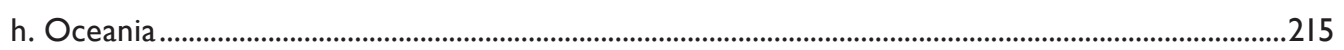

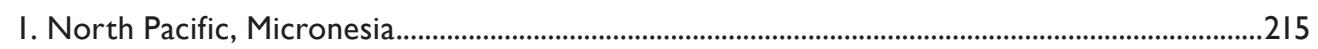

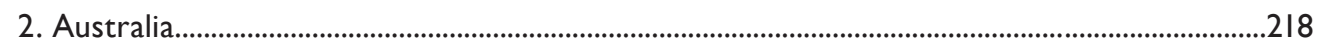

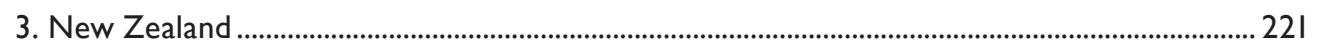

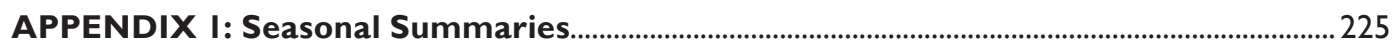

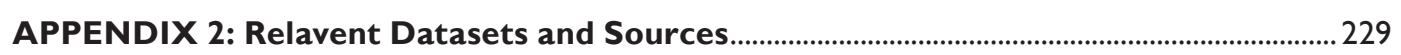

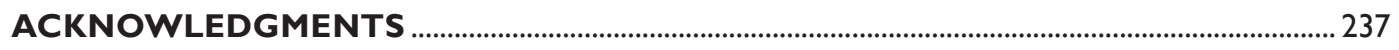

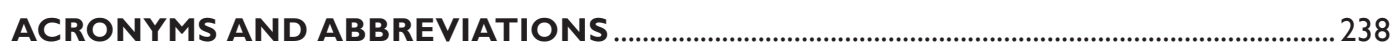

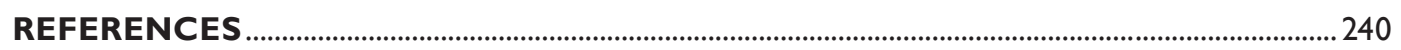


Large-scale climate patterns influenced temperature and weather patterns around the globe in 20II. In particular, a moderate-to-strong La Niña at the beginning of the year dissipated during boreal spring but reemerged during fall. The phenomenon contributed to historical droughts in East Africa, the southern United States, and northern Mexico, as well the wettest two-year period (2010-II) on record for Australia, particularly remarkable as this follows a decade-long dry period. Precipitation patterns in South America were also influenced by La Niña. Heavy rain in Rio de Janeiro in January triggered the country's worst floods and landslides in Brazil's history.

The $201 \mathrm{l}$ combined average temperature across global land and ocean surfaces was the coolest since 2008 , but was also among the 15 warmest years on record and above the 1981-2010 average. The global sea surface temperature cooled by $0.1^{\circ} \mathrm{C}$ from 2010 to 2011 , associated with cooling influences of La Niña. Global integrals of upper ocean heat content for 2011 were higher than for all prior years, demonstrating the Earth's dominant role of the oceans in the Earth's energy budget. In the upper atmosphere, tropical stratospheric temperatures were anomalously warm, while polar temperatures were anomalously cold. This led to large springtime stratospheric ozone reductions in polar latitudes in both hemispheres. Ozone concentrations in the Arctic stratosphere during March were the lowest for that period since satellite records began in 1979. An extensive, deep, and persistent ozone hole over the Antarctic in September indicates that the recovery to pre-1980 conditions is proceeding very slowly.

Atmospheric carbon dioxide concentrations increased by $2.10 \mathrm{ppm}$ in $201 \mathrm{I}$, and exceeded $390 \mathrm{ppm}$ for the first time since instrumental records began. Other greenhouse gases also continued to rise in concentration and the combined effect now represents a $30 \%$ increase in radiative forcing over a 1990 baseline. Most ozone depleting substances continued to fall. The global net ocean carbon dioxide uptake for the 2010 transition period from El Niño to La Niña, the most recent period for which analyzed data are available, was estimated to be $1.30 \mathrm{Pg} \mathrm{C} \mathrm{yr}^{-1}$, almost $12 \%$ below the 29 -year long-term average.

Relative to the long-term trend, global sea level dropped noticeably in mid-2010 and reached a local minimum in 2011. The drop has been linked to the La Nina conditions that prevailed throughout much of 20I0-II. Global sea level increased sharply during the second half of 2011.
Global tropical cyclone activity during 2011 was wellbelow average, with a total of 74 storms compared with the 1981-2010 average of 89. Similar to 2010, the North Atlantic was the only basin that experienced abovenormal activity. For the first year since the widespread introduction of the Dvorak intensity-estimation method in the 1980s, only three tropical cyclones reached Category 5 intensity level-all in the Northwest Pacific basin.

The Arctic continued to warm at about twice the rate compared with lower latitudes. Below-normal summer snowfall, a decreasing trend in surface albedo, and aboveaverage surface and upper air temperatures resulted in a continued pattern of extreme surface melting, and net snow and ice loss on the Greenland ice sheet. Warmerthan-normal temperatures over the Eurasian Arctic in spring resulted in a new record-low June snow cover extent and spring snow cover duration in this region. In the Canadian Arctic, the mass loss from glaciers and ice caps was the greatest since GRACE measurements began in 2002, continuing a negative trend that began in 1987. New record high temperatures occurred at $20 \mathrm{~m}$ below the land surface at all permafrost observatories on the North Slope of Alaska, where measurements began in the late 1970s. Arctic sea ice extent in September 2011 was the second-lowest on record, while the extent of old ice (four and five years) reached a new record minimum that was just $19 \%$ of normal.

On the opposite pole, austral winter and spring temperatures were more than $3^{\circ} \mathrm{C}$ above normal over much of the Antarctic continent. However, winter temperatures were below normal in the northern Antarctic Peninsula, which continued the downward trend there during the last 15 years. In summer, an all-time record high temperature of $-12.3^{\circ} \mathrm{C}$ was set at the South Pole station on 25 December, exceeding the previous record by more than a full degree. Antarctic sea ice extent anomalies increased steadily through much of the year, from briefly setting a record low in April, to well above average in December. The latter trend reflects the dispersive effects of low pressure on sea ice and the generally cool conditions around the Antarctic perimeter. 


\section{INTRODUCTION-D. S. Arndt and J. Blunden}

This is the 22nd annual edition of the State of the Climate series, from its origin as NOAA's Climate Assessment, and the 17th consecutive year of its association with the Bulletin of the American Meteorological Society. As always, its primary goals are to document the weather and climate events of the year and place them into accurate historical perspective, and to provide information on the state, trends, and variability of the climate system's many variables and phenomena.

The vast influence of La Niña across much of the climate system was pervasive during 2011, and is understandably pervasive in this document. La Niña's influence is shared among climate's many disciplines and across its many regions, but in different ways, and with different sensitivities. As such, multiple definitions have evolved to characterize it. In this report, La Niña is described in some sections as a protracted episode beginning in late 2010 and lasting through 2011, and in some as a "double dip" episode, separated by a brief ENSO-neutral period during mid-2011. We have chosen not to enforce a standard description across the document, opting to preserve the authors' perspective on a sectionby-section basis.

This series has been consciously conservative with statements of attribution regarding drivers of events on the scale of climate variability and change. Only widely-understood and established attribution relationships, such as those for ENSO's influence, are employed here. However, recognizing emerging demand and utility for event-focused attribution, the Bulletin has decided to publish an annual collection of such analyses, coincident with this series, the first of which was produced this year (Peterson et al. 2012). This allows this series to continue its focus as a chief scorekeeper of the climate's evolving state.

In recent years, this series has pursued a broader representation of the climate system by adding essential climate variables (ECVs, as defined in GCOS 2003). This year's edition adds albedo to the ECVs addressed in this series. It is fitting that this new section draws upon satellite-borne observations for its analysis. As satellite-based data records continue to evolve and mature, they have become more integrated into the climate monitoring community's various portfolios, and indeed through the sections of this document. This chapter's Sidebar (1.1) takes a broad view of the advantages, challenges, and opportunities of constructing climate data records from multiple satellite sensors. In the Global Climate chapter, another Sidebar (2.2) focuses on how satellite information is used to examine a single ECV, soil moisture. Ocean acidity, a recently-recognized GCOS $\mathrm{ECV}$, is an important climate indicator and is now the focus of both a new section in the Arctic chapter and a new subsection in the Global Oceans chapter.

The following ECVs, included in this edition, are considered "fully monitored", such that they are observed and analyzed across much of the world, with a sufficiently long-term dataset that has peer-reviewed documentation:

- Atmospheric Surface: air temperature, precipitation, air pressure, water vapor.

- Atmospheric Upper Air: earth radiation budget, temperature, water vapor, cloud properties.

- Atmospheric Composition: carbon dioxide, methane, ozone, nitrous oxide, chlorofluorocarbons, hydrochlorofluorocarbons, hydrofluorocarbons, sulfur hexafluorides, perflurocarbons, aerosols.

- Ocean Surface: temperature, salinity, sea level, sea ice, current, ocean color.

- Ocean Subsurface: temperature, salinity.

- Terrestrial: snow and ice cover, albedo.

ECVs in this edition that are considered "partially monitored", meeting some but not all of the above requirements, include:

- Atmospheric Surface: wind speed and direction.

- Atmospheric Composition: long-lived greenhouse gases not listed as fully monitored above.

- Ocean Surface: carbon dioxide.

- Ocean Subsurface: current, carbon.

- Terrestrial: soil moisture, permafrost, glaciers and ice sheets, river discharge, groundwater, lake levels, fraction of absorbed photosynthetically-active radiation, biomass, fire disturbance.

ECVs that are expected to be added in the future include:

- Atmospheric Surface: surface radiation budget.

- Atmospheric Upper Air: wind speed and direction.

- Ocean Surface: sea state.

- Ocean Subsurface: nutrients, ocean tracers, phytoplankton.

- Terrestrial: surface ground temperature, subsurface temperature and moisture, water use, land cover, leaf area index. 
An overview of this report's findings is presented in the Abstract and Fig. 1.1. Chapter 2 features global-scale climate variables; Chapter 3 highlights the global oceans; and Chapter 4 includes tropical climate phenomena including tropical cyclones. The Arctic and Antarctic respond differently through time and are reported in separate chapters (5 and 6, respectively). Notably, the Arctic chapter has been freshened and broadly reorganized by its editors. Chapter 7 provides a regional perspective authored largely by local government climate specialists. Sidebars included in each chapter are intended to provide background information on a significant climate event from 2011, a developing technology, or an emerging dataset germane to the chapter's content.
Chapter 8 has been renamed Appendix 1. Additionally, a list of relevant datasets and their sources for all chapters is now provided in Appendix 2.

Finally, we have often commented that the State of the Climate series not only offers annual snapshots of the climate's state, but also of our capacity to monitor it. However, this year's edition served as a sober reminder that the series also reflects our ability to compile and collaborate. Human events and economies contributed to the loss of data or authorship from several nations, including Egypt, Iraq, and parts of the South Pacific. We wish our colleagues in these places our best and look forward to working with them in a future with fewer obstacles to their participation. 


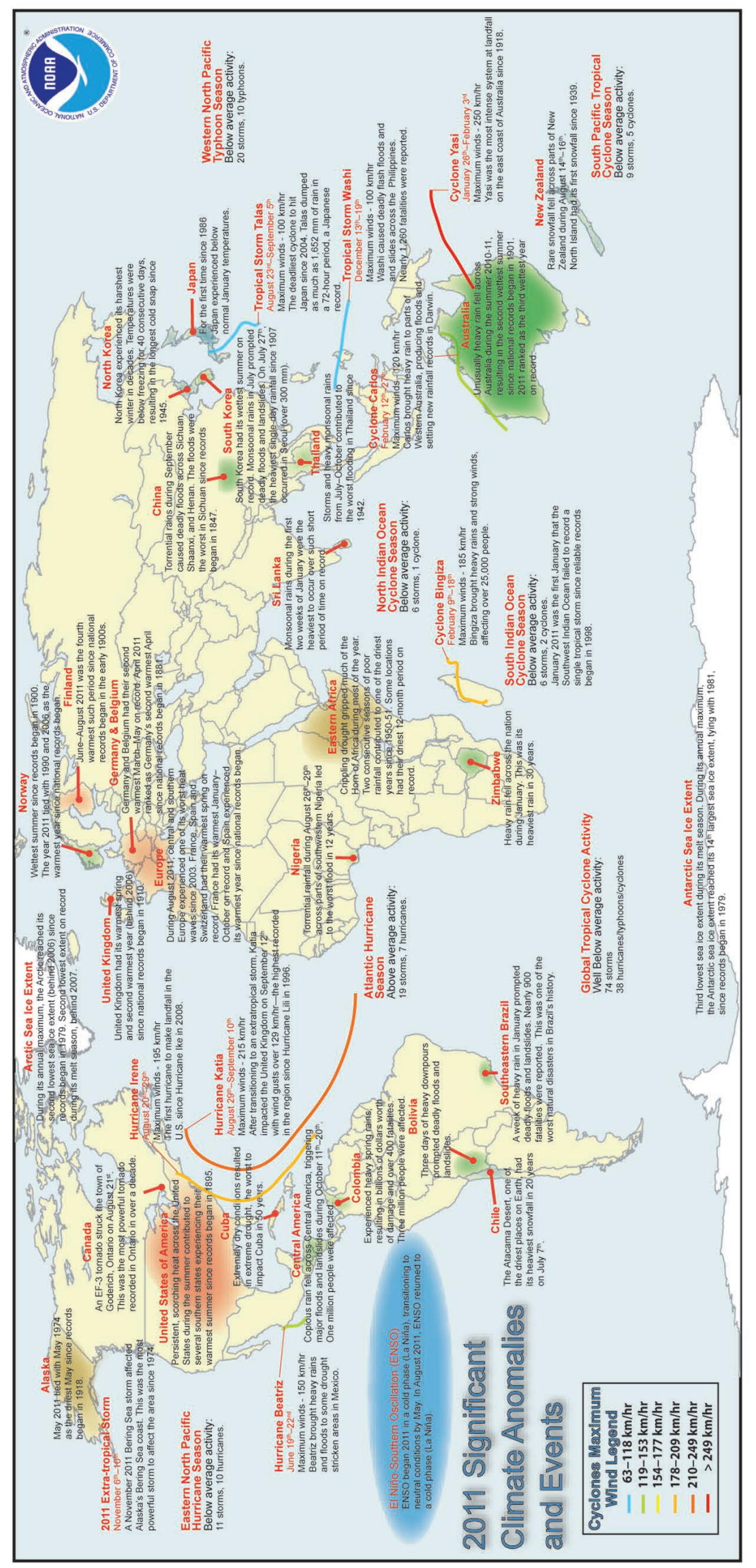

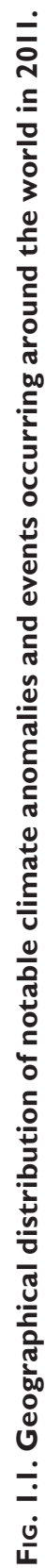




\section{SIDEBAR I.I: SATELLITE CLIMATE DATA RECORDS COME OF AGE-J. L. PRIIETTE AND J. J. BATES}

Climate assessments in prior BAMS State of the Climate supplements have primarily drawn on the many in situ measurements available for the land, oceans, atmosphere, and ice sheets. These records tend to be long term-some spanning more than a century-and mature, in that their characteristics are well understood. Nevertheless, they are often limited in their spatial extent for multiple reasons. Thus, while some parts of Earth are densely measured by in situ techniques, other parts remain unmeasured.

In the late 1970s, NOAA and the Department of Defense $(\mathrm{DoD})$ initiated routine observations of Earth's environment through operational satellite programs. The early satellite sensors and algorithms were designed primarily for weather applications and were basic by today's standards. However, a continuing stream of technological and scientific advancements has so increased the diversity and quality of satellite products (in many cases retroactively) that these records are now the desired input to many large-scale analyses. Perhaps more importantly, the periods of record for many satellite observations have achieved climate-relevant lengths in recent years (e.g., see Sidebar 2.2). It is fair to say that satellite climatology has come of age.

The National Research Council (NRC 2004) defines a climate data record (CDR) as a time series of measurements of sufficient length, consistency, and continuity to determine climate variability and change. Satellite CDRs offer unique information that can complement or supplement traditional in situ records. Indeed, the two observation types are necessary companions in that satellite products are usually calibrated, validated, or corroborated with in situ measurements, and in situ data are often put in spatial context using satellite observations.
The development of climate-quality satellite records has been neither fast nor easy. The inhospitable environment of space, the complexity of satellite sensors, and the inability to repair hardware in orbit means that sensor performance tends to deteriorate continuously with time. Thus, new satellitessometimes with improved designs-are regularly launched to carry on the work of ailing instruments. The cumulative result is long-term records composed of multiple sensor-specific segments of data, each with unique idiosyncrasies. To create a valid CDR, experts must scientifically correct, normalize, and stitch together these segments (Fig. SBI.I).

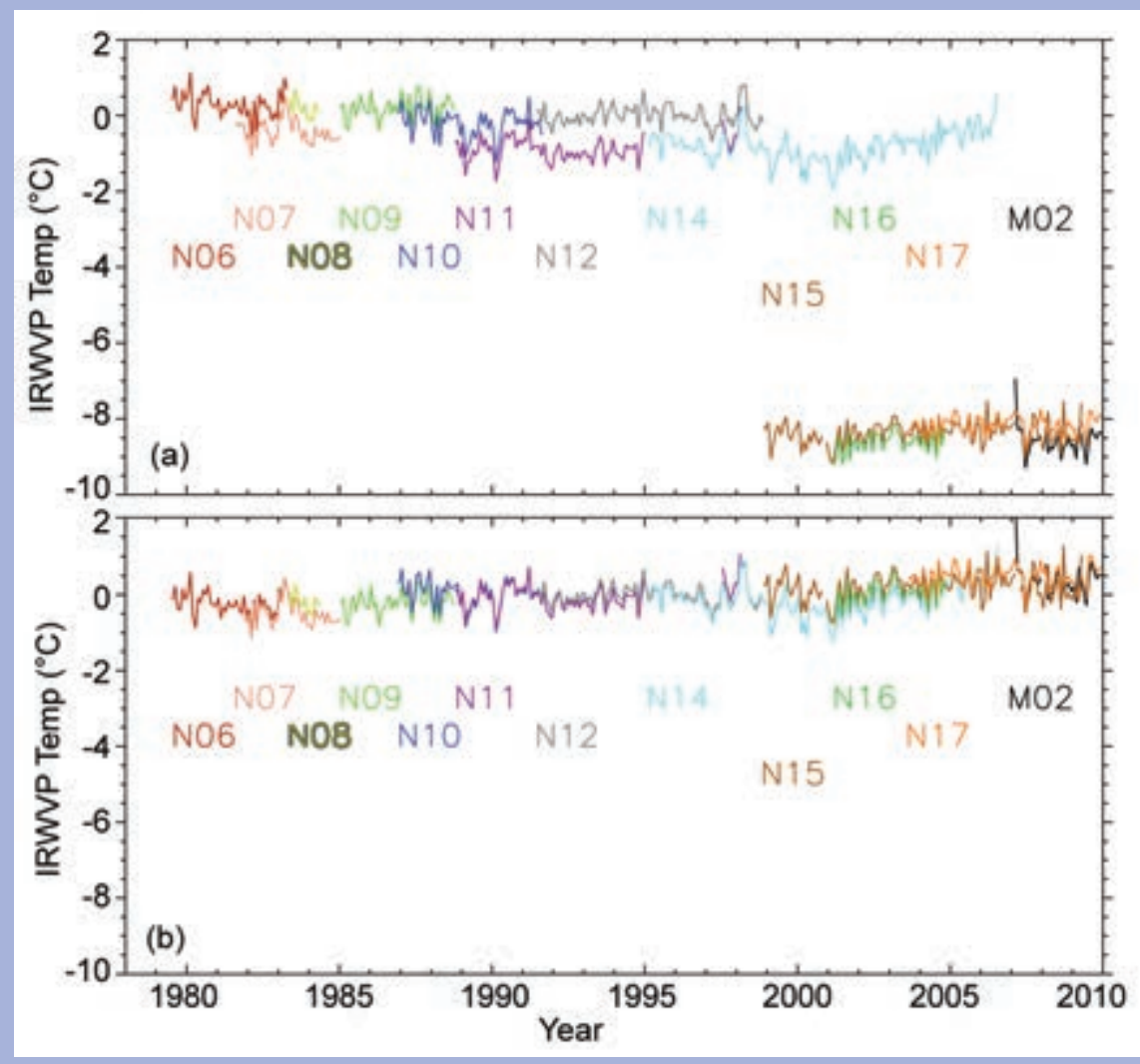

FIG. SBI.I. Raw data from the High Resolution Infrared Radiation Sounder (HIRS) instruments, carried onboard successive NOAA's Polar-Orbiting Environmental Satellites, is initially inconsistent due to the unique and changing character of the different flight instruments. The top pane (a) shows the monthly-averaged temperature over the tropics for HIRS channel 12, a channel sensitive to upper tropospheric water vapor. After cocalibration and normalization, the data can be merged into a coherent climate data record from which climate signals can be detected (b). Figures courtesy of Lei Shi, NOAA's National Climatic Data Center. 
More than two decades of community research has produced a wide set of proven techniques for these tasks. Starting in the early 1990s, NOAA and NASA cosponsored the Pathfinder Program to develop precursor CDRs and to advance satellite data management methods (NOAA 2004). This marked the first time that the incongruent data segments from multiple NOAA and DoD operational satellites had been fully recovered, cataloged, cocalibrated, and processed into coherent long-term records. Subsequent funding solicitations further developed the methods.

In recent years, several US and foreign agencies have leveraged the Pathfinder lessons to produce modern CDRs. For example, NOAA initiated a Climate Data Record Program (CDRP) in 2009 to develop and sustain CDRs in an operational context (Privette et al. 2009). Here, "operational" is loosely defined as the generation of products on time, all the time, including decision-support systems, modeling, and climatology. Following guidance from the NRC (2004), the CDRP developed its CDR requirements, specifically that they be:

- scientifically defensible

- extensible

- continuously assessed and improved

- transparent

- reproducible

- sustainable

- preserved

- accessible

The CDRP is currently developing and implementing systems and processes based on these requirements.

NOAA is initially focused on CDRs that address Earth's water and energy cycles to facilitate integrative assessments. Nearly a dozen competitively-selected CDRs -including data sets, algorithms, and documentation-have been developed, are publicly available, and are being sustained operationally.
Three of these are in the present State of the Climate supplement, namely sea ice extent, mean layer temperatures, and sea surface temperature. Additional CDRs are in various stages of development. The program is also developing climate information records (CIRs), i.e., CDR-derived products of particular phenomena or regions of interest to society or industry. Detailed information about NOAA's CDR program and related CDR products are available at: http://www.ncdc. noaa.gov/cdr.

As CDR development has matured and interest proliferated, several international organizations have become active in fostering CDR quality, interoperability, and agency coordination. For example, the Global Climate Observing System (GCOS 20II) recently issued guidelines for CDR producers. The Sustained, Coordinated Processing of Environmental Satellite Data for Climate Monitoring (SCOPE-CM; WMO 2009) activity seeks to, among other things, ensure continuity and overlap in the reprocessing of climate-relevant data to support integrated climate analysis and reanalysis. The recently-formed Committee for Earth Observing System (CEOS 2012) Working Group on Climate seeks to facilitate the implementation and exploitation of essential climate variable time series through coordination of CEOS member agencies.

After decades of progress in satellite technology and remote sensing science, NOAA and others have instituted programs that reprocess the more than three decades of global satellite data into consistent and accurate time series records that provide new insights into climate change and variability. These records, in concert with traditional in situ measurements, are leading to more precise and comprehensive climate assessments, including those in the State of the Climate supplements. By sustaining these records operationally, producers will also be able to support increasingly sophisticated decision-support systems throughout society. 
2. GLOBAL CLIMATE-K. M. Willett, A. J. Dolman, B. D. Hall, and P. W. Thorne, Eds.

a. Overview-P. W. Thorne, K. M. Willett, A. J. Dolman, and B. D. Hall

The year 2011 was dominated by La Niña and by divergent Arctic Oscillation conditions at year start (negative) and year end (positive). The La Niña that developed in mid-2010 and lasted through boreal spring 2011 was one of the strongest La Niña events in the historical instrumental record and is looking very much like a protracted La Niña episode (with typical boreal spring to fall neutral conditions) that has continued into early 2012. Typical signatures of La Niña, such as enhanced rainfall over Australia and reduced temperatures over much of the eastern Pacific, are the dominant geographical features in Plate 2.1 for the majority of climate variables considered. The divergent behavior of the Arctic Oscillation had significant impacts on boreal winter season climate at the beginning and end of the year over Northern Hemisphere mid-to-high latitude regions.

La Niña events typically lead to a reduction in nearsurface and tropospheric temperatures globally, and 2011 was no exception. It was, however, still above the 1981-2010 average being between 9th and 12th warmest at the surface (since the late 19th century) and between 8th and 12th warmest in the troposphere (since 1958 for radiosonde and 1979 for satellite datasets). This followed near-record warmth in 2010 associated with the moderate El Niño present at the start of 2010, which rapidly decayed to La Niña conditions.

During 2011, the hydrological cycle exhibited substantial global variability. The Southern Hemisphere positive anomalies in precipitation led to significant anomalies in soil moisture and terrestrial water storage, particularly in Australia. Conversely, many Northern Hemisphere subtropical locations, most notably northern Mexico, much of the southern United States, and East Africa experienced major droughts. These hydrological cycle anomaly imprints dominate many of the atmospheric and terrestrial variables considered herein.

The year 2011 was especially interesting in the stratosphere. The combination of La Niña's influence on the tropical circulation and phase of the quasi-biennial oscillation were associated with a marked slowdown in the Brewer Dobson circulation. Tropical stratospheric temperatures were anomalously warm while, conversely, polar temperatures were anomalously cold. This led to large spring-time ozone reductions in polar latitudes in both hemispheres. It also had implications for transport of stratospheric water vapor.
Trace gas concentrations continued to change largely as expected, given knowledge of anthropogenic source inventories and natural sink mechanisms. Carbon dioxide concentrations exceeded 390 ppm for the first time since instrumental records began. Other greenhouse gases also continued to rise in concentration and the combined effect represented a 30\% increase in radiative forcing over a 1990 baseline. Most ozone depleting substances continued to fall. Relative to peak concentrations, a fall of $33 \%$ has accrued back towards 1980 levels, when it is believed ozone depletion was not significant.

The inclusion of terrestrial indicators continues to expand and their inclusion helps to inform on the interconnectedness of the climate system. For example, despite substantially above-average rainfall over Australia, biomass burning was anomalously high over much of the country, an apparently counterintuitive finding. In fact, the rainfall anomalies promoted above-average vegetation growth, which subsequently produced above-average biomass burning during the dry season. It is only through a complete characterization of all relevant elements of the climate system that such insights can accrue. In the same vein, certain indicators cannot be updated for logistical or technological reasons in real-time, but their inclusion in delayed mode provides a valuable context.

Sidebars this year highlight: issues of data stewardship, rescue, and provenance; soil moisture; and solar transmission. Publicly available datasets used in this chapter are detailed in Appendix 2. Anomaly maps for 2011 for the majority of variables are given in Plate 2.1 and all available time series are compiled into Plate 2.2, allowing ease of comparison. In addition, an online resource contains additional figures using alternative choices of dataset at http://dx.doi .org//10.1175/2012BAMSStateoftheClimate.3. 

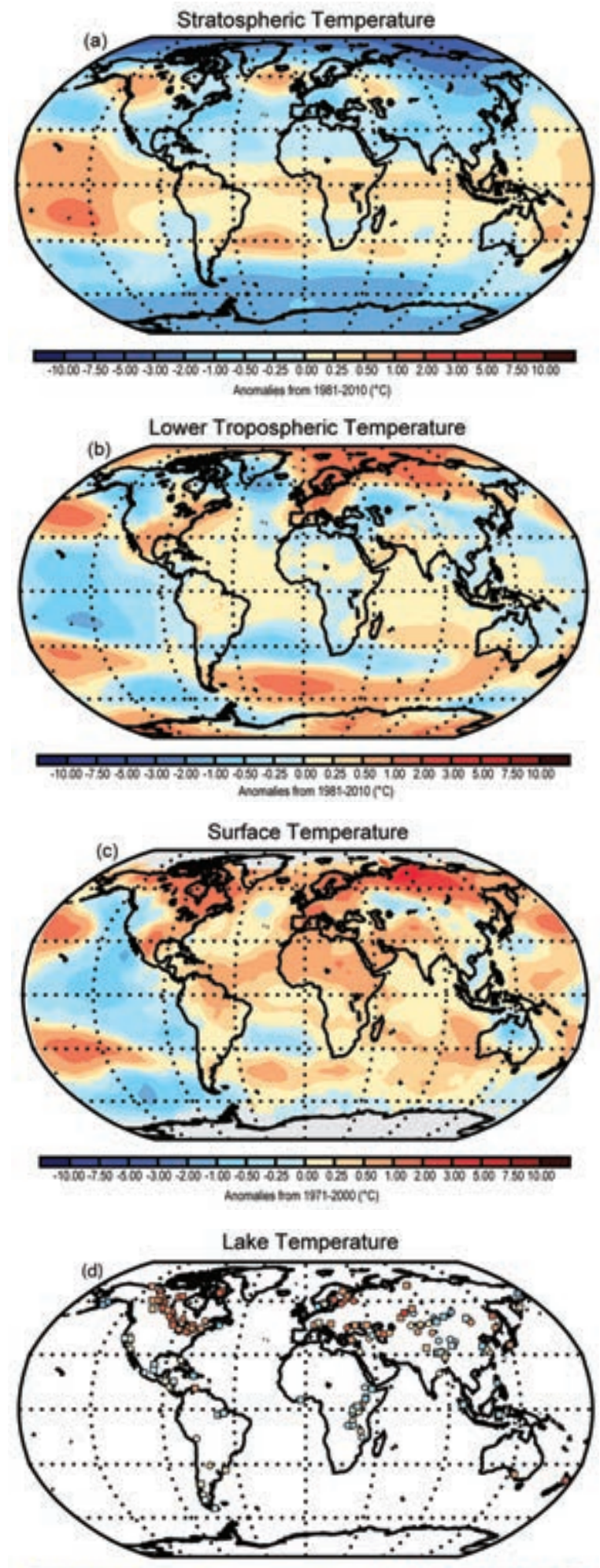

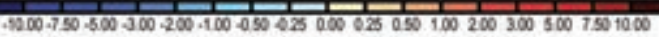
Anomiles flom mavort (ce)
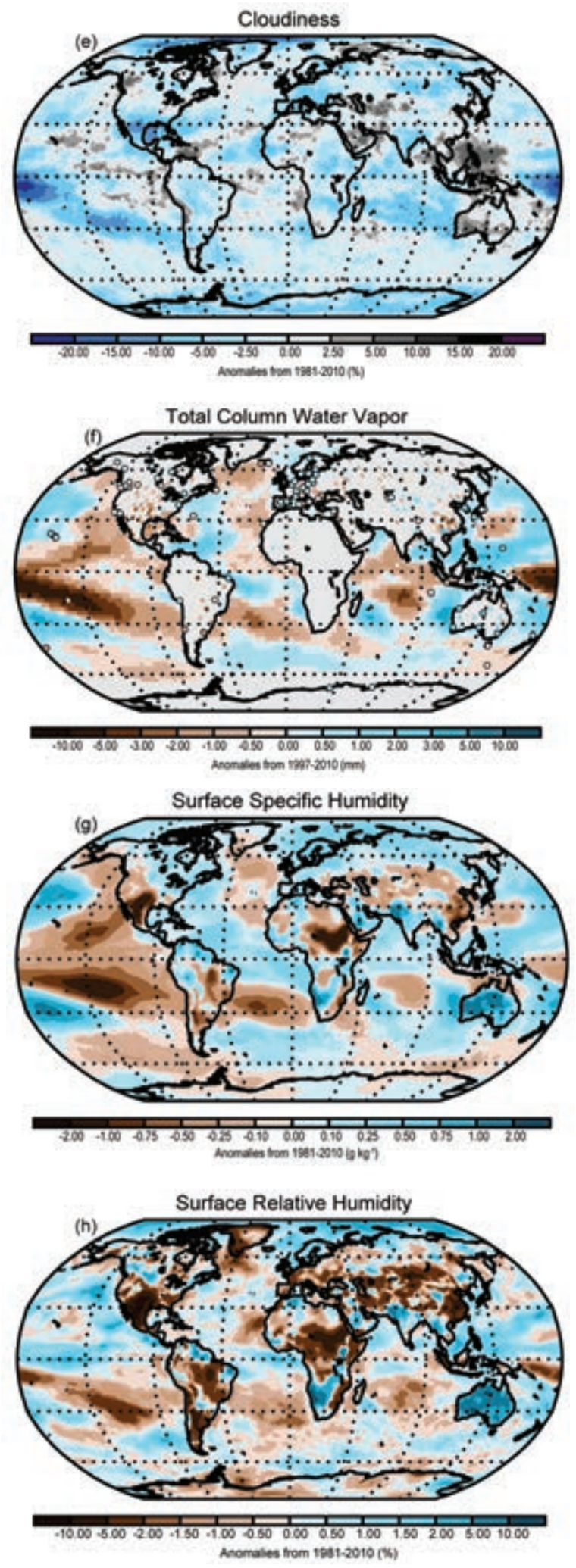

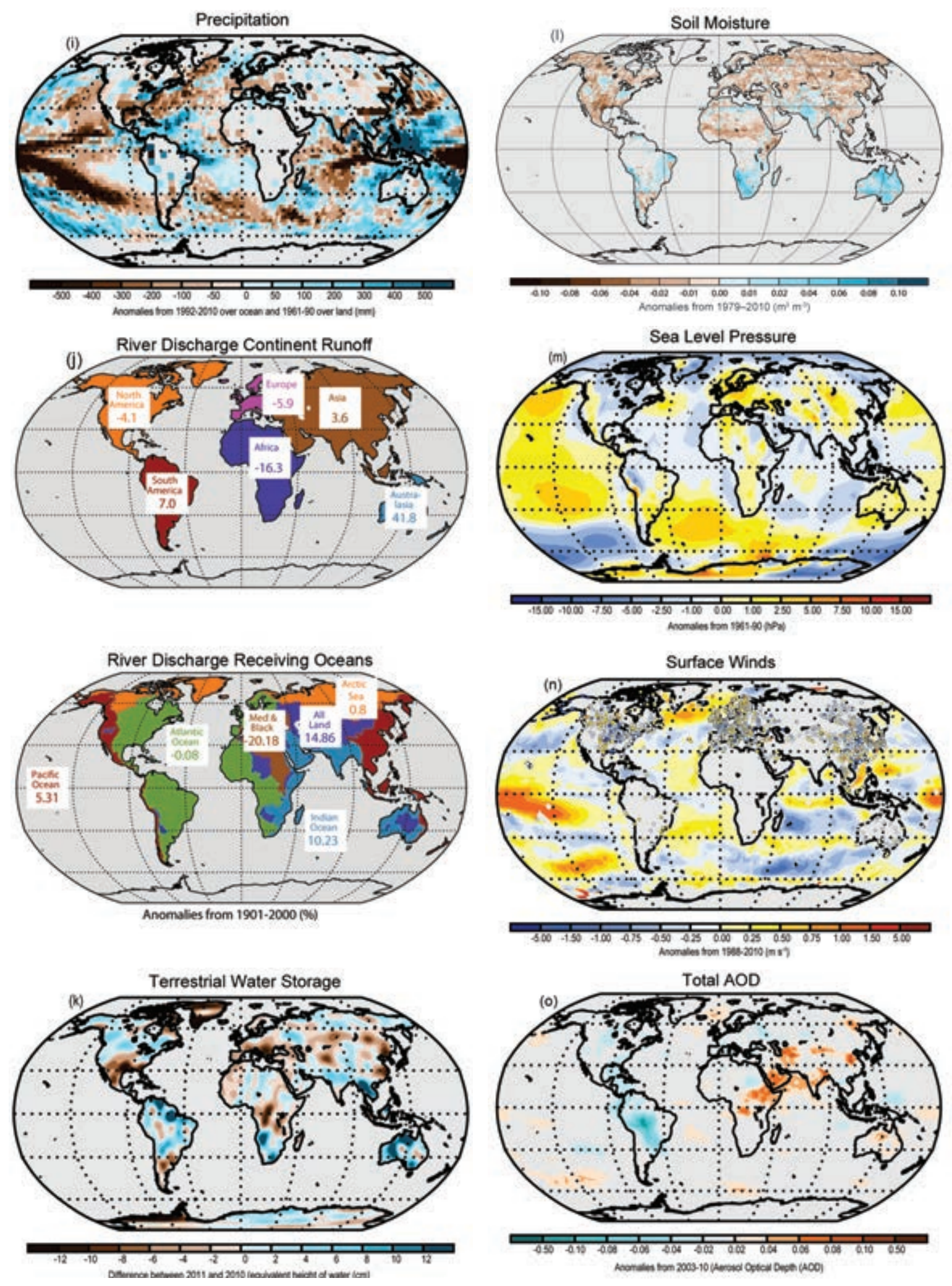

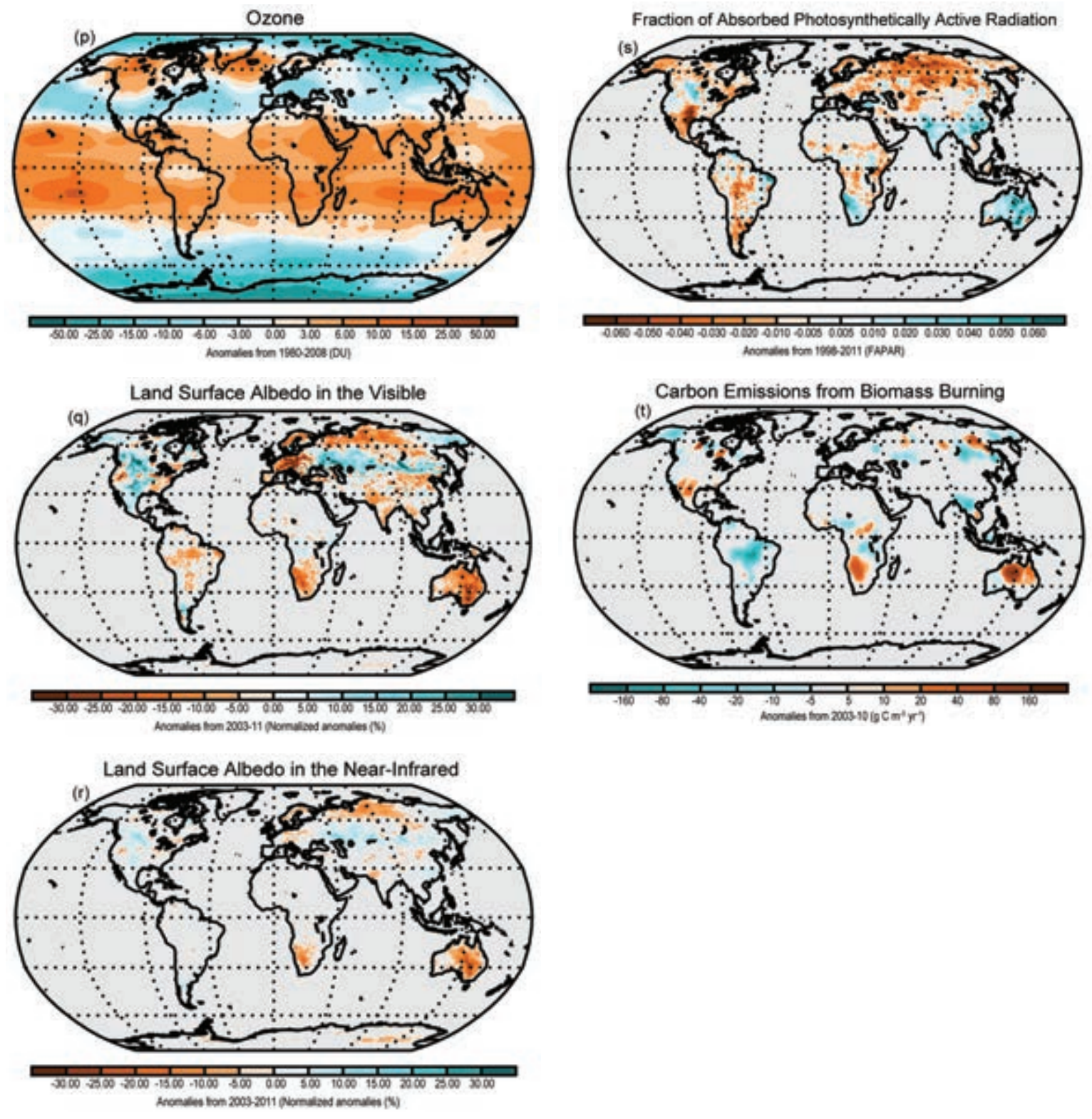

PLATE 2.I. (a) ERA-Interim 20 II anomalies of MSU Channel 4 equivalent for the lower stratospheric temperature; (b) ERA-Interim 20 II anomalies of MSU Channel 2LT equivalent for the lower tropospheric temperature; (c) NOAA-NCDC 20 II anomalies of surface temperature; (d) ARCLAKE 20 II summer season anomalies of lake surface temperature; (e) PATMOS-x 20 II anomalies of cloudiness; (f) SSMIS (Ocean) and radiosonde and ground-based GPS (circles) (Land) $201 \mathrm{I}$ anomalies map of TCWV anomalies of total column water vapour; (g) ERA-Interim 20 II anomalies of surface specific humidity; (h) ERA-Interim 20 II anomalies of surface relative humidity; (i) RSS and GHCN precipitation; (j) Water Balance Model (WBM) analysis by authors showing 20I I anomalies of river discharge over continents and into oceans; (k) GRACE satellite observations of $201 \mathrm{I}$ minus 2010 annual mean terrestrial water storage (the sum of groundwater, soil water, surface water, snow, and ice, as an equivalent height of water in $\mathrm{cm}$ ); (I) WACMOS satellite observations of $20 \mathrm{II}$ anomalies of soil moisture; (m) HadSLP2r 20 II anomalies of sea level pressure; (n) Satellite radiometer (ocean) and in situ (land; II 52 sites from ISD-Lite and Tim McVicar) $201 \mathrm{I}$ anomalies of surface wind speed; (o) MACC reanalysis for 20II anomalies of total aerosol optical depth; (p) GOME/SCIAMACHY/GOME2 $20 \mathrm{II}$ anomalies of stratospheric ozone; (q) MODIS White Sky broadband $201 \mathrm{I}$ anomalies of land surface albedo from the visible spectrum; (r) MODIS White Sky broadband $201 \mathrm{I}$ anomalies of land surface albedo from the near-infrared spectrum; (s) Combined SeaWiFS (NASA) and MERIS (ESA) 2011 anomalies of fraction of absorbed photosynthetically active radiation (FAPAR); (t) MACC GFAS processed MODIS observations for $20 \mathrm{II}$ anomalies of biomass burning in terms of annual carbon emission per unit area. 

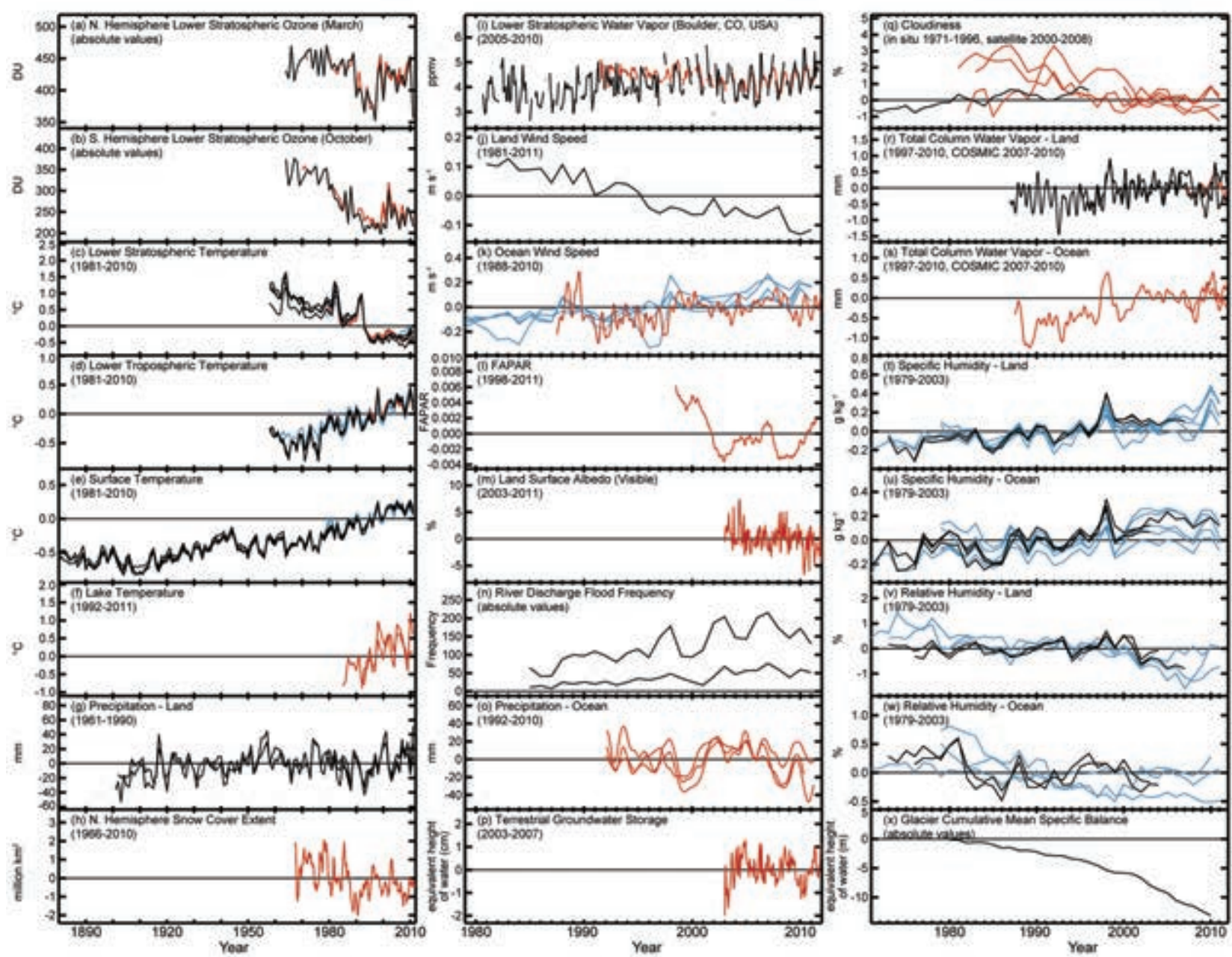

Plate 2.2 Global (or representative) average time series for essential climate variables. Anomalies are shown relative to the base period in parentheses although original base periods may differ. Data products are colored black for in situ (IS), red for satellite (S) and blue for reanalyses (R); (a) Northern Hemisphere lower stratospheric ozone in March (IIS, 2S); (b) Southern Hemisphere lower stratospheric ozone in October (IIS, 2S); (c) Lower stratospheric temperature (4IS, 2S, 2R); (d) Lower tropospheric temperature (4IS, 2S, 4R); (e) Surface temperature (4IS, 3R); (f) Lake surface temperature (2S); (g) Precipitation over land (3IS); (h) Northern Hemisphere continental snow cover extent (IS); (i) Lower stratospheric water vapor over Boulder, Colorado (IIS, 2S); (j) Surface wind speed over land (IIS); (k) Surface wind speed over ocean (IS, 4R); (I) FAPAR (IS); (m) Land surface albedo in the visible spectrum (IS); (n) River discharge flood frequency (2IS showing two magnitudes of flood); (o) Precipitation over ocean (3S); (p) Terrestrial groundwater storage (IS); (q) Cloudiness (IIS, 5S); (r) Total column water vapor over land (2IS, IS); (s) Total column water vapor over ocean (2S); (t) Surface specific humidity over land (3IS, 5R); (u) Surface specific humidity over ocean (3IS, 5R); (v) Surface relative humidity over land (3IS, 3R); (w) Surface relative humidity over ocean (2IS, 3R); (x) Glacier cumulative mean specific balance (IIS). See relevant sections and figures for more details. 


\section{SIDEBAR 2.I: CLIMATE DATA RESCUE AND STEWARDSHIP: FILLING THE GAPS IN 2IST CENTURY NEEDS-R. ALLEN, P. BROHAN, S. LEDUC, AND}

\section{K. M. WILLETT}

Decisions of substantial socioeconomic importance are being made based on climate data. Ideally, this requires high spatial and temporal resolution, globally complete coverage, well-documented metadata, long temporal length, and quantified uncertainties, in addition to free access and full traceability. However, climate data are recorded by a variety of sources, sometimes without a direct interest in weather and/or climate, and do not yet meet these requirements.

The longest instrumental records are those of temperature, precipitation, and pressure. For many times and places, digitized material is available only on monthly timescales but, with concerns about the modulation of climate extremes under global warming, there is a growing need for the recovery and digitization of daily and subdaily data.

Many records remain only in paper form, scattered in repositories around the world. It is estimated that there are at least as many undigitized as there are currently digitized data (Fig. SB2.I), and that many hard copy records are rapidly deteriorating beyond recognition. A compounding issue is that in some countries historical data are seen as a potential source of revenue, and are therefore not shared openly. Thus, there are gaps in our global holdings that could, albeit with considerable effort, be filled.

The major impediments to data rescue are finance, personnel, infrastructure, and the administration to coordinate a coherent global program. Key activities center on short-term

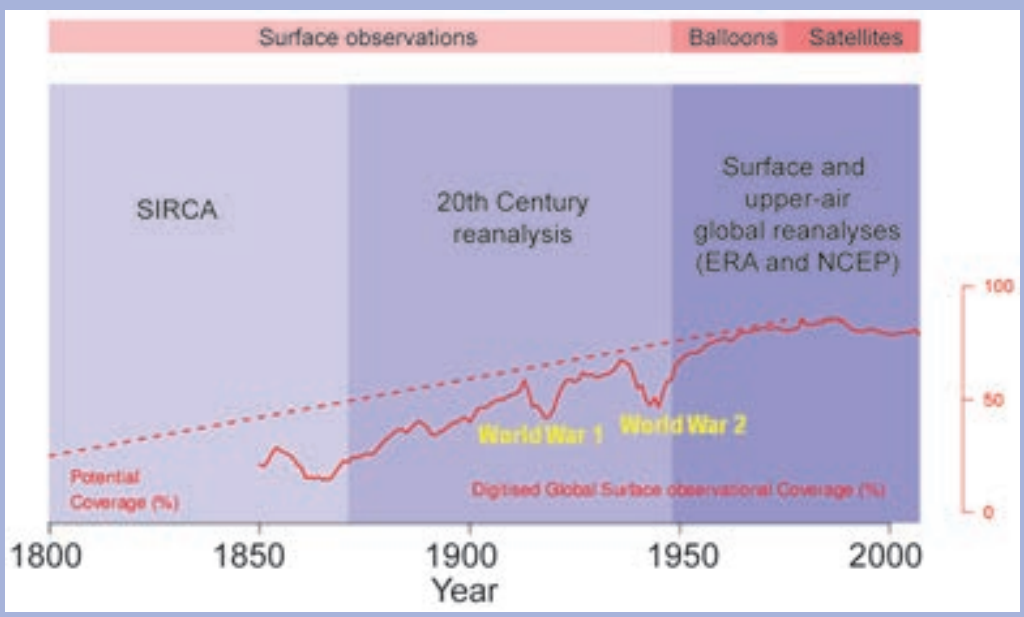

FIG. SB2.I. Digitized (solid red line) versus likely undigitized (dashed red line) data including potential available data for historical reanalyses. The blocks shaded blue through time show the range of ACRE-facilitated historical weather reanalyses in the context of contemporary international NCEP-NCAR and ECMWF reanalyses. (Source: Allan et al. 20II, Fig. 3) funded regional data rescue projects. International global efforts, such as the International Environmental Data Rescue Organization (IEDRO; http://iedro.org/), International Atmospheric Circulation Reconstructions over the Earth Initiative (ACRE; http://www.met-acre.org/), and the International Surface Temperature Initiative (ISTI; http://www. surfacetemperatures.org/), have evolved from "grassroots" actions by the climate community. Such initiatives are, however, insufficiently resourced to make the needed, additional data available for research and societal applications. Recent global economic downturns have exacerbated this situation. All of this is happening among continued calls for more data in order to improve the evidence basis for climatic variability and change. Nevertheless, considerable efforts worldwide are being made to rescue, digitize, image, combine, log, and store historical weather observations for posterity, and also facilitate greater data sharing and openness. These are summarized in Fig. SB2.2 and described in more detail below.

\section{Data rescue and digitization}

Data rescue is time consuming and costly. There are archives all over the world, for example, National Meteorological Service (NMS) repositories, archives of marine and terrestrial records from colonial eras, and records held by individuals. These data need to be located, scanned, transcribed into a machine readable format, and then assimilated into appropriate, well-resourced international databases, ideally where provenance is well maintained.

ACRE is the largest current global historical terrestrial and marine weather data rescue project (Allan et al. 20II). As Fig. SB2.2 shows, the initiative has many links and collaborators around the globe. Whereas ACRE focuses on mainly pre-World War II weather data from local, regional, and international repositories from all sources, IEDRO complements ACRE by working closely with NMSs to develop their capacity to recover, image, and digitize any important surface and upper air records, especially in developing countries.

Often these records contain material of historical interest (Fig. SB2.3). ACRE has established inter/cross-disciplinary engagements between climate, social, economic, environmental, and political sciences and the humanities worldwide, i.e., Historic Weather 


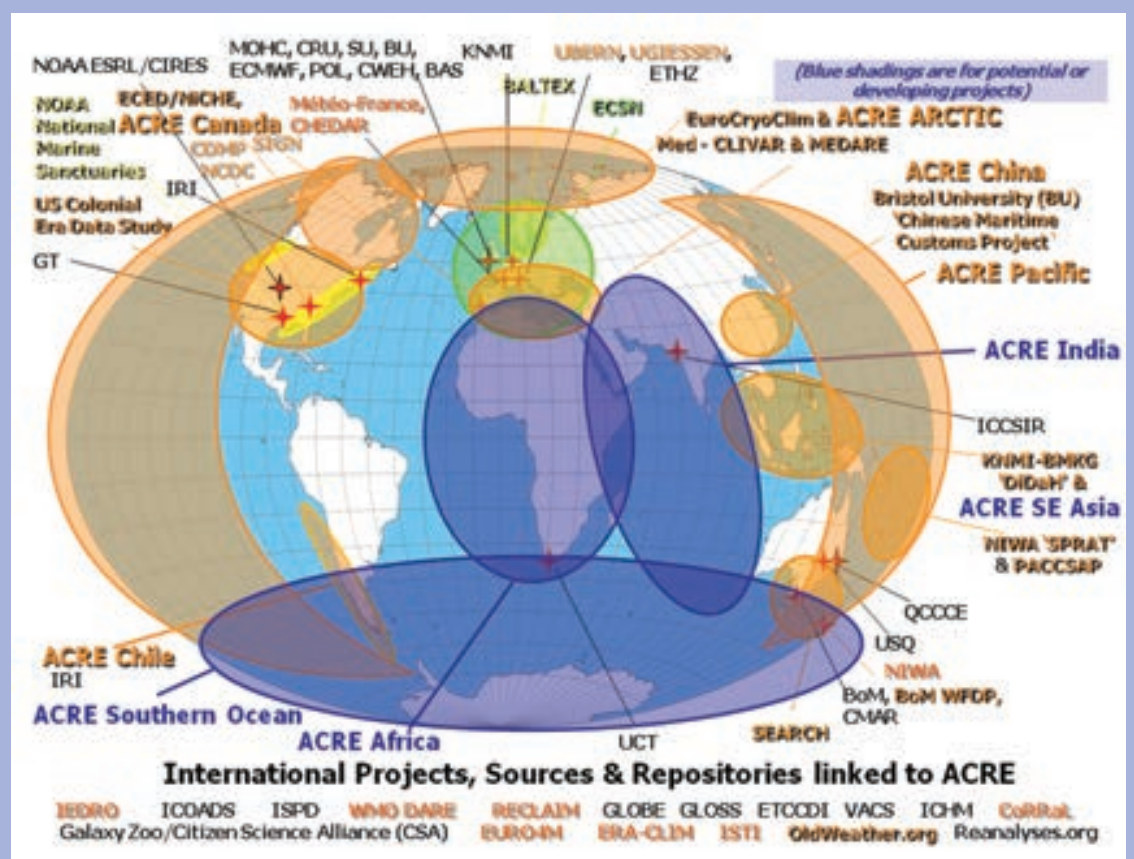

Fig. SB2.2. The full global range of collaborations, linkages, and projects involved in ACRE to date. Acronyms not defined in the text in Figs. SB2.I and SB2.2 are defined and detailed at http://sites.google.com/a/met-acre. org/acre/links.

(http://historicweather.cerch.kcl.ac.uk/node//2) and Shipping Archives and Integrated Logbooks of Ships (SAILS) (http:// sailsproject.cerch.kcl.ac.uk/). The combination of human interest and scientific value in the historical records has led to the successful oldWeather project (http://oldweather .org/), where thousands of volunteers transcribe weather and historical information in records from the UK and US national archives.

\section{Data repositories}

There are many online databanks. Often, they are regional in scope [e.g., European Climate Assessment and Dataset (ECAandD) or the Southeast Asian Climate Assessment and
Dataset (SACAandD)] or for specific variables [e.g., the International Surface Pressure Databank (ISPD)]. Most were developed and are maintained by a small number of people with limited resources. It is vital to transition such arrangements to guaranteed longterm funding through international partnerships with stable finances. Few databanks contain full traceability to data origin or measurement standards, and metadata are very sparse. To attempt true comprehensiveness and data provenance, these repositories need a framework of international effort and cooperation, combining expertise beyond climate science such as metrologists, statisticians, and software engineers. ISTI is attempting just that. It aims to be a resource for the creation of multiple climate data products by providing an open comprehensive databank with traceability and a data portal with visualization tools for derived products (Thorne et al. 20II).

\section{Data sharing}

Having open access to all climate data is a major objective. Until worldwide data sharing becomes a reality, various international efforts from the scientific data community will continue to champion this cause. Such efforts include databanks as mentioned above, specified networks such as the Global Climate Observing System (GCOS) Surface Network (http://gosic.org/gcos /GSN-program-overview.htm) or international collaboration projects such as CLIMDEX (http://www.climdex.org). The value of truly open global climate data cannot be overstated.

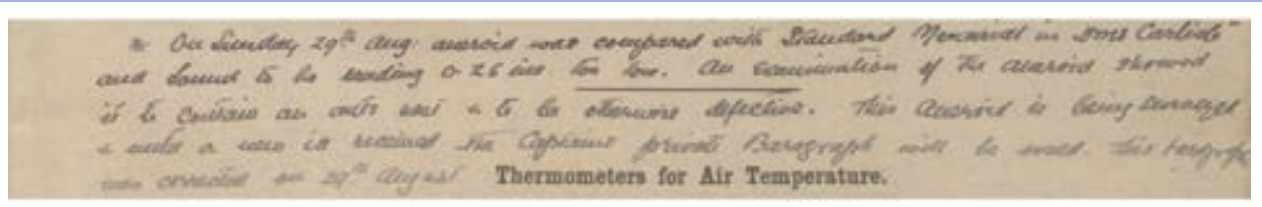

FIG. SB2.3. Human interest in a historical weather record: “On Sunday 29th Aug: aneroid was compared with standard mercurial in HMS Carlisle and found to be reading 0.26 ins. too low. An examination of the aneroid showed it to contain an ants nest and to be otherwise defective. This aneroid is being surveyed and until a new [one] is received the Captain's private barograph will be used. This barograph was corrected on 29th August" - from the logbook of HMS Tarantula (in 1920), via http://oldweather.org. 


\section{b. Temperature}

I) Surface temperature-A. Sánchez-Lugo, J. J. Kennedy, and P. Berrisford

La Niña conditions in the tropical Pacific Ocean during much of 2011 contributed to an overall cooler year than 2010 (Fig. 2.1, see online supplemental Figs. S2.1 and S2.2 for comparison), which ranked as either warmest or second warmest year on record, according to four independent analyses with periods of records extending back to the mid-to-late 1800 s [NASA-GISS, Hansen et al. 2010; HadCRUT3, Brohan et al. 2006; NOAA-NCDC, Smith et al. 2008; and, for the first time in this section, Japan Meteorological Agency (JMA), Ishihara 2006]. Nevertheless, the global surface temperature in 2011 was above the 1981-2010 base period average (Fig. 2.2a). Compared with other years in which La Niña was present (section 2e1, Fig. 2.31), 2011 was unusually warm, only matched by 2001 which featured a relatively weak La Niña episode.

2011-the coolest year since 2008-was among the top 15 years on record, ranking from 9 th to 12 th warmest since records began. The year was $0.09^{\circ} \mathrm{C}$ above the 1981-2010 average annual value in HadCRUT3, $0.11^{\circ} \mathrm{C}$ in the NOAA-NCDC analysis, $0.16^{\circ} \mathrm{C}$ in the NASA-GISS analysis, and $0.07^{\circ} \mathrm{C}$ in the JMA analysis. Each agency analyzes air temperatures over land and sea surface temperatures (SSTs) observed from ships and buoys separately and then merges the land and SST datasets to form a global analysis. While their methods differ, leading to minor differences in anomalies, all four analyses are in close agreement (Fig. 2.2a). The datasets show global temperatures rising gradually at a rate of between $0.71^{\circ} \mathrm{C}$ and $0.77^{\circ} \mathrm{C}$

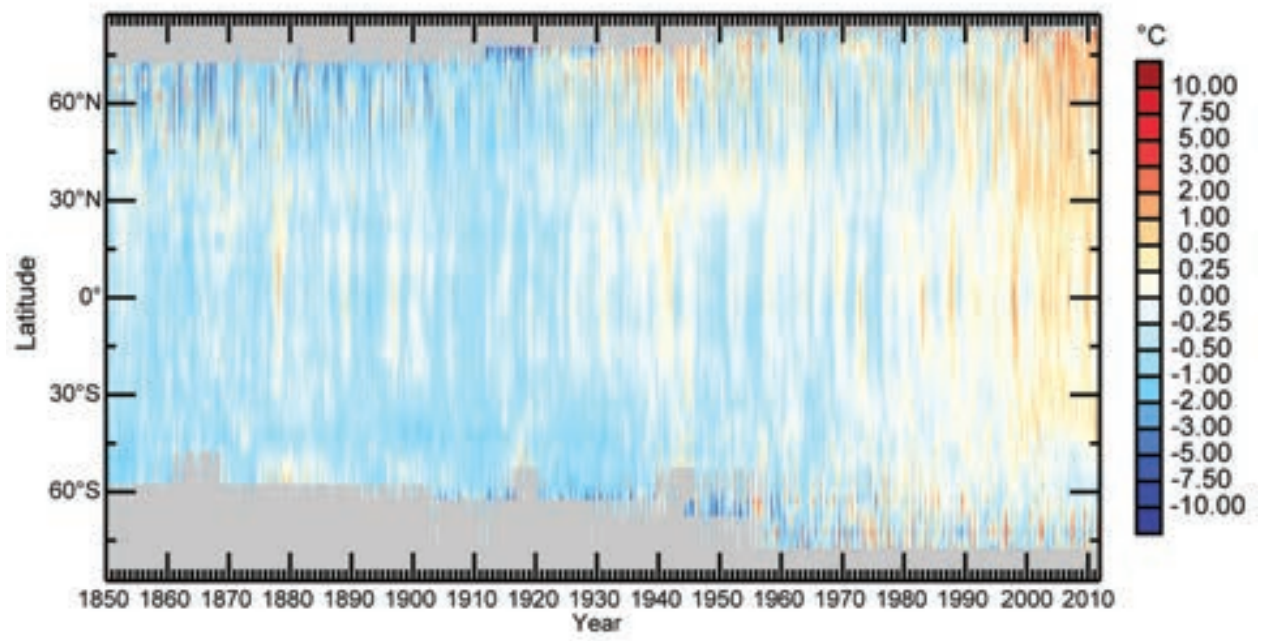

Fig. 2.I. HadCRUT3 monthly mean anomalies ( ${ }^{\circ} \mathrm{C}$, 197I-2000 base period) for surface temperature by latitude. Gray areas indicate regions where data are unavailable.

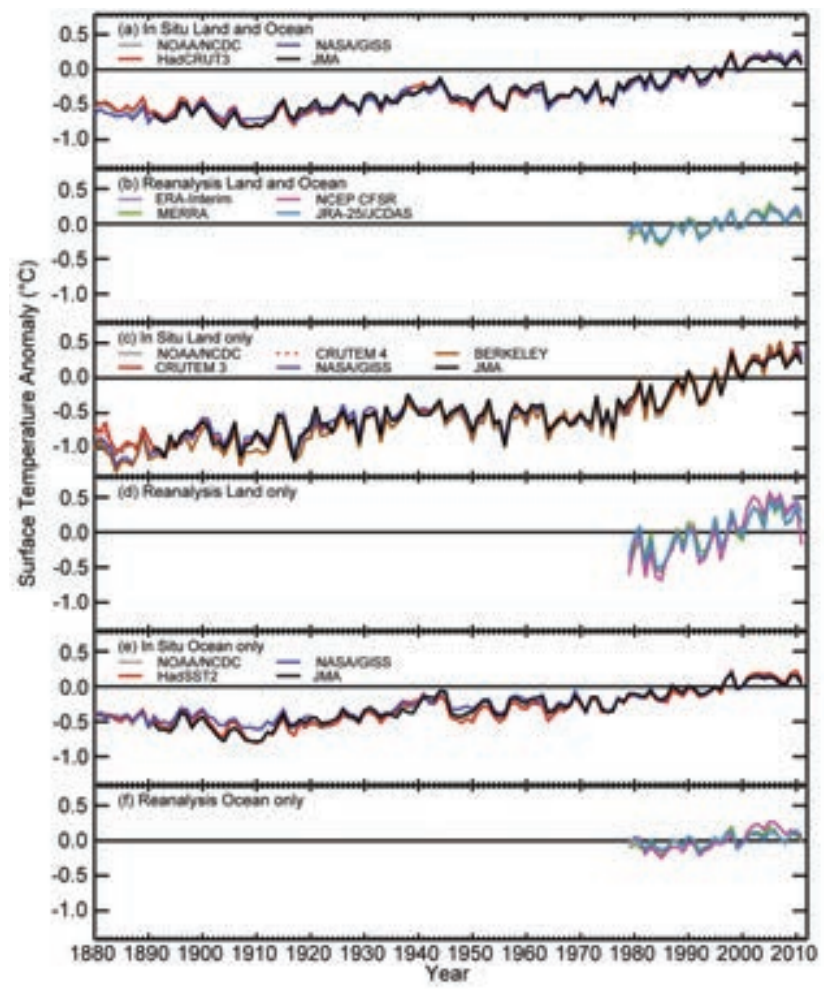

FIG. 2.2. Global average surface temperature annual anomalies $\left({ }^{\circ} \mathrm{C}, 198 \mathrm{I}-2010\right.$ base period). In situ datasets for the globe: as listed in the text. In situ datasets for land only: NOAA/NCDC (see text), CRUTEM3 (see text), CRUTEM4 (Jones et al. 20I2), NASA/GISS (see text), BERKELEY (Rohde et al. 2012, submitted to J. Geophys. Res.), and JMA (see text). In situ dataset for ocean only: NOAA/NCDC, HadSST2 (see text), NASA/GISS, and JMA. Reanalyses datasets: ERAInterim (Dee et al. 20Ila), MERRA (Rienecker et al. 20II), NCEP CFSR (Saha et al. 20I0), and JRA-25/ JCDAS (Onogi et al. 2007). 
ocean surface temperatures, the global land-only surface temperatures and global SSTs, analyzed separately, also show increasing trends (Fig. 2.2c-f). The global average land surface temperature increased at a rate of between $0.09^{\circ} \mathrm{C}$ and $0.10^{\circ} \mathrm{C}$ decade $^{-1}$ since 1901 and between $0.23^{\circ} \mathrm{C}$ and $0.28^{\circ} \mathrm{C}$ decade $^{-1}$ since 1971 , while the global average SST increased at a rate of between $0.06^{\circ} \mathrm{C}$ and $0.07^{\circ} \mathrm{C}$ decade ${ }^{-1}$ since 1901 and between $0.10^{\circ} \mathrm{C}$ and $0.13^{\circ} \mathrm{C}$ decade $^{-1}$ since 1971 .

Despite two La Niña episodes (the first strong and the second weaker), global-average SSTs remained above-average throughout the year (Figs. 2.2e-f), ranking as either 11th or 12th warmest on record. The global SST in 2011 was $0.02^{\circ} \mathrm{C}$ above the $1981-2010$ average in the NASA-GISS analysis, $0.06^{\circ} \mathrm{C}$ in the NOAA-NCDC analysis, $0.09^{\circ} \mathrm{C}$ in the HadSST2 (Rayner et al. 2006), and $0.04^{\circ} \mathrm{C}$ in the JMA analysis. Annualmean SSTs were above average across the Atlantic, Indian, and western Pacific

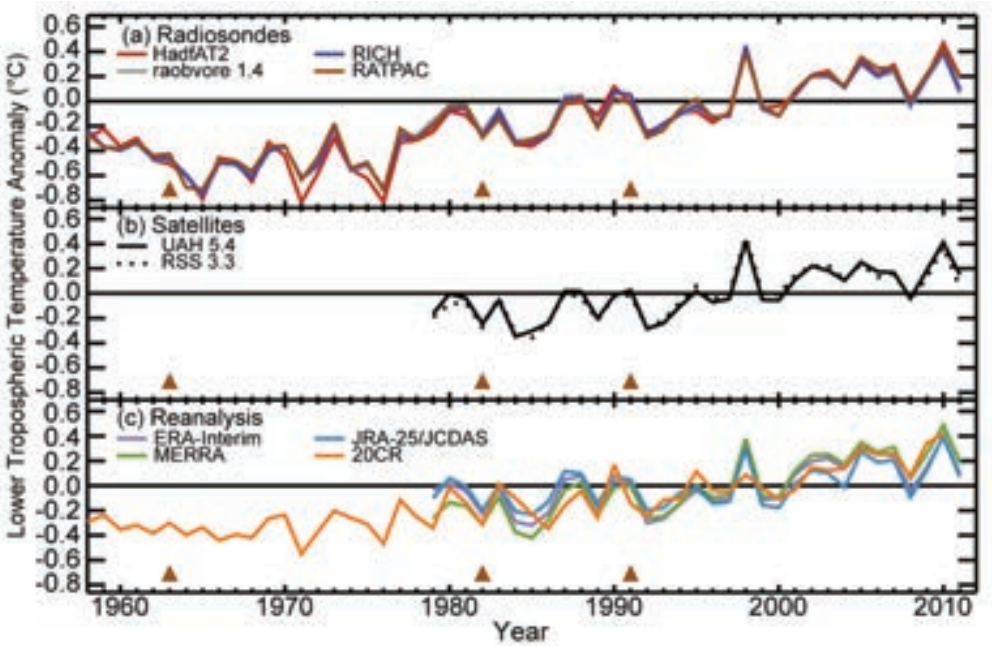

Fig. 2.3. Global average lower tropospheric temperature annual anomalies ( ${ }^{\circ} \mathrm{C}$; 198I-2010 base period) for the MSU channel 2LT equivalent layer. Radiosondes: HadAT2 (Thorne et al. 2005 - 465 day, 384 night stations), RATPAC (Free et al. 2005 - 85 stations), RAOBCORE (Haimberger et al. 20II, manuscript submitted to J. Climate - II 84 stations) and RICH (Haimberger et al. 20 I I , manuscript submitted to J. Climate - II84 stations). Satellites: UAHv5.4 (Christy et al. 20II) and RSSv3.3 (Mears and Wentz 2009). Reanalyses: as described in Fig. 2.2 in addition to 20CR (Compo et al. 20II). Major volcanic eruptions which cause 2-3 year cooling episodes are indicated by triangles in 1963, 1982, and 1991 .
Oceans, and below average across the eastern and equatorial Pacific Ocean, southern Atlantic Ocean, and some regions of the Southern Oceans (Plate 2.1c, see online supplemental Figs. S2.3, S2.4, and S2.5 for comparison; see also section $3 b$ ).

Unusually high temperatures affected most land areas during 2011, with the most prominent warmth across Russia (Plate 2.1c; see also section 7g1). Unusually low temperatures were observed across parts of Australia, the northwestern United States, and central and southeastern Asia (see also sections 7h2, 7b2, and $7 \mathrm{~g} 2$, respectively). Averaged globally, the 2011 land surface temperature was $0.29^{\circ} \mathrm{C}$ above the $1981-2010$ average in the NASA-GISS analysis, $0.25^{\circ} \mathrm{C}$ in the NOAA-NCDC analysis, and $0.20^{\circ} \mathrm{C}$ in the CRUTEM3 (Brohan et al. 2006) and JMA analysis, ranking from 5 th to 10th warmest on record, depending on choice of dataset. In ERA-Interim the 2-m temperature over land was $0.30^{\circ} \mathrm{C}$ above the $1981-2010$ average, making 2011 the eighth warmest year on record.

2) LOWER tRopospheric temperature-J. R. Christy

Based on several sources of observational evidence, the temperature of the global lower tropospheric layer (MSU channel 2LT equivalent, surface to $\sim 8 \mathrm{~km}$ ) was approximately $+0.15^{\circ} \mathrm{C}\left(0.05^{\circ} \mathrm{C}-0.20^{\circ} \mathrm{C}\right)$ above the 1981-2010 period average (Fig. 2.3). Global monthly tropospheric temperature anomalies reflect La Niña progression by being cooler in January-March and October-December than in the mid-year period, relative to the long-term average. Since the major global atmospheric temperature responses to these tropical ocean temperature changes are in the boreal winter, calendar-year anomalies do not capture their main impact very well. Considering the previous 33 (satellite) and 54 (radiosonde) years of records, 2011 ranked from 8th to 12th warmest, depending on the dataset examined.

New versions of some of the datasets are used. RAOBCORE and RICH radiosonde datasets have been updated. Satellite dataset RSSv3.3 has had very minor new adjustments applied to v3.2, while UAHv5.4 merely recalculated anomalies relative to 1981-2010 rather than 1979-1998 as in v5.3. HadAT and RATPAC are much the same.

Reanalysis products are also included. These assimilate all available observational data into a global forecast model that provides dynamical and thermodynamical coherency in space and time (Dee et al. 2011b). The period of record for ERA-Interim now dates back to 1979. MERRA, JRA-25/JCDAS, and 20CR are also included. Issues with incorporating new observing systems and controlling for errors are two of the factors that lead to differences among the 


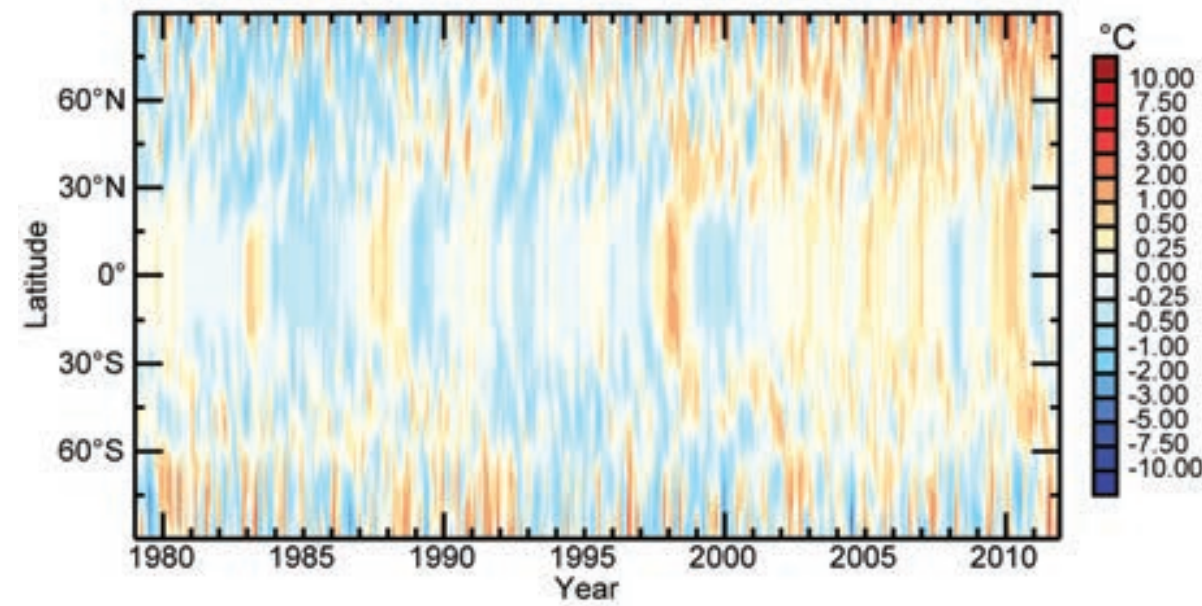

FIG. 2.4. ERA-Interim monthly mean anomalies ( ${ }^{\circ} \mathrm{C}, 1981-2010$ base period) of lower tropospheric temperature MSU channel 2 LT equivalent by latitude. ence between the linear and stair-step approximations is not great. The spatial distribution of trends from 1979 to 2011 (Fig. 2.5) shows latitudinal symmetry between $40^{\circ} \mathrm{N}$ and $40^{\circ} \mathrm{S}$. This broadly reflects the presence of early, strong El Niño warm events (e.g., 1983) and later La Niña cool events (e.g., 2010/11) in the cooling tropical central Pacific, with warming elsewhere. reanalysis datasets and relative to the observationonly datasets.

The latitude cross section with time (Fig. 2.4) displays the major impacts, mainly tropical, of El Niño warming (e.g., 1998, 2010), La Niña cooling (e.g., 1989, 2011), and volcanic cooling (e.g., El Chichón in 1982, Pinatubo in 1991). Areas poleward of $30^{\circ} \mathrm{N}$ have experienced noticeable warming over the period.

The estimated linear trend for the entire time series (Fig. 2.3) beginning in 1958 (radiosonde era) and also beginning in 1979 (satellite era) is +0.150 $\pm 0.025^{\circ} \mathrm{C}$ decade $^{-1}$ where “ $\pm 0.025^{\prime}$ " represents the spread of the various datasets - an indication of error arising from different methodological choices. In terms of statistical confidence, the spread is $\pm 0.06^{\circ} \mathrm{C}$ decade $^{-1}$. However, an examination of the time series indicates a somewhat stair-step evolution (not strictly linear) with what may be viewed as quasi-shifts to warmer temperatures in the late 1970s and during the large 1997/98 ENSO event. Note that the differ-

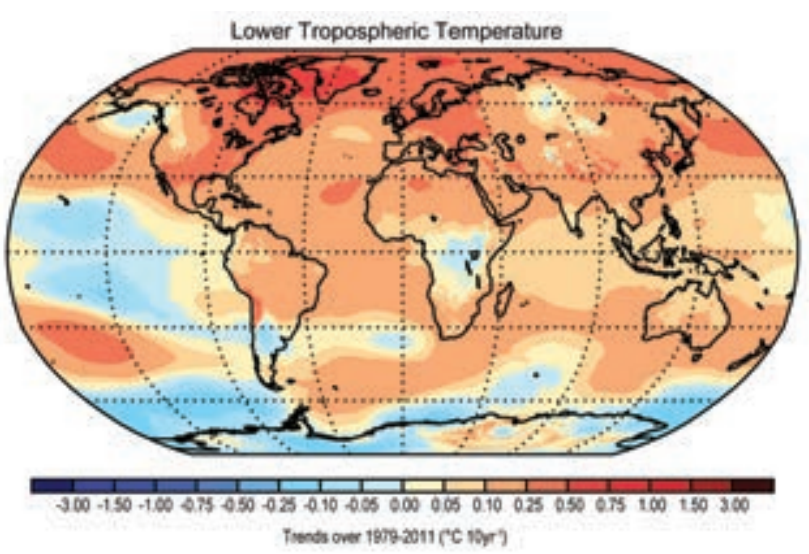

FIG. 2.5. ERA-Interim decadal trends in lower tropospheric temperature $\left({ }^{\circ} \mathrm{C} 10 \mathrm{yr}^{-1}\right)$ for the MSU channel 2LT equivalent layer 1979-20II.
This warming is due in part to two substantial volcanic eruptions in the first half of the 33-year record, the cooling effect of which depressed tropical tropospheric temperatures for two to three years at those times. The pattern of trends in the extratropics, however, reveal an opposing anomaly structure, with the northern regions indicating significant warming since 1979 while the southern polar areas largely experienced little warming or actual cooling.

The pattern of anomalies associated with the La Niña mode is seen in their 2011 spatial distribution (Plate 2.1b). The areas of cooler atmospheric temperatures over the Pacific Ocean, symmetric about the equator, are balanced by warmer anomalies farther poleward and eastward, then by negative anomalies poleward and eastward again. Elsewhere, in 2011, northwest North America and southern Greenland were cool while the south and east of North America was warm. In particular, the exceedingly hot and dry summer in the southern US and northern Mexico appear in the annual average. Noteworthy positive anomalies occurred from Europe to northern Asia and the North Pole, with negative anomalies in southern Asia. Somewhat similarly, in the Southern Hemisphere, positive anomalies were experienced generally around $30^{\circ} \mathrm{S}-60^{\circ} \mathrm{S}$ and negative anomalies toward the equator.

3) LoWer stratospheric temperature-C. Long and J. R. Christy

The lower stratosphere during the early months of 2011 was strongly influenced by the La Niña conditions and the phase of the quasi-biennial oscillation (QBO). The cooler tropical troposphere associated with a La Niña (section 2b2) is generally accompanied by a warmer tropical lower stratosphere. Descending 


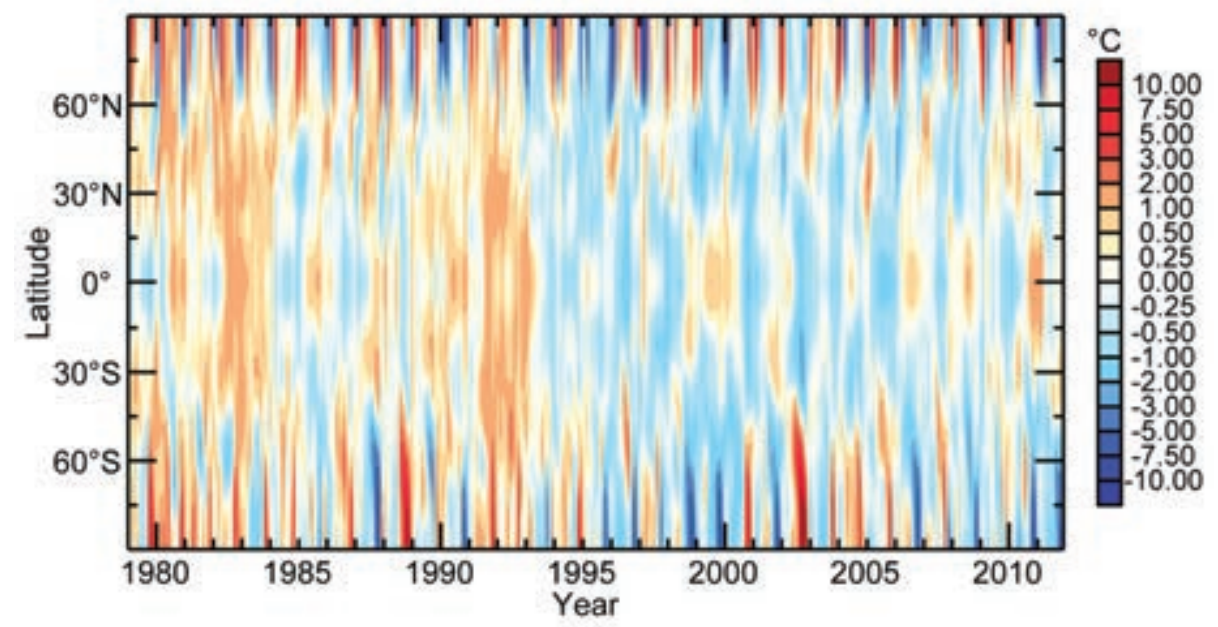

FIG. 2.6. ERA-Interim monthly mean anomalies ( ${ }^{\circ} \mathrm{C}$; $198 \mathrm{I}-2010$ base period) of lower stratospheric temperature MSU channel 4 equivalent by latitude. for most of 2011. The Northern Hemisphere winter 2010/11 was also atypical for recent years in that no midwinter warming occurred. Minimal poleward heat flux was observed during the January-February time frame, associated with colder February-March polar temperatures (see online supplemental Fig. S2.6).

The lower stratospheric global mean temperatures, as meawesterly winds in the tropical lower stratosphere, as in 2011, are associated with a decrease in the residual Brewer Dobson circulation, reducing transport from the tropics to the extratropics and polar latitudes (Baldwin et al. 2001). Associated with this phase of the $\mathrm{QBO}$ is a warmer tropical lower stratosphere and higher ozone amounts (section 2g3). In the polar regions, cooler temperatures are found with lower amounts of ozone. This pattern dominated the 2011 anomalies over the globe (Plate 2.1a), quite in contrast to 2010 (Free 2011, Plate 2.1a). Figure 2.6 shows that in the Northern Hemisphere winter months of 2010/11, cold anomalies were present in the mid-tohigh latitudes, while the tropics were anomalously warm. Similarly, the Southern Hemisphere lower stratosphere polar temperatures were below normal

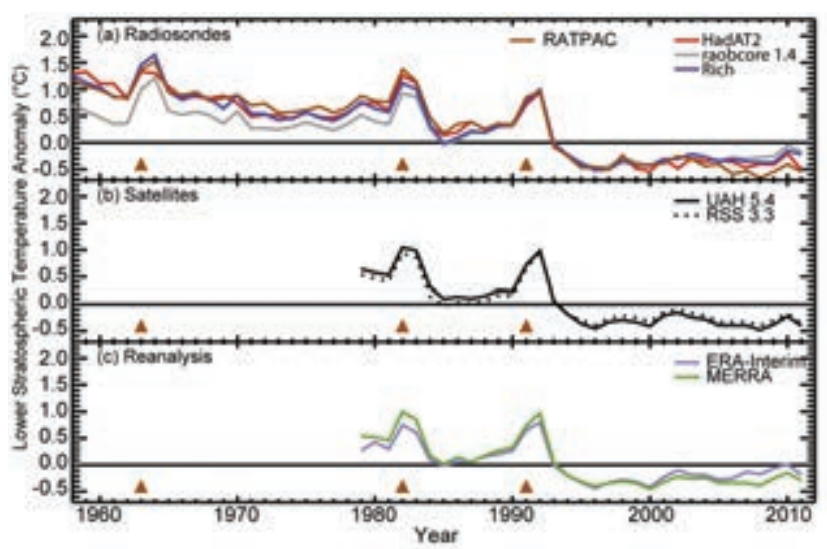

FIG. 2.7. Global average lower stratospheric temperature annual anomalies ( ${ }^{\circ} \mathrm{C}$; 198I-2010 base period) for the MSU channel 4 equivalent layer. Radiosondes, satellites, and reanalyses are as shown in Fig. 2.3. Major volcanic eruptions which cause 2-3 year warming episodes are indicated by triangles in 1963, 1982, and 1991. sured by the MSU channel 4 and its equivalent channel 9 of AMSU, are shown in Fig. 2.7. They show a general downward trend from 1979 to 1996 $\left(-0.505^{\circ} \mathrm{C}\right.$ decade $^{-1}$ and $-0.402^{\circ} \mathrm{C}$ decade $^{-1}$ for UAH and RSS, respectively) interrupted by the El Chichón and Mount Pinatubo volcanic eruptions. From 1996 to present, there has been very little trend $\left(-0.022^{\circ} \mathrm{C}\right.$ decade $^{-1}$ and $-0.034^{\circ} \mathrm{C}$ decade $^{-1}$ for UAH and RSS, respectively). The warm tropical temperatures during December 2010-February 2011 show up in the global mean. Three of the four radiosonde datasets have a stronger cooling trend than the satellites during the period $1979-1996\left(-0.628^{\circ} \mathrm{C}\right.$ decade $^{-1},-0.566^{\circ} \mathrm{C}$ decade $^{-1}$, and $-0.714^{\circ} \mathrm{C}$ decade $^{-1}$ for HADAT2, RICH, and RATPAC, respectively). The exception was the RAOBCORE dataset, with a cooling trend of $-0.395^{\circ} \mathrm{C}$ decade $^{-1}$. In the later 2000 s, the radiosonde datasets are less consistent. Their trends during $1996-2011$ are $0.046^{\circ} \mathrm{C}$ decade $^{-1}, 0.170^{\circ} \mathrm{C}$ decade $^{-1}$, $0.139^{\circ} \mathrm{C}$ decade $^{-1}$, and $-0.111^{\circ} \mathrm{C}$ decade ${ }^{-1}$ for HADAT2, RAOBCORE, RICH, and RATPAC, respectively. The reanalyses should reproduce the lower stratospheric temperatures that the satellites observe quite well as these satellite channels are the primary source of temperature information. However, the ERA-Interim and MERRA show smaller cooling trends from 1979 to $1996\left(-0.316^{\circ} \mathrm{C}\right.$ decade $^{-1}$ and $-0.397^{\circ} \mathrm{C}$ decade $\left.^{-1}\right)$ than the satellites and radiosonde datasets (see online supplemental Fig. S2.7 for trends over the globe). The two reanalyses have increasing differences in the later 2000s with the ERA-Interim showing a warming trend from 1996 -present $\left(0.195^{\circ} \mathrm{C}\right.$ decade $\left.^{-1}\right)$ and MERRA showing a slight cooling trend $\left(-0.037^{\circ} \mathrm{C}\right.$ decade $^{-1}$ ) during this period. 
Despite efforts to utilize the Stratospheric Sounding Unit (SSU) observations pre-1998 and then transition to AMSU-A post-1998, trend determination of the upper and mid-stratosphere is still suspect (Seidel et al. 2011). The NESDIS/STAR (L. Wang et al. 2012) evaluation of the SSU channels does offer hope that the SSU data can soon be utilized for middle and upper stratospheric monitoring. Several institutes (NESDIS, CPC, RSS) are looking into extending the SSU long-term dataset with the AMSU-A on the current POES satellites and AMSR data from NPP and JPSS satellites.

4) Lake surface temperature-S. Hook, R. C. Wilson, S. MacCallum, and C. Merchant

In addition to the Inland Water Body Project (IWBP) satellite thermal infrared (TIR) lake product (Schneider and Hook 2010) introduced last year, the Along-track scanning radiometer Reprocessing for Climate / Lake (ARCLAKE) (MacCallum and Merchant 2012), also TIR, is included here. For the average of the 84 lakes (quasi-global) common to both datasets 2011 is cooler than 2010. There are notable differences between the two, highlighting the uncertainty due to different methodological choices.

The IWBP contains 184 lakes, with 111 lakes yielding at least 15 valid seasonal means covering 1985 to 2011. Seasonal means are constructed from summer nighttime data averaged over the warm season (see Fig. 2.8) from the Advanced Very High Resolution Radiometers (AVHRR; 1985-2009), the Along-Track Scanning Radiometers (ATSR; 1992-2011), and the Moderate Resolution Imaging Spectroradiometer (MODIS; 2010-2011) aboard the Terra satellite. For

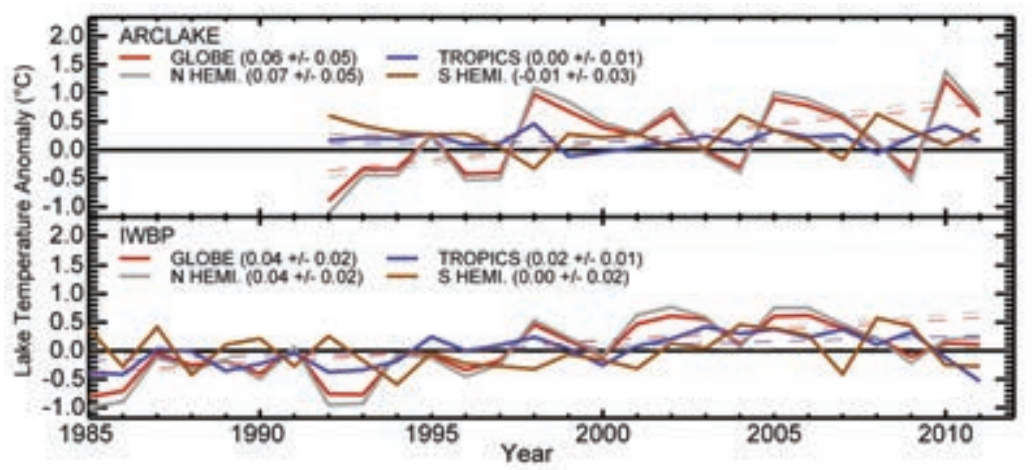

FIG. 2.8. Global and regional annual average anomalies $\left({ }^{\circ} \mathrm{C}\right)$ for $84 \mathrm{com}$ mon sites for (top) ARCLAKE (1992-20II base period) computed from ATSR data and (bottom) IWBP (1985-20II base period) computed from merged satellite data (AVHRR, ATSR, and MODIS). Tropical $\left(30^{\circ} \mathrm{S}-30^{\circ} \mathrm{N}\right)$ anomalies for ARCLAKE are computed as all-year averages while IWBP tropical anomalies are computed for the dry season. The extratropical Northern and Southern Hemisphere anomalies are warm-season averages (Jul-Sep and Jan-Mar respectively).
MODIS and ATSR, skin temperatures were retrieved whereas AVHRR measurements were retrieved as bulk temperatures. To merge the datasets, the skin measurements of MODIS and ATSR were adjusted to equivalent AVHRR measurements. This maximizes data coverage and extends the satellite records, which improves trend calculation (Schneider and Hook 2010).

The ARCLAKE project covers 258 large lakes, with 164 yielding warm season average time series covering both hemispheres from 1992 to 2011 (MacCallum and Merchant 2012). It is based only on the series of three ATSRs, reprocessed with improved ARCLAKE cloud detection and physics-based surface temperature estimation. Overlaps between sensors in the series have been used to stabilize the calibration of the full time series, minimizing the potential for instrument-related artifacts in trend calculations.

Using ARCLAKE, 2011 warm season average lake temperatures were generally above average in the Northern Hemisphere, especially over Europe and northeastern North America (Plate 2.1d), agreeing with land-air and sea surface temperatures (Plate 2.1c). Cool anomalies over eastern and southeastern Asia and Alaska are also reasonably consistent. Elsewhere, the signal is more mixed and less consistent with land-air and sea temperatures, with cooling over parts of Africa and Central and South America. Global and regional average anomaly time series are presented for 84 lakes common to both datasets (Fig. 2.8). Year-to-year variability is large both within and among regions, and also between IWBP and ARCLAKE, which use different methodologies. From 2010 to 2011 IWBP shows a small warming in the Northern Hemisphere, cooling in the tropics, and no change in the Southern Hemisphere. ARCLAKE shows 2011 as cooler than 2010 generally, except for the Southern Hemisphere. The IWBP global mean trend is +0.04 $\pm 0.02^{\circ} \mathrm{C} \mathrm{yr}^{-1}(\mathrm{p}<0.001)$, likely dominated by the large number of Northern Hemispheric lakes. Weighting the three regions (northern, southern, and tropical) equally yields a global trend of $+0.02^{\circ} \mathrm{C} \mathrm{yr}^{-1}$. ARCLAKE trends are less certain because of the shorter time period and apparently greater interannual variability. The year-to-year variations show similar features, and all the trends are consistent within uncertainties with those 

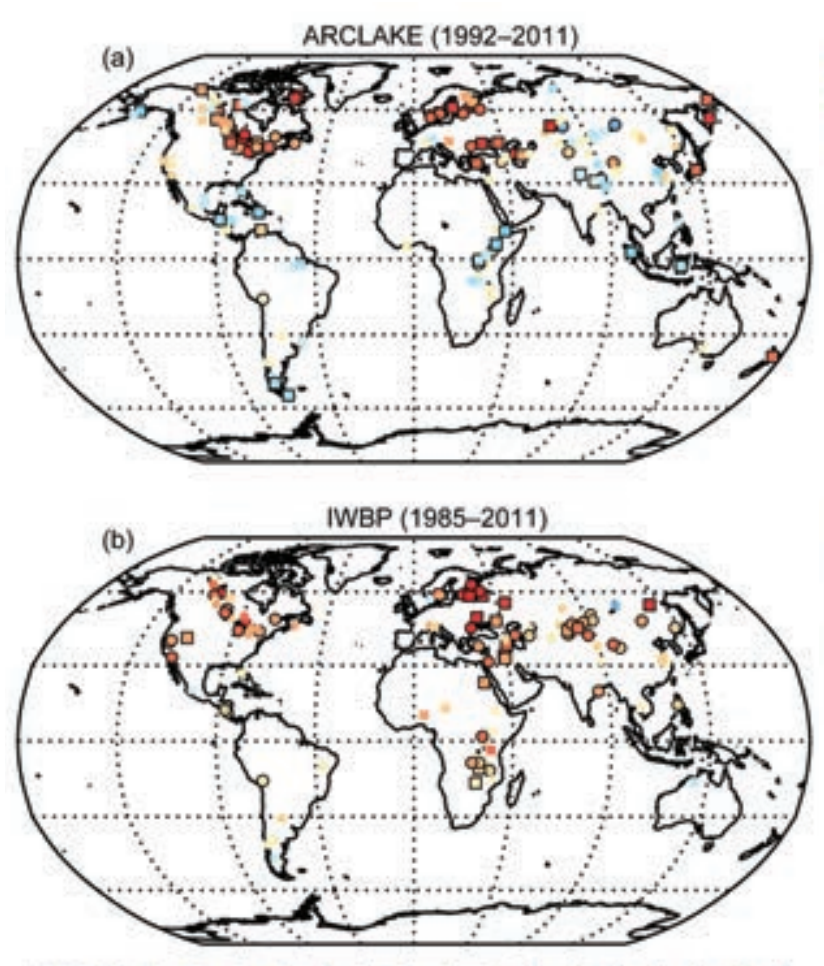

$-1.00-0.50-0.25-0.10-0.06-0.06-0.04-0.020 .000020 .040 .060 .050 .100 .250 .501 .00$ Trends $\left({ }^{\circ} \mathrm{C} \mathrm{yr}^{-1}\right)$

Fig. 2.9. Lake temperature trends $\left({ }^{\circ} \mathrm{C}\right)$ for (a) 164 lakes in ARCLAKE for 1992-20II, and (b) III IWBP lakes with I5 valid seasons for $1985-20 \mathrm{II}$. In each plot, circles indicate lakes present in both datasets, and black borders indicate trends that are larger than the trend uncertainty.

of IWBP. Cooling from the 1991 Mount Pinatubo eruption and warming from the strong $1998 \mathrm{El} \mathrm{Niño}$ event are apparent.

The 164 lakes in the ARCLAKE dataset (Fig. 2.9a) show several spatially coherent patterns in trends (1992-2011). Trends for the African rift valley, Caribbean, and central Asian lakes are negative (0 to $\left.-0.05^{\circ} \mathrm{C} \mathrm{yr}^{-1}\right)$. In contrast, there are generally larger warming trends for lakes in North America and Europe (up to $+0.16^{\circ} \mathrm{C} \mathrm{yr}^{-1}$ in the case of Lake Nipigon, Canada). The 111 IWBP lakes (Fig. 2.9b) show more widespread warming, strongest in Northern Europe, where Lake Vanern, Lake Vattern, Lake Ladoga, and Lake Onega have warmed between $0.05^{\circ} \mathrm{C} \mathrm{yr}^{-1}$ and $0.10^{\circ} \mathrm{C} \mathrm{yr}^{-1}$. Trends are slightly smaller in southeastern Europe and the Middle East. Despite differing periods and methods, both ARCLAKE and IWBP are consistent in identifying relatively rapid warming in the lakes of both North America and Europe.
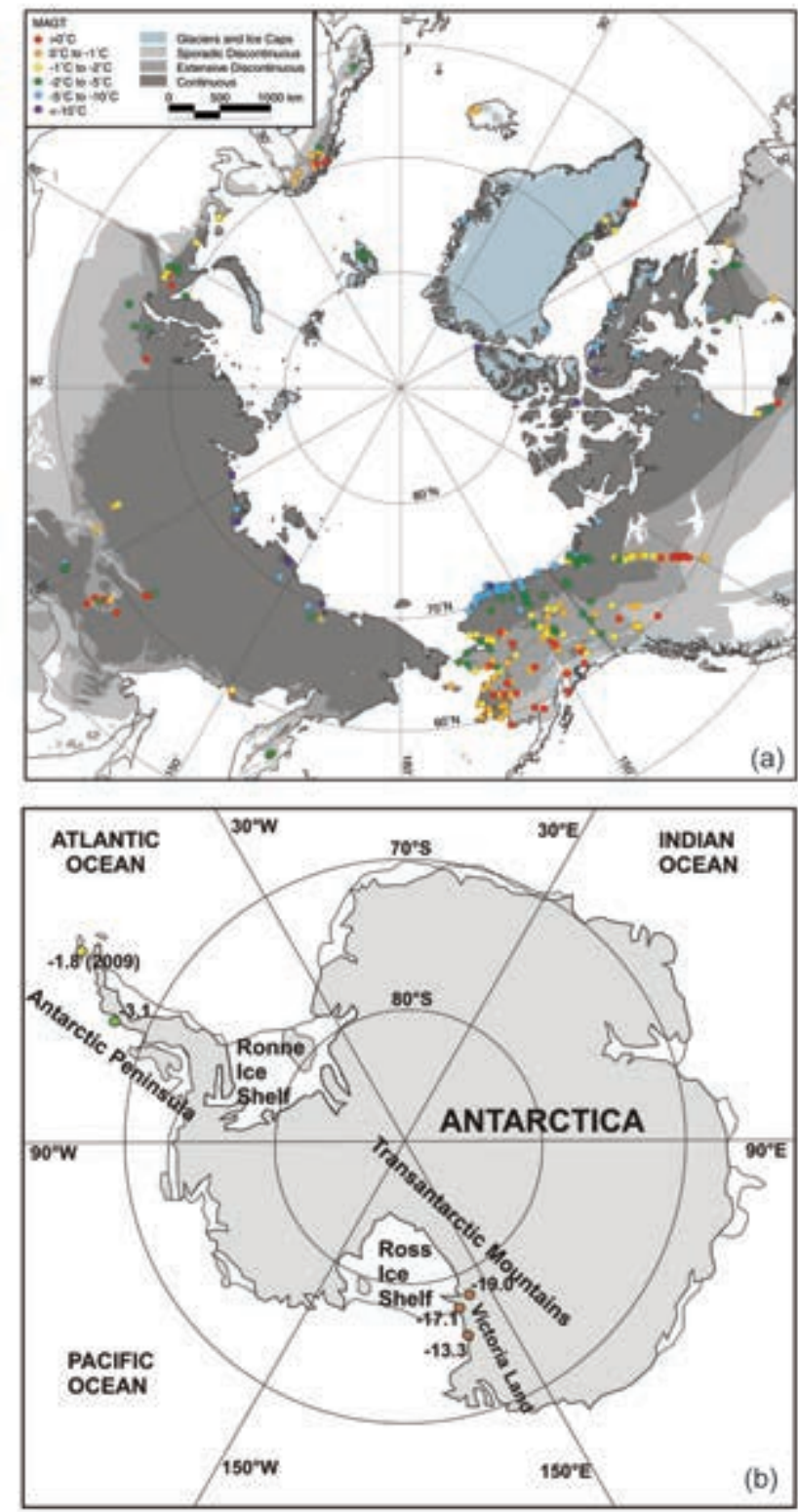

FIG. 2.10. Mean annual ground temperature (MAGT; ${ }^{\circ} \mathrm{C}$ ) for (a) the Arctic averaged over 2007-09 and (b) the Antarctic for 2010 (except King George Island, 2009). The MAGT, at the depth of zero annual amplitude, or at the nearest measurement point to it, is presented for all boreholes from which data are available. Permafrost zones after Brown et al. (1997). (Source: Romanovsky et al. 20I0b)

\section{c. Cryosphere}

I) Permafrost thermal state-H. H. Christiansen, M. Guglielmin, J. Noetzli, V. Romanovsky, N. Shiklomanov, S. Smith, and L. Zhao

Permafrost temperatures are collected in the Global Terrestrial Network on Permafrost (GTN-P), and available through national databases such as the Alaskan repository at http://www.permafrostwatch. 
org and the Norwegian repository at http://www.ngu.no/ kart/permafrost. A Northern Hemisphere Arctic permafrost thermal snapshot (2007-09) shows significant regional differences (Fig. 2.10a). Warm ocean currents influence the climate of northern Scandinavia, Svalbard, and northwest Russia, resulting in up to $0^{\circ} \mathrm{C}$ permafrost temperatures in the discontinuous permafrost. In high Arctic Svalbard, the $-3^{\circ} \mathrm{C}$ permafrost temperature is the highest in the continuous permafrost zone (Christiansen et al. 2010). In the rest of Russia and North America, permafrost temperatures vary from $0^{\circ} \mathrm{C}$ to $-2.5^{\circ} \mathrm{C}$ within the discontinuous zone with colder conditions in the continuous zone; permafrost temperatures reach as low as $-15^{\circ} \mathrm{C}$ in the high Arctic (Romanovsky et al. 2010a; Smith et al. 2010).

In Antarctica, the first ground thermal snapshot (Vieira et al. 2010) has been updated (Fig. 2.10b). In Northern Victoria Land, the active layer thickened by $1 \mathrm{~cm}$ year $^{-1}$ from 1996 to 2009 (Guglielmin and Cannone 2011), while in McMurdo Sound no clear trend was recognized from 1999 to 2007 (Adlam et al. 2010). In Northern Victoria Land, mean annual permafrost temperature increased by $0.1^{\circ} \mathrm{C}$ year ${ }^{-1}$ between $0.3 \mathrm{~m}$ and $3.6 \mathrm{~m}$ depth despite stable air temperatures
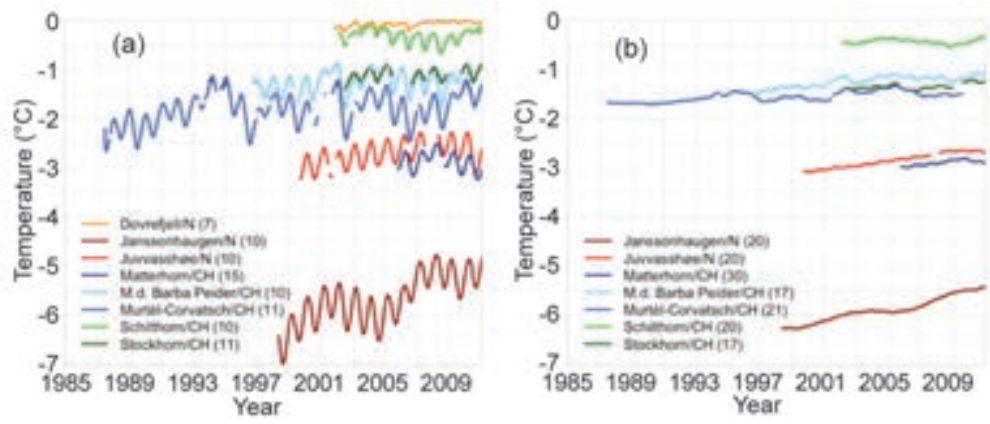

Fig. 2.II. Observed permafrost temperatures $\left({ }^{\circ} \mathrm{C}\right)$ from (a) $10 \mathrm{~m}$ and (b) $20 \mathrm{~m}$ depth for selected boreholes in European mountains. Data from Swiss sites are provided by PERMOS, and for Norwegian sites by the Norwegian Meteorological Institute. (Modified from Haeberli et al. 2010, Fig. 4)
(Guglielmin and Cannone 2011). Conversely, a reconstructed ground surface temperature history from McMurdo Sound boreholes, suggests a slight cooling from 1998 to 2003, followed by a slight warming to 2008 (Guglielmin et al. 2011).

Permafrost generally warmed across the Northern Hemisphere during the past 20 to 25 years (Romanovsky et al. 2011; Isaksen et al. 2007). Smaller warming rates are generally observed in permafrost at temperatures close to $0^{\circ} \mathrm{C}$, especially if it is ice-rich, because latent heat effects dominate the ground thermal regime (see section $5 \mathrm{~g}$ ).

The permafrost in the European Alps and Scandinavian mountains is discontinuous, with mean annual ground temperature generally between $0^{\circ} \mathrm{C}$ and $-3^{\circ} \mathrm{C}$ (Haeberli et al. 2010). The steep topography, heterogeneous surface characteristics, and snow cover result in high spatial variability of the ground thermal conditions. Decadal records (Fig. 2.11) for European moun- 
tain permafrost show a general warming trend with smaller increases in temperature where permafrost temperatures are close to $0^{\circ} \mathrm{C}$ (Isaksen et al. 2007; Haeberli et al. 2010; PERMOS 2010). Permafrost temperature anomalies associated with extreme warm years $(2003,2009)$ are superimposed on the warming trend (PERMOS 2010; Phillips et al. 2009; Zenklusen-Mutter et al. 2010). Scandinavian trends are more pronounced (Isaksen et al. 2011). The observed trends in permafrost temperatures are consistent with changes in air temperatures, but snow cover, soil properties (including ice and moisture content), and vegetation also determine the magnitude of the changes in ground temperature (e.g., Haeberli et al. 2010; Romanovsky et al. 2010b).

In the warm permafrost of the higher altitudes of Central Asia, ground temperatures have increased by up to $0.5^{\circ} \mathrm{C}$ decade $e^{-1}$ since the early $1990 \mathrm{~s}$, with a general increase in active layer thickness (e.g., Zhao et al. 2010).

Decadal trends in active layer thickness (ALT) vary by region (Fig. 2.12). Permafrost has disappeared in several of the Circumpolar Active Layer Monitoring
(CALM) sites. A progressive increase in ALT has been observed since the 1990s in all regions, with the exception of northern Alaska, western Canadian Arctic, and West Siberia. Smaller increases have been observed in Scandinavian sites such as Arctic Sweden and Svalbard compared to East Siberia, the Russian Far East, and Greenland. In North America, a progressive increase of ALT is observed only at sites in the Alaskan Interior, whereas ALT on the Alaskan North Slope was relatively stable over the 1995-2011 period.

2) Northern Hemisphere continental snow cover EXTENT-D. A. Robinson

Annual mean snow cover extent (SCE) over Northern Hemisphere $(\mathrm{NH})$ lands averaged 24.7 million $\mathrm{km}^{2}$ in 2011 (Fig. 2.13). This was 0.3 million $\mathrm{km}^{2}$ less than the 42-year average, ranking 2011 as having the 17th least extensive cover on record (Table 2.1). This evaluation considers snow over the continents, including the Greenland ice sheet. The SCE in 2011 ranged from 48.5 million $\mathrm{km}^{2}$ in January to 2.3 million $\mathrm{km}^{2}$ in August. Monthly SCE is calculated at the Rutgers Global Snow Lab from daily SCE maps produced by

TABLE 2.I. Monthly and annual climatological information on Northern Hemisphere and continental snow extent between November 1966 and December 20II. Years 1968, 1969, and 197I have I, 5, and 3 missing months respectively, thus are not included in the annual. Ranks are from most extensive (I) to least (ranges from 42 to 46 depending on the month).

\begin{tabular}{|c|c|c|c|c|c|c|c|}
\hline & $\begin{array}{l}\text { Number } \\
\text { of Years }\end{array}$ & $\begin{array}{l}\text { Annual } \\
\text { Mean }\end{array}$ & Std. Dev. & 2011 & $\begin{array}{c}\text { Northern } \\
\text { Hemisphere }\end{array}$ & Eurasia Rank & $\begin{array}{c}\text { North } \\
\text { America } \\
\text { (inc. Greenland). }\end{array}$ \\
\hline Jan & 45 & 46.7 & 1.5 & 48.5 & 6 & II & 4 \\
\hline Feb & 45 & 45.6 & 1.8 & 47.4 & 10 & 13 & 8 \\
\hline Mar & 45 & 40.4 & 1.8 & 42.1 & 9 & II & 6 \\
\hline Apr & 45 & 30.5 & 1.7 & 29.6 & 31 & 41 & 10 \\
\hline May & 45 & 19.5 & 1.9 & 16.6 & 43 & 44 & 26 \\
\hline Jun & 44 & 10.1 & 2.2 & 6.1 & 43 & 44 & 43 \\
\hline Jul & 42 & 4.2 & 1.2 & 2.5 & 41 & 41 & 41 \\
\hline Aug & 43 & 3.1 & 0.7 & 2.3 & 42 & 42 & 37 \\
\hline Sep & 43 & 5.3 & 0.9 & 5.2 & 22 & 23 & 21 \\
\hline Oct & 44 & 17.9 & 2.5 & 17.2 & 30 & 27 & 27 \\
\hline Nov & 46 & 33.6 & 2.0 & 36.4 & 4 & 5 & 13 \\
\hline Dec & 46 & 43.2 & 1.8 & 42.7 & 34 & 26 & 36 \\
\hline Ann & 42 & 25.0 & 0.9 & 24.7 & 26 & 27 & 22 \\
\hline
\end{tabular}




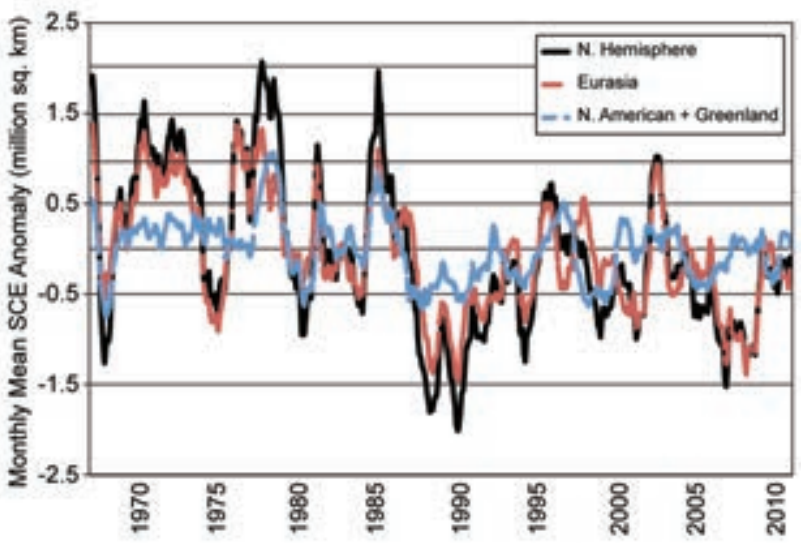

Fig. 2.13. Twelve-month running anomalies of monthly snow cover extent (million $\mathrm{km}^{2}$ ) over Northern Hemisphere lands (including Greenland) as a whole and Eurasia and North America separately between November 1966 and December 2011. Anomalies are calculated from NOAA snow maps. Mean hemispheric

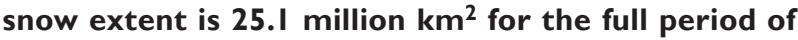
record. Monthly means for the period of record are used for nine missing months between 1968 and I97I in order to create a continuous series of running means. Missing months fall between June and October, no winter months are missing.

meteorologists at the National Ice Center (a US joint NOAA, Navy, and Coast Guard facility), who rely primarily on visible satellite imagery to construct the maps. Comprehensive summaries may be viewed at the Rutgers Global Snow Lab website (http://climate .rutgers.edu/snowcover).

The first three months of 2011 had snow cover extents near or in the upper quartile over Eurasia (EU) and North America (NA), resulting in the sixth most extensive January SCE. Eurasian cover began a rapid retreat in April, leading to the fifth least extensive cover over this continent. Meanwhile, above-average April SCE was noted over NA, to end a very snowy season. By May, NA had caught up with EU losses, thus there was an early end to the melt season over both continents.

The 2011/12 snow season commenced in a rather average manner in September and October. Storms quickly spread snow across the $\mathrm{NH}$ from late October to mid-November, ranking as the fourth most extensive SCE achieved in November. The seasonal advance of snow cover slowed considerably in December, resulting in a ranking of 13th least extensive $\mathrm{NH}$ cover over the past 46 years.

The Arctic Oscillation (AO) was strongly negative in winter 2010/11 but strongly positive for much of late November and December 2011. This was associated with November to
April 2010/11 SCEs for the contiguous United States ranking in the top 20\%, and December 2011 ranking in the lower quartile (see section $7 \mathrm{~b} 2$ for more detail on US snow cover).

\section{3) Alpine glaciers-M. S. Pelto}

The World Glacier Monitoring Service (WGMS) record of mass balance and terminus behavior (WGMS 2011) provides a global index for alpine glacier behavior. Mass balance was $-766 \mathrm{~mm}$ in 2010, negative for the 20th consecutive year. Preliminary data for 2011 from Austria, Norway, New Zealand, and United States indicate it is highly likely that 2011 will be the 21st consecutive year of negative annual balances.

Alpine glaciers have been studied as sensitive indicators of climate for more than a century, most commonly focusing on changes in terminus position and mass balance (Oerlemans 1994). The worldwide retreat of mountain glaciers is one of the clearest signals of ongoing climate change (Haeberli at al. 2000). The retreat is a reflection of strongly negative mass balances over the last 30 years (WGMS 2011). Glacier mass balance is the difference between accumulation and ablation. The recent rapid retreat and prolonged negative balances has led to some glaciers disappearing and others fragmenting (Pelto 2010; Bhambri et al 2011; Shahgedanova et al. 2010).

The cumulative mass balance loss of the last 30 years is $13.6 \mathrm{~m}$ w.e. (Fig. 2.14), equivalent to cutting a $15 \mathrm{~m}$ thick slice off the top of the average glacier. The trend is remarkably consistent from region to region (WGMS 2011). WGMS mass balance results based on a global dataset of 30 reference glaciers with 30 years of record is not appreciably different, $-13.1 \mathrm{~m}$ w.e. The decadal mean annual mass balance was $-198 \mathrm{~mm}$ in the $1980 \mathrm{~s},-382 \mathrm{~mm}$ in the $1990 \mathrm{~s}$, and $-740 \mathrm{~mm}$ for $2000-10$. The declining mass balance trend during a

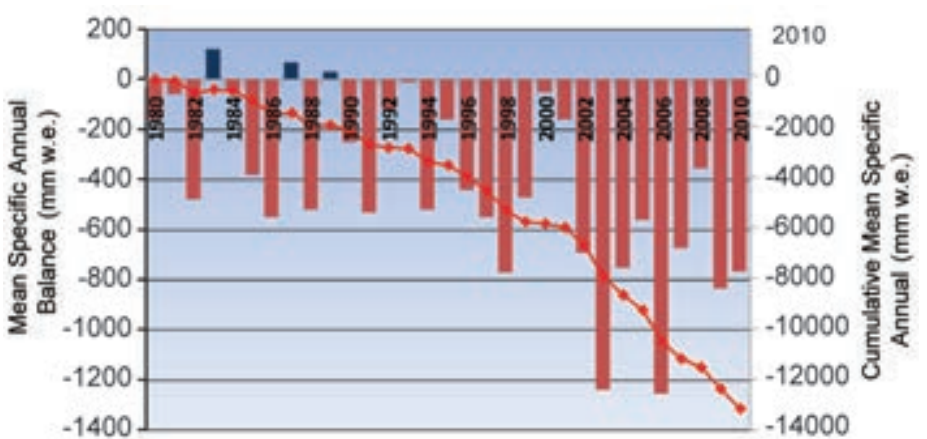

Fig. 2.14. The mean annual balance (bars, left axis) reported for all glaciers reported to the WGMS and their cumulative annual balance since 1980 (line, right axis). Units are in $\mathbf{m m}$ water equivalent (w.e.). 
period of retreat indicates that alpine glaciers are not approaching equilibrium and retreat will continue to be the dominant terminus response.

In 2011 there was below-average winter accumulation in the Alps and significantly above-average spring and summer temperatures. This resulted in consistently strong negative balances on Austrian glaciers in 2011: Sonnblickkees, -2460 mm; Jamtalferner, $-1434 \mathrm{~mm}$; Kesselwandferner, $-640 \mathrm{~mm}$; and Hintereisferner, and $-1420 \mathrm{~mm}$ (Fischer 2012). The Austrian Glacier Inventory examined 90 glaciers. Of these, 87 were in retreat, 3 were stationary, and average terminus change was $-17 \mathrm{~m}$, reflecting the continued negative mass balances of the region.

In Norway, terminus fluctuation data from 31 glaciers for 2011 indicated 27 retreating, 2 stable, and 2 advancing. The average terminus change was $-17.2 \mathrm{~m}$ (Elverhoi 2012). The retreat rate closely matched the 2010 rates. Mass balance surveys found deficits on all Norwegian glaciers. In the North Cascades, Washington (Pelto 2011), La Niña conditions and record wet and cool conditions from March to June led to positive mass balances on all 10 glaciers examined. In southeast Alaska, 2011 snowlines were $50 \mathrm{~m}$ above average on Lemon Creek and Taku Glacier of the Juneau Icefield, indicative of moderate negative balances.

In New Zealand, observations on 50 glaciers found snowlines that were much higher than normal, indicating strong mass balance losses (NIWA 2011). Summer melt conditions were considerably above average.

In the high mountains of central Asia, detailed glacier mapping inventories, such as from GLIMS (Global Land Ice Measurements from Space) using ASTER, Corona, Landsat, and SPOT imagery, of thousands of glaciers indicated increased strong thinning and area loss since 2000 throughout the region except the Karakorum. In the Russian Altai, mapping of 126 glaciers indicated a $19.7 \%$ reduction in glacier area from 1952 to 2004, with a sharp increase in losses after 1997 (Shahgedanova et al. 2010). In Garhwal Himalaya, India, for 58 glaciers examined from 1990 to 2006, area loss was 6\% (Bhambri et al 2011). In the Nepal Himalaya area, loss from 1963 to 2009 was nearly 20\%, (Bajracharya et al. 2011), and thickness losses increased from an average of $320 \mathrm{~mm} \mathrm{yr}^{-1}$ during 1962-2002 to $790 \mathrm{~mm} \mathrm{yr}^{-1}$ during 2002-07 in the Khumbu region, including area losses at the highest elevation on the glaciers (Bolch et al. 2011). In the Tien Shan Range, over 1700 glaciers were examined: from 1970 to 2000 , glacier area decreased by $13 \%$, and from 2000 to 2007 glacier area shrank by $4 \%$ (Narama et al.
2010). An inventory of 308 glaciers in the Nam Co Basin, Tibet, noted an increased rate of area loss for the 2001-09 period; 6\% area loss (Bolch et al. 2010).

A new means of assessing global glacier volume is via GRACE (Rodell et al. 2011), which, due to its spatial resolution, is unable to resolve specific changes of individual glaciers or watersheds. In the high mountains of central Asia, GRACE imagery found mass losses of $-264 \mathrm{~mm} \mathrm{yr}^{-1}$ for the 2003-09 period (Matsuo and Heki 2010). This result is in relative agreement with the other satellite image assessments, but is at odds with another more recent global assessment from GRACE that estimated Himalayan glacier losses at $10 \%$ of that found in the aforementioned examples for volume loss for the 2003-10 period (Jacob et al. 2012). At present, the detailed inventories are better validated.

\section{d. Hydrological cycle}

I) Surface humidity-K. M. Willett, D. Berry, and A. Simmons

There was little progress during 2011 in the development of global surface humidity products. Therefore, 2011 updates are limited to the NOCS 2.0 marine specific humidity analysis (Berry and Kent 2011) and the reanalyses. Given that ERA-Interim's (Dee et al. 2011a) earlier validation of its land surface humidity (Simmons et al. 2010) showed good behavior, this product was used to map surface humidity anomalies during 2011 (Plates 2.1g,h). ERA-Interim background 2-m humidity fields (specific and relative) were used over ocean rather than the assimilated fields due to issues of quality in the ingested humidity and temperature data from ships. Reanalysis estimates are also provided by NCEP CFSR, MERRA, and 20CR. JRA25/JCDAS humidity fields suffered a large discontinuity due to the end of precipitable water retrieval data from microwave imagers during 2011. This is clear in the monthly means but not so apparent in the annual mean. The in situ data were quality controlled and, in the case of NOCS 2.0, bias and height corrected. Issues still remain to be resolved over the pre-1982 marine humidity data in HadCRUH (Willett et al. 2008) and Dai (Dai 2006). NOCS 2.0 provides estimates over all ice-free regions of the oceans but only those regions with high confidence were used in this assessment, predominantly the shipping lanes in the Northern Hemisphere. Confidence in the in situ data decreases post-2006 due to reducing numbers of observations and loss of call sign information in the source data (ICOADS; Woodruff et al. 2011), which removes the ability to reliably link observations to their metadata 


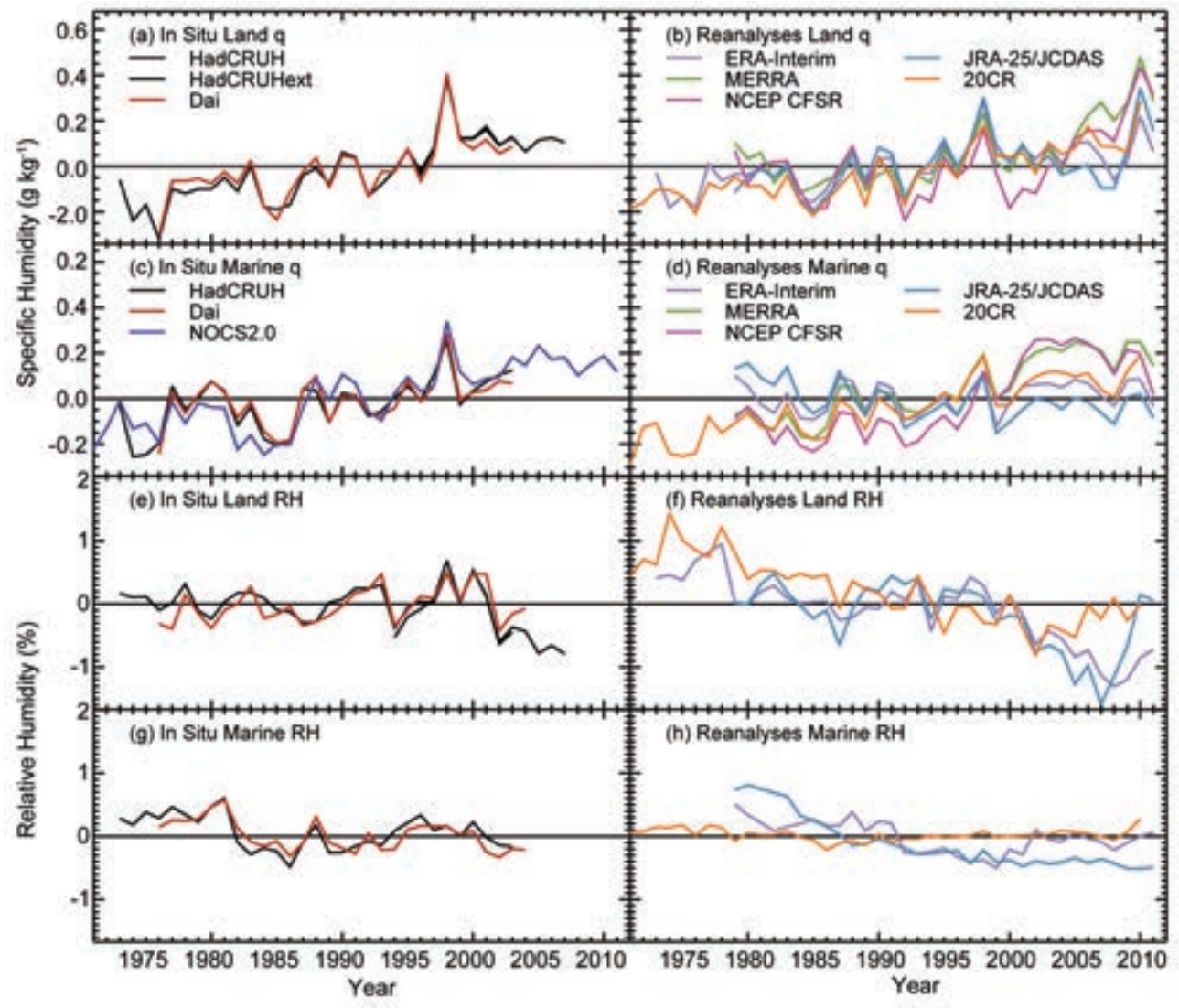

Fig. 2.15. Global average surface humidity annual anomalies (1979-2003 base period). For the in situ datasets $2 \mathrm{~m}$ surface humidity is used over land and $\sim 10 \mathrm{~m}$ over the oceans. For the reanalyses $\mathbf{2} \mathbf{m}$ humidity is used over the whole globe. For ERA-Interim only points over open sea are evaluated. HadCRUH and HadCRUHext use the 1974-2003 base period. Dai uses the 1976-2003 base period. All reanalyses products use the 198I-2010 base period. NOCS 2.0 used a 1979-2003 base period. All data have been adjusted to have a mean of zero over the common period 1979-2003 to allow direct comparison.

the reanalyses or in situ data and 2011 showed little change. The issues noted above for reanalyses specific humidity are likely also to affect the relative humidity and so further investigation is necessary.

The global pattern of specific humidity (Plate 2.1g) shows clear La Niña characteristics over the Pacific Ocean consistent with the continuing La Niña conditions throughout 2011. There are notable dry regions, such as the southern US and Mexico, eastern China, and east central Africa. Australia is particularly moist. The global pattern

(e.g., Kent et al. 2007). HadCRUH and Dai updates are underway-the original data are included here for completeness.

In terms of absolute moisture content at the surface, following a fairly moist and very warm 2010, 2011 was drier on average although moist relative to the last 39 years. This can be seen in both the land and marine averages (Fig. 2.15) and is consistent with 2011 being cooler than 2010 (section 2b1). While limited in coverage, the in situ data tell a concurrent story of surface moistening over the oceans. Globally, MERRA and 20CR show a similar moistening over the oceans but the other reanalyses do not reproduce the observed trends. The uncertainties in the marine datasets, both in situ and reanalyses, are likely to be as large as the trends themselves.

Over land, the relative drying of the atmosphere since 2000 (Simmons et al. 2010), in terms of relative humidity, continued to abate slightly, as in 2010. Over oceans, no such drying was observed in either of relative humidity (Plate $2.1 \mathrm{~h}$ ) shows similar or reduced spatial coherence. There is agreement among different data sources on the large features mentioned

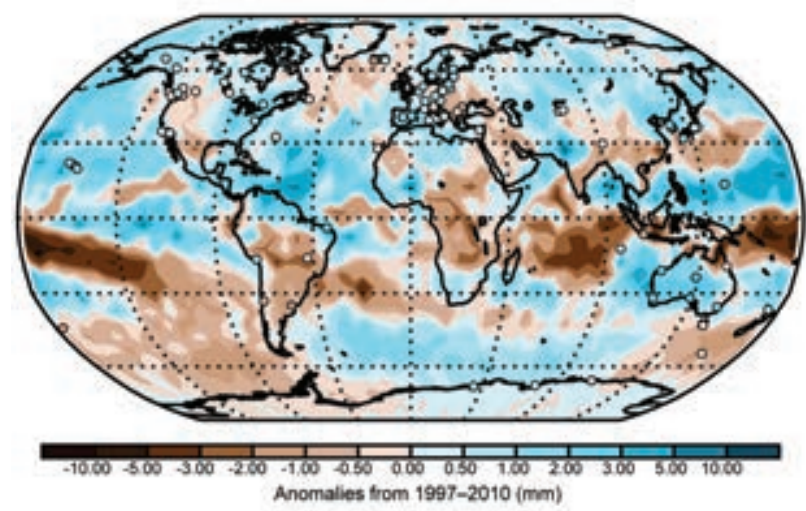

FIG. 2.16. COSMIC and ground based GPS radio occultation measurements (circles) $20 \mathrm{II}$ anomalies $(\mathrm{mm}$; 2007-2010 base period for COSMIC; 1997-2010 base period for GPS) of total column water vapor. 


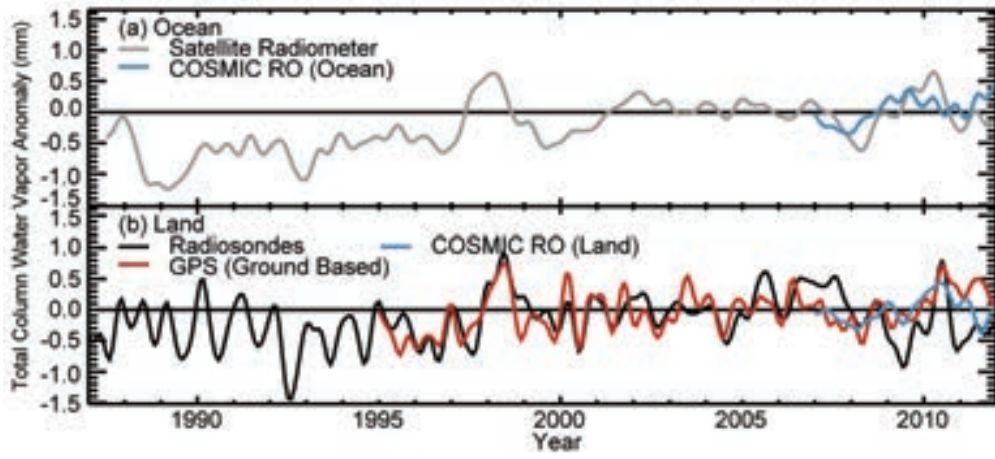

FIG. 2.I7. Global average total column water vapor anomalies (mm; 1997-2010 base period, COSMIC uses 2007-10) from satellite-borne microwave radiometers (SSM/I, SSMIS, AMSR-E and WindSat) over ocean, COSMIC over land and ocean, radiosondes, and radio occultation measurements from ground based GPS over land. The time series were smoothed to remove variability on time scales shorter than six months.

above, but care should be taken in interpretation over typically data sparse regions, such as central Africa.

2) TOtal Column WATER VAPOR-C. Mears, J. Wang, S. Ho, L. Zhang, and X. Zhou

The map of total column water vapor (TCWV) anomalies for 2011 (Plate 2.1f) includes data from satellite-borne microwave radiometers, homogenized radiosonde, and ground-based GPS measurements (Wentz 1997; Wentz et al. 2007; J. Wang et al. 2007; Dai et al. 2011). In the tropical Pacific Ocean there is a C-shaped dry anomaly that is most pronounced south of the equator. This is similar to 2010 although smaller in spatial extent. In the western tropical Pacific, there is a strong wet anomaly that extends with diminished intensity to the northeast and south. Many of these features are associated with the La Niña event. Over land, radiosondes indicate dry anomalies over eastern China and southern North America.

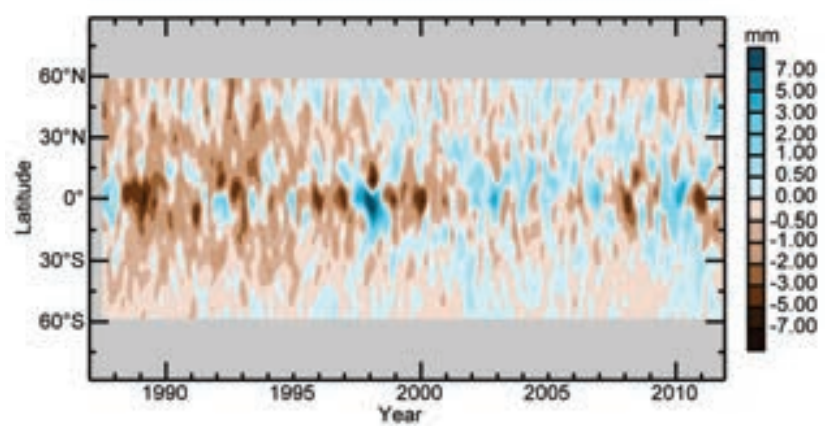

FIG. 2.I8. Satellite radiometer (SSM/I, SSMIS, AMSR-E and WindSat measurements) monthly mean anomalies (mm; 1997-2010 base period) for total column water vapor (ocean only) by latitude. Data were smoothed in the time direction to remove variability on time scales shorter than four months.
Many of the same features are present in the 2011 surface specific humidity and precipitation anomalies (Plates 2.1g and 2.1i, respectively). The pattern in TCWV anomalies is confirmed by COSMIC measurements (Fig. 2.16; Ho et al. 2010), which have the advantage of extending over land regions. GPS sites generally concur with COSMIC and the radiosondes, except over central Europe.

Potential biases in European GPS sites due to a change in processing in April 2011 are being investigated.

Over the ocean, the TCWV global anomaly time series (Fig. 2.17a) from the microwave radiometers shows maxima in $1987 / 88,1997 / 98$, and $2009 / 10$, associated with El Niño events, as well as a more subtle increasing trend corresponding with increasing global temperatures. Relative minima are apparent in Northern Hemisphere winters during the La Niña events of 1988/89, 1992/93, 1999/00, 2007/08, and from late 2010 onwards. The ocean-only COSMIC data also show the strong maximum in 2009/10. This feature is apparent in the land-only COSMIC data (Fig. 2.17b) in 2010/11 but is larger in the GPS and radiosonde data. A time vs. latitude Hovmuller plot derived from the satellite radiometers (Fig. 2.18) shows that, over the

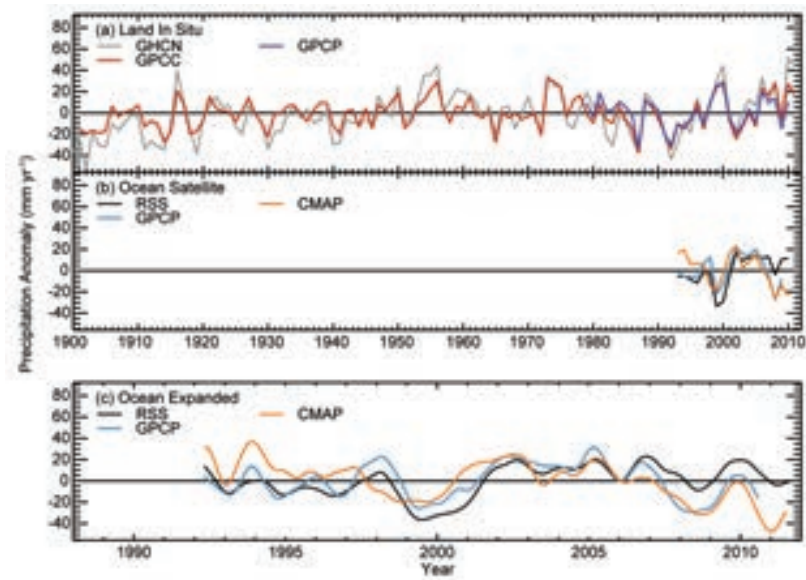

FIG. 2.19. Globally averaged precipitation anomalies (mm $\mathrm{yr}^{-1}$; 196I-90 base period over land, 1992-2011 base period over oceans) for (a) three in situ datasets over land, and (b) and (c) three satellite-based datasets over ocean. Global ocean averages cover $60^{\circ} \mathrm{S}$ to $60^{\circ} \mathrm{N}$ using a common definition of "ocean". Panel (c) shows low-pass filtered time series by convolution with a Gaussian distribution with four-month width at halfpeak power whereas panel (b) shows annual averages of this for comparison with land data. 
ocean domain, the changes associated with El Niño/ La Niña are largest in the tropics.

\section{3) Precipitation-D. E. Parker, K. Hilburn, P. Hennon, and} A. Becker

Globally, precipitation over land remained above the 1961-90 average in 2011 in records from both the Global Historical Climatology Network Monthly Version 2 (GHCN; Peterson and Vose 1997) and the Global Precipitation Climatology Centre (GPCC) Monitoring Product (Schneider et al. 2011; Fig. 2.19a). 2011 was the 2nd wettest year in the GHCN record, behind 2010, but only the 12th wettest year in the GPCC record where 2010 was the 6th. The Global Precipitation Climatology Project Version 2.1 (GPCP; Adler et al. 2003) is not yet updated to include 2011 but is shown in Fig. 2.19a for completeness. The positive anomalies of 2011 rainfall over land from GHCN and GPCC were about $20 \mathrm{~mm}-40 \mathrm{~mm}$, slightly lower than in 2010. The GPCC record, which indicates the smaller anomaly, is based on more observing stations.

Figure 2.20, from the GHCN data, suggests that zonal average precipitation was above the 1961-90 normal around $15^{\circ} \mathrm{S}-25^{\circ} \mathrm{S}, 0^{\circ}-25^{\circ} \mathrm{N}$, and $35^{\circ} \mathrm{N}-50^{\circ} \mathrm{N}$. The world map of land and ocean precipitation in Plate 2.1i uses GHCN precipitation over land; coverage is sparse, especially over Africa and Amazonia. Seasonal and annual precipitation anomalies from GPCC are shown in online supplemental Figs. S2.8, S2.9, and S2.10. There are some differences between the GPCC and GHCN annual anomalies, especially over Australia, likely due to both sampling and methodological differences. Note that GPCC data contain statistically infilled estimates over regions with few or no stations. Droughts are apparent in Europe and the southern US / northern Mexico region. The latter, a La Niña-related drought, likely contributed to the slightly-below-average precipitation at $25^{\circ} \mathrm{N}-35^{\circ} \mathrm{N}$ in Fig. 2.20. The year 2011 was the second successive wet year in Australia, contributing to the above-average

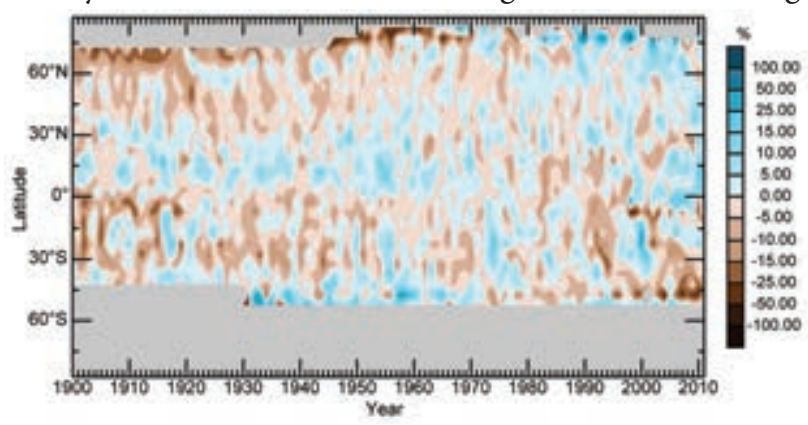

FIG. 2.20. GHCN land precipitation anomalies (\%, 1961-90 base period) by latitude. Gray areas indicate regions where data are unavailable.

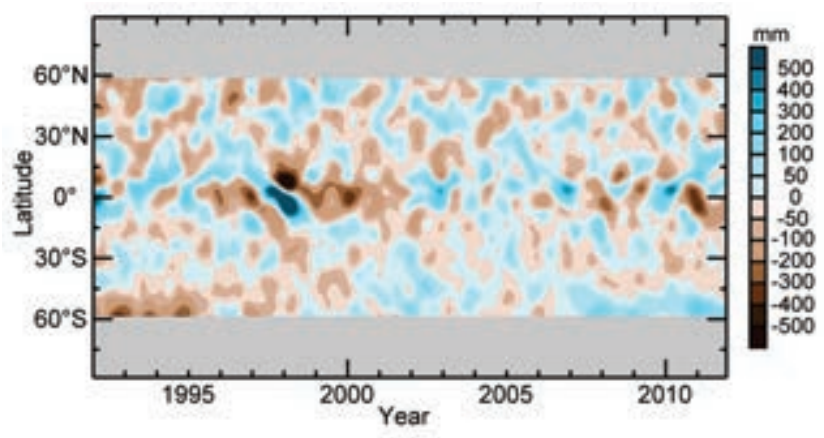

FIG. 2.2I. RSS ocean precipitation anomalies $(\mathrm{mm}$; 1992-20 II base period) by latitude. Gray areas indicate regions where data are unavailable.

zonal mean at $15^{\circ} \mathrm{S}-25^{\circ} \mathrm{S}$ in Fig. 2.20. This reflects the influence of La Niña and the warm eastern Indian Ocean, which also contributed to the strongest ever monsoon season across Thailand (see section $7 \mathrm{~g}$ ). Plentiful rains over parts of the Horn of Africa during September-November 2011 (see online supplemental Figs. S2.9 and S2.10) somewhat relieved the drought arising from the failure of the previous two rainy seasons (see Sidebar 7.2).

The global ocean precipitation climatology uses Remote Sensing Systems (RSS) Version-7 intercalibrated passive microwave rain retrievals (Hilburn and Wentz 2008). Version-7 data available at the time of writing include: F11, F13, F14, and F15 SSM/I, F17 SSMIS, AMSR-E, and WindSat. For Version-7, a change made to the beamfilling correction in the RSS rain algorithm has increased light rain rates in the extratropics, which led to an overall increase in the global mean rain rate. The 1992-2011 global average rain rates over the ocean from $60^{\circ} \mathrm{S}$ to $60^{\circ} \mathrm{N}$ are: $1113 \mathrm{~mm} \mathrm{yr}^{-1}, 1109 \mathrm{~mm} \mathrm{yr}^{-1}$, and $1147 \mathrm{~mm} \mathrm{yr}^{-1}$ from RSS, GPCP (through 2010), and CMAP, respectively. Figure 2.19b,c shows global ocean time series for RSS, Version 2.2 GPCP through 2010 (Adler et al. 2003), and V1201 CMAP (Xie and Arkin 1997). All three datasets trended downward over 2010, but this has reversed in RSS and CMAP and they trended upward slightly in 2011. On a longer time scale, GPCP and CMAP have trended downward since 2006, while RSS has not.

A time-latitude section of precipitation over the oceans (Fig. 2.21) shows that the equatorial wet anomaly in early 2010 was replaced by a very strong dry anomaly in mid-2010, which persisted throughout 2011. The anomaly map for 2011 (Plate 2.1i) shows a La Niña pattern with an expansive and intense dry anomaly over the central Pacific. The dry anomaly extends deep into the Southern Hemisphere along the South Pacific convergence zone. In the Northern 


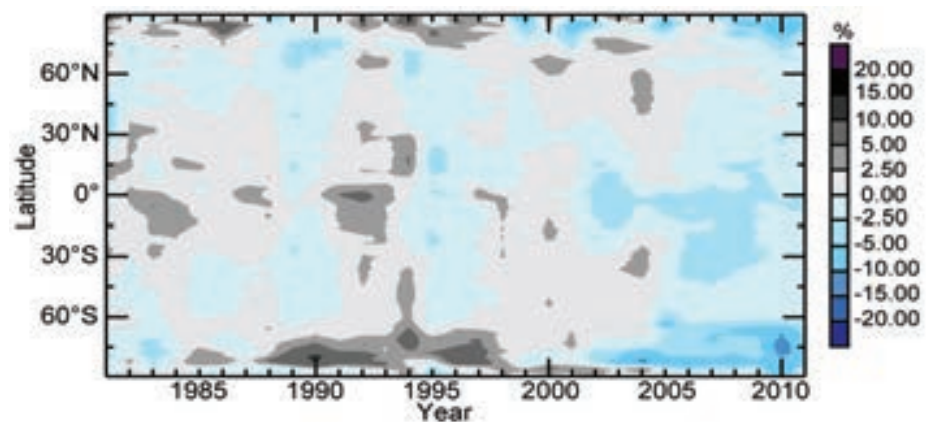

FIG. 2.22. Annual global cloudiness anomalies (\%; I98I-20I0 base period) from the PATMOS-x record calculated zonally for each degree latitude.

Hemisphere, the anomaly extends north across the Pacific towards Mexico. A moist anomaly is present in the far western Pacific, just east of the Philippines. Relative to 2010, the precipitation anomaly pattern for 2011 shifted to the east about $30^{\circ}$ and greatly intensified, especially the dry anomaly in the central Pacific.

4) Cloudiness-M. J. Foster, S. A. Ackerman, A. K. Heidinger, and B. C. Maddux

Observed global cloudiness in 2011 reflected La Niña. Several continental anomalies corresponded to severe drought or flooding, again consistent with La Niña, coupled with positive phases of the Arctic Oscillation in the boreal spring and fall, and a pronounced Siberian High (section 2el). The primary dataset used for this anlaysis, Pathfinder Atmospheres Extended (PATMOS- $\mathrm{x}$ ), is a 30-year record of cloud retrievals taken from the Advanced Very High Resolution Radiometers (AVHRR). Global cloudiness in 2011 was $1.5 \%$ lower than the climatological annual mean relative to 1981-2010; this marks the seventh least-cloudy year on record.

The La Niña resulted in enhancement of convective cloudiness in the western equatorial Pacific and over Indonesia, with a corresponding reduction in the central equatorial and southeastern Pacific (Plate 2.1e). This was driven by SST anomaly patterns (Plate 2.1c) and positive low-level easterly wind anomalies. Large portions of the negative annual anomalies in the central equatorial and southeastern Pacific are significant at the $5 \%$ (greater than two standard deviations) level. Some of the year-to-year variability in the global cloudiness record, especially over oceans, corresponds with phases of ENSO (Fig. 2.22).
Noteworthy continental cloudiness events included positive anomalies over Australia and negative anomalies over the southern United States, eastern Africa, south-central Siberia, and much of Europe. Of these, the southern United States (extending into the Gulf of Mexico) and the south-central Siberian events experienced annual anomalies with the highest confidence of statistical significance, while areas over Europe, eastern Africa, and Australia were still significant at the $5 \%$ level. The negative annual anomalies over Europe are consistent with the positive phases of the Arctic Oscillation in the boreal spring and fall. The negative anomalies in Siberia are consistent with a strong Siberian High.

Figure 2.23 shows global mean annual cloudiness anomalies from six data records. The surface weather observations are shown separately from the five satellite records, highlighting the difference between observing clouds from below (including observations from weather stations and ship observations by both human and automated methods) versus top-down from satellites. Surface-based observations differ in the spatial extent of the field-of-view as well as the configuration of the cloud field itself. In addition, there are fundamental differences in resolution ( both spatial and temporal), units of measurement, viewing

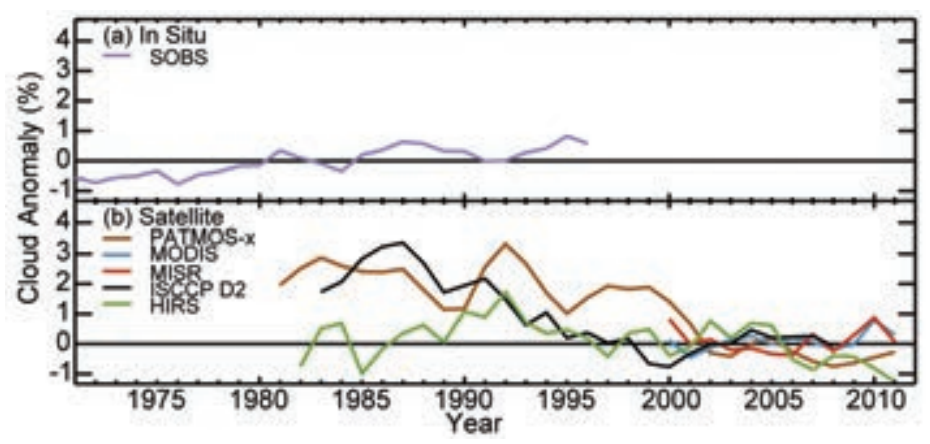

FIG. 2.23. Annual global cloudiness anomalies (\%; 197|-1996 base period for in situ and 2000-08 base period for satellites). (a) Surface weather observations (SOBS; Hahn and Warren 2007), (b) Satellite observations: Moderate Resolution Imaging Spectroradiometer (MODIS; Ackerman et al. 2008) and Multiangle Imaging Spectroradiometer (MISR; Di Girolamo et al. 20I0) instruments, which are located on NASA's Terra satellite and are ongoing (a MODIS instrument is also located on NASA's Aqua satellite and is included in the MODIS cloud product from 2003); International Satellite Cloud Climatology Project (ISCCP D2) data derived from the imaging radiometers on the operational weather satellites of several nations; High Resolution Infrared Sounder (HIRS; Wylie et al. 2005); and PATMOS-x AVHRR (Heidinger and Pavolonis 2009), which are instruments located on the NOAA polar-orbiting satellite series. 
angle, and spectral range, among satellite and surface methods. So, while it is useful and often enlightening to track clouds both from above and below, when these measurements are condensed to single points in a time series, the conclusions that can be drawn from their direct comparison are ambiguous at best (Hughes 1984; Mokhov and Schlesinger 1994). Since 2000, the various satellite cloud records are much more stable than previously, though not in complete harmony. This difference is likely due in part to referencing to a $2000-08$ average base period; also, the advent of additional satellites, with more advanced sensors and more stable orbits, allowed for development of intercalibration techniques that consequently reduced the range among cloud detection algorithms. Extreme events, such as the eruption of Mount Pinatubo and strong phases of ENSO, may also contribute to the large differences between the earlier records.

5) River Discharge-B. M. Fekete, R. B. Lammers, and G. R. Brakenridge

The Dartmouth Flood Observatory, operated from University of Colorado, maintains an operational system to monitor floods worldwide from satellite systems. The observatory also compiles a comprehensive database of floods reported by news media outlets since 1985. The limited consistency of this database (particularly prior to the Internet era) does not allow for straightforward assessment of trends in the frequency of flood events, but it is still informative (Fig. 2.24).

The apparent increase in both modest and major flood events from 1985 to 2007 may reflect, in part, better reporting. The year-to-year variation describes the global interannual patterns of flood events. According to this database, 2011 was not extraordinary in terms of number of flood events.

The water balance model (WBM) analysis (Fekete and MacDonald 2011; Fekete et al. 2010), with the

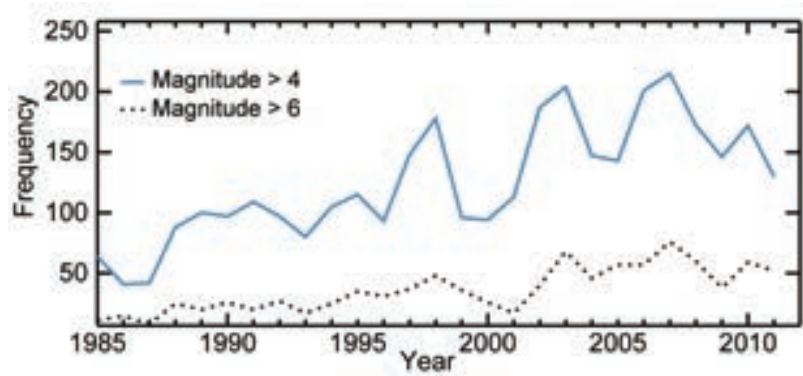

FIG. 2.24. Major floods worldwide from 1985 to $201 \mathrm{I}$ according to the Dartmouth Flood Observatory database. Magnitude is defined as a product of the severity of the flood event (expressed as an index ranging between I and 2), the duration of the flood, and the affected area. same configuration (Vörösmarty et al. 1998; Wisser et al. 2010a,b) as used in the 2009 and 2010 State of the Climate discharge assessments, shows more detail. It was driven by daily air temperature from the NCEP/ NCAR reanalysis (Kalnay et al. 1996; Kistler et al. 2001) and monthly precipitation forcing from the latest version (V4.0) of the Global Precipitation Climate Center's (GPCC) monitoring product, which was downscaled to daily time steps by daily partitioning of the monthly precipitation based on the NCEP reanalysis. The runoff variations of the last three years (2009-11) are compared to the 1901-2000 average from Wisser et al. (2010a) for continents and receiving ocean basins in Fig. 2.25, and 2011 anomalies are highlighted in Plate 2.1j.

2011 was wetter than the 1901-2000 long-term mean on three continents (Asia, Australia, and South America) and remaining islands. Australia stands out with $42 \%$ more runoff than the long-term mean, which is consistent with the numerous major flood events reported during the year (see Sidebar 7.4). The high runoff in Australia can be seen in the elevated runoff discharging into the Indian and Pacific Oceans. Africa experienced continued hydrological drought although less severe than the previous two

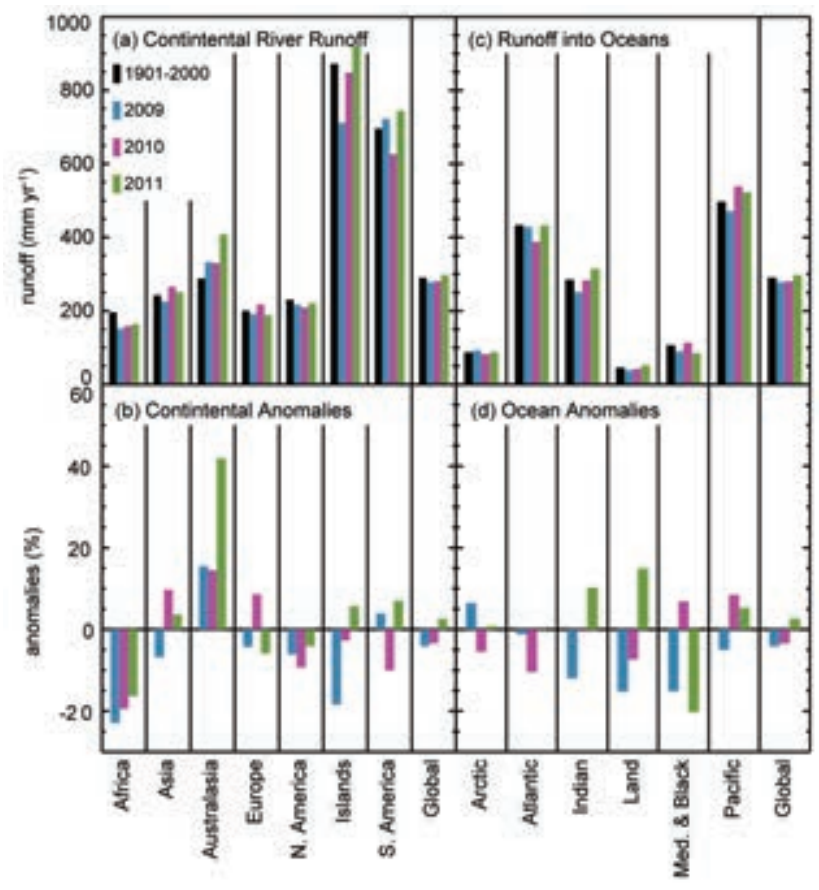

FIG. 2.25. Water balance model runoff estimates (a) and (b) over continents, and (c) and (d) by receiving oceans. (a) and (c) Long-term mean runoff ( $\mathrm{mm} \mathrm{yr}^{-1}$; for the 1901-2000 period) and annual runoff for each of the last three years $(2009,2010,201 \mathrm{l})$. (b) and (d) Annual anomalies (\%; 190I-20II base period) for 2009, 2010 , and 2011 . 


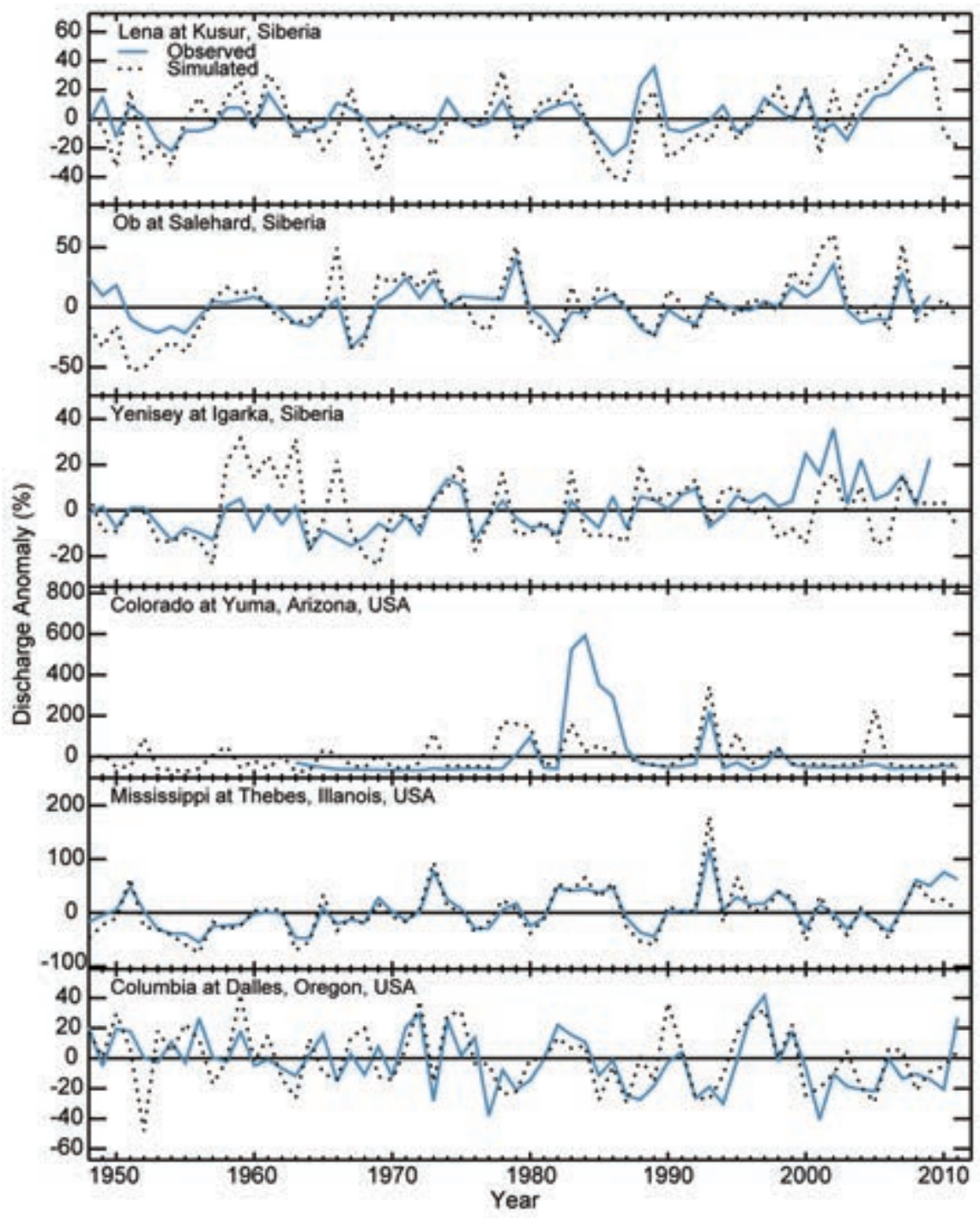

FIG. 2.26. Mean annual river discharge anomalies (\%) for observed and simulated time series for the three largest Siberian rivers (observed near the river mouth) and three major river basins in the conterminous United States from the Arctic-RIMS archive. Data for the Siberian rivers are only available up to 2008. Simulations are based on the WBM analysis.

years (see Sidebar 7.2). Runoff into Arctic and Atlantic Oceans stayed near normal, while the Mediterranean and Black Seas experienced severe drought.

To assess these results, mean annual discharge anomalies with respect to their long-term means from six large river basins (three in Siberia from Arctic-RIMS1 archive and three in North America from USGS2) are compared with the WBM simulations in Fig. 2.26. With the exception of the Colorado River at Yuma (which is heavily regulated and significantly altered by extensive consumptive water use and interbasin transfers that are not currently adequately accounted for), the simulated river discharge anomalies follow the same patterns as the observations, but often with different magnitude. These results suggest that the overall global runoff assessments are realistic for macroscale assessments of the hydrological cycle.

6) Groundwater and TERRESTRIAL WATER STORAGE-M. Rodell, D. P. Chambers, and J. S. Famiglietti

Groundwater is a vital resource and a dynamic component of the water cycle. Unconfined aquifer storage is less responsive to short-term weather conditions than the near-surface terrestrial water storage (TWS) components (soil moisture, surface water, and snow). However, with the exception of permanently frozen regions, it typically exhibits a larger range of variability over multiannual periods than the other components (Rodell and Famiglietti 2001; Alley et al. 2002). Groundwater is poorly monitored at the global scale, but TWS change data from the Gravity Recovery and Climate Experiment (GRACE; Tapley et al. 2004) satellite mission are a reasonable proxy for unconfined groundwater at climatic scales.

Plate $2.1 \mathrm{k}$ maps changes in mean annual TWS from 2010 to 2011, based on GRACE, reflecting hydroclimatic conditions in 2011 (see Plates 2.1e-i). Widespread drying occurred between $20^{\circ} \mathrm{N}$ and $60^{\circ} \mathrm{N}$, contrasting with wetting between $10^{\circ} \mathrm{S}$ and $30^{\circ} \mathrm{S}$. Severe drought impacted the southern United States and northern Mexico. Southern Europe, the north Atlantic coast of Africa, and parts of western and eastern China, experienced net losses of water in 2011 after having surpluses in 2010. Northern Sudan, which was already in drought, did not get any relief. South of the equator, the lower Amazon basin and some other parts of northern South America recovered from drought, while southern Africa had a relatively wet 


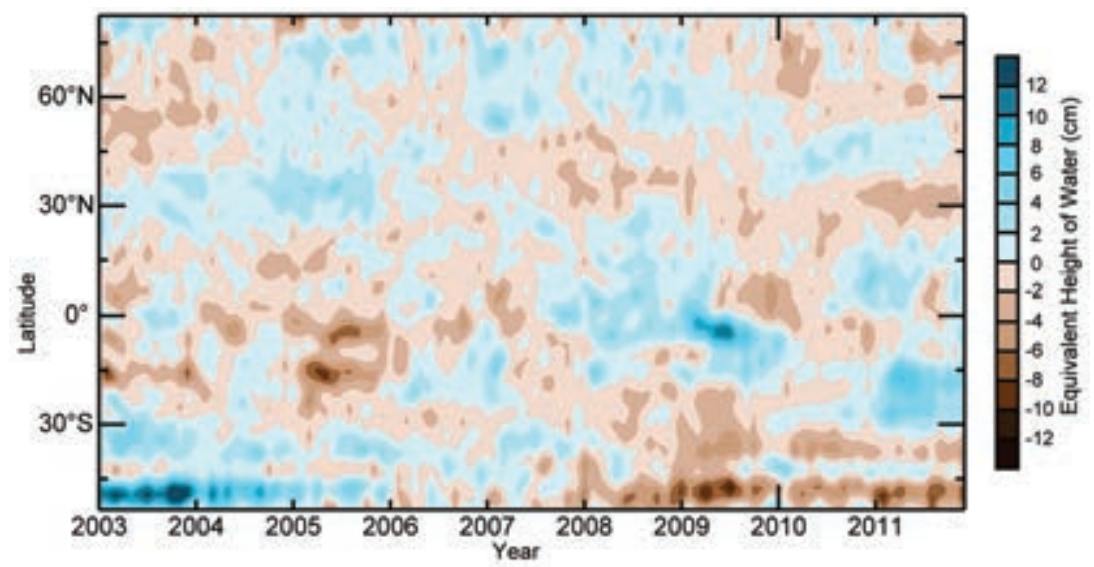

(Fig. 2.27). On average, Earth's land was relatively wet in 2011 (Fig. 2.28). From June 2010 to May 2011, global TWS increased by about $2.2 \mathrm{~cm}$, which is equivalent to an 8 $\mathrm{mm}$ decline in mean sea level during that period (see Fig. 3.27), and TWS peaked again in December.

7) SOIL MOISTURE-R. A. M. De Jeu, W. A. Dorigo, R. M. Parinussa, W. W. Wagner, and D. Chung

Soil moisture retrievals from

FIG. 2.27. GRACE satellite observations of annual mean terrestrial water satellite observations are excellent storage (the sum of groundwater, soil water, surface water, snow, and ice, indicators for climate variability as an equivalent height of water in $\mathrm{cm}$ ) anomalies (2003-07 base period) because they integrate precipitaby latitude.

year. Other than continued replenishment of aquifers in the southeast, Australia reversed course from 2010, becoming wetter in the west and dryer in the northeast. Drought in equatorial Africa and recovery from drought in the Indochinese peninsula also stand out. Aquifers in central California (Famiglietti et al. 2011) and northern India (Rodell et al. 2009; Tiwari et al. 2009), which are stressed by groundwater pumping at

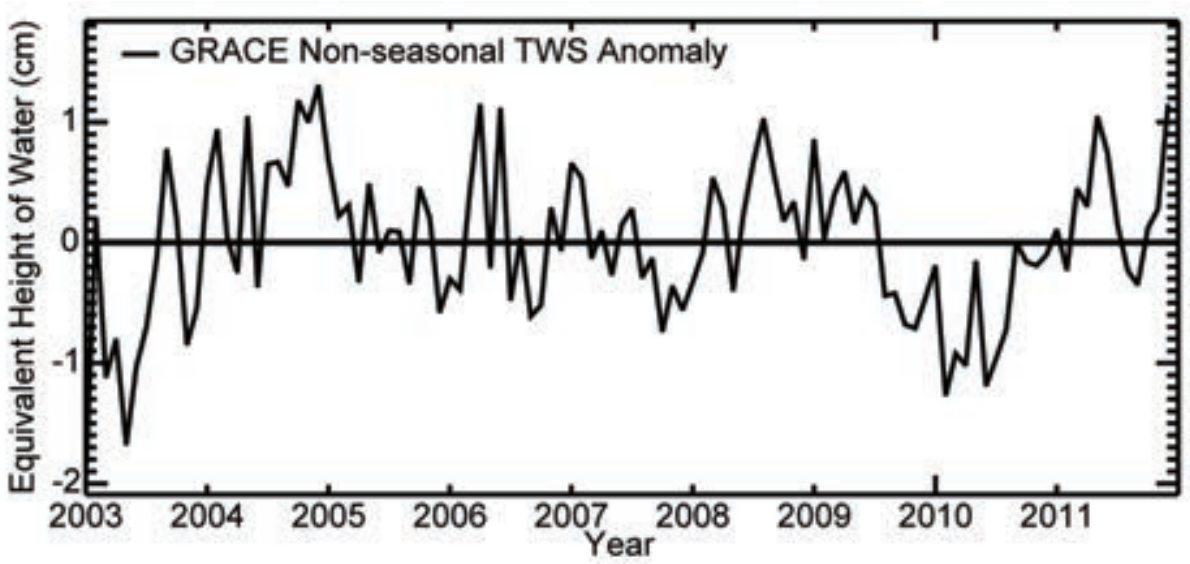

FIG. 2.28. As for Fig. 2.27 but for near-global average terrestrial water storage monthly mean anomalies (2003-07 base period) in cm equivalent height of water.

unsustainable rates, both raised their water levels in 2011. Significant reductions in TWS along the coast of Alaska, in the Patagonian Andes (also seen in Fig. 2.27), and in Greenland (see section 5f) and Antarctica (see section 6e) represent ongoing glacier and ice sheet ablation, not groundwater depletion.

Figures 2.27 and 2.28 show time series of zonal mean and global GRACE-derived non-seasonal, monthly mean TWS anomalies, excluding Greenland and Antarctica. Drying in the northern latitude band and wetting in the southern band in 2011 are clear large spatial scales the variation of soil moisture, in turn, affects evaporation and precipitation, via the water availability for evaporation and the subsequent partitioning of the Earth surface energy fluxes (Seneviratne et al. 2010).

Soil moisture has been globally observed from space since 1978 using microwave satellites (both passive and active), with a typical spatial resolution of about $0.25^{\circ}$. Satellite soil moisture represents the water content of the top few centimeters. Recently, a consistent multidecadal record of global soil moisture was developed by harmonizing and merging different satellite soil moisture datasets (Y. Y. Liu et al. 2012; see Sidebar 2.2). This homogenized dataset was used to calculate surface soil moisture anomalies for 2011 by subtracting the 1979-2010 climatology. Annual 2011 anomalies (Plate 2.11) are predominantly positive in the Southern Hemisphere and negative in the Northern Hemisphere. Figure 2.29 reflects the major monthly hydroclimatic variations for 2011.

In early 2011, Australia suffered from several flooding events, especially in Queensland and Victoria, associated with La Niña conditions. From January to May the Okavango delta in southern Africa was completely flooded, resulting in a strong positive anomaly in the soil moisture data. This exceeded a 


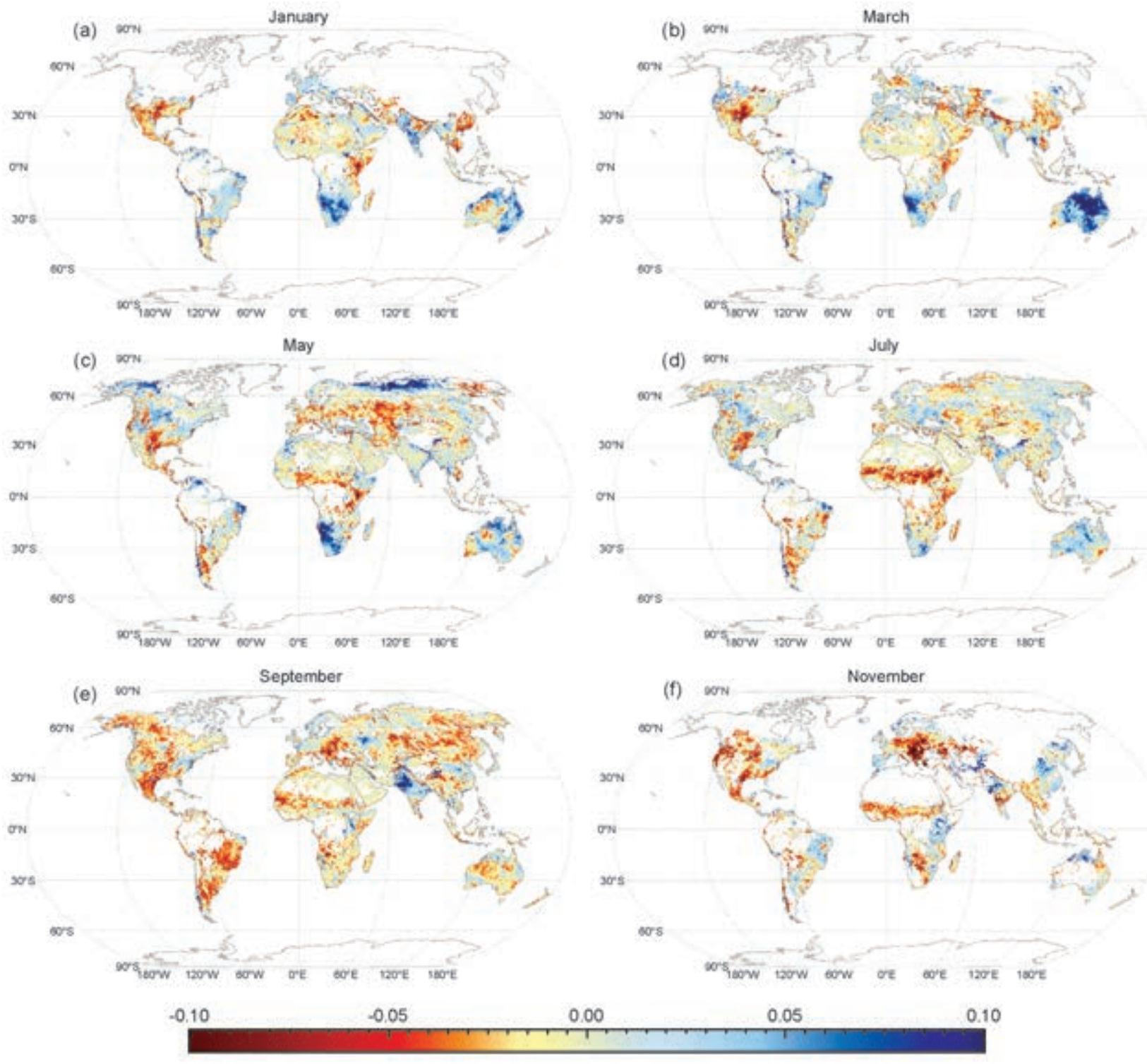

FIG. 2.29. Monthly soil moisture anomaly images for $\mathbf{2 0 I I}$ as derived from the multidecadal satellite soil moisture dataset. The anomalies are relative to a base period of 1979-2010. Note: The November anomaly image should carefully be interpreted; this image is solely based on ASCAT observations, because AMSR-E was switched off in October $201 \mathrm{I}$.

similar flooding event in 2010 (De Jeu et al. 2011; Ives 2011). The delta is a large, flood-pulsed wetland and the flood was primarily caused by the seasonal flood wave of the Okavango River. Local rainfall variations played a smaller role. The flooding was asynchronous with the local rainy season and a result of interannual differences in local and upstream rainfall, as well as longer-term effects of surface-groundwater interactions within the delta (Wolski and Hudson 2008). The area of inundation displays a strong interannual variability, varying between $3500 \mathrm{~km}^{2}$ and 14000 $\mathrm{km}^{2}$ (McCarthy et al. 2004; Gumbricht et al. 2004)
Following major flood events in 2010, Pakistan again experienced a series of flood events between July and September due to strong monsoonal rains. These are clearly visible in the September anomaly image of Fig. 2.29. However, the flood events of 2011 covered a smaller area than the events in 2010 (De Jeu et al. 2011).

In 2011, three regions experienced severe droughts: the Horn of Africa, the southern US, and eastern Europe (see sections 7e, 7b, and 7f, respectively). The Horn of Africa drought became visible in soil moisture in March 2011 and persisted for the rest of the year. The southern US drought region showed a 


\section{SIDEBAR 2.2: BUILDING A CLIMATE RECORD OF SOIL MOISTURE FROM HISTORICAL SATELLITE OBSERVATIONS-R. A. M. DE JEU, W. A. DORIGO, R. M. PARINUSSA, W. W. WAGNER, Y. Y. LIU, D. CHUNG, AND D. FERNÁNDEZ-PRIETO}

Since the launch of the Nimbus-7 satellite in October 1978, there is a long legacy of satellite observations suitable for global soil moisture monitoring (Fig. SB2.4), but it took more than 20 years to develop the first satellite global soil moisture dataset. In 2002, a dataset was developed from scatterometer observations onboard the European Remote Sensing Satellites ERS-I and ERS-2 (Wagner et al. 2003). Other research groups soon followed. De Jeu and Owe (2003) made a global soil moisture product from the historical Nimbus-7 SMMR data and Njoku et al. (2003) presented the first dataset based on AMSR-E observations.

Today, numerous global soil moisture products from various satellites and research groups are freely available. These datasets vary in quality but all provide global soil moisture estimates of the top few centimeters at a rather coarse spatial resolution of $25 \mathrm{~km}-50 \mathrm{~km}$ (GCOS 20II). Global datasets are increasingly important in environmental research. For example, Liu et al. (2007) demonstrated the impact of El Niño on water resources in eastern Australia using TRMM soil moisture. Brocca et al. (2010) showed that runoff prediction for the Tiber River in Italy can be improved by incorporating ASCAT soil moisture, and Jung et al. (2010) used TRMM soil moisture to investigate a recent decline in global evaporation.

These different datasets are even more valuable if combined into one consistent multidecadal climate data record. This was addressed as part of the Water Cycle Multimission Observation Strategy (WACMOS) project from the Support To Science Element (STSE) program of the European Space Agency (ESA). Within this project, two extensively validated soil moisture products were selected to create a harmonized dataset; one from the Vienna University of Technology (TU Wien) based on active microwave observations (Wagner et al. 2003; Bartalis et al. 2007) and one from the VU University Amsterdam in collaboration with NASA, based on passive microwave observations (Owe et al. 2008). The harmonization of these datasets incorporates the strengths of both microwave techniques and spans continuously from 1978 onwards (Fig. SB2.4). However, there were several challenges to developing such a dataset, e.g., differences in instrument specifications result in different absolute soil moisture values, the global passive and active microwave retrieval methods produce conceptually different quantities, and products vary in their relative performances depending on vegetation cover (Y. Y. Liu et al. 2012, manuscript submitted to Remote Sens. Environ.). This is clearly visible in Fig. SB2.5, where the original soil moisture retrievals from various satellites are plotted for a region in the Sahel. Here, both the active and passive soil moisture retrievals show similar seasonality but they have different magnitudes. TU Wien soil moisture retrievals are expressed as a degree of saturation (with a value between 0 and I) while VUA retrievals are given in volumetric values $\left(\mathrm{m}^{3} \mathrm{~m}^{-3}\right)$. Besides this, the SSM/I-based estimates are less accurate than for the other sensors, owing to its limited soil moisture retrieval capabilities. It carries a Ku band $(19 \mathrm{GHz})$ radiometer, which is less suitable for soil moisture retrieval than $\mathrm{L}(\mathrm{I} .4 \mathrm{GHz}), \mathrm{C}(6.9 \mathrm{GHz})$, and $\mathrm{X}(10.7 \mathrm{GHz})$ band radiometers (Owe et al. 2008). A statistical methodology based on scaling, error characterization, ranking, and blending was developed to address these issues to create one consistent dataset (Liu et al. 2011, 2012). A third soil moisture dataset, provided by a land surface model (GLDAS-I-Noah), was used to scale the different satellite-based products to the same range. The blending of the active and passive datasets was based on their respective sensitivity to vegetation cover. While this approach imposes 
the absolute values of the land surface model dataset to the final product, it preserves the relative dynamics (e.g., seasonality, interannual variations) and trends of the original satellitederived retrievals (Y. Y. Liu et al. 20I2). The ranking and blending strategy used does not increase the accuracy of the final product with respect to the merged ones, but allows a selective use of the most accurate measurements and increases the temporal density of the observations available. Finally, this method allows the long-term product to be extended with data from other current (e.g., SMOS) and future operational satellites and will be further improved as part of ESA Climate Change Initiative program (http://www.esa-cci.org/).

A simple trend analysis of this harmonized dataset is presented in Fig. SB2.6. Subtle soil moisture trends can be seen over the entire globe varying from $-0.06 \mathrm{~m}^{3} \mathrm{~m}^{-3}$ to $0.06 \mathrm{~m}^{3} \mathrm{~m}^{-3}$ over the last 31 years. The strongest negative
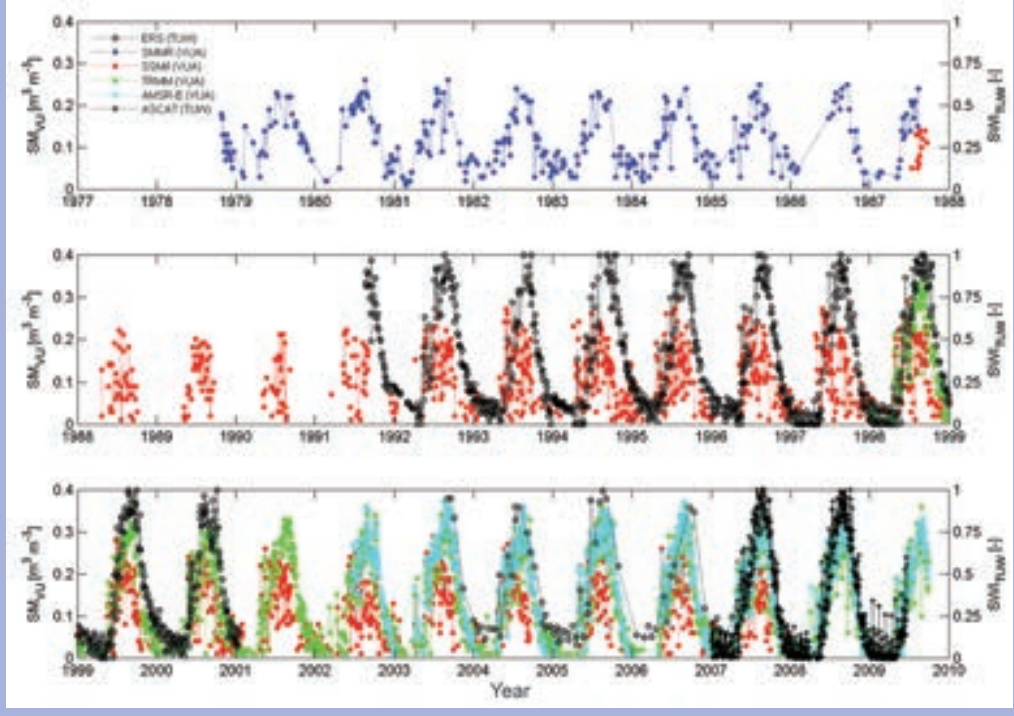

FIG. SB2.5. Soil moisture over an area in the Sahel region $\left(7^{\circ} \mathrm{N}, 12^{\circ} \mathrm{E}\right)$ according to different satellite observations. Note that soil moisture derivations from scatterometer sensors (indicated in black) are expressed as an index (right axis) and the VU soil moisture retrievals are expressed in $\mathrm{m}^{3} \mathrm{~m}^{-3}$ (left axis). (Source: De Jeu et al. 2009)

trends can be found in Russia, Kazakhstan, and the Sahel region. Strong positive trends are observed in northeastern Brazil and southern Africa. Most of these trends can directly be linked to the behavior of ocean oscillation systems. For example, the trends over Australia could be related to the polar movement of the Subtropical Ridge (STR), the Indian dipole, and the severe El Niño conditions within this period (Liu et al. 2007; Murphy and Timbal 2008; Y. Y. Liu et al. 2009).

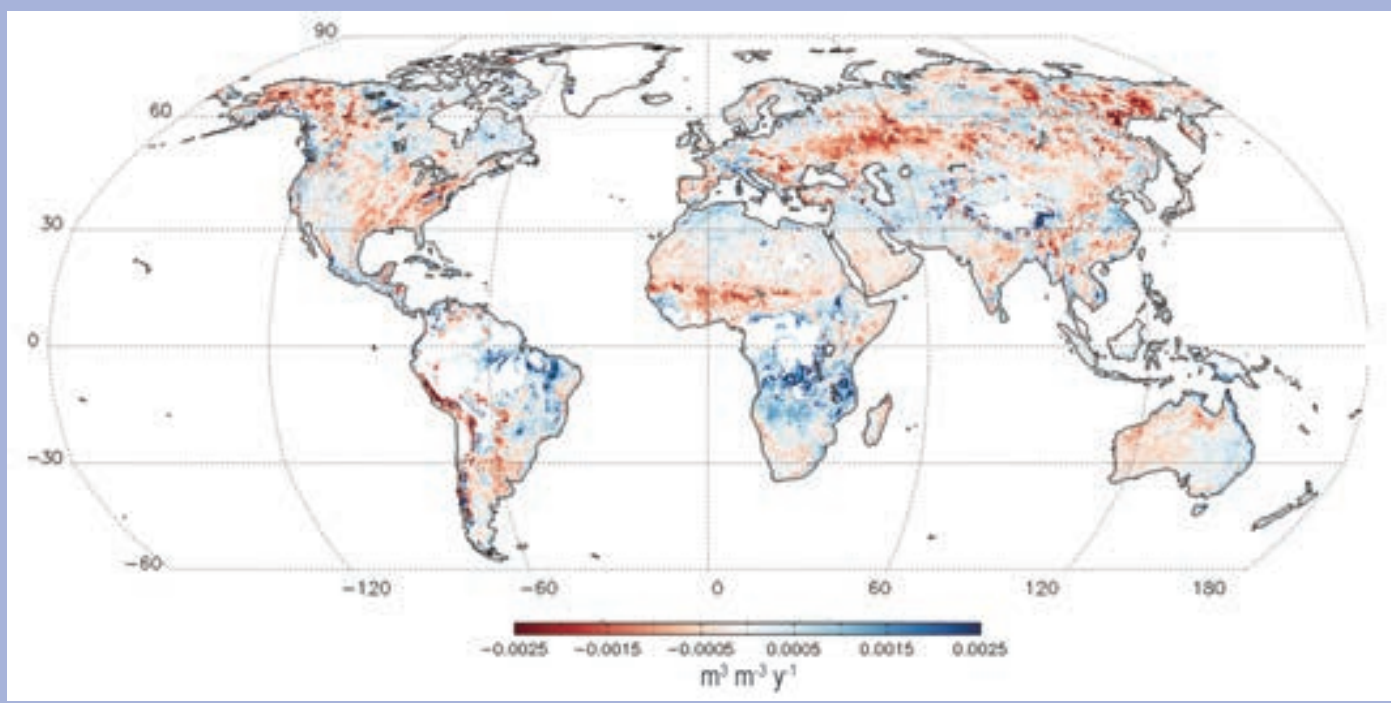

FIG. SB2.6. Trends in annual average satellite soil moisture (in $\mathrm{m}^{3} \mathrm{~m}^{-3} \mathrm{yr}^{-1}$ ), 1979-2010 base period. These values were derived from the harmonized soil moisture dataset, a $30+$ year harmonized satellite soil moisture data record based on (historical) passive and active microwave observations. 
negative anomaly throughout the year, and the Central and Eastern European drought was observable in the soil moisture data in November 2011.

\section{8) LAKE LeVels-C. Birkett and J.-F. Cretaux}

Lake volumes are indirect indicators of climatic change because they respond to changes in precipitation integrated over their catchment basins. The response can be seen in open lakes and reservoirs but is particularly marked for closed lakes, i.e., those having no significant surface or subsurface outflow. Closed lakes can act as low-pass filters to variations in aridity, with a characteristic time constant of between 1 and 1000 years, depending largely on lake geomorphology. Deep lakes with steep shore topography are good proxies for high amplitude-low frequency changes, while shallow water basins are better indicators for rapid low-amplitude changes (Hostetler 1995). Lake variations can correlate with several modes of variability, e.g., ENSO, Indian Ocean, Pacific decadal, or North Atlantic Oscillations.

Research studies in 2011 continued to be regional or local in scope (Lee et al. 2011; Sarmiento and Palanisami 2011; Zhang et al. 2011), but global analyses require the systematic monitoring of all global lake volumes. Satellite imagery could provide changing lake surface area but currently no operational products exist. Satellite-based radar altimetry continues to provide surface water elevation products with datasets spanning 20 years (1992-2012). These lake level datasets can stand alone or be combined with ground-based measurements. They have varying temporal/spatial resolutions and varying accuracies, ranging from a few centimeters to tens of centimeters. Several web sites offer altimetric lake level products (e.g., NASA/USDA, ESA, LEGOS). The NASA/USDA website currently provides a first-order water-level status guide to drought or high water conditions in both lakes and reservoirs (Fig. 2.30). This is based on a mean nine-year lake level datum derived from a subset of the Topex/Poseidon dataset (1993-2002). Of the 75 lakes, in February 2012, a third had belowaverage levels, another third above-average water levels. True climatic interpretation of the reservoir results are hampered by the magnitude of unknown anthropogenic effects. This status map at the NASA/ USDA web site will be discontinued during 2012 as the operational program changes its policy to employ a datum based on a single date to enable an improvement in product accuracy. An ideal global lakes database would continue with such a level or volume
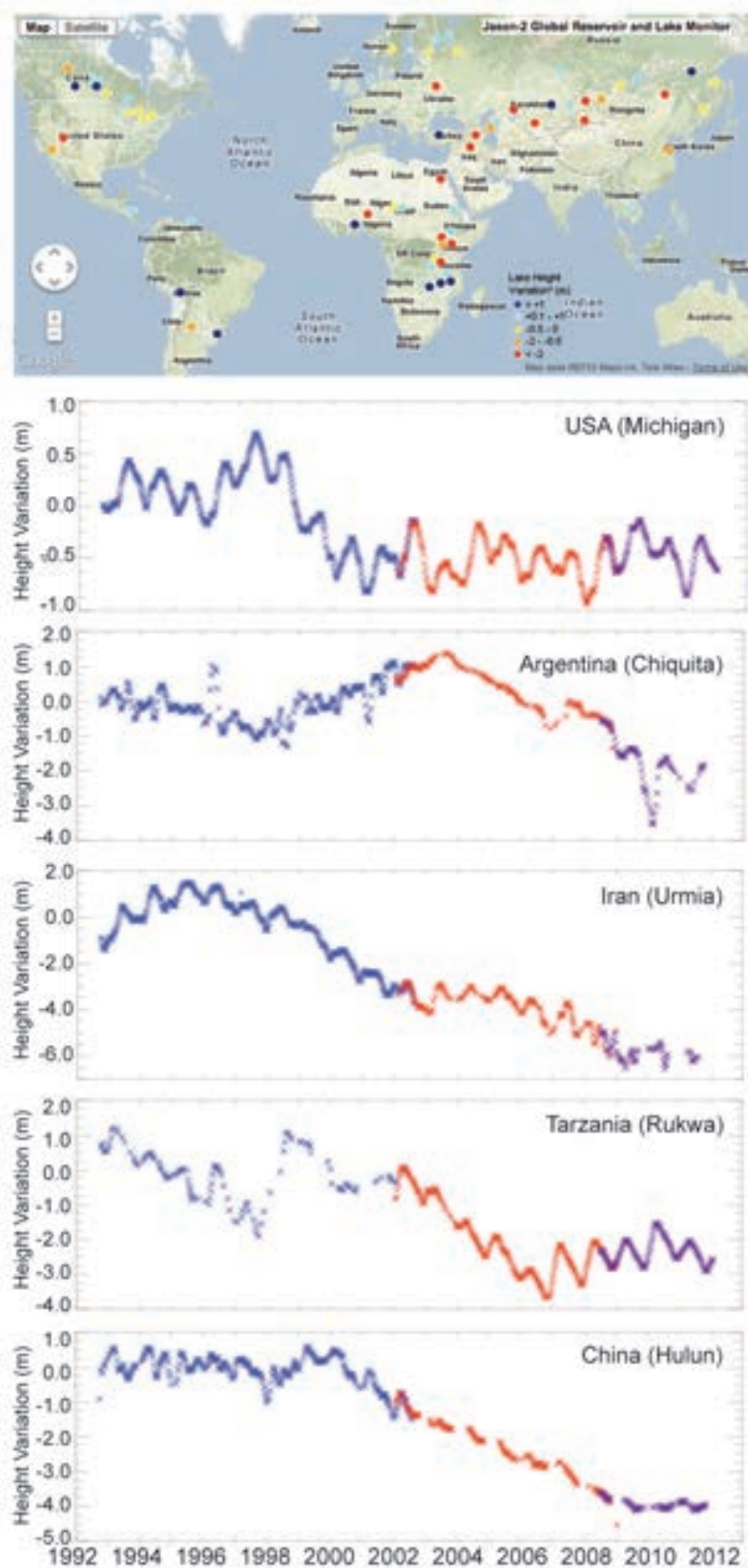

FIG. 2.30. (Top) Map showing the near-real-time (as of end of 20I I) lake-level status of $\sim 70$ lakes with respect to a short-term mean (1993-2002). Red depicts low water drought and navy depicts high water. (Bottom) Examples of lake level time series $(m)$ for five countries. (Source: USDA/FAS CropExplorer)

status indicator, as well as provide other parameters such as lake areal extent, surface water temperature and salinity, ice cover duration and thickness and basin-scale water storage anomalies. The type of lake included should also expand to include ephemeral lakes in both water-challenged and high latitude regions. 

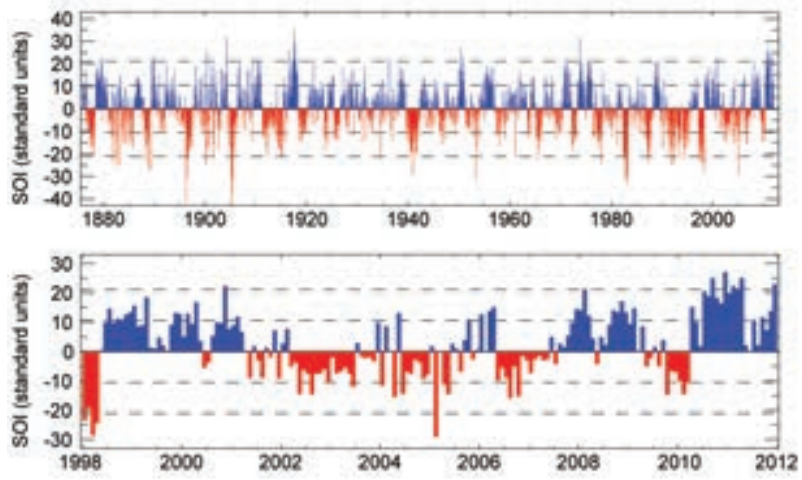

FIG. 2.3I. The Southern Oscillation index (SOI) time series (top) from 1876-2012 and (bottom) for the 1998-20II period. Data are from HadSLP2r (Allan and Ansell 2006).

\section{e. Atmospheric circulation}

I) Mean sea level pressure-R. Allan and C. K. Folland

The La Niña that developed in mid-2010 (apparent in Plate $2.1 \mathrm{~m}$ ) became one of the strongest, in terms of the Southern Oscillation index (SOI) in the historical instrumental record (Fig. 2.31, top). By mid2011 it had declined but then later resurged to a more moderate La Niña (Fig. 2.31, bottom). It resulted in major precipitation and temperature impacts across the entire IndoPacific region, and at higher latitudes in both hemispheres (Plate 2.1).

El Niño and La Niña can be measured by the SOI, the normalized mean sea level pressure (MSLP) difference between Tahiti and Darwin (Allan et al. 1996). Other indices using SST are also commonly utilized (see Kaplan 2011), and these can differ in year-toyear magnitude relative to the atmospheric indicators shown here. El Niño (negative SOI) and La Niña (positive SOI) events vary in magnitude, duration, and evolution, with no two events or episodes exactly the same. There is also the propensity in the climate system for the occasional development of protracted $\mathrm{El}$ Niño and La Niña episodes (Allan et al. 2003), when a La Niña (El Niño) event appears to be ending and/or moving into an El Niño (La Niña) only to be revitalized and continue as an La Niña (El Niño). Figure 2.31 (top) shows the presence of these protracted El Niño and La Niña episodes in the SOI record since 1876, and that they can last for up to six years (e.g., 1990-95 protracted El Niño). El Niño and La Niña events can be near-global in their influence on world weather patterns, owing to ocean-atmosphere interactions across the
Indo-Pacific region with teleconnections to higher latitudes in both hemispheres.

The Antarctic Oscillation (AAO), otherwise known as the southern annular mode (SAM; Kaplan 2011), was notably positive from December 2011 through January 2012. This is clearly identified by the low pressure anomalies over southern high latitudes in Fig. 2.32b (see also section 6b).

The Northern Hemisphere winters of 2010/11 and 2011/12 experienced contrasting North Atlantic Oscillation (NAO)/Arctic Oscillation (AO) conditions (Figs. 2.32a,c compared with 2.32b,d). In 2010/11, the $\mathrm{NAO} / \mathrm{AO}$ indices were dominated, especially initially, by long periods of extremely negative values, with positive pressure anomalies over higher latitudes and negative anomalies over the midlatitudes, and an associated reduction in the westerlies over the North Atlantic-European sector. This contrasted with the early 2011/12 boreal winter, when a major phase of the opposite conditions prevailed.
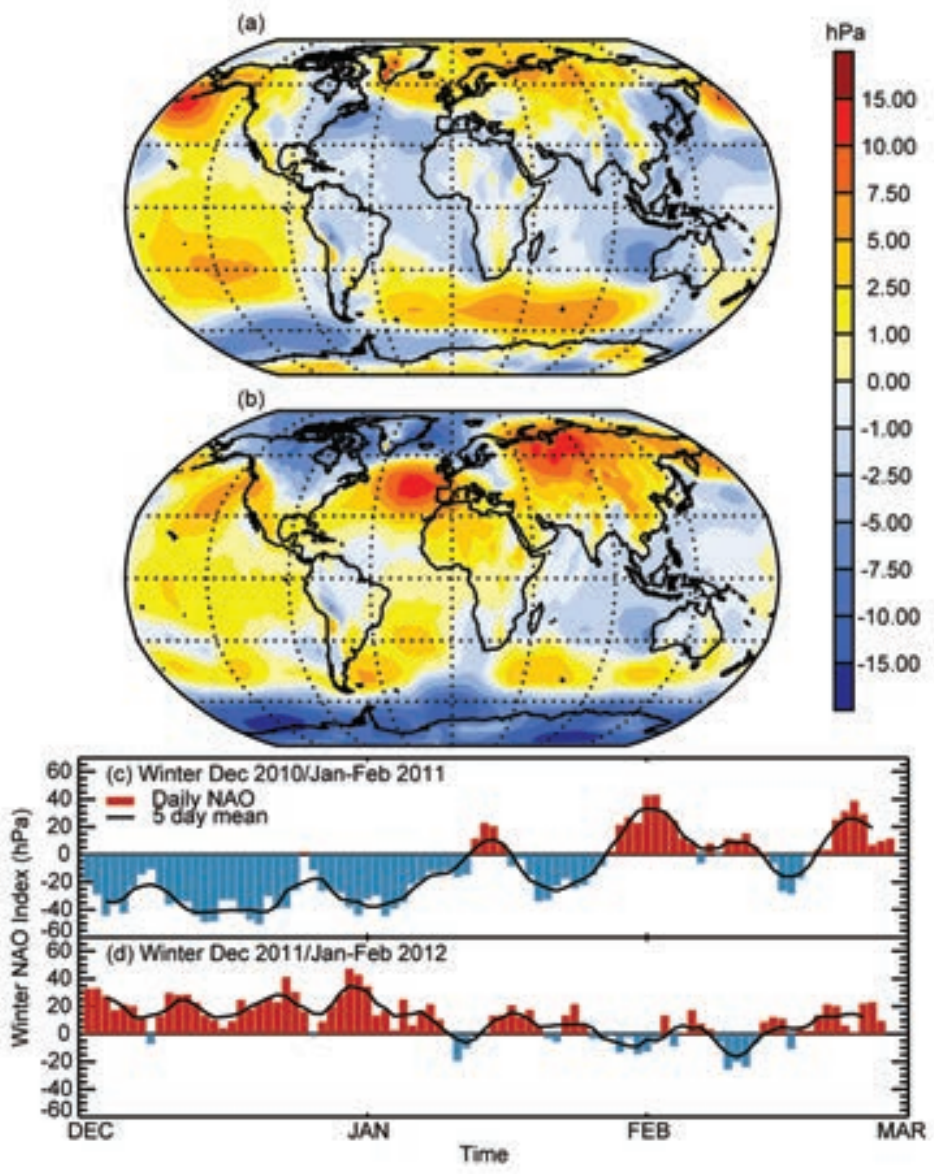

FIG. 2.32. Winter NAO patterns for December 2010-February $20 \mathrm{II}$ and December $20 \mathrm{II}-F e b r u a r y ~ 20 I 2$. (a) and (b) HadSLP2r sea level pressure anomalies (hPa; 196I-1990 base period). (c) and (d) Daily NAO Index $(\mathrm{hPa})$ where red bars show the positive phase and blue bars show the negative phase. 


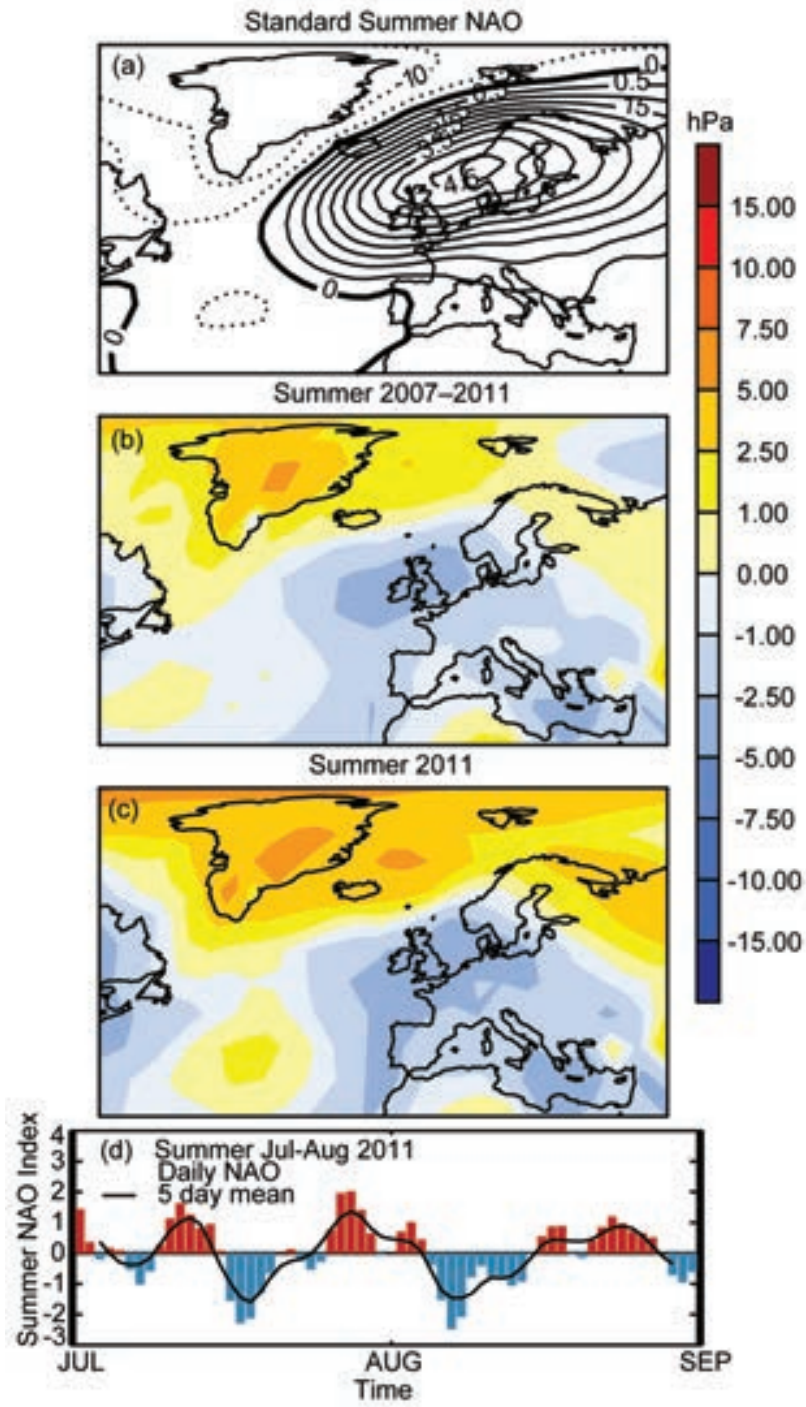

FIG. 2.33. Summer NAO patterns for July to August. (a) Standard pattern in $\mathrm{hPa}$ anomalies, (b) and (c) HadSLP2r sea level pressure anomalies (hPa; 196I-90 base period), and (d) daily summer NAO index (Folland et al. 2009) where red bars show the positive phase and blue bars show the negative phase.

In boreal summer, especially July and August, there is a comparable atmospheric circulation pattern to the winter NAO known as the summer NAO (SNAO; Folland et al. 2009). This is more restricted in latitude (Fig. 2.33a) and explains a somewhat smaller fraction of sea level pressure variance. Its southern node stretches from the northeast Atlantic to Scandinavia, such that when the SNAO is positive, this area has an anticyclonic anomaly, bringing generally warm and dry conditions to northwest Europe. There is a corresponding northward shift of the jet stream. Figure $2.33 \mathrm{~d}$ shows the standardized daily time series of the SNAO index for summer 2011, indicating a neutral mean state. However, this reflected a southward shifted negative southern node (Fig. 2.33c) that gave a rather cool, wet, summer over many parts of the UK, though Scandinavia, while rather wet overall was generally warm (see section $7 \mathrm{f}$ for more details). The SNAO shows pronounced multiannual to multidecadal variations like the winter NAO, but uncorrelated with winter NAO variability over the last 150 years. Figure $2.33 \mathrm{~b}$ shows sea level pressure anomalies in July and August averaged over 2007-11 near Europe. A strong impact of the negative SNAO pattern (-0.66 standard deviations) was wetter than normal conditions over the southern node (not shown). The previous five-year mean (2002-06), including the two very warm UK summers of 2003 and 2006, was by contrast +0.64 standard deviations.

2) SuRface WINDS

(i) Land surface winds and atmospheric evaporative demand-R. Vautard, T. R. McVicar, J.-N. Thépaut, and M. L. Roderick

Land surface winds have a major influence on society and the economy, impacting infrastructure, forests, wind energy production, hydrology, and ecosystems through land-surface exchanges. Longterm wind changes are difficult to characterize because measurements have undergone changes in location, observation protocols, and techniques in many places. Nevertheless, many regional studies concur in declining surface wind speeds in the mid-

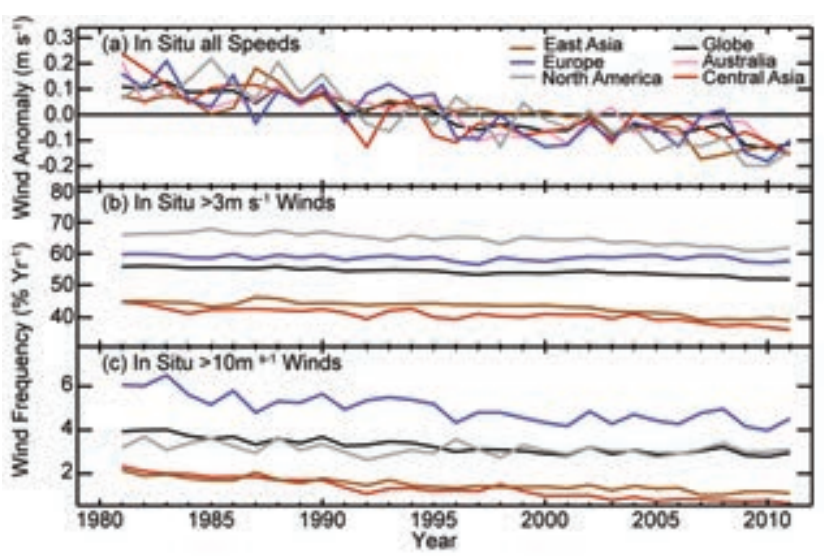

FIG. 2.34. Global and regional average annual mean land wind speed (a) anomalies (198I-20II base period), (b) frequency of wind speeds $>3 \mathrm{~m} \mathrm{~s}^{-1}$ and (c) frequency of wind speeds $>10 \mathrm{~m} \mathrm{~s}^{-1}$. Region definitions, means, and trends are shown in Table 2.2. In all panels global data do not include Australian data since the two datasets have undergone different processing procedures, and while the mean Australian anomaly is shown in (a), occurrence frequencies were not calculated for Australia in (b) and (c). 
TABLE 2.2. Global and regional average wind speeds and trends over the 198I-20II period. Number of stations varies year to year. Global data do not include Australian data since the two datasets have undergone different processing procedures.

\begin{tabular}{|c|c|c|c|c|}
\hline Region & Area definition & $\begin{array}{c}\text { Mean Wind } \\
\text { Speed }\left(\mathrm{m} \mathrm{s}^{-1}\right)\end{array}$ & $\begin{array}{c}\text { Trend } \\
\left(\mathrm{m} \mathrm{s}^{-1} \mathrm{yr}^{-1}\right)\end{array}$ & $\begin{array}{c}\text { Number of } \\
\text { Stations }\end{array}$ \\
\hline Globe & $\mathrm{NA}$ & 3.5 & -0.0078 & 1100 \\
\hline Europe & $\begin{array}{c}20^{\circ} \mathrm{W}, 40^{\circ} \mathrm{E} ; \\
30^{\circ} \mathrm{N}, 75^{\circ} \mathrm{N}\end{array}$ & 3.9 & -0.0086 & 410 \\
\hline Central Asia & $\begin{array}{c}40^{\circ} \mathrm{W}, 100^{\circ} \mathrm{E} ; \\
30^{\circ} \mathrm{N}, 75^{\circ} \mathrm{N}\end{array}$ & 2.5 & -0.0085 & 50 \\
\hline East Asia & $\begin{array}{c}100^{\circ} \mathrm{W}, 160^{\circ} \mathrm{E} ; \\
30^{\circ} \mathrm{N}, 75^{\circ} \mathrm{N}\end{array}$ & 2.7 & -0.0077 & 230 \\
\hline North America & $\begin{array}{c}17^{\circ} \mathrm{W}, 50^{\circ} \mathrm{W} ; \\
30^{\circ} \mathrm{N}, 75^{\circ} \mathrm{N}\end{array}$ & 4.1 & -0.0105 & 250 \\
\hline Australia & $\mathrm{NA}$ & 2.1 & -0.0069 & 44 \\
\hline
\end{tabular}

The wind anomaly pattern resembled that of 2010 (see Peterson et al. 2011a and Plate $2.1 \mathrm{n}$ ), with strong negative anomalies over China, eastern North America, Asia, Australia, and western Europe contrasting with positive anomalies found at several high-latitude regions $(\mathrm{McVicar}$ et al. 2012, table 2). Over northwest North America and Scandinavia, ERA-Interim (Dee et al. 2011a), reproduced the observed positive anomalies reasonably well, although with smaller magnitude (compare Fig. 2.35 with Plate 2.1n). Negative anomalies are found over central Europe, Asia, and, to a lesser extent, eastern North America. The dissimilarity between reanalysis and observed land wind speed trends has been previously latitudes and the tropics and increasing winds in the high latitudes (see McVicar et al. 2012 for a global review). A major part of this trend in the Northern Hemisphere appears attributable to land cover changes, including forest growth, reforestation programs, cropland abandonment, and urbanization (Vautard et al. 2010), and also increased aerosol levels (Jacobson and Kaufman 2006).

In 2010, mean land surface wind speeds, as averaged over a site ensemble selected by Vautard et al. (2010), were shown to reach record-low values (Peterson et al. 2011a). Here, the NOAA ISD-LITE database was utilized, quality controlled similarly to Vautard et al. (2010), and augmented with Australian data (McVicar et al. 2008). The quality control leads to an objective selection retaining more than 1000 stations with observations over 1981 to 2011. With this dataset, 2011 constitutes the third weakest land surface winds year (Fig. 2.34a). In each large region of the Northern Hemisphere, mean surface wind speed was also very low, especially over Asia (record low over central Asia, second lowest value over East Asia). Over North America, the mean wind was third lowest and over Europe, sixth lowest. In the Southern Hemisphere, 2011 mean wind over Australia was also record low.

Changes in the mean frequency of surface wind speeds larger than $3 \mathrm{~m} \mathrm{~s}^{-1}$ are shown in Fig. 2.34b. Globally, this frequency for 2011 (51.8\%) was a new record low, just below the 2010 value (51.9\%). For stronger wind speeds (> $10 \mathrm{~m}$ $\mathrm{s}^{-1}$ ), the 2011 frequency was $25 \%$ below the frequencies found $~ 30$ years ago; note the record low in central Asia (Fig. 2.34c). Exactly how these changes relate to wind speeds aloft remains an interesting research question, with potential implications for renewable wind energy (McVicar et al. 2012; Mostafaeipour 2010; Cheng et al. 2012). documented in both the Northern (Pryor et al. 2009) and Southern Hemispheres (McVicar et al. 2008). Many global climate models also do not concur with observed land winds (Johnson and Sharma 2010, table 5). On the other hand, reanalyses over oceans are in broad agreement with observations (section 2e2ii).

These anomalies and trends in wind speed bear significance for water resources. The kinetic energy in the wind is small by comparison with the turbulent (latent and sensible) heat fluxes at the surface (Peterson et al. 2011b). Despite this, the worldwide declines in pan evaporation, known as the "pan evaporation paradox" (i.e., declining pan evaporation rates in a warming globe), have been partly attributed to declining wind speeds (Roderick et al. 2007; McVicar et al. 2012, table 7). Reported declines in pan evaporation vary substantially between sites, but in the most intensively studied regions to date (US, China, and Australia), large-scale spatial averages decline at a rate of $\sim 2 \mathrm{~mm} \mathrm{yr}^{-1} \mathrm{yr}^{-1}$ over the last $30-50$ years (Fig. 2.36;

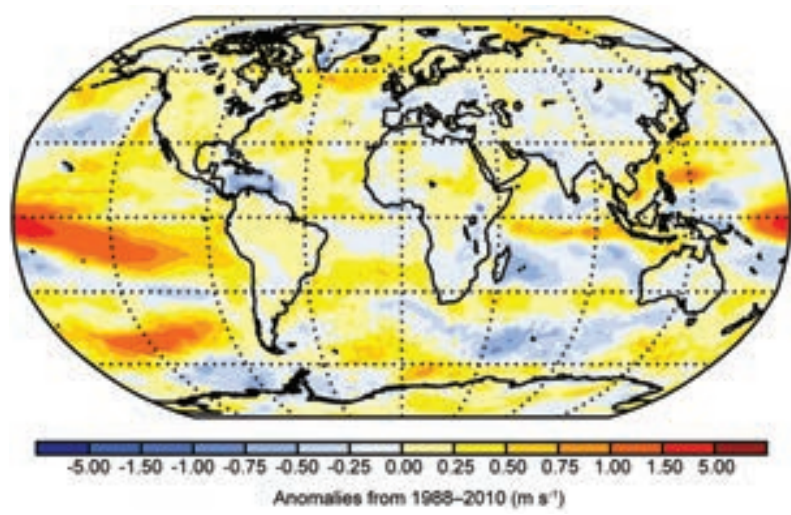

FIG. 2.35. ERA-Interim $201 \mathrm{I}$ anomalies ( $\mathrm{m} \mathrm{s}^{-1}$; 19882010 base period for comparison with Plate 2.In) for surface wind speed. 


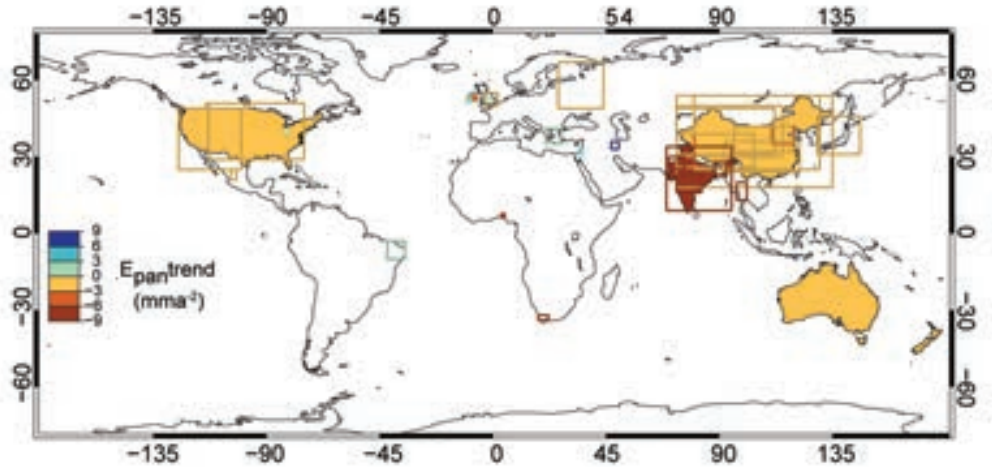

FIG. 2.36. Recent observed rates of pan evaporation trends $\left(\mathrm{mm} \mathrm{yr}^{-1}\right)$ from 55 regional studies. There is incomplete geographic coverage (as shown) and the studies have different start and end dates. (Source: McVicar et al. 2012, Table 5)

McVicar et al. 2012). The hydrological implications of changing atmospheric evaporative demand are geographically variant (see Donohue et al. 2007). In extremely water-limited locations this change will have negligible implications for water resources as evaporation is already limited by water. However, in energy-limited locations and those straddling the energy-limit / water-limit divide (Viviroli et al. 2007), observed trends in atmospheric evaporative demand will have important impacts for water resource availability (Roderick et al. 2009; McVicar et al. 2012).

(ii) Ocean surface winds-C. Mears

Surface wind speed over the oceans has been monitored continuously by satellite-borne microwave radiometers since the launch of the first Special Sensor Microwave/Imager (SSM/I) satellite in late 1987. These instruments make measurements of upwelling microwave radiation to infer the surface roughness of the world's oceans, and thus the surface wind speed (Wentz 1997). Since the first SSM/I instrument, a number of additional microwave imaging sensors have been launched and intercalibrated to the accuracy necessary for climate studies (Wentz et al. 2007). Globally-averaged ocean surface winds (Fig. 2.37) exhibited a maximum in 1988-89, followed by a minimum in 1991, and an increasing trend from 1990 to 2007. In 2008-09, global ocean wind speed fell slightly, followed by recovery in 2010-11. Reanalyses show a steady increase over time, with some variability between the products. The earlier record (up to early 1990s) is less certain than later times due to fewer simultaneous satellite observations and calibration uncertainty for the first two SSM/I instruments.

Global anomalies for 2011, relative to the 19882010 base period, showed large positive anomalies in the central tropical Pacific, the South Pacific east of $180^{\circ} \mathrm{W}$, and in the North Atlantic near $55^{\circ} \mathrm{N}$. The

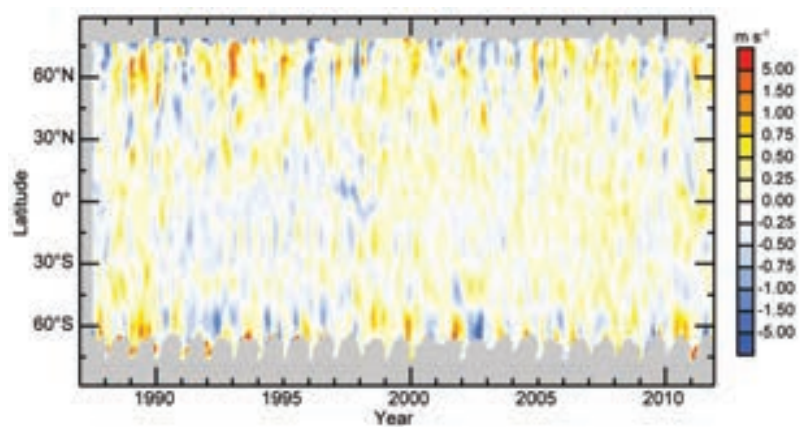

FIG. 2.38. Satellite radiometer monthly mean anomaly $\left(\mathrm{m} \mathrm{s}^{-1} ; 1988-2010\right.$ base period) surface wind speed over the ice-free oceans averaged by latitude. Data have been smoothed in time to remove variability on time scales shorter than four months. Gray areas indicate regions where data are unavailable.

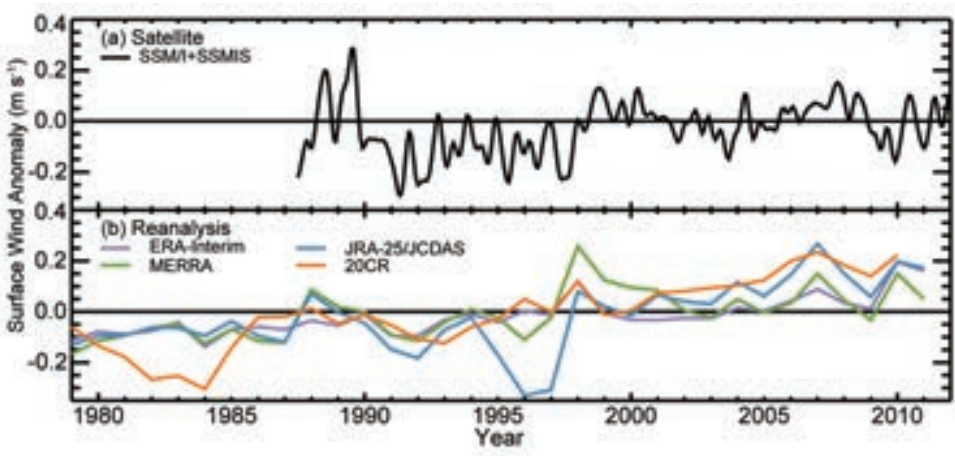

FIG. 2.37. Surface wind speed anomalies $\left(\mathrm{m} \mathrm{s}^{-1}\right.$; 1988-2010 base period) over the global ice-free oceans as measured by Remote Sensing Systems from satellite-borne microwave radiometers (available online at http://www.remss.com) and reanalyses products as described in Fig. 2.I. The satellite time series has been smoothed to remove variability on time scales shorter than four months. latter coincided with the positive phase of the NAO (Hurrell et al. 2003; section 2el) during the cool season months in 2011. Strong negative anomalies occurred east of Madagascar, in the Caribbean Sea, and in the mid-latitude North Pacific (Fig. 2.38; Plate 2.1n).

f. Earth radiation budget at the top-ofatmosphere-T. Wong, P. W. Stackhouse Jr., D. P. Kratz, P. Sawaengphokhai, A. C. Wilber, and N. G. Loeb Analyses of the Clouds and the Earth's Radiant Energy System (CERES; Wielicki et al. 1998) instrument data taken from the combined NASA Terra and Aqua 
TABLE 2.3. Global annual mean TOA radiative flux changes between 2010 and 2011 , the 2011 global-annual mean radiative flux anomalies relative to the $200 \mathrm{I}-\mathrm{II}$ base period, and the 2-sigma interannual variabilities of $2001-1 /$ global-annual mean fluxes (units in $\mathrm{W} \mathrm{m}^{-2}$ ) for the outgoing longwave radiation (OLR), total solar irradiance (TSI), reflected shortwave (RSW), and total net fluxes. All flux values have been rounded to the nearest $0.05 \mathrm{~W} \mathrm{~m}^{-2}$.

\begin{tabular}{|c|c|c|c|}
\hline & $\begin{array}{c}\text { One Year Change } \\
(201 \mathrm{I} \text { minus 2010) }\end{array}$ & $\begin{array}{c}\text { 20II Anomaly } \\
\text { (relative to } \\
\text { climatology) }\end{array}$ & $\begin{array}{c}\text { Interannual } \\
\text { Variability } \\
\text { (200I to 20II) }\end{array}$ \\
\hline OLR & -0.45 & -0.30 & \pm 0.55 \\
\hline TSI & +0.05 & +0.05 & \pm 0.20 \\
\hline RSW & -0.20 & +0.15 & \pm 0.40 \\
\hline Net & +0.70 & +0.20 & \pm 0.65 \\
\hline
\end{tabular}

2007 through February 2011. The 2 -sigma monthly uncertainty of the merge procedure is $\pm 0.20 \mathrm{~W} \mathrm{~m}^{-2}$, $\pm 0.10 \mathrm{~W} \mathrm{~m}^{-2}$, and $\pm 0.15 \mathrm{~W} \mathrm{~m}^{-2}$ for the OLR, RSW, and total net radiation, respectively. The OLR oscillated irregularly in 2010 and 2011, in accord with anomalies from the Atmospheric Infrared Sounder (AIRS) OLR data (monthly AIRX3STM.005 product) for the same period (not shown). Besides ENSO variations, large changes in the North Atlantic Oscillation (NAO) during 2011 may have contributed to the observed large fluctuations in OLR anomaly spacecraft revealed that between 2010 and 2011, the global-annual mean outgoing longwave radiation (OLR) decreased by $\sim 0.45 \mathrm{~W} \mathrm{~m}^{-2}$ and the reflected shortwave radiation (RSW) also decreased by $\sim 0.20$ $\mathrm{W} \mathrm{m} \mathrm{m}^{-2}$ (Table 2.3). Data from the Solar Radiation and Climate Experiment (SORCE; Kopp et al. 2005; Kopp and Lean 2011) indicated that the global annual average total solar irradiance (TSI) increased by $\sim 0.05 \mathrm{~W} \mathrm{~m}^{-2}$ from 2010 to 2011 . Thus, the changes in the combined global-annual averaged OLR and absorbed shortwave (TSI - RSW) fluxes resulted in an enhancement of $\sim 0.70 \mathrm{~W} \mathrm{~m}^{-2}$ in total net radiation into the Earth climate system for 2011 as compared with 2010. The data between July 2011 and December 2011, however, may include modest instrument drift artifacts (below $\pm 0.1 \%$ ), since the final instrument calibration coefficients for those months are not yet available. Relative to the multiyear dataset average for 2001-11, the 2011 global-annual mean anomaly (Table 2.3) is $-0.30 \mathrm{~W} \mathrm{~m}^{-2},+0.05 \mathrm{~W} \mathrm{~m}^{-2},+0.15 \mathrm{~W}$ $\mathrm{m}^{-2}$, and $+0.20 \mathrm{~W} \mathrm{~m}^{-2}$ for OLR, TSI, RSW, and total net radiation, respectively. These results are within the corresponding 2-sigma interannual variability for this period.

Global monthly mean deseasonalized anomalies since March 2000 have been produced by merging Earth Radiation Budget (ERB) datasets from two sources: (1) the CERES EBAF (Energy Balanced And Filled) Top-of-Atmosphere (TOA) Ed2.6r $1^{\circ} \times 1^{\circ}$ product using the Edition 3 instrument calibration; and (2) the CERES Fast Longwave and Shortwave Radiative Fluxes (FLASHFlux) product (Stackhouse et al. 2006; L'Ecuyer et al. 2008). The results are presented in Fig. 2.39, where the FLASHFlux data have been normalized to the EBAF 1Deg data using TOA fluxes from both datasets for the four-year period from March at the end of the record, which require further study. Changes in the absorbed shortwave (TSI - RSW) showed similar features with a smoother curve. The total net anomaly, which contains the combined OLR and absorbed shortwave anomaly, oscillated between positive and negative during 2011. This oscillation is an intrinsic feature of the climate system. Since

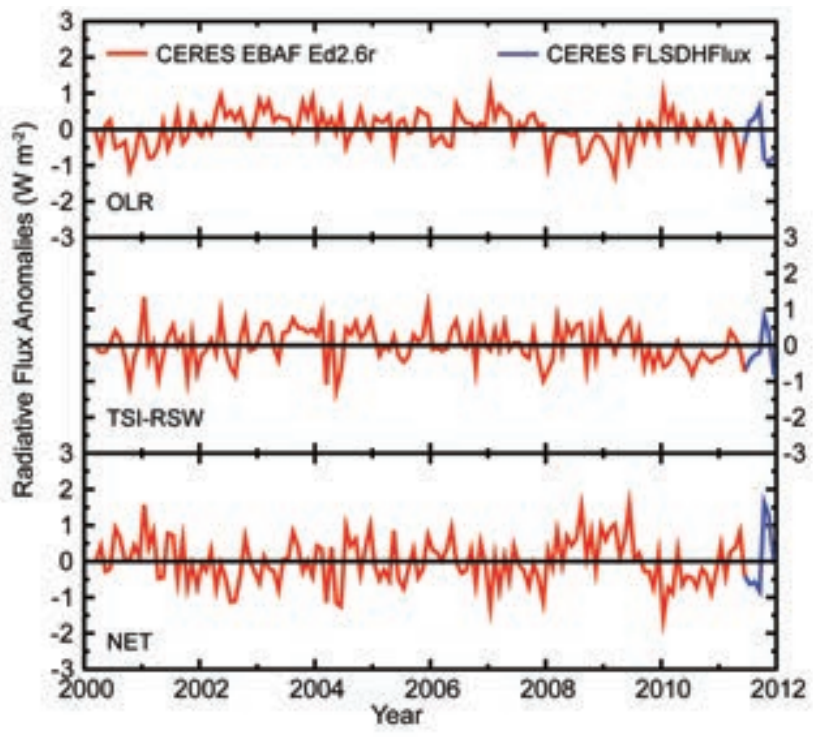

FIG. 2.39. Global monthly-mean deseasonalized anomalies (Mar 2000-Dec 201 I base period) of TOA Earth Radiation Budget for (upper panel) OLR, (middle panel) absorbed shortwave (TSI-RSW), and (lower panel) total net (TSI-RSW-OLR). Anomalies are computed relative to the calendar month climatology. The time series show the CERES EBAF Ed2.6r I ${ }^{\circ}$ data (Mar 2000-Jun 20II) by a red line and the CERES FLASHFlux data (Jul-Dec 20II) by a blue line. Mean differences between datasets were removed using available data from the overlap period (Mar 2007-Feb 20II) and the combined time series was anchored to the absolute value of the CERES EBAF Ed2.6r I ${ }^{\circ}$ results before deseasonalization. 
changes in the ENSO intensity strongly influence the global averaged monthly TOA radiation budget variability during much of CERES period (Loeb et al. 2012), further fluctuations in TOA radiation budget are anticipated as the ENSO cycle evolves. Long-term trend analyses from this combined CERES EBAF and FLASHFlux record are discouraged due to the natural fluctuation in ERB relating to ENSO activity in the short record, the uncertainty from the data merging process, and instrument drift potential in the FLASHFlux data. A long-term homogeneous data source with in-depth instrument stability analysis (e.g., extended CERES EBAF-only dataset) is required to reduce uncertainties in the future.

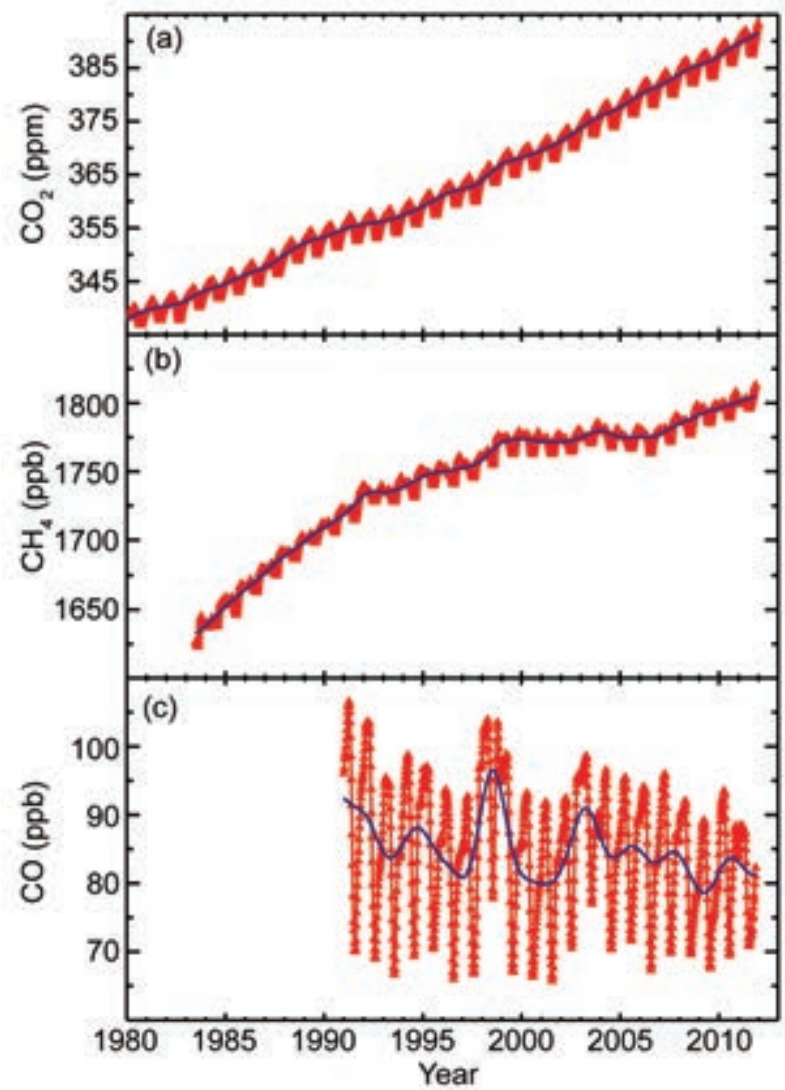

Fig. 2.40. Globally averaged trace gas dry air mole fractions of (a) $\mathrm{CO}_{2}$ (ppm), (b) $\mathrm{CH}_{4}$ (ppb), and (c) $\mathrm{CO}$ (ppb) from discrete air samples collected approximately weekly from sites in NOAA's global cooperative air sampling network and analyzed at ESRL in Boulder, Colorado. Symbols are weekly zonal means, red lines are smooth curves fitted to the data, and blue lines are deseasonalized trend curves.

\section{g. Atmospheric composition}

I) AtMospheric CHeMicAl COMPOSITION

(i) Carbon dioxide, methane, and carbon monoxideE. J. Dlugokencky

Anthropogenic carbon dioxide $\left(\mathrm{CO}_{2}\right)$ emissions from fossil fuel combustion are the main source of anthropogenic greenhouse gases. Despite concerns about the radiative impacts of increasing atmospheric $\mathrm{CO}_{2}$ (Forster et al. 2007), global fossil fuel emissions have increased in recent decades (Peters et al. 2012). Based on preliminary emissions estimates in Peters et al., the recent global financial crisis resulted in only a small (1.4\%) decrease in $\mathrm{CO}_{2}$ emissions from fossil fuel combustion and cement production. In 2010, emissions are estimated to have increased globally by $5.9 \%$ over 2009 to $9.1 \pm 0.5 \mathrm{Pg} \mathrm{C}\left(1 \mathrm{Pg}=10^{15} \mathrm{~g}\right)$. Most of this increase resulted from a $10 \%$ increase in emissions by the world's largest fossil fuel $\mathrm{CO}_{2}$ emitter, China.

The terrestrial biosphere is both a source and sink for atmospheric $\mathrm{CO}_{2}$. Estimated average emissions of $\mathrm{CO}_{2}$ from land-use change (e.g., deforestation) were $1.1 \pm 0.7 \mathrm{Pg} \mathrm{C} \mathrm{yr}^{-1}$ for the period 2000-09 (Friedlingstein et al. 2010; see also section $2 \mathrm{~h} 1$ ). The net effect of vegetation is a sink for $\mathrm{CO}_{2}$, with estimated uptake during 2010 of $2.6 \pm 1.0 \mathrm{Pg} \mathrm{C}$, mostly by the world's forests (Pan et al. 2011). The other major sink for anthropogenic $\mathrm{CO}_{2}$ is ocean uptake, which was estimated to be $2.4 \pm 0.5 \mathrm{Pg} \mathrm{C}$ (Peters et al. 2012), but in some ocean regions this sink may be decreasing (McKinley et al. 2011).

In 2011, globally averaged atmospheric $\mathrm{CO}_{2}$ at Earth's surface reached $390.4 \mathrm{ppm}\left(\mathrm{ppm}=\mu \mathrm{mol} \mathrm{mol}^{-1}\right.$, dry air), surpassing $390 \mathrm{ppm}$ for the first time (Fig. 2.40a). Globally averaged $\mathrm{CO}_{2}$ increased by $2.10 \pm$ $0.09 \mathrm{ppm}$ (where uncertainty is $68 \%$ confidence limit) over 2011. This was slightly larger than the average increase from 2000 to 2011 of $1.96 \pm 0.36 \mathrm{ppm} \mathrm{yr}^{-1}$.

After carbon dioxide, methane $\left(\mathrm{CH}_{4}\right)$ is the most important long-lived greenhouse gas, contributing $\sim 0.5 \mathrm{~W} \mathrm{~m}^{-2}$ direct radiative forcing (see section $2 \mathrm{~g} 1 \mathrm{v}$ ). Indirect effects, from production of tropospheric ozone $\left(\mathrm{O}_{3}\right)$ and stratospheric water $\left(\mathrm{H}_{2} \mathrm{O}\right)$, add another $\sim 0.2 \mathrm{~W} \mathrm{~m}^{-2}$. Methane has a global warming potential (GWP) of 25 ; this means that, integrated over a 100-year time scale, the radiative forcing from a given pulse of $\mathrm{CH}_{4}$ emissions is estimated to be 25 times greater than a pulse of the same mass of $\mathrm{CO}_{2}$. Its GWP includes the indirect effects of tropospheric $\mathrm{O}_{3}$ and stratospheric $\mathrm{H}_{2} \mathrm{O}$, and the impact of increasing $\mathrm{CH}_{4}$ on atmospheric chemistry, which increases its lifetime. 
After about a decade of steady mixing ratios (mole fraction), atmospheric $\mathrm{CH}_{4}$ began increasing again in 2007 (Fig. 2.40b). That increase continued in 2011, although the causes remain uncertain (Dlugokencky et al. 2009; Rigby et al. 2008). Bousquet et al. (2011) used observations from multiple independent measurement programs within a model framework to assess the changes in emissions and sinks responsible for renewed growth in atmospheric $\mathrm{CH}_{4}$. They found that changes in tropical wetland emissions were the dominant driver in 2007 , with a minor contribution from Arctic wetlands. For 2008, two independent model approaches were not consistent. Neither a strong increase in emissions from wetlands in the tropics nor the Arctic was implied. They found that changes in the concentration of hydroxyl radical $(\mathrm{OH})$, which would affect the $\mathrm{CH}_{4}$ sink, were less than $1 \%$, and they had only a small impact on observed $\mathrm{CH}_{4}$ changes. During 2011 globally averaged atmospheric $\mathrm{CH}_{4}$ at Earth's surface increased by $\sim 5 \pm 2 \mathrm{ppb}$ (ppb $=\mathrm{nmol} \mathrm{mol}{ }^{-1}$, dry air) to an annual mean of $1803 \mathrm{ppb}$ (preliminary values; Fig. 2.40b). The causes are likely related, in part, to increasing emissions from rapidly developing economies in Asia and to larger-than-average emissions from tropical wetlands (Dlugokencky et al. 2009; Bousquet et al. 2011; EDGAR 2009).

Carbon monoxide (CO) does not absorb strongly in the thermal infrared region, so it does not contribute directly to radiative forcing. However, it is a key species in atmospheric chemistry, particularly in cycling of reactive species like the $\mathrm{OH}$ and hydroperoxyl radical $\left(\mathrm{HO}_{2}\right)$. Changes in the atmospheric $\mathrm{CO}$ burden affect the lifetimes of other long-lived greenhouse gases, such as methane, hydrochlorofluorocarbons (HCFCs), and hydrofluorocarbons (HFCs), so it has an indirect effect on climate. No significant long-term trend has been detected in globally averaged $\mathrm{CO}$ determined from NOAA/ESRL measurements, which began in 1990 (Novelli et al. 2003), but CO anomalies occurred during 1997-98, and again in 2002-03 (Fig. 2.40c). These anomalies are likely the result of interannual variability in emissions from tropical and boreal biomass burning. Since the lifetime of $\mathrm{CO}$ is relatively short (few months), the $\mathrm{CO}$ enhancements quickly disappeared. The preliminary globally averaged CO mole fraction in 2011 is $\sim 80.5 \mathrm{ppb}$, slightly less than in 2010.

(ii) Nitrous oxide and sulfur hexafluoride-B. Hall, J. W. Elkins, and G. Dutton

Atmospheric nitrous oxide $\left(\mathrm{N}_{2} \mathrm{O}\right)$ and sulfur hexafluoride $\left(\mathrm{SF}_{6}\right)$ have significant manmade sources

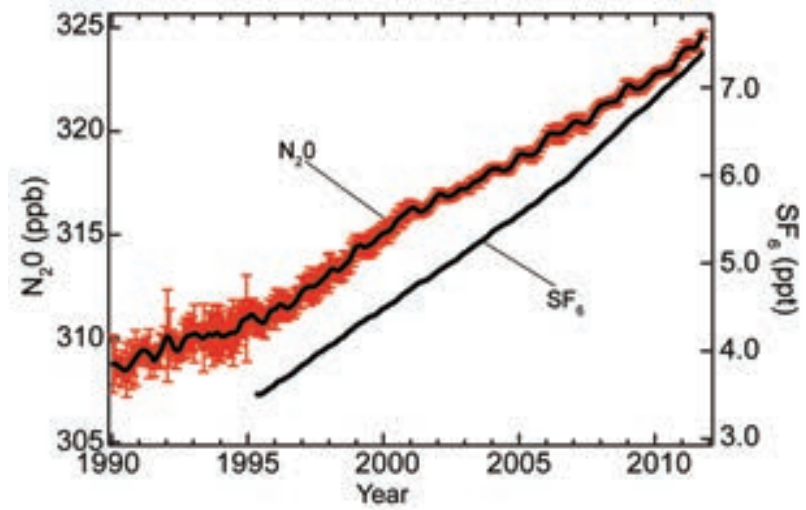

FIG. 2.4I. Global average nitrous oxide $\left(\mathrm{N}_{2} \mathrm{O}, \mathrm{ppb}\right)$ and sulfur hexafluoride $\left(\mathrm{SF}_{6}\right.$, $\left.\mathrm{ppt}\right)$ mole fractions determined from NOAA discrete and in situ samples. Error bars for $\mathrm{N}_{2} \mathrm{O}$ are based on monthly averages ( $\mathrm{I}$ std. dev.). Error bars for $\mathbf{S F}_{6}$ are omitted for clarity, and are approx. 0.04 ppt in the 1990 s and 0.02 ppt thereafter.

and are two of six gases selected for emission reduction under the Kyoto Protocol of the United $\mathrm{Na}$ tions Framework Convention for Climate Change (UNFCCC). Atmospheric $\mathrm{N}_{2} \mathrm{O}$ currently has the third strongest climate forcing of the long-lived greenhouse gases after carbon dioxide and methane. Current emissions of $\mathrm{N}_{2} \mathrm{O}$ are expected to contribute more to future ozone depletion than current emissions of halogenated ozone-depleting substances (ODS) (Ravishankara et al. 2009). Nitrous oxide is produced naturally by both the oxidation of ammonium and the denitrification of nitrate. Significant emissions of $\mathrm{N}_{2} \mathrm{O}$ can occur following the application of nitrogen fertilizers (including manure) on agricultural crops (Davidson 2009). Recent work suggests strong sources from tropical land areas with high temporal variability (Kort et al. 2011), although the cause of the variability has not been determined. The mean global atmospheric $\mathrm{N}_{2} \mathrm{O}$ mixing ratio for 2011 was 324.3 ppb, an increase of $1.1 \mathrm{ppb}$ over 2010 (Fig. 2.41). This year-on-year increase is higher than the average growth rate of $0.75 \pm 0.01 \mathrm{ppb} \mathrm{yr}^{-1}$ observed from 1977 to 2010 (Elkins and Dutton 2011).

Sulfur hexafluoride $\left(\mathrm{SF}_{6}\right)$ is an important greenhouse gas because it has a large global warming potential (GWP; 23900 times greater than $\mathrm{CO}_{2}$ for a 100-year time horizon). This large 100-year GWP is primarily the result of its very long atmospheric lifetime of 3200 years (Solomon et al. 2007). Sulfur hexafluoride is primarily used as a dielectric insulator for transmission of electricity and emissions are entirely anthropogenic. Its global average mixing ratio in 2011 was $7.31 \mathrm{ppt}$ (ppt = pmol mol ${ }^{-1}$, dry air), an increase of 0.28 ppt over 2010 (Fig. 2.41). The average 
linear growth rate was $0.22 \pm 0.01 \mathrm{ppt} \mathrm{yr}^{-1}$ from 1995 to 2007. Since 2007, the growth rate has averaged 0.28 ppt yr $^{-1}$.

(iii) Ozone-depleting gases and their replacements -S. A. Montzka and G. Dutton

Long-lived halocarbons are important greenhouse gases and contribute significantly to present-day radiative forcing. Those halocarbons that contain bromine $(\mathrm{Br})$ and chlorine $(\mathrm{Cl})$ also influence radiative forcing indirectly through destruction of stratospheric ozone. Because of concern over stratospheric ozone depletion, production of many halocarbons has been restricted in recent years through amendments and adjustments to the 1987 Montreal Protocol on Substances that Deplete the Ozone Layer. As a result, mixing ratios of most of the potent ozone-depleting gases have been declining at Earth's surface; this decline continued in 2011 (Fig. 2.42).

While mixing ratios of many ODSs are declining, those of some halogenated gases continue to increase globally (Fig. 2.42c,d). The most rapid increases are observed for HCFCs and HFCs, which are common replacements for CFCs, halons, and other ODSs. HCFCs contain chlorine and deplete ozone with a reduced efficiency compared to CFCs. HFCs do not participate in ozone-destroying reactions.

Future levels of ozone-depleting halogen in the stratosphere (and, therefore, the threat to strato-
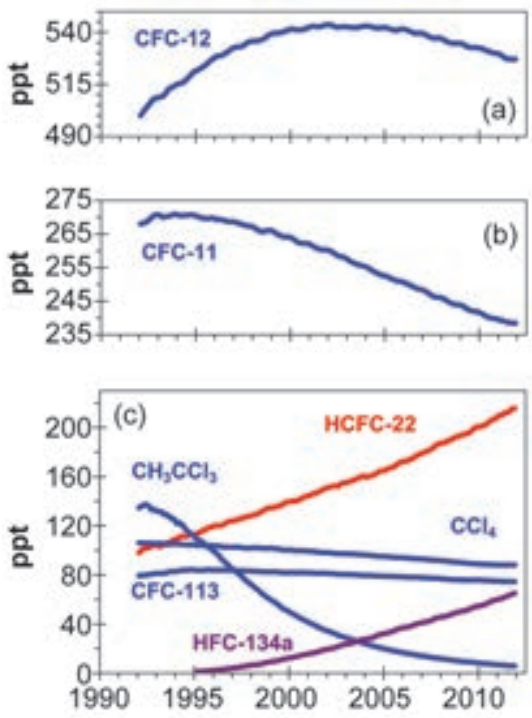
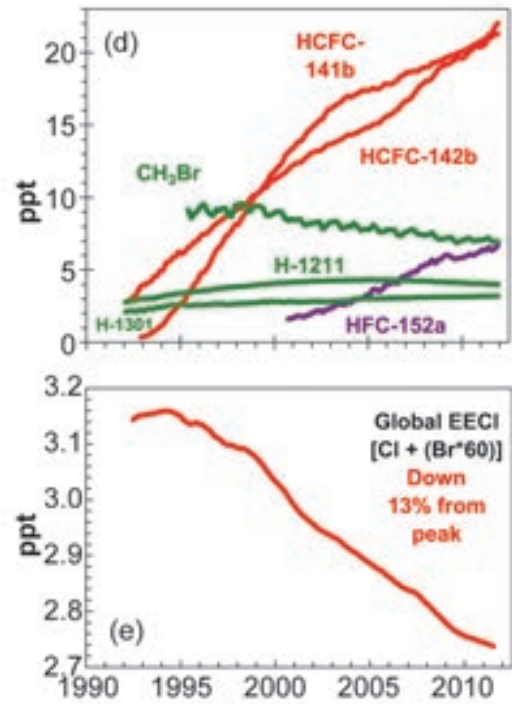

FIG. 2.42. (a)-(d) Atmospheric abundances (global mean tropospheric mixing ratios, dry air mole fraction) of the most abundant CFCs, HCFCs, HFCs, chlorinated solvents, and brominated gases, and (e) changes in atmospheric Equivalent Effective Chlorine ( $\mathrm{EECl})$ where $\mathrm{EECl}$ is derived as the sum of $[\mathrm{Cl}+(\mathrm{Br} \cdot 60)]$ from observed mixing ratios of ODS appearing in the other four panels.

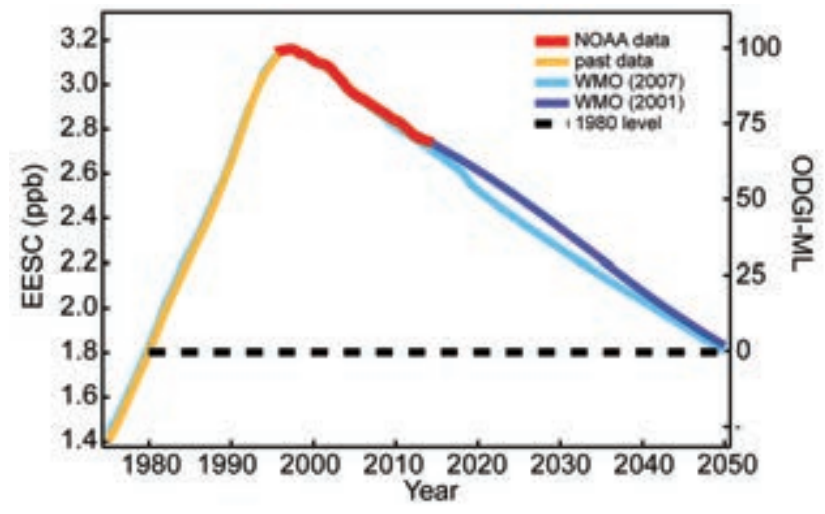

FIG. 2.43. Equivalent Effective Stratospheric Chlorine (EESC, left axis) and the Ozone Depleting Gas Index (ODGI) for midlatitudes (right axis) derived from NOAA/GMD data (red) and for various scenarios (blue) (Daniel et al. 20II). EESC is derived from EECI by adding three years to the time axis to represent the lag associated with mixing air from the troposphere to the middle stratosphere where the ozone layer resides.

spheric ozone) can be estimated from weighted sums of tropospheric halocarbon abundances. Since the efficiency for $\mathrm{Br}$ to destroy ozone is higher than that of $\mathrm{Cl}, \mathrm{Br}$ atoms are assigned a higher weighting factor (a factor of 60 is used here, after Montzka et al. 2011). These sums are derived from surface-based measurements and are expressed as Equivalent Effective Chlorine (EECl; Fig. 2.42e).

The EECl content of the lower atmosphere declined fairly steadily through 2011 at a mean rate of $27 \mathrm{ppt} \mathrm{yr}^{-1}$ since the peak in 1994 (Fig. 2.42e). Despite these substantial changes, full recovery of stratospheric ozone is not expected until the middle to latter part of the 21st century, owing to the long lifetimes of many of these chemicals (Table 2.4; Montzka et al. 2011). A similar conclusion can also be drawn from measurements of trace gases obtained by the AGAGE group (Prinn et al. 2000). Both NOAA and AGAGE measurements show similar trends in $\mathrm{EECl}$ in recent years (Montzka et al. 2011). Progress towards EECl declining back to the 1980 level can be readily assessed with the NOAA Ozone-Depleting Gas Index (ODGI) in Table 2.4 (Hofmann and Montzka 2009). This index (Fig. 2.43) is derived from EECl (Fig. 2.42e), scaled so that a value 


\begin{tabular}{|c|c|c|c|c|c|c|}
\hline $\begin{array}{l}\text { Industrial Designation } \\
\text { or Common Name }\end{array}$ & $\begin{array}{l}\text { Chemical } \\
\text { Formula }\end{array}$ & AGGI & ODGI & 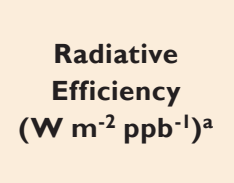 & $\begin{array}{c}\text { Mean Sur- } \\
\text { face Mixing } \\
\text { Ratio 20II } \\
\text { [change } \\
\text { from prior } \\
\text { year] }\end{array}$ & $\begin{array}{l}\text { Lifetime } \\
\text { (year) }^{\mathrm{a}}\end{array}$ \\
\hline Carbon Dioxide & $\mathrm{CO}_{2}$ & $\mathrm{Y}$ & $\mathrm{N}$ & $1.41 \times 10^{-5}$ & $390.4[1.9]^{\mathrm{c}}$ & \\
\hline Methane & $\mathrm{CH}_{4}$ & Y & $\mathrm{N}$ & $3.7 \times 10^{-4}$ & $1803.0[3.8]^{c}$ & $\sim 9$ \\
\hline Nitrous oxide & $\mathrm{N}_{2} \mathrm{O}$ & $\bar{Y}$ & $\mathrm{~N}$ & $3.03 \times 10^{-3}$ & $324.2[1.1]$ & 114 \\
\hline \multicolumn{7}{|c|}{ Chlorofluorocarbons } \\
\hline CFC-II & $\mathrm{CCl}_{3} \mathrm{~F}$ & Y & $\mathrm{Y}$ & 0.25 & $238.5[-2.1]$ & 45 \\
\hline CFC- 12 & $\mathrm{CCl}_{2} \mathrm{~F}_{2}$ & $\mathrm{Y}$ & $\mathrm{Y}$ & 0.32 & $527.4[-2.6]$ & 100 \\
\hline CFC-113 & $\mathrm{CCl}_{2} \mathrm{FCClF}_{2}$ & $\mathrm{Y}$ & $\mathrm{Y}$ & 0.30 & $74.7[-0.7]$ & 85 \\
\hline \multicolumn{7}{|c|}{ Hydrochlorofluorocarbons } \\
\hline HCFC-22 & $\mathrm{CHClF}_{2}$ & $\mathrm{Y}$ & $Y$ & 0.20 & $212.6[6.8]$ & 11.9 \\
\hline HCFC-I4Ib & $\mathrm{CH}_{3} \mathrm{CCl}_{2} \mathrm{~F}$ & $\mathrm{Y}$ & $\mathrm{Y}$ & 0.14 & $21.3[0.9]$ & 9.2 \\
\hline HCFC-142b & $\mathrm{CH}_{3} \mathrm{CClF}_{2}$ & $\mathrm{Y}$ & $Y$ & 0.20 & $21.0[0.8]$ & 17.2 \\
\hline \multicolumn{7}{|c|}{ Hydrofluorocarbons } \\
\hline HFC-134a & $\mathrm{CH}_{2} \mathrm{FCF}_{3}$ & $\mathrm{Y}$ & $N$ & 0.16 & $62.6[5.4]$ & 13.4 \\
\hline HFC-152a & $\mathrm{CH}_{3} \mathrm{CHF}_{2}$ & $\mathrm{Y}$ & $\mathrm{N}$ & 0.09 & $6.5[0.4]$ & 1.5 \\
\hline HFC-143a & $\mathrm{CH}_{3} \mathrm{CF}_{3}$ & $\mathrm{Y}$ & $\mathrm{N}$ & 0.13 & II.I[1.0] & 47.1 \\
\hline HFC- 125 & $\mathrm{CHF}_{2} \mathrm{CF}_{3}$ & $\mathrm{Y}$ & $\mathrm{N}$ & 0.23 & $9.7[1.4]$ & 28.2 \\
\hline HFC-23 & $\mathrm{CHF}_{3}$ & $\mathrm{Y}$ & $\mathrm{N}$ & 0.19 & $24.0[0.8]$ & 222 \\
\hline \multicolumn{7}{|c|}{ Chlorocarbons } \\
\hline Methyl Chloroform & $\mathrm{CH}_{3} \mathrm{CCl}_{3}$ & $\mathrm{Y}$ & $\mathrm{Y}$ & 0.06 & $6.3[-1.3]$ & 5.0 \\
\hline Carbon Tetrachloride & $\mathrm{CCl}_{4}$ & $\mathrm{Y}$ & $\mathrm{Y}$ & 0.13 & $87.1[-1.3]$ & 26 \\
\hline Methyl Chloride & $\mathrm{CH}_{3} \mathrm{Cl}$ & $N$ & $\mathrm{Y}$ & 0.01 & $538[-1.9]$ & 1.0 \\
\hline \multicolumn{7}{|c|}{ Bromocarbons } \\
\hline Methyl Bromide & $\mathrm{CH}_{3} \mathrm{Br}$ & $\mathrm{N}$ & $\mathrm{Y}$ & 0.01 & $7.05[-0.03]$ & 0.8 \\
\hline Halon I2II & $\mathrm{CBrClF}_{2}$ & $\mathrm{Y}$ & $\mathrm{Y}$ & 0.30 & $4.0[-0.1]$ & 16.0 \\
\hline Halon I30I & $\mathrm{CBrF}_{3}$ & $Y$ & $\mathrm{Y}$ & 0.32 & $3.2[0.02]$ & 65 \\
\hline Halon 2402 & $\mathrm{CBrF}_{2} \mathrm{CBrF}_{2}$ & Y & $\mathrm{Y}$ & 0.33 & $0.45[-0.01]$ & 20 \\
\hline \multicolumn{7}{|c|}{ Fully fluorinated species } \\
\hline Sulfur Hexafluoride & $\mathrm{SF}_{6}$ & $\begin{array}{ll}\mathrm{Y} \\
\end{array}$ & $\mathrm{N}$ & 0.52 & $7.31[0.28]$ & 3,200 \\
\hline PFC-14 & $\mathrm{CF}_{4}$ & $\mathrm{~N}$ & $\mathrm{~N}$ & 0.10 & $79.0[0.7]^{\mathrm{c}}$ & $>50000$ \\
\hline PFC-116 & $\mathrm{C}_{2} \mathrm{~F}_{6}$ & $\mathrm{~N}$ & $\mathrm{~N}$ & 0.26 & $4.2[0.11]^{\mathrm{c}}$ & $>10000$ \\
\hline
\end{tabular}

${ }^{a}$ Radiative efficiencies and lifetimes are taken from Daniel et al. (2011), Montzka et al. (2011), and Prinn et al. (2005). For CO ${ }_{2}$, numerous removal processes complicate the derivation of a lifetime.

${ }^{\mathrm{b}}$ Mixing ratios are global surface means determined from the NOAA global cooperative sampling network (Hofmann et al. 2006), except for PFC-14 and PFC-116, and HFC-23 which were measured by the AGAGE group (Mühle et al. 2010; Miller et al. 2010).

${ }^{\mathrm{c}}$ Preliminary estimate for 2011.

of 100 represents the EECl [or Effective Equivalent Stratospheric Chlorine (EESC)] abundance at its peak, and 0 represents the 1980 level (a reference point during which ozone depletion was thought to have been small). In 2011, the ODGI-Mid-Latitudes was 66.6. Less progress is evident for the index when the tropospheric data are weighted to be relevant for considering Antarctic changes; the ODGI-Antarctica was 82.4 in 2011. 


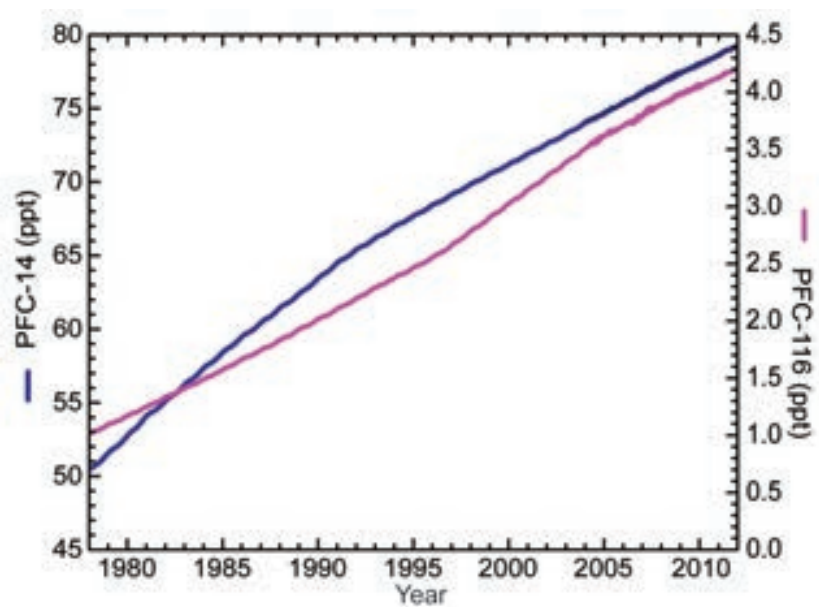

FIG. 2.44. Global average surface concentrations of PFC-I4 (blue) and PFC-II6 (magenta) (ppt) from the AGAGE network (Mühle et al. 20l0).

\section{(iv) Perfluorocarbons-J. Mühle}

Perfluorocarbons (PFCs) are extremely long-lived, potent greenhouse gases. PFC-14 $\left(\mathrm{CF}_{4}\right)$ and PFC-116 $\left(\mathrm{C}_{2} \mathrm{~F}_{6}\right)$ have lower limits for atmospheric lifetimes of 50000 and 10000 years, respectively, and global warming potentials (100-year time horizon) of 7390 and 12 200, respectively (Montzka et al. 2011). Anthropogenic PFC-14 and PFC-116 were historically emitted as by-products of aluminum production (IAI 2011) and are also emitted from the electronics industry. However, the onset and extent of PFC emissions from the electronics industry is poorly known due to limited reporting (Worton et al. 2007; Mühle et al. 2010). A small natural source of $\mathrm{CF}_{4}$ from degassing of Earth's crust has been identified (Harnisch and Eisenhauer 1998; Harnisch et al. 2000), which, because of its extraordinarily long atmospheric lifetime, accounts for its significant preindustrial abundance (Harnisch et al. 1996a,b) of $34.7 \pm 0.2$ ppt (Mühle et al. 2010), or $\sim 44 \%$ of its 2011 abundance.

Based on preliminary data, global average surface mixing ratios of PFC-14 and PFC-116 were $\sim 79 \mathrm{ppt}$ and $\sim 4.2 \mathrm{ppt}$ in 2011, respectively (Fig. 2.44). Mixing ratios of PFC-14 rose at $\sim 1.1 \mathrm{ppt} \mathrm{yr}^{-1}$ from the late 1970 s to the early 1990s and by $\sim 0.7$ ppt yr $^{-1}$ after-

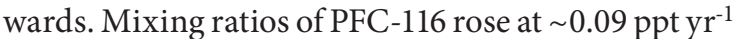
from the late 1970s to the mid-1990s, at $\sim 0.12 \mathrm{ppt} \mathrm{yr}^{-1}$ until the mid-2000s, and at $\sim 0.08 \mathrm{ppt} \mathrm{yr}^{-1}$ in recent years (Mühle et al. 2010 and preliminary data).

(v) The combined influence of long-lived trace gases on the radiative balance of the atmosphere- $B$. Hall and S. A. Montzka

Greenhouse gases affect the radiative balance of the atmosphere because they efficiently absorb

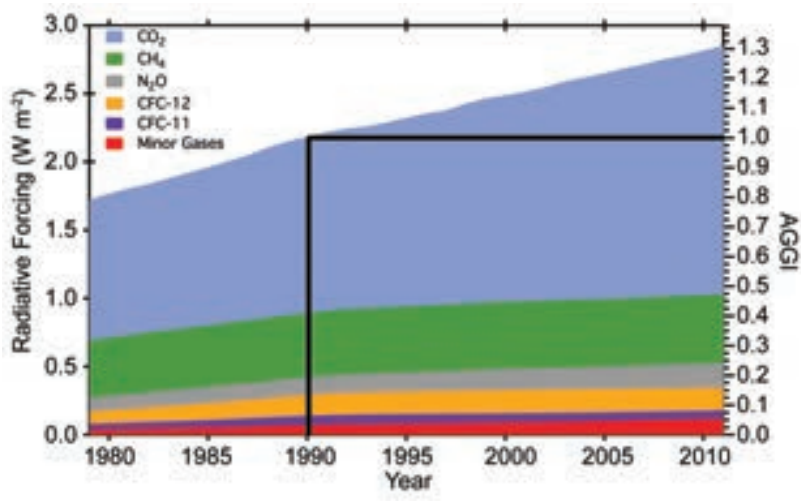

FIG. 2.45. Direct radiative forcing $\left(\mathrm{W} \mathrm{m}^{-2}\right)$ due to longlived trace gases (left axis), and the radiative forcing from long-lived trace gases, relative to 1990 , defined as the Annual Greenhouse Gas Index (right axis). The value of the AGGI was 1.30 in 201 I, an increase of $30 \%$ since 1990.

terrestrial infrared (IR) radiation. Recent trends in the radiative forcing (RF) of radiatively important gases are shown in Fig. 2.45. The NOAA Annual Greenhouse Gas Index (AGGI) was developed based upon the direct radiative influence from long-lived greenhouse gases, also known as radiative forcing, relative to the preindustrial era (1750; Hofmann et al. 2006). It represents the additional influence (over preindustrial values) due to long-lived trace gases in a given year relative to 1990, the Kyoto Protocol baseline year. Indirect effects (e.g., arising from ozone depletion or water-vapor feedbacks) are not considered in this index. The index is derived from global surface measurements of $\mathrm{CO}_{2}, \mathrm{CH}_{4}, \mathrm{~N}_{2} \mathrm{O}, \mathrm{CFC}-12$, and CFC-11 (the major long-lived greenhouse gases) and 15 minor greenhouse gases (e.g., HCFCs, HFCs; see Table 2.4).

Based on preliminary global mean data through 2011, the increases in the abundances of these gases over their preindustrial values amounted to an additional direct $\mathrm{RF}$ to the atmosphere totaling approximately $2.84 \mathrm{~W} \mathrm{~m}^{-2}$. This compares with $2.18 \mathrm{~W} \mathrm{~m}^{-2}$ in 1990. Thus, the accumulation of long-lived trace gases in the atmosphere since 1990 has resulted in a $30 \%$ increase in RF due to long-lived gases.

2) Aerosols-A. Benedetti, J.-J. Morcrette, J. W. Kaiser, and L. T. Jones

Atmospheric aerosols have been recognized as a major source of uncertainty in future climate prediction (Forster et al. 2007; Denman et al. 2007). Most have a general cooling effect, reflecting incoming solar radiation back to space. However, black carbon has the potential to enhance warming through absorption of solar radiation (Ramanathan and 


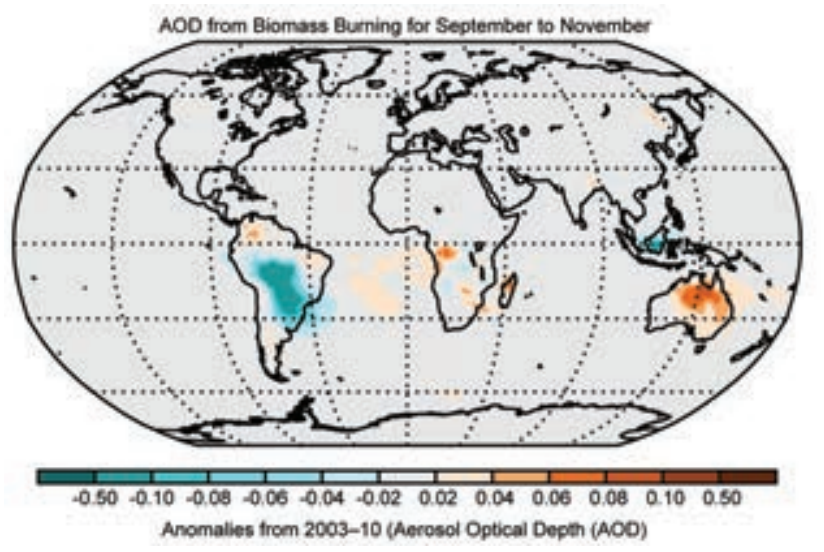

FIG. 2.46. MACC aerosol reanalysis aerosol optical depth anomaly in carbonaceous aerosols (dominated by biomass burning) for the 201 I Sep-Nov season.

Carmichael 2008). Quantifying the relative impact of the different aerosol types, including volcanic aerosols and those associated with biomass burning, along with aerosol-induced feedbacks in clouds and

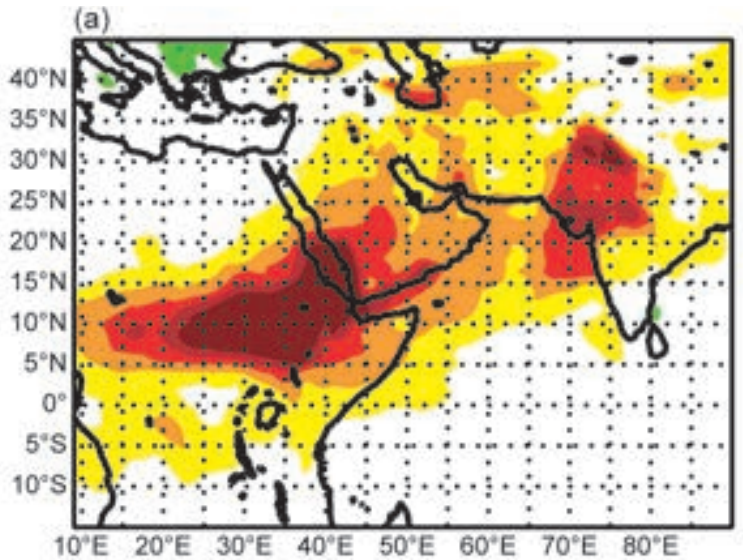

(c)

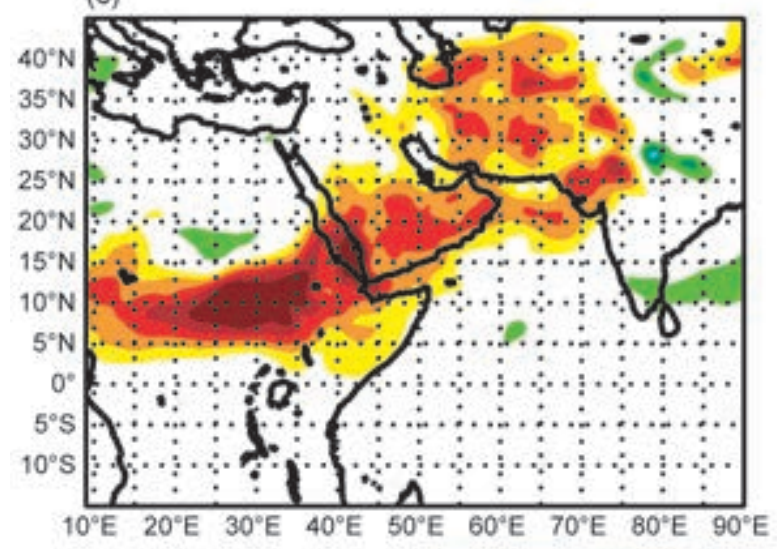

precipitation, is crucial for understanding current climate (Lohmann and Feitcher 2005).

Reanalyses have been heavily used by the scientific community since their introduction in the 1980s (Dee et al. 2011a). Atmospheric composition from reanalyses poses greater problems due to unknown biases in emissions, limited availability of constraining observations, shorter periods covered, and the complexity associated with accounting for all atmospheric constituents and modeling their interactions.

ECMWF has recently completed an eight-year reanalysis of atmospheric composition from 2003 to 2010, including aerosols, reactive gases, and greenhouse gases, under the EU-funded project Monitoring Atmospheric Composition and Climate (MACC; Simmons 2010). The aerosol analysis is based on assimilation of aerosol optical depth (AOD) observations (MODIS sensor) and the latest inventories and parameterizations for sea salt, desert dust, black carbon, organic matter, and sulfate aerosol. Preliminary assessments show that the MACC aerosol

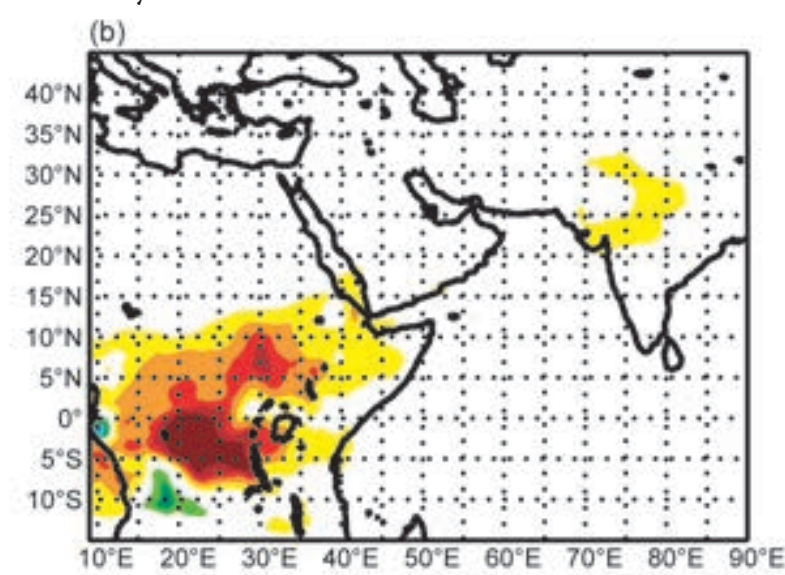

(d)

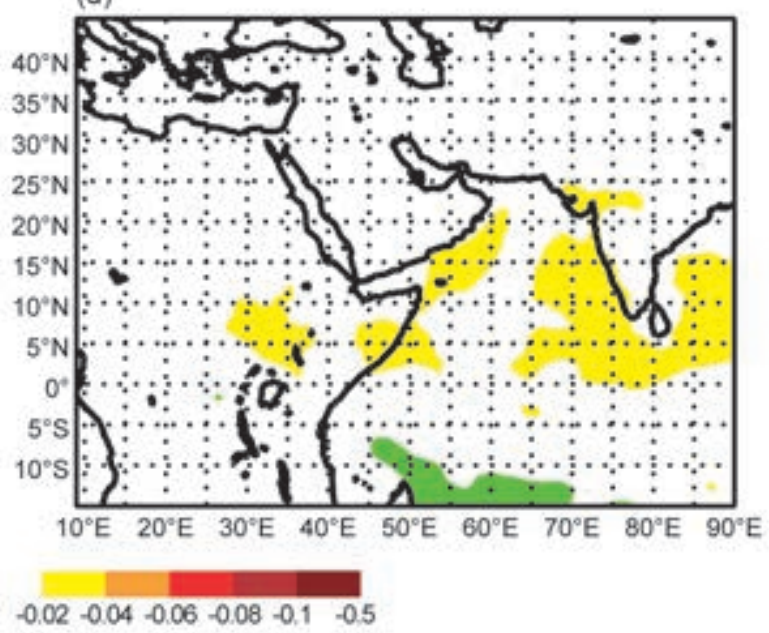

Fig. 2.47. Aerosol optical depth anomalies for the East Africa/Middle East/Indian Ocean area over Jun-Aug in 2011: (a) sulfate, (b) biomass burning, (c) desert dust, and (d) sea salt. The location of the Nabro volcano $\left(13.36^{\circ} \mathrm{N}, 41.69^{\circ} \mathrm{E}\right)$ is marked with a star in (a). 

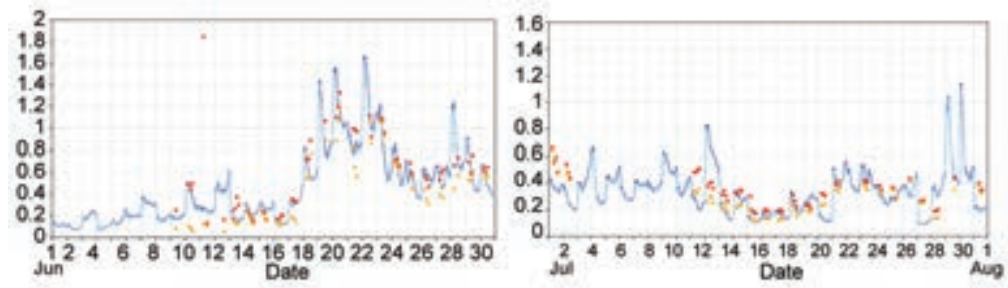

FIG. 2.48. Time series of aerosol optical depth (AOD) at the station of ICIPE_Mbita $\left(0.42^{\circ} \mathrm{S}, 34.2^{\circ} \mathrm{E}\right)$ during June (left) and July (right) 20II. Red dots are the AERONET total AOD, yellow dots are the AERONET fine-mode AOD. The dark blue line represents the MACC reanalysis total AOD, while the light blue line represents the MACC reanalysis fine-mode AOD.

reanalysis tends to underestimate Saharan dust and overestimate sea salt. These are constant biases and do not necessarily affect estimates of anomalies. Anthropogenic aerosols, particularly biomass burning, appear to have realistic amplitude and distribution, and benefit from estimates of fire emissions from fire radiative power [Global Fire Assimilation System (GFAS); Kaiser et al. 2012; Plate 2.1t]. Recently, the MACC reanalysis was extended through 2011 to provide consistent data for this State of Climate report.

A map of time-averaged total AOD anomaly for 2011 is shown in Plate 2.1o, relative to a 2003-10 base period. This shows enhanced total AOD in parts of East Africa and the Middle East, mainly due to an anomalous amount of sulfate and dust, related to the eruption of the volcano Nabro $\left(13.4^{\circ} \mathrm{N}, 41.7^{\circ} \mathrm{E}\right)$. A positive anomaly in AOD is also visible over Australia as a result of the intense fire activity during the months of September and October. The biomass burning activity over South America in 2011 appeared to be less intense than climatological expectations. This is shown clearly by September-November anomalies of carbonaceous aerosols, which are dominated by biomass burning (Fig. 2.46; section $2 \mathrm{~h} 4$ ).

The boreal summer (JJA) of 2011 (Fig. 2.47) exhibited a large anomaly in AOD across the whole of north-equatorial Africa, especially west of the Horn of Africa. This was due to the volcano Nabro, situated in Eritrea, near the Ethiopian border, which erupted from 12 June through 7 July. The combination of volcanic emissions and seasonally dry conditions, i.e., lack of wet removal of soluble aerosol particles (Plate 2.1; Sidebar 7.2), helps to explain the lasting presence of aerosol particles. Large positive anomalies in AOD are evident over the entire Middle East and the Indian Ocean, the latter consistent with an increase in sea salt (Fig. 2.47d).

The MACC reanalysis is constrained by observations of total AOD, hence the redistribution into different species is entirely dependent on the model. At present, the MACC model does not represent volcanic aerosol sources explicitly. Instead, the observed AOD signal from volcanic ash is attributed to other species. In the region shown in Fig. 2.47, the volcanic ash signal has been attributed mainly to dust and sulfate. Independent data from the AERONET station close to Lake Victoria (Fig. 2.48) show high values of fine-mode AOD starting in the second half of June and persisting through July, which is indicative of the presence of fine aerosols being advected southward from the volcanic source.

3) Stratospheric ozone-M. Weber, W. Steinbrecht, C. Long, V. E. Fioletov, S. H. Frith, R. Stolarski, and P. A. Newman

The 2011 annual mean total ozone was above the 1980-2008 mean in the tropics and below at higher latitudes and, in particular, both polar regions (Plate 2.1p). This pattern is related to the westerly phase of the quasi-biennial oscillation $(\mathrm{QBO})$, as discussed in section $2 \mathrm{~b} 3$.

Figure 2.49 shows time series of total ozone in polar regions $\left(60^{\circ}-90^{\circ}\right)$ from different ground and

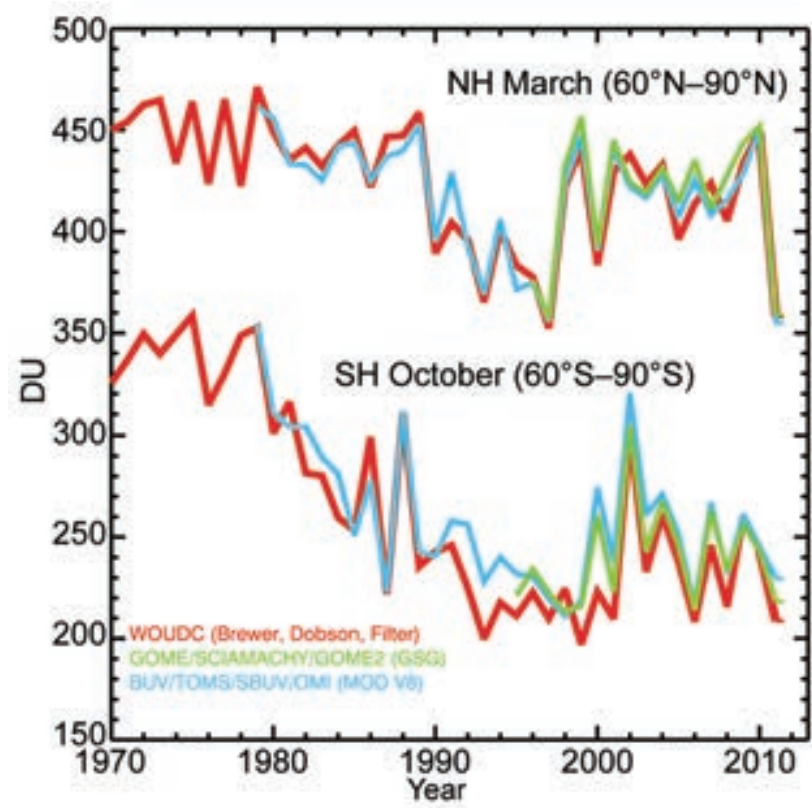

FIG. 2.49. March and October polar total ozone (in Dobson Units, DU) in the Northern and Southern Hemisphere, respectively. WOUDC ground-based measurements combining Brewer, Dobson, and filter spectrometer data (red: Fioletov et al. 2002, 2008), the merged BUVISBUVITOMS/OMI MOD V8 (blue: Stolarski and Frith 2006), and GOME/SCIAMACHYI GOME-2 “GSG” (green: Weber et al. 2007). 


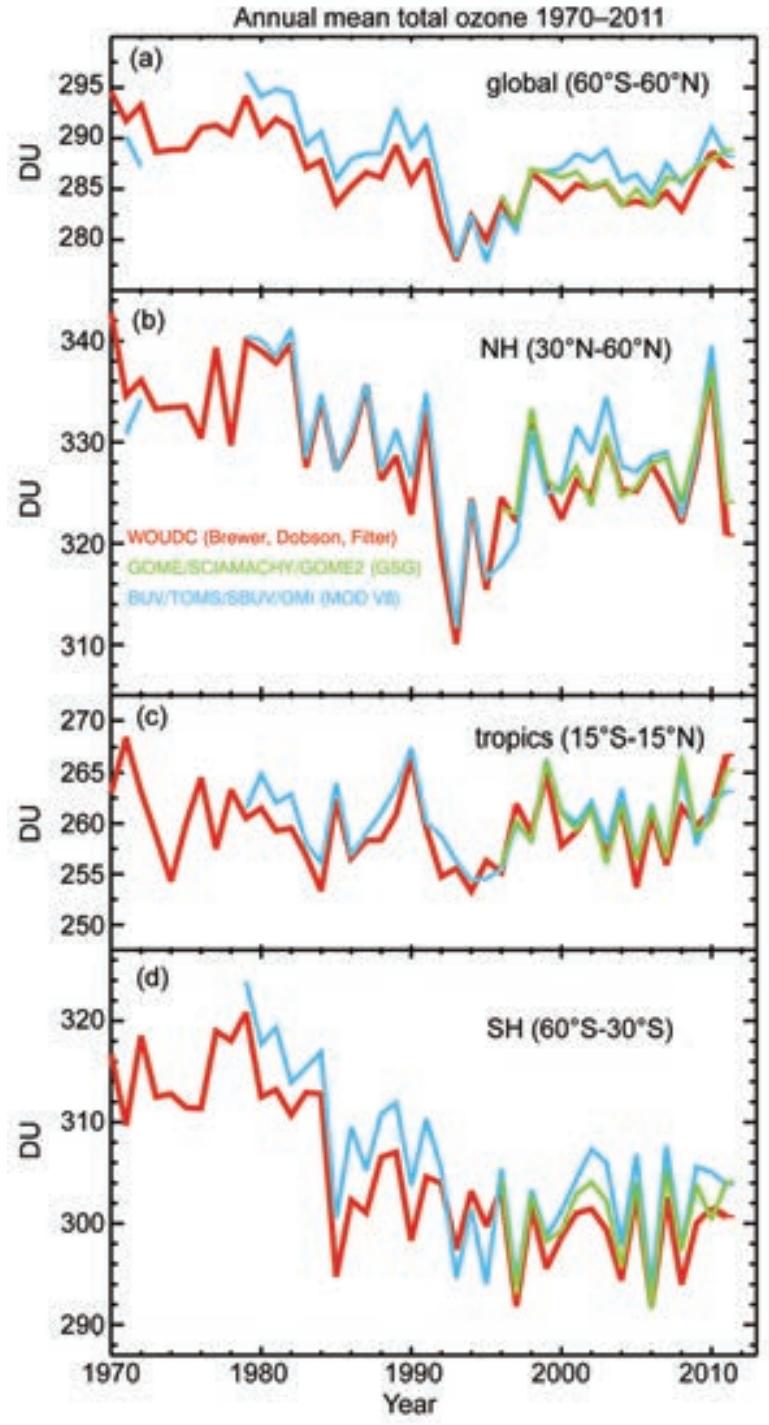

Fig. 2.50. Annual mean total ozone (DU) time series of ground-based measurements as described in Fig. 2.49 for the (a) $60^{\circ} \mathrm{S}-60^{\circ} \mathrm{N}$ (globe), (b) $30^{\circ} \mathrm{N}-60^{\circ} \mathrm{N}$ (Northern Hemisphere), (c) $15^{\circ} \mathrm{S}-15^{\circ} \mathrm{N}$ (tropics), and (d) $30^{\circ} \mathrm{S}-60^{\circ} \mathrm{S}$ (Southern Hemisphere) zonal bands.

satellite data in March (Arctic) and October (Antarctica). The March Arctic mean was extremely low and comparable to the lowest values of the 1990s, owing to low temperatures (section 2b3). These low temperatures allowed polar stratospheric clouds to form, leading to record-high chemical ozone losses. These were close to typical Antarctic ozone hole conditions (see section 6g; Manney et al. 2011; Sinnhuber et al. 2011). The Antarctic ozone hole in austral spring was among the largest on record (see section $6 \mathrm{~g}$ ). The seasonal persistence of extratropical ozone anomalies from winter/spring into the summer months (Fioletov and Shepherd 2003; Weber et al. 2011) resulted in marked negative anomalies in the annual mean (Plate 2.1p).
Long-term trends in total ozone (Figs. 2.49, 2.50) are statistically significant only in the extratropics. The midlatitude losses between 1980 and the early 1990 s were followed by stable but variable values in the Southern Hemisphere and a significant increase and subsequent leveling off in the 2000s in the Northern Hemisphere. The substantial minimum in the Northern Hemisphere in the early 1990s arose from additional ozone loss associated with the Mount Pinatubo volcanic eruption and a series of unusually cold Arctic stratospheric winters (e.g., Dhomse et al. 2006). Despite the low extratropical ozone observed in 2011, there is evidence that ozone has started recovering as ozone depleting substances are phased out in accordance with the Montreal Protocol and amendments (see section 2g1iii; Mäder et al. 2010; Salby et al. 2011; Weber et al. 2011).

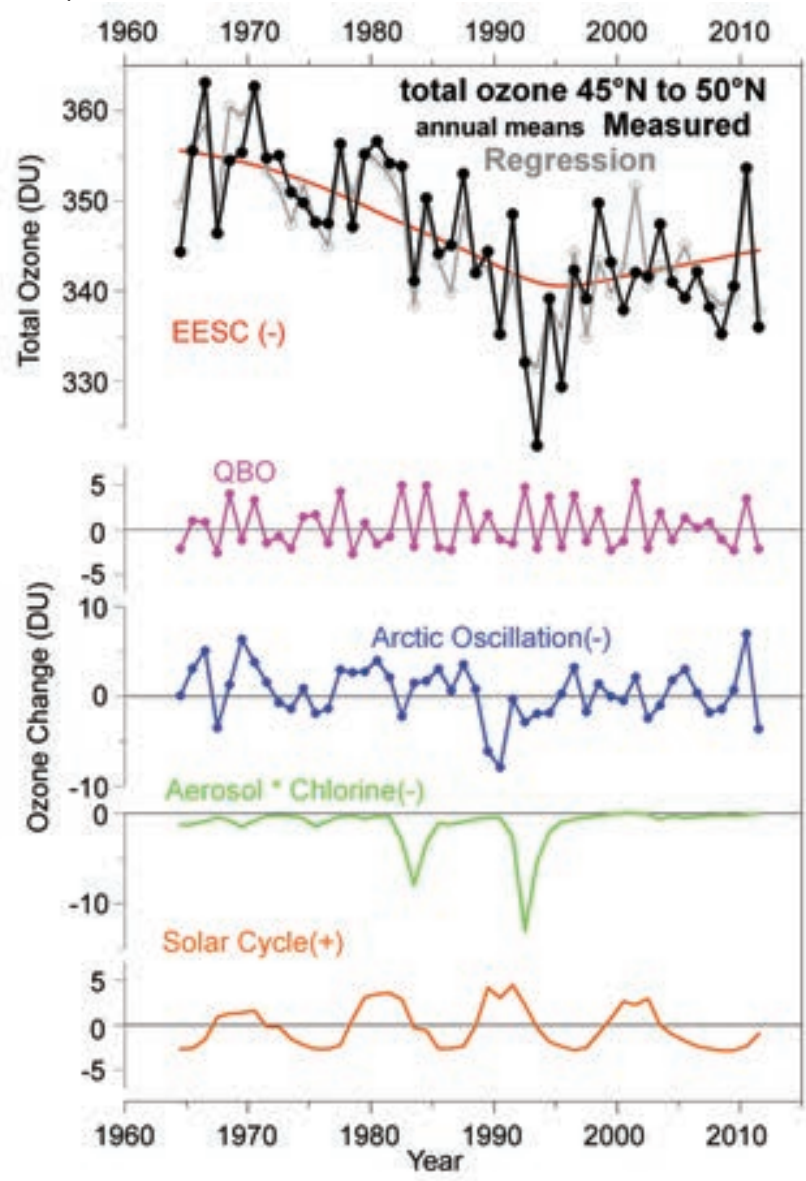

FIG. 2.5I. Observed total ozone and magnitude of contributing factors obtained by multiple linear regression. Annual and zonal mean total ozone (DU) at $45^{\circ} \mathrm{N}-50^{\circ} \mathrm{N}$ from WOUDC ground-based data (black) and multiple linear regression results (gray) partitioned into ozone variation attributed to EESC (red), QBO (magenta), AO (blue), enhanced stratospheric aerosol multiplied by EESC (green), and the II-year solar cycle (orange). 
Figure 2.51 shows a multivariate linear regression with different explanatory variables considered to be major factors in ozone changes (Steinbrecht et al. 2011) applied to the $45^{\circ} \mathrm{N}-50^{\circ} \mathrm{N}$ zonal annual mean total ozone from the World Ozone and Ultraviolet Radiation Data Centre (WOUDC) ground data (Fioletov et al. 2002, 2008). Major factors include the QBO, $\mathrm{AO}$ (Arctic Oscillation), solar activity, major volcanic eruptions, and changes in stratospheric halogen or EESC (Equivalent Effective Stratospheric Chlorine; Newman et al. 2007). The large downward swing in ozone from 2010 to 2011 follows the large changes in AO (-12 DU) and QBO (-5 DU). The anthropogenic ozone recovery as expressed by the EESC curve is a modest increase of 3 DU since 1997.

Following an upper stratospheric decline of $10 \%$ to $15 \%$ from the early 1980 s to the mid-1990s, mainly attributed to the anthropogenic release of ozone depleting substances (ODS), upper stratospheric ozone has leveled off. In the last 10 years, the various records even show signs of an increase (Steinbrecht et al. 2009; Jones et al. 2009; WMO 2011).

Ozone trends in the tropical lowermost stratosphere are mainly driven by tropical upwelling (SPARC 2010; Lamarque and Solomon 2010). Randel and Thompson (2011) observed a negative trend of
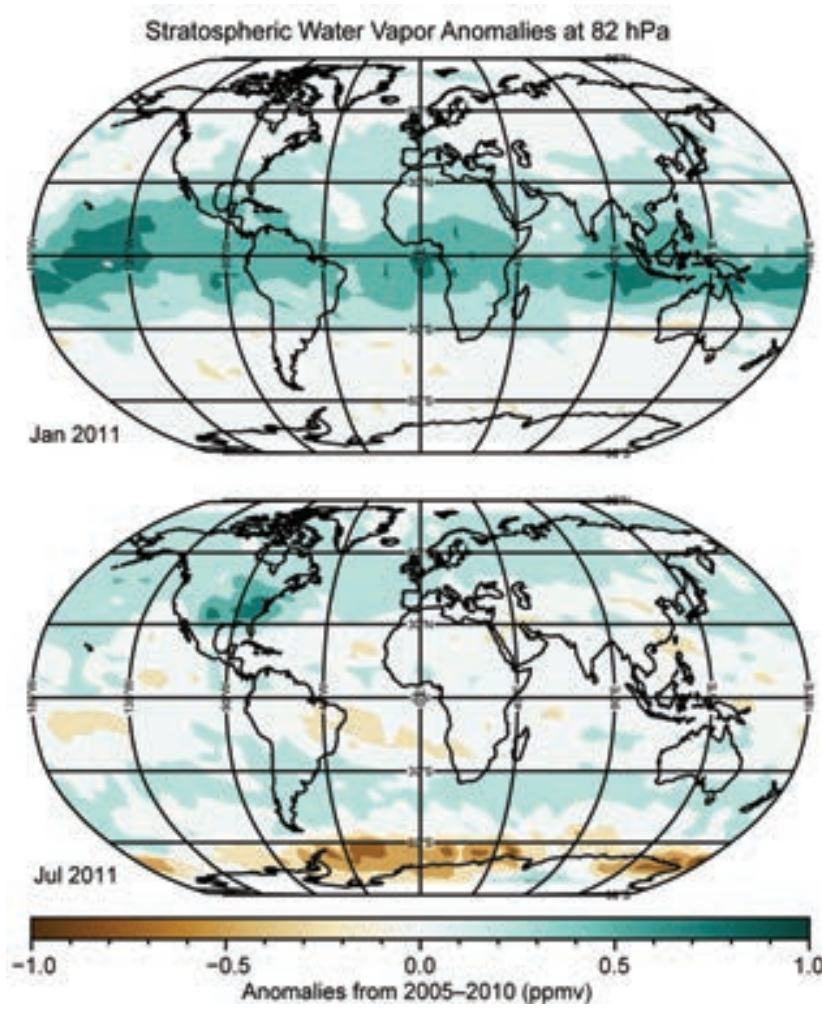

Fig. 2.52. Global stratospheric water vapor anomalies (ppmv) at $82 \mathrm{hPa}$ for January (upper) and July (lower) 2011 from the Aura Microwave Limb Sounder (MLS).
$-2 \%$ to $-4 \%$ decade $^{-1}$ in the $17-\mathrm{km}-21-\mathrm{km}$ altitude range from a combination of satellite (SAGE I+II) and ozonesondes. This indicates a long-term increase in the tropical upwelling and associated strengthening of the meridional circulation.

4) STRATOSPHeRIC WATER VAPOR一D. Hurst and K. Rosenlof Stratospheric water vapor continued to increase during 2011 over most of the globe, but the anomalies varied significantly with latitude and altitude. Based on data from the Aura Microwave Limb Sounder (MLS), lower stratospheric tropical anomalies at 82 hPa were strongly positive during January, and high southern latitude anomalies were strongly negative during July (Fig. 2.52). Negative anomalies that encircled Antarctica during July were likely associated with polar vortex dehydration. In the tropics, the coldest temperatures that determine stratospheric entry values of water vapor occur near $82 \mathrm{hPa}$. Entry values are normally lowest in January and highest in July, so the positive tropical anomalies in January imply that 2011 annual minimum cold point temperatures were warmer than the 2005-10 January average. Lower stratospheric water vapor anomalies
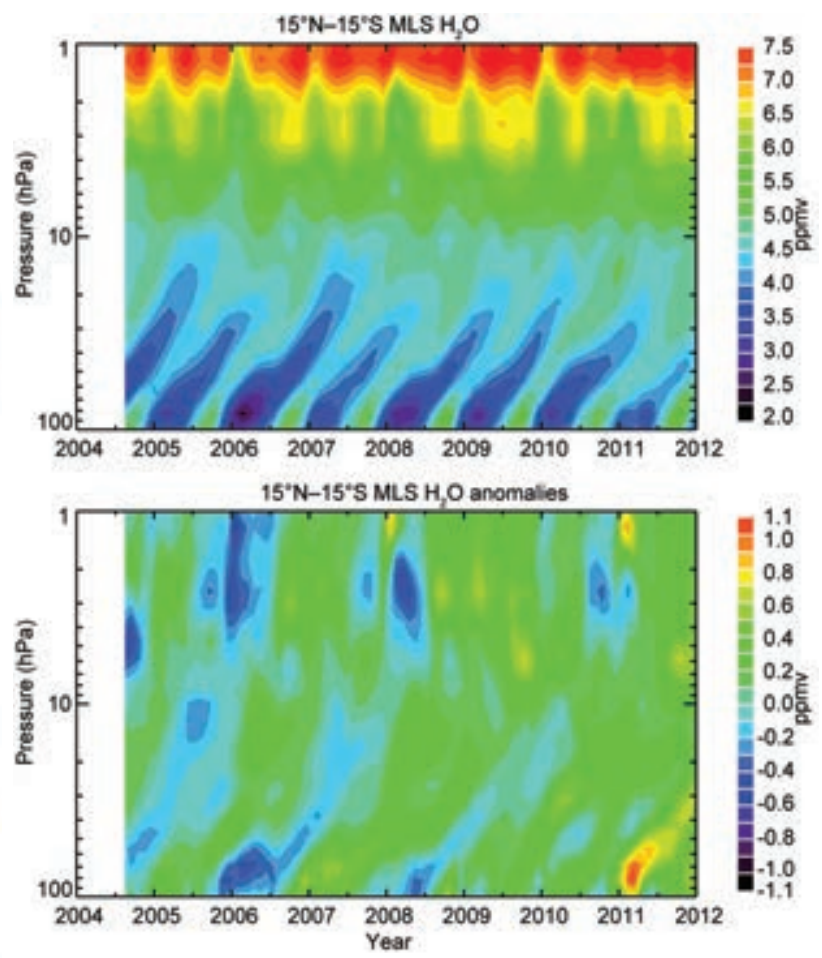

FIG. 2.53. Time series of MLS vertical profiles of monthly water vapor mixing ratios (upper) and anomalies (lower; 2005-10 base period) in the tropics $\left(15^{\circ} \mathrm{N}-15^{\circ} \mathrm{S}\right)$. The prominent and reoccurring lower stratospheric QBO signals observed from 2004-08 are not apparent during 2009-II (lower figure). 

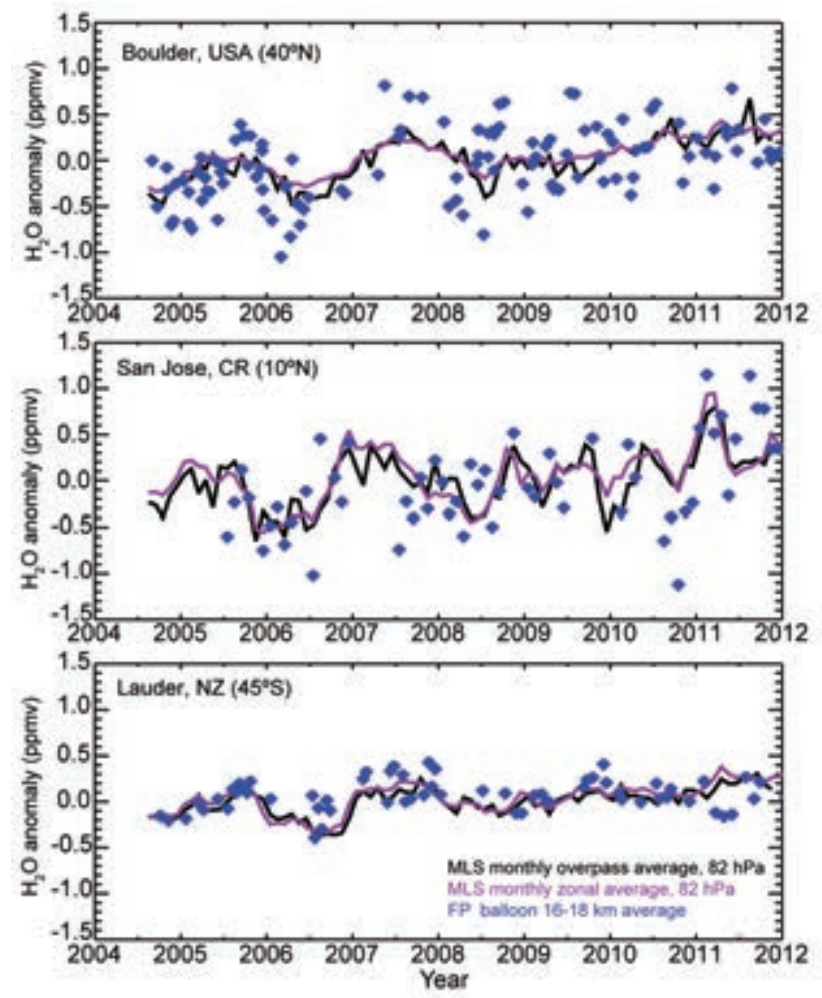

FIG. 2.54. Lower stratospheric water vapor anomalies (ppmv; differences from 2005-10 monthly averages) from three frost point sonde locations: Boulder, Colorado, USA; San Jose, Costa Rica; and Lauder, New Zealand. Blue symbols depict mean anomalies between $16 \mathrm{~km}$ and $18 \mathrm{~km}$ for individual soundings with balloon-borne frost point hygrometers; black lines are monthly mean anomalies at $82 \mathrm{hPa}$ from MLS retrievals within $\pm 2^{\circ}$ latitude and $\pm 15^{\circ}$ longitude of the sonde sites; purple lines are MLS zonal monthly mean anomalies at $82 \mathrm{hPa}$ within the $\pm 2^{\circ}$ latitude band surrounding each sonde site.

during January were strongest over the central Pacific region. The underlying dynamical mechanisms (see below) are unclear.

Time series of water vapor vertical profiles and their anomalies from August 2004 through 2011 also show the strong positive anomaly in the tropical lower stratosphere during January-February 2011 (Fig. 2.53). Unlike the previous dry anomalies that originated in the lower tropical stratosphere and propagated to the upper stratosphere, the strong January 2011 wet anomaly was almost completely eroded before reaching the middle stratosphere. The weak vertical propagation of this strong anomaly suggests a slowing of the tropical upwelling.

Time series of lower stratospheric water vapor anomalies at three locations where routine frost point hygrometer soundings are made (Fig. 2.54) depict increasing trends since late 2004. These are from MLS and balloon-borne frost point hygrometer measurements. The current water vapor increase started after a rapid drop of $\sim 0.5$ ppmv (10\%) in 2000-01 and several subsequent years of low mixing ratios. Over the longer term, the frost point hygrometer record over Boulder, Colorado $\left(40^{\circ} \mathrm{N}\right)$, depicts a net increase of $1.0 \pm 0.2$ ppmv (27 $\pm 6 \%$ ) from 1980 to 2010 (Hurst et al. 2011). Only about $30 \%$ of this long-term growth is attributable to increased stratospheric water vapor production associated with increasing atmospheric methane (section 2g1i). Complete global satellitebased water vapor records are too short to corroborate or refute the magnitude of the 30-year Boulder trend. High spatial and temporal coverage began with operational MLS in August 2004. Before then, satellite-borne solar occultation instruments did not offer complete global measurement coverage, while balloon-borne frost point hygrometers provided data with sparse spatial and temporal density.

The MLS record reveals strong tropical water vapor signals related to the QBO from 2004 through 2008 (Figs. 2.53, 2.54; Zhou et al. 2001). The QBO influence results in a quasi-two-year cycle of low and high water vapor values originating at $\sim 100 \mathrm{hPa}$ and propagating upward with time. Damped QBO signals are also apparent at higher latitudes prior to 2009 (e.g., Lauder and Boulder). Since 2009, these QBO signals are no longer evident in the tropical and midlatitude water vapor records.

In summary, the increasing trend in stratospheric water vapor since 2006 continued through 2011 . Large positive anomalies in tropical entry values $(82 \mathrm{hPa})$ during January-February 2011 point to abnormally warm tropical cold point temperatures. Anomalies in tropical entry values related to the $\mathrm{QBO}$ during 2004-08 have not been observed since 2009. The exact mechanisms behind the 2011 stratospheric water vapor anomalies are currently unknown and require additional study.

\section{h. Land surface properties \\ I) FOREST BIOMASS AND BIOMASS CHANGE-S. Quegan, P. Ciais, and A. Baccini}

The focus of recent forest biomass estimates has been on: (1) reducing the large uncertainties in the tropical land use change flux and the associated tropical sink due to regrowth of secondary forest; (2) quantification of the tropical sink in intact forest; and (3) identification of the location, cause, and strength of the land carbon sink at temperate and boreal latitudes consistently seen in atmospheric inversion studies (e.g., http://transcom.lsce.ipsl.fr). A major motiva- 


\section{SIDEBAR 2.3: LONG-TERM CHANGES OF ATMOSPHERIC SOLAR TRANSIMISSION-E. DUTTON}

Both the solar and thermal infrared transmission of the atmosphere play important roles in Earth's energy balance. For example, the anticipated long-term worldwide decrease in infrared atmospheric transmission, due to increasing greenhouse gas abundance, gives rise to the issues and concerns of global warming. Similarly, long-term increases in the solar transmission would contribute to warming, while a decrease would have the opposite effect. While considerable attention and effort has gone into observations necessary to track and understand the long-term global background of the atmospheric infrared transmission, relatively few similar records of the solar transmission exist.

One of the longest, continuous observational records of solar transmission through the free troposphere and above is maintained by NOAA at the Mauna Loa observatory in Hawaii (Dutton and Bodhaine 200I). This consists of qualified daily and monthly averages of clear-sky morning "apparent" solar transmission obtained from pyrheliometer observations by the methodology first described by Ellis and Pueschel (197I). The "apparent" is an optical term applied to the solar transmission values used here because they are determined from ratios of direct beam solar irradiances observed at different solar zenith angles (atmospheric paths) such that the computed transmission is relative to the irradiance already transmitted along the shorter path. The irradiance is measured with a calibrated pyrheliometer. The linear calibration factor cancels out in the apparent transmission ratio, yielding a more accurate and stable result.

This measure of solar transmission is particularly sensitive to aerosols. The computational procedure diminishes the effect of water vapor, which is the other major contributor to variable clear-sky solar transmission, due to saturation effects. There is also a minor ozone contribution, although this is not significant on the scale of the variations seen. Spectral aerosol optical depth is also observed (sun photometer) at the site and confirms the primary aerosol role in current observed solar transmission variability. Although only a single site, Mauna Loa can be considered representative of a much larger portion of the Earth because of its remote central Pacific location and high elevation, above most local effects, especially in the early morning during downslope-wind conditions when daily transmission measurements are made.

The complete apparent transmission (AT) record (Fig. SB2.7a) shows the extended impact of three major explosive volcanic eruptions (Agung, 1964; El Chichón, 1982; and Pinatubo, 1991). These injected large quantities of sulfur dioxide $\left(\mathrm{SO}_{2}\right)$ into the stratosphere, where it was converted to sulfate aerosol and remained for many months while spreading around the world. A certain amount of month-to-month variability and a small amplitude ( 0.007 AT) annual cycle (spring minimum, winter maximum) persisting throughout much of the record are also seen. This annual cycle has been attributed to the seasonally enhanced transport of Asian tropospheric aerosol over the site (Bodhaine et al. 198I). Not so apparent in the record are potential variations in the overall background transmission, which have the most enduring effects. Examination of the last decade (Fig. SB2.7b) and other information by Solomon et al. (20II) has shown a small net downward tendency, possibly due to multiple periods of injection of stratospheric aerosols. Figure S2.7b suggests a general decrease of about 0.003 AT occurring between 1998 and 2010 . This trend is also seen in collocated spectral aerosol optical depth measurements. However, the downturn appears to have ended in the last 2-3 years. Currently, it is not possible to discern a continuing coherent long-term behavior in the record, but the 55-year AT record permits putting the current variability into historical context.

Using these and other data, Solomon et al. (20II) computed that the decline in transmission (or equivalently, an increase in AOD) from the late 1990 s to 2010 was sufficient to reduce tropospheric warming by about $0.07^{\circ} \mathrm{C}$ compared to a scenario with a relatively "clean" stratosphere, as was previously widely used in global climate models for that decade. The source of the general decrease in solar transmission is suspected to be several small, largely unnoticed, volcanic eruptions that together have increased the stratospheric component of the total column aerosol over a large portion of the globe (Vernier et al. 20II).

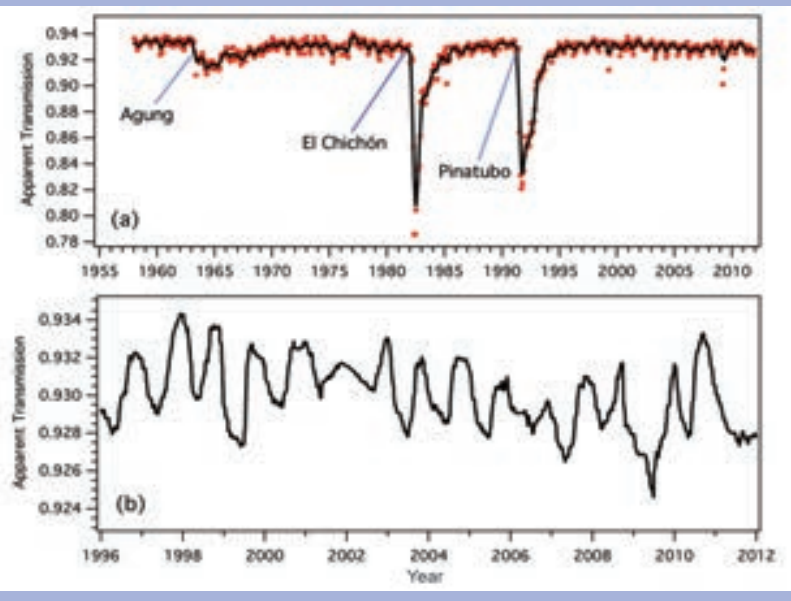

FIG. SB2.7. Mauna Loa, Hawaii, apparent transmission in (a) monthly means (points), with 5-month running smoother (line) and (b) 100 -point running means (converging to 49 points at the end of 20II) of available clear-sky morning daily averages from the NOAA MLO observatory at $3.4 \mathrm{~km}$ ASL using a tracking solar pyrheliometer converted following Ellis and Pueschel (197I). Major explosive volcanoes are indicated. Smoothing in (b) gives anomalous periods with fewer observed days less weight than in the presentation of monthly averages (a). 


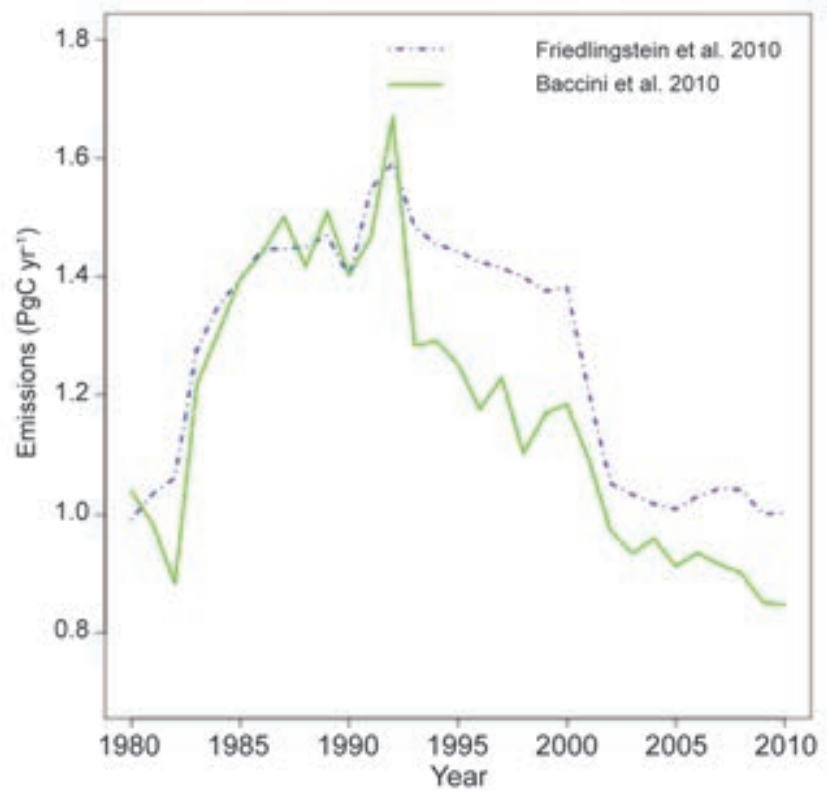

FIg. 2.55. Annual net emissions ( $\left.\mathrm{Pg} C \mathrm{yr}^{-1}\right)$ from landuse change in the tropics calculated by Friedlingstein et al. (20l0) and Baccini et al. (20I2).

tion for improved information on biomass has also been the UNFCCC Decision 1.1 (2010 Conference of the Parties, Cancun; http://www.unfcc.int/resource/ docs/2010/cop16/eng/07a01.pdf) which encourages developing country Parties to contribute to mitigation actions in the forest sector.

Although the periodic reports of the Food and Agricultural Organization (FAO 2006, 2010) remain a key source for information on biomass, they are based on national forest inventories/statistics and suffer from lack of systematic inventory data in many forest biomes, particularly in developing countries, leading to data gaps, sampling biases, inconsistency of methods, lack of spatial information, and unrepresentative samples (Grainger 2008). The search for more consistent global approaches, particularly for the tropics, has prompted use of satellite data calibrated against

TABLE 2.5. Biomass increments for $1990-99$ and 2000-07 by latitude zone; the global values are also shown (values taken from Pan et al. 20II).

\begin{tabular}{|l|c|c|}
\hline Biomass increment $\left(\mathrm{Tg} \mathrm{C} \mathrm{yr}^{-1}\right)$ & $1990-99$ & $2000-07$ \\
\hline Boreal & 117 & 120 \\
\hline Temperate & 345 & 454 \\
\hline Tropical intact & 1167 & 870 \\
\hline Tropical regrowth & 1361 & 1497 \\
\hline All tropics & 2529 & 2367 \\
\hline Global & 2991 & 2941 \\
\hline
\end{tabular}




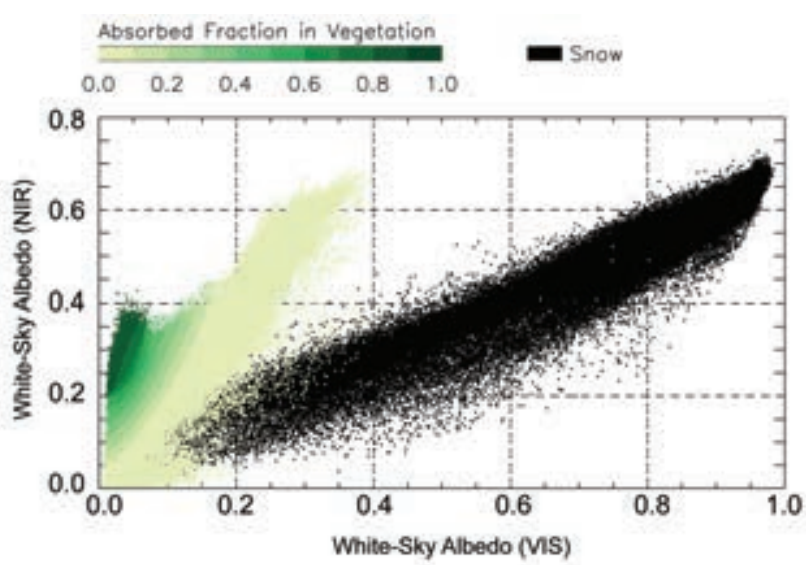

FIG. 2.56. MODIS broadband visible and near-infrared white-sky surface albedo (NASA) collection 5 (after re-sampling). Snow-covered pixels (according to the MODIS snow flag) are identified in black. Snow-free pixels are associated with an estimate of the Fraction of Absorbed Photosynthetically Active Radiation (derived from the JRC-TIP) represented by the green color scale.

European forests can be derived by using a process model (ORCHIDEE) to combine the reconstructed forest age structure (a proxy for biomass stocks) with the effects of carbon dioxide $\left(\mathrm{CO}_{2}\right)$ increase and climate. They found that the aging of forest stands accounts for most of the inventory-observed forest sink across European countries. However, the sink trend is explained predominantly by $\mathrm{CO}_{2}$ fertilization and by the effects of climate trends ( $87 \%)$, with a smaller contribution (13\%) from trends in forest age structure. In the United States, Williams et al. (2012) also used a process model (CASA) driven by satellite observation of disturbance history at very high spatial resolution (Landsat time series data) to separate the effect of forest age structure (disturbance recovery) from those of climate and $\mathrm{CO}_{2}$. They found carbon sinks to be mainly explained by age structure in the South Central, Pacific Northwest, and Pacific Southwest regions. In other regions, the effect of age was smaller. At country scale, the age structure contribution to forest NEP (the sink before harvest and disturbance) was modeled to be $0.16 \mathrm{Pg} \mathrm{C} \mathrm{yr}^{-1}$, which is smaller than former estimates based on inventory data $\left(0.27 \mathrm{PgC}_{\mathrm{yr}}^{-1}\right.$ to $\left.0.41 \mathrm{Pg} \mathrm{C} \mathrm{yr}^{-1}\right)$. The difference was attributed either to the effects of $\mathrm{CO}_{2}$ and climate, or to undersampling of disturbed areas by the forest inventory sampling scheme, due to the smaller scale of disturbance compared to the mesh of the US inventory.
2) LAND surfaCe ALBEDO-B. Pinty

The land surface albedo, i.e., the fraction of solar radiation scattered backward by land surfaces, results from complex nonlinear radiation transfer processes determining the amount of radiation that is scattered by the vegetation and its background, transmitted through the vegetation layer, or absorbed by the vegetation layer and its background.

Figure 2.56 illustrates the range of variations of surface albedo quantities observed for a full year over the globe in the two-dimensional visible (VIS) and near-infrared (NIR) broadband spectral domains. These data result from a resampling of the MODIS white-sky albedo (equivalent to a bihemispherical reflectance under perfect isotropic illumination, i.e., independent from ambient atmospheric conditions) product collection 5 at $0.01^{\circ}$ spatial resolution (Schaaf et al. 2002). Partial or full snow cover conditions are associated with a large dynamical range of albedo values particularly in the visible domain. By contrast, the spectral signature of snow-free conditions is restricted to a much smaller domain (Fig. 2.56 bottom left). In the latter instances, the variability in albedo is largely controlled by the amount of vegetation covering the background featured by the Fraction of Absorbed Photosynthetically Active Radiation derived from the JRC-Two-stream Inversion Package (TIP; Pinty et al. 2011a,b). Note that very small changes in visible surface albedo can be associated with significant variations in vegetation dynamics.
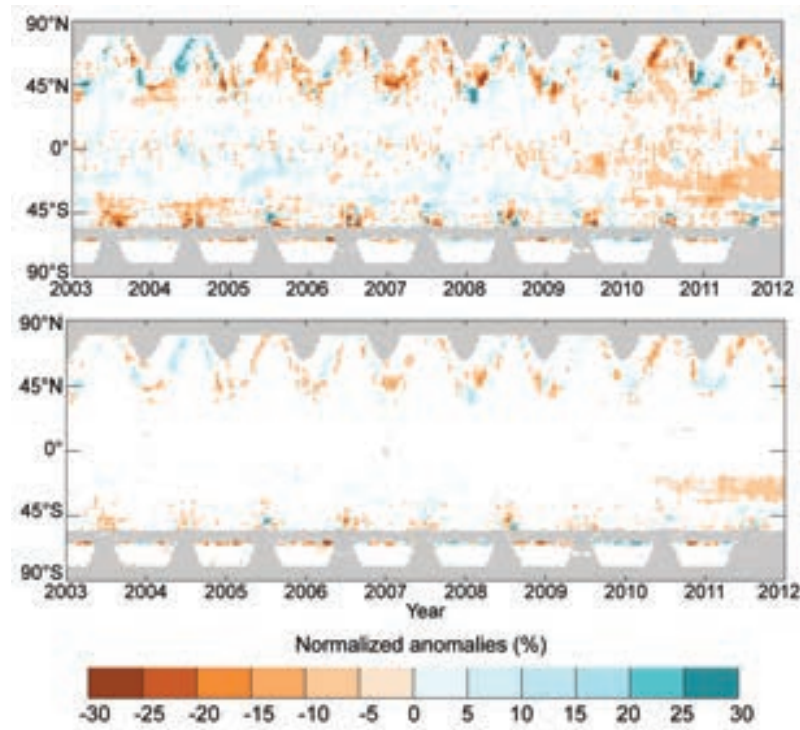

FIG. 2.57. Zonal means of the MODIS white-sky broadband surface albedo (NASA) normalized anomalies in the (a) visible and (b) near-infrared domain relative to a 2003-II base period. 


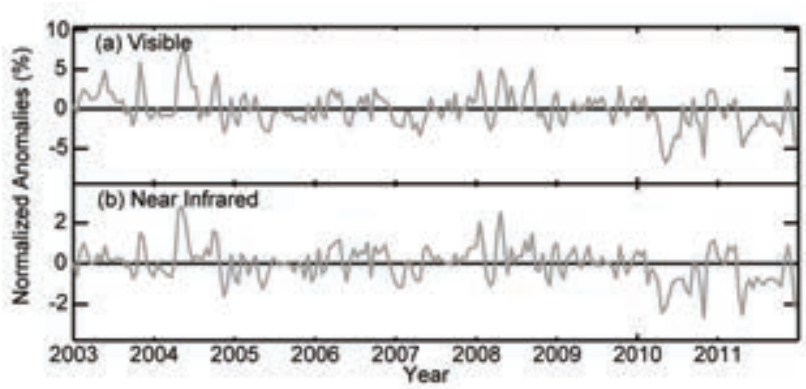

FIG. 2.58. Globally averaged MODIS White Sky broadband surface albedo (NASA) normalized anomalies in the (a) visible and (b) near-infrared domain relative to a 2003-II base period.

The geographical distribution of normalized anomalies in visible and near-infrared surface albedo for 2011 relative to a 2003-11 base period (for which two MODIS sensors are available) are shown in Plates 2.1q and r, respectively. Mid- and high-latitude regions of the Northern Hemisphere are characterized mainly as a consequence of interannual variations in snow cover amount and duration in winter and spring seasons (section 2c2). The amplitude of these changes can reach $\pm 30 \%$ in relative units, and are slightly larger in the visible than in the near-infrared domain. Snow-free regions experienced dramatic variations with noticeable positive anomalies over the southwestern United States as a consequence of the exceptionally persistent summer heat and drought (see section $7 \mathrm{~b} 2$ for more details). The situation in Australia and southern Africa contrasts notably with strong negative anomalies in both spectral domains. These changes are associated with more favorable vegetation growing conditions by comparison to previous years (see sections $2 \mathrm{~d} 3,2 \mathrm{~h} 3$ ). More subtle variations in albedo occur in a number of other regions, in particular over Central and South America, as well as the intertropical zone of Africa (especially the eastern part), India, and China. These variations are attributed to vegetation dynamics over these regions sensitive to stress from ambient conditions, such as water availability and temperature.

Analysis of the zonally-averaged albedo anomalies in the visible (Fig. 2.57a) and near-infrared (Fig. 2.57b) spectral domain indicates considerable interannual variations related to the occurrence of snow events in winter and spring at mid- and high-latitudes but also in vegetation conditions during the summer periods. Persistent negative

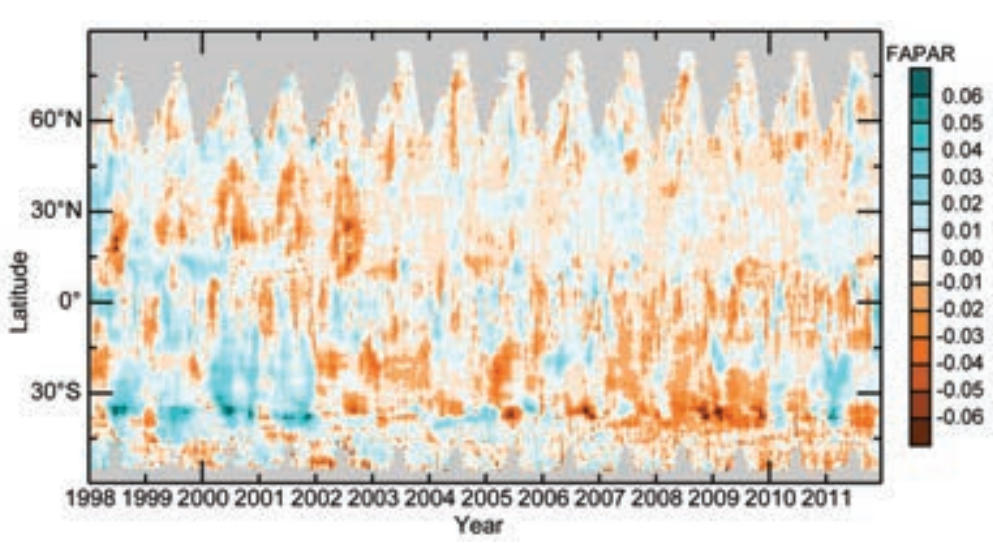

FIG. 2.60. SeaWiFS and MERIS I0-day anomalies (1998-20II base period) of FAPAR by latitude. Gray areas indicate regions where data are unavailable.
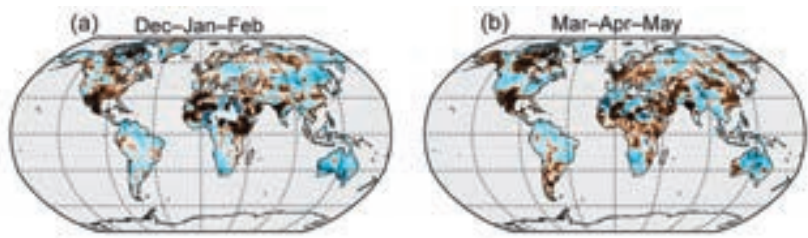

(c)

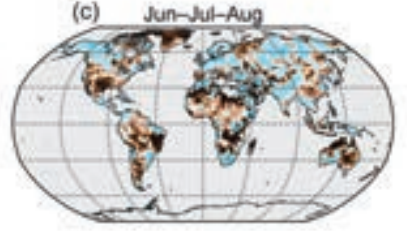

(d) Sep-Oct-Nov

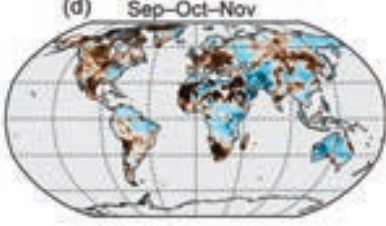

$\begin{array}{lllllllllllll}20 & 40 & 60 & 70 & 80 & 50 & 100 & 110 & 120 & 150 & 200 & 300 & 400 \\ \text { Ancmales from } 1951-2000 & (\mathrm{w} / \mathrm{y} \text { ear }\end{array}$

FIG. 2.59. SeaWiFS and MERIS 20 II seasonal anomalies (1998-20II base period) for FAPAR. Positive anomalies indicate favorable vegetation growing conditions (blue) while negative values are markers of vegetation under stress (orange).

anomalies are noticeable for 2010 and 2011 between $20^{\circ} \mathrm{S}$ and $40^{\circ} \mathrm{S}$.

The amplitude of the globally averaged normalized anomalies (Fig. 2.58) are within $\pm 7 \%$ (3\%) in the visible (near-infrared) domain. Limited positive anomalies dominate the start and end of 2011 while the remaining seasons exhibit well-marked negative anomalies. Figure 2.58 also suggests the presence of spectrally correlated multi-annual variations during 2003-11, with positively biased values at the beginning of the record.

3) Terrestrial vegetation dynamics FRACTION OF ABSORBED PHOTOSYNTHETICALLY ACTIVE RADIATION-N. Gobron

Significant spatiotemporal variations in vegetation dynamics occurred on regional and continental scales during 2011. The state of vegetation is examined using estimates of the Fraction of Absorbed Photosyntheti- 


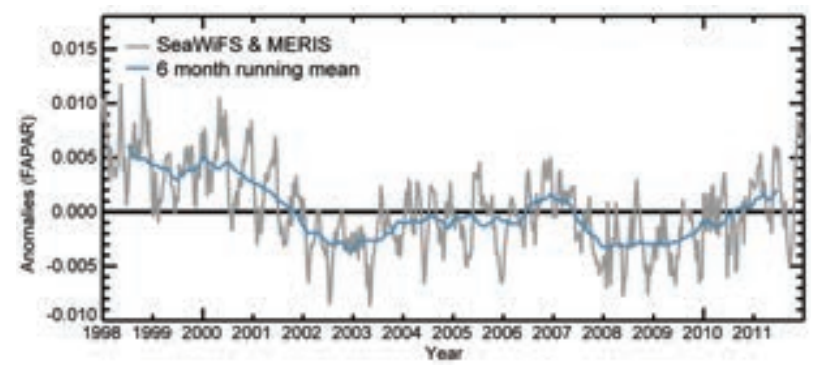

FIG. 2.6I. Global average ten-day anomalies with a 6-month running mean (1998-20II base period) for FAPAR.

cally Active Radiation (FAPAR) from 1998 to 2011 (Gobron et. al. 2010). Global anomalies highlight geographical regions subject to changes in 2011 with respect to previous years (Plate 2.1s).

The largest positive (favorable for vegetation) annual anomalies are observed over Australia and southern Africa, northeastern Brazil, central United States, Asia, and central Europe. The strongest negative anomalies occurred over the southern United States and northern Russia, eastern Africa, and Amazonia to a lesser extent. Over central Russia, the extreme negative FAPAR anomalies that occurred in 2010 have recovered towards a more normal state. Australia and southern Africa had plentiful precipitation and soil moisture in 2011 (sections 2d3, 2d7, 7e4).

The southern United States, in particular Texas, suffered precipitation deficit in spring and a summer heat record, which translated into strong negative seasonal (Fig. 2.59c) and annual anomalies. Amazonia did not fully recover from the droughts of 2010, as the signature of this event is still noticeable. The drought that occurred over the eastern regions of Africa is well depicted, especially at the seasonal level during the first half of the year.

Zonally averaged anomalies (Fig. 2.60) illustrate hemispheric differences, with persistent negative anomalies occurring over the Southern Hemisphere during all seasons from approximately 2002 to 2009. In contrast, since 2010, rather strong positive anomalies are observed over regions located between $20^{\circ} \mathrm{S}-40^{\circ} \mathrm{S}$. This figure highlights strong summer negative anomalies above $20^{\circ} \mathrm{S}$ and below $40^{\circ} \mathrm{S}$ for 2011 .
When globally averaged, FAPAR anomalies (Fig 2.61) indicate that 2011 marked the return of vegetation to a positive state following a more than threeyear period of negative departures.

4) Biomass burning一J. W. Kalser and G. R. Van Der Werf

The burning of vegetation releases large amounts of trace gases and aerosols to the atmosphere. While fires occur naturally, humans have modified background fire regimes both by lighting more fires and by modification of land and land cover types. In addition, fire fighting and prescribed burning present a departure from background fire conditions.

Fire emissions for contemporary times are calculated either by multiplying burned area, biomass, and the fraction of biomass that is actually consumed in a fire (Seiler and Crutzen 1980), or by using measurements of emitted energy from fires (Wooster et al. 2005). Both approaches rely heavily on satellite data, and the calculated dry matter consumed is subsequently multiplied by emission factors derived from field measurements to estimate trace gas and aerosol emissions (Andreae and Merlet 2001). The MACC Global Fire Assimilation System (GFAS; Kaiser et al. 2012) developed in the Monitoring Atmospheric Composition and Climate (MACC) project for the European Union's (EU) GMES (Global Monitoring
TABLE 2.6. Annual continental-scale biomass burning budgets in terms of carbon emission ( $\mathrm{Tg} \mathrm{C} \mathrm{yr}^{-1}$ ) reported in GFASvI.0. Definition of regions as in Kaiser et al. 2011, 2012.

\begin{tabular}{|c|c|c|c|c|c|}
\hline Time Period & \multicolumn{2}{|c|}{$2003-10$} & 2011 & \multicolumn{2}{c|}{2011 w.r.t. 2003-10 } \\
\hline Quantity & Mean & Range & Value & $\begin{array}{c}\text { Absolute } \\
\text { Anomaly }\end{array}$ & $\begin{array}{c}\text { Relative } \\
\text { Anomaly }\end{array}$ \\
\hline Global & 2043 & $1774-2312$ & 1987 & -57 & $-3 \%$ \\
\hline N America & 99 & $7 I-138$ & 111 & +11 & $+12 \%$ \\
\hline C America & 65 & $53-91$ & 72 & +7 & $+11 \%$ \\
\hline SH America & 357 & $177-456$ & 199 & -159 & $-44 \%$ \\
\hline $\begin{array}{c}\text { Europe and } \\
\text { Mediterranean }\end{array}$ & 37 & $30-62$ & 26 & -11 & $-30 \%$ \\
\hline NH Africa & 413 & $331-458$ & 409 & -5 & $-1 \%$ \\
\hline SH Africa & 521 & $488-591$ & 564 & +42 & $+8 \%$ \\
\hline N Asia & 202 & $105-470$ & 159 & -43 & $-21 \%$ \\
\hline SE Asia & 135 & $111-162$ & 95 & -40 & $-29 \%$ \\
\hline Tropical Asia & 93 & $22-218$ & 80 & -12 & $-13 \%$ \\
\hline Australia & 120 & $52-176$ & 273 & +153 & $+127 \%$ \\
\hline
\end{tabular}


for Environment and Security) atmospheric services merges both approaches and is capable of estimating emissions in near-real time.

Over 2003-10, GFASv1.0 estimates carbon emis-

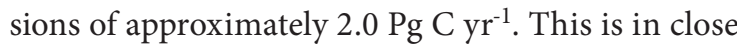
agreement with estimates from the Global Fire Emissions Database (GFED3; Giglio et al. 2010; van der Werf et al. 2010), which has a longer record starting in 1997, but cannot be updated as frequently as GFAS. The 1997-2002 years not included in GFASv1.0 did not deviate much from the 2003-10 period, with the notable exception of 1997-98. At that time, recordhigh emissions from Indonesia, in combination with higher-than-average emissions from the boreal region and Central America, yielded emissions that were, on a global scale, over $30 \%$ above average.

The global fire emissions of $2.0 \mathrm{Pg} \mathrm{C}$ in 2011 were close to the 2003-10 climatological mean (Table 2.6). On a regional scale, Australia experienced an exceptionally active fire season; its emission was $127 \%$ higher than the $2003-10$ average and $47 \%$ higher than the largest value reported (for 2001) in the longer time series of GFED3. Plate 2.1t shows that the fires
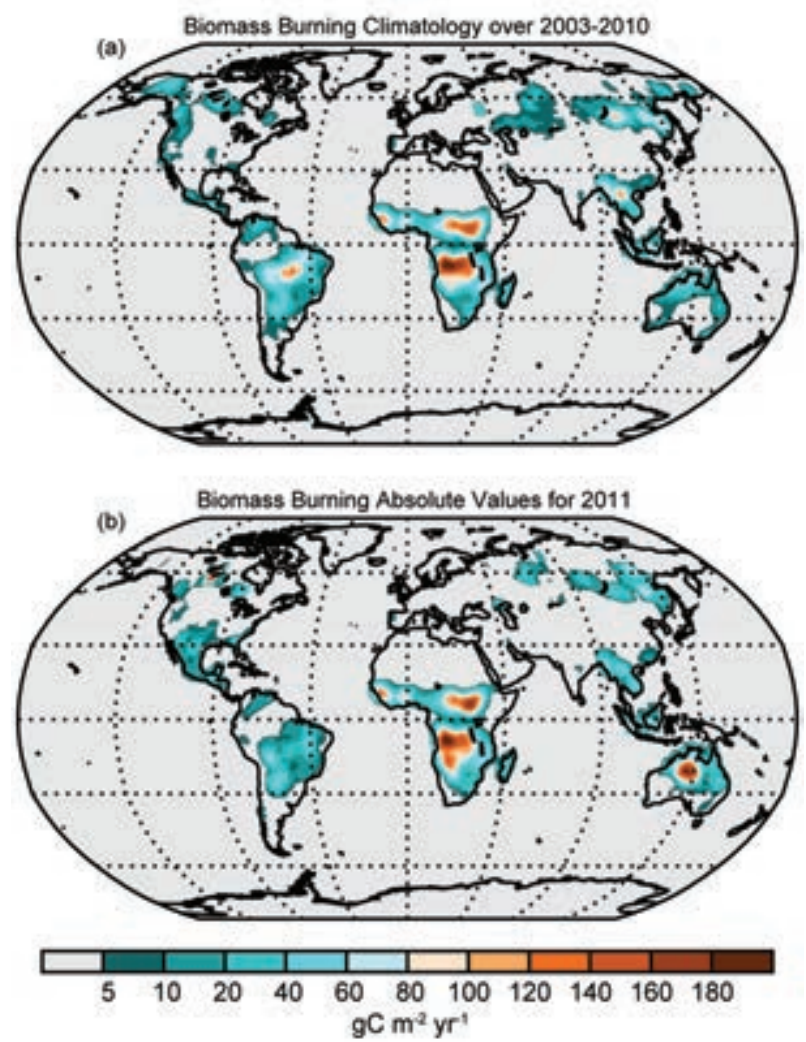

Fig. 2.62. Biomass burning in terms of annual carbon emission per unit area at $0.5^{\circ}$ resolution: (a) climatology, and (b) values for 20II. Derived from MODIS observations processed in the MACC GFAS (Kaiser et al. 20I2). in 2011 burned mostly in the interior of Australia, while in other years most fires were detected farther north (Fig. 2.62).

In most regions, fire activity increases during fire seasons with drought conditions. This happened in 2011 in Texas and northern Mexico, where hot and dry anomalies are exhibited (Plate 2.1). The larger land surface albedo and lower FAPAR (Plates 2.1q-s) are manifestations of associated vegetation mortality.

In arid regions such as the interior of Australia, however, fire activity is, in large part, a function of available biomass, which depends on rainfall during the wet season preceding the fire season. In Australia, there was enough rainfall (Plate 2.1i) for the grasses in this arid region to form a continuous fuel bed (Plates $2.1 \mathrm{q}-\mathrm{s}$ ), which subsequently burned in austral spring of 2011. The smoke from these fires were recorded as a strong positive smoke aerosol anomaly (Fig. 2.46). A similar mechanism appears to lie behind the increased fire activity in southern Africa.

Fire activity in South America was the second lowest since 2003, in line with decreasing deforestation rates reported by the Brazilian Space Agency (INPE 2012). Fires are used in the deforestation process to remove biomass and usually the amount of deforestation and fire activity are related, although 2007 and 2010 saw elevated emissions, possibly related to fires in cerrados (savanna) and degraded forests (Kaiser et al. 2011). The low fire activity is also reflected in a negative aerosol anomaly over South America (Plate 2.10; Fig. 2.46). In most other regions including the boreal and deforestation regions, fire activity in 2011 was within the 2003-10 range. 
3. GLOBAL OCEANS - M. C. Gregg and M. L. Newlin, Eds.

a. Overview-M. C. Gregg and M. L. Newlin

The state of the oceans during 2011 was dominated by a moderate-to-strong La Niña during winter 2010/11 in the Pacific Ocean, followed by a return to near-normal conditions until the reemergence of another La Niña in August 2011. A strengthening of a negative Pacific decadal oscillation (PDO) also followed in the second half of 2011, with the development of a positive Indian Ocean dipole in the fall, and above-normal sea surface temperatures (SST) in the tropical North Atlantic and midlatitude southern oceans (section $3 \mathrm{~b}$ ). The global SST cooled by $0.1^{\circ} \mathrm{C}$ from 2010 to 2011 and changed from the 5 th to 12 th highest year since 1982, being associated with cooling influences of the 2010-12 La Niña (section $3 \mathrm{~b}$ ). However, the 2011 global integrals of upper ocean heat content are higher than for all prior years analyzed (section 3c). Overall in 2011, saltier (higher evaporation) regions of the ocean surface continued to be anomalously salty, and fresher (higher precipitation) regions anomalously fresh. This pattern, which has held since at least 2004, suggests an increase in the hydrological cycle, consistent with climate model predictions for a warming atmosphere (section 3e). These surface-forced changes extend to subsurface levels (section 3f) where long-term freshening in the water column of high latitudes in the Pacific Ocean is observed. A general year-to-year freshening was also seen in 2011 across much of the Atlantic, as well as in the Indian Ocean.

Relative to the long-term trend, global sea level dropped noticeably in mid-2010 and reached a local minimum in 2011. The drop was linked to the strong La Niña conditions throughout the latter part of 2010 and most of 2011. This sea level drop was followed by a sharp increase in global sea level during the second half of 2011 (section 3i). High values of chlorophyll were observed throughout much of the tropical Pacific Ocean, subtropical North Atlantic Ocean, tropical Indian Ocean, and in portions of the Southern Ocean. Conspicuously low values of chlorophyll were found in the western Indian Ocean, the tropical Atlantic, and globally throughout the subtropics (section $3 \mathrm{j}$ ). The global net ocean $\mathrm{CO}_{2}$ uptake for the 2010 transition period from $\mathrm{El}$ Niño to La Niña is estimated to be $1.30{\mathrm{PgC} \mathrm{yr}^{-1}}^{-1}\left(\mathrm{PG}=10^{15} \mathrm{~g}\right)$, lower than the 29 -year long-term mean of $1.47 \mathrm{Pg} \mathrm{Cyr}^{-1}$ (section 3j). The 2010 global ocean inventory of anthropogenic $\mathrm{CO}_{2}$ is $160 \pm$ $26 \mathrm{Pg} \mathrm{C}$ (estimated using a Green's function method). The ocean inventory represents $\sim 43 \%$ and $~ 29 \%$ of fossil fuel and total (fossil fuel and land use changes) anthropogenic $\mathrm{CO}_{2}$ emissions, respectively, over the industrial period.

On a basin scale, the Pacific Ocean was dominated by both a negative Pacific decadal oscillation and two La Niña events (winter and fall). This resulted in below-normal 2011 sea surface temperatures in the tropical Pacific (coolest since 1985; section 3b). Zonal surface current anomalies in the tropical Pacific basin switched from negative values in late 2010 to El Niño-like (positive) values in early 2011, as SST anomalies reached their peak negative value. For the next months, as the surface current anomaly remained positive, the SST anomaly decreased in magnitude (section 3g). In the latter half of 2011, the surface current anomaly returned to neutral-to-La Niñalike (negative) values, leading the return of cold SST anomalies by several months. The warming trend in the western tropical Pacific and the cooling trend in the eastern tropical Pacific from 1993 to 2011 are consistent with a general trade wind intensification during that time period.

The Indian Ocean was influenced by a positive Indian Ocean dipole. The sea surface became fresher in 2011 relative to 2010 in the eastern equatorial Indian Ocean and the western equatorial Pacific, likely owing to La Niña, but saltier in the western tropical Pacific near $5^{\circ} \mathrm{S}$, likely owing to a southward shift in the South Pacific convergence zone (section 3e). Overall, the tropical Indian Ocean cooled by $0.24^{\circ} \mathrm{C}$ from a historical high in 2010.

The Atlantic Ocean is characterized by the remote influence from the previous year El Niño, a persistent negative North Atlantic Oscillation (NAO), and a long-term cooling trend. The ocean net heat flux (i.e., the sum of shortwave radiation, longwave radiation, turbulent latent and sensible heat flux) anomalies showed a tripole structure in the North Atlantic associated with the change of NAO from a negative phase in 2010 to a more positive phase in 2011, and the fluxes were a forcing for SST variability (section 3d). The tropical Atlantic SST reached a historical high in 2010, and cooled by $0.33^{\circ} \mathrm{C}$ from 2010 to 2011 (section 3b). This continued a downward trend in North Atlantic SST since 2006.

After six years of data, a clear seasonal signal is beginning to emerge with a low Meridional Overturning Circulation (MOC) in April and a high MOC in October. The seasonal cycle of the MOC appears to be largely attributed to seasonal vari- 
ability in the interior rather than Ekman or Florida current fluctuations. This is being shown as likely due to seasonal upwelling through a direct wind-driven response off Africa (section 3h).

Results for 2010 show the equatorial Pacific $\left(14^{\circ} \mathrm{N}-14^{\circ} \mathrm{S}\right)$ was the major source for atmospheric

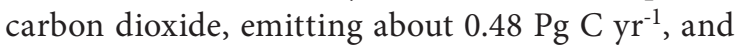
the temperate oceans between $14^{\circ}$ and $50^{\circ}$ in both hemispheres are the major sink zones, with an uptake flux of $0.70 \mathrm{Pg} \mathrm{C} \mathrm{yr}^{-1}$ for the northern and 1.05 Pg C $\mathrm{yr}^{-1}$ for the southern zone. Both $\mathrm{CO}_{2}$ effluxes for the El Niño and La Niña periods in the eastern equatorial Pacific are higher than the 29-year mean fluxes. The highest $\mathrm{CO}_{2}$ effluxes over the past 29 years are due to intensified upwelling of deep water rich in $\mathrm{CO}_{2}$ caused by an increase of wind speed for 2010 .

Details on changes in the patterns of variability from 2010 to 2011 are presented in this chapter. Some sections in this chapter describe the state of the oceans during 2011 whereas others describe 2010 due to lags in availability of quality-controlled data streams. This chapter consists of nine sections describing the ocean climate for 2010 and 2011: (b) Sea surface temperatures, (c) Ocean heat content, (d) Global ocean heat fluxes, (e) Surface salinity, (f) Sub surface salinity, (g) Surface currents, (h) Meridional overturning circulation in the North Atlantic for 2010, (i) Sea level variations, and (j) the global ocean carbon cycle, which is subdivided into sections on air-sea carbon (results mostly for 2010), subsurface carbon inventory (results for 2010), a new section on ocean acidification, and global ocean phytoplankton. Sidebar 3.1 highlights the NASA Aquarius satellite launched June 2011 to study the links between ocean circulation and the global water cycle.

\section{b. Sea surface temperatures-Y. Xue, Z. Hu, A. Kumar,}

\section{Banzon, T. M. Smith, and N. A. Rayner}

Sea surface temperatures (SST) play a key role in regulating climate and its variability by modulating air-sea fluxes. In particular, slow variations in SST such as those associated with El Niño-Southern Oscillation (ENSO), the Atlantic multidecadal oscillation (AMO), the Pacific decadal oscillation (PDO), the Indian Ocean dipole (IOD), and the Atlantic Niño, are a source of potential predictability for climate fluctuations on timescales of a season and longer (Deser et al. 2010). A summary of global SST variations in 2011 is provided, with emphasis on the recent evolutions of ENSO, PDO, and IOD, and the 2011 SST is put in the context of the historical record since 1950. To quantify uncertainties in SST variations, three SST products are analyzed: (1) the Optimal Interpolation SST version 2 (OISST; Reynolds et al. 2002), (2) the Extended Reconstructed SST version 3b (ERSST; Smith et al. 2008), and (3) the Met Office Hadley Centre's sea ice and SST dataset (HadISST; Rayner et al. 2003). The weekly OISST is a satellite-based analysis that uses in situ data for bias adjustments of the Advanced Very High Resolution Radiometer (AVHRR) data, which has been available since November 1981. The ERSST and HadISST analyses are historical analyses beginning in the 19th century, and both analyses use statistics developed over the more recent period to extend the SST analysis back in time when in situ observations were sparse. The ERSST includes in situ data only, while the HadISST includes both in situ measurements and AVHRR retrievals from 1982 onwards. Thus, all three SST products represent a "bulk" SST at the depth of the ship and buoy instruments, which can range from less than a meter to several meters from the surface. In this section, SST variations are quantified as SST anomalies (SSTAs) defined as departures from the 1981-2010 climatology (http://www.cpc.ncep.noaa. gov/products/people/yxue/sstclim).

The yearly mean SSTA in 2011 was characterized by below-normal SST in the central and eastern tropical Pacific (Fig. 3.1a), reflecting the La Niña conditions in early 2011 and then again in fall/winter 2011 (see section $4 \mathrm{~b}$ for detailed descriptions of the La Niña
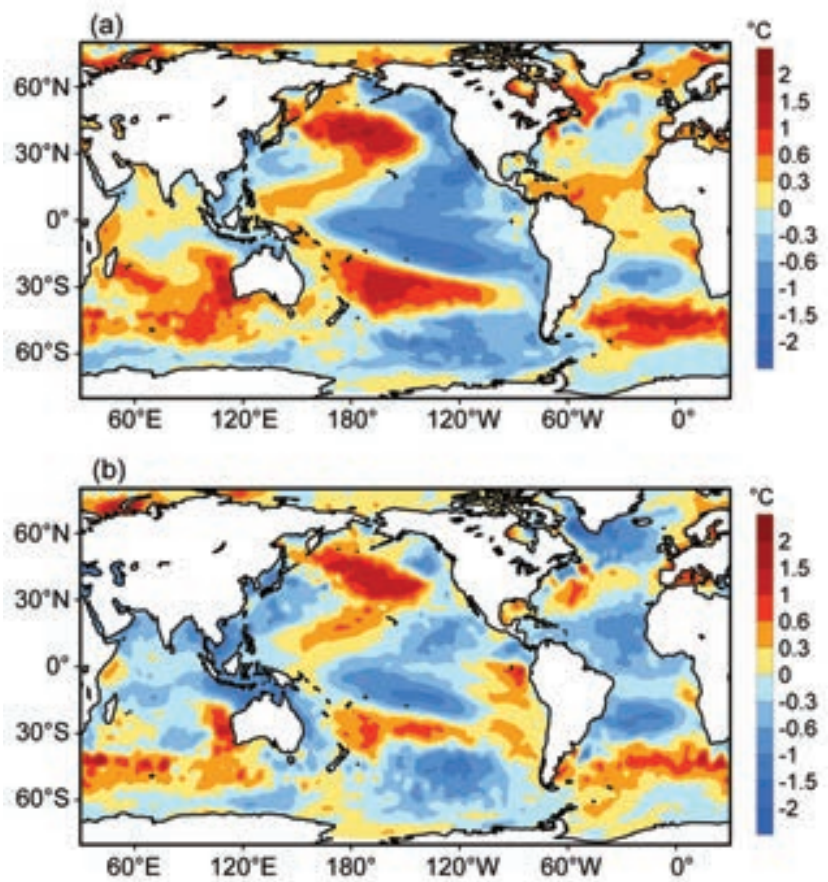

FIG. 3.I. (a) Yearly mean OISST anomaly $\left({ }^{\circ} \mathrm{C}\right.$, relative to $198 \mathrm{I}-2010$ base period) in 20II, (b) $201 \mathrm{I}$ minus 2010 OISST anomaly. 
conditions in 2011). The negative SSTAs in the tropical Pacific extended into the subtropics in both hemispheres and along the west coast of North America, and were surrounded by a horseshoelike pattern of positive SSTAs in the far western tropical Pacific and the central North and South Pacific. The SSTA pattern in the Pacific Ocean resembled the negative phase of the Pacific decacal oscillation (PDO) pattern of Power et al. (1999), while the SSTA in the North Pacific resembled the negative phase of the PDO pattern of Mantua et al. (1997). Negative SSTA was present in the northwest subtropical Pacific and near the Maritime Continent. Outside of the Pacific Ocean, positive SSTA occurred in the western and southern Indian Ocean while alternating positive and negative SSTA prevailed in the North Atlantic.

The 2011 minus 2010 SSTA differ-
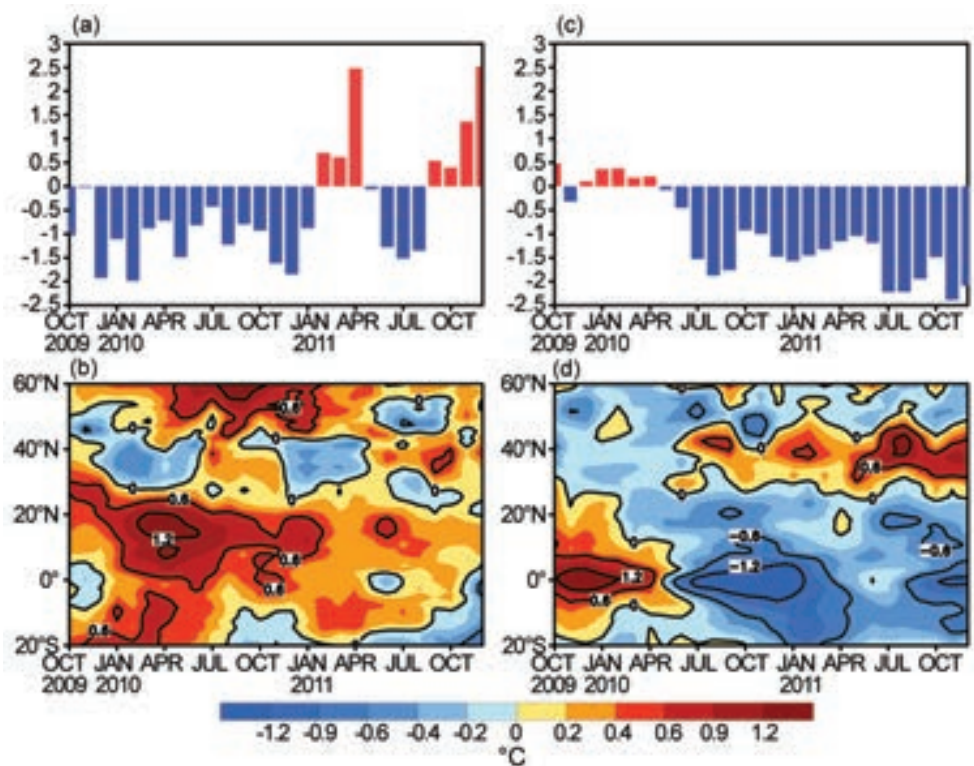

FIG. 3.2. (a) Monthly standardized NAO index from http://www. cpc.ncep.noaa.gov. (b) Time-latitude section of SSTA averaged between $80^{\circ} \mathrm{W}$ and $10^{\circ} \mathrm{W}$. (c) Monthly standardized PDO index. (d) Time-latitude section of SSTA averaged between $160^{\circ} \mathrm{E}$ and $90^{\circ} \mathrm{W}$. SSTA is relative to $198 \mathrm{I}-2010$ base period $\left({ }^{\circ} \mathrm{C}\right)$. ences show that relative to the previous year, SST cooled substantially across the tropical oceans and warmed in midlatitude oceans (Fig. 3.1b). The cooling in the tropical Pacific was related to the contrast between La Niña conditions in 2011 and a combination of El Niño followed by La Niña conditions in 2010. The warming in the central North Pacific was associated with strengthening of the negative PDO in the second half of 2011 (see Fig. 3.2c). The

Pacific, indicating a moderate-strength La Niña (Fig. 3.3a). The La Niña conditions weakened during March-May 2011 (Fig. 3.3b) and SSTA returned to near-normal conditions by June-August 2011 (Fig. 3.3c). However, the decline of La Niña did not continue, and a second La Niña (SSTA is $<-0.5$ STD) reemerged during September-November 2011 (Fig. $3.3 \mathrm{~d})$.

cooling near the Kuroshio Extension and in the IndoPacific region and the tropical Atlantic was likely associated with the remote influences of the 2009/10 El Niño and the 2010/11 La Niña, and will be discussed in detail later in this section. The substantial cooling in the subpolar North Atlantic was probably associated with the evolution of North Atlantic Oscillation (NAO).

The temporal evolution of normalized seasonal mean SSTA in 2011 is shown in Fig. 3.3. The winter $2010 / 11$ (December-February) SSTA was less than -1.5 standard deviation (hereafter referred to as STD) in the central tropical

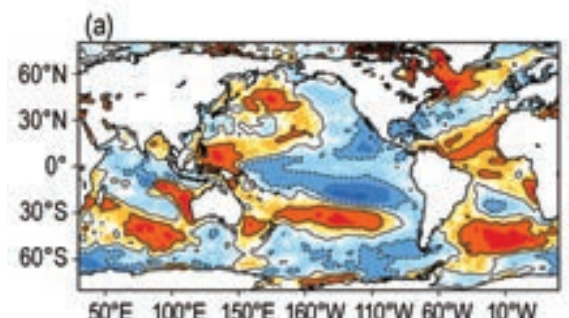

(c)

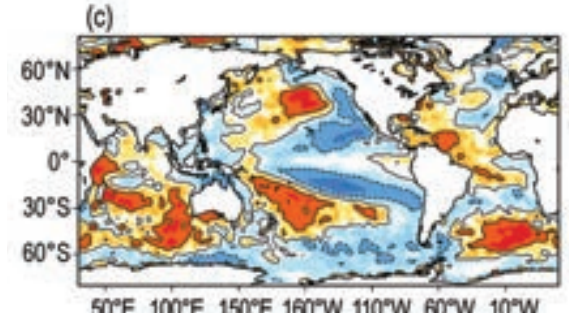

$50^{\circ} \mathrm{E} 10^{\circ} \mathrm{E} 150^{\circ} \mathrm{E} 160^{\circ} \mathrm{W} 110^{\circ} \mathrm{W}$ 60\% $10^{\circ} \mathrm{W}$

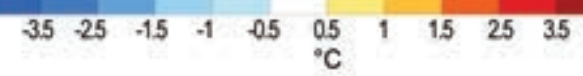

Fig. 3.3. Seasonal mean SSTAs $\left({ }^{\circ} \mathrm{C}\right.$, relative to $198 \mathrm{I}-2010$ base period) for (a) Dec 2010-Feb 20II, (b) Mar-May 20II, (c) Jun-Aug 20II, and (d) Sep-Nov 2011. 
Following the peak phase of the La Niña conditions in spring 2011, negative SSTA ( $<-1.5$ STD) emerged in the northwest subtropical Pacific and near the Maritime Continent and the positive SSTA in the tropical North Atlantic weakened substantially (from +1.5 STD to +0.5 STD; Fig. 3.3b). The cooling in the Indo-Pacific region and the tropical Atlantic in spring 2011 may be associated with the remote influences of La Niña. The tropical Indian Ocean and tropical Atlantic are usually cooled after the peak phase of La Niña and warmed after the peak phase of El Niño with a 3-6 month lag (Enfield and Mayer 1997; Klein et al. 1999; Hu et al. 2011). By summer 2011, positive SSTA larger than +1.5 STD emerged in the far western tropical Indian Ocean (Fig. 3.3c). In fall 2011, positive SSTA expanded to the whole tropical Indian Ocean except the area south of Java where negative SSTA persisted in summer and fall. The east-west SSTA gradient resembled the positive phase of the IOD pattern (Saji et al. 1999).

The evolution of SSTAs across the tropical oceans is further analyzed using the time-longitude plot of SSTA averaged in $20^{\circ} \mathrm{S}-20^{\circ} \mathrm{N}$ from October 2009 to December 2011 (Fig. 3.4). In early 2010, the SST

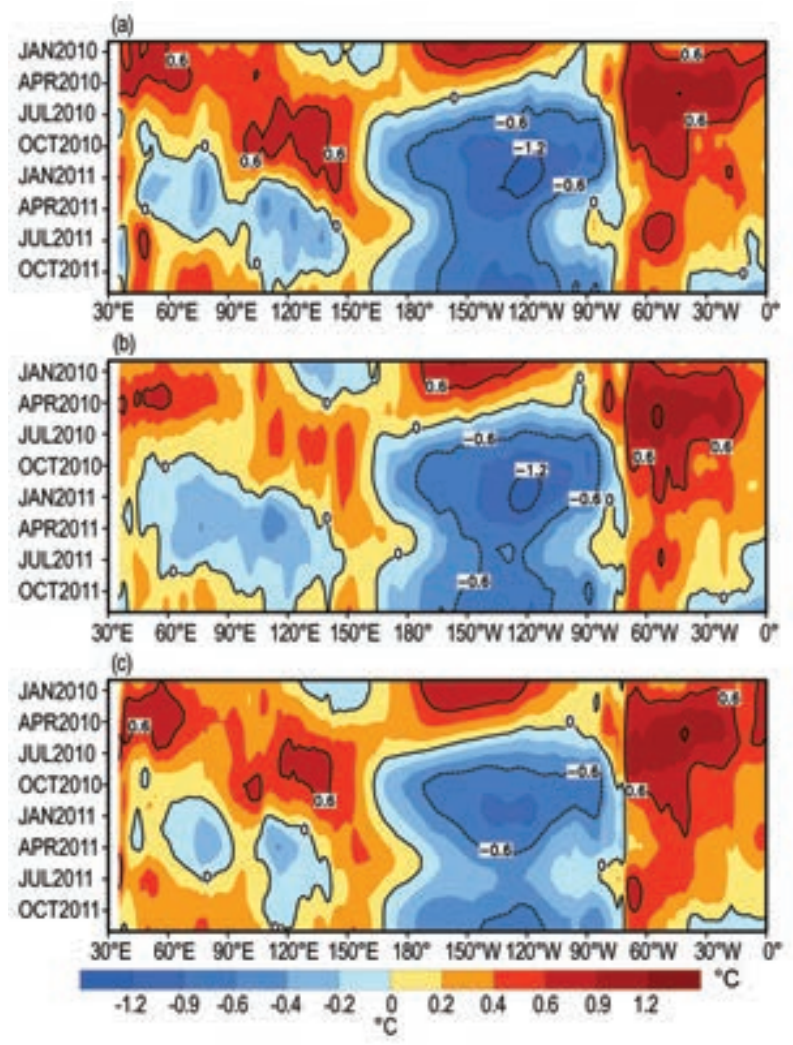

FIG. 3.4. Time-longitude section of SSTA $\left({ }^{\circ} \mathrm{C}\right.$, relative to $198 \mathrm{I}-2010$ base period) averaged between $20^{\circ} \mathrm{S}$ and $20^{\circ} \mathrm{N}$ from Oct 2009 to Dec $201 \mathrm{l}$ for the datasets (a) OISST, (b) HadISST, and (c) ERSST. was more than $0.6^{\circ} \mathrm{C}$ above normal in the eastern tropical Pacific, the western tropical Indian Ocean, and the tropical Atlantic related to the influences of the 2009/10 El Niño. The SST in the tropical North Atlantic actually reached a historical high in April 2010, and this warming has been attributed to the combined effects of the remote influences of the 2009/10 El Niño, persistent negative NAO, and longterm trend ( $\mathrm{Hu}$ et al. 2011). The yearly mean SSTA in the tropical Indian Ocean also reached a historical high in 2010 (see Fig. 3.5b), probably also due to the combined influences of El Niño and long-term trend.

In the tropical Pacific, there was a fast transition from El Niño to La Niña during spring 2010. At about the same time, SST near the Maritime Continent warmed up and the western Indian Ocean cooled down. This was probably related to the return of the La Niña conditions in the tropical Pacific. The SST near the Maritime Continent was more than $0.6^{\circ} \mathrm{C}$ above normal according to OISST and ERSST but was $0.3^{\circ} \mathrm{C}$ above normal based on HadISST. The offset between OISST and HadISST is consistent with what was found in 2010 (Xue et al. 2011, figure 3.5), which might be related to differences in satellite bias correction in the two SST products. It is also noted that the peak value of the negative SSTA in the eastern tropical Pacific was about $-1.2^{\circ} \mathrm{C}$ in OISST and HadISST while it was only $-0.9^{\circ} \mathrm{C}$ in ERSST. Based on a simple comparison of the Niño 3.4 SST, the average SSTA in $5^{\circ} \mathrm{S}-5^{\circ} \mathrm{N}, 170^{\circ} \mathrm{W}-120^{\circ} \mathrm{W}$, over the period $1982-2011$, ERSST generally underestimates the amplitude of strong SST anomalies associated with ENSO, probably due to the lack of satellite observations and the procedure used for SST reconstruction.

In early 2011 when the 2010/11 La Niña reached its peak phase, negative SSTA emerged in the tropical Indian Ocean. There was an eastward propagation of negative SSTA to the Maritime Continent (Fig. 3.3b). During summer 2011, positive SSTA emerged in the far western tropical Indian Ocean and expanded to the central tropical Indian Ocean in fall 2011. The east-west gradient of SSTA led to establishment of positive IOD conditions in July-October 2011 (see CPC's Monthly Ocean Briefing at http://www.cpc. ncep.noaa.gov/products/GODAS). On the other hand, the tropical North Atlantic SST cooled down substantially in spring 2011 under the remote influences of La Niña conditions, but remained about $0.6^{\circ} \mathrm{C}$ above normal during the North Atlantic hurricane season that favoreds above-normal hurricane activities.

A tripole SSTA in the North Atlantic, characterized by positive SSTA in the subtropics and high 
latitudes and negative SSTA in midlatitudes, persisted from spring 2010 to the winter 2010/11 (Figs. 3.2b, 3.3a). Xue et al. (2011) pointed out that the long persistence of the tripole SSTA was largely forced by persistent negative NAO, which often warms the SST in the subtropics and high latitudes, and cools the SST in midlatitudes by modifying evaporative heat loss from the ocean (Deser and Blackmon 1993). When NAO switched to positive in early spring 2011 (Fig. 3.2a), the tripole SSTA weakened substantially (Fig. $3.3 b)$. In the remaining months of 2011 , NAO fluctuated between positive and negative phases and did not provide consistent forcing to the ocean.

The connection between the two-year La Niña cycle and the persistent negative PDO is explored further. The PDO index is calculated as the standardized time series of the projection onto the first empirical orthogonal function (EOF) of monthly ERSST in the North Pacific north of $20^{\circ} \mathrm{N}$ in the period $1900-93$, following the approach of Mantua et al. (1997) in which the global mean SSTA in each month was first removed before the calculation. Zonal average SSTA between $160^{\circ} \mathrm{E}-$ $90^{\circ} \mathrm{W}$ was used to highlight the evolution of SSTA associated with the PDO. Figure $3.2 \mathrm{~d}$ shows that positive SSTA emerged in the central North Pacific around June 2010, coincident with the onset of negative phase of the PDO (Figs. 3.2c,d). This also corresponded well with the onset of La Niña around June 2010 in the tropical Pacific. The negative PDO intensified to -1.5 during summer 2010 when the mixed layer depth was the shallowest in the central North Pacific. The PDO weakened slightly and remained at about - 1 from October 2010 to June 2011, and then suddenly intensified to be less than -2 in and (f) global ocean.
July-August 2011. The strengthening of negative PDO was about one month earlier than the strengthening of negative SSTA in the tropical Pacific in August 2011. It appears that the development of negative PDO around June 2010 and strengthening of negative PDO in July 2011 may not be directly forced by La Niña, although the persistence of negative PDO was probably related to forcings from La Niña. A future study is needed to understand the connections between $\mathrm{La}$ Niña and negative PDO.

The historical perspective of the yearly mean SSTA in 2011 is shown in Fig. 3.5 as a basin average (a) Tropical Pacific $\left(30^{\circ} \mathrm{S}-30^{\circ} \mathrm{N}\right)$
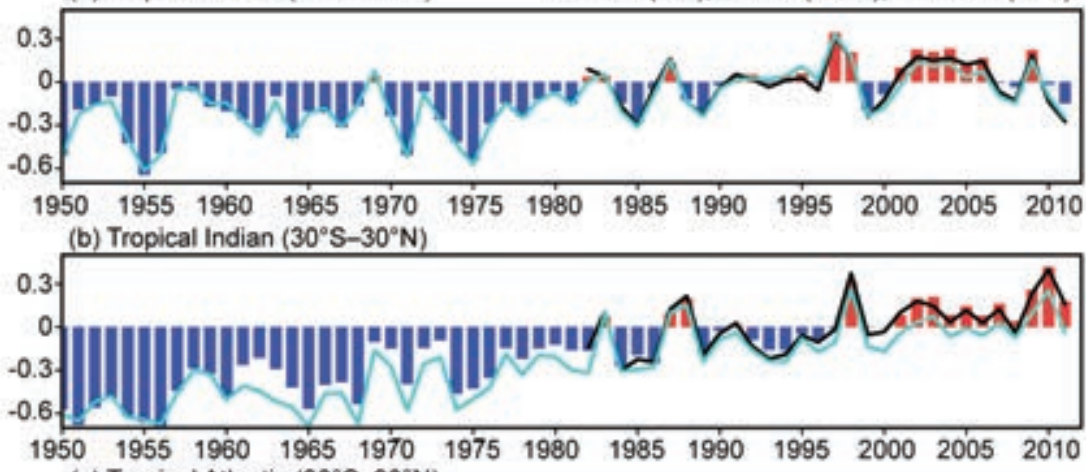

(c) Tropical Atlantic $\left(30^{\circ} \mathrm{S}-30^{\circ} \mathrm{N}\right)$

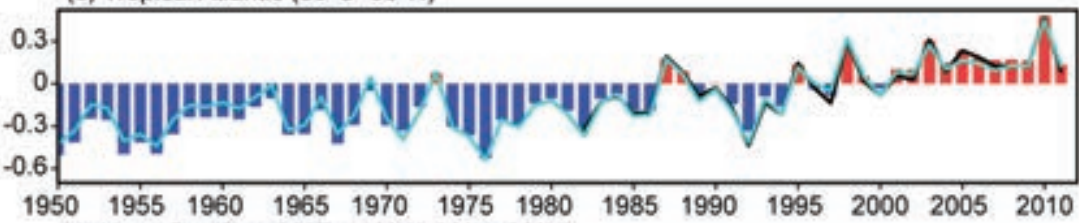

(d) North Pacific $\left(120^{\circ} \mathrm{E}-110^{\circ} \mathrm{W}, 30^{\circ} \mathrm{N}-60^{\circ} \mathrm{N}\right)$
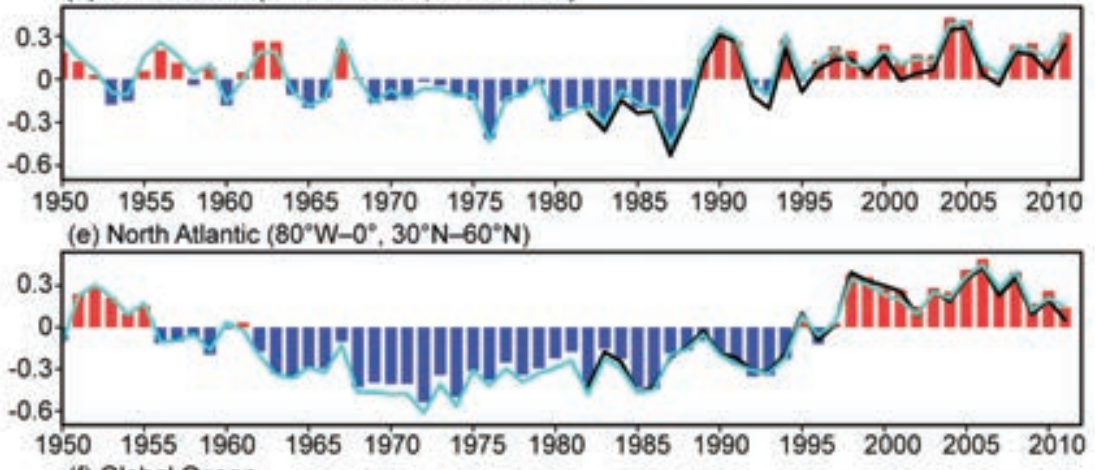

FIG. 3.5. Yearly mean SSTA $\left({ }^{\circ} \mathrm{C}\right.$, relative to $198 \mathrm{I}-2010$ base period) from ERSST (bar) and HadISST (blue line) for 1950-20II (bar) and OISST for 1982-20II (black line) averaged over the (a) tropical Pacific, (b) tropical Indian Ocean, (c) tropical Atlantic, (d) North Pacific, (e) North Atlantic, 
for the (a) tropical Pacific, (b) tropical Indian Ocean, (c) tropical Atlantic, (d) North Pacific, (e) North Atlantic, and (f) global ocean. The SSTA time series of OISST are largely consistent with those of ERSST in the common period 1982-2011. However, ERSST is generally warmer than OISST, and the difference can reach $0.1^{\circ} \mathrm{C}$ in some cases. HadISST also agrees well with OISST and ERSST, except it is generally cooler in the tropical Indian Ocean and the differences can reach $0.2^{\circ} \mathrm{C}$.

The mean SSTA in the global ocean has a dominant warming trend over which are superimposed interannual variations largely associated with El Niño and La Niña events (Fig. 3.5f). For example, the peaks and valleys in the global ocean SSTA often correspond with those in the tropical Pacific SSTA (Fig. 3.5a). However, the correspondence was not good in 2010, during which the tropical Pacific SST was weakly below normal while the global ocean SST was close to the historical high, which can be attributed to the historical high value in the tropical Indian and tropical Atlantic Ocean. From 2010 to 2011, under the influence of the two-year La Niña cycle, the tropical Pacific SSTA cooled by about $0.14^{\circ} \mathrm{C}$ (Fig. 3.5a) and became the second coolest year since 1982 ranked using OISST. At the same time, the global ocean SSTA cooled by about $0.1^{\circ} \mathrm{C}$ (Fig. 3.5f) and became the 12th highest year since 1982 .

The tropical Indian Ocean SSTA was dominated by an upward trend with an increase of $0.9^{\circ} \mathrm{C}$ over the period 1950-2010 when the historical high value was reached (Fig. 3.5b). The interannual variations in the tropical Indian Ocean SSTA corresponded well with those in the tropical Pacific SSTA due to the remote influences of ENSO. From 2010 to 2011, the tropical Indian Ocean SSTA decreased by $0.24^{\circ} \mathrm{C}$. In the tropical Atlantic, SSTA increased by $0.33^{\circ} \mathrm{C}$ from 2009 to 2010 when the historical high value was reached (Fig. 3.5c). From 2010 to 2011, the tropical Atlantic Ocean SSTA decreased by $0.4^{\circ} \mathrm{C}$ and the cooling tendency was the strongest since 1982. The North Pacific SSTA trended downward from 1950 to 1987, and then rebounded from $-0.5^{\circ} \mathrm{C}$ in 1987 to $0.31^{\circ} \mathrm{C}$ in 1990 , and has been persistently positive since then (Fig. $3.5 \mathrm{~d}$ ). The North Atlantic SSTA trended downward from 1951 to early 1970s, and then trended upward and reached a historical high in 2006. It has been decreasing since 2006 (Fig. 3.5e).

In summary, the 2011 SSTA was characterized by reemergence of the second La Niña in August 2011, strengthening of negative PDO in the second half of 2011, development of positive Indian Ocean dipole in fall 2011, and positive SSTA in tropical North Atlantic. The 2011 minus 2010 SSTA differences show that SST cooled down substantially cross the tropical oceans but warmed up in midlatitudes.

c. Ocean heat content-G. C. Johnson, J. M. Lyman, J. K. Willis, S. Levitus, T. Boyer, J. Antonov, and S. A. Good

Storage and transport of heat in the ocean are central to aspects of climate such as El Niño (Zebiak 1989), the North Atlantic Oscillation (Curry and McCartney 2001), hurricanes (Mainelli et al. 2008), sea-level rise (Johnson and Wijffels 2011), the global energy budget (Church et al. 2011), and constraining global warming scenarios (Knutti and Tomassini 2008).

First, an estimate of upper $(0 \mathrm{~m}-700 \mathrm{~m})$ ocean heat content anomaly (OHCA) for the period 1 January-31 December 2011 (Fig. 3.6a) is discussed, computed from a combination of in situ ocean temperature data (World Ocean Database 2009 Johnson et al. 2009; and Argo - Roemmich et al.

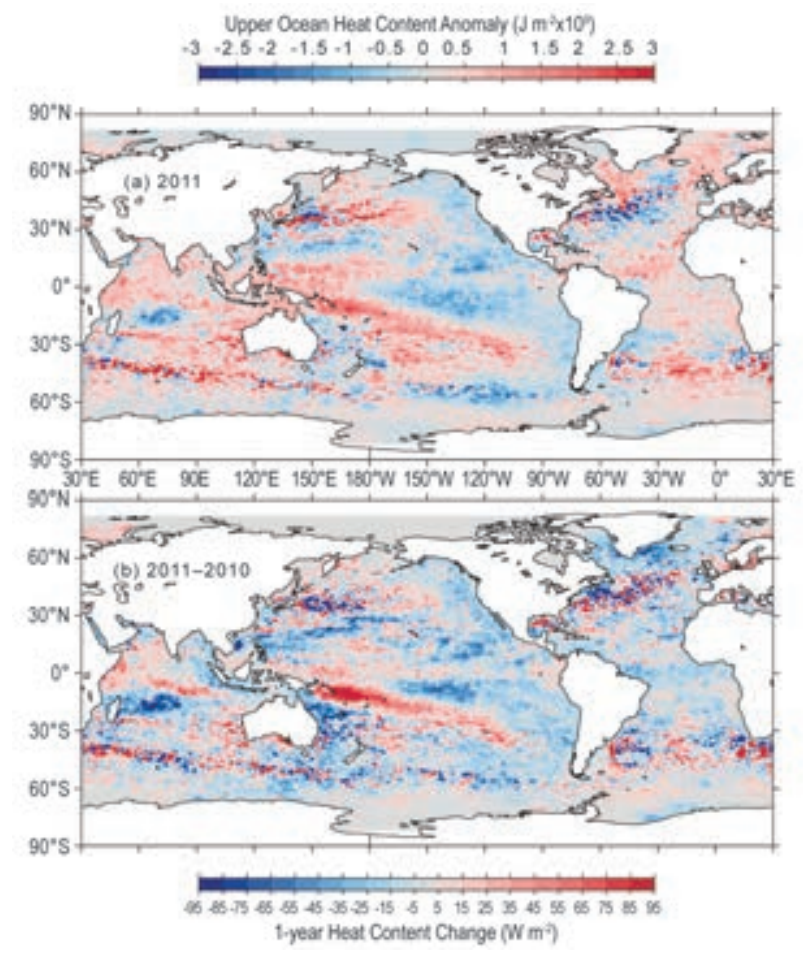

FIG. 3.6. (a) Combined satellite altimeter and in situ ocean temperature data estimate of upper $(0 \mathrm{~m}-700$ m) ocean heat content anomaly OHCA $\left(10^{9} \mathrm{~J} \mathrm{~m}^{-2}\right)$ for $201 \mathrm{l}$ analyzed following Willis et al. (2004), but relative to a 1993-20II base period. (b) The difference of 20II and 2010 combined estimates of OHCA expressed as a local surface heat flux equivalent $\left(\mathrm{W} \mathrm{m}^{-2}\right)$. For panel comparisons, note that $95 \mathrm{~W} \mathrm{~m}^{-2}$ applied over one year results in a $3 \times 10^{9} \mathrm{~J} \mathrm{~m}^{-2}$ change of OHCA. 
2009) and satellite altimetry data following Willis et al. (2004), but displayed relative to a 1993-2011 baseline, hereafter the combined estimate. Changes in the combined estimate between 2011 and 2010 (Fig. $3.6 \mathrm{~b}$ ), as well as a map of the linear trend of the combined estimate from 1993 to 2011 and its statistical significance (see Fig. 3.7), are then described. Three different time series of global integrals of in situ only estimates of upper OHCA are presented (see Fig. 3.8). Since OHCA changes are related to depth-integrated ocean temperature changes, increases in OHCA are sometimes referred to below as warming and OHCA decreases as cooling.

In recent years, many of the globally distributed in situ subsurface ocean temperature data are from Argo. Annual estimates of expendable-bathythermograph (XBT) fall rate corrections have been applied for deep and shallow probe data using table 2 of Wijffels et al. (2008), but with no XBT data used after 2005. Details of fields analyzed here may change after more Argo real-time data are subject to delayed-mode scientific quality control, as more data are reported, and as XBT corrections improve.

The combined estimate of OHCA in 2011 (Fig. 3.6a) shows eddy and meander variability down to the $100-\mathrm{km}$ mapping scales, as does, to a greater extent, the difference of the 2011 and 2010 combined estimates (Fig. 3.6b). Strong small-scale spatial variability in OHCA fields is associated with the western boundary currents in every gyre, as well as the Antarctic Circumpolar Current (Fig. 3.6b). The difference in the combined estimates between 2011 and 2010 (Fig. 3.6b) illustrates the large year-to-year variability in regional OHCA, with changes reaching or exceeding the equivalent of a $95 \mathrm{~W} \mathrm{~m}^{-2}$ magnitude surface flux applied over one year $\left(\sim 3 \times 10^{9} \mathrm{~J} \mathrm{~m}^{-2}\right)$. For comparison, the global average of incident solar radiation on Earth is $\sim 340 \mathrm{~W} \mathrm{~m}^{-2}$. Ocean advection likely plays a dominant role in many of these changes.

Local sea level anomalies are the result of OHCA and salinity variability throughout the water column, even to the bottom (e.g., Purkey and Johnson 2010), as well as mass signals (Llovel et al. 2009). Despite this, there are many large-scale visual similarities between the combined estimate of upper OHCA (Fig. 3.6a) and sea level (see Fig. 3.26a) fields in 2011. This similarity reflects both the large contribution of upper OHCA variations to sea-level variations and the influence of the altimeter data in the combined estimate.

Large-scale patterns are evident in the combined estimate of OHCA for 2011 (Fig. 3.6a) and its difference from 2010 (Fig. 3.6b). The pattern of annual mean OHCA (Fig.3.6a) on the equator in the Pacific mostly reflects La Niña conditions, with anomalously low values around the equator in the east and anomalously high values in the west. This pattern is to be expected, since the La Niña that began in early 2010 persisted into 2011 (section 3b).

In 2011, the North Pacific shows an OHCA dipole in the midlatitudes west of $160^{\circ} \mathrm{E}$ (Fig. 3.6a), perhaps associated with a Kuroshio Extension position southward of the long-term mean. The pattern of anomalous warmth in the central Pacific and cold in the subpolar, eastern subtropical, and eastern tropical Pacific is typical of the negative phase of the Pacific decadal oscillation (PDO; Mantua et al. 1997) and La Niña. The band of high OHCA in the South Pacific that extends from the Solomon Islands in the west to about $40^{\circ} \mathrm{S}$ west of Chile (Fig. 3.6a) has been present at various latitudes since 2006 (see previous State of the Climate reports). This year, it migrated several degrees south of its 2010 position, as seen in the northsouth dipole in year-to-year OHCA (Fig. 3.6b), and is associated with anomalous zonal currents in 2011, as well as the change since 2010 (see Fig. 3.17). Wind stress curl changes between 2010 and 2011 (see Fig. $3.10 \mathrm{~b})$ are well correlated with this shifting band, as are positive salinity anomalies both surface (see Fig. 3.12) and subsurface (see Fig. 3.14).

Except for a cold anomaly patch centered around $15^{\circ} \mathrm{S}, 75^{\circ} \mathrm{E}$, in 2011 the Indian Ocean was mostly higher in OHCA than the base period (Fig. 3.6a). This cold anomaly is associated with a positive anomaly in sea surface salinity (see Fig. 3.12).

In the subpolar North Atlantic, the Labrador Sea remained high in OHCA in 2011 (Fig. 3.6a), although it cooled quite a bit since 2010 (Fig. 3.6b). This ocean cooling is consonant with an increasing NAO index since the very low values in the winter of 2009/10. The continued high OHCA values in the eastern subpolar North Atlantic (Fig. 3.6a) suggest that subtropical influences are strong there (e.g., Johnson and Gruber, 2007), consistent with anomalously salty surface conditions in that region in 2010 (see Fig. 3.12). In 2011, a band of low OHCA was still present in the region of the Gulf Stream Extension (Fig. 3.6a), as it was in 2010. This band is consistent with a southward shift of that current (see Fig. 3.17), expected given the low NAO index in the winter of 2009/10 (e.g., Taylor and Stephens 1998). While the tropical Atlantic mostly cooled from 2010 to 2011 (Fig. 3.6b) it remained warmer than the 1993-2011 average (Fig. 3.6a).

A few distinct (Fig. 3.7a) and statistically significant (Fig. 3.7b) regional patterns stand out in the 


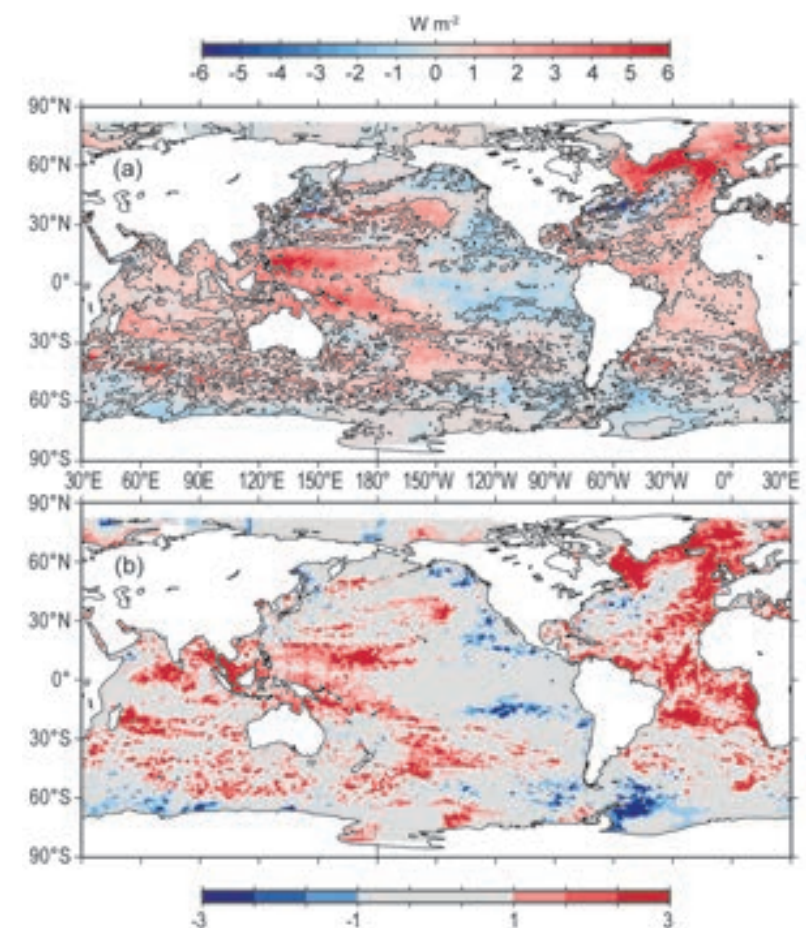

FIG. 3.7. (a) Linear trend from 1993 to $201 \mathrm{I}$ of the combined satellite altimeter and in situ ocean temperature data estimate of upper $(0 \mathrm{~m}-700 \mathrm{~m})$ OHCA $\left(\mathrm{W} \mathrm{m}^{-2}\right)$ analyzed following Willis et al. (2004). Areas with statistically significant trends are outlined in black. (b) Signed ratio of the linear trend to its $95 \%$ uncertainty estimate, with increasing color intensity showing regions with increasingly statistically significant trends.

1993-2011 OHCA local linear trends. In the Indian Ocean, the warming trend was widespread and statistically significant in many locations.

In the Atlantic Ocean, the Labrador, Irminger, and Greenland-Iceland-Norwegian Seas have all trended warmer over 1993-2011 (Fig. 3.7a), reflecting a robust regional warming trend over the interval despite the cooling from 2010 to 2011 (Fig. 3.6b). These changes may be owing to an overall decrease in the NAO index from 1993 to 2011. Eastern portions of the Atlantic also trended warmer across both hemispheres. Areas with warming trends in the Atlantic are widespread, including highly statistically significant trends in eastern portions of both hemispheres. Cooling trends are limited in the Atlantic to the Gulf Stream Extension, probably related to a southward shift in that current, also expected with an overall declining NAO index.

Statistically significant (Fig. 3.7b) 1993-2011 regional trends in the Pacific Ocean (Fig. 3.7a) include warming in the western tropical Pacific and extratropical cooling in the east, consistent (via the geostrophic relation) with general strengthening of the interior subtropical-tropical circulation attributed to trade wind intensification (Merrifield and Maltrud 2011). The statistically significant warming in the central North Pacific and cooling south of Alaska and off the west coast of North America are also consistent with an overall downward trend in the PDO index from 1993 to 2011. There is a similar-looking trend pattern in the South Pacific.

The overall 1993-2010 trends in Southern Ocean OHCA were towards warming, consistent with previous analyses (e.g., Böning et al. 2008), but with some local cooling trends on both sides of the Antarctic Peninsula and near Antarctica in the Indian Ocean (Fig. 3.7a).

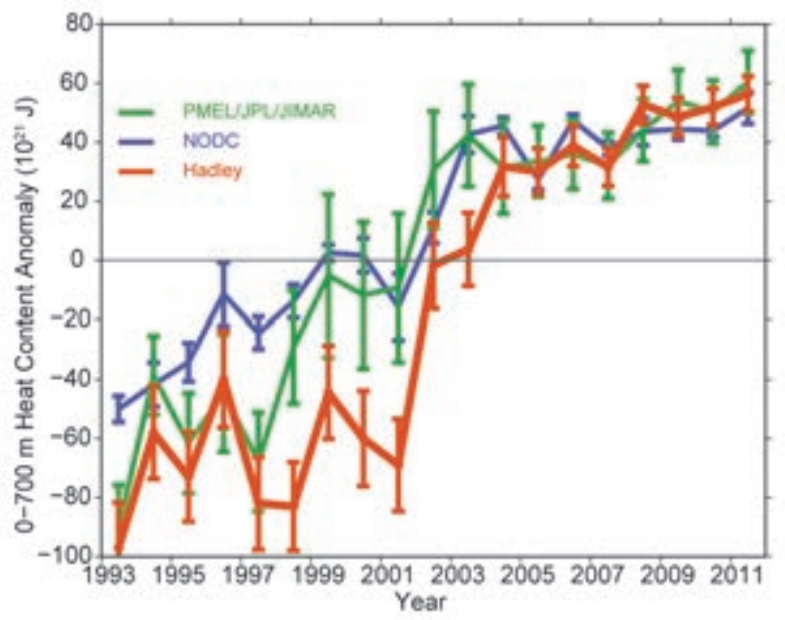

FIG. 3.8. Time series of annual average global integrals of in situ estimates of upper $(0 \mathrm{~m}-700 \mathrm{~m})$ OHCA $\left(10^{21}\right.$ J, or ZJ) for 1993-20II with standard errors of the mean. The NODC estimate (http://www.nodc.noaa. gov/OC5/indprod.html) follows Levitus et al. (2009). Uncertainties are estimated solely from the variance of quarterly estimates of OHCA. The PMEL/JPL/JIMAR estimate is a weighted integral (Lyman and Johnson 2008) using Argo and WOD 2009 (Johnson et al. 2009) data with the Wijffels et al. (2008) Table 2 XBT bias adjustments applied and no XBT data after 2005. Uncertainty estimate methodology follows Lyman et al. (2010). The Hadley estimate applies XBT bias adjustments from Table I of Wijffels et al. (2008) to the EN3 dataset (Ingleby and Huddleston 2007; http:// www.metoffice.gov.uk/hadobs) and is computed from estimates of monthly OHCA following Palmer et al. (2007). Uncertainty estimate methodology follows Palmer and Brohan (20II) but adds uncertainty in the XBT bias correction. For comparison, all estimates have been individually offset (vertically on the plot), first to their individual 2004-II means (the best sampled time period), and then to their collective 1993-20II mean (the record length). 
Three different upper ocean estimates $(0 \mathrm{~m}-$ $700 \mathrm{~m}$ ) of globally-integrated in situ OHCA (Fig. 3.8) reveal a large increase in global integrals of that quantity since 1993. While levels appear to be increasing more slowly since around 2003 or 2004 than over the previous decade, the sum of the mass and thermal expansion components of the global sea level budget agree with observed sea-level rise rates since at least 2005 (see Fig. 3.28). The highest values for each global OHCA estimate are for 2011, although uncertainties only permit statistically significant trends to be estimated over about ten years or longer (Lyman 2011). Interannual details of the time series differ for a variety of reasons, including differences in climatology, treatment of the seasonal cycle, mapping methods, instrument bias corrections, quality control, and other factors (Lyman et al. 2010). Some of these factors are not taken into account in some of the displayed uncertainties, so while the error bars shown do not always overlap among the three estimates, they are not necessarily statistically different from each other. However, all three curves agree on a significant warming of the upper ocean since 1993, accounting for a large portion of the global energy imbalance over this time period (Church et al. 2011).

\section{d. Global ocean heat fluxes - L. Yu, P. W. Stackhouse Jr., and R. A. Weller}

The net heat flux (Qnet) at the ocean surface is the sum of the four air-sea heat transfer processes: shortwave radiation (SW), longwave radiation (LW), latent heat (LH), and sensible heat (SH) fluxes. Solar radiation is the ultimate heat source for the Earth. About $47 \%$ of the total solar radiation reaching the Earth is absorbed by the surface ocean and land (Trenberth et al. 2009). Of the energy absorbed by the ocean, some is radiated back to the atmosphere by $\mathrm{LW}$, some is transformed into $\mathrm{SH}$ and $\mathrm{LH}$ and released to the atmosphere through conduction and evaporation, and the remaining energy is either transported by currents or stored and sequestered in the ocean. Knowing how these heat exchange processes balance at the ocean surface and how much the net residual heat flux has changed are fundamental to the understanding of the role of the ocean in mitigating radiative perturbations and modulating the global climate.

Daily estimates of $\mathrm{LH}$ and $\mathrm{SH}$ on $1^{\circ}$ grids over the global oceans are routinely produced by the Objectively Analyzed air-sea Fluxes (OAFlux) project (http://oaflux.whoi.edu) at the Woods Hole Oceanographic Institution (Yu and Weller 2007). The computation of the OAFlux products uses the state- of-the-art bulk flux algorithm version 3.0 developed from the Coupled Ocean-Atmosphere Response Experiment (COARE; Fairall et al. 2003), with the surface meteorological variables determined from an optimal blending of satellite retrievals of surface wind and temperatures and surface meteorology from reanalysis/forecast models. The accuracy of the OAFlux LH and $\mathrm{SH}$ estimates was evaluated using 120-plus buoys available over the global oceans (Yu et al. 2008). The averaged root-mean-square (rms) differences between OAFlux and buoy over the buoy locations are $9.6 \mathrm{~W} \mathrm{~m}^{-2}(8 \%)$ for $\mathrm{LH}$ and $2.6 \mathrm{~W} \mathrm{~m}^{-2}$ (15\%) for SH. The OAFlux project also develops global daily vector wind analysis from synergizing passive radiometer wind speed retrievals and radar scatterometer vector wind retrievals (Yu and Jin 2012, manuscript submitted to J. Geophys. Res.). The wind analysis for the post-QuikSCAT (after November 2009) period uses satellite measurements from the Special Sensor Microwave Imager/Sounder (SSMIS), the Advanced Scatterometer (ASCAT) aboard the EUMETSAT METOP satellite, and the WindSat (a passive polarimetric microwave sensor) aboard the Department of Defense Coriolis satellite.

Global daily surface SW and LW flux products on $1^{\circ}$ grids are now delivered in near real-time (within one week) by the CERES (Clouds and Earth's Radiant Energy Systems) Fast Longwave And SHortwave Radiative Fluxes (FLASHFlux) project (http://flashflux. larc.nasa.gov) at the NASA Langley Research Center (Stackhouse et al. 2006). This output data product is made possible by processing Terra and Aqua observations from CERES and cloud property retrievals from the Moderate-resolution Imaging Spectroradiometer (MODIS) using simplified calibration assumptions with fast radiation algorithms (Kratz et al. 2010). Evaluation of the FLASHFlux surface radiation with ground measurements from the Surface Radiation Budget Network (SURFRAD) stations shows an rms error of $29.3 \mathrm{~W} \mathrm{~m}^{-2}$ (15.7\%) for downward SW and $18.6 \mathrm{~W} \mathrm{~m}^{-2}(6.0 \%)$ for downward LW.

The annual mean Qnet in 2011 produced by combining FLASHFlux and OAFlux datasets is displayed in Fig. 3.9 (next page). An area-weighted spatial mean of $25 \mathrm{~W} \mathrm{~m}^{-2}$ was removed to adjust global mean balance. The regions of net heat gain (positive Qnet) and net heat loss (negative Qnet) are in broad agreement with the climatological mean pattern (Josey et al. 1999). The tropical oceans receive an excess of heat energy owing to the high rate of insolation throughout the year, and the strongest heating $\left(>140 \mathrm{~W} \mathrm{~m}^{-2}\right)$ is located on the equator in the eastern Pacific. The 

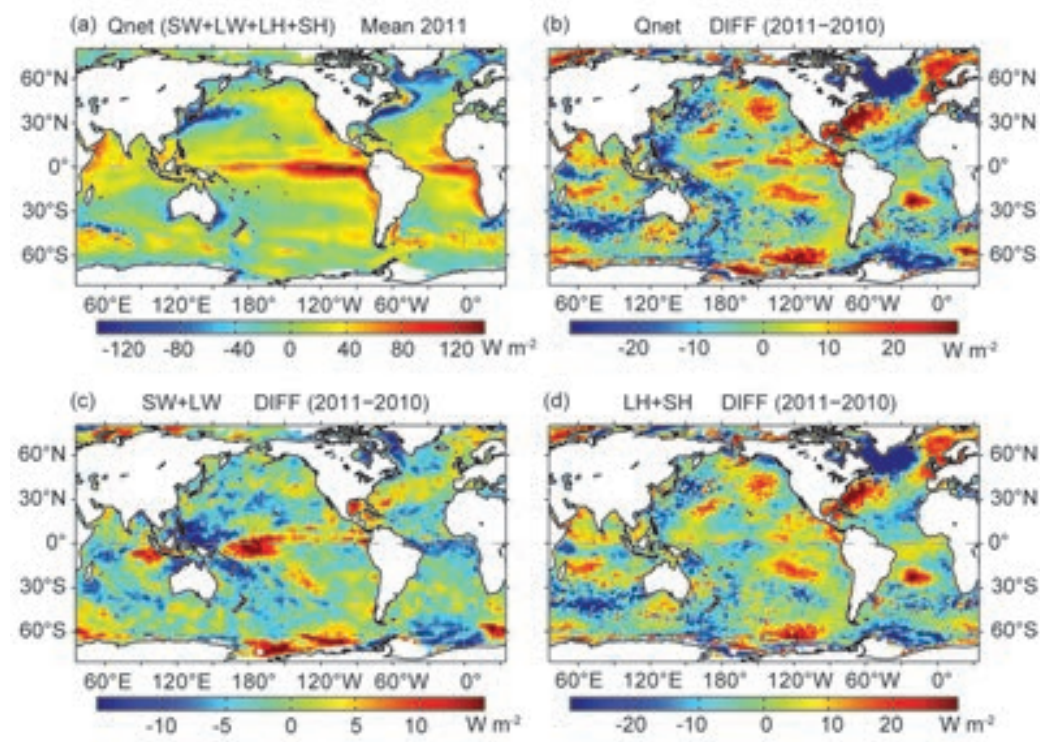

FIG. 3.9. (a) Annual mean net heat flux $\left(\mathrm{W} \mathrm{m}^{-2}\right)$ into the ocean (Qnet) in 20 II. Positive (negative) values denote ocean heat gain (loss). (b) Annual mean difference in Qnet between $20 \mathrm{II}$ and 2010 . The $20 \mathrm{II}$ minus 2010 mean difference in surface radiation (SW+LW) and turbulent heat fluxes (LH+SH) are shown in (c) and (d), respectively. In (b)-(d), positive (negative) values denote where the ocean gained more (lost less) heat in 2011 compared to 2010.

subtropics and high latitudes experience net heat loss to the atmosphere, with the maximum heat loss $\left(<-140 \mathrm{~W} \mathrm{~m}^{-2}\right)$ occurring over the western boundary currents (WBCs) in the northern midlatitudes. The primary mechanism of the large net heat loss in the vicinity of the WBCs is latent and sensible heat fluxes in the fall and winter seasons, during which the cold and dry air masses advected from the lands by strong westerly winds induce sharp air-sea temperature and humidity contrasts, intensifying latent and sensible heat release to the atmosphere.

The 2011 minus 2010 difference plot of Qnet (Fig. 3.9b) shows organized large-scale changes in net heat flux into the global oceans. One marked change was observed in the North Atlantic, characterized by a tripole structure with an area of significant negative anomalies (more ocean heat loss) in the Labrador and Irminger Seas between $45^{\circ} \mathrm{N}$ and $65^{\circ} \mathrm{N}$, a band of positive anomalies (more ocean heat gain) in the midlatitudes centered over the Gulf Stream pathway and stretching northeastward to the Norwegian Sea, and a band of negative anomalies (more ocean heat loss) in the subtropics between the equator and $30^{\circ} \mathrm{N}$. The tripole pattern reflected the atmospheric conditions of a generally more positive NAO phase in 2011 compared to the persistently negative phase in 2010 (see Fig. 3.2). The anomaly pattern of surface net radiation $\mathrm{SW}+\mathrm{LW}$ (Fig. 3.9c) was very similar to that of $\mathrm{LH}+\mathrm{SH}$ (Fig. 3.9d), but $\mathrm{LH}+\mathrm{SH}$ accounts more for the magnitude of Qnet anomalies. This is in good agreement with the study of Cayan (1992) that, in the extratropical oceans, the variance in SW and LW is small and Qnet is dominated by the variance of LH and $\mathrm{SH}$.

The North Atlantic tripole pattern is also seen in the 2011 minus 2010 wind speed difference field (Fig. 3.10a), but with opposite signs. The 2011 mean wind vectors is superimposed to help characterize the change in prevailing winds. Compared to 2010, there was a strengthening of westerlies across the midlatitudes on a more northerly track and a strengthening of trade winds in the tropical Atlantic. The pattern is consistent with past positive NAO phase (Hurrell 1995; Visbeck et al. 2001). It can be observed that enhanced $\mathrm{LH}+\mathrm{SH}$ (negative anomalies in Fig. 3.9d) occurred in regions of strengthened wind speeds (positive anomalies). Similarly, the regions of weakened $\mathrm{LH}+\mathrm{SH}$ (positive anomalies) coincided with the regions of weakened wind speeds (negative anomalies). Wind direction

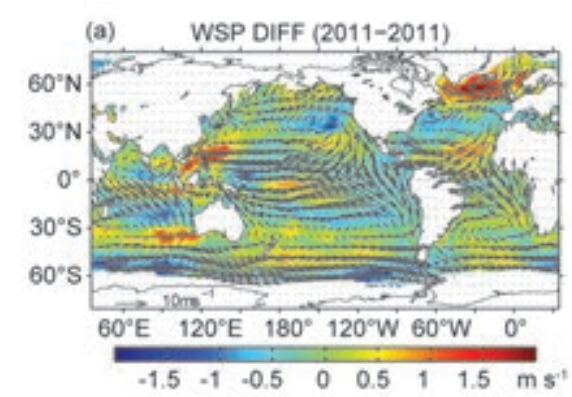

$\begin{array}{llllllll}-1.5 & -1 & =0.5 & 0 & 0.5 & 1 & 1.5 & \mathrm{~m} \text { s }\end{array}$

FIG. 3.10. (a) Differences between the $201 \mathrm{I}$ and 2010 wind speed at $10-\mathrm{m}$ height (colored background), with the $20 \mathrm{II}$ mean wind vector superimposed (black arrows). Positive (negative) values denote a strengthening (weakening) of prevailing winds compared to 2010. (b) Differences between the $20 \mathrm{II}$ and 2010 wind stress curl (colored background), with the wind stress vector differences between 2011 and 2010 superimposed (black arrows). Positive (negative) values denote anticyclonic (cyclonic) curl anomalies. 
is also important. For instance, the excessive turbulent heat loss in the Labrador and Irminger Seas resulted from both the intensified subpolar cyclonic wind circulation and the cold and dry air advected to the region by the westerlies. It is known that the basin-scale NAO SST variability is driven primarily by the atmospheric forcing via the effects of $\mathrm{LH}+\mathrm{SH}$, mixing, and the wind-driven Ekman currents (Cayan 1992; Deser and Blackmon 1993). The 2011 surface warming tendency of the North Atlantic Ocean from 2010 corresponded well with positive (more ocean heat gain) Qnet anomaly and concurring negative (weakened) wind anomaly. Meanwhile, the regional surface cooling tendency also correlated well with negative (more ocean heat loss) Qnet anomaly and positive (strengthened) wind anomaly. The North Atlantic is clearly an example that surface net heat flux is a forcing for SST anomalies.

Surface heat flux plays a dual role in dynamics of large-scale SST anomalies. While it contributes to the generation of SST anomalies in the North Atlantic, surface heat flux also responds to the SST anomalies that have been generated from other processes and can act to oppose those anomalies. The latter role of Qnet is displayed in the Pacific and Indian Oceans. The sea surface in the eastern part of the Pacific in 2011 was dictated by a developing La Niña in the tropics and negative PDO phase in the North Pacific. Compared to 2010, colder SST anomalies appeared over the central tropical Pacific between $160^{\circ} \mathrm{E}$ and $120^{\circ} \mathrm{W}$ with a center on the equator near the date line (see Fig. 3.1). In general, the upper OHCA year-to-year tendency also appears to be damped by year-to-year changes in Qnet. Unlike the North Atlantic where negative SST anomalies were well correlated with negative Qnet anomalies, the negative SST anomalies here were associated with positive Qnet anomalies that can be attributed primarily to the $\mathrm{LH}+\mathrm{SH}$ component. In the tropics, ENSO SSTs are governed by ocean dynamics through wind-driven upwelling of cold water from the thermocline (Wyrtki 1981). The cooler ocean surface led to a weaker evaporative heat loss, which together with enhanced downward radiation, resulted in more downward Qnet. In the tropical Indian Ocean, SST anomalies follow the ENSO index. As the regional sea surface cooled from 2010 to 2011, an increase in Qnet, owing to reduced evaporative heat loss and enhanced radiation, was also observed. These positive Qnet anomalies acted as a damping to the existing negative SST anomalies, suppressing the growth of ENSO-induced SSTs.
Consistent with past La Niña events (Ropelewski and Halpert 1989), the western Pacific warm pool and deep tropical convection in 2011 were retracted to the far west of the date line. As a result, the convection across the Maritime Continent was enhanced. The increased cloudiness led to a reduction of downward SW+LW by more than $10 \mathrm{~W} \mathrm{~m}^{-2}$ and dominated the change of Qnet in the region. Away from the convergence center in both zonal directions, convection was suppressed in both directions, resulting in large increase in SW+LW $\left(>15 \mathrm{~W} \mathrm{~m}^{-2}\right)$ across the central equatorial Pacific and eastern Indian Oceans. Corresponding change in wind was evident, with weaker wind speed in the center of convergence and enhanced equatorial westerlies in the Indian Ocean and enhanced easterlies near the date line. The change in wind speed governed the change in $\mathrm{LH}+\mathrm{SH}$ in the warm pool (Zhang and McPhaden 1995). It can be seen that the tropical western Pacific and eastern Indian Oceans were regions where the SW+LW anomalies compensated the $\mathrm{LH}+\mathrm{SH}$ anomalies in producing the Qnet anomalies. In other regions such as the eastern Pacific and North Atlantic, the SW+LW anomalies worked in concert with the $\mathrm{LH}+\mathrm{SH}$ anomalies to increase the Qnet anomalies.

In the North Pacific, Qnet served primarily as a forcing for the PDO SSTs, and the anomalies of the two variables have the similar sign. In the southern oceans between $30^{\circ} \mathrm{S}$ and $50^{\circ} \mathrm{S}$, the Qnet anomalies were overwhelmingly negative due to the increased heat loss by $\mathrm{LH}+\mathrm{SH}$ in response to positive SST anomalies. The changing relationships between Qnet and SST with the ocean basins demonstrate that the global climate system is ruled by intricate feedbacks between the ocean and the atmosphere.

Overall, yearly variability of Qnet over the global oceans is attributable more to variability of $\mathrm{LH}+\mathrm{SH}$.

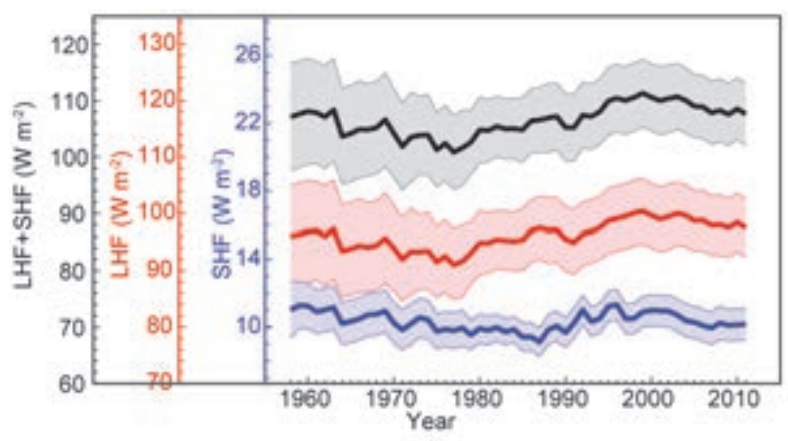

FIG. 3.II. Year-to-year variations of global averaged annual mean latent flux plus sensible heat flux (LHF+SHF; black curve), LHF (red curve), and SHF (blue curve). The shaded areas indicate the error bars of the flux estimates at the $95 \%$ confidence level. 
The long-term perspective of the change in 2011 $\mathrm{LH}+\mathrm{SH}$ is shown in the annual mean time series averaged over the global oceans from 1958 to 2011 (Fig. 3.11). The $2011 \mathrm{LH}+\mathrm{SH}$ was slightly down from the 2010 mean, continuing the downward trend that started around 2000. A tendency toward reversing the upward trend that characterized the decades of 1980 s and 1990s is thus indicated. The 54-year time series displays decadal oscillations dominated by LH, with a low at $99 \mathrm{~W} \mathrm{~m}^{-2}$ in 1977 and a high at $109 \mathrm{~W}$ $\mathrm{m}^{-2}$ in 1999. It is worth noting that LH is not only an important component in the global heat and energy balance but also a key component of the freshwater flux over the oceans that contributes to the change of ocean surface salinity (see Fig. 3.13).

\section{e. Sea surface salinity-G. C. Johnson and J. M. Lyman}

Ocean storage and transport of freshwater are intrinsic to aspects of global climate, including the water cycle (e.g., Schanze et al. 2010), El Niño (e.g., Maes et al. 2006), and anthropogenic climate change (e.g., Held and Soden 2006). Only since 2004 has the advent of Argo (an array of profiling floats that measures temperature and salinity year-round in the upper $2 \mathrm{~km}$ of the ice-free global ocean, nominally at 10 day intervals and $3^{\circ} \times 3^{\circ}$ spacing; Roemmich et al. 2009) allowed an annual assessment of global upper ocean salinity and its complement, freshwater.

The near-global Argo data are used to determine near-global annual average bulk (viz. near-surface, as opposed to skin) sea surface salinity (SSS) anomalies for 2011 relative to a long-term climatology, describe how annual SSS anomalies have changed in 2011 relative to 2010, and assess 2004-11 SSS trends and their statistical significance. The data, downloaded from an Argo global data assembly center in January 2012, are a mix of real time (preliminary) and delayed mode (scientific quality-controlled). The estimates presented here could change after all the data have been subjected to careful scientific quality control, and as other data sources (e.g., Aquarius satellite, Sidebar 3.1) are integrated into the estimates.

The shallowest salinity value flagged as good from each Argo profile is used in this analysis, generally at 9-m depth, with some as shallow as $4 \mathrm{~m}$, and those with depth $>25 \mathrm{~m}$ are excluded. These data are subjected to a statistical check to discard extreme outliers, defined as points within a $3^{\circ}$-radius of a grid point with temperature or salinity values three times the interquartile range above the third or below the first quartiles. After this check, the remaining data are cast as differences from climatological monthly mean surface salinity fields from the World Ocean Atlas 2009 (WOA 2009; Antonov et al. 2010). The resulting anomalies are objectively mapped (Bretherton et al. 1976) for each year using a covariance function combining a $6^{\circ}$ (latitude and longitude) length-scale Gaussian with a $9^{\circ}$ length-scale exponential and a noise-to-signal variance ratio of 2.2 .

Climatological SSS patterns are correlated with surface freshwater flux [the sum of evaporation, precipitation, and river runoff (e.g., Beránger et al. 1999)] but horizontal and vertical advection and mixing are also important in many locations, at least on seasonal time scales (Yu 2011). In each ocean basin, subtropical salinity maxima centered between roughly $20^{\circ}$ and $25^{\circ}$ in latitude (Fig. 3.12, grey contours) are signatures of the predominance of evaporation over precipitation. Conversely, in most regions where climatological surface salinities are relatively fresh, such as the

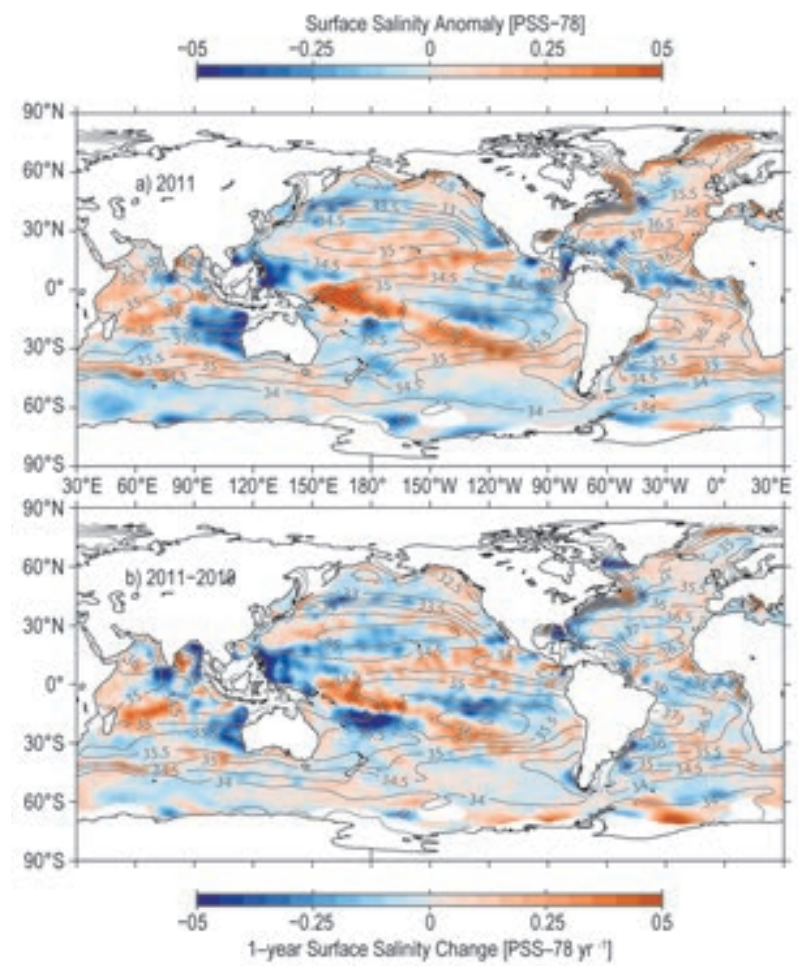

FIG. 3.12. (a) Map of the $201 \mathrm{I}$ annual surface salinity anomaly estimated from Argo data [colors in 1978 Practical Salinity Scale (PSS-78)] with respect to monthly climatological salinity fields from WOA 2009 (yearly average, gray contours at 0.5 PSS-78 intervals). (b) The difference of $201 \mathrm{I}$ and 2010 surface salinity maps estimated from Argo data [colors in PSS-78 $\mathrm{yr}^{-1}$ to allow direct comparison with (a)]. White ocean areas are too data-poor to map. While salinity is often reported in practical salinity units, or PSU, it is actually a dimensionless quantity reported on the PSS-78. 
high latitudes and the intertropical convergence zones (ITCZs), precipitation generally dominates over evaporation.

The 2011 SSS anomalies (Fig. 3.12a, colors) reveal some large-scale patterns that also hold in 2004 through 2011. The regions around the subtropical salinity maxima are on balance salty with respect to WOA 2009. Most of the high-latitude climatologically fresh regions appear fresher than WOA 2009, including in the vicinity of the Antarctic Circumpolar Current near $50^{\circ} \mathrm{S}$ and in the western subpolar gyre of the North Pacific. These patterns are consistent with an intensified hydrological cycle (that is, more evaporation in drier locations, and more precipitation in rainy areas), as seen in simulations of global warming. These simulations suggest this signal might be discernible over the last two decades of the 20th century (Held and Soden 2006), consistent with the multiyear nature of these anomalies. While anomalous ocean advection could influence the SSS pattern over decadal time scales, changes observed at the local extrema are presumably relatively insensitive to such effects because horizontal gradients there are minimal. This SSS anomaly pattern and its interpretation are consistent with other analyses (Hosoda et al. 2009; Durack and Wijffels 2010). Changes in ocean interior salinity values also appear consistent with an increase in the hydrological cycle (Helm et al. 2010; section 3f).

In contrast to some other high-latitude areas, the subpolar North Atlantic and Nordic Seas in 2011 were mostly anomalously salty with respect to the historical WOA 2009 climatology (Fig. 3.12a, colors), as they have been since at least 2004 (see previous State of the Climate reports). The salty anomaly in this region is consistent with a stronger influence of subtropical gyre waters in the northeastern North Atlantic in recent years coupled with a reduced extent of the subpolar gyre (Häkkinen et al. 2011). On the basin scale, the North Atlantic loses freshwater to the atmosphere whereas the North Pacific gains it (Schanze et al. 2010), so the changes here may again be consistent with an increased hydrological cycle (Durack and Wijffels 2010).

Sea surface salinity changes from 2010 to 2011 (Fig. $3.12 \mathrm{~b}$, colors) strongly reflect 2011 anomalies in precipitation (see Fig. 2.21 and Plate 2.1i), and to a lesser extent year-to-year changes in evaporation, with the latter being closely related to latent plus sensible heat flux changes (see Fig. 3.9d). Advection by anomalous ocean currents (see Fig. 3.17) also plays a role in sea surface salinity changes. For instance, prolonged La Niña conditions over the last few years, associated with an anomalously strong Indonesian Throughflow (England and Huang 2005), may be partly responsible for the freshening observed northwest of Australia, as the throughflow does bring relatively fresh water into the Indian Ocean. Precipitation anomalies in this region, while consistent with freshening, are not large (see Fig. 2.21 and Plate 2.1i). The South Pacific convergence zone also appears to have shifted south from 2010 to 2011, consistent with the dipole in salinity changes centered around $10^{\circ} \mathrm{S}$ in the southwest tropical Pacific. Farther to the southeast, the apparent southward shift in the subtropical surface salinity maximum is associated with year-to-year changes in the ocean heat content (see Fig. 3.6b), so the salty shift is associated with a warm shift.

There are also correspondences between the surface salinity changes from 2010 to 2011 and subsurface changes over the same period (see Figs. 3.14, $3.15,3.16)$. Some of the surface changes are confined mostly to the upper one or two hundred meters, including many of those in the tropics. However, others apparently extend deep into the water column, suggesting influences of shifting ocean currents and fronts. Deeper-penetrating changes are found in the high southern latitudes, near the Antarctic Circumpolar Current, and in the North Atlantic, near the Gulf Stream Extension and the North Atlantic Current.

Trends from 2004 through 2011 are estimated by local linear fits to annual average SSS maps (Fig. $3.13 \mathrm{a}$ ), as are the ratio of these trends to their $95 \%$ significance (Fig. 3.13b). The starting year is 2004, when Argo coverage became near-global. The most striking trend patterns are in the Pacific and Indian Oceans. Saltier surface values in the western and central tropical Pacific extend into the eastern Pacific subtropics in both hemispheres. Some freshening also occurs in the western subtropics of each hemisphere in the Pacific and around the Philippine Sea, extending into the Indian Ocean northwest of Australia (the latter again perhaps owing to the La Niña of the past few years). Large-scale freshening is also evident in the eastern tropical South Pacific. These recent trends differ from the previously reported 50 -year trends discussed above. The differences are not surprising given the very different time periods over which the trends are computed. 


\section{SIDEBAR 3.I: AQUARIUS SATELLITE MISSION PROVIDES NEW, DETAILED VIEW OF SEA SURFACE SALINITY—G. LAGERLOEF, F. WENTZ, S. YUEH, H.Y. KAO, G. C. JOHNSON, AND J. M. LYMAN}

The Aquarius satellite mission (http://aquarius. nasa.gov), launched on 10 June 20II, has been measuring sea surface salinity (SSS) from space since 25 August 20II. Aquarius's primary scientific goal is to study links among the ocean circulation, the global water cycle, and climate by measuring ocean surface salinity (Lagerloef et al. 2008). Recent multidecadal SSS trends provide a strong indication of changes in the global water cycle, with wetter areas gaining in rainfall and low rainfall regions becoming more arid (see section 3e; also Gordon and Giulivi 2008). Aquarius data will allow analyses of these changes at higher spatial and temporal resolution than presently possible with the in situ SSS observing system (Figs. SB3.1-3). Aquarius will complete a year of measurements in autumn 2012, allowing the start of detailed exploration of the annual coupling of SSS, rainfall, surface currents, and sinks such as subduction and vertical mixing. Aquarius data in subsequent years will improve annual cycle statistics, yield new information on ENSO and other interannual climate variations, and advance our understanding of the marine freshwater budget (Lagerloef et al. 2010).

Sea surface salinity data from Aquarius and the previously launched European Soil Moisture Ocean Salinity (SMOS) mission (http://www.esa. int/smos; Font et al. 2004; Lagerloef and Font 2010) provide a fundamentally new ocean remote sensing capability. The Aquarius microwave sensor, built by NASA, is the prime instrument on the joint United States and Argentina Aquarius/SAC-D observatory. The Argentine Comisión Nacional de Actividades Espaciales (CONAE) developed the Satélite de Aplicaciones Científicas (SAC-D) spacecraft, which carries Aquarius and other scientific sensors.

Salinity remote sensing involves measuring the
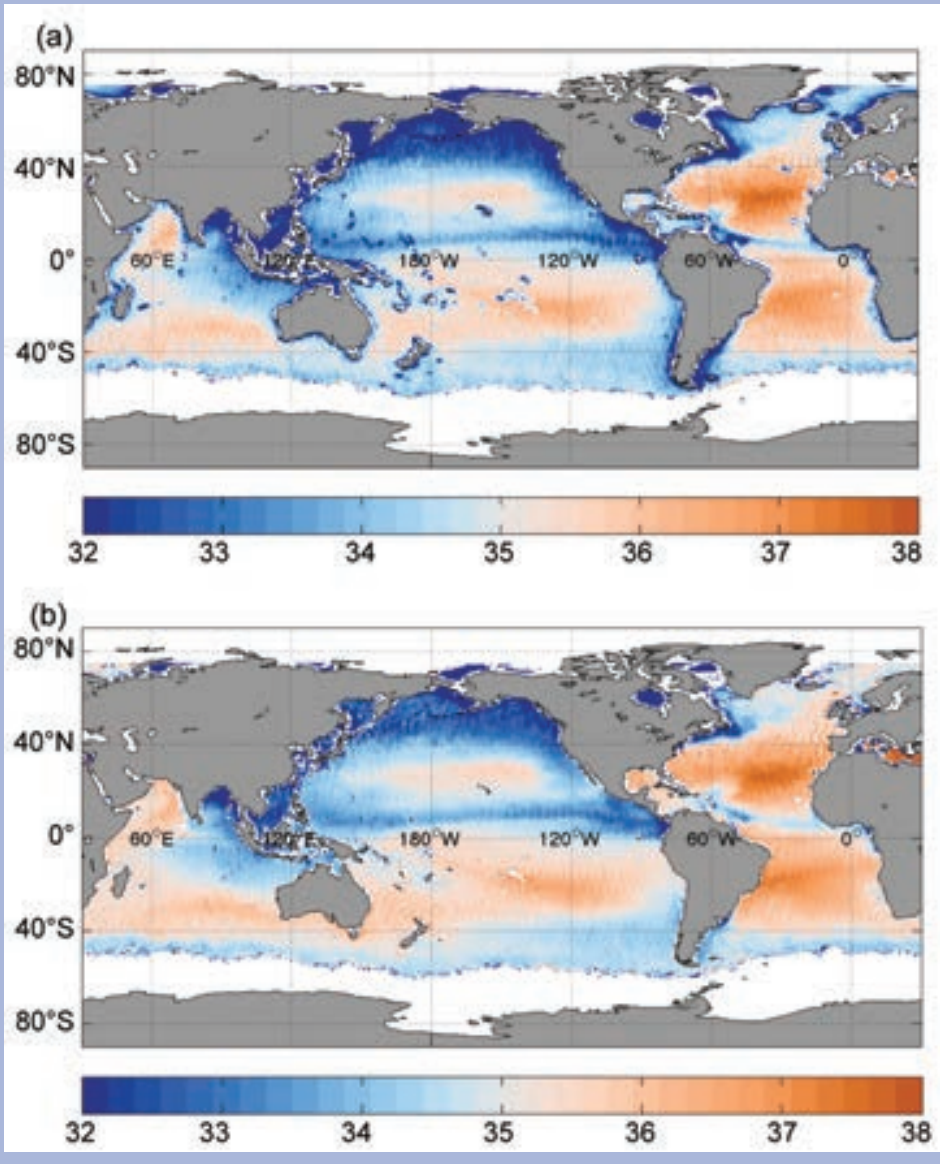

Fig. SB3.I. (a) Mean global map of the first four months (Sep-Dec 20II) of Aquarius satellite sea surface salinity (PSS-78) measurements omitting a land correction (see text) near coastlines and using an optimized combined active-passive algorithm of Yueh and Chaubell (20I2). (b) Same as (a) but with the land correction applied, and using the present roughness correction that combines NCEP operational analysis winds and Aquarius scatterometer data. Data are interpolated to $0.5^{\circ}$ grid resolution, and Aquarius data have a $150-\mathbf{k m}$ smoothing scale applied. ocean's surface microwave emission at $1.413 \mathrm{GHz}$ (in the L-band portion of the spectrum protected for radio astronomy). This emission is modulated by the electrical conductivity of seawater, hence salinity, of the top few $\mathrm{cm}$. Aquarius also measures radar backscatter at $1.26 \mathrm{GHz}$, to mitigate the emission variations due to surface roughness (Yueh et al. 2010; Le Vine et al. 2007), the largest error source in the salinity retrieval. Aquarius provides seven-day global coverage and is designed to achieve a monthly average global root-mean-square (rms) measurement error less than 0.2 (PSS-78) at $150-\mathrm{km}$ resolution (Lagerloef et al. 2008).

Aquarius composite four-month mean (SeptemberDecember 20II) global SSS maps, using two experimental processing algorithms (Figs. S3.Ia.b), differ mainly in the inclusion of the land correction and also in their methods of surface roughness correction. The size of the Aquarius footprint limits the accuracy for measurements close to coastal boundaries where the land emission adds a negative bias for which a land correction has been developed. The data without the correction (Fig. SB3.2a) exhibit a spurious low-salinity shadow along 
the continental boundaries that is absent in the image with the correction applied (Fig. SB3.2b). This land correction appears to be effective and will continue to be studied and improved. Both the land and roughness corrections in Fig. SB3.2b are part of the present baseline data processing. Subtle differences between these images in the ocean interior, far from the coast, are associated with a slight difference in roughness correction. Data where wind speed is greater than $15 \mathrm{~m} \mathrm{~s}^{-1}$ and SST is less than $5^{\circ} \mathrm{C}$ have been ignored in these figures because the SSS retrievals are not yet reliable under those conditions.

An SSS map derived from Argo data for the same fourmonth period (Fig. SB3.2a), objectively analyzed as described in section 3e shows the same predominant large-scale and wellknown climatological ocean salinity features that can be seen in both Aquarius maps. These features include higher salinity in the subtropics versus lower salinity in high-precipitation belts near the equator and at high latitudes, an Atlantic Ocean that is generally saltier than the Pacific, as well as the striking saltyfresh contrast between the Arabian Sea and the Bay of Bengal.

Differences between the Aquarius and Argo maps (Fig. SB3.2b) highlight some important features. The Aquarius Southern Ocean SSS values are biased high relative to the Argo fields. This bias is actively under study, and is partly associated with high winds and low surface temperatures that complicate the retrieval processing. In the tropics, however, the Aquarius data reveal important details at spatial and temporal scales that Argo does not resolve, such as prominent low-salinity water associated with outflow from the Amazon and Orinoco Rivers, and the sharper and better-defined SSS gradients around the intertropical convergence zones (ITCZ) of both the Atlantic and Pacific. In addition, the shallowest salinity measurements for most Argo floats, often between $4 \mathrm{~m}$ and $10 \mathrm{~m}$, may miss surface-intensified, highly-stratified fresh pools from precipitation and river outflows found in low wind conditions. The two data sources are highly complementary, with Argo data vital for analyzing and correcting biases in Aquarius SSS data and
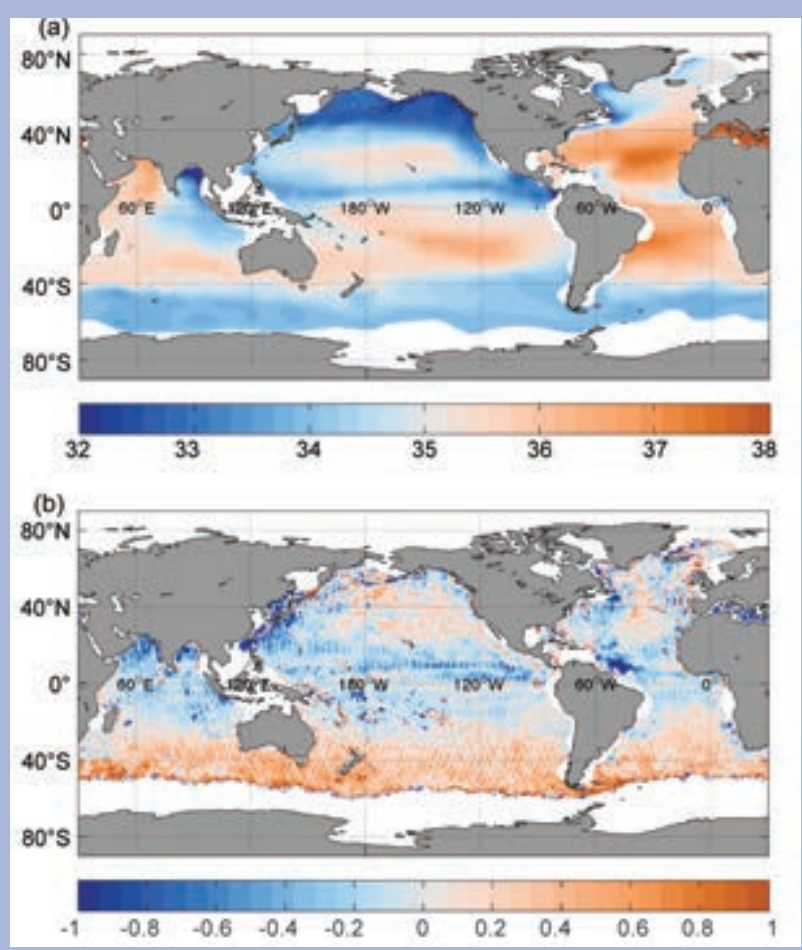

FIG. SB3.2. (a) Objectively analyzed Argo SSS for the same four-month period as Fig. SB3.I. (b) The difference between the Aquarius data in Fig. SB3.Ib minus the Argo map in (a). Crosshatch patterns are parallel to the orbit path and are attributed to small residual calibration differences that are currently under investigation.

Aquarius data resolving temporal and spatial SSS variability missed by Argo.

A seven-day composite of Aquarius SSS with current vectors overlaid across most of the North Pacific ITCZ (Fig. SB3.3) illustrates the close relation between surface currents (Dohan and Maximenko 2010) and SSS patterns associated with the narrow, meandering, eastward-flowing North Equatorial Counter Current (NECC). Such newly resolved detail of SSS, not as evident from

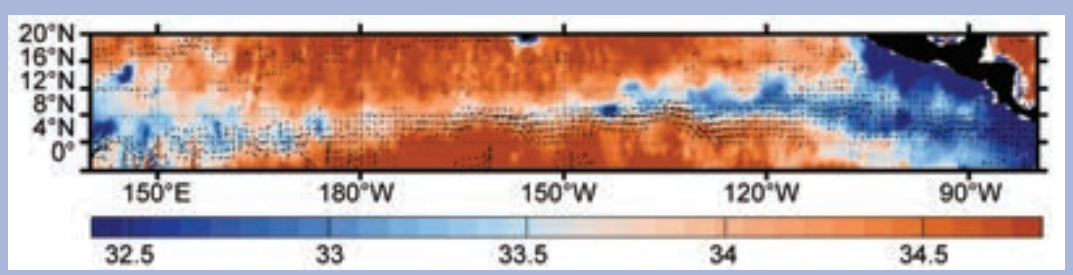

FIG. SB3.3. A 7-day (29 Aug-04 Sep) snapshot of a portion of the Pacific low salinity region within the ITCZ showing small-scale salinity structure related to surface current meanders and eddies. Aquarius data are interpolated to $0.33^{\circ}$-grid resolution, surface currents are $1^{\circ}$ resolution. spatially smoother SSS maps constructed from in situ data alone, will allow new insights about the interactions among net air-sea freshwater flux, ocean currents, and SSS. Unvalidated Aquarius data are presently available for evaluation, and the first validated data will be released in December 2012. 


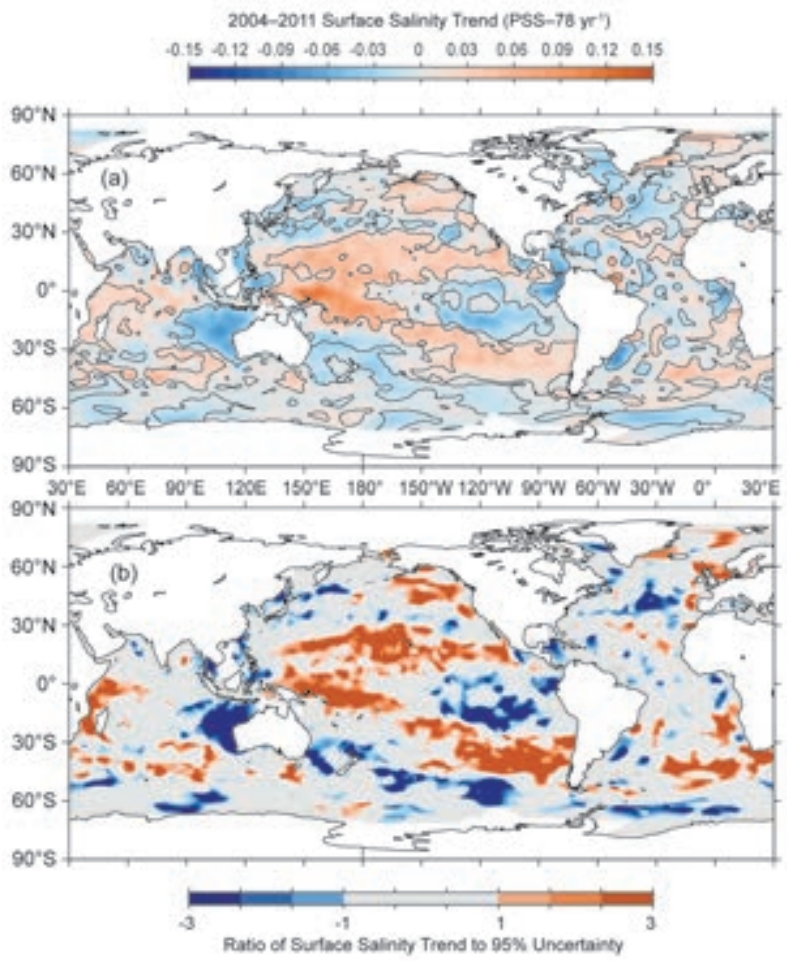

FIG. 3.13. (a) Map of local linear trends estimated from annual surface salinity anomalies for 2004-II from Argo data (colors in PSS-78 $\mathrm{yr}^{-1}$ ). (b) Signed ratio of the linear trend to its $95 \%$ uncertainty estimate, with increasing color intensity showing regions with increasingly statistically significant trends. White ocean areas are too data-poor to map.

f. Subsurface salinity-T. Boyer, S. Levitus, J. Antonov, J. Reagan, C. Schmid, and R. Locarnini

Mixed layer salinity and evaporation minus precipitation (E-P) are well correlated in many parts of the world's oceans (Yu 2011). Since E-P is difficult to accurately measure over the ocean, it has been proposed that near-surface salinity could be used to constrain $\mathrm{E}-\mathrm{P}$ estimates, acting as a sort of rain gauge (Schmitt 2008; Yu 2011). Durack and Wijffels (2010) have shown that E-P surface forcing has led to an intensification of the global hydrological cycle over the last 50 years, exemplified by increasing salinity at the sea surface in areas dominated by evaporation and decreasing surface salinity in areas dominated by precipitation. These surface-forced changes extend to subsurface levels. Globally-averaged near-surface waters have increased in salt content in recent times compared to long-term means, while intermediate waters have decreased in salt content (Roemmich and Gilson 2009; Helm et al. 2010). These changes can have major implications for water mass composition and circulation patterns. Investigating interannual and long-term variability of subsurface salinity, in conjunction with sea surface salinity (SSS) and surface fluxes, can improve understanding not only of changes in the ocean, but also changes in the atmosphere affecting the global climate system.

The method used to investigate changes to subsurface salinity was to use all available subsurface ocean salinity profile data for year 2011 and construct $1^{\circ}$ gridded fields of salinity anomalies at different depths from these data for comparison with similarly calculated fields from 2010 and the long-term mean salinity field. The majority of data used in this analysis are from the Argo profiling float program (Roemmich et al. 2009). For 2011, 121414 Argo salinity profiles were recorded, the majority of which extend from the near surface to 2000-m depth. The geographic distribution of these data includes most of the ice-free ocean with bottom depth deeper than $2000 \mathrm{~m}$. Only 14682 of these profiles have yet undergone rigorous Argo scientific quality control because at least six months of data from the same Argo float subsequent to a profile's date are needed for proper drift analysis. However, more than half of the nondelayed mode (real-time) data were adjusted, if necessary, based on knowledge of the salinity drift for a float that was obtained during the scientific quality control done on earlier float cycles. In addition to the Argo data, 32662 profiles of daily averaged salinity at different depths down to $750 \mathrm{~m}$ from the TAO/ TRITON (Pacific), PIRATA (Atlantic), and RAMA (Indian) Equatorial Ocean moored buoy arrays were included. A total of 10274 real-time ship-based on conductivity temperature depth (CTD) salinity profiles, obtained through the Global Temperature and Salinity Profile Project (GTSPP), were also used in this analysis. Data from a few additional cruises were provided by the International Council for the Exploration of the Seas (ICES), the CLIVAR program, and the New Zealand Ministry of Fisheries. A final contribution to the analysis is 30825 salinity profiles from gliders, also obtained through GTSPP. These glider data are regional, with many profiles in a limited area over a short time period. However, the geographic regions are diverse: the western North Pacific Ocean, around Australia, the Mediterranean Sea, tropical Atlantic Ocean, Gulf of Mexico, and coastal North Pacific Ocean. Additional scientific quality control was performed on all salinity and salinity anomaly data as per Boyer et al. (2009). Data from 2010 were reanalyzed to account for the increased number of delayed mode Argo data (52 124 of 112642 profiles) and additional CTD data (4439 profiles). The 2010 fields 
did not change significantly with regards to largescale patterns from the fields used in the 2010 State of the Climate analysis (Levitus et al. 2011). All data and quality control flags used in the present analysis are available through the World Ocean Database (Boyer et al. 2009). All calculated fields are available at http:// www.nodc.noaa.gov/OC5/3M_HEAT_CONTENT/.

The above described salinity data were analyzed as follows: Individual profiles of observed salinity were interpolated to 26 standard levels from the surface to 2000-m depth. Each standard level value was subtracted from the appropriate World Ocean Atlas (WOA; Antonov et al. 2010) long-term mean monthly salinity value for the $1^{\circ}$ geographic grid box in which the salinity profile was taken. This removes the annual salinity cycle, leaving salinity anomaly profiles relative to the long-term mean. Salinity anomalies were bin averaged over the $1^{\circ}$ grid boxes for each standard depth. The binned mean salinity anomalies are then objectively analyzed (Antonov et al. 2010) to generate a salinity anomaly value for each $1^{\circ}$ ocean grid box at each standard depth from the surface to $2000 \mathrm{~m}$, or the ocean bottom, whichever is encountered first. The 12 analyzed monthly salinity anomaly fields are averaged at each standard depth to produce an annual mean salinity anomaly field on a $1^{\circ}$ global field for each depth level. This process is followed for years 2010 and 2011 . The gridded $1^{\circ}$ mean anomalies were averaged along each $1^{\circ}$ latitude belt separately for the Atlantic, Pacific, and Indian Oceans. Zonal mean salinity anomalies for 2011 compared with the long-term mean are shown along with the zonal mean difference between salinity for 2011 and 2010. The latter give an indication of interannual change between the two years, while the former provides the context via a comparison with long-term salinity change patterns. A Student's $t$ test was performed on all zonal mean anomalies at each standard depth. The mean anomalies are significant for all values $>0.1$ (red and blue shading in Fig. 3.14) at the 99\% level. For comparison with SSS and to understand upper ocean salinity in more detail, analyzed salinity anomaly values at each depth level in the upper $100 \mathrm{~m}$ for each $1^{\circ}$ grid box were averaged using volume weighting to give a mean salinity anomaly for the upper $100 \mathrm{~m}$. This mean salinity anomaly of the upper 100 meters exhibits the same large-scale patterns of positive and negative salinity anomaly as Fig. 3.12a, with reduced amplitude.

The Pacific Ocean zonal mean salinity difference between 2011 and the long-term mean (Fig. 3.14a) reveals long-term freshening of the water column of the southern high latitudes (e.g., Böning et al. 2008) to depths $>1000 \mathrm{~m}$ and as far north as $35^{\circ} \mathrm{S}$. Meijers et al. (2011) attribute the freshening in this area to southward movement of the Antarctic Circumpolar Current and water mass changes possibly due to increased precipitation and ice melt. There was little change in the salinity anomaly in this region from 2009 to 2010 (Levitus et al. 2011) and an increase in salinity near $60^{\circ} \mathrm{S}$ from 2010 to 2011 (Fig. 3.14b) illustrates the year-to-year variability about the long-term trend. The increased salinity in the upper $200 \mathrm{~m}$ between $40^{\circ} \mathrm{S}$ and the equator, interrupted by a band of freshening between $20^{\circ} \mathrm{S}$ and $10^{\circ} \mathrm{S}$, evident in the 2011 salinity anomaly compared with the long-term mean was reinforced from 2010 to 2011, with the exception of the near surface (upper $50 \mathrm{~m}$ ) salinity north of $10^{\circ} \mathrm{S}$. Figure 3.12a (in section 3e) shows that the reason for this banding is, generally, salinification in the top $100 \mathrm{~m}$ in the western South Pacific and freshening in the eastern South Pacific from $40^{\circ} \mathrm{S}$ to the equator, with the freshening in the east weaker except in the area $20^{\circ} \mathrm{S}$ to $10^{\circ} \mathrm{S}$. Figure $3.12 \mathrm{a}$ also shows very strong salinification under the SPCZ which intensified from 2010 to 2011, with salinification $>0.1$ to depths of $400 \mathrm{~m}$. This interannual change effectively counters the pattern of subsurface freshening propagating from the south seen between 2009 and 2010. In both

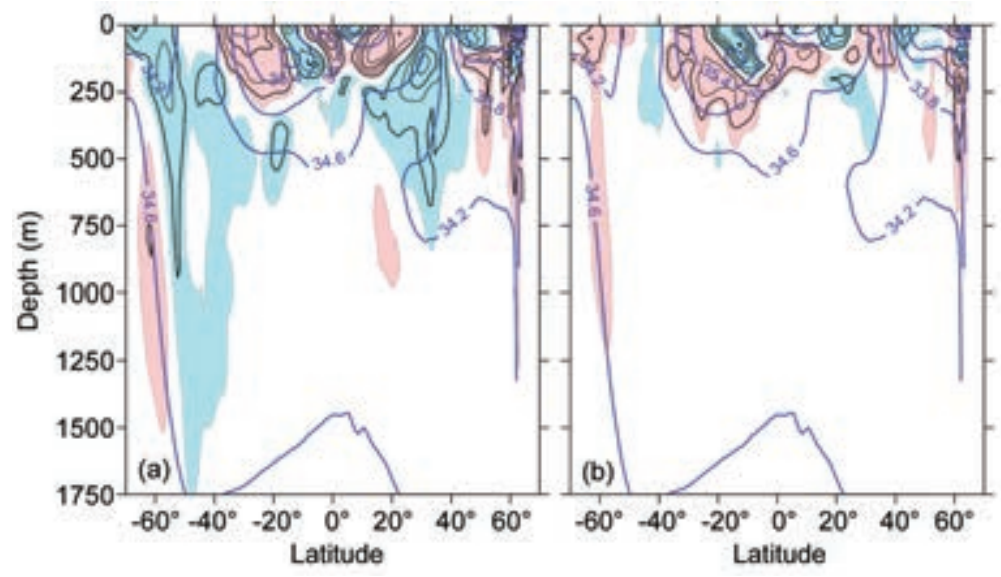

FIG. 3.14. Zonally averaged (a) $201 \mathrm{I}$ salinity anomaly and (b) $201 \mathrm{I} \mathrm{mi-}$ nus 2010 salinity field for the Pacific Ocean. Blue shading represents negative (fresh) anomalies <-0.I, red shading represents positive (salty) anomalies $>0.1$. The contour interval for the anomalies is $\mathbf{0 . 2}$. In the background of each figure (thick blue contours) is the zonally averaged climatological mean salinity (Antonov et al. 2010). Contour intervals for the background are 0.4. All values are on the PSS. 
2010 and 2011, the North Pacific was saltier in the upper $200 \mathrm{~m}$ than the long-term average between $20^{\circ} \mathrm{N}$ and $30^{\circ} \mathrm{N}$ (Fig. 3.14a; Levitus et al. 2011), counter to the trend shown in Boyer et al. (2005) for 1955 to 1998 , and it was fresher in the main thermocline for the subtropics down to $600 \mathrm{~m}$. The latter is a continuation of the trend described in Ren and Riser (2010). Except for changes in the high southern latitudes, differences between 2010 and 2011 in the Pacific were $>0.2$, mainly in the upper $300 \mathrm{~m}$ of the water column. The salinity changes from 2009 to 2010 in the Pacific were also confined to the upper $300 \mathrm{~m}$ (Levitus et al. 2011).

An increase of salinity in the subtropical and tropical North Atlantic and a decrease in salinity in the subpo-
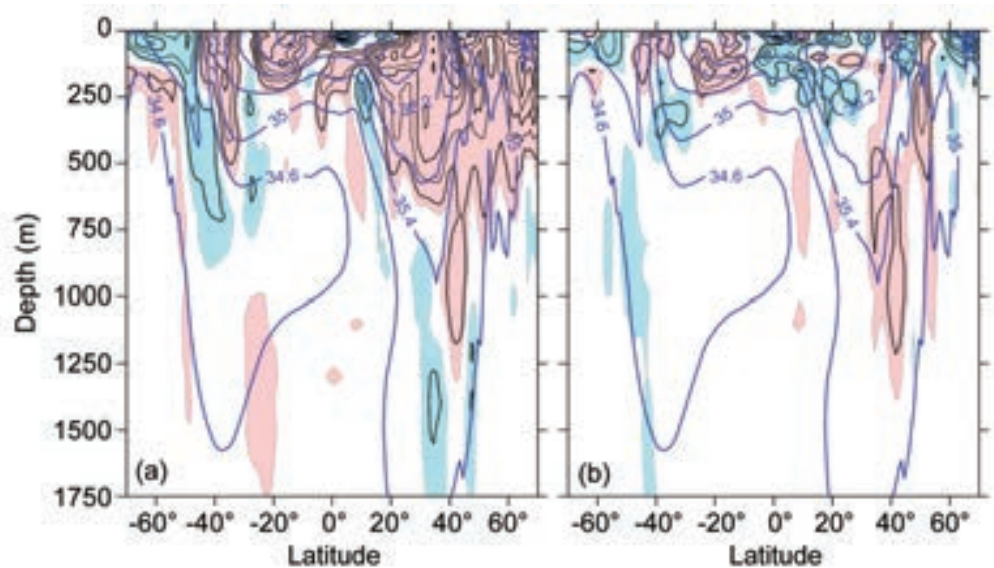

FIG. 3.15. Zonally averaged (a) $201 \mathrm{I}$ salinity anomaly and (b) $20 \mathrm{II} \mathrm{mi-}$ nus 2010 salinity field for the Atlantic Ocean. Blue shading represents negative (fresh) anomalies <-0.1, red shading represents positive (salty) anomalies $>\mathbf{0 . 1}$. The contour interval for the anomalies is $\mathbf{0 . 2}$. In the background of each figure (thick blue contours) is the zonally averaged climatogical mean salinity (Antonov et al. 2010). Contour intervals for the background are 0.4. All values are on the PSS.

lar North Atlantic has been described

from the mid-1950s through the mid-1990s (Curry et al. 2003; Boyer et al. 2007; Wang et al. 2010). More recently, both the subpolar North Atlantic and the subtropic North Atlantic have become saltier (Boyer et al. 2007; Wang et al. 2010). The 2011 analysis (Fig. 3.15a) is consistent with these patterns. The 2011 Atlantic zonal mean salinity anomalies exhibit deep $(>500 \mathrm{~m}$ ) large-scale increases $(>0.2)$ in salinity over most of the North Atlantic compared with the longterm mean. In the South Atlantic, salinification is confined mainly north of $40^{\circ} \mathrm{S}$, deeper than $400 \mathrm{~m}$ to $30^{\circ} \mathrm{S}$, reaching only to $200 \mathrm{~m}$ from that latitude to the equator. Freshening to depths $>500 \mathrm{~m}$ is found in the Atlantic, similar to the Pacific, south of $40^{\circ} \mathrm{S}$. The near-surface signature of this freshening is stronger in the Atlantic than the Pacific in the high southern latitudes. The zonal mean salinity for 2011 minus 2010 shows a general year-to-year freshening across much of the Atlantic in the upper 100 m (Fig. 3.15b). Figure 3.12, section 3e, reveals a more patchy distribution of small positive and negative anomalies between the two years, with general freshening along the equator and in the western North Atlantic. The freshening along the equator extends to 300 $\mathrm{m}$. Deeper down, the larger freshening that occurred between 2009 and 2010 to $1000 \mathrm{~m}, 30^{\circ} \mathrm{N}$ to $40^{\circ} \mathrm{N}$ (Levitus et al. 2011), reversed in 2010 to 2011, with salinification $>0.2$ from $500 \mathrm{~m}$ to $>1000 \mathrm{~m}$ in this area.

In the Indian Ocean, mean zonal salinity anomalies for 2011 (Fig. 3.16a) for the high southern latitudes $\left(>45^{\circ} \mathrm{S}\right)$ were fresher from the surface to $>1000 \mathrm{~m}$ than the long-term mean, except for latitudes farther south of $60^{\circ} \mathrm{S}$, which were fresher only in the upper $100 \mathrm{~m}$ of the water column, and more saline at deeper levels. This is the same pattern seen in the Pacific
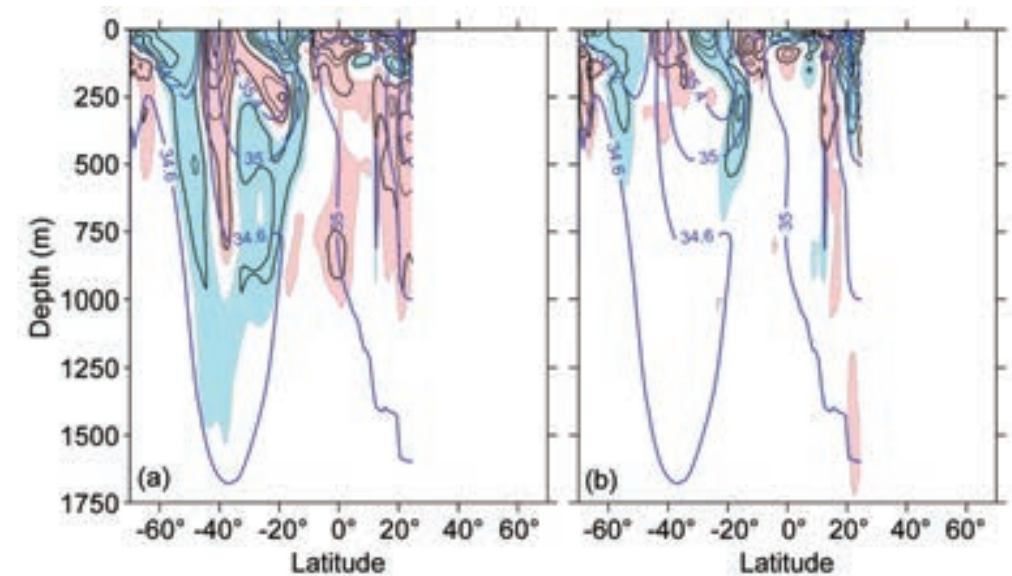

FIG. 3.16. Zonally averaged (a) $201 \mathrm{I}$ salinity anomaly and (b) $201 \mathrm{I} \mathrm{mi-}$ nus 2010 salinity field for the Indian Ocean. Blue shading represents negative (fresh) anomalies $<-\mathbf{0 . I}$, red shading represents positive (salty) anomalies $>0.1$. The contour interval for the anomalies is $\mathbf{0 . 2}$. In the background of each figure (thick blue contours) is the zonally averaged climatogical mean salinity (Antonov et al. 2010). Contour intervals for the background are 0.4. All values are on the PSS. 
and Atlantic basins as well. The Indian Ocean was also fresher in the upper $200 \mathrm{~m}$ from $30^{\circ} \mathrm{S}$ to $10^{\circ} \mathrm{S}$, and from $300 \mathrm{~m}$ to $1000 \mathrm{~m}$ in roughly the same latitude span. The latitude band from $45^{\circ} \mathrm{S}$ to $30^{\circ} \mathrm{S}$ was more saline down to $700 \mathrm{~m}$, with a subsurface extension northward to almost $10^{\circ} \mathrm{S}$ that reaches as deep as $300 \mathrm{~m}$. North of $10^{\circ} \mathrm{S}$, most of the water column is more saline than the long-term mean. Much of the freshening in the Indian Ocean, outside high southern latitudes, is in the eastern Indian extending westward from the west coast of Australia (see Fig. 3.12). Comparing 2011 to 2010 (Fig. 3.16b), the freshening in the band $15^{\circ} \mathrm{S}-35^{\circ} \mathrm{S}$ was more intense between the two years than between 2009 and 2010 (Levitus et al. 2011), to depths of $500 \mathrm{~m}$. In the western Indian Ocean, there was a large $(>0.2)$ increase in salinity from $20^{\circ} \mathrm{S}$ to the equator which is confined to the upper $200 \mathrm{~m}$. In the North Indian Ocean, the eastern Arabian Sea and eastern Bay of Bengal were fresher compared to the year before (Fig. 3.12), with this freshening dominating the zonal mean salinity anomalies down to $400 \mathrm{~m}$.

\section{g. Surface currents-R. Lumpkin, G. Goni, and K. Dohan}

This section describes ocean surface current changes, transports derived from ocean surface currents, and features such as rings inferred from surface currents. Surface currents are obtained from in situ and satellite (altimetry and wind) observations.

Near-surface currents are measured in situ by drogued satellite-tracked drifting buoys and by current meters on moored buoys (see Appendix 2 for specific dataset information). During 2011, the drifter array ranged in size from a minimum of 352 drogued buoys to a maximum of 576 , with a median size of 416 drogued drifters (undrogued drifters continue to measure SST, but are subject to significant wind slippage; Niiler et al. 1987). The moored array included 36 buoys with current meters, all between $16^{\circ} \mathrm{S}$ and $21^{\circ} \mathrm{N}$. These tropical moorings compose the TAO/ TRITON (Pacific; 16 buoys with current meters reporting in 2012), PIRATA (Atlantic; 6 buoys) and RAMA (Indian; 14 buoys) arrays.

Global fields of ocean currents are estimated using two methodologies, both using the AVISO Ssalto/ Duacs multimission altimeter near-real time gridded product. The first is a synthesis of AVISO with in situ drifter measurements and reanalysis winds (Niiler et al. 2003), which adjusts the altimeter-derived geostrophic velocity anomalies to match the observed in situ eddy kinetic energy. The second is the purely satellite-based OSCAR (Ocean Surface Current Analyses-Real time) product, which uses AVISO altimetry, winds, SST, and the Rio05 mean dynamic topography (Rio and Hernandez 2004) to create $1 / 3^{\circ}$-resolution surface current maps averaged over the $0 \mathrm{~m}-30 \mathrm{~m}$ layer of the ocean (Bonjean and Lagerloef 2002). In both cases, anomalies are calculated with respect to the time period 1992-2007. Ocean transports are derived from a combination of sea height anomaly (from altimetry) and climatological hydrography.

Global zonal current anomalies and changes in anomalies from 2010 are shown in Fig. 3.17 and discussed below for individual ocean basins.

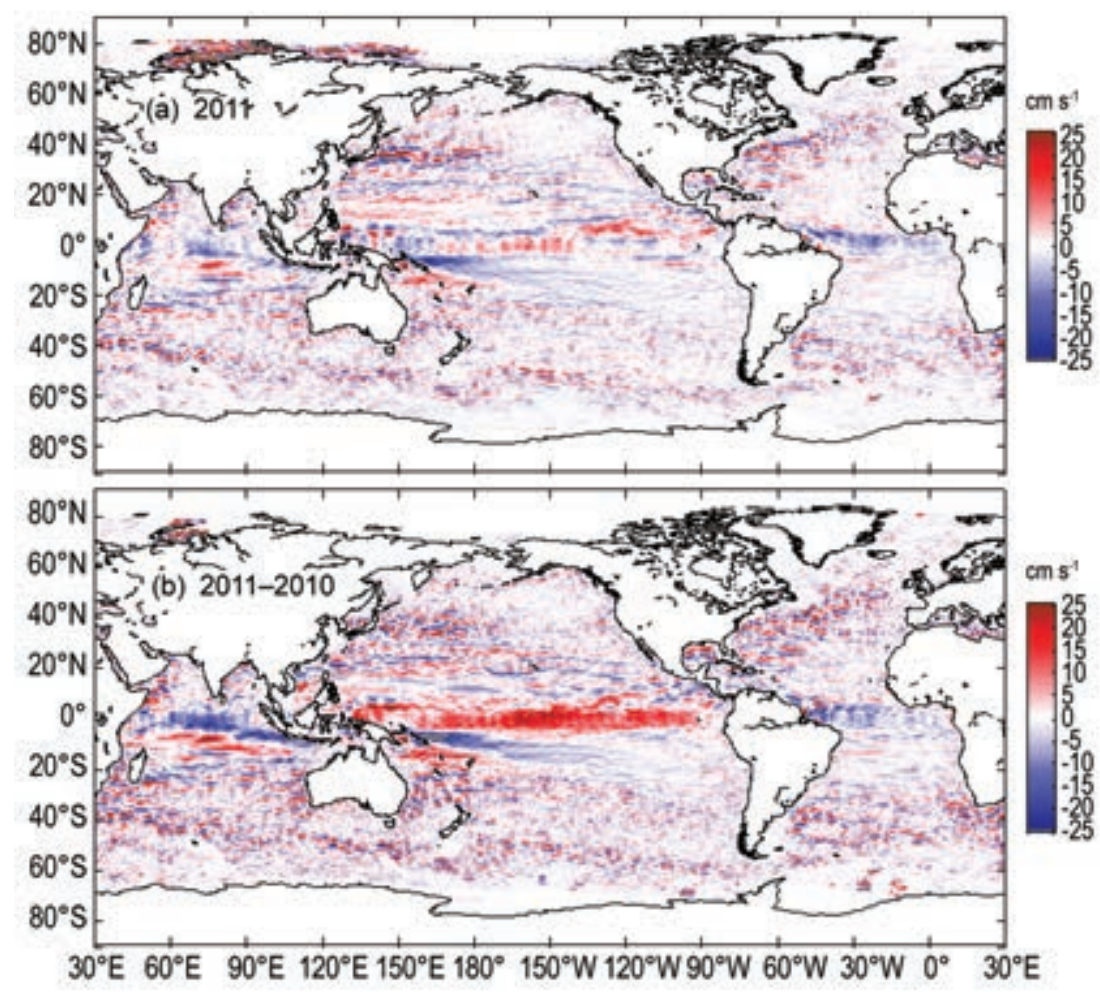

Fig. 3.17. Global zonal geostrophic anomalies (cm s-1) for (a) 2011 and (b) $201 \mathrm{I}$ minus 2010 derived from a synthesis of drifters, altimetry, and winds. 


\section{I) Pacific Ocean}

In the tropical Pacific, 2011 began with surface currents near their climatological January values. This changed dramatically by February, however, with eastward anomalies developing from the South American coast to $\sim 170^{\circ} \mathrm{W}$, with maxima of 30 $\mathrm{cm} \mathrm{s}^{-1}-40 \mathrm{~cm} \mathrm{~s}^{-1}$ in the band $100^{\circ} \mathrm{W}-150^{\circ} \mathrm{W}$. By March, the eastward equatorial anomalies spanned the basin. They persisted in strength in April, and then weakened quickly in May. By June, large-scale surface currents had returned to their climatological values. During the peak of this event in March-April, eastward anomalies peaked at $30 \mathrm{~cm} \mathrm{~s}^{-1}-40 \mathrm{~cm} \mathrm{~s}^{-1}$ at $110^{\circ} \mathrm{W}$ to $170^{\circ} \mathrm{E}$. These surface current anomalies, with their associated advection of warm SST, acted to quickly erase the La Niña (cold) SST anomalies in the eastern tropical Pacific that had persisted since 2010 (Fig. 3.18; see also section 3b), yielding near-neutral values for the Niño 3, 3.4, and 4 indices by midyear.

In July 2011, westward equatorial anomalies of 10 $\mathrm{cm} \mathrm{s}^{-1}-20 \mathrm{~cm} \mathrm{~s}^{-1}$ began developing at $110^{\circ} \mathrm{W}-160^{\circ} \mathrm{W}$. This anomalous pattern expanded westward through August and September, at which point westward anomalies of $15 \mathrm{~cm} \mathrm{~s}^{-1}-20 \mathrm{~cm} \mathrm{~s}^{-1}$ were seen from $\sim 100^{\circ} \mathrm{W}$ to the western edge of the basin. By October, the pattern began weakening in the band $160^{\circ} \mathrm{W}-$ $170^{\circ} \mathrm{E}$, and by November the pattern was much patchier, with westward anomalies dominant only in the band $90^{\circ} \mathrm{W}-160^{\circ} \mathrm{W}$. In December, westward
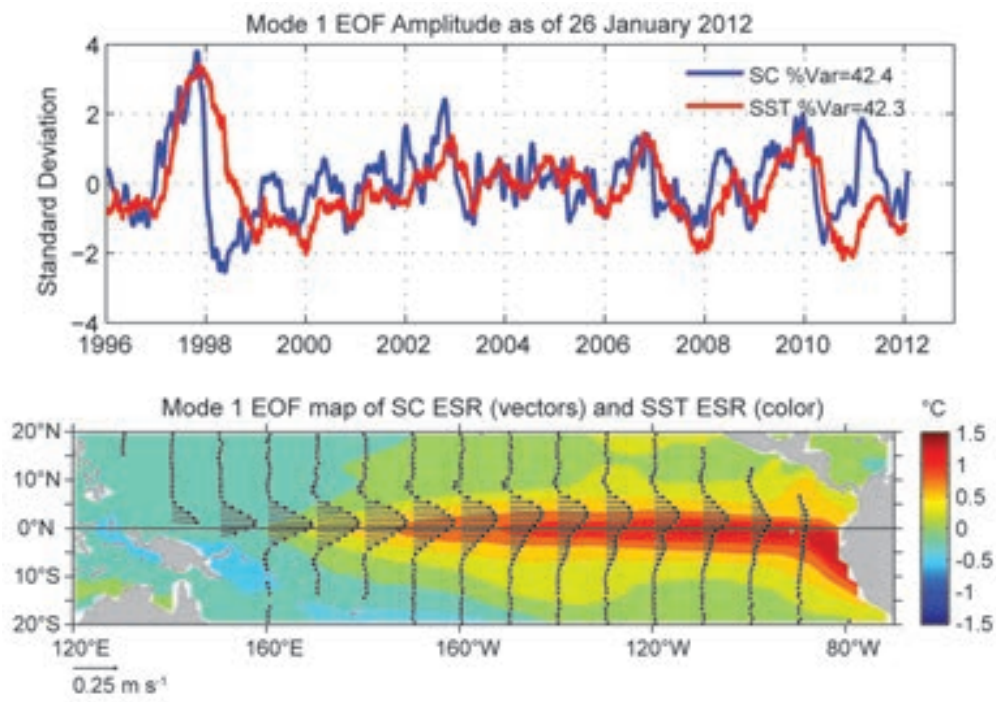

Fig. 3.18. Principal empirical orthogonal functions (EOF) of surface current (SC) and SST anomaly variations in the tropical Pacific from the OSCAR model. (Top) Amplitude time series of the EOFs normalized by their respective standard deviations. (Bottom) Spatial structures of the EOFs. anomalies of $15 \mathrm{~cm} \mathrm{~s}^{-1}-25 \mathrm{~cm} \mathrm{~s}^{-1}$ again developed in the western Pacific, in the band $130^{\circ} \mathrm{W}-160^{\circ} \mathrm{E}$.

Because of the alternating signs of zonal current anomalies in early vs. late 2011 , annual mean zonal anomalies (Fig. 3.17) are not as dramatic as they were in 2010 (a predominantly La Niña year for zonal current anomalies). The 2010 anomalies dominate 2011 minus 2010 (Fig. 3.17b).

Surface current anomalies in the equatorial $\mathrm{Pa}$ cific typically lead SST anomalies by several months, with a magnitude that scales with the SST anomaly magnitude. Recovery to normal current conditions is also typically seen before SST returns to normal. Thus, current anomalies in this region are a valuable predictor of the evolution of SST anomalies and their related climate impacts. This leading nature can be seen clearly in the first principal empirical orthogonal function (EOF) of surface current (SC) anomaly and separately of SST anomaly in the tropical Pacific basin (Fig. 3.18). In the altimetry time period 1993-2011, the maximum correlation between SC and SST is $\mathrm{R}=0.68$ with SC leading SST by 81.1 days. In 2011, the most dramatic feature of this mode was the extremely rapid change in the SC anomaly from negative values in late 2010 to El Niño-like (positive) values in early 2011. This switch in the sign of the SC anomaly happened as the SST anomaly reached its strongest negative value (Fig. 3.18); for the next few months, while the SC anomaly remained positive, the negative SST anomaly decreased in magnitude. In the latter half of 2011, the SC anomaly returned to neutral-to-La Niña-like (negative) values, leading the return of cold SST anomalies by several months (Fig. 3.18). It is interesting to note that, unlike earlier years, a positive SST anomaly did not follow the positive SC anomaly in early 2011; this is likely due to the extreme magnitude of the 2010 La Niña SST anomaly (the most negative value in this time series) and the relatively brief duration of the positive SC anomaly in 2011.

In the State of the Climate in 2010, it was noted that the Kuroshio exhibited a narrower and stronger annual mean signature, and shifted approximately $1^{\circ}$ in latitude to the north compared to 2006-09. This pattern continued through 2011, with no large-scale pattern in the 2011 minus 2010 difference (Fig. 3.17b) indicating a shift in 
the Kuroshio Extension latitude with respect to 2010 .

\section{2) INDIAN OCEAN}

In January 2011, westward equatorial anomalies of $\sim 20 \mathrm{~cm} \mathrm{~s}^{-1}$ were seen in the central Indian Ocean $\left(75^{\circ} \mathrm{E}-\right.$ $90^{\circ} \mathrm{E}$ ), north of a band of eastward anomalies at $50^{\circ} \mathrm{E}-100^{\circ} \mathrm{E}, 10^{\circ} \mathrm{S}$. The westward equatorial anomalies persisted through June, with the pattern shifting westward through this period. In July, eastward equatorial anomalies

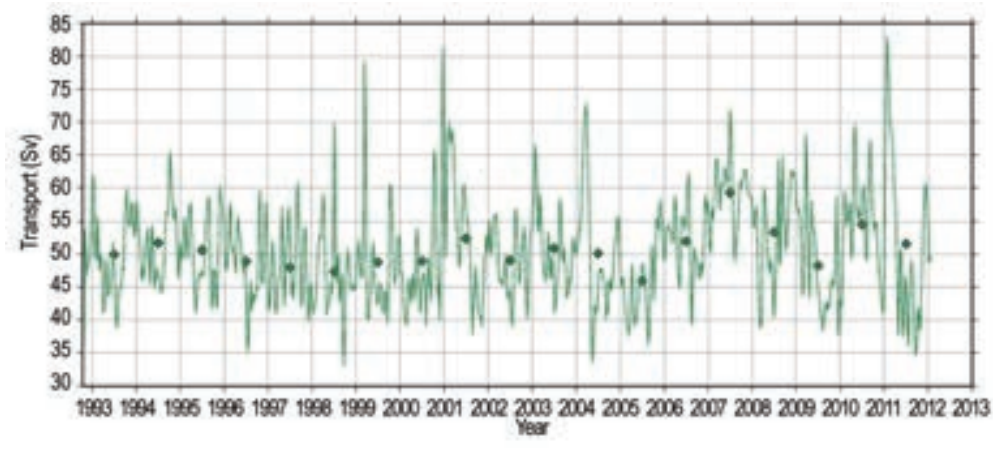

Fig. 3.19. Transport of the Agulhas Current from a combination of sea height anomaly and climatological hydrography (http://www.aoml. noaa.gov/phod/altimetry/cvar/agu/index.php). of $10 \mathrm{~cm} \mathrm{~s}^{-1}-20 \mathrm{~cm} \mathrm{~s}^{-1}$ developed at

$60^{\circ} \mathrm{E}-85^{\circ} \mathrm{E}$; this pattern weakened and shifted to the west in August, and was extremely weak in September when westward equatorial anomalies again developed in the center of the basin. These anomalies developed in intensity through November, reaching peak values of $30 \mathrm{~cm} \mathrm{~s}^{-1}-40 \mathrm{~cm} \mathrm{~s}^{-1}$ in November at $65^{\circ} \mathrm{E}-75^{\circ} \mathrm{E}$. They then rapidly weakened, and December saw a return to near-normal climatological surface current values across the basin at large scales. In the annual mean (Fig. 3.17), westward anomalies dominated the basin in 2011, in contrast to the weak eastward anomalies of 2010.

The shedding of eddies from the Agulhas Current into the Atlantic basin as seen in altimetry remained at its climatological value. The transport of the Agulhas can be estimated by combining sea height anomaly and climatological hydrography; in 2011, the transport of the Agulhas decreased by $\sim 5 \mathrm{~Sv}$ (Sverdrup, equal to $10^{6} \mathrm{~m}^{3} \mathrm{~s}^{-1}$, a unit commonly used for ocean volume transports) with respect to the 2010 mean, with much weaker values seen for the second half of 2011 (Fig. 3.19). A dramatic, brief maximum of $84 \mathrm{~Sv}$ was observed at the beginning of 2011, exceeding all previous maxima observed since 1993.

\section{3) Atlantic Ocean}

In the first few months of 2011, the tropical Atlantic basin did not exhibit any basin-wide zonal surface current anomalies, although westward anomalies tended to dominate near the equatorial band east of $\sim 30^{\circ} \mathrm{W}$. Through boreal spring to summer, these relatively weak westward equatorial anomalies expanded across the basin. These anomalies persisted through September and October, and intensified in
November to $10 \mathrm{~cm} \mathrm{~s}^{-1}-20 \mathrm{~cm} \mathrm{~s}^{-1}$ at $20^{\circ} \mathrm{W}-30^{\circ} \mathrm{W}$. The overall annual mean anomaly (Fig. 3.17) was westward in 2011, similar to the 2010 pattern.

In the Gulf of Mexico, surface current speed anomalies of $30 \mathrm{~cm} \mathrm{~s}^{-1}-35 \mathrm{~cm} \mathrm{~s}^{-1}$ were present along and north of the climatological Loop Current path in 2011. An overall increase in the Loop Current strength is not likely, as the measured transport of the Florida Current between Florida and the Bahamas increased by less than 1 Sv between 2010 and 2011 (see section $3 \mathrm{~h}$ ). Thus, this pattern suggests that the Loop Current penetrated farther north on average during 2011.

The North Brazil Current, which sheds rings that carry waters from the South Atlantic Ocean into the North Atlantic, continued to exhibit anomalous behavior as reported in the State of the Climate in 2010 report (Fig. 3.20). Sea heights associated with the current and rings continued having the large values observed in 2010; and seven rings were identified to shed. Transport values of this current and its retroflection remained average during 2011.

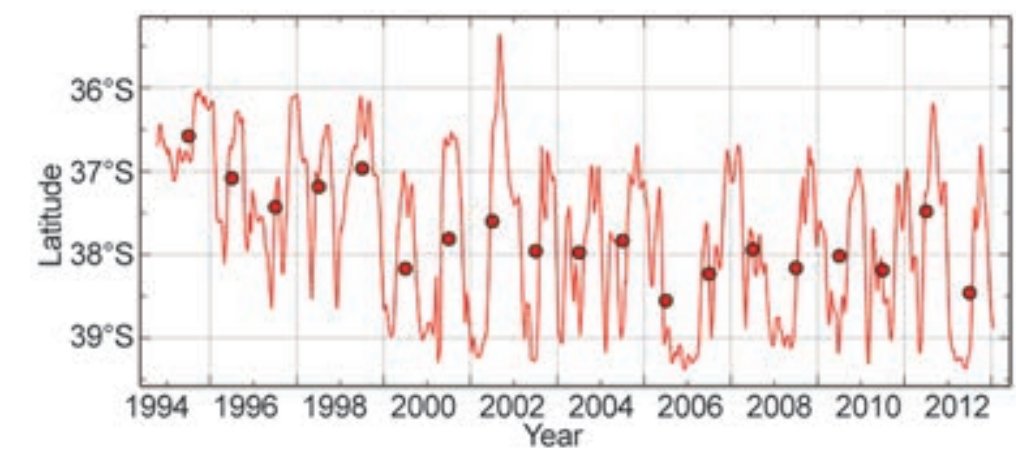

FIG. 3.20. Position of the Brazil-Malvinas front at its separation from the South American continental shelf break, resolved by the change in sea height across the front (http://www.aoml.noaa.gov/phod/altimetry/cvar/mal/BM_ts.php). The solid line is a 28-day running average; dots indicate annual averages. 
Against the east coast of South America, the southward-flowing warm, salty Brazil Current meets the northward flowing cold, fresh Malvinas Current to create the Confluence Front. During 2011, the separation of the front from the continental shelf break continued to exhibit annual periodicity driven by wind stress curl variations (cf., Goni and Wainer 2001). The annual mean position of the front in 2011 was $38.5^{\circ} \mathrm{S}$, a shift to the south from the $37.5^{\circ} \mathrm{S}$ position in 2010 . This location is as far south as the annually-averaged front has been seen since the launch of the TOPEX/ Poseidon altimeter in 1992, and was matched by only one other year (2004). Since 1992, the front has shifted significantly southward in response to wind stress curl changes driven by SST anomalies advected from the Indian Ocean (Lumpkin and Garzoli 2010; Goni et al. 2011).

h. Meridional overturning circulation observations in the subtropical North Atlantic-M. 0. Baringer, S. A. Cunningham, C. S. Meinen, S. Garzoli, J. Willis, M. Lankhorst,

A. Macdonald, U. Send, W. R. Hobbs, E. Frajka-Williams,

T. O. Kanzow, D. Rayner, W. E. Johns, and J. Marotzke

For several years, this section has reported on the meridional redistribution of mass associated with the large-scale vertical circulation within ocean known as the meridional overturning circulation (MOC). Here, the MOC is defined as the maximum of the vertically integrated basin-wide stream function, which changes as a function of latitude and time and is influenced by many physical systems embedded within it. It is related to the meridional transport of heat (MHT) in the oceans, although the relationship may not be direct and can vary with latitude; for example, where horizontal gyre circulation is strong, the heat transport can largely be ascribed to the wind-driven circulation. Variability in oceanic MHT can in turn contribute to heat storage, sea-level rise, and air-sea fluxes and hence influence local climate on land. Therefore, closing the ocean heat budget is a central area of study for understanding and predicting societally-relevant impacts from the oceans. Changes in MOC and MHT can be inferred from "fingerprint" changes in ocean temperature, sea-level rise, and changes in individual current systems (see Baringer et al. 2011 and previous State of the Climate reports for more discussion). This annual report focuses on the longest time series observations of ocean heat and mass transport currently available and what can be inferred from them about the current state of the MOC and MHT.

Recommendations for a coordinated observing system to begin to measure MOC were presented at the international conference OceanObs'09 in September 2009 (e.g., Cunningham et al. 2010; Rintoul et al. 2010) and subsequent planning workshops focused on expanding existing observations to include the subpolar North and South Atlantic (e.g., Garzoli et al. 2010). The most complete MOC observing system has been in place since April 2004, and spans the subtropical gyre in the North Atlantic near $26.5^{\circ} \mathrm{N}$. The system is composed of UK-NERC RAPID-WATCH moorings, US-NSF Meridional Overturning Circulation Heat-Transport Array (MOCHA), and the US-NOAA Western Boundary Time Series program (see also Rayner et al. 2010; Chidichimo et al. 2010).

The estimates of MOC from the $26.5^{\circ} \mathrm{N}$ array include data from April 2004 to December 2010 (see also Rayner et al. 2010), shown in Fig. 3.21. Over this

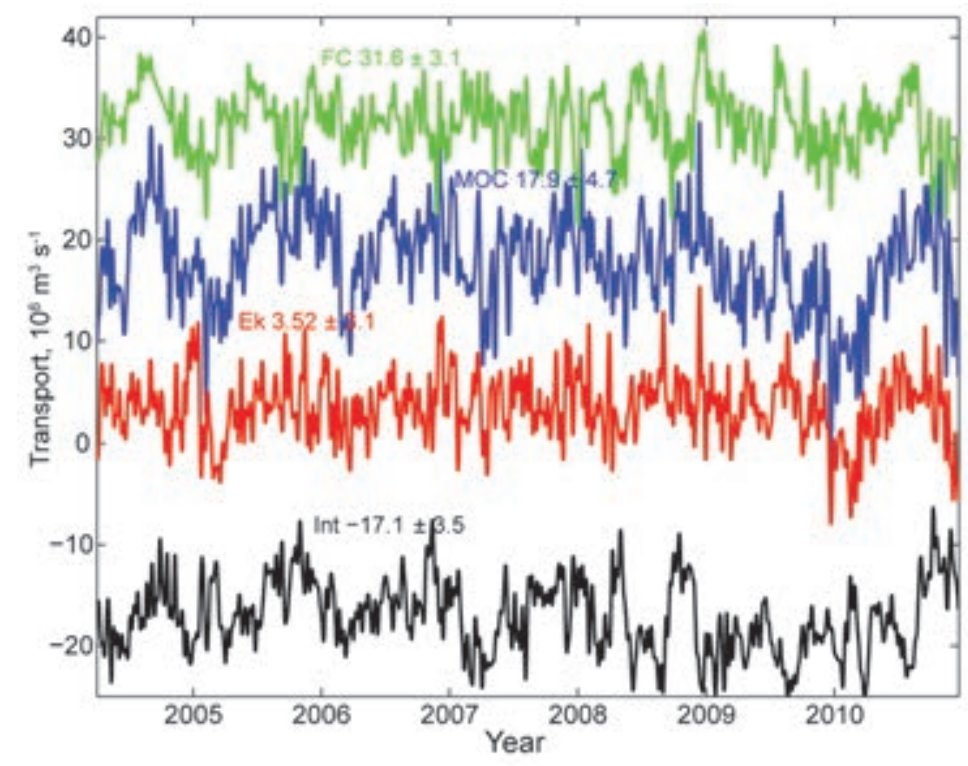

FIG. 3.2I. Daily estimates of the strength of the meridional overturning circulation (MOC; blue line) and its components, the Florida Current (FC; green), wind-driven Ekman transport (Ek; red), and the geostrophic interior (Int; black), as measured by the UK National Environmental Research Council Rapid Climate Change Program, the National Science Foundation's Meridional Overturning and Heat transport Array, and the NOAA Western Boundary Time Series Program. The interior volume transport estimate (accurate to I Sv, Cunningham et al. 2007) is based on the upper ocean transport from April 2004 to December 2010 (see also Rayner et al. 20I0; Kanzow et al. 2010), with a 10-day low pass filter applied to the daily transport values. 
time period, the MOC had a mean transport of 18.1 Sv with a high of $31.6 \mathrm{~Sv}$, a low of $-2.6 \mathrm{~Sv}$ in December 2009 and a standard deviation of $4.7 \mathrm{~Sv}$ (using the twice daily values filtered with a 10 -day cutoff as described in Cunningham et al. 2007). From early December 2009 through the end of April 2010, the MOC sustained low values with a mean of $9.8 \mathrm{~Sv}$. At the end of the time series in December 2010, the MOC was again relatively low, with a transport of about 13 Sv. These two low MOC "events" were produced by a combination of changes occurring on different time scales (e.g., short-term Ekman and Florida Current transport changes) and long-term changes in the southward geostrophic flow. Overall, the Florida Current and Ekman (EK) transport were about 2 Sv less northward than usual and the southward thermohaline circulation was about $2 \mathrm{~Sv}$ stronger, leading to a year-long anomaly of about $5 \mathrm{~Sv}-6 \mathrm{~Sv}$ in the MOC. With these two events present at the end of the multiyear time series, a linear regression of MOC versus time yields a decrease of $-6 \pm 0.3 \mathrm{~Sv}$ decade $^{-1}$ (95\% confidence). A linear trend estimated with the time series ending in December 2009 has a trend of only $-4.8 \mathrm{~Sv}$ decade ${ }^{-1}$. Baringer et al. (2011) reported an insignificant trend through April 2009 of $-0.8 \pm 1.6 \mathrm{~Sv}$ decade $^{-1}$. It is clear that 2010 was an unusual year for MOC transport across $26^{\circ} \mathrm{N}$, but given the large variability of MOC estimates, it would be imprudent to ascribe too much to the last year of values in determining a decadal trend. After six years of data, however, a clear seasonal signal is beginning

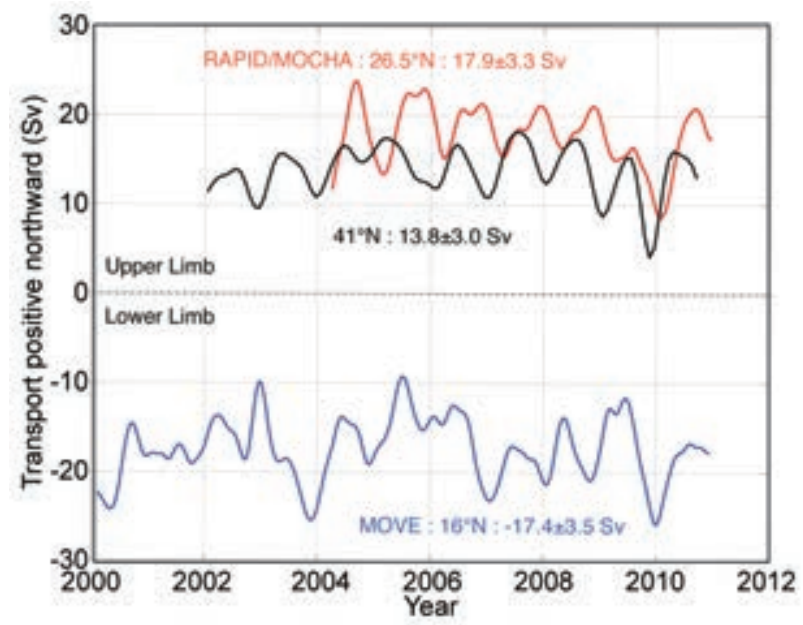

FIG. 3.22. Estimates of the MOC in the Atlantic Ocean from the Argo/Altimetry estimate at $4 I^{\circ} \mathrm{N}$ (black; Willis 2010), the Rapid/MOC/MOCHA/WBTS $26^{\circ} \mathrm{N}$ array (red; Cunningham et al. 2007), and the German/ NOAA MOVE array at $16^{\circ} \mathrm{N}$ (blue; Send et al. 20II) are shown for 2000-12. All time series have a three-month running mean applied. to emerge (Kanzow et al. 2010), with a low MOC in April and a high MOC in October with peak to peak range of $6.9 \mathrm{~Sv}$. The seasonal cycle of the MOC appears to be largely attributable to seasonal variability in the interior rather than Ekman or Florida Current fluctuations; Kanzow et al. (2010) show that the interior seasonal cycle is likely due to seasonal upwelling through a direct wind-driven response off Africa.

Two other approaches for estimating Atlantic MOC were developed by Willis and Fu (2008) and Send et al. (2011). Near $41^{\circ} \mathrm{N}$, Willis and Fu (2008) used a combination of Argo data and satellite altimetry (measuring sea-surface height fluctuations on 10-day global grid) to determine the absolute geostrophic transports in the upper 2000 m of ocean referenced to subsurface Argo drift velocities. The use of altimetry data, which is well resolved in time, helps to reduce aliasing from the Argo profile data. The MOC time series from $41^{\circ} \mathrm{N}$ following Willis (2010) is shown in Fig. 3.22 with a three-month running mean applied. The mean value is $13.8 \mathrm{~Sv}$, with similar, slightly smaller variability than found in the $26^{\circ} \mathrm{N}$ MOC time series ( $3.0 \mathrm{~Sv} v$ vs. $3.3 \mathrm{~Sv}$ ). The decrease in mean MOC strength with increasing latitude is a common feature of observations and models (e.g., Ganachaud and Wunsh 2000; Wuncsh and Heimbach 2009). Willis (2010) reported an insignificant trend in the MOC from 2002 to 2009 , consistent with the insignificant trend in the $26^{\circ} \mathrm{N}$ data to April 2009, before the relatively low transport "event" in late 2009-early 2010. Of note is that the low MOC "event" described earlier in the $26^{\circ} \mathrm{N}$ data, appears in the $41^{\circ} \mathrm{N}$ data slightly earlier in time. Both time series have relatively strong annual cycles, slightly shifted in phase. Further examination of the causes of this likely basin-scale "event" and the causes of the shift of seasonal variability is needed.

Since 2000, an array of dynamic height moorings and one current meter mooring have been in place near $16^{\circ} \mathrm{N}$ to measure the transport fluctuations of the North Atlantic Deep Water (NADW; Kanzow et al. 2008). This NADW time series provides transport estimates of the deepest part of the MOC and has been shown by Kanzow et al. (2008) to be a reasonable index for the strength of the MOC at $16^{\circ} \mathrm{N}$ for multiannual timescales (e.g., a stronger southward negative flow of NADW corresponds to an increased MOC). The NADW transport time series shows substantial variability (on the order of $3.5 \mathrm{~Sv}$ ), with a weaker annual cycle than at $26^{\circ} \mathrm{N}$ or $41^{\circ} \mathrm{N}$ (Fig. 3.22). There is some suggestion of a decrease in the southward NADW of $20 \%$ over the observation period that 
would imply a decrease in the MOC (Send et al. 2011). This is consistent with the trend computed from the complete $26^{\circ} \mathrm{N}$ time series; however, multidecadal fluctuations of the MOC are expected from natural variability and cannot as yet be ascribed to climate change (Send et al. 2011).

Another time series of a major ocean current that contributes to the MOC variability is also the longest open ocean transport time series. Figure 3.23 shows the time series of the Florida Current, which has been measured since 1982 using a submarine cable across the Straits of Florida in combination with regular hydrographic sections Bahamas (e.g., Meinen et al. 2010; Baringer and Larsen 2001). In 2011, the median transport through the Florida Straits was $31.4 \pm 1.1$ Sv. For the previous four years, the annual average Florida Current transport decreased from $32.1 \pm 1.0$ Sv in 2007 to $30.7 \pm 1.5 \mathrm{~Sv}$ in 2010 (error bars represent

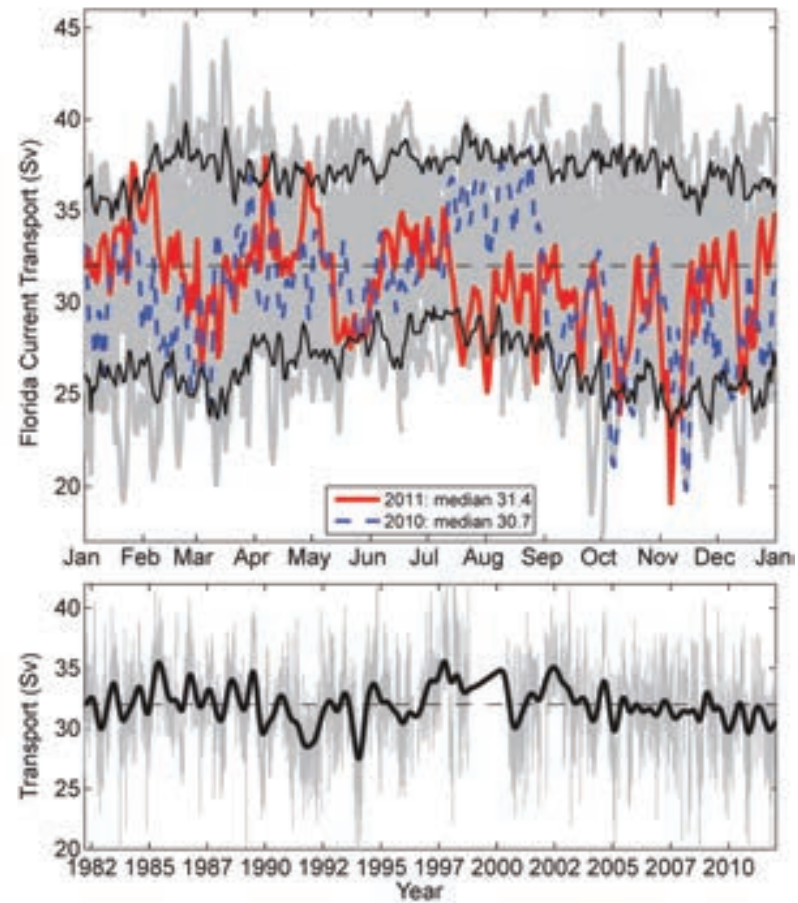

Fig. 3.23. (Top) Daily estimates of the transport of the Florida Current during $201 \mathrm{I}$ (red solid line) compared to 2010 (dashed blue line). The daily values of the Florida Current transport for other years since 1982 are shown in gray and the $95 \%$ confidence interval of daily transport values computed from all years is shown in black (solid line); the long-term annual mean is dashed gray. The mean transport in $201 \mathrm{I}$ was $31.4 \pm$ I.I Sv, which is less than the long-term mean for the daily values of the Florida Current transport (32.2 Sv). (Bottom) Daily estimates of the Florida Current transport for the full time series record (gray), a smoothed version of transport (heavy black line; using a 30-day running mean six times) and the mean transport for the full record (dashed gray). the standard deviation of daily values divided by the square root of the degrees of freedom calculated for each year where typical decorrelation time scales are about 20 days). The annual mean of 2011, no longer falls within the lowest quartile of mean annual values (long-term median annual average and interquartile range of $31.8 \pm 0.5 \mathrm{~Sv}$ ). Note that while recently the annual means appear to have decreased (April 2004 to December 2010 trend of $-1.9 \pm 0.2 \mathrm{~Sv}$ decade $^{-1}$, $95 \%$ significance), there is only a small significant long-term trend to the Florida Current transport (Fig. 3.23 , bottom; trend for complete daily time series is $-0.2 \pm 0.06 \mathrm{~Sv}$ decade $\left.^{-1}\right)$. The daily fluctuations of Florida Current transport generally fall within 95\% confidence levels $(32.0 \pm 1.0 \mathrm{~Sv})$; the $95 \%$ confidence range of daily transport values is shown in Fig. 3.23. There were, however, five extreme low transport events during the year (Fig. 3.23); the most significant events lasting over three days or more occurred during 17-19 July and 30 July-2 August, with values as low as $25.1 \mathrm{~Sv}$. In comparison, there were only three events with transport higher than the $95 \%$ confidence range, and no such event lasted for more than a day. Due to the fact that these events were relatively short lived, it is likely they were local responses to atmospheric forcing and coastally-trapped wave processes and are not particularly indicative of a climatically important shift (e.g., Mooers et al. 2005). Nevertheless, these transient fluctuations can have important environmental consequences due to dynamic sea-level changes. For example, it was previously reported that in the summer of 2009, the east coast of the United States experienced a high sea-level event that was unusual due to its unexpected timing, large geographic scope, and coastal flooding that was not associated with any storms (Sweet et al. 2009). Sweet et al. showed that this anomalous event was related to the anomalously low Florida Current transport; a reduced Florida Current transport corresponds to a lower sea-surface height gradient across the front and hence higher sea-level onshore. In 2011, the low transport events could reasonably be inferred to have influenced sea-level along the eastern US; however, as of this report, no relationship has been documented.

In the South Atlantic, a time series of MOC and MHT has been maintained since 2002 (Fig. 3.24), using a high-density expendable-bathythermograph (XBT) line (Garzoli and Baringer 2007; Dong et al. 2009). The mean heat transport across $35^{\circ} \mathrm{S}$ is 0.55 $\pm 0.14 \mathrm{PW}$ (petawatt, $1 \mathrm{PW}=10^{15}$ watts). Following an increase in heat transport since 2008, the year 2011 had a substantial increase in the mean annual 


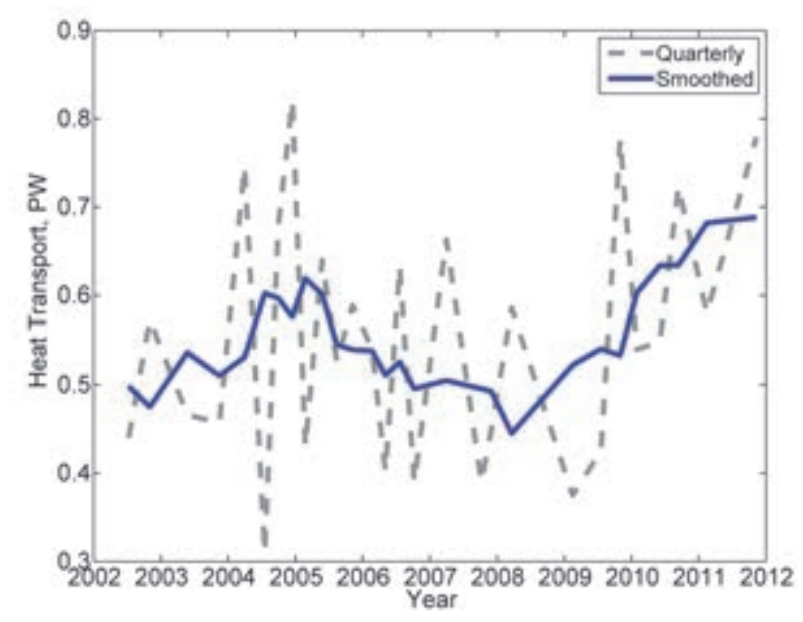

FIG. 3.24. Heat transport in the South Atlantic near $35^{\circ} \mathrm{S}$ derived from quarterly transects along the highdensity line AXI8 (gray dashed line) and smoothed values of heat transport (using a five-point running mean; blue solid line). Heat transport values are computed following the methodology of Baringer and Garzoli (2007).

transport value (0.68 PW), the highest recorded annual mean (however, still within one standard error of the mean). According to Dong et al. (2009) the changes in MHT are well correlated with changes in the MOC. This correlation implies an increase in the MOC in the South Atlantic since 2008. The meridional coherence of changes in MOC and heat transport and the relative lead/lag is an active area of research. Heimbach et al. (2011) found that changes in the upper ocean near $35^{\circ} \mathrm{S}$ could be precursors to changes in the MOC across $26^{\circ} \mathrm{N}$ as early as four years into the future.

i. Sea level variability and changeM. A. Merrifield, P. Thompson, D. P. Chambers, G. T. Mitchum, M. Menéndez, R. S. Nerem, E. Leuliette, L. Miller, S. Holgate, J. J. Marra, and $W$. Sweet

Sea level is a primary indicator of climate variability and change over a wide range of time and space scales. Global mean sea level provides a measure of volume changes associated with ocean heat content changes and water mass exchange with the land. Regional sea level variations reflect changes in the wind-forced circulation and transports of heat and salt. Extreme sea levels reflect storm patterns and their variation from year to year, as well as sea level extremes associated with ENSO and other climate modes of variability. Not only is sea level change a key climate indicator, it is also potentially one of the more important impacts of climate change.

Sea level variability during 2011 is characterized by first examining seasonal anomalies (Fig. 3.25), which highlight changes associated with variable winds and climate modes of variability. Annual mean sea level deviations and changes from the previous year are considered (Fig. 3.26), and global mean sea level is shown to have been significantly below the long-term trend during 2011 (Fig. 3.27), but is trending sharply back upwards late in the year. Ongoing assessments of the sea level budget are reviewed (Fig. 3.28) to provide context for the 2011 sea level drop in terms of the La Niña conditions that dominated the year. Lastly, extreme sea level conditions during 2011 are characterized based on 30-plus-year tide gauge records (Fig. 3.29). Data for this assessment were obtained from the multimission gridded sea surface height (SSH) altimeter product produced by Ssalto/Duacs and distributed by AVISO, with support from CNES (http://www.aviso.oceanobs.com), and from the University of Hawaii Sea Level Center (http://uhslc.soest.hawaii.edu/), with support from the NOAA Climate Observations Division.

The regional sea level patterns (Fig. 3.25) show that La Niña conditions prevailed during 2011. The La Niña event peaked during the winter of 2010/11

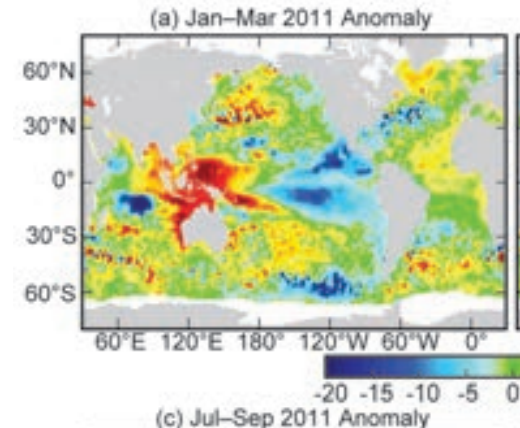

(c) Jul-Sep 2011 Anomaly

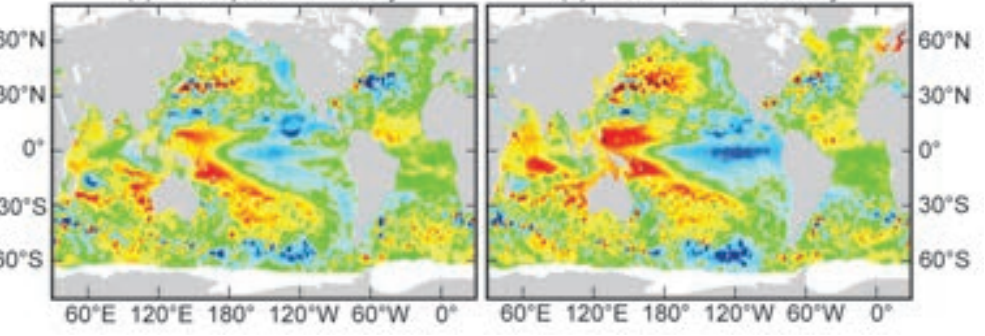

FIG. 3.25. Seasonal SSH anomalies $(\mathrm{cm})$ for $201 \mathrm{I}$ relative to the 1993-20II base period are obtained using the multimission gridded sea surface height altimeter product produced by Ssalto/Duacs and distributed by AVISO, with support from CNES (http://www.aviso. oceanobs.com). 
with high sea levels in the western tropical Pacific and low values in the eastern tropical Pacific (Fig. 3.25a). The stronger trade winds associated with La Niña weakened during the middle of 2011 (see Fig. 3.10), causing a reduction of the zonal sea level gradient and the buildup of positive anomalies in the equatorial Pacific off South America (Fig. 3.25b). As the trades picked up again during the second half of 2011, Pacific sea level anomalies ended the year with an enhanced La Niña state (Fig. 3.25d), although not as strong as the first quarter of the year (Fig.3.25a). Sea levels in the eastern Indian Ocean were positive throughout the year, with a peak in the first quarter. A westward propagating negative anomaly in the central Indian Ocean was evident south of the equator, which was followed by a positive anomaly in the last quarter of the year.

In the Atlantic, the continuation of the negative North Atlantic Oscillation (NAO) index into January was reflected in a negative anomaly in the Baltic (Fig. 3.25a). The index then turned strongly positive for most of the year, excluding the months of June,
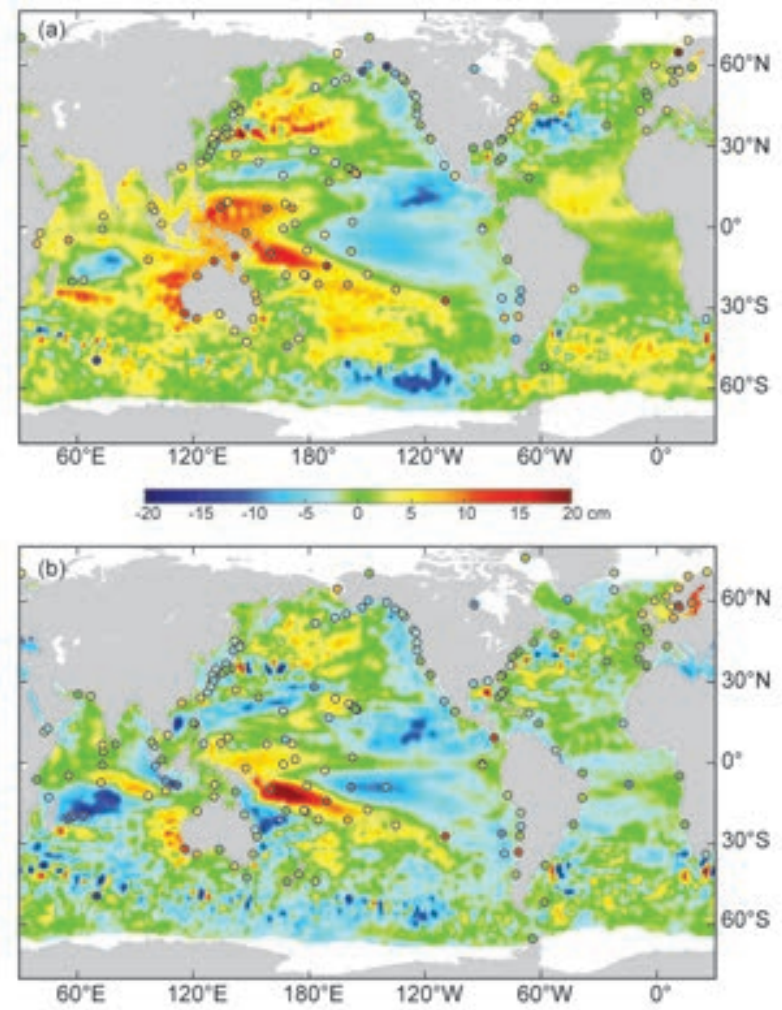

FIG. 3.26. (a) The 20II SSH anomaly (Ssalto/Duacs product with anomaly, cm) from the 1993-20II base period is compared to the $20 \mathrm{II}$ anomaly computed for tide gauge data (dots) obtained from the University of Hawaii Sea Level Center (http://uhslc.soest.hawaii. edu/). (b) The difference between $201 \mathrm{I}$ and 2010 annual means $(\mathrm{cm})$.
July, and August. The strongly positive index at the end of 2011 is reflected in the negative Mediterranean anomalies and a reversal to positive anomalies in the Baltic (Fig. 3.25d).

Annually-averaged sea level during 2011 was dominated by a La Niña pattern across the Pacific and Indian Oceans (Fig. 3.26a). In the North Pacific, anomalous winds in the Aleutian Low region exhibited a negative wind stress curl (see Fig. 3.10), which contributed to high sea levels in the central Pacific and low sea levels along the western coast of North America. This wind and sea level pattern is typical of the negative phase of the Pacific decadal oscillation (PDO; Mantua et al. 1997; Cummins et al. 2005), which is consistent with the negative values of the PDO index since mid-2010. Over the Southern Ocean, wind stress curl changes in the region of strong westerlies accompanied a broad negative sea level anomaly west of the southern tip of South America (Fig. 3.26a). Annual sea levels were generally high in the tropical Indian Ocean, with the exception of the strong negative anomaly in the eastern Indian Ocean mentioned previously. Sea level deviations in the Atlantic Ocean showed bands of relatively high sea level in the South Atlantic just north of the equator, and in the subpolar North Atlantic.

The sea level tendency for 2011, measured as the difference between the 2011 and 2010 annual means, shows weak to negative changes over broad regions of the ocean (Fig. 3.26b). Positive changes were most evident in the South Pacific convergence zone (SPCZ), off the west coast of Australia, and in the central North Pacific (Fig. 3.26b). The changes in the tropical Pacific suggest a tendency for stronger trades in 2011 relative to 2010, and a net strengthening of $\mathrm{La}$ Niña conditions. In general, enhanced rates of sealevel rise have been observed in the western tropical Pacific for at least the past two decades (Merrifield 2011; Becker et al. 2012). These changes appear to be associated with a multidecadal enhancement of the trade winds in the Pacific (Merrifield and Maltrud 2011). Negative sea level changes were most evident in the Southern Ocean, the Indian Ocean south of the equator, and the off-equatorial regions in the eastern Pacific. Annual sea level changes in the Atlantic were relatively weak compared to the other ocean basins, but Baltic sea levels showed a large increase relative to 2010 while the Mediterranean showed a decrease (Fig. 3.26b). These changes are associated with a NAO index that showed the most positive value since 1994 in 2011, as compared to the most negative value on record in 2010. 


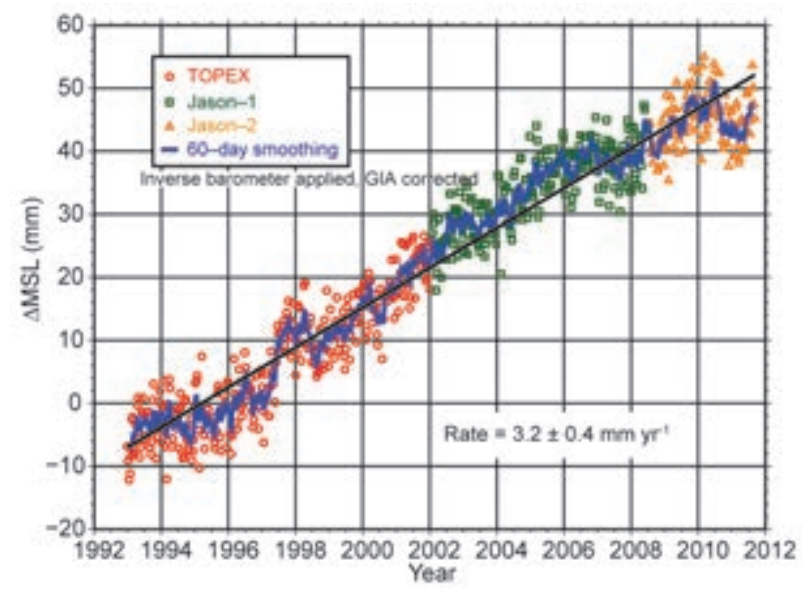

FIG. 3.27. Time series of global mean sea level $(\mathrm{mm})$ since 1993 from the TOPEX and Jason series of satellite radar altimeters. Seasonal signals have been removed from the data and inverse barometer and global isostatic adjustment corrections have been applied (see Nerem et al. 2010).

The average global rate of sea level change computed over the years 1993-2011 is $3.2 \pm 0.4 \mathrm{~mm} \mathrm{yr}^{-1}$ (Fig. 3.27; Beckley et al. 2010; Leuliette and Scharroo 2010; Nerem et al. 2010). Relative to the long-term trend, global sea level dropped noticeably in mid-2010 and reached a local minimum in 2011. The drop has been linked to the strong La Niña conditions that have prevailed throughout 2010-11 (section 3b). Global sea level increased sharply during the second half of 2011.

The relative contributions to the total sea level changes from addition of mass and density changes has been measured since 2005 when global upper ocean temperature and salinity observations from the Argo float array and ocean mass variations from the Gravity Recovery and Climate Experiment (GRACE) became available (Leuliette and Willis 2010; Llovel et al. 2009). The observations show (Fig. 3.28a) that the sea level budget since 2005 can be closed to within the range of uncertainties over a variety of time scales. Although the contribution of deep ocean heat content to the long-term trend in sea level deserves attention, for now this contribution appears to be smaller than the uncertainty. Over this brief time period and for latitudes between $\pm 66^{\circ}$ where altimetry observations are available, the mean rate of total sea level rise is $1.4 \pm 0.4 \mathrm{~mm} \mathrm{yr}^{-1}$ ( 1 standard error; Leuliette and Willis 2010). This rate computed with the data since 2005 is not comparable to the longer-term rate from 1993 since at least 10 years of data are required to determine a reliable long-term rate (Nerem et al. 1999). This rate is, however, in agreement (Fig. 3.28a) with the sum $\left(1.3 \pm 0.4 \mathrm{~mm} \mathrm{yr}^{-1}\right)$ of the rates of the upper ocean steric $\left(0.2 \pm 0.2 \mathrm{~mm} \mathrm{yr}^{-1}\right)$ and ocean mass components (1.2 $\left.\pm 0.3 \mathrm{~mm} \mathrm{yr}^{-1}\right)$ (Fig. 3.28b).

This sea level budget material is based on a short record, but shows proximity to the ability to understand total sea level changes measured by altimetry and tide gauges in terms of ocean density and mass changes. In addition, these contributions can be understood both in terms of buoyancy and mass inputs as well as redistributions of each quantity. In future years, such analyses will be of central importance in this annual review.

Extreme sea level events are measured in daily tide gauge records. The highest sea level events are primarily caused by a combination of storm surges associated with midlatitude and tropical storms and tidal fluctuations, but other factors such as mean sea level variation can contribute to extreme sea level values. The daily averages considered here exclude the semidiurnal and diurnal tidal contributions to
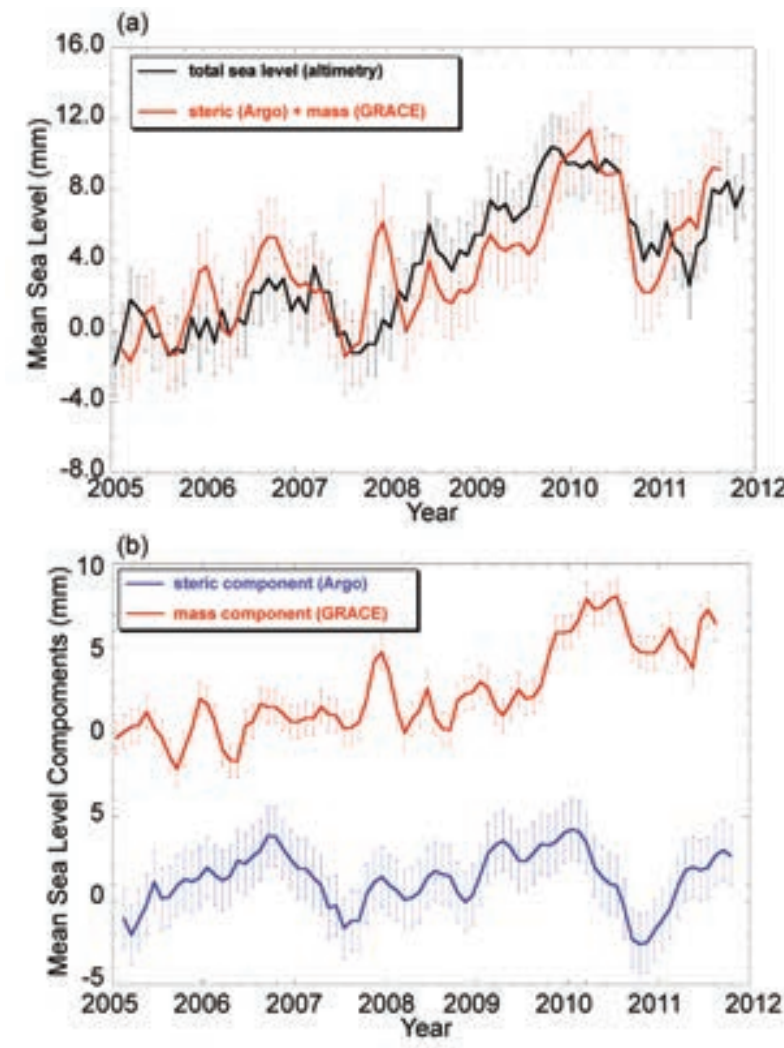

FIG. 3.28. Monthly estimates (in $\mathrm{mm}$ ) from (a) Jason-I and Jason-2 of global mean sea level (black), which are in general agreement with the sum of the steric component from Argo and ocean mass component from GRACE (red), and (b) the individual components (in $\mathrm{mm}$ ) as measured by GRACE (red) and Argo (blue). Seasonal signals were removed and the time series were smoothed with a three-month running mean. Error bars represent one standard error. 


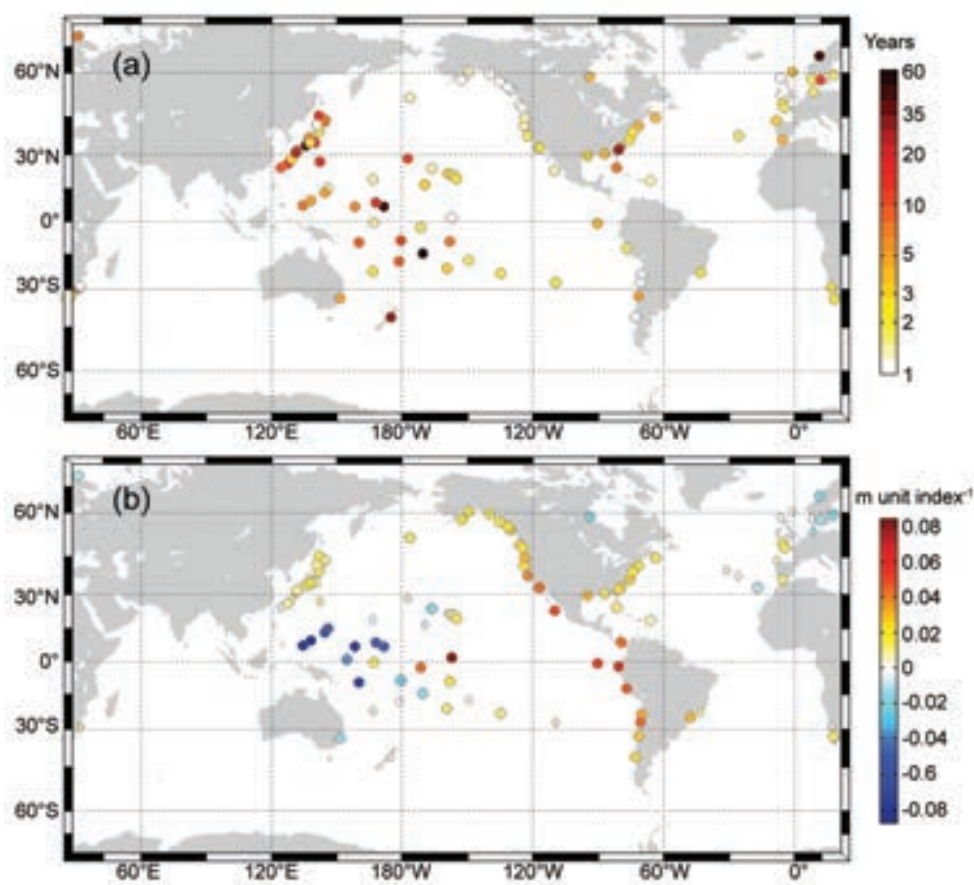

FIG. 3.29. (a) Return period/averaged recurrence interval (years) associated with the highest sea level event during $201 \mathrm{I}$ at each station. (b) Influence of Niño 3.4 index on extreme sea levels (m unit index $\left.{ }^{-1}\right)$.

extreme levels. An estimation of the return period associated with the measured annual maxima of daily averaged sea level for 2011 provides a means of comparing last year's extremes with previous years (Fig. 3.29a). The return periods are estimated from the empirical distribution function of the annual maxima for each tide gauge record. The more unusual sea level extremes during 2011 were in the SPCZ region, along the coast of Florida, and in parts of the coast of the Scandinavian countries in northern Europe. Extreme events along the west coast of North America and Europe were unremarkable. The extremes in the western Pacific were consistent with the strengthening of La Niña conditions during 2011, whereas the higher extreme values in northeast Europe were coincident with the positive phase of the Arctic Oscillation (a close relative of the NAO) during the 2011 winter, which drives ocean storms farther north. The larger values obtained along the Florida coast are associated with the passage of a strong nontropical storm.

Interannual fluctuations in extreme sea levels can depend on regional climate patterns. To investigate the climate variability in extreme sea levels, a nonstationary extreme value analysis has been applied to the monthly maxima of daily-averaged tide gauge records, following Menéndez and Woodworth (2010). The statistical relationship of ENSO in extreme sea levels is studied by adding the linear covariate (Niño 3.4 climate index) in the location parameter of the generalized extreme value (GEV) distribution. Although a higher influence of ENSO is expected across the tropical Pacific, the sensitivity of extreme sea levels to ENSO has a worldwide effect (Fig. 3.29b). A negative value of the Niño 3.4 index characterizes a La Niña event, hence the negative values in Fig. 3.29b correspond to a positive extreme sea level change during La Niña, and positive values correspond to negative extreme sea level change. The higher return periods in the western tropical Pacific and low values along the eastern Pacific (Fig. 3.29a) are generally consistent with La Niña conditions.

j. Global ocean carbon cycle-C. L. Sabine, R. A. Feely, R. Wanninkhof, T. Takahashi, S. Khatiwala, and G.-H. Park

I) AIR-SEA CARBON DIOXIDE FLUXES

Although independent estimates of decadal-scale ocean carbon uptake agree within their uncertainty (Gruber et al. 2009), databased studies suggest regional, year-to-year variations in oceanic carbon dioxide $\left(\mathrm{CO}_{2}\right)$ uptake (Doney et al. 2009). These studies underscore the need for global, long-term observations of the surface ocean carbon cycle and for systematic handling of such data to secure their long-term accessibility. The number of annual surface $\mathrm{CO}_{2}$ observations has been growing exponentially since the 1960s such that today well over one million observations are reported to data centers each year. In 2011, a new product called the Surface Ocean $\mathrm{CO}_{2}$ Atlas (SOCAT) was released. SOCAT contains 6.3 million surface water $\mathrm{CO}_{2}$ measurements from more than 1850 voyages in the global oceans and coastal seas between 1968 and 2007. Two SOCAT products are publicly available: (1) a global dataset of recalculated surface ocean $\mathrm{fCO}_{2}$ (fugacity of $\mathrm{CO}_{2}$, similar to partial pressure) in a uniform format which have been subject to data quality control; and (2) a global, gridded monthly mean surface water $f \mathrm{CO}_{2}$ data product with minimal temporal and spatial interpolation (http://www.socat.info). The SOCAT products are intended to complement the LDEO database, which contains much of the same data but was processed with different quality control procedures. The latest release of the LDEO database includes 3.7 million data points from 1957 to 2010 (Takahashi et al. 2011). 
The LDEO database is used to generate the LDEO $\mathrm{CO}_{2}$ climatology, which provides the monthly patterns of air-sea $\mathrm{CO}_{2}$ fluxes during a "normal" non-El Niño year taken to be 2000 (Takahashi et al. 2009). The annual mean for the 2000 net $\mathrm{CO}_{2}$ uptake flux over the global oceans is estimated to be $1.4 \pm 0.7 \mathrm{Pg}$ $\left(10^{15} \mathrm{~g}\right){\mathrm{C} \mathrm{yr}^{-1}}^{-1}$. The equatorial Pacific $\left(14^{\circ} \mathrm{N}-14^{\circ} \mathrm{S}\right)$ is the major source for atmospheric $\mathrm{CO}_{2}$, emitting about $0.48 \mathrm{Pg} \mathrm{C} \mathrm{yr}^{-1}$, and the temperate oceans between $14^{\circ}$ and $50^{\circ}$ in the both hemispheres are the major sink zones with an uptake flux of $0.70 \mathrm{Pg} \mathrm{C} \mathrm{yr}^{-1}$ for the

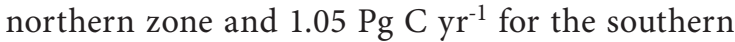
zone. The uncertainty in the gas exchange rate is estimated at $\pm 30 \%$, and hence the estimated sea-air $\mathrm{CO}_{2}$ flux climatology is uncertain to at least this magnitude. Improvements in wind speed products and parameterization of gas exchange rate are needed for a reduction of the uncertainty in $\mathrm{CO}_{2}$ flux estimates.

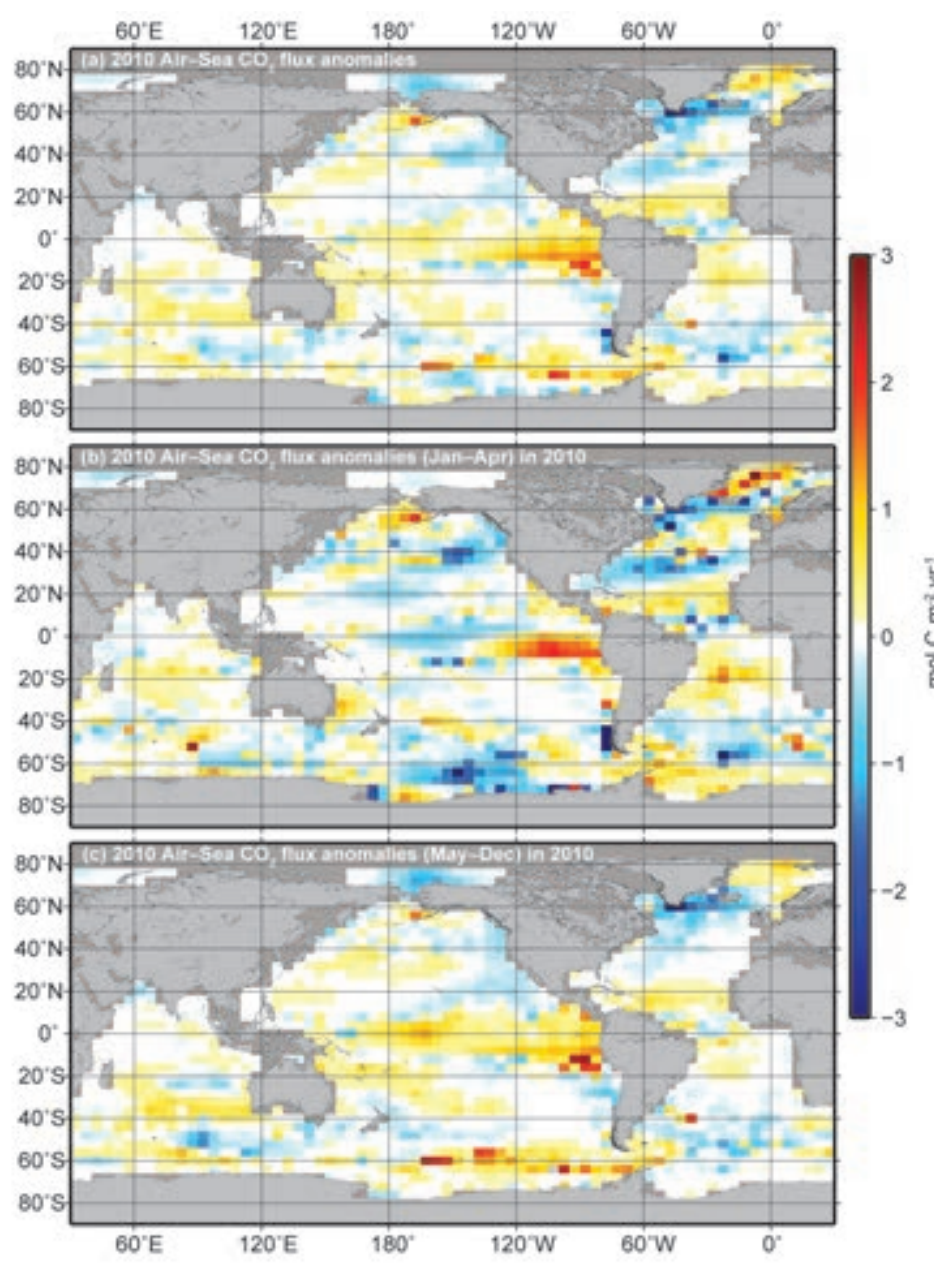

FIG. 3.30. Global distributions of air-sea $\mathrm{CO}_{2}$ flux anomalies (mol $\mathrm{C} \mathrm{m}^{-2} \mathrm{yr}^{-1}$ ) for (a) 20I0, (b) Jan-Apr, and (c) May-Dec, compared to the 1982-2010 mean values for the corresponding months as calculated from the Park et al. (2010) approach. Positive values indicate less uptake or more release of $\mathrm{CO}_{2}$ by the ocean.
The seasonal and interannual variability in $\mathrm{CO}_{2}$ fluxes for the last three decades is estimated using the algorithms of Park et al. (2010). Due to lags in availability of quality-controlled data streams, the surface air-sea $\mathrm{CO}_{2}$ fluxes reported in the State of the Climate reports are a year behind. The global net uptake $\mathrm{CO}_{2}$ flux for the 2010 transition period from El Niño to La

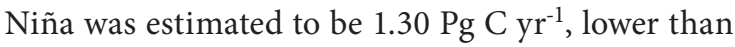
the 1982-2010 long-term mean of 1.47 $\mathrm{Pg} \mathrm{C} \mathrm{yr}^{-1}$. The smaller $\mathrm{CO}_{2}$ effluxes in the equatorial Pacific during the first four months of the El Niño period partially compensate $\mathrm{CO}_{2}$ effluxes in the remaining months during the La Niña (Fig. 3.30). During the El Niño period, the central equatorial Pacific shows less $\mathrm{CO}_{2}$ outgassing compared to the 29-year mean values (Fig. 3.30b). This flux anomaly pattern is a result of the El Niño Modoki, showing greater SST anomalies in the central equatorial Pacific than in the eastern equatorial Pacific (Ashok et al. 2007). However, despite the El Nino conditions at the start of 2010, the equatorial Pacific still showed high $\mathrm{CO}_{2}$ effluxes. Effluxes of $\mathrm{CO}_{2}$ for both the El Niño and La Niña periods in the eastern equatorial Pacific are higher than the 29-year average (Fig. $3.30 \mathrm{~b}, \mathrm{c})$. These high $\mathrm{CO}_{2}$ effluxes are attributed to intensified upwelling of deep water rich in $\mathrm{CO}_{2}$ caused by an increase of wind speed observed for 2010.

Compared to long-term averages, higher $\mathrm{CO}_{2}$ uptake is found in the high latitudes of the northern and southern Atlantic Ocean, and higher $\mathrm{CO}_{2}$ effluxes and less $\mathrm{CO}_{2}$ uptakes are observed in the high southern Pacific Ocean. Negative $\mathrm{CO}_{2}$ flux anomalies (blue colors in Fig. 3.30a) found in the high-latitude Atlantic Ocean are predominantly caused by SST anomalies in the regions. For the high southern Pacific Ocean, the positive $\mathrm{CO}_{2}$ flux anomalies (red colors in Fig. 3.30a) are caused primarily by SST anomalies and partially reinforced by wind speed anomalies. The monthly flux maps and anomalies from 1982 to 2010 can be obtained from http://cwcgom.aoml.noaa. gov/erddap/griddap/aomlcarbonfluxes. graph.

During 2011 a comprehensive comparison of model-based and data-based estimates of sea-air $\mathrm{CO}_{2}$ fluxes and trends over the past two decades was performed. 


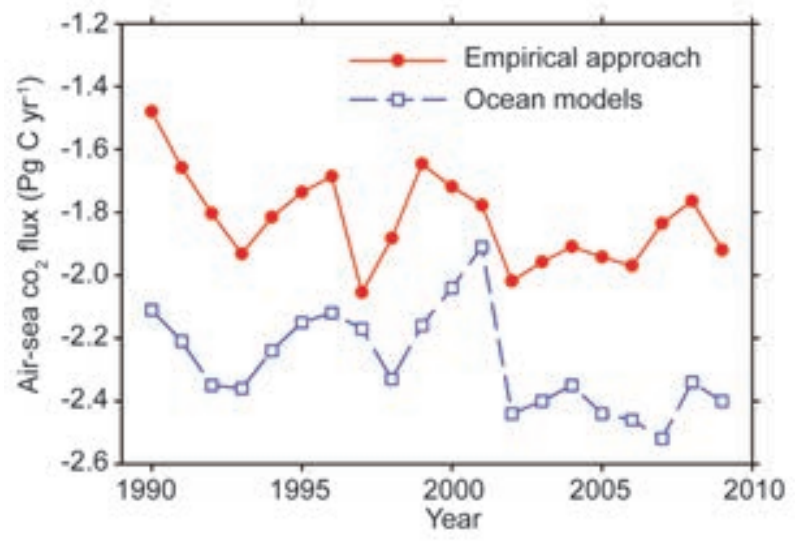

FIG. 3.3I. Comparison of anthropogenic air-sea $\mathrm{CO}_{2}$ fluxes ( $\mathrm{Pg} \mathrm{C} \mathrm{yr}^{-1}$ ) based on a composite of ocean models (blue line with squares) and an empirical data-based approach (red line with circles). For the comparison, $\mathrm{CO}_{2}$ fluxes caused by atmospheric $\mathrm{CO}_{2}$ increase, the riverine $\mathrm{CO}_{2}$ flux $\left(0.45 \mathrm{Pg} \mathrm{C} \mathrm{yr}^{-1}\right)$, and

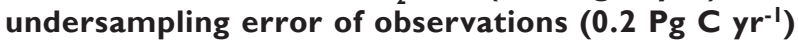
are added to the net air-sea $\mathrm{CO}_{2}$ fluxes derived in the Park et al. (2010) approach. The $\mathrm{CO}_{2}$ fluxes from the empirical approach, here, were calculated using the cross-calibrated multiplatform (CCMP) wind speeds (Atlas et al. 20II).

There is good agreement of increasing uptake trends of about $0.12 \mathrm{Pg} \mathrm{C}$ decade $^{-1}$ with significant interannual variability driven by large-scale climate reorganizations such as ENSO. However, there are appreciable offsets in the absolute magnitudes. The empirical approach, numerical ocean biogeochemistry models such as those from the National Center for Atmospheric Research (NCAR), and atmospheric inverse models all show anthropogenic $\mathrm{CO}_{2}$ uptake of 1.4 Pg C yr ${ }^{-1}-2.0 \mathrm{Pg} \mathrm{C} \mathrm{yr}^{-1}$. In contrast, global constraints and models adjusted to global constraints, such as the University of East Anglia (UEA) model

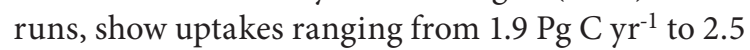
$\mathrm{Pg} \mathrm{C} \mathrm{yr}{ }^{-1}$ (Fig. 3.31). The differences may be related to the carbon cycle representation in the model, but they may also be related to differences in the physical forcing in the models. The various wind products are improving. Since $98 \%$ of the ocean area has fairly low wind speeds in the $4 \mathrm{~m} \mathrm{~s}^{-1}-11 \mathrm{~m} \mathrm{~s}^{-1}$ range where the different wind products generally agree, this is not a huge problem for most areas. However, there are still issues in certain key regions (e.g., Southern Ocean and coastal regions) with the available wind products. The use of different wind products and different exchange coefficients in publications makes it challenging to objectively compare results. Moreover, reanalyses products are continually updated and version and source of the wind product used should be specified. For example, the global $\mathrm{CO}_{2}$ fluxes calculated using the $p \mathrm{CO}_{2}$ climatology normalized to year 2000 and two different wind products, NCEP Reanalysis II and

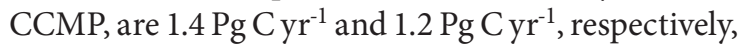
despite normalization of parameterization of gas transfer and wind speed for the different global mean winds of the products. This is caused by systematic large-scale differences in the two products with the NCEP II product showing lower winds in the equatorial band and higher winds at higher latitudes. The $\mathrm{CO}_{2}$ fluxes estimated from NCEP winds show less $\mathrm{CO}_{2}$ effluxes in the equatorial Pacific and greater $\mathrm{CO}_{2}$ uptake in the subtropic and northern areas than from CCMP winds, and therefore show a greater net uptake.

\section{2) SUBSURFACE CARBON INVENTORY}

The U.S. CLIVAR/CO 2 Repeat Hydrography Program has spent the last decade reoccupying 19 hydrographic sections initially sampled in the 1990s as part of the World Ocean Circulation Experiment (WOCE) hydrographic survey. These reoccupations provide information on how ocean carbon and other physical and biogeochemical tracers are changing over time (http://ushydro.ucsd.edu /). Between Febru-

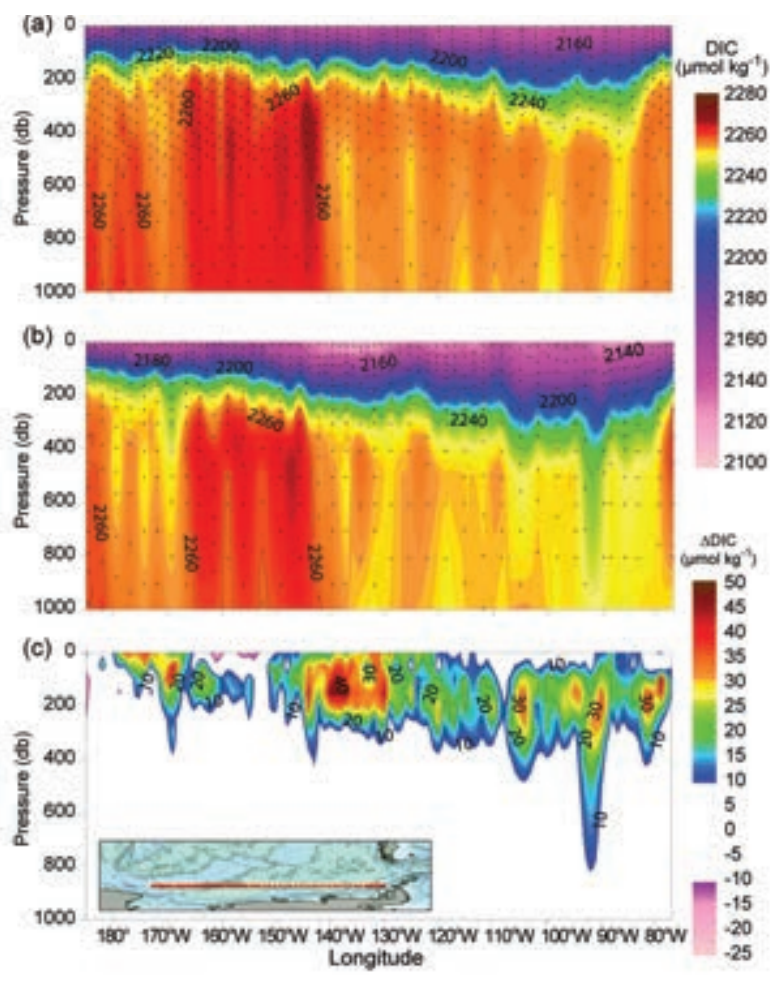

FIG. 3.32. Sections of dissolved inorganic carbon across the Pacific sector of the Southern Ocean (S4P) in (a) Feb-Apr 20II, (b) Feb-Mar 1992, and (c) the 2011 minus 1992 difference $\left(\mu \mathrm{mol} \mathrm{kg}^{-1}\right)$. The 1992 data are from Chipman et al. (1997). 
ary and April 2011, an east-west cruise line (S4P) in the South Pacific, nominally along $67^{\circ} \mathrm{S}$, was occupied as a repeat of a similar cruise run between February and March 1992. Figure 3.32 shows the observed dissolved inorganic carbon (DIC) distributions from each of these cruises. The bottom panel on Fig. 3.32 shows the estimated DIC increases over the 19-year interval, which varies from no change below $800 \mathrm{~m}$ to values greater than $40 \mu \mathrm{mol} \mathrm{kg}^{-1}$ at approximately $200 \mathrm{~m}$ depth near $138^{\circ} \mathrm{W}$. The main concentration increases are between the surface and $300 \mathrm{~m}$, as expected from an uptake of atmospheric $\mathrm{CO}_{2}$. The lack of observable changes in the initial analysis of the deep ocean is consistent with previous observations that any changes in deep ocean carbon in the Pacific sector of the Southern Ocean are below reliable detection limits (Sabine et al. 2008). Additional analyses are being conducted to improve the techniques for isolating the anthropogenic component of the DIC concentrations.

While repeat hydrographic measurements are critical for documenting regional changes in the uptake and storage of anthropogenic $\mathrm{CO}_{2}$, on a global scale, inverse methods have been instrumental in mapping out spatial variations. Figure 3.33a shows one such global estimate of the storage rate of anthropogenic $\mathrm{CO}_{2}$ for 2010 based on a Green's function method utilizing transient tracers (Khatiwala et al. 2009, 2012, manuscript submitted to Biogeosciences). The map shows the largest storage rate is in the North Atlantic associated with the transport of anthropogenic $\mathrm{CO}_{2}$ into the ocean interior associated with the formation of North Atlantic Deep Water and Labrador Sea Water. High storage rates are also seen at $40^{\circ} \mathrm{S}-50^{\circ} \mathrm{S}$ associated with the subtropical convergence, another area where intermediate and mode waters are formed and move $\mathrm{CO}_{2}$ into the ocean interior.

On a global scale, the 2010 open ocean inventory of anthropogenic $\mathrm{CO}_{2}$ is estimated using Green's function method to be $151 \pm 26 \mathrm{PgC}$ (Khatiwala et al. 2009, 2012, manuscript submitted to Biogeosciences). This estimate is based on the GLODAP database of hydrographic and biogeochemical observations (Key et al. 2004) and does not cover the coastal and marginal seas. Estimates for the latter have been recently compiled and updated to 2010 by Khatiwala et al. (2012, manuscript submitted to Biogeosciences) and are as follows: Arctic Ocean, 2.7 Pg C - 3.5 Pg C (Tanhua et al. 2009); Nordic Seas, 1.0 Pg C - 1.6 Pg C (Olsen et al. 2010); Mediterranean Sea, 1.6 Pg C - 2.5 Pg C (Schneider et al. 2010); and the East Sea/Sea of Japan, $0.40 \pm 0.06$ Pg C (Park et al. 2006). This gives a total ocean inventory of approximately $160 \mathrm{Pg} \mathrm{C}$ for 2010.

In the Pacific, both inverse methods and repeat hydrography estimates are in reasonable agreement. Both methods show higher storage in the South Pacific compared with the North Pacific (Murata et al. 2007; Sabine et al. 2008), and higher rates in the western North Pacific compared with the eastern ba$\sin$ (Sabine et al. 2008). In other regions, however, the methods do not agree. For example, inverse estimates show higher storage in the North Atlantic relative to the South Atlantic, opposite of the pattern found by studies based on repeat hydrography (Wanninkhof et al. 2010), possibly due to temporal variability not accounted for by the former (Khatiwala et al. 2012, manuscript submitted to Biogeosciences).

With the exponential growth of atmospheric $\mathrm{CO}_{2}$ in the atmosphere, the global rate of annual anthropogenic $\mathrm{CO}_{2}$ storage is increasing dramatically with time (Fig. 3.33b). Based on a Green's function estimates, the annual storage rate has doubled since the 1970s. As discussed in the previous section, different methods vary in the estimated current uptake

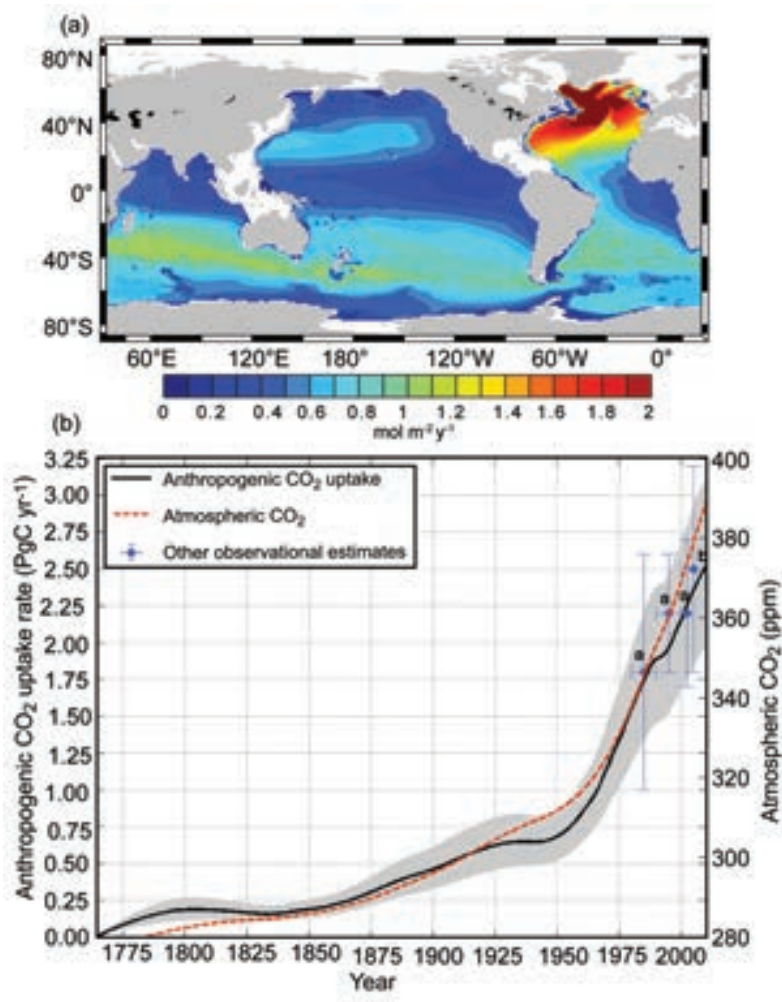

FIG. 3.33. (a) Map of the 2010 annual change in anthropogenic $\mathrm{CO}_{2}$ column inventory $\left(\mathrm{mol} \mathrm{m}^{-2} \mathrm{yr}^{-1}\right)$. (b) Time history of the global ocean anthropogenic $\mathrm{CO}_{2}$ uptake rate ( $\left.\mathrm{Pg} \mathrm{C} \mathrm{yr}^{-1}\right)$ based on the Green's Function approach of Khatiwala et al. (2009, 20I2, manuscript submitted to Biogeosciences). 
and storage rate, but these differences are within the stated uncertainties. As long as atmospheric $\mathrm{CO}_{2}$ continues to increase, the oceans will continue to store anthropogenic carbon.

Based on a recent compilation of emissions by Andres et al. (2012, manuscript submitted to Biogeosciences), the ocean inventory represents $\sim 43 \%$ of fossil fuel and $29 \%$ of total (fossil fuel and land use changes) anthropogenic $\mathrm{CO}_{2}$ emissions over the industrial period. This is consistent with the earlier work of Sabine et al. (2004) who found that the ocean inventory accounted for nearly half of the fossil fuel $\mathrm{CO}_{2}$ emitted since the preindustrial era. It should be noted that these values are based on the total accumulation of $\mathrm{CO}_{2}$ in the ocean since the preindustrial era. If, as in some recent publications (e.g., Le Quéré et al. 2009), the computation is carried out on the basis of the annual rate of $\mathrm{CO}_{2}$ uptake, which varies significantly with time (Fig. 3.33b), rather different values would be obtained. Thus, at a current ocean

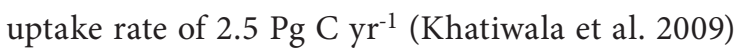
and fossil fuel and total emission rates of $\sim 8.5 \mathrm{Pg} \mathrm{C}$ $\mathrm{yr}^{-1}$ and $\sim 10 \mathrm{Pg} \mathrm{C} \mathrm{yr}^{-1}$, respectively, (Solomon et al. 2007; Andres et al. 2012, manuscript submitted to Biogeosciences; Carbon Dioxide Information Analysis Center), values of $1 / 3$ and $1 / 4$ of emissions are arrived at for the ocean sink. This highlights the importance of clearly stating the assumptions and qualifications when making statements concerning the efficiency of the ocean sink.

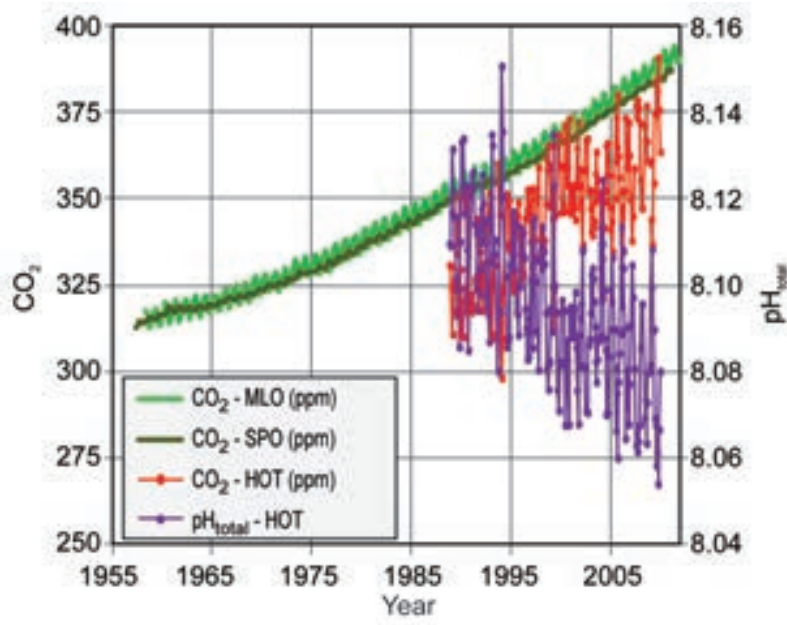

FIG. 3.34. Time series of atmospheric $\mathrm{CO}_{2}(\mathrm{ppm})$ at Mauna Loa (MLO) and the South Pole (SPO) and

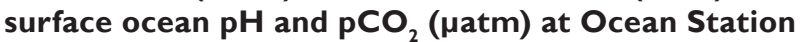
Aloha (HOT) in the subtropical North Pacific Ocean. [Source: Mauna Loa data: Dr. Pieter Tans, NOAA/ ESRL (http://www.esrl.noaa.gov/gmd/ccgg/trends); HOTS/Aloha data: Dr. Matthew Church, University of Hawaii (http://hahana.soest.hawaii.edu)].

\section{3) OCEAN ACIDIFICATION}

The ocean absorption of $\mathrm{CO}_{2}$ from the atmosphere has reduced the accumulation of greenhouse gases in the atmosphere, thus slowing the rate of climate change (Solomon et al. 2007). However, when $\mathrm{CO}_{2}$ enters the ocean it reacts with water to form carbonic acid and its dissociation products. This $\mathrm{CO}_{2}$ increases ocean acidity and decreases ocean $\mathrm{pH}$ in a process commonly referred to as "ocean acidification" (Caldeira and Wickett 2003). The addition of $\mathrm{CO}_{2}$ to the ocean causes a decrease in carbonate ions, thus lowering calcium carbonate saturation states, making it more difficult for organisms to produce calcium carbonate shells or skeletons (Fabry et al. 2008; Guinotte and Fabry 2008). Since the beginning of the industrial era, the $\mathrm{pH}$ of open-ocean surface waters has decreased by about $0.1 \mathrm{pH}$ units, equivalent to an overall increase of $30 \%$ in the hydrogen ion concentration. For example, over the past twenty years atmospheric and oceanic $\mathrm{CO}_{2}$ near Hawaii have increased by approximately $40 \mathrm{ppm}$ and $40 \mu \mathrm{atm}$, respectively, while the $\mathrm{pH}$ of those same surface waters have decreased by about 0.04 units (Fig. 3.34).

Recent models have suggested that undersaturated waters, that is, waters with carbonate ion concentrations low enough to dissolve calcium carbonate shells, would shoal to depths affecting western US shelf ecosystems, home to

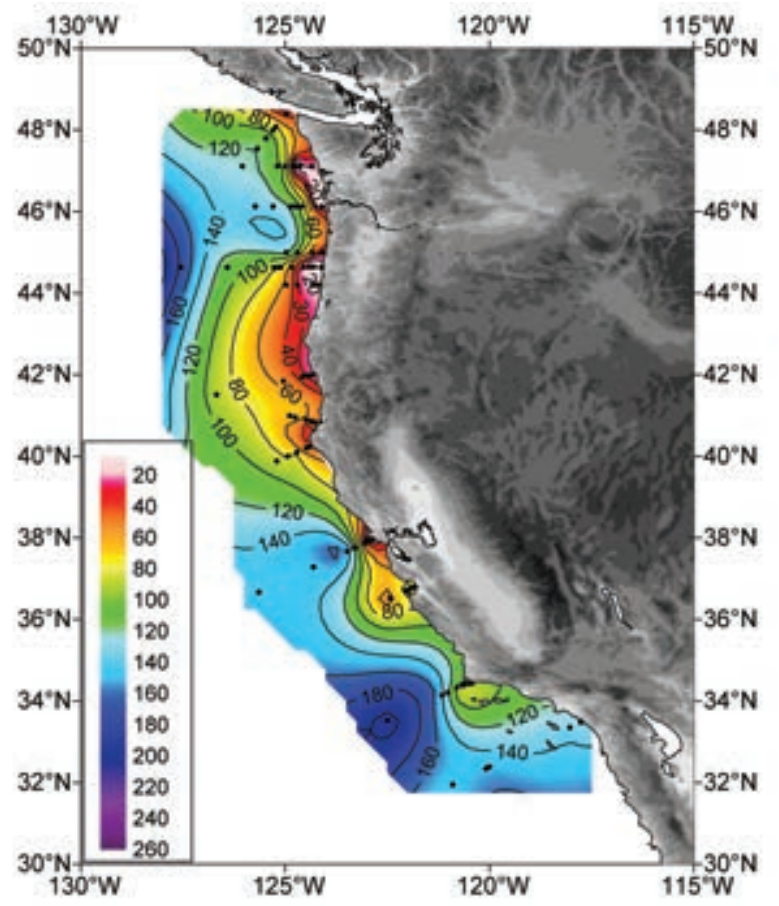

FIG. 3.35. Depth distribution of corrosive undersaturated water $(\Omega$ arag $<\mathrm{I} .0, \mathrm{pH}<7.75)$ along western North American continental margin in Aug-Sep $201 \mathrm{I}$. The undersaturated waters are the direct result of the combined impacts of acidification, upwelling, and hypoxic conditions on the continental shelf. 
rich fisheries and diverse communities, over the next several decades to a century (Orr et al. 2005; Hauri et al. 2009). However, in 2007, the first detailed observations of carbon chemistry in this region revealed that anthropogenically-acidified waters, undersaturated in aragonite, were already upwelling onto the continental shelf to depths of $40 \mathrm{~m}-120 \mathrm{~m}$ in most areas and all the way to the surface along a transect in northern California (Feely et al. 2008). Figure 3.35 shows the depth distribution of the undersaturated waters along the continental shelf from a recent

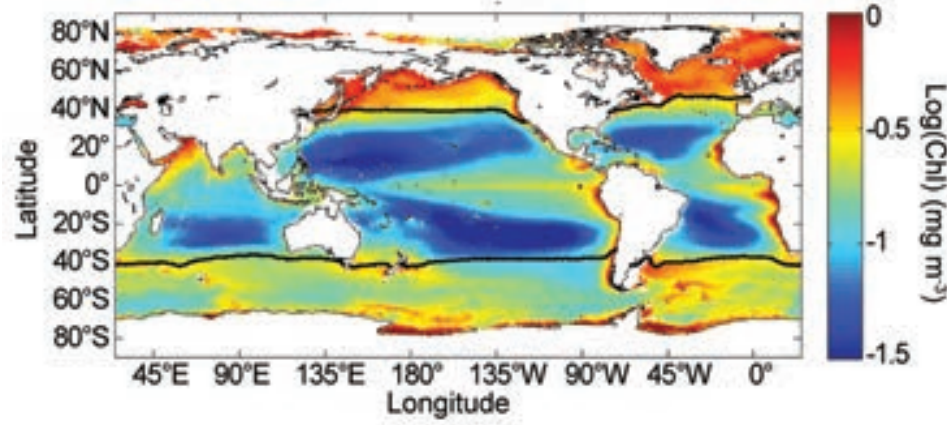

FIG. 3.36. Mean Chl distribution calculated over the entire SeaWiFS record from monthly level 3 imagery (I Nov 1997-30 Nov $2010)$ in units of $\log \left(\mathrm{mg} \mathrm{Chl} \mathrm{m}^{-3}\right)$. Also shown is the location of the mean $15^{\circ} \mathrm{C} \mathrm{SST} \mathrm{isotherm} \mathrm{(black} \mathrm{line).}$ cruise in August-September 2011. The

undersaturated waters reach depths as shallow as 20 $\mathrm{m}-30 \mathrm{~m}$ off the Washington, Oregon, and northern California coasts.

One area of new research in ocean acidification is linking ocean acidification with low oxygen (hypoxic) events along the continental shelves. Oxygen-poor environments present physiological challenges for marine organisms and these are also expected to increase in prevalence under anthropogenic climate change as a result of surface ocean warming and increased stratification (Bopp et al. 2002; Matear and Hirst 2003; Stramma et al. 2008; Rykaczewski and Dunne 2010). The term "hypoxia" implies levels of oxygenation under which macrofauna are negatively impacted. Conditions ranging from hypoxic $(<65 \mu \mathrm{M})$ to anoxic $(0 \mu \mathrm{M})$ have been observed in near-bottom waters on the inner continental shelf within the California Current System with an apparent increase in the frequency and intensity of the oxygen deficit since 2000 (Chan et al. 2008; Grantham et al. 2004; Hales et al. 2006). The conditions of corrosivity and hypoxia are linked on a process level because when remineralization of organic matter occurs under oxic conditions, oxygen is consumed approximately in stoichiometric equivalence (170:117) with the production of $\mathrm{CO}_{2}$. Processes that create aquatic oxygen deficits can also exacerbate the formation of corrosive conditions for calcareous organisms. Thus, globally there may be connections between regional hypoxia and ocean acidification on a global scale.

4) Global ocean phytoplankton-D. A. Siegel, D. Antoine, M. J. Behrenfeld, O. H. Fanton d'Andon, E. Fields, B. A. Franz, P. Goryl, S. Maritorena, C. R. McClain, M. Wang, and J. A. Yoder

Phytoplankton photosynthesis in the sunlit upper layer of the global ocean is the overwhelmingly dominant source of organic matter that fuels marine ecosystems. Phytoplankton contribute roughly half of the global (land and ocean) net primary production (NPP; gross photosynthesis minus plant respiration) and phytoplankton carbon fixation is the primary conduit through which atmospheric $\mathrm{CO}_{2}$ concentrations interact with the ocean's carbon cycle. Phytoplankton productivity depends on the availability of sunlight, macronutrients (e.g., nitrogen, phosphorous), and micronutrients (e.g., iron), and thus is sensitive to climate-driven changes in the delivery of these resources to the euphotic zone.

From September 1997 until December 2010, a near-continuous record of global satellite ocean color observations was available from the Sea viewing Wide-Field of view Sensor (SeaWiFS) mission (e.g., McClain et al. 2004; McClain 2009). Great efforts were made to insure the stability and accuracy of the SeaWiFS radiometric calibration, enabling investigators to address relationships among ocean environmental conditions and phytoplankton productivity (e.g., Behrenfeld et al. 2006; McClain 2009; Siegel et al. 2012, manuscript submitted to Remote Sens. Environ.). The ecosystem property most often derived from ocean color data is surface chlorophyll concentration (Chl). Chl provides a measure of phytoplankton pigments and its variability reflects the combined influences of changes in phytoplankton biomass and its physiological responses to light and nutrient levels (e.g., Falkowski 1984; Behrenfeld et al. 2005, 2008; Siegel et al. 2005; Siegel et al. 2012, manuscript submitted to Remote Sens. Environ.). Figure 3.36 shows the SeaWiFS mission (November 1997-November 2010) mean fields of Chl. Values of Chl span three orders of magnitude globally $(0.03 \mathrm{mg}$ $\mathrm{m}^{-3}$ to $>30 \mathrm{mg} \mathrm{m}^{-3}$ ) and their spatial patterns mimic large scale climatological patterns in Ekman pump- 
ing and seasonal convective mixing (Sverdrup 1955; Yoder et al. 1993). Higher values of $\mathrm{Chl}$ are found in regions of seasonal deep mixing (e.g., North Atlantic and Southern Oceans) and sustained vertical upwelling (e.g., equatorial Atlantic and Pacific Oceans, off California and Peru coasts), while low values are found in the low-nutrient, permanently stratified central ocean gyres (Fig. 3.36).

Unfortunately, the SeaWiFS ceased operating in December 2010 and assessments of global ocean phytoplankton for 2011 require other satellite data assets. Here, observations from NASA's Moderate Resolution Imaging Spectroradiometer (MODIS) on the Aqua platform and the European Space Agency's (ESA) Medium-Resolution Imaging Spectrometer (MERIS) instruments ${ }^{1}$ are used. Observations of chlorophyll concentration, using bio-optical algorithms similar to the SeaWiFS operational algorithms, were available from both sensor datasets and monthly binned imagery starting in July 2002 for both MODIS and MERIS. Raw data from the two satellite sensors are collected and processed by different groups, although many of the same field data and algorithms are employed for both (processing details are in the references listed in the caption for Fig. 3.37). Consequentially, the methods and source data used to track temporal changes in the satellite calibrations are different for MODIS and MERIS (e.g., NRC 2011).

Anomalies of $\log _{e}(\mathrm{Chl})$ for the year 2011 for both MODIS and MERIS are shown in Figs. 3.37a and b, respectively. Annual anomalies were calculated from monthly anomalies for each dataset summed over the year 2011. Natural log transformations are commonly used to interpret data that vary over many orders of magnitude and $\log _{\mathrm{e}}(\mathrm{Chl})$ anomalies can be interpreted as the difference in Chl normalized by its mean value, or simply a percentage change (Campbell 1995).

Both MODIS and MERIS chlorophyll values in 2011 show differences from the long-term mean that are greater than $40 \%$ in many areas (Figs. 3.37a,b). A good correspondence is found in the spatial locations of anomalous Chl values between the two datasets, although the MODIS Chl anomalies appear to be more negative overall. Both datasets find high values of Chl for 2011 throughout much of the tropical Pacific Ocean, subtropical North Atlantic Ocean, tropi-

1 Note communication with the Envisat satellite (which hosts MERIS) ceased on April 8, 2012. This will likely end the MERIS satellite ocean color record presented here (see http://www.esa.int/esaCP/SEMQ2EHWP0H_index_0.html for further details).

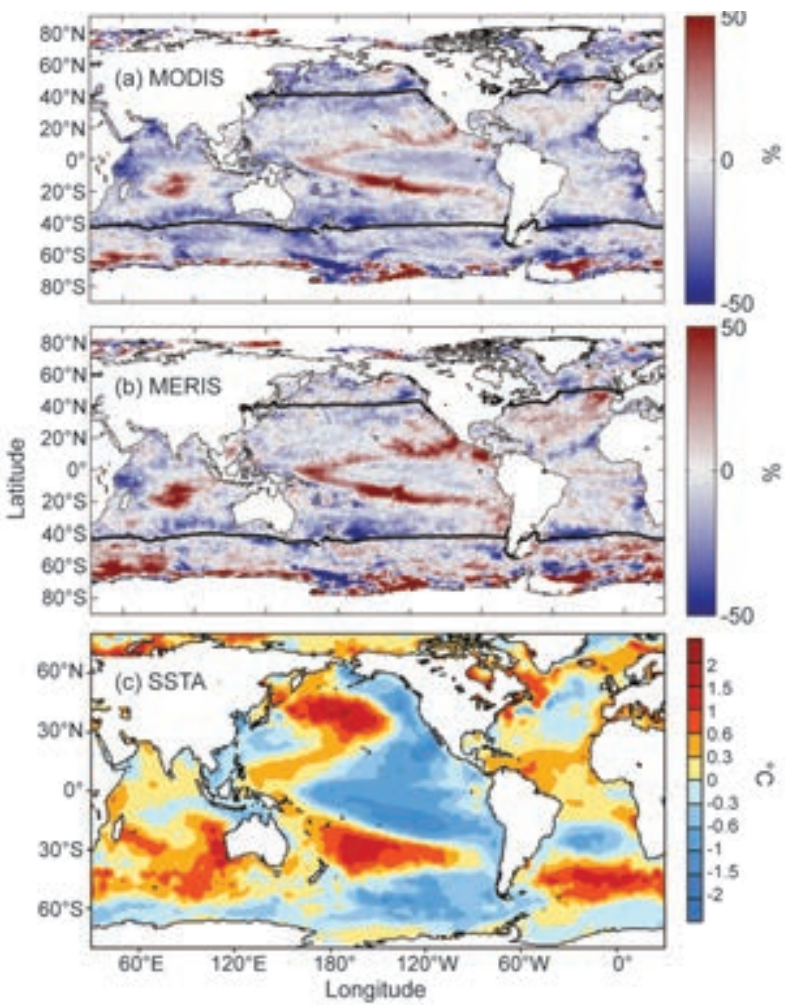

FIG. 3.37. Spatial distribution of summed monthly anomalies for $20 \mathrm{II}$ for (a) MODIS $\log _{\mathrm{e}}(\mathrm{Chl})$ (\% difference from climatology), (b) MERIS $\log _{e}(\mathrm{Chl})$ (\% difference from climatology), and (c) SST ( $\left.{ }^{\circ} \mathrm{C}\right)$. Anomalies are calculated on a $1^{\circ}$ basis as differences in the year 2011 from monthly mean distribution over available data from each mission. MODIS observations are from Reprocessing 2010.0 (http://oceancolor.gsfc.nasa.gov/ WIKI/OCReproc20I00MA.htmI). MERIS observations are from its third data processing (http://earth.eo.esa. int/pcs/envisat/meris/documentation/meris_3rd_reproc/MERIS_3rd_Reprocessing_Changes.pdf). SST anomalies are based upon the Reynolds weekly SST version 2.

cal Indian Ocean, and in portions of the Southern Ocean. Conspicuously low values of Chl during 2011 were found in the western Indian Ocean, the tropical Atlantic, and globally throughout the subtropics.

The climate state of 2011 can be characterized by the development of a strong La Niña event during the second half of the year and a strong negative Pacific decadal oscillation (PDO; see section $3 \mathrm{~b}$ ). In fact, the "wishbone" shaped feature indicative of a La Niña transition can be seen in the log-transformed Chl distribution across the tropical Pacific (Figs. 3.37a,b). The 2011 SST anomaly (SSTA; Fig. 3.37c) is indicative of a reemergence of La Niña conditions, strengthening of negative PDO, development of a positive Indian Ocean dipole, and above-normal SST values in the tropical North Atlantic and midlatitude Southern 

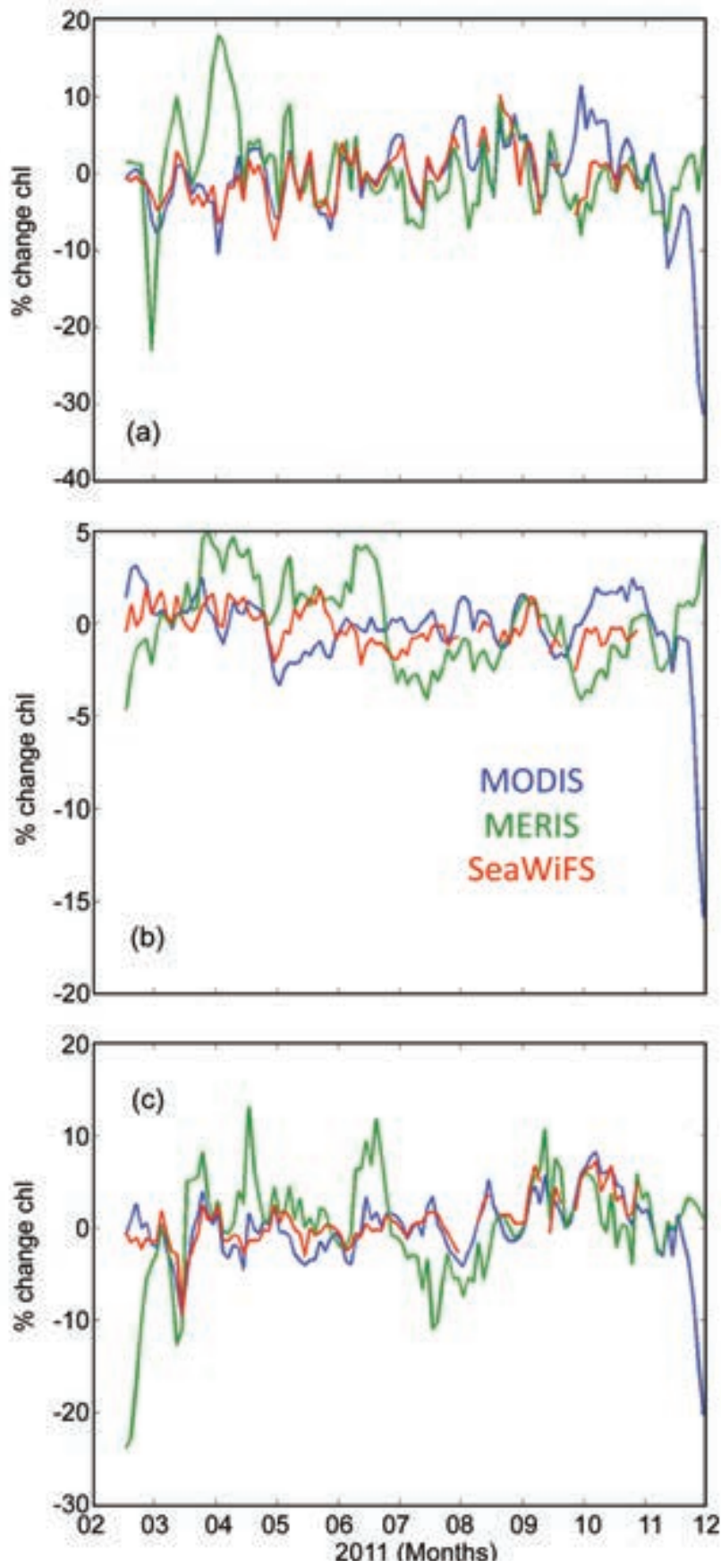

FIG. 3.38. Monthly anomalies for $\log _{\mathrm{e}}(\mathrm{Chl})$ averaged over (a) the cool region of the Northern Hemisphere oceans (mean SST $<15^{\circ} \mathrm{C}$ ), (b) the warm ocean (mean SST $>15^{\circ} \mathrm{C}$ ), and (c) the cool region of the Southern Hemisphere oceans for the SeaWiFS (red), MODIS (blue), and MERIS (green) data records. Figure 3.36 shows the location of the mean $15^{\circ} \mathrm{C}$ isotherm. Values are calculated from $I^{\circ}$ gridded monthly log-transformed anomalies using each mission's climatology following procedures from previous State of the Climate reports and other publications (e.g., Behrenfeld et al. 2006; 2009; O'Malley et al. 2010; Siegel et al. 20II).
Oceans (see section 3b). These patterns in SSTA imprint generally inverse signals in the $\mathrm{Chl}$ anomalies (compare Figs. 3.37a,b with Fig. 3.37c). However, the expected inverse relationship is not perfect and high/ low Chl anomalies are found where the SSTA signals are mixed, such as in the tropical Indian Ocean.

To place the year 2011 in a broader climatological context monthly anomalies of $\log _{\mathrm{e}}(\mathrm{Chl})$ averaged over the cool region of the Northern Hemisphere $(\mathrm{NH})$ oceans (Fig. 3.38a, mean SST $<15^{\circ} \mathrm{C}$ ), the warm ocean (Fig. 3.38b, mean SST $>15^{\circ} \mathrm{C}$ ), and the cool region of the Southern Hemisphere (SH) oceans (Fig. 3.38c) for the SeaWiFS (red), MODIS (blue) and MERIS (green) data records are compared. (The black line in Fig. 3.36 shows the location of the mean $15^{\circ} \mathrm{C}$ isotherm.) Anomalies are calculated as the difference in monthly log-transformed chlorophyll determinations for each $1^{\circ}$ bin from the respective mission's climatology and then summed over the three regions of interest. As before, the natural log-transformed anomalies can be interpreted as percent differences from normal conditions. This evaluation of long-term temporal anomalies follows procedures from previous State of the Climate reports and other publications (e.g., Behrenfeld et al. 2006, 2009; O’Malley et al. 2010; Siegel et al. 2012, manuscript submitted to Remote Sens. Environ.).

For the most part, aggregate $\mathrm{Chl}$ anomalies are bounded approximately by $\pm 10 \%$ differences from normal conditions for the cool oceans (Figs. 3.38a,c) and roughly $\pm 4 \%$ for the warm oceans (Fig. 3.38b). Conspicuous outliers are found for the MERIS mission early in the record (particularly for the cool ocean aggregates) and for the MODIS record in late 2011. Sampling is likely to have an important role in the dispersion of results for the high latitude aggregates during the winter because high solar zenith angles greatly reduce the extent of the regions where good ocean color assessments can be made. The MODIS record for the last part of 2011 is $15 \%$ to about $30 \%$ lower than normal conditions, depending on the ocean region. This extreme result is neither expected nor supported by the MERIS data record, which instead shows positive Chl anomalies in late 2011 for the warm ocean (Fig. 3.38b).

The disparity among satellite data records illustrated in Fig. 3.36, especially for 2011, clearly challenges the ability to distinguish global ocean ecosystem changes over interannual time scales. While the global aggregate time series (Fig. 3.38) shows only a fair correspondence between missions, the spatial patterns for 2011 anomalies look broadly similar for 
MODIS and MERIS (Figs. 3.37a,b). The calculation of the global aggregates averages over many regionalscale anomaly features, creating a time series where smaller, persistent biases become apparent. This means that details in satellite sensor performance, data processing, and tracing of radiometric standards are very important when global aggregates are created and long-term trends are interpreted (e.g., Antoine et al. 2005; Siegel and Franz 2010; NRC 2011; Siegel et al. 2012, manuscript submitted to Remote Sens. Environ.).

The SeaWiFS data record made extensive use of external standards (lunar views and intense ground efforts) to monitor changes in sensor gains and offsets over time and to set the sensor's absolute calibration (e.g., Franz et al. 2007; McClain 2009). The relative uncertainty levels in lunar calibrations for SeaWiFS's top of the atmosphere reflectance determinations were $\sim 0.1 \%$ (compared with the low-frequency fit relationship), making SeaWiFS the long-term standard against which other satellite ocean color records are compared (e.g., Franz et al. 2007; Eplee et al. 2011; NRC 2011; Siegel et al. 2012, manuscript submitted to Remote Sens. Environ.). The recent Sustained Ocean Color Observations report (NRC 2011) made important recommendations based on lessons learned from previous ocean color missions such as SeaWiFS. Several recommendations from the report highlighted the importance of assessing changes in radiometric calibration over time and the repeated reprocessing of these data streams (NRC 2011).

Neither MODIS nor MERIS were designed to make monthly lunar views through the Earth viewing telescope that illuminates the complete optical path and all radiometric detectors (as SeaWiFS does). Consequently, other means have been employed to trace changes in sensor calibration over time (summarized in NRC 2011). Briefly, MERIS relies on a dual solar diffuser approach where changes in the primary diffuser are monitored by a second diffuser that is infrequently exposed to sunlight (Rast and Bezy 1999; Delwart and Bourg 2011). The tracking of radiometric changes in MERIS is further complicated by the sensor design, which employs multiple cameras with multiple detectors per camera to span the crosstrack view. Similarly, MODIS temporal calibration is complicated by the scanner design, which relies on a rotating scan mirror (rather than a rotating telescope) for cross-track observation and leads to different temporal changes at each scan angle. MODIS requires both a solar diffuser calibration and lunar observations to track changes in radiometric calibration (Xiong et al. 2010). However, these on-board measurements are insufficient to fully characterize the changes at all scan angles or to assess changes in polarization sensitivity (Franz et al. 2008) and additional calibration sources have been used to augment the on-board calibration system (Kwiatkowska et al. 2008; Meister et al. 2012). The MODIS Aqua dataset presented here (version 2010.0) used SeaWiFS as a calibration source when it was available (Meister et al. 2012). The severe underestimates of Chl levels for 2011 shown in Fig. 3.38 are caused to large degree by the lack of SeaWiFS observations to cross-calibrate the MODIS sensor signals. Work is currently underway to use natural ground (land) targets to correct the MODIS Aqua signals in the absence of SeaWiFS observations (B. Franz 2012, personal communication). These are details, but the details are critical for assessing long-term changes in satellite ocean color observations-particularly at global scales.

The ecology and biogeochemistry of the oceans are constantly changing in response to climate variability and change. These changes of the ocean biosphere exhibit tremendous spatial heterogeneity that cannot be sampled adequately from point-source or ship-based measurements. Viewing integrated global ocean responses is the province of satellite observations and, for the moment, the ability to visualize these changes is impaired. Regaining full vision will require creative approaches for characterizing current space assets, continually reevaluating and reprocessing existing datasets, and focusing priorities of future sensors on the end-to-end mission requirements that ensure the retrieval of global, climate-quality data products over the lifetime of ocean sensor missions. 
4. THE TROPICS - H. J. Diamond, Ed.

a. Overview-H. J. Diamond

The year was characterized by two distinct La Niña episodes sandwiched around a period of ENSOneutral conditions from April to August. The La Niña at the beginning of the year was of moderate strength with NOAA's Oceanic Niño Index (ONI) between $-1.0^{\circ} \mathrm{C}$ and $-1.4^{\circ} \mathrm{C}$, while the La Niña the latter part of the year was weaker, with the ONI between $-0.5^{\circ} \mathrm{C}$ and $-0.9^{\circ} \mathrm{C}$.

Overall, global tropical cyclone (TC) activity during 2011 was well-below normal, with a total of 74 storms the $1981-2010$ global average is 89 ). This activity was only slightly higher than the record-low number of global TCs (since the start of the satellite era) set in 2010. Only the North Atlantic basin experienced above-normal activity in 2011. It was also the first year since the widespread introduction of the Dvorak intensity-estimation method in the 1980s when only three TCs globally briefly reached the Saffir-Simpson Category 5 intensity level, all in the Northwest Pacific basin.

This chapter consists of seven sections: (1) ENSO and the tropical Pacific; (2) Tropical intraseasonal activity; (3) seasonal TC activity in the seven TC basins: the North Atlantic, Eastern North Pacific, Western North Pacific, North Indian and South Indian Oceans, Southwest Pacific, and Australia; (4) TC heat potential, which aids in summarizing the section for TCs from an ocean heat perspective; (5) Intertropical convergence zone (ITCZ) behavior in the Pacific and Atlantic basins; and (6) the Indian Ocean dipole (IOD). A section detailing the Atlantic Multidecadal Oscillation (AMO) complements some of the other work related to Atlantic hurricane activity, ENSO, the IOD, and the Madden-Julian oscillation (MJO). In picking up on some information published in last year's report on the use of indigenous knowledge related to tropical activity in the South Pacific, a sidebar on the use of indigenous knowledge as an indicator for tropical cyclone activity in Polynesia is included in this year's chapter.

b. ENSO and the tropical Pacific-M. L'Heureux, M. Halpert, and G. D. Bell

I) OCEANIC CONDITIONS

The El Niño-Southern Oscillation (ENSO) is a coupled ocean-atmosphere phenomenon over the tropical Pacific Ocean. Opposite warm and cool phases of ENSO, called El Niño and La Niña, respectively, are classified by NOAA's Climate Prediction Center (CPC) using the Niño-3.4 index, which is

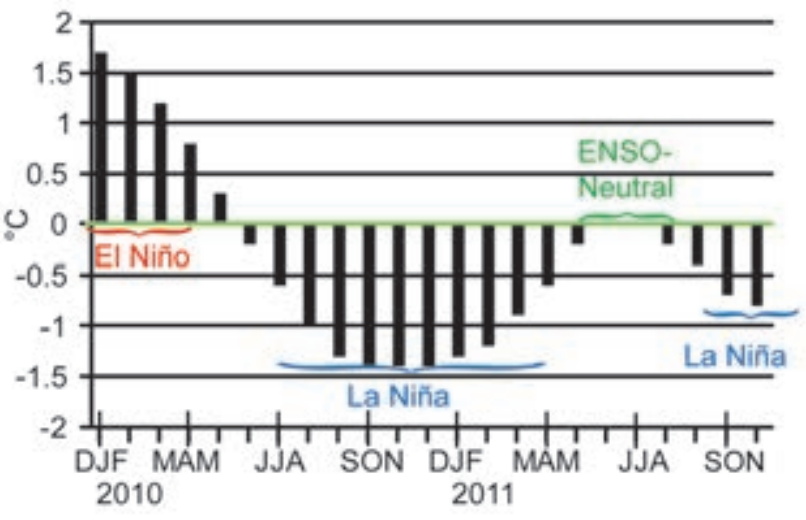

Fıg. 4.I. Time series of the Oceanic Niño Index (ONI, $\left.{ }^{\circ} \mathrm{C}\right)$ during DJF 2010/II through OND 20II. The data are derived from the ERSST-v3b dataset (Smith et al. 2008).

based on the area-averaged sea surface temperature (SST) anomalies in the east-central equatorial Pacific $\left(5^{\circ} \mathrm{N}-5^{\circ} \mathrm{S}, 170^{\circ} \mathrm{W}-120^{\circ} \mathrm{W}\right)$. The Oceanic Niño Index (ONI) is a three-month running average of the Niño3.4 index and is used by NOAA to classify ENSO events historically ${ }^{1}$.

A time series of the ONI shows two distinct $\mathrm{La}$ Niña episodes during 2011 (Fig. 4.1). The first lasted from June-August (JJA) 2010 through March-May (MAM) 2011, reaching moderate strength (ONI between $-1.0^{\circ} \mathrm{C}$ and $-1.4^{\circ} \mathrm{C}$ ) between July-September (JAS) 2010 and January-March (JFM) 2011. ENSOneutral conditions then prevailed from April-June (AMJ) to August-October (ASO) 2011, followed by a return to weak La Niña conditions through the end of the year (ONI between $-0.5^{\circ} \mathrm{C}$ and $-0.9^{\circ} \mathrm{C}$ ).

The spatial structure and evolution of the tropical Pacific SSTs and anomalies during 2011 are shown in Fig. 4.2. During December 2010-February 2011 (DJF), La Niña conditions were associated with an enhanced equatorial cold tongue that extended from the west coast of South America to the International Date line (hereafter date line) $)^{2}$, and with a westward retraction in the area of warmest SSTs $\left(>30^{\circ} \mathrm{C}\right)$ to the area north of New Guinea (Fig. 4.2a). Negative SST anomalies cooler than $-1.0^{\circ} \mathrm{C}$ extended across the cen-

\footnotetext{
${ }^{1}$ For historical purposes, the CPC classifies an El Niño (La Niña) episode when the ONI is greater (less) than or equal to $+0.5^{\circ} \mathrm{C}\left(-0.5^{\circ} \mathrm{C}\right)$ for five consecutive overlapping seasons (as measured by the ERSST-v3b dataset using 1971-2000 monthly mean normals, Smith et al. 2008).

2 The date line has no physical significance as it merely traverses around the Antimeridian at $180^{\circ}$ longitude, but is still a useful and popularly used reference point for describing activity in the tropics.
} 

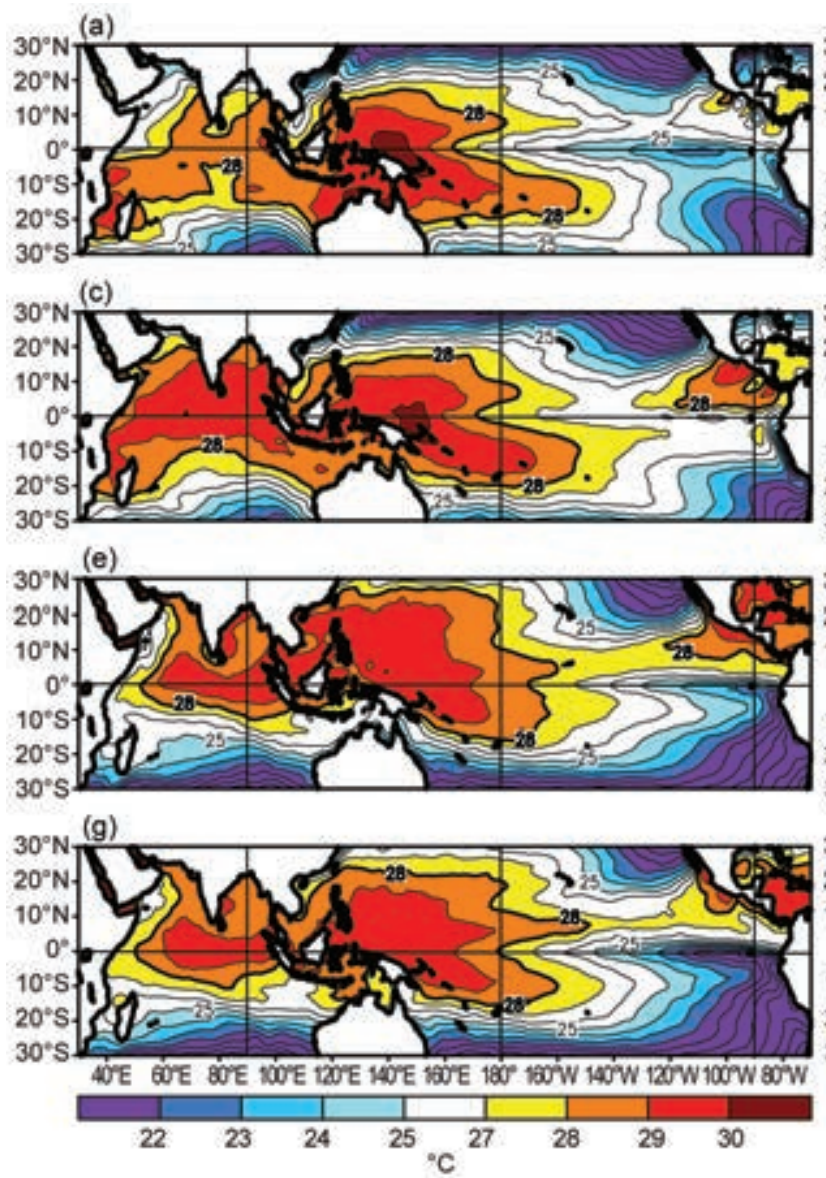

(b)

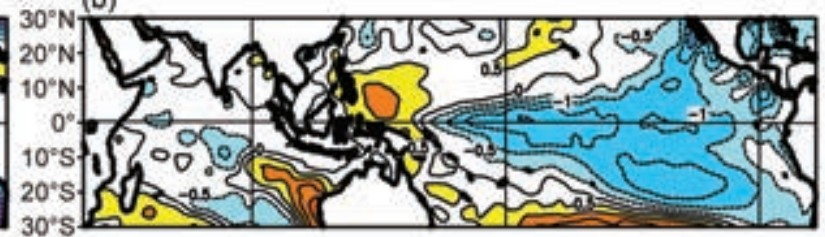

(d)
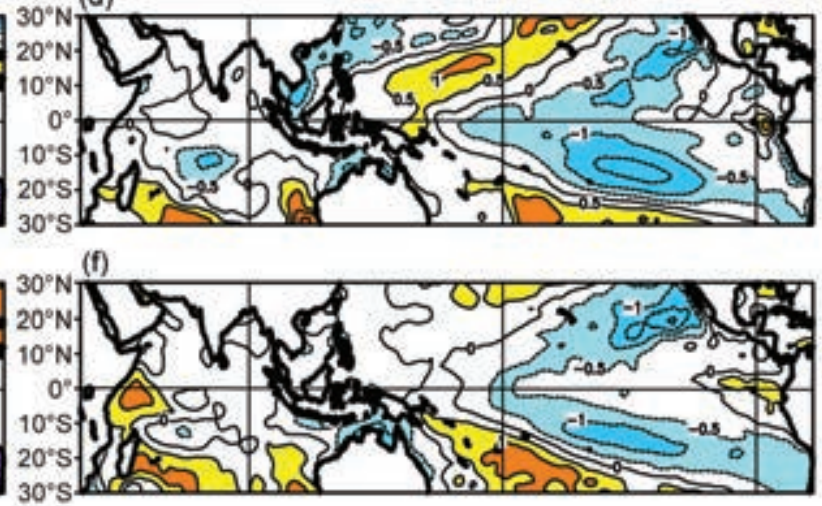

(h)

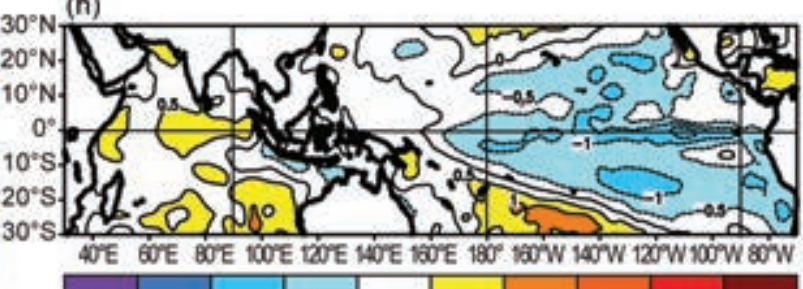

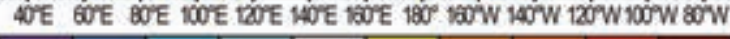

$\begin{array}{lllllllll}3 & -2 & -1 & -0.5 & 0.5 & 1 & 2 & 3 & 4 \\ & & & & & \end{array}$

FIG. 4.2. Seasonal SSTs (left) and anomalies (right) for (a) and (b) DJF 20I0/II, (c) and (d) MAM 20II, (e) and (f) JJA $20 \mathrm{II}$ and $(\mathrm{g})$ and $(\mathrm{h})$ SON 20II. Contour interval for total (anomalous) SST is $1^{\circ} \mathrm{C}\left(0.5^{\circ} \mathrm{C}\right)$. Anomalies are departures from the 198I-2010 seasonal-adjusted Optimum Interpolation (OI) SST climatology (Smith and Reynolds 1998).

tral and eastern equatorial Pacific, and throughout the subtropical eastern Pacific in both hemispheres (Fig. 4.2b). Conversely, SSTs were above average in the western equatorial Pacific and portions of the western subtropical Pacific of both hemispheres. The resulting horseshoe-shaped anomaly pattern is typical of La Niña.

During MAM, La Niña became weak (ONI of $-0.6^{\circ} \mathrm{C}$ ) as SST anomalies weakened throughout the tropical Pacific and conditions returned to near-average in the eastern Pacific (Figs. 4.2c,d). This evolution is consistent with the 1950-2010 trend during boreal springtime La Niña events, which favors relatively warmer conditions in the eastern equatorial Pacific and relatively cooler conditions in the central Pacific (L'Heureux et al. 2012).

During JJA, ENSO-neutral conditions were present, with near-average SSTs observed across much of the central and east-central equatorial Pacific (Figs. 4.2e,f). However, large regions of below-average SSTs persisted in the off-equatorial central and eastern
Pacific. By September-November (SON), a weak La Niña had returned $\left(\mathrm{ONI}\right.$ of $\left.-0.7^{\circ} \mathrm{C}\right)$ as the equatorial cold tongue again became stronger than average (Fig. $4.2 \mathrm{~g}$ ) and SST anomalies colder than $-1.0^{\circ} \mathrm{C}$ covered the eastern equatorial Pacific (Fig. 4.2h).

Consistent with the above evolution, the subsurface temperature structure varied considerably during the year (Fig. 4.3). In DJF, temperatures were below average from the surface to $150 \mathrm{~m}$ depth east of $160^{\circ} \mathrm{W}$, and above average (anomalies exceeding $+4^{\circ} \mathrm{C}$ ) in the western Pacific between $100 \mathrm{~m}$ and $200 \mathrm{~m}$ depth (Fig. 4.3a). This overall anomaly pattern is typical of La Niña, and reflected a shallower(deeper-) than-average thermocline in the eastern (western) Pacific.

During MAM, subsurface temperatures returned to near average across the eastern half of the equatorial Pacific and the area of above-average temperatures expanded eastward (Fig. 4.3b). This evolution reflected the transition to ENSO-neutral conditions that began in AMJ, partly in association with the 

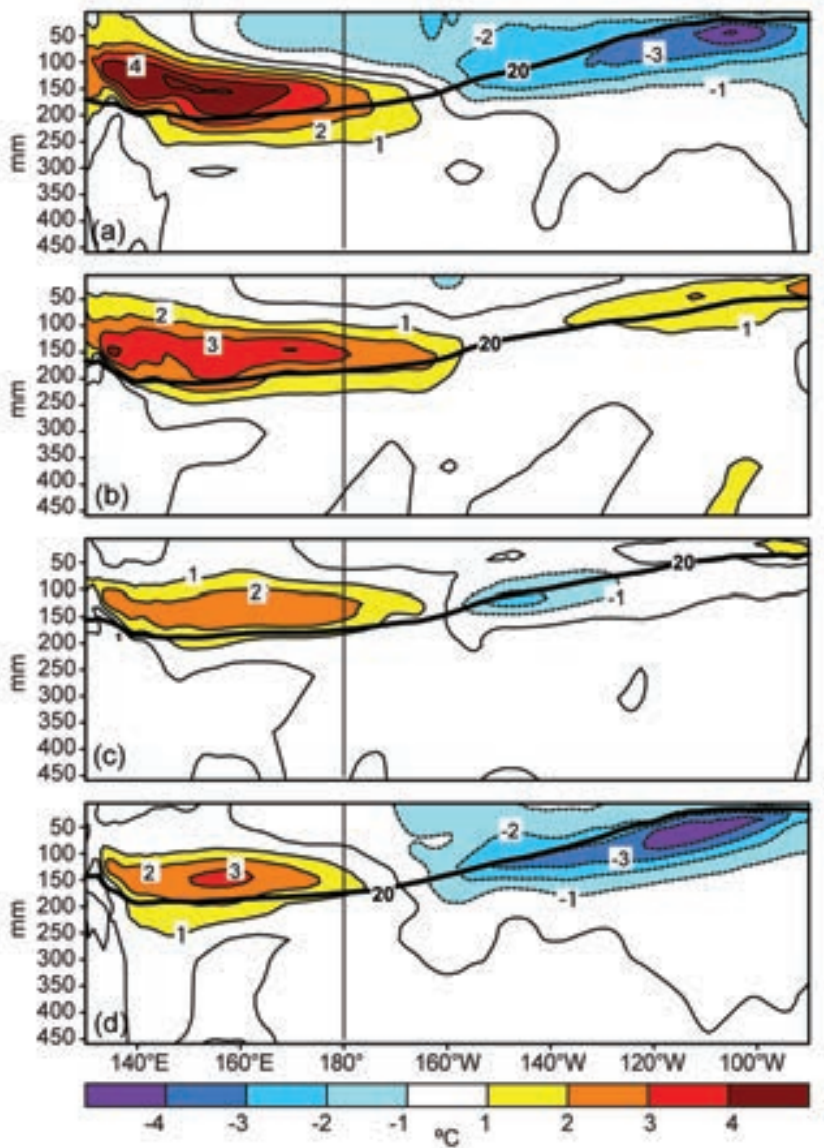

FIG. 4.3. Equatorial depth-longitude section of ocean temperature anomalies $\left({ }^{\circ} \mathrm{C}\right)$ averaged between $5^{\circ} \mathrm{N}$ and $5^{\circ} \mathrm{S}$ during (a) DJF 2010/II, (b) MAM 20II, (c) JJA $20 \mathrm{II}$, and (d) SON 20II. The $20^{\circ} \mathrm{C}$ isotherm (thick solid line) approximates the center of the oceanic thermocline. The data are derived from an analysis system that assimilates oceanic observations into an oceanic global circulation model (Smith et al. 2008). Anomalies are departures from the $1981-2010$ period monthly means.

downwelling phase of a strong equatorial oceanic Kelvin wave (see section 4c). By SON, the subsurface temperature pattern again reflected an increased east-west thermocline gradient more reminiscent of conditions during DJF, heralding the return of $\mathrm{La}$ Niña (Fig. 4.3d).

\section{2) AtMOsPHeric CirCUlation: Tropics}

Although SSTs and subsurface temperatures in the equatorial Pacific were near average during the boreal summer, many aspects of the tropical atmospheric circulation retained their La Niña characteristics. As a result, the low-level $850-\mathrm{hPa}$ trade winds in the western and central equatorial Pacific (west of $150^{\circ} \mathrm{W}$ ) were enhanced throughout the year, as was the crossequatorial flow over the eastern Pacific (Fig. 4.4). (a)

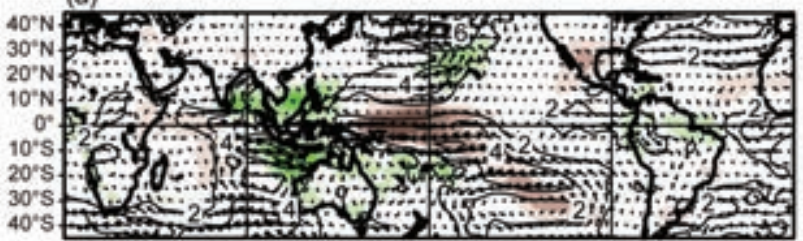

(b)

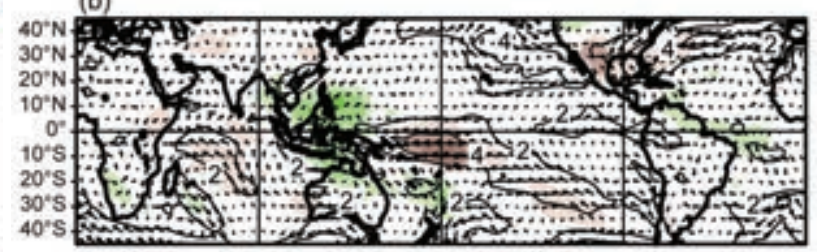

(c)

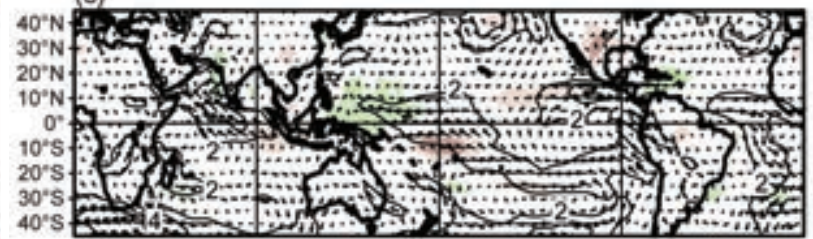

(d)

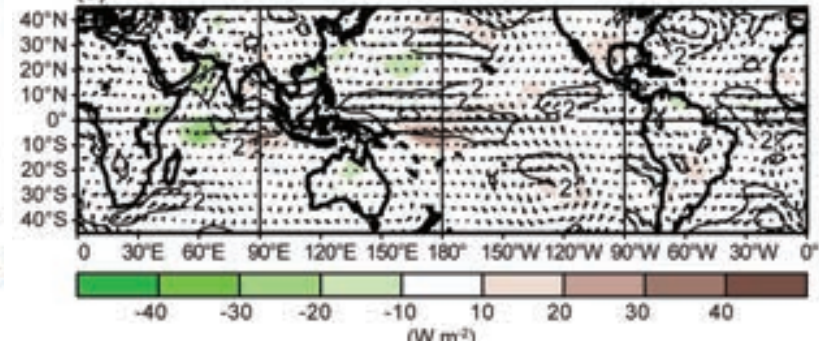

Fig. 4.4. Anomalous $850-\mathrm{hPa}$ wind vector and speed (contours, $\mathrm{m} \mathrm{s}^{-1}$ ) and anomalous OLR (shaded, $\mathrm{W} \mathrm{m}^{-2}$ ) during (a) DJF 20I0/II, (b) MAM 20II, (c) JJA 20II, and (d) SON 20II. Anomalies are departures from the 1981-2010 period monthly means.

Additionally, westerly wind anomalies prevailed at $200 \mathrm{hPa}$ throughout the year across the central equatorial Pacific, as did a cyclonic circulation couplet straddling the equator (near $150^{\circ} \mathrm{W}$ ) in the subtropics of both hemispheres (Fig. 4.5). These conditions were associated with below-average precipitation near the date line in all seasons (brown shading in Figs. $4.4,4.5)$. Collectively, they reflected well-known La Niña-related features such as an enhanced equatorial Walker circulation and a suppressed Hadley circulation over the central Pacific.

While the large-scale tropical atmospheric circulation retained general La Niña characteristics throughout the year, there were some notable circulation differences among the seasons. The pattern of enhanced convection over Indonesia (green shading) and suppressed convection over the west-central equatorial Pacific was strongest during DJF as mature La Niña conditions developed (shading in Figs. 4.4a, 4.5a). The region of suppressed convection near the 
(a)

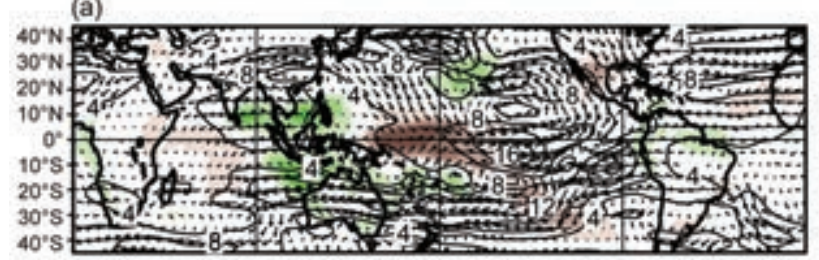

(b)

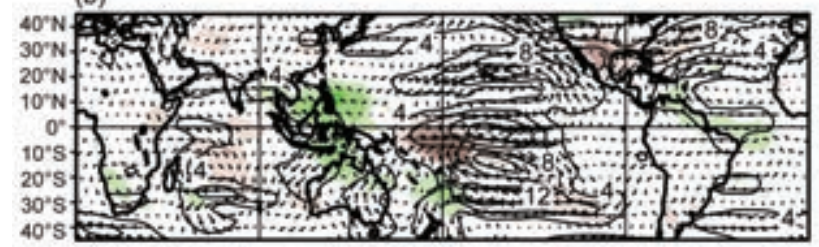

(c)

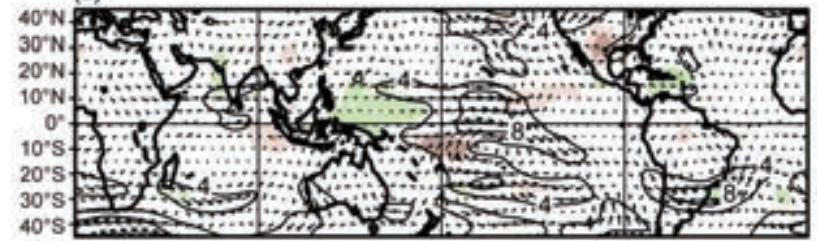

(d)

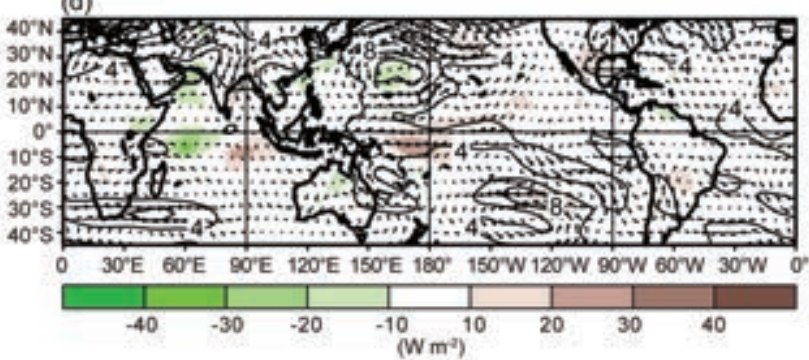

Fig. 4.5. Anomalous 200-hPa wind vector and speed (contours, $\mathrm{m} \mathrm{s}^{-1}$ ) and anomalous OLR (shaded, $\mathrm{W} \mathrm{m}^{-2}$ ) during (a) DJF 2010/II, (b) MAM 20II, (c) JJA 20II, and (d) SON 20II. Anomalies are departures from the 1981-2010 period monthly means.

date line was weakest during the second half of the year, even as La Niña reemerged (Figs. 4.4c,d; $4.5 c$,d). The enhanced convection near Indonesia gradually weakened into JJA (Figs. 4.4c, $4.5 \mathrm{c}$ ), and by SON had become near to below average across the region (Figs. $4.4 \mathrm{~d}, 4.5 \mathrm{~d})$.

Consistent with the declining strength of the convective anomalies through the year, the anomalous 200-hPa equatorial westerlies over the tropical Pacific were also strongest during DJF (Fig. 4.5a) and weakest during SON (Fig. 4.5b). The anomalous cyclonic circulation anomalies in the subtropics of both hemispheres, located just to the east of suppressed convection, also weakened as the year progressed.

At $850 \mathrm{hPa}$, the anomalous low-level easterlies were strongest during MAM (Fig. 4.4b) and remained close to their peak intensity though the rest of the year, although the core of the largest anomalies shifted into the western equatorial Pacific during JJA and SON (Figs. 4.4c,d).
3) AtMOSPHERIC CIRCULATION: EXTRATROPICS

While the strongest extratropical anomalies associated with La Niña occurred during DJF and MAM, an anomalous anticyclone was evident over the extratropical central-to-eastern North Pacific Ocean throughout the year (see Figs. A1.2-A1.5). This feature likely reflected the persistence of belowaverage convection over the central equatorial Pacific.

The position of the East Asian jet stream (located $30^{\circ} \mathrm{N}-40^{\circ} \mathrm{N}$ ) is sensitive to the location of anomalous convective heating during ENSO and to the associated subtropical circulation anomalies. During La Niña, the lack of convection over the central equatorial Pacific and increased convection over Indonesia causes a westward retraction of the East Asian jet stream to west of the date line, along with a westward shift and amplification of the jet exit region.

This jet structure favors an anomalous westward shift in the downstream ridge axis normally located over western North America. Such a shift during 2011 was indicated by the lack of a mean ridge over western North America throughout the year, along with the anomalous anticyclone over the central and eastern North Pacific.

Another indication of this westward shift during DJF (see Fig. A1.2) was the presence of a mean upperlevel ridge in the vicinity of the climatological mean Aleutian Low. Over the United States, this anomalous circulation translated into a storm track that was shifted north of normal, and contributed to aboveaverage precipitation across the northern US and below-average precipitation across the southern US.

ENSO often occurs in combination with other climate factors or teleconnection patterns, such as the Arctic Oscillation (AO) or North Atlantic Oscillation (NAO), and the tropical multidecadal signal or AMO (see section 4d2). For example, while the 500-hPa circulation over the North Pacific during DJF reflected characteristics of La Niña, the largerscale hemispheric circulation showed strong links to the negative phase of the $\mathrm{AO} / \mathrm{NAO}$.

As this $\mathrm{AO}$ pattern dissipated, the 500 -hPa heights near Hudson Bay flipped from above average during DJF to below average during MAM (Fig. A1.3). Also during this period, the axis of the anomalous North Pacific ridge shifted eastward from the Aleutian Islands, near the date line, to $150^{\circ} \mathrm{W}$. Downstream, the anomalous trough over the northwestern US and western Canada strengthened considerably during MAM. Over North America, this evolution contributed to temperature and precipitation patterns dur- 
ing MAM that more closely resembled the canonical wintertime La Niña signal.

La Niña also affected the circulation over the South Pacific Ocean. For example, the anticyclonic anomalies over the central subtropical South Pacific reflected a strengthening of the normal mid-Pacific trough and a westward retraction of the ridge axis to the extreme western Pacific. These conditions were associated with easterly 200 -hPa wind anomalies across the central Pacific near $30^{\circ} \mathrm{S}$, which coincided with the exit region of the South Pacific jet core (Fig. 4.5) and therefore mirrored the weakening and westward retraction of the East Asian jet to west of the dateline.

4) ENSO TEMPERATURE AND PRECIPITATION IMPACTS

During DJF and MAM, the precipitation patterns typically associated with La Niña (Ropelewski and Halpert 1989; see also http://www.cpc.ncep.noaa. gov/products/precip/CWlink/ENSO/regressions/) were observed over many parts of the world. These included below-average precipitation over the equatorial western and central Pacific Ocean, much of the southern tier of the contiguous United States, the Horn of Africa, and southeastern South America. Impacts also included above-average precipitation over northern Australia, Indonesia, the Philippines, Southeast Asia, and northeastern South America.

La Niña-related temperature impacts during DJF and MAM included cooler-than-average conditions over northern Australia, the west coast of South America, and the northwestern and north-central United States extending into Canada and Alaska. During DJF, cooler-than-average conditions across parts of the northern US were influenced by the negative phase of the AO/NAO.

\section{c. Tropical intraseasonal activity-J. Gottschalck and G. D. Bell}

The Madden-Julian oscillation (MJO; Madden and Julian 1971, 1972, 1994; Zhang 2005) is a leading climate mode of tropical convective variability that occurs on intraseasonal timescales. The convective anomalies associated with the MJO often have the same spatial scale as ENSO, but differ in that they exhibit a distinct eastward propagation and generally traverse the globe in 30-60 days. The MJO can strongly affect the tropical and extratropical atmospheric circulation patterns, and may produce ENSOlike anomalies (Mo and Kousky 1993; Kousky and Kayano 1994; Kayano and Kousky 1999). The MJO is often quite variable in a given year, with periods of moderate-to-strong activity sometimes followed by little or no activity. Overall, the MJO tends to be most active during neutral and weak ENSO periods, and is often absent during strong El Niño events (Hendon et al. 1999; Zhang and Gottschalck 2002; Zhang 2005).

The MJO is seen by continuous eastward propagation of $200-\mathrm{hPa}$ velocity potential anomalies around the globe. A time-longitude section of this parameter shows three periods during 2011 with MJO activity (Fig. 4.6). These include: (1) a short-lived episode during January (MJO \#1); (2) moderate-strength activity during March to mid-May (MJO \#2); and (3) strong activity from late September to early December (MJO \#3). There was little MJO activity during the summer, when the intraseasonal variability was often dominated by higher frequency and faster propagating

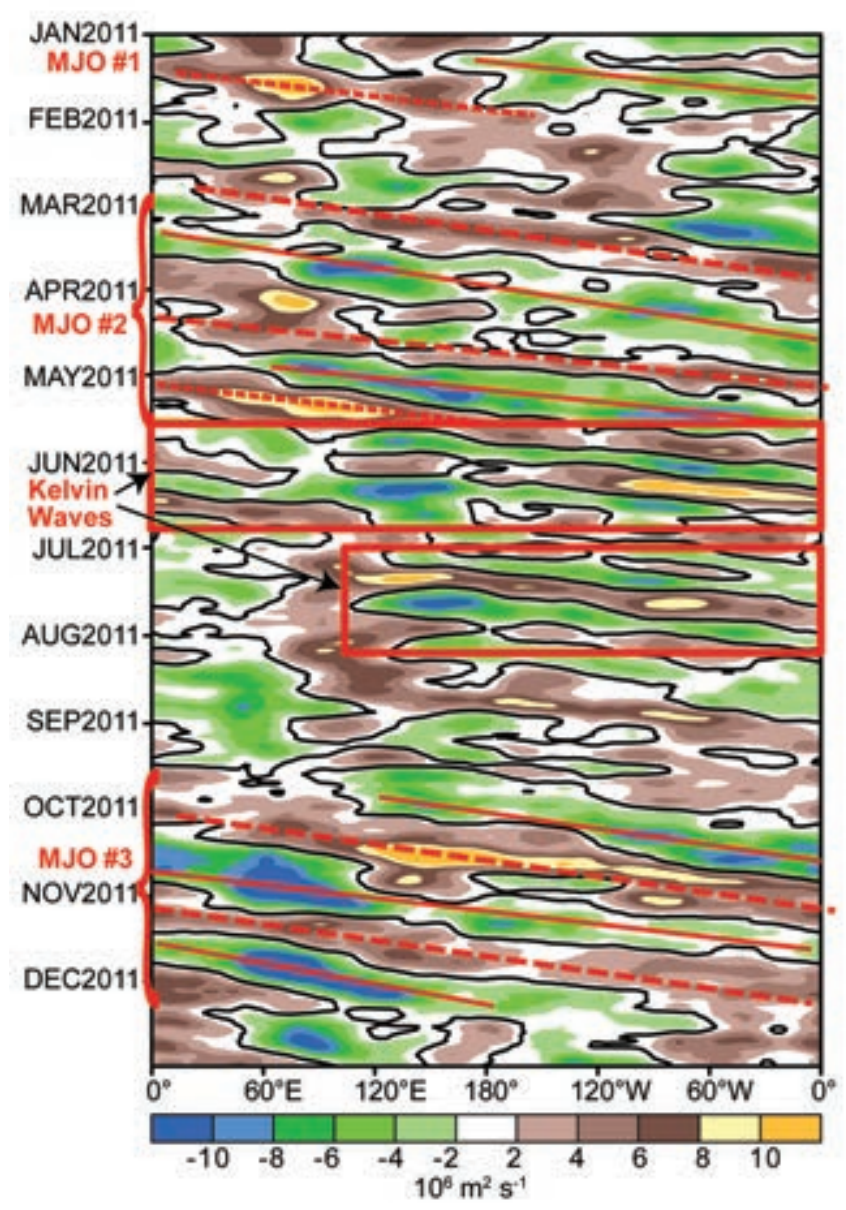

FIG. 4.6. Time-longitude section for $201 \mathrm{l}$ of anomalous 200-hPa velocity potential $\left(\times 10^{6} \mathrm{~m}^{2} \mathrm{~s}^{-1}\right)$ averaged between $5^{\circ} \mathrm{N}$ and $5^{\circ} \mathrm{S}$. For each day, the period mean is removed prior to plotting. Green (brown) shading highlights likely areas of anomalous divergence and rising motion (convergence and sinking motion). Red lines and labels highlight the main MJO episodes. The June-August atmospheric Kelvin wave activity is also indicated. Anomalies are departures from the I98I-2010 base period daily means. 
atmospheric Kelvin waves (Wheeler and Kiladis 1999; Wheeler and Weickmann 2001).

The first period of MJO activity (MJO \#1) featured the eastward propagation of enhanced equatorial convection (green shading) across the Western Hemisphere and suppressed convection (brown shading) across the Eastern Hemisphere. Although this activity was generally short-lived, it caused a significant weakening of the low-level trade winds across the western Pacific, which helped to trigger a downwelling oceanic Kelvin wave (Roundy and Kiladis 2006) in late January (Fig. 4.7, dashed line). This oceanic Kelvin wave acted to increase the subsurface temperatures in the central and eastern Pacific during March and April as it approached the South American coast, thereby contributing to the weakening of the 2010/11 La Niña episode. This was the only appreciable downwelling oceanic Kelvin wave of the year.

A longer period of MJO activity began in early March and lasted well into May (MJO \#2), with the most robust convective signatures seen during March and early May. Two complete cycles were evident

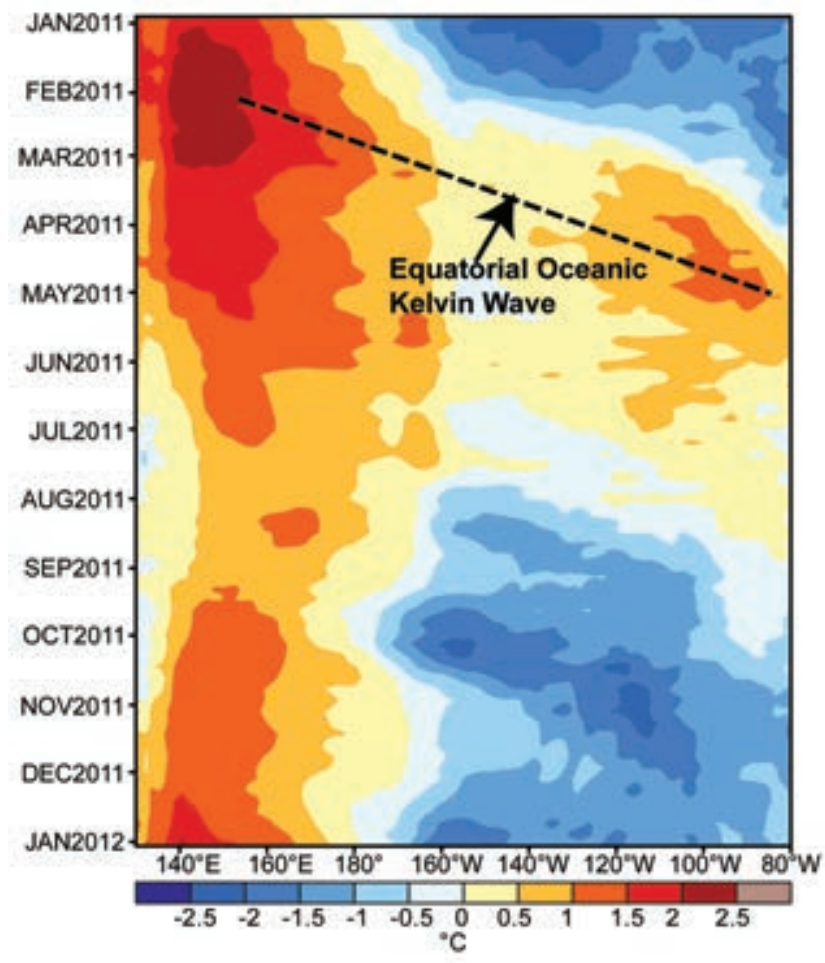

FIG. 4.7. Time-longitude section for $201 \mathrm{I}$ of the anomalous upper ocean $(0 \mathrm{~m}-300 \mathrm{~m})$ heat content $\left({ }^{\circ} \mathrm{C}\right)$ averaged between $5^{\circ} \mathrm{N}$ and $5^{\circ} \mathrm{S}$. Blue (yellow/red) shading indicates below- (above-) average heat content. The downwelling phases (dashed lines) of equatorial oceanic Kelvin waves are indicated. Anomalies are departures from the 1981-2010 base period means. during this three-month period, as seen by multiple traverses around the globe of the areas of enhanced and suppressed convection. Although these propagating anomaly patterns continued into June, their forward speed and spatial scale at that time became more characteristic of higher-frequency atmospheric Kelvin wave activity.

The third period of MJO activity occurred from late September to early December (MJO \#3), and reflected the strongest and longest $\mathrm{MJO}$ episode since October 2007-February 2008 (Gottschalck and Bell 2009). The MJO again displayed two successive complete cycles, with the enhanced convective phase over the Maritime Continent in late September shifting eastward and returning to this region in early November and again in early December. The periods of the two cycles to traverse the global tropics were approximately 45 and 30 days, respectively. The enhanced convective phase of the first cycle, during its time in the Western Hemisphere, contributed to the development of favorable conditions over the Atlantic basin for the formation of Major Hurricane Rina in mid-October.

Convection was particularly intense over the Indian Ocean during late October/early November and again in late November/early December. The initiation and continuation of this strong MJO activity coincided with the Intensive Observing Period (IOP) of the Dynamics of the MJO (DYNAMO) field campaign, whose objective was to better understand the mechanisms of MJO onset and maintenance. Consequently, this MJO activity was well sampled by various in situ measurements, the NOAA P3 aircraft, and two ship research vessels.

\section{d. Tropical cyclones}

I) OVERVIEW-H. J. Diamond and B. C. Trewin

The International Best Track Archive for Climate Stewardship (IBTrACS) comprises historical tropical cyclone best-track data from numerous sources around the globe, including all of the Regional Specialized Meteorological Centers (RSMC; Knapp et al. 2010). To date, IBTrACS represents the most complete compilation of tropical cyclone data and offers a unique opportunity to revisit the global climatology of tropical cyclones. Using IBTrACS data (Schreck et al. 2012), a 30-year average value for storms (based upon WMO-based RSMC numbers) will be noted for each basin.

The global tallying of total tropical cyclone (TC) numbers is challenging and involves more than simply adding up basin totals because some storms cross 
basin boundaries, some basins overlap, and multiple agencies are involved in tracking and forecasting TCs. Compiling the activity over all seven TC basins, the 2011 season $(2010 / 11$ in the Southern Hemisphere) saw a well-below-average (1981-2010 base period) number of named storms (NS; wind speeds $\geq 34$ kts or $\left.17.5 \mathrm{~m} \mathrm{~s}^{-1}\right)$ and hurricanes/ typhoons/cyclones (HTC; wind speeds $\geq 64 \mathrm{kts}$ or $32.9 \mathrm{~m} \mathrm{~s}^{-1}$ ) and an above-average number of major HTCs (wind speeds $\geq$ $96 \mathrm{kts}$ or $\left.49.4 \mathrm{~m} \mathrm{~s}^{-1}\right)$. Globally, 74 named storms ${ }^{3}$ developed during the 2011 season (global average is 89 ), with 38 becoming HTCs (global average is 44). Of these, 22 (compared to 26 in

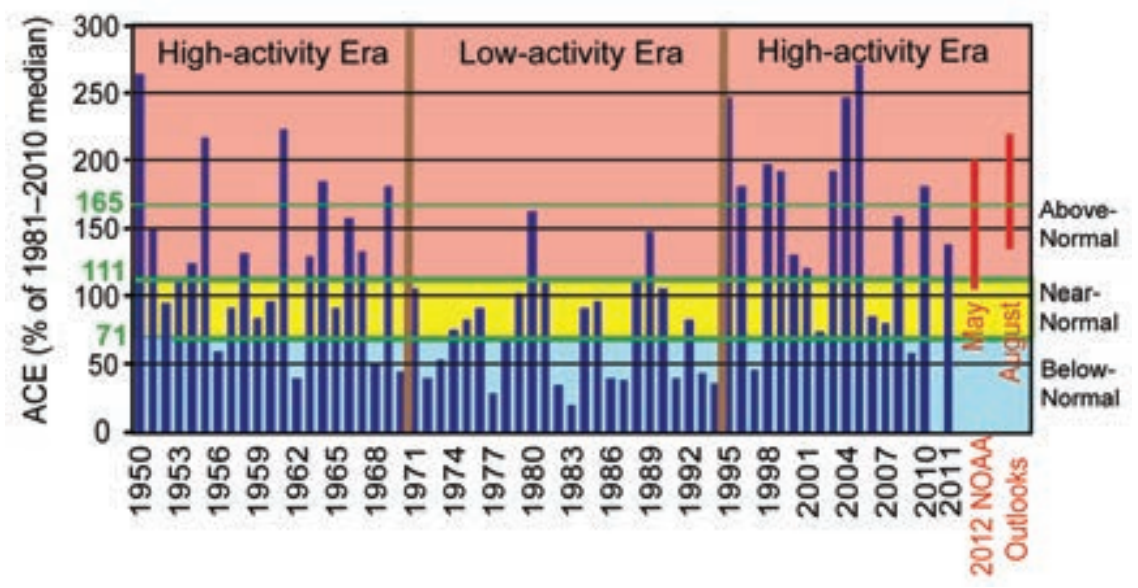

FIG. 4.8. NOAA's ACE index expressed as percent of the $1981-2010$ median value. ACE is calculated by summing the squares of the six-hourly maximum sustained wind speed (knots) for all periods while the storm has at least tropical storm strength. Red bars show NOAA's predicted ACE ranges in their May and August seasonal hurricane outlooks. Pink, yellow, and blue shadings correspond to NOAA's classifications for above-, near-, and belownormal seasons, respectively. The $165 \%$ threshold for a hyperactive season is indicated. Vertical brown lines separate high- and low-activity eras.
2006, 18 in 2007, 20 in 2008, 16 in 2009, and 22 in 2010) attained major/intense status (global average is 19). Therefore, while the overall NS count was wellbelow average, the number of major/intense storms was above the IBTrACS global average.

On the whole, while global tropical cyclone activity was again below normal in 2011, it was higher than in 2010, which set the record for the lowest number of global TCs since the start of the satellite era. There were no clear-cut Category 5 systems during the year, an unusual occurrence, with the year's most intense systems: (1) Adrian, Dora, Eugene, Hilary, and Kenneth in the Northeast Pacific; (2) Ophelia in the North Atlantic; (3) Nanmadol, Songda, and Muifa in the Northwest Pacific; and (4) Yasi in the Australian region, all peaking at Category $4^{4}$.

The only basin which had substantially abovenormal activity in 2011 was the North Atlantic, where elevated TC activity is a typical response to La Niña has been seen in 12 of the last 17 seasons since 1995 . Conversely, the South Indian, North Indian, and

\footnotetext{
${ }^{3}$ It should be noted that in the Western North Pacific there were an additional seven unnamed tropical depressions recorded by the Japan Meteorological Agency (JMA) that were not included in this total.

${ }^{4}$ Typhoons Songda and Muifa were classified as Category 5 operationally by the Joint Typhoon Warning Center but Category 4 in the best-track dataset produced by Japan Meteorological Agency, the responsible World Meteorological Organization center for the Northwest Pacific.
}

Northeast Pacific basins experienced well-belownormal TC numbers (although the Northeast Pacific had an above-normal average number of hurricanes and major hurricanes). Part of the explanation for the low global number of tropical cyclones was that the characteristic La Niña boost to numbers in the Australian region, which would normally offset $\mathrm{La}$ Niña-induced deficits in many other hurricane regions, was absent in 2011, with both the Australian region and the Southwest Pacific basins experiencing near-normal activity.

2) Atlantic basin-G. D. Bell, E. S. Blake, C. W. Landsea, T. B. Kimberlain, S. B. Goldenberg, J. Schemm, and R. J. Pasch

(i) 2011 Seasonal activity

The 2011 Atlantic hurricane season produced 19 tropical storms (TS), of which 7 became hurricanes and 4 became major hurricanes. The 30 -year IBTrACS seasonal averages are 11.9 named storms, 6.4 hurricanes, and 2.7 major hurricanes $(\mathrm{MH})$. The August-October (ASO) period is typically the peak of the season, and all but five named storms during 2011 formed in ASO.

The 2011 seasonal Accumulated Cyclone Energy (ACE) value (Bell et al. 2000) was $126.3 \times 10^{4} \mathrm{kt}^{2}$, which corresponds to $137 \%$ of the 1981-2010 median (Fig. 4.8). NOAA classifies the 2011 season as above normal (http://www.cpc.ncep.noaa.gov/products/ outlooks/background_information.shtml). This is the 12th above-normal season since the current high activity era for Atlantic hurricanes began in 1995 
(Goldenberg et al. 2001), and the 14th busiest season since 1966. NOAA's seasonal hurricane outlooks, issued in late May and early August (http://www.cpc .ncep.noaa.gov/products/outlooks/hurricane-archive .shtml) by the CPC, indicated a high likelihood of an above-normal 2011 season (red bars).

Four global climate factors influenced the 2011 Atlantic hurricane season. Three of these contributed to more conducive conditions within the Main Development Region (MDR), including the activeAtlantic phase of the tropical multidecadal signal (sections $4 \mathrm{~d} 2 v i$ and $4 \mathrm{~g}$ of this report, and Bell and Chelliah 2006); La Niña (discussed in section 4b); and anomalously warm SSTs in the MDR (section $4 \mathrm{~d} 2 i v$ ). A fourth climate factor, the Indian Ocean dipole, may have acted to limit the overall activity for the 2011 season and is discussed in sections $4 \mathrm{~d} 2$ viii and $4 \mathrm{~h}$ of this report.

\section{(ii) Storm tracks}

The Atlantic storm tracks during 2011 (Fig. 4.9, brown lines) were generally divided into three clusters. One cluster comprised six storms that formed over the central and eastern tropical Atlantic, which is the eastern half of the MDR (Fig. 4.9, green boxed region encompassing the tropical Atlantic Ocean and Caribbean Sea between $9.5^{\circ} \mathrm{N}$ and $21.5^{\circ} \mathrm{N}$; Goldenberg et al. 2001). Five of these storms eventually became hurricanes (three became major) and three made landfall. Maria and Ophelia made landfall in Newfoundland, Canada, with tropical storm strength, and Irene made landfall as a hurricane along the US Atlantic coast.

The second cluster consisted of six systems (four named storms and two hurricanes, with one be-

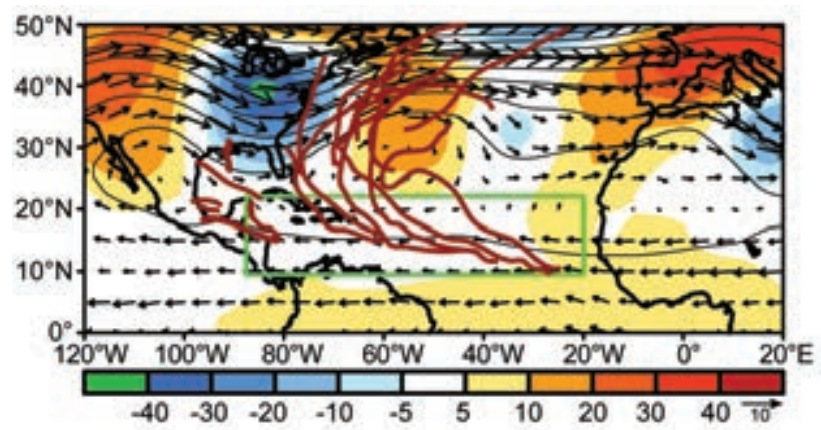

FIG. 4.9. ASO 20II: 500-hPa heights (contours, m), anomalies (shading), and layer mean wind vectors $\left(\mathrm{m} \mathrm{s}^{-1}\right)$ between $600 \mathrm{hPa}$ and $300 \mathrm{hPa}$. Atlantic named storm tracks are shown in brown. Green box denotes the MDR. Vector scale is below right of color bar. Anomalies are with respect to the $1981-2010$ period monthly means. coming Major Hurricane Rina) that formed over the western Caribbean Sea and Bay of Campeche, regions that often see increased activity during La Niña (e.g., 1989, 1996, and 2010). Five of these six systems made landfall as tropical storms, with only Don weakening to a tropical depression before moving over southeastern Texas. Arlene and Nate struck Mexico; Harvey made landfall in Belize and Mexico; Lee came ashore in south-central Louisiana, and Rina struck the Yucatan Peninsula.

The third cluster of tracks consisted of seven tropical storms that formed north of the MDR over the subtropical North Atlantic, and remained at sea throughout their life cycle (though Jose and Sean did pass close to Bermuda). This is one of the largest number of baroclinically-initiated (i.e., not from tropical waves) tropical storms since the satellite era began. On average, three to four named storms form over the subtropical North Atlantic per season and roughly two become hurricanes (McTaggart-Cowan et al. 2008; Kossin et al. 2010).

\section{(iii) Hurricane landfalls}

Irene was the first US hurricane landfall since 2008. This storm initially made US landfall in North Carolina (after making landfall in the Bahamas as a major hurricane), and then made another landfall as a tropical storm in New Jersey, subsequently causing major flooding in the Northeast. Irene was the most significant hurricane to strike the northeastern US since Hurricane Bob in 1991.

An analysis of the low US hurricane landfall frequency during 2009-11 (e.g., only one landfall in three seasons) was performed. The lack of landfalls during the below-normal 2009 season (Bell et al. 2010), and the occurrence of one landfall during the above-normal 2011 season, are consistent with past seasons of similar strength, although at the lower end of the distribution (Blake et al. 2011). However, the lack of hurricane landfalls during the hyperactive 2010 season (ACE $>165 \%$ of the median) is quite anomalous (Bell et al. 2011), as all previous hyperactive seasons had featured at least one US landfall, $92 \%$ had at least two landfalls, and $67 \%$ had at least three landfalls.

Two main atmospheric factors known to limit US hurricane landfalls were present during both 2010 and 2011: (1) a persistent mid-level trough and strong southwesterly flow over the western North Atlantic (Fig. 4.9) which steered all but one approaching hurricane (Irene) away from the US Atlantic coast; and (2) the absence of hurricanes either forming or 


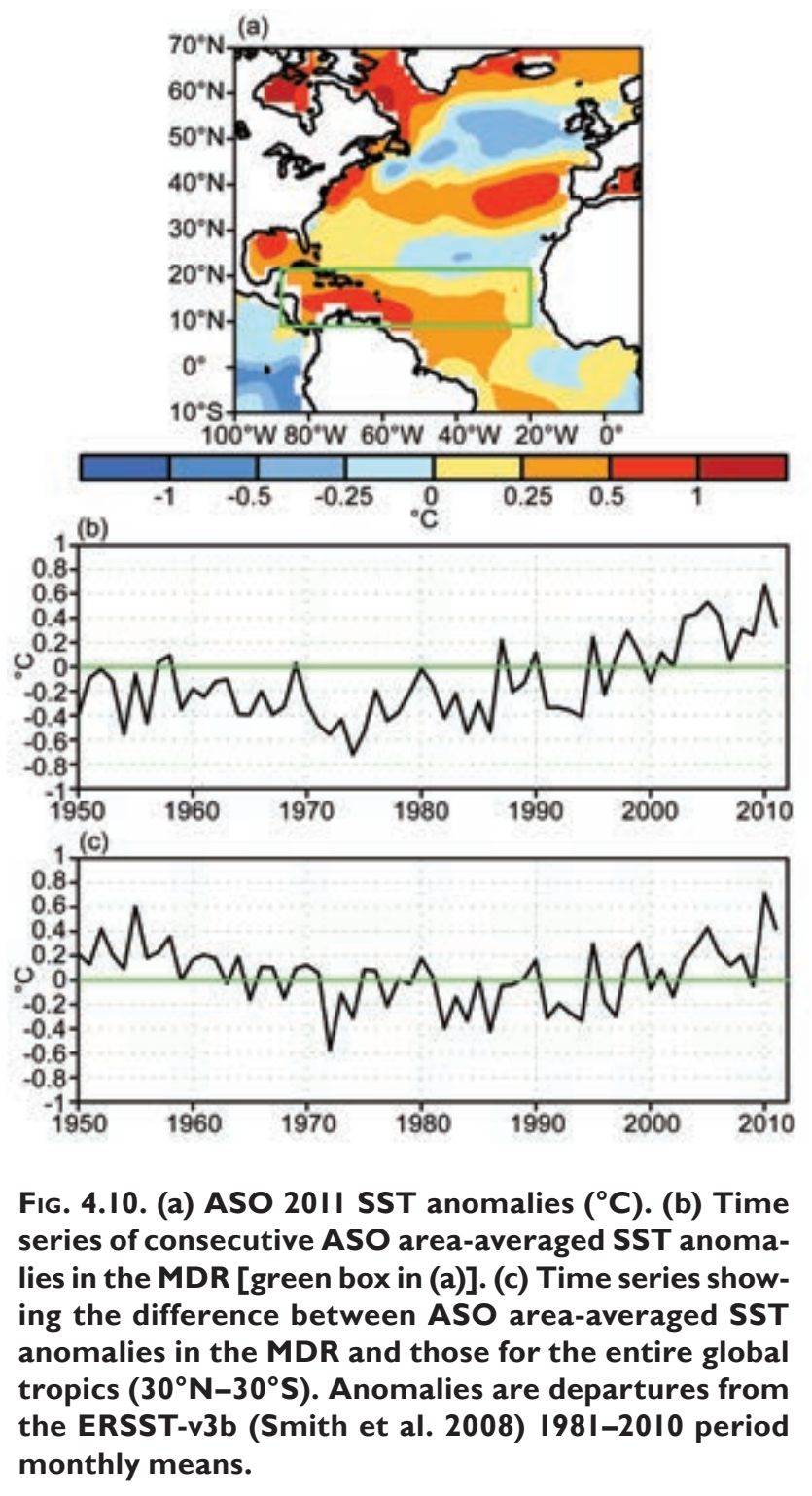

propagating over the central and northern Gulf of Mexico. Historically, 50\% of above-normal seasons have previously featured at least one hurricane formation in these regions. Also, such seasons often feature hurricanes that move into the central Gulf from the Caribbean Sea, yet none took such a track during either 2010 or 2011.

\section{(iv) Atlantic sea surface temperatures}

Sea surface temperatures (SST) in the MDR were above average during August-October 2011, with the largest departures (between $+0.5^{\circ} \mathrm{C}$ and $+1.0^{\circ} \mathrm{C}$ ) observed in the Caribbean Sea and western tropical North Atlantic (Fig 4.10a). The mean SST departure within the MDR was $+0.33^{\circ} \mathrm{C}$ (Fig $4.10 \mathrm{~b}$ ), which is $+0.44^{\circ} \mathrm{C}$ warmer than the average departure for the entire global tropics (Fig 4.10c). These conditions were partly responsible for the above-normal Atlantic hurricane season.

This anomalous warmth is related to weaker-thanaverage easterly trade winds (e.g., westerly anomalies) across the tropical Atlantic (Fig 4.11a). This combination of weaker trade winds and anomalously warm SSTs in the MDR (both of which typically become established prior to the start of the season) has generally prevailed since 1995 (Fig 4.11b) in association with the warm phase of the Atlantic Multidecadal Oscillation (AMO; Enfield and Mestas-Nuñez 1999) and the active Atlantic phase of the tropical multidecadal signal.

\section{(v) Atmospheric circulation}

The atmospheric circulation during ASO 2011 featured an interrelated set of conditions known to be exceptionally conducive for TC formation and inten-

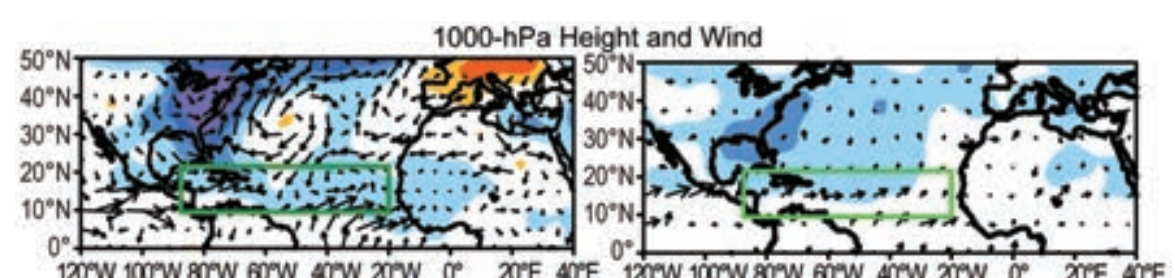

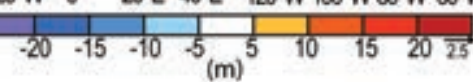

700-hPa Vorticity and Wind

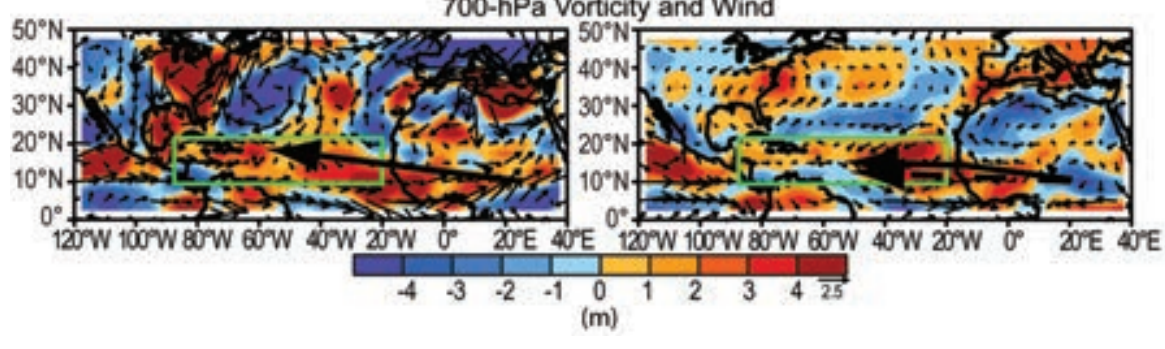

FIG. 4.II. (a) and (c) ASO 20 II anomalies and (b) and (d) difference between the 1995-2010 and 1971-1994 ASO means. Panels (a) and (b) show 1000 hPa heights (shading, $\mathrm{m}$ ) and wind vectors $\left(\mathrm{m} \mathrm{s}^{-1}\right)$. Panels (c) and (d) show 700-hPa relative vorticity (shading, $\times 10^{-6} \mathrm{~s}^{-1}$ ) and wind vectors. In (c) thick arrow shows the axis of the African easterly jet (AEJ). In (d) thick solid (dashed) arrow indicates the mean position of the AEJ during 1995-2010 (197|-1994). Vector scales are below right of color bars. Green boxes denote the MDR. Anomalies are with respect to the $1981-2010$ period monthly means. 

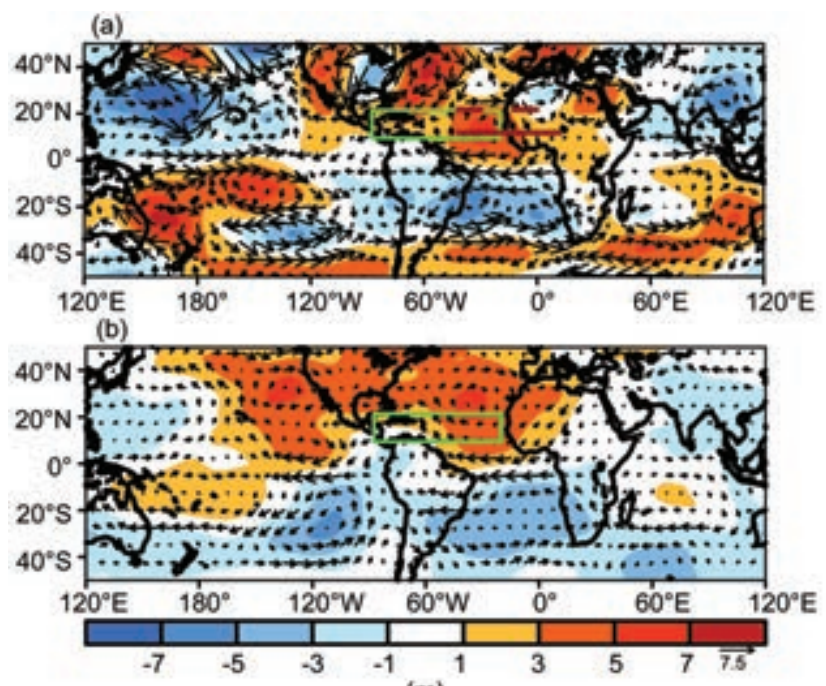

(m)

FIG. 4.12. 200-hPa streamfunction (shading, $\times 10^{6}$ $\mathrm{m}^{2} \mathrm{~s}^{-1}$ ) and wind vectors ( $\left.\mathrm{m} \mathrm{s}^{-1}\right)$. (a) Anomalies during ASO 20II and (b) difference between 1995-2010 and 197|-1994 ASO means. In (a) brown solid (dashed) line over the eastern MDR shows location of mean ridge axis during ASO 20II (ASO 1995-2010). Anomalous ridges are indicated by positive values (red) in the NH and negative values (blue) in the SH. Anomalous troughs are indicated by negative values in the NH and positive values in the SH. Green boxes denote the MDR. Vector scale is below right of color bar. Anomalies are with respect to the 198I-2010 base period monthly means.

sification within the MDR (Landsea et al. 1998; Bell et al. 2011; Goldenberg et al. 2001; Bell and Chelliah 2006; Kossin and Vimont 2007). Ten tropical storms formed in the MDR this year, eventually producing six of the seven total hurricanes, all major hurricanes, and $88 \%$ of the seasonal ACE value.

In the lower atmosphere, ASO conditions within the MDR included weaker trade winds, a deep layer of anomalous cross-equatorial flow, and below-average 1000-hPa heights (Fig. 4.11a, blue shading). Across the Atlantic basin and sub-Saharan Africa, the low-level westerly anomalies extended above $700 \mathrm{hPa}$, the approximate level of the African Easterly jet (AEJ; Fig. 4.11c), and were associated with an anomalous $2.5^{\circ}-5^{\circ}$ latitude northward shift of the AEJ core (black arrow, Fig. 4.11c).

As a result, the bulk of the African easterly wave energy (Reed et al. 1977) was often centered well within the MDR. The AEJ also featured increased cyclonic shear along its equatorward flank (Fig. 4.11c, red shading), which dynamically favors stronger easterly waves. These conditions have generally prevailed since 1995, and are opposite to those seen during the low activity era of 1971-94 (Fig 4.11d).
Also during ASO 2011, anomalous easterly flow at $200 \mathrm{hPa}$ extended from the Gulf of Guinea to the eastern North Pacific (Fig 4.12a), although this flow was less extensive than seen in 2010. This pattern reflected a stronger and more westward extension of the tropical easterly jet, and occurred in association with enhanced upper-level ridges that spanned the entire subtropical Atlantic in both hemispheres. This interhemispheric symmetry is another prominent feature of the current high activity era (Fig. 4.12b).

The above circulation anomalies resulted in weaker vertical wind shear (less than $8 \mathrm{~m} \mathrm{~s}^{-1}$ ) across the southern and western MDR (Fig 4.13), with the most anomalously weak shear located over the central tropical Atlantic and Caribbean Sea (Fig 4.13b). However, the area of anomalously weak shear was far less extensive than in 2010.

These conditions were part of the larger-scale pattern that included increased shear over both the eastern equatorial Atlantic and the eastern tropical North Pacific (Fig. 4.13b, blue shading), and are typical of other above-normal seasons since 1995 (Bell and Chelliah 2006; Bell et al. 2011). There was also an area of weaker-than-average shear over the northwestern Atlantic near Bermuda during ASO 2011, which could have helped promote the high number of named storms that formed in the subtropics.
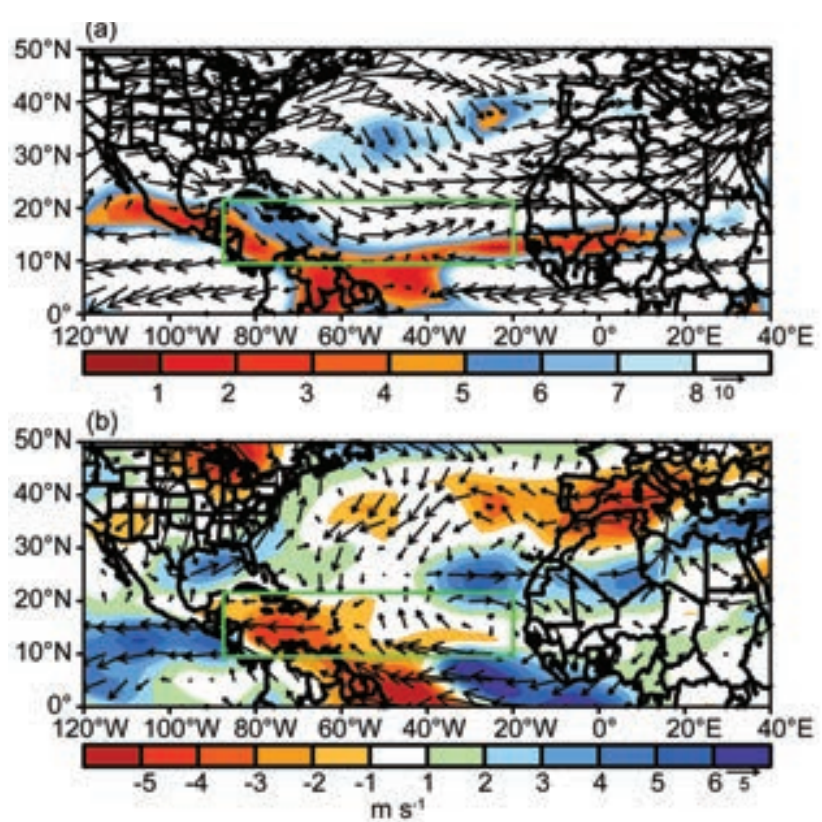

FIG. 4.I3. ASO 2011 vertical wind shear magnitudes and vectors ( $\left.\mathrm{m} \mathrm{s}^{-1}\right)$ : (a) total and (b) anomalies. Green boxes denote the MDR. Vector scales are below right of color bars. Anomalies are with respect to the $1981-2010$ period monthly means. 


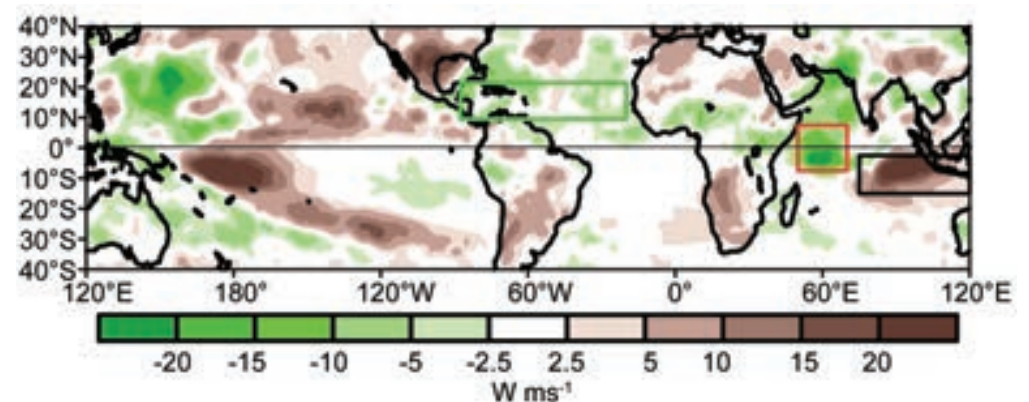

FIG. 4.I4. ASO $20 \mathrm{II}$ anomalous outgoing longwave radiation (OLR, $\mathrm{W} \mathrm{m}^{-2}$ ). Red (black) box denotes the western (eastern) portion of the Indian Ocean dipole (IOD). Green box denotes the MDR. Anomalies are with respect to the $1981-2010$ period monthly means.

These circulation anomalies were accompanied by a stronger Atlantic ITCZ and enhanced convection across the MDR (Fig 4.14). They were also associated with an enhanced West African monsoon system, as indicated by enhanced convection across the African Sahel and Sudan regions and by a large area of negative velocity potential anomalies over northern Africa (Fig 4.15a). Similar anomaly patterns have been present throughout the current high activity era (Fig 4.15b).

For the Atlantic basin, the above conditions meant that many tropical storms formed within the MDR, primarily from easterly waves moving westward from Africa. These systems entered an extensive area of below-average pressure, deep tropical moisture, increased low-level convergence, and increased cyclonic shear south of the AEJ core-conditions known to be conducive for tropical cyclone formation. Many of these systems then generally strengthened while propagating westward within the extended region of weak vertical wind shear and anomalously warm SSTs.

\section{(vi) The tropical multidecadal signal}

Since 1995, more than 70\% (12 of 17) of Atlantic hurricane seasons have been above normal, and only 2 have been below normal (Fig. 4.8). This elevated level of activity contrasts sharply with the 1971-94 low-activity era, when one-half of seasons were below normal and only three were above normal.

The sharp transition to the current high activity era reflected a phase change in the tropical multidecadal signal. This signal includes the leading modes of tropical convective rainfall variability and Atlantic SSTs occurring on multidecadal time scales (Bell and Chelliah 2006; Bell et al. 2007). It directly links atmospheric variability across the central and eastern MDR to multidecadal fluctuations in the strength of the West African monsoon system (Landsea and
Gray 1992; Landsea et al. 1998; Bell et al. 2009; Goldenberg and Shapiro 1996; Goldenberg et al. 2001; Bell and Chelliah 2006; Kossin and Vimont 2007).

Between 1994 and 1995, the oceanatmosphere system switched to the active Atlantic phase of the tropical multidecadal signal, which features an enhanced West African monsoon system (Fig. 4.15b) and above-average SSTs in the MDR (i.e., the warm phase of the AMO; Fig. 4.10). As a result, the atmospheric circulation within the MDR

became much more conducive to Atlantic hurricane activity in 1995, as also indicated by the transition to weaker vertical wind shear (Fig. 4.16a), weaker 700hPa zonal winds (Fig. 4.16b), and cyclonic (rather than anticyclonic) relative vorticity at $700 \mathrm{hPa}$ across the southern MDR (Fig. 4.16c).

\section{(vii) Indian Ocean dipole}

The Indian Ocean dipole (IOD) reflects opposite patterns of anomalous tropical convection between the western and eastern Indian Ocean (Saji et al. 1999; Saji and Yamagata 2003a,b). A strong positive phase of the IOD was present during ASO 2011 (Fig. 4.17a), as indicated by enhanced convection over the western equatorial Indian Ocean and suppressed convection

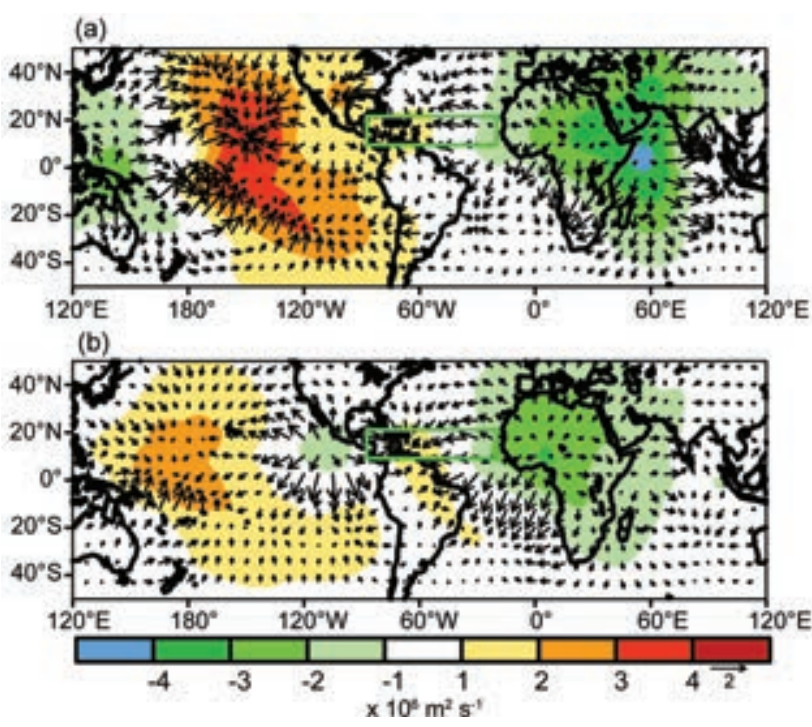

FIG. 4.I5. 200-hPa velocity potential (shading, $\left.\times 10^{6} \mathrm{~m}^{2} \mathrm{~s}^{-1}\right)$ and divergent wind vectors $\left(\mathrm{m} \mathrm{s}^{-1}\right):(a)$ ASO 2011 anomalies and (b) difference between the 1995-20I0 and 197I-94 ASO means. Green boxes denote the MDR. Vector scale is below right of color bar. Departures are with respect to the $1981-2010$ period monthly means. 

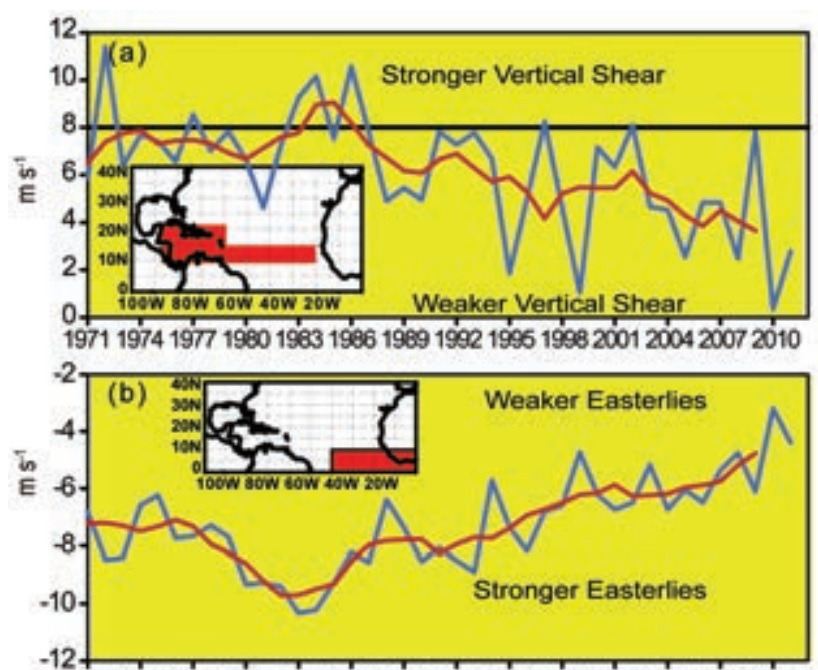

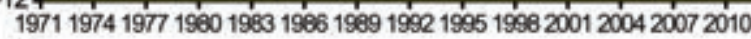

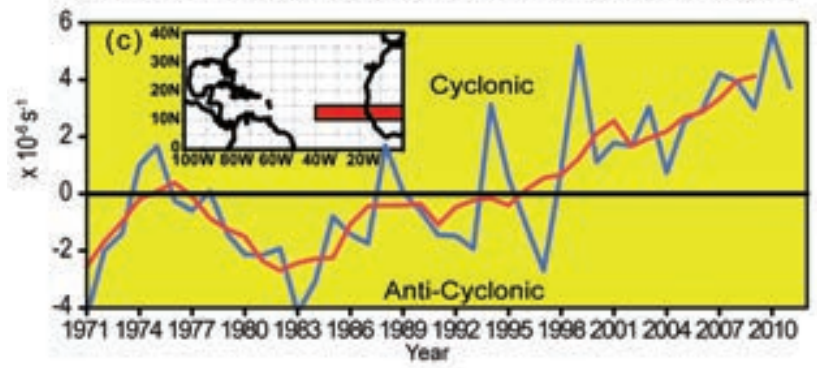

FIG. 4.16. Time series showing consecutive ASO values of area-averaged (a) 200-hPa-850-hPa vertical shear of the zonal wind $\left(\mathrm{m} \mathrm{s}^{-1}\right),(b) 700-\mathrm{hPa}$ zonal wind $\left(\mathrm{m} \mathrm{s}^{-1}\right)$ and (c) $700-\mathrm{hPa}$ relative vorticity $\left(\times 10^{-6} \mathrm{~s}^{-1}\right)$. Blue line shows unsmoothed values and red line shows a five-point running mean of the time series. Averaging regions are shown in the insets.

over the eastern tropical Indian Ocean (Fig. 4.14, red and black boxes, respectively).

There have been eight significant positive IOD events since reliable global outgoing longwave radiation (OLR) data became available in 1979. Figure $4.17 \mathrm{~b}$ shows the Atlantic hurricane activity for these eight seasons. While these events have occurred during all phases of ENSO, they are typically associated with reduced Atlantic hurricane activity. The positive IOD event in 2011 may have been one reason why the overall Atlantic activity was lower (i.e., at the low end of the NOAA seasonal outlook issued in August, see Fig. 4.8) than what might have been expected given the combination of conducive climate factors present.

Specifically, the observations suggest that the IOD may have acted to limit the 2011 Atlantic hurricane activity by weakening both the West African monsoon circulation and the La Niña-related convection patterns. There are three indications of a weaker West African monsoon system compared to the 1995-2010 mean. First, the anomalous upper-level divergent cir- culation over northern Africa was weaker and less focused, and the anomalies were actually less than those over the western equatorial Indian Ocean (Fig. 4.15a). Second, the position of the 200-hPa subtropical ridge axis over the eastern MDR was located approximately $10^{\circ}$ latitude farther south than the 1995-2010 mean (red lines, Fig. 4.12a). A similar southward shift of the ridge axis was seen during the 2007 Atlantic hurricane season, which also featured a strong positive IOD (Bell et al. 2008). Third, the anomalous southerly flow in the lower atmosphere was confined to the southern MDR and Gulf of Guinea region, rather than extending well into the central MDR and the African Sahel region (Fig. 4.11a).

The positive IOD also appears to have affected the La Niña-related convection patterns. One component of La Niña is an extensive area of enhanced convection across Indonesia and the eastern Indian Ocean. However, convection was suppressed over the eastern
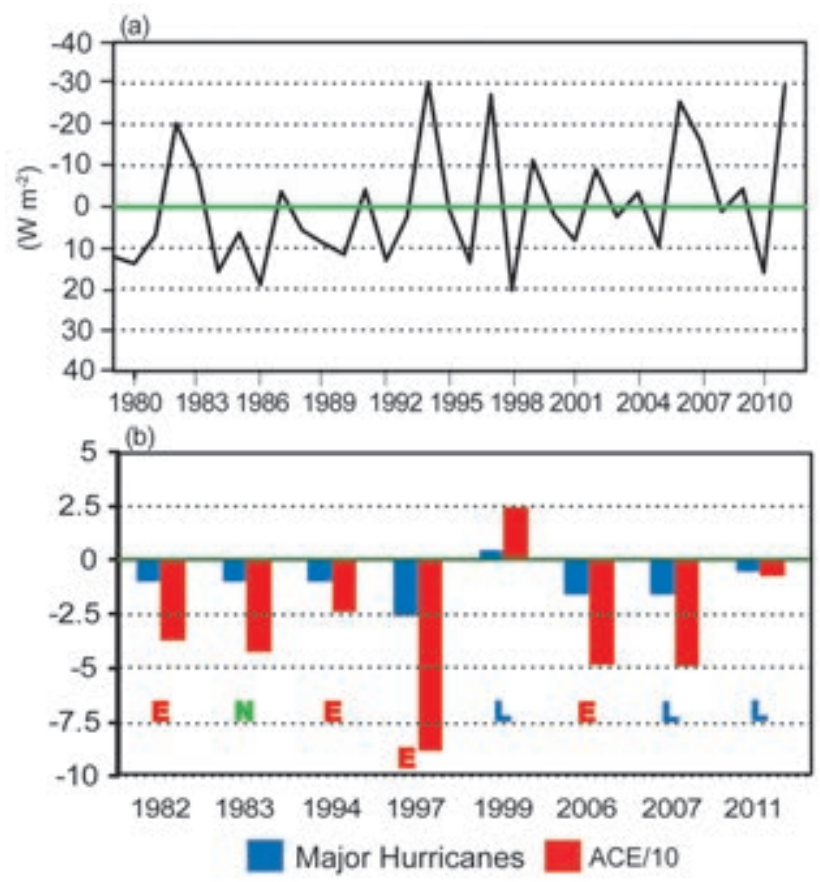

FIG. 4.I7. (a) ASO time series of the IOD, calculated as the difference in area-averaged OLR anomalies (W $\mathrm{m}^{-2}$ ) between the western and eastern Indian Ocean (western minus eastern; boxes shown in Fig. 4.14). Anomalies are with respect to the 198I-2010 base period. (b) Anomalous Atlantic major hurricane (blue) and ACE/IO (i.e., $\times 10^{3} \mathrm{kt}^{2}$ ) activity associated with storms first named in the MDR when there was a strong positive IOD during ASO. Anomalies for years during 1979-1994 (low-activity era) and 1995-20II (high-activity era) are based on the respective period means. Corresponding EI Niño (red E), La Niña (blue L), and ENSO-neutral (green $\mathbf{N}$ ) periods are indicated. 
Indian Ocean during ASO 2011 in association with the positive IOD (Fig. 4.15), meaning that the La Niña forcing onto the atmospheric circulation was weaker than if no IOD signal had been present. A similar observation was made by Bell et al. (2008) for the 2007 Atlantic hurricane season.

3) Eastern North Pacific basin-M. C. Kruk, C. J. Schreck, and P. A. Hennon

(i) Seasonal activity

The Eastern North Pacific (ENP) basin is officially split into two separate regions for the issuance of warnings and advisories by NOAA's National Weather Service. NOAA's National Hurricane Center (NHC) is responsible for issuing warnings in the eastern part of the basin that extends from the Pacific Coast of North America to $140^{\circ} \mathrm{W}$, while NOAA's Central Pacific Hurricane Center (CPHC) in Honolulu, Hawaii, is responsible for issuing warnings in the Central North Pacific region between $140^{\circ} \mathrm{W}$ and the date line. In this section, analysis summarizing the tropical cyclone (TC) activity in both these warning areas will be presented using combined statistics, along with information specifically addressing the observed activity and impacts in the Central North Pacific (CNP) region.

The ENP hurricane season officially spans from 15 May to 30 November, although storms can develop outside of the official season, especially during El Niño events. Hurricane and TC activity in the eastern area of the basin typically peaks in September, while in the central Pacific TC activity normally reaches its seasonal peak in August (Blake et al. 2009).

Only 11 named storms (NSs) formed in the ENP during 2011 and none formed in the CNP (Fig. 4.17). The 1981-2010 IBTrACS seasonal averages for the basin are 16.7 NSs, 8.9 hurricanes, and 4.3 major hurricanes. While the 2011 numbers are below average, all but one of the NSs (TS Fernanda) strengthened to at least hurricane status. The number of resulting hurricanes (10) and major hurricanes (6) were actually both above average. Five of the six major hurricanes even reached Category 4 status. This was the first time since records began in 1949 that more than $90 \%$ of the NSs became hurricanes and more than $50 \%$ also became major hurricanes. Despite the large fraction of strong storms, the ACE index for 2011 was $121.8 \times 10^{4} \mathrm{kt}^{2}$ (Fig. 4.18), which is below the 1981-2010 mean of $144.0 \times 10^{4} \mathrm{kt}^{2}$ (Bell et al. 2000; Bell and Chelliah 2006).

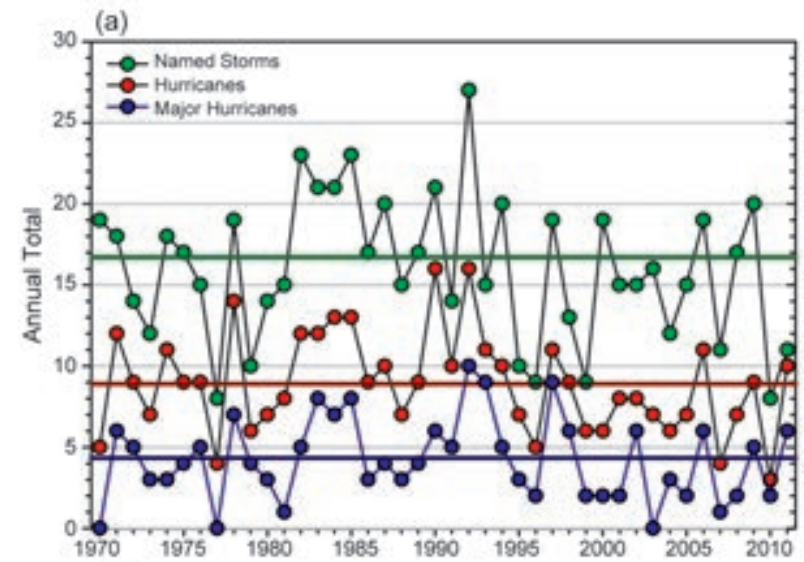

(b)

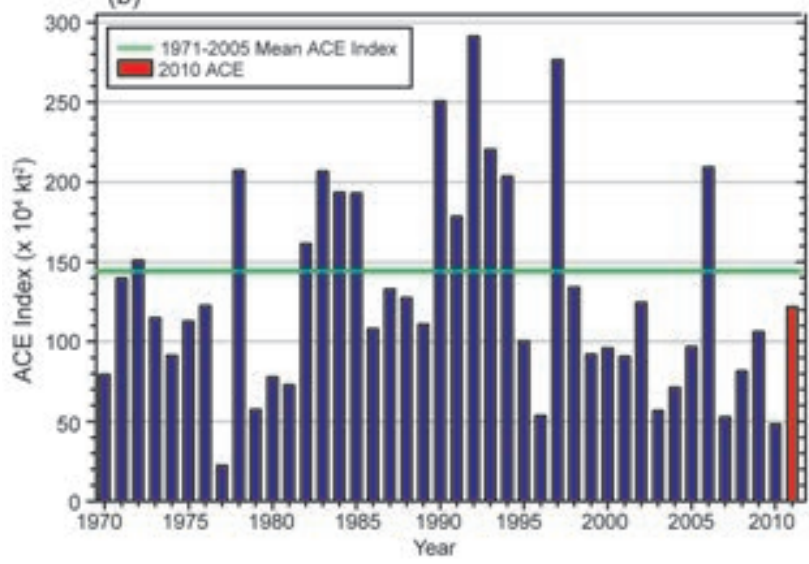

FIG. 4.18. Seasonal TC statistics for the ENP basin over the period 1970-20II: (a) number of named storms, hurricanes, and major hurricanes, and (b) the ACE index with the seasonal total of 20II highlighted in red. The time series shown includes the corresponding 198I-2010 base period means for each parameter.

(ii) Environmental influences on the 2011 season

Figure 4.19 illustrates the background conditions for TC activity in the ENP during 2011. The overall patterns were dominated by La Niña. Sea surface temperatures (SSTs) were below normal over most of the ENP (Fig. 4.19a) and positive outgoing longwave radiation (OLR) anomalies (Fig. 4.19b, warm colors) suggest that convection was suppressed in the ITCZ. Enhanced vertical wind shear existed over most of the basin (Fig. 4.19c). Each of these factors acted to suppress TC activity, particularly in the ITCZ. Conditions were somewhat more favorable along the Central American coastline. Enhanced convection was observed along the coast (Fig. 4.19b, cool colors) and the SST anomalies were less negative in that area. Consistent with these patterns, most of the TCs did form near the coast.

Although conditions over the ENP were generally unfavorable for TCs during 2011, Fig. 4.19d shows 850 -hPa westerly wind anomalies over the basin. 
(a)

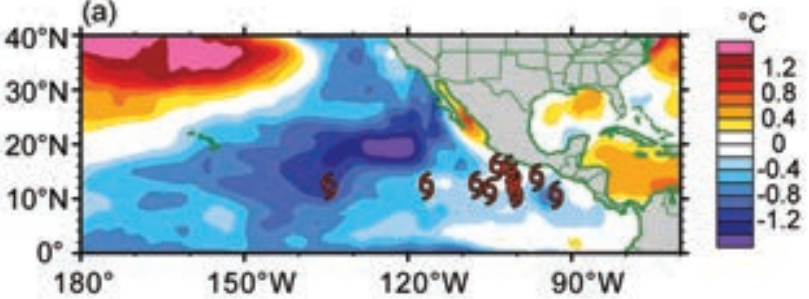

(b)
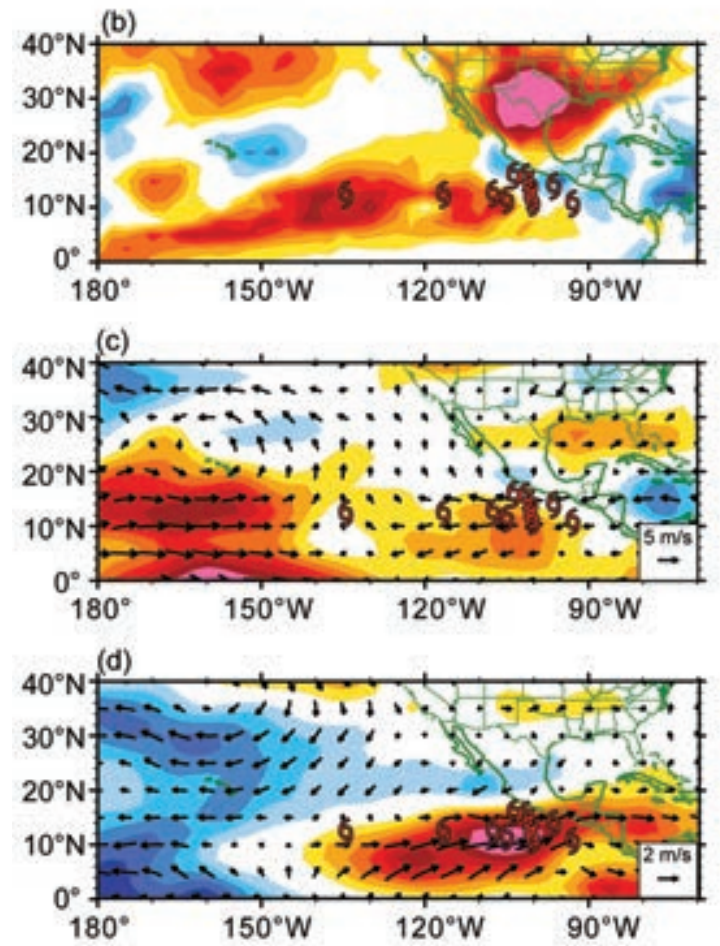

FIG. 4.19. Maps of Jun-Nov 20 II anomalies of (a) SST, (b) OLR, (c) $850-\mathrm{hPa}-200-\mathrm{hPa}$ vertical wind shear vector (arrows) and scalar (shading) anomalies, and (d) 850-hPa winds (arrows) and zonal wind (shading) anomalies. Anomalies are relative to the annual cycle from 198I-2010, except for SST, which is relative to 1982-2010 due to data availability. Hurricane symbols denote where each ENP TC attained TS strength. Wind data are obtained from the NCEP-DOE Reanalysis 2.

These anomalies favored TC genesis by enhancing the low-level cyclonic vorticity. The westerlies would also enhance easterly wave activity through barotropic energy conversion and wave accumulation (Maloney and Hartmann 2001; Aiyyer and Molinari 2008).

Eastern North Pacific TC activity is strongly influenced by the Madden-Julian oscillation (MJO; Maloney and Hartmann 2001; Aiyyer and Molinari 2008). Figure 4.20 shows the evolution of unfiltered (shading) and MJO-filtered (contours) OLR during the 2011 ENP hurricane season. The MJO filter contains eastward propagation with wave numbers 0-9 and periods of 30-96 days following Kiladis et al. (2005). While convection was generally suppressed over the ENP (Fig. 4.19b), Fig. 4.20 shows periods of enhanced convection (negative OLR anomalies) associated with the MJO. The TCs generally formed during these convective periods. Irwin, Jova, and Tropical Depression Twelve (not shown) developed in association with a particularly strong MJO during October 2011 (Fig. 4.20). The Wheeler and Hendon (2004) Real-time Multivariate MJO (RMM) Index shows a record value of 3.63 standard deviation amplitude during this event (M. C. Wheeler, 2011, personal communication).

\section{(iii) TC impacts}

Just one TC made landfall along the Pacific coast of Mexico during the season (Major Hurricane Jova). Two other TCs made a close brush against the shoreline, but never came ashore. In comparison with climatology, the 2011 season is near the 1951-2000 average of 1.34 landfalling TCs (Jáuregui 2003).

Along the Pacific coast of Mexico, Hurricane Beatriz (19-22 June) made a close approach to land from Acapulco northward to Manzanillo, causing some flooding and the closure of many popular tourist hotels. The rainfall was welcome, however, as it helped alleviate an ongoing severe drought across

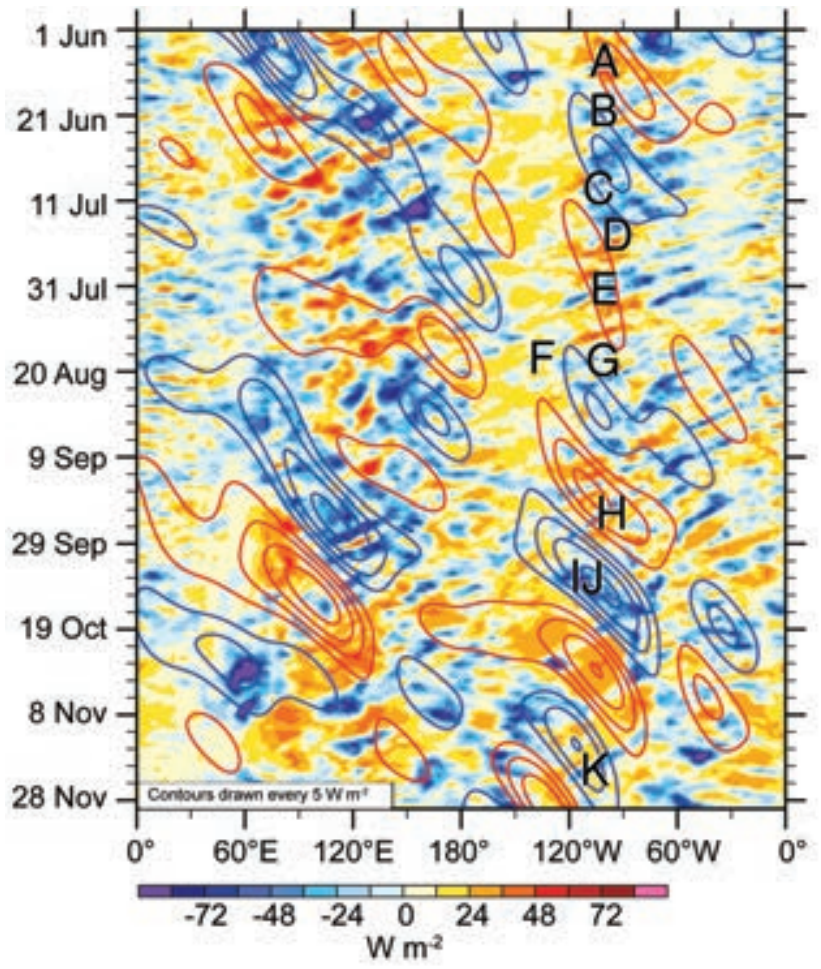

FIG. 4.20. Longitude-time Hovmöller of unfiltered (shading) and MJO-filtered (contours) anomalies of OLR averaged $10^{\circ} \mathrm{N}-20^{\circ} \mathrm{N}$. Negative contours are drawn in blue, positive in red, and the zero contour is omitted. Letters indicate the genesis of ENP TCs. 
the region. Beatriz eventually turned west and then southwest on 22 June and dissipated over the cooler waters of the open ocean.

The strongest storm of the season in the ENP was Major Hurricane Dora, which attained 135 kt (69 m $\left.\mathrm{s}^{-1}\right)$ winds and a minimum central pressure of $929 \mathrm{hPa}$ on 21 July. Just two days later the storm had weakened to tropical storm strength over the open waters of the eastern Pacific. The hurricane was impressively large and had a well-defined eye during its most intense phase. The only impacts to Mexico were high seas, dangerous rip currents, and a few rain showers along the south shores near Acapulco.

Major Hurricane Hilary (21-30 September) was a powerful Category 4 hurricane with peak wind speeds of $125 \mathrm{kt}\left(64 \mathrm{~m} \mathrm{~s}^{-1}\right)$. This storm peaked in intensity very close to the Mexican coastline, but never made landfall. The impacts from Hilary were focused near Tabasco, Mexico, where more than $210 \mathrm{~mm}$ of rain was attributed to spiral bands around the storm. Lowlying agricultural fields were plagued by the rains, forcing some farmers to evacuate their livestock.

Jova (6-13 October) was the most damaging storm of the season and was blamed for eight deaths and six injuries as it made landfall near Jalisco, Mexico, as a Category 2 hurricane. Rainfall from Jova was estimated at over $250 \mathrm{~mm}$, which left the key city streets and port of Manzanillo under 1-2 meters of standing water.

Kenneth was the strongest recorded late-season major hurricane (19-25 November) in the ENP basin, with peak winds at $125 \mathrm{kt}\left(64 \mathrm{~m} \mathrm{~s}^{-1}\right)$. The storm's track was nearly due west along the $10^{\circ} \mathrm{N}$ line of latitude. Despite its strength, no major impacts were reported because it stayed far from land.

\section{4) Western North PaCific basin—S. J. Camargo}

The tropical cyclone (TC) data used here is from the Joint Typhoon Warning Center (JTWC) Western North Pacific (WNP) best-track dataset for the 1945-2010 period and from the JTWC preliminary operational data for 2011. The 1981-2010 IBTrACS seasonal averages for the basin are 25.4 (total systems), 15.5 (typhoons), and 6.0 (super typhoons). The total number of TCs in the season was 27, with 20 named storms (TSs), 10 typhoons (TYs), and 4 super typhoons (STYs). Furthermore, a tropical depression (TD) was named as Tokage by the Regional Specialized Meteorological Center (RSMC)-Tokyo, but was not assessed as a named storm by the JTWC. In Fig. 4.21a, the number of named storms, typhoons, and super typhoons per year is shown for the period 1945-2011 (based on JTWC data).

The 2011 WNP TC season started in April with two TDs (1W and 2W), followed by Tropical Storm Aere in early May. At the end of May, Super Typhoon Songda occurred. In June, three TSs formed in the WNP (Sarika, Haima, and Meari), but none intensified into a typhoon. From the four TCs that formed in July, one was a TD (Tokage) and three became typhoons (Ma- On, Nock-ten, Muifa), with Muifa reaching super typhoon status. Another super typhoon occurred at the end of August (Nanmadol), which was preceded by Typhoon Merbok and TD 13W, with Tropical Storm Talas forming a few days after Super Typhoon Nanmadol. Seven TSs occurred during September, the highest monthly number of the season, tying the maximum number of September NSs in the historical record (Fig. 4.21c). Of these seven TCs, four became typhoons (Roke, Sonca, Nesat, and Nalgae), with Nalgae becoming the fourth super typhoon of the 2011 season. In contrast, October was quiet, with only one TS forming in the WNP (Fig. 4.21c), an unusual event, which has only happened during three previous years of the historical record $(1945,1946$, and 1976). Low TC activity continued in November, when only two TDs developed (24W and 25W; Figs. $4.21 \mathrm{c}, \mathrm{e})$. Only three other years in the historical record had no named storms during November $(1963,1994$, and 2010). The season finished with TD 26W and TS Washi forming during December.

The total accumulated cyclone energy (ACE) in the 2011 season was below normal, in the bottom quartile of the climatological distribution (Fig. 4.22a). Due to the occurrence of Super Typhoon Songda, the value of ACE for the month of May was in the top quartile of the climatological distribution (Fig. 4.22b). Songda was responsible for $88 \%$ of the May ACE. July and August ACE values were also above the climatological median for those months, due mainly to Super Typhoons Muifa and Nanmadol. September ACE was slightly below the climatological median, even with the presence of Super Typhoon Nalgae. The ACE in October was in the bottom 10th percentile of the climatological distribution, while the ACE value in November was zero, which occurred previously only in 1963 and 2010. The highest value of ACE for a single TC in 2011 was Super Typhoon Muifa (top fifth percentile of the climatological and historical distributions), followed by Super Typhoon Songda, Typhoon Ma-on, and Super Typhoon Nanmadol, all in the top quartile of the climatological and historical distributions of ACE for individual storms. 

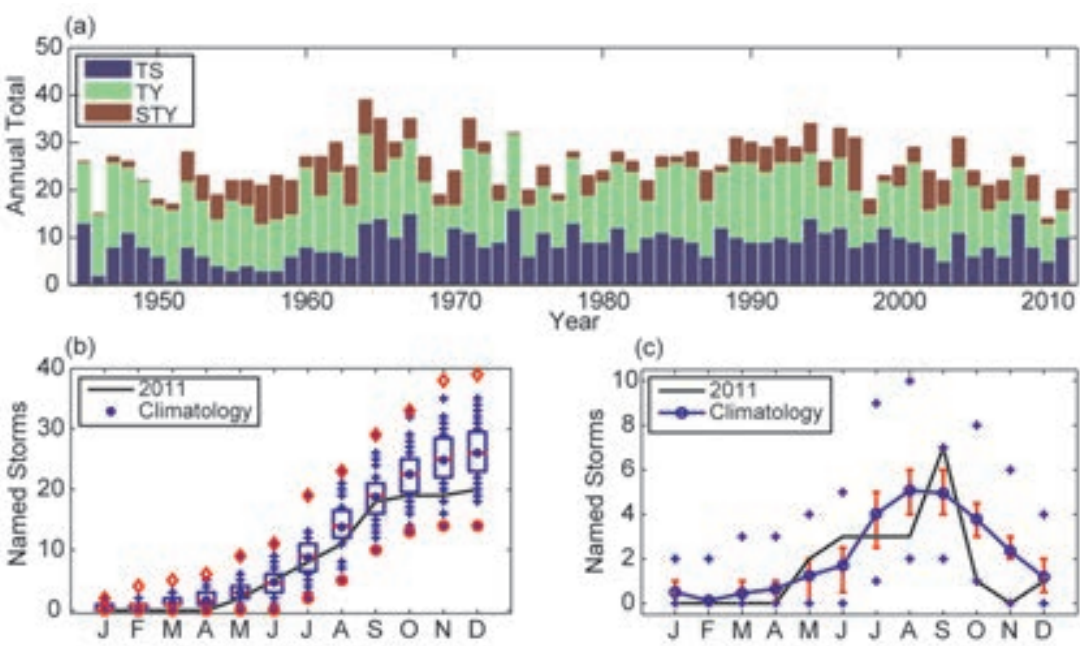

(c)

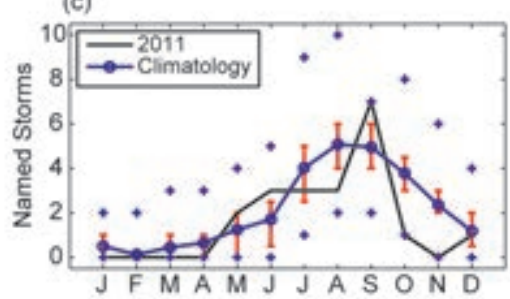

(d)
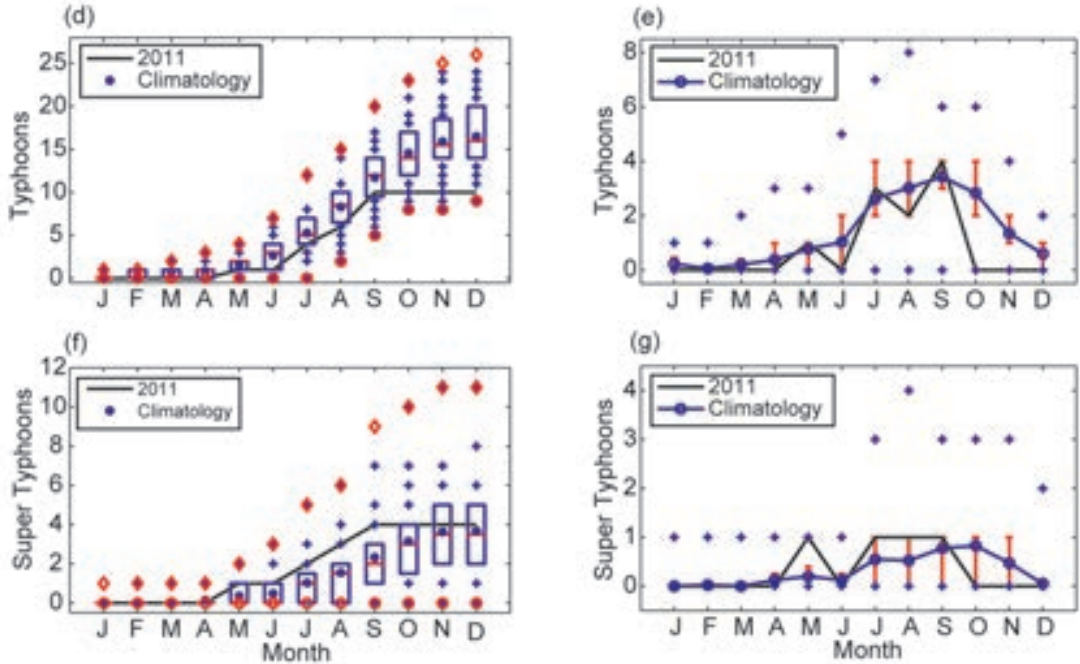

the climatological median of 20 days. In 2011 the number of TC days with TYs and intense TYs were $63 \%$ and $12 \%$, respectively (climatological average is $74 \%$ and $12 \%)$. The median lifetime for TSs and TYs in 2011 was 6.87 days, below the median climatology of 8 days. From the 20 TSs and TYs, 2 (5) had a lifetime in the top (bottom) quartile of the distribution (25th percentile: 5.75 days; 75 th percentile: 10.75 days). The storms with the longest lifetimes in 2011 were Super Typhoon Muifa (14.25 days) and Typhoon Ma-on (13.25 days).

The mean genesis location in 2011 was $14.9^{\circ} \mathrm{N}, 137.6^{\circ} \mathrm{E}$, which was shifted northwestward of the climatological mean genesis position $\left(13.1^{\circ} \mathrm{N}\right.$, $\left.142.8^{\circ} \mathrm{E}\right)$. The mean track position $\left(21.4^{\circ} \mathrm{N}, 129.8^{\circ} \mathrm{E}\right)$, was also shifted northwestward of the mean climatological track position $\left(19.4^{\circ} \mathrm{N}, 133.7^{\circ} \mathrm{E}\right)$. This northwestward shift is typical of La Niña years (Camargo et al. 2007; Chan 2000; Lander 1994). The 2010/11 moderate La Niña event weakened considerably during the 2011 Northern Hemisphere spring and summer months, returning in the Northern Hemisphere fall as a weak-to-moderate La Niña, influencing the genesis and track positions of the typhoons in the 2011 season. There were 13 storms that made landfall in 2011, slightly below the JTWC
There were 124 days with TCs and 109.5 days with TSs in 2011 in the WNP, both in the bottom quartile of the climatological distribution (climatological medians: 157.25 and 134.5 days, respectively). From these active days, only 78.5 had TYs, also in the bottom quartile of the climatological distribution (climatological median 117.75 days). There were 14.5 days with intense typhoons (Categories 3-5), below
1951-2010 climatological median of 15 . Two systems made landfall as TDs (median is three), eight made landfall as TSs (median is six), and two struck as TYs (median is four).

One of the remarkable features of the 2011 season was the dramatic change in western North Pacific TC activity from September (tying the historical maximum for that month) to October (tying the historical 

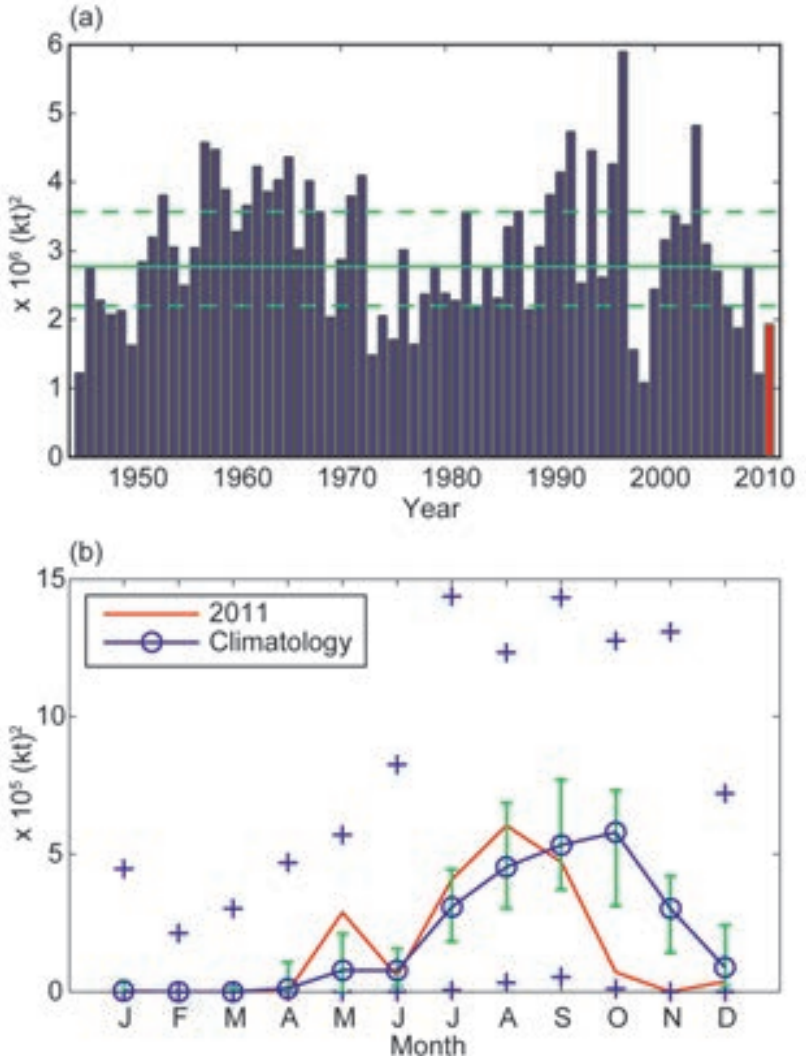

FIG. 4.22. (a) ACE index per year in the WNP for 194520II. The solid green line indicates the median for the climatology years 197I-2010, and the dashed lines show the climatological 25 th and 75 th percentiles. (b) ACE index per month in $20 \mathrm{II}$ (red line) and the median during 197|-2010 (blue line), where the green error bars indicate the 25 th and 75 th percentiles. In case of no error bars, the upper and/or lower percentiles coincide with the median. The blue "+" signs denote the maximum and minimum values during the period 1945-20II. (Source: 1945-2010 JTWC best-track dataset, 201 I JTWC preliminary operational track data)

minimum for that month). The reason for this abrupt change appears to be a combination of two factors: the strengthening of the La Niña event and an MJO event in the suppressed phase in October over the western North Pacific. Figure 4.23 shows the environmental conditions in the July-September (JAS) season (left panels) and the October-December (OND) season (right panels) over the western North Pacific. In Fig. 4.23, the anomalies of the potential intensity (Emanuel 1988, 1995; Figs. 4.23a,b), genesis potential index (GPI; Camargo et al. 2007; Figs. 4.23c,d) and 600-hPa relative humidity (Figs. $4.23 \mathrm{e}, \mathrm{f}$ ) are shown in the top, middle, and bottom panels, respectively. The potential intensity positive anomalies are dominant in OND. In contrast, the positive anomalies of GPI in OND occur only in a small region near the Philip- pines and very near the equator, in agreement with the low occurrence of TCs in OND. While neither the JAS nor the OND GPI has the typical La Niña pattern, with positive anomalies in the northeast and negative anomalies in the southwestern part of the basin, the OND GPI is more similar to other La Niña events, confirming that the cold event only affected the TC activity in the later part of the season. The relative humidity anomalies are dominantly below normal in OND in the region, which appears to be the main reason for the negative anomalies in GPI in OND, similar to other La Niña events (Camargo et al. 2007).

The largest impacts of the 2011 season occurred due to a late-season storm in December. Tropical Storm Washi (named Sendong in the Philippines) first made landfall in the island of Mindanao in the Philippines on 16 December, then made a second landfall over the island of Palawan (Philippines) the next day. Though the Philippines are often struck by tropical cyclones, the storms usually take a more northern path, affecting the island of Luzon and rarely make landfall in Mindanao. Lyon and Camargo (2009) have shown that during La Niña events, there is a tendency to have below-normal rainfall in Philippines during JAS (mainly in northern Philippines), while during OND there is above-normal rainfall in the whole Philippines, including Mindanao, and that these rainfall anomalies can be related to TCs affecting the Philippines. The flash flooding caused by Washi in Mindanao was catastrophic, with more than 1250 deaths. The storm was unusually wet. Torrential rain fell over a period of 10 hours, bringing more than 200 $\mathrm{mm}$ in some places, destroying some villages with flood waters and landslides (see http://www.mb.com. ph/articles/345284/pagasa-typhoons-142mm-rain12-hours-super-heavy). On 17 December, more than 100000 people were evacuated. The economic damage in infrastructure and agriculture in the region was also very high.

\section{5) INDIAN OCEAN BASINS}

(i) North Indian Ocean-M. C. Kruk and K. L. Gleason

The North Indian Ocean (NIO) tropical cyclone (TC) season typically extends from April to December, with two peaks in activity during May-June and November, when the monsoon trough is positioned over tropical waters in the basin. TCs in the NIO basin normally develop over the Arabian Sea and Bay of Bengal between latitudes $8^{\circ} \mathrm{N}$ and $15^{\circ} \mathrm{N}$. These systems are usually short lived and relatively weak and often quickly move into the Indian subcontinent. However, strong and "severe cyclonic storms" 

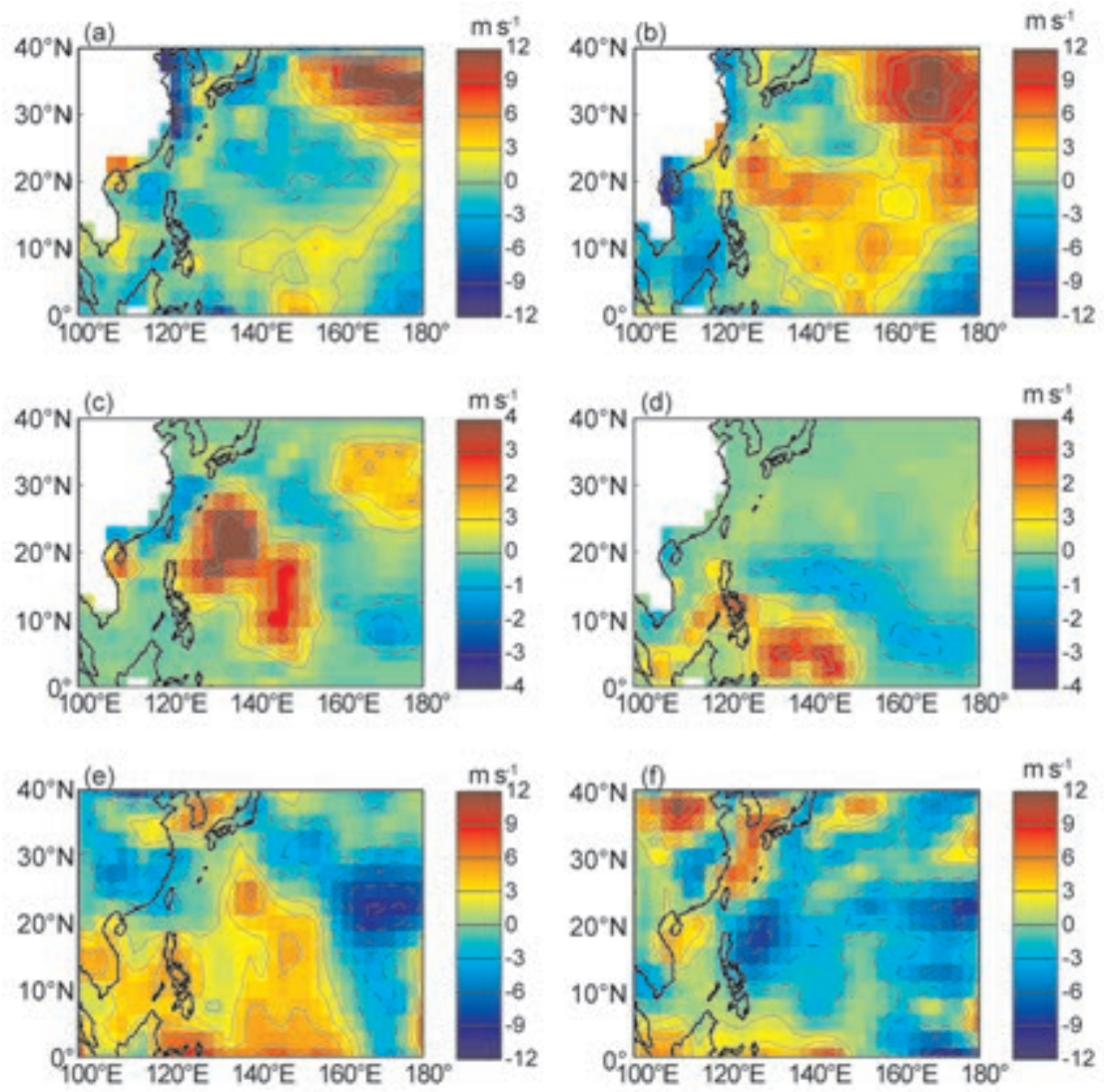

FIG. 4.23. Potential intensity anomalies $\left(\mathrm{m} \mathrm{s}^{-1}\right.$ ) for (a) JAS and (b) OND $20 \mathrm{II}$ from 197I-2010 climatology. Genesis potential index anomalies for (c) JAS and (d) OND 2011. 600-hPa relative humidity anomalies (in \%) for (e) JAS and (f) OND 20II. In all panels, positive contours are shown in solid lines, negative contours in dash dotted lines and the zero contour in a dotted line. [Source: atmospheric variables: NCEP/NCAR Reanalysis data (Kalnay et al. 1996); SST (Smith and Reynolds 2005).]

can develop with winds exceeding $130 \mathrm{kt}\left(67 \mathrm{~m} \mathrm{~s}^{-1}\right.$; Neumann et al. 1993).

The 2011 TC season produced six named storms (NSs), one cyclone (CYC), and no major cyclones (MCYC; Fig. 4.24a). While the number of NSs is slightly above the 1981-2010 IBTrACS seasonal average of $4.0 \mathrm{NSs}$, the numbers of CYCs and MCYCs are below the long-term averages of 1.4 and 0.6 , respectively. The season produced an ACE index value of $12.4 \times 10^{4} \mathrm{kt}^{2}$, which is below the 1981-2010 average of $16.2 \times 10^{4} \mathrm{kt}^{2}$ (Fig. 4.24b). There is generally an enhancement in tropical cyclone activity, especially in the Bay of Bengal, during the cool phase of ENSO (Singh et al. 2000), which was the prevailing condition for that season. The strongest storm of the year, Cyclone Thane, developed in the Bay of Bengal late in the season.

The first three storms of the season (Tropical Storms One, Two, and Keila) formed close to land and remained relatively weak as they came ashore.
The major impact from these systems was heavy rainfall. All storms weakened below tropical storm strength within about 12 hours of being named as they interacted with land and gradually dissipated.

Tropical Storm Two (19-20 October) was the most damaging storm of the year, despite having peak winds of only $35 \mathrm{kt}\left(18 \mathrm{~m} \mathrm{~s}^{-1}\right)$. The storm formed off the coast near the border of Bangladesh and Myanmar and slowly moved ashore. Early estimates indicate that over 200 people died from the storm and economic damages exceeded \$1.5 million (US dollars). The storm caused massive flash flooding, washed away over 2000 homes and left many stranded in high water for days after the storm (http://thewatchers.adorraeli. com $/ 2011 / 10 / 21 /$ myanmarbattered-with-flash-floodsand-tropical-cyclone).

In the Arabian Sea, Tropical Storm Keila (1-3 November) caused havoc and damages in Muscat, Oman, as it made landfall on 2 November. Widespread heavy rains flooded city streets, forced the evacuation and closure of hospitals, and resulted in 14 deaths and 200 injuries (http://earthobservatory.nasa.gov/NaturalHazards/ view.php?id=76346). The last storm to hit the Muscat region was in May 2002.

The strongest storm of the year, Cyclone Thane (Fig 4.25), occurred very late in the season (25-30 December). The storm developed as a tropical disturbance within the monsoon trough in the Bay of Bengal and intensified into a cyclone west of Indonesia with maximum sustained winds of $80 \mathrm{kt}$ (40 $\mathrm{m} \mathrm{s}^{-1}$ ). The storm made landfall on 30 December near Tamil Nadu and Andhra Pradesh in India as a weakening very severe cyclonic storm. Damages and injuries from the storm in Andhra Pradesh were minimized by good planning and preparation, as well as adequate logistics and supplies in place. However, in Tamil Nadu, closer to where the storm made landfall, some cities were completely cut off as 

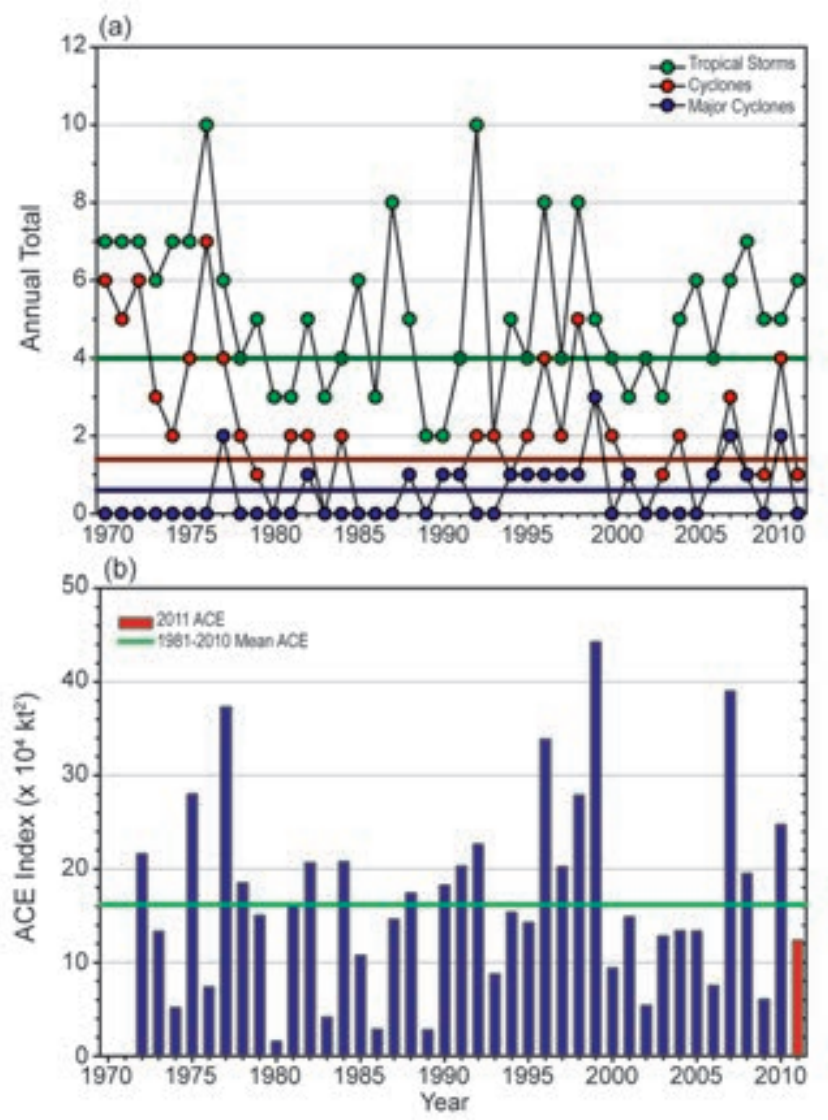

Fig. 4.24. Annual TC statistics for the NIO over the period 1970-20II: (a) number of tropical storms, cyclones, and major cyclones, and (b) the estimated annual ACE Index $\left(\mathrm{kt}^{2} \times \mathrm{I0}^{4}\right)$ for all tropical cyclones during which they were at least tropical storm or greater intensities (Bell et al. 2000). The I98I-20I0 base period means are included in both (a) and (b). Note that the ACE Index is estimated due to a lack of consistent six-hour-sustained winds for every storm.

interior road networks were damaged and washed away. Nearly three dozen fatalities are blamed on the storm in Cuddalore, India (http://www.disasterwatch. net/resources/NeedAssessment-Thanecylone.pdf).

(ii) South Indian Ocean-K. L. Gleason and M. C. Kruk

The South Indian Ocean (SIO) basin extends south of the equator from the African coastline to $105^{\circ} \mathrm{E}$, with most cyclones (CYCs) developing south of $10^{\circ} \mathrm{S}$. The SIO tropical cyclone (TC) season extends from July to June encompassing equal portions of two calendar years (e.g., the 2010/11 season is comprised of storms from July 2010 to June 2011). The peak activity typically occurs from December to April when the ITCZ is located in the Southern Hemisphere and is migrating toward the equator. Historically, the vast majority of the landfalling CYCs in the SIO impact
Madagascar, Mozambique, and the Mascarene Islands, including Mauritius and Réunion.

The historical SIO TC data is probably the least reliable of all the TC basins (Atkinson 1971; Neumann et al. 1993), primarily due to a lack of historical record keeping by individual countries and no centralized monitoring agency; however, the historical dataset for the region has been updated (Knapp et al. 2010). The historical data are noticeably deficient before reliable satellite data were operationally implemented in the region beginning about 1983 .

The 2010/11 SIO season storm numbers were below average, with six named storms (NSs), two CYCs, and one major cyclone (MCYC; Fig. 4.26a). The 1981-2010 IBTrACS seasonal averages are 12.5 NSs, 6.1 CYCs, and 2.1 MCYCs. The quiet season is also reflected in the 2010/11 ACE index of $27.5 \times 10^{4}$ $\mathrm{kt}^{2}$, which was below the 1981-2010 average of 91.5 $\times 10^{4} \mathrm{kt}^{2}$ (Fig. 4.26b). This is the third consecutive year with below-normal ACE values, and the lowest since 1983.

The strongest cyclone and the only one to make landfall during the 2010/11 season was Major Cyclone Bingiza. On 8 February, an area of convection developed approximately $880 \mathrm{~km}$ north-northeast of

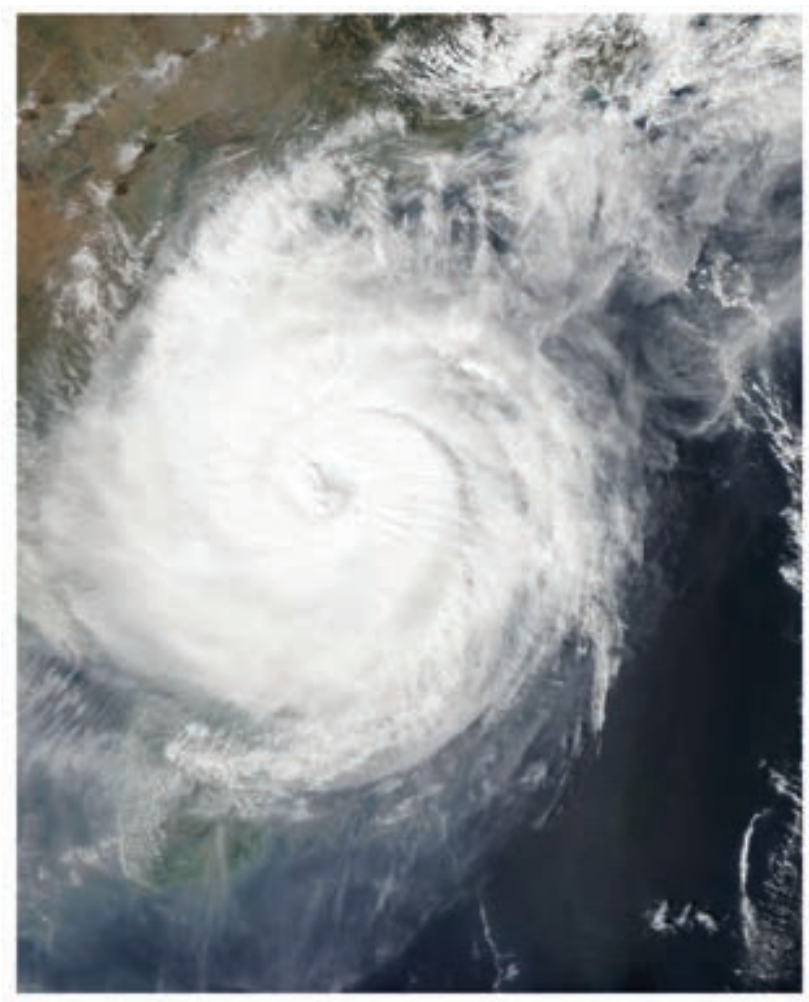

FIG. 4.25. Satellite image of Cyclone Thane over the NIO at the apex of its strength prior to landfall. (Source: NASA Earth Observatory, AQUA MODIS satellite imagery) 

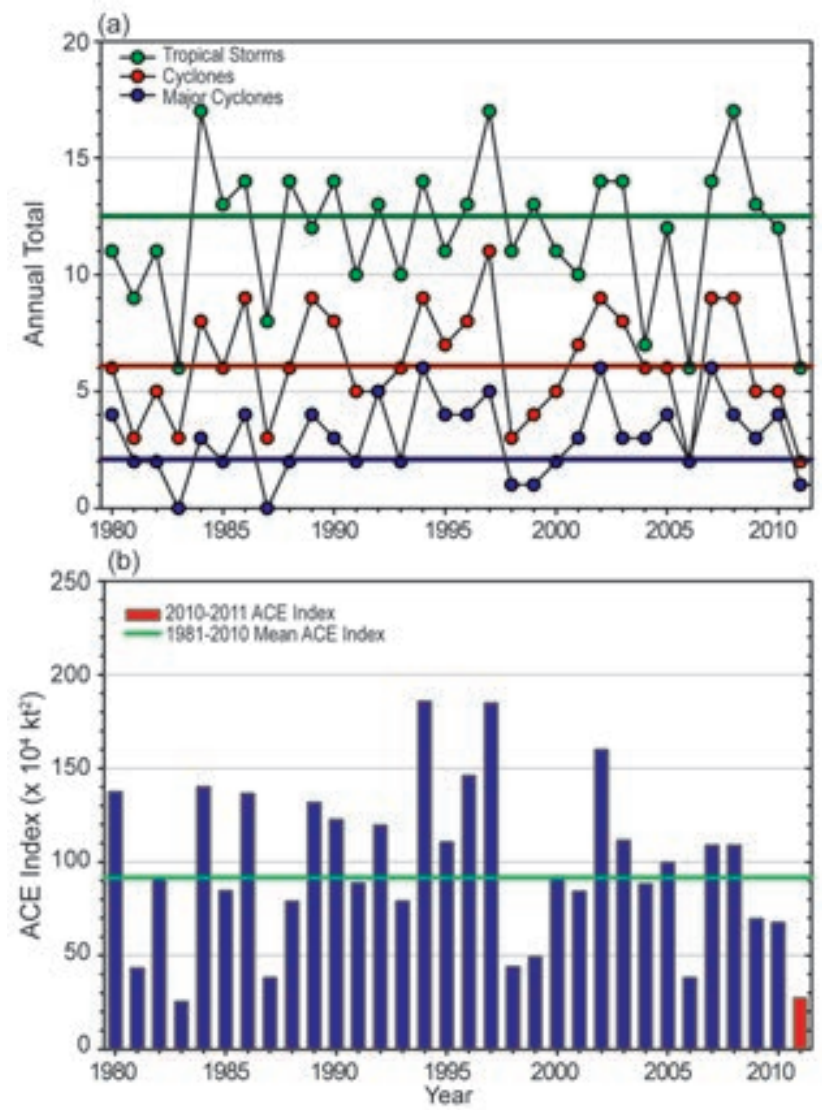

FIG. 4.26. Annual TC statistics for the SIO over the period of 1970-20II: (a) number of tropical storms, cyclones, and major cyclones and (b) the estimated annual ACE Index $\left(\mathrm{kt}^{2} \times \mathrm{I0}^{4}\right)$ for all tropical cyclones during which they were at least tropical storm or greater intensities (Bell et al. 2000). The 198I-2005 base period means are included in both (a) and (b). Note that the ACE Index is estimated due to a lack of consistent six-hour-sustained winds for every storm.

La Réunion Island. As this convection moved westsouthwestward, the system gradually became more organized and was named Bingiza late on 9 February. A slow moving cyclone, Bingiza continued to migrate to the southwest and was upgraded to a severe tropical storm about $335 \mathrm{~km}$ east of the northeast coast of Madagascar on 12 February. Bingiza began to develop rapidly as it continued to move toward the Madagascar coast, reaching peak intensity on 13 February with maximum sustained winds of 89 knots $\left(46 \mathrm{~m} \mathrm{~s}^{-1}\right)$ and a minimum pressure of $953 \mathrm{hPa}$, making it an intense tropical cyclone. On 14 February, Major Cyclone Bingiza made landfall near Saranambana, along Madagascar's northeastern coast, and quickly weakened over land. After Bingiza emerged over the Mozambique Channel between Africa and Madagascar on 15 February as a tropical depression, it reintensified into a tropical storm over the warm wa- ters and made a second landfall along Madagascar's southwestern coast, producing five days of rainfall in a region already saturated by previous flooding events. The storm was responsible for 22 deaths and the destruction of 25000 homes; a large portion of the food crops in several districts was destroyed as a result of the heavy wind and rains (http://reliefweb. int/node/392511).

6) Southwest Pacific basin-A. M. Lorrey, S. McGree, J. A. Renwick, and S. Hugony

The 2010/11 TC season for the southwest Pacific (between $135^{\circ} \mathrm{E}$ and $120^{\circ} \mathrm{W}$ ) started up in late December with the formation of Tropical Cyclone Tasha and concluded in late March with Tropical Cyclone Bune. A total of nine TCs occurred in the region, which was consistent with the number of predicted storms based on the Island Climate Update analog forecast (see http://www.niwa.co.nz/climate/icu). Five TCs reached at least Category 3 on the Saffir-Simpson scale, and three systems reached at least Category 4. This activity was also in line with the prediction of at least three storms reaching Category 3 status and at least one storm reaching Category 4 strength. There were more numerous TCs during the early part of the season-the peak activity occurred in January, which had five named storms. Several tropical depressions also formed late in the season; however, none developed into a named storm. Damages associated with TC activity for the 2010/11 season are estimated to have exceeded at least $\$ 3.5 \mathrm{~B}$ (US dollars), with a total of four reported fatalities. Forecasts indicated an increased risk of TCs impacting island nations surrounding the Coral Sea and to the southwest of Fiji. New Zealand was also at higher risk of experiencing an extratropical cyclone interaction this season.

The distribution of TC activity was in line with expectations, with six extratropical cyclones (Sinclair 2002) entering the New Zealand sector (some having greater impacts than others). Australia (as noted in section $4 \mathrm{~d} 7$ ) was significantly affected by the strongest event of the season when TC Yasi made landfall in Queensland on 3 February. Yasi is estimated to be the second costliest TC in Australian history. The 1981-2010 IBTrACS seasonal averages for the basin are 7.9 named storms, 7.7 TCs, and 4.3 major TCs. 
7) Australian Region basin-B. C. Trewin

(i) Seasonal activity

The 2010/11 tropical cyclone (TC) season was near normal in the broader Australian basin (areas south of the equator and between $90^{\circ} \mathrm{E}$ and $160^{\circ} \mathrm{E}^{5}$, which includes Australian, Papua New Guinea, and Indonesian areas of responsibility). The season produced 11 TCs, near the 1983/84 - 2010/11 average (the average coincides with comprehensive satellite coverage of the region) of 10.8 and somewhat counter to the well-above-normal activity typical of strong La Niña seasons in the Australian region; the season was wellabove average during the first half of the season, but only 1 TC formed after mid-February. There were no TCs in March for only the second time since the satellite era began around 1970. The 1981-2010 IBTrACS seasonal averages for the basin are 9.9 NSs, 7.5 TCs, and 4.0 major TCs.

There were four TCs in the eastern sector ${ }^{6}$ of the Australian region during 2010/11 (one of these, Yasi, entered from the Southwest Pacific region), and seven TCs in the western sector (two of which, Carlos and Errol, formed in the northern sector, that sector's only TCs of the season). Four systems made landfall in Australia as TCs, while one was dissipating when it made landfall on the Indonesian portion of Timor.

\section{(ii) Landfalling and other significant TCs}

The most significant TC of the season was Yasi, the most intense TC to make landfall in Queensland since at least 1918. Yasi formed north of Vanuatu on 30 January and entered the Australian region late on 31 January. It continued to track west-southwest towards the Australian coast, passing directly over Willis Island on the morning of 2 February and reaching Category 5 intensity that afternoon (see http:// www.bom.gov.au/cyclone/about/intensity.shtml for Australian tropical cyclone classification system).

Yasi made landfall on 3 February near Mission Beach, about halfway between Cairns and Townsville. At landfall it was near its peak intensity of 110 $\mathrm{kt}\left(57 \mathrm{~m} \mathrm{~s}^{-1}\right)$, and a pressure of $929 \mathrm{hPa}$ was recorded by a barometer near Mission Beach. There was also a peak storm surge of $5.3 \mathrm{~m}$ near Cardwell, to the

\footnotetext{
${ }^{5}$ The Australian Bureau of Meteorology's warning area overlaps both the southern Indian Ocean and Southwest Pacific.

${ }^{6}$ The eastern sector covers areas east of the eastern Australian coast to $160^{\circ} \mathrm{E}$, as well as the eastern half of the Gulf of Carpentaria. The western sector covers areas between $90^{\circ} \mathrm{E}$ and $125^{\circ} \mathrm{E}$. The northern sector covers areas from $125^{\circ} \mathrm{E}$ to the western half of the Gulf of Carpentaria.
}

eye's south. There were heavy rains along Yasi's track, with a maximum 24-hour total of $471 \mathrm{~mm}$ at South Mission Beach. Yasi weakened steadily after landfall but remained a TC until it reached the Mount Isa area, while moisture from the TC contributed to flash flooding in South Australia and Victoria on 4-5 February. There was widespread and severe damage to property and vegetation from wind and storm surge, with Tully, Mission Beach, and Cardwell the worst-affected centers.

Two other TCs reached Category 4 intensity, but neither made landfall. Zelia tracked parallel to the east coast of Australia between 14 and 18 January, passing southwest of New Caledonia and just northeast of Norfolk Island towards the end of its life. Its peak intensity of $100 \mathrm{kt}\left(51 \mathrm{~m} \mathrm{~s}^{-1}\right)$ was reached on 16 January near $19^{\circ} \mathrm{S}, 158^{\circ} \mathrm{E}$, to the west of New Caledonia. Bianca formed on 26 January west of Broome, and then tracked parallel to the northwest coast, before moving farther offshore after passing north of Exmouth and reaching its peak intensity of $95 \mathrm{kt}\left(49 \mathrm{~m} \mathrm{~s}^{-1}\right)$ near $25^{\circ} \mathrm{S}, 106^{\circ} \mathrm{E}$. It then recurved southeast, resulting in a TC warning being issued for metropolitan Perth for the first time since 1989, but ultimately weakened below TC intensity before reaching the coast.

Carlos, which was an identifiable system from 13 to 26 February, only briefly reached Category 1 intensity near Darwin on 16 February. After tracking west-southwest across the Kimberley region, it reintensified after crossing out to sea near Broome, before returning to track along the coast between Karratha and Exmouth as a Category 2 system on 22-23 February. Carlos continued to move westward away from the coast on 24 February, reaching its peak intensity of $65 \mathrm{kt}\left(33 \mathrm{~m} \mathrm{~s}^{-1}\right)$ as it did so, before dissipating off the coast on 26 February. The main impacts of Carlos arose from extremely heavy rain in the Darwin area as the system formed, with Darwin setting new records for one-day $(367.6 \mathrm{~mm})$, threeday $(684.8 \mathrm{~mm})$, seven-day $(847.4 \mathrm{~mm})$, and monthly $(1110.2 \mathrm{~mm})$ rainfall. Widespread flooding occurred through the region. A tornado associated with the TC also caused significant damage in Karratha.

The other two landfalls on the Australian mainland during the season were both in Queensland: Tasha made landfall just south of Cairns on 25 December as a Category 1 system [40 kt $\left.\left(21 \mathrm{~m} \mathrm{~s}^{-1}\right)\right]$ and Anthony near Bowen on 30 January as a Category 2 system [50 kt $\left(26 \mathrm{~m} \mathrm{~s}^{-1}\right)$ sustained winds]. Both made landfall near their peak intensity. Neither caused any major wind or storm surge damage but moisture 


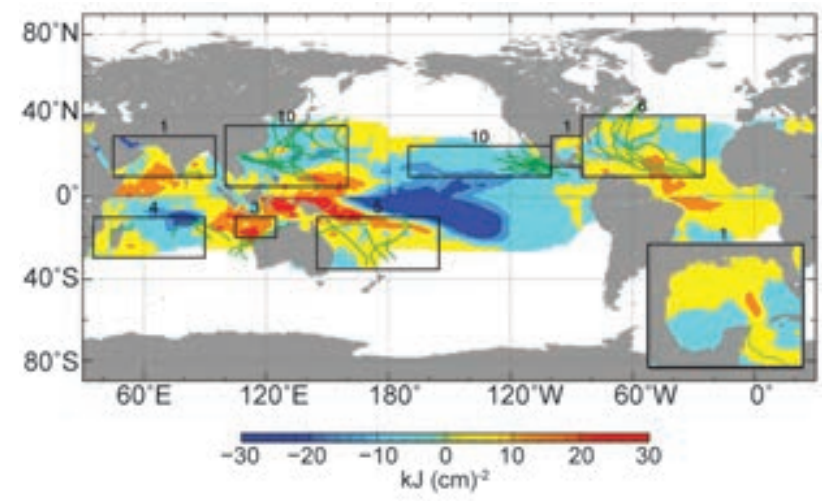

FIG. 4.27. Global anomalies of TCHP corresponding to 2011 computed as described in the text. The numbers above each box correspond to the number of Category I and above cyclones that traveled within each box. The Gulf of Mexico conditions during Jun-Nov 201 I are shown in the insert shown in the lower right corner.

from both, particularly Tasha, contributed to flooding farther inland. Errol, with a peak intensity of 65 $\mathrm{kt}\left(33 \mathrm{~m} \mathrm{~s}^{-1}\right)$, formed west of Darwin and moved to the northwest dissipating as it made landfall on the Indonesian island of Timor (not to be confused with the independent nation of East Timor) on 18 April.

\section{e. Tropical cyclone heat potential-G. J. Goni, J. A. Knaff, and $\mathrm{I}-\mathrm{I}$ Lin}

This section summarizes the seven previously described TC basins from the standpoint of tropical cyclone heat potential (TCHP), by focusing on upper ocean temperature conditions during the season with respect to average values. TCHP, defined as the ocean heat content contained between the sea surface and the depth of the $26^{\circ} \mathrm{C}$ isotherm, has been shown to be more closely linked to intensity changes of tropical cyclones than sea surface temperature (SST) alone (Shay et al. 2000; Goni and Trinanes 2003; Lin et al. 2008, 2009a), provided that atmospheric conditions are also favorable. In general, fields of TCHP show high spatial and temporal variability associated with oceanic mesoscale features that can be globally detected with satellite altimetry (Lin et al. 2008; Goni et al. 2009). It has been shown that areas with high values of TCHP can be an important factor for the rapid intensification of tropical cyclones (TCs; e.g., Shay et al. 2000; Mainelli et al. 2008; Lin et al. 2009a).

To examine TCHP interannual variability, anomalies are computed during the months of TC activity in each hemisphere: June through November in the Northern
Hemisphere and November through April in the Southern Hemisphere. Anomalies are defined as departures from the mean TCHP calculated during the same months for the period 1993-2011. These anomalies show large variability within and among the tropical cyclone basins. During the 2011 season, the basins exhibited the following TCHP anomalies:

- The Western North Pacific (WNP) basin exhibited both positive and negative TCHP anomaly values, while the Eastern North Pacific (ENP) had slightly negative values (Fig. 4.27).

- The Southwest Pacific basin had both positive and negative anomalies, although the cyclone basin continued exhibiting mostly high positive values.

- In the North Indian Ocean (NIO) basin, both the Bay of Bengal and Arabian Sea exhibited positive anomalies.

- In the Atlantic basin, the Gulf of Mexico (Fig. 4.27 insert, lower right) showed positive and negative anomalies associated with the variability of the Loop Current. In contrast to 2009 and 2010, the tropical Atlantic exhibited mostly negative values, which were largely observed in the sea height and sea surface temperature fields ${ }^{7}$.

- In general, with respect to the 2010 anomalies, the WNP and NIO basins exhibited lower values of TCHP. On the other hand, the SIO and Southwest Pacific basins, as well as sections of the Gulf of Mexico, showed elevated TCHP values (Fig. 4.28).

${ }^{7}$ It should be noted that there were warm SST anomalies in the Atlantic in 2011, and SSTs do not necessarily equate to TCHP values.

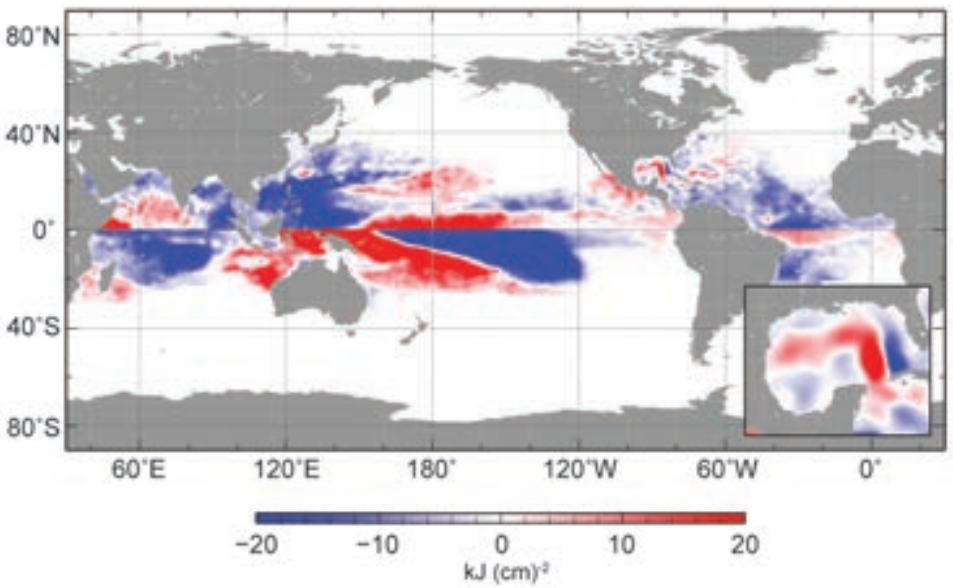

FIG. 4.28. Differences between the TCHP fields in $201 \mathrm{I}$ and 2010. 

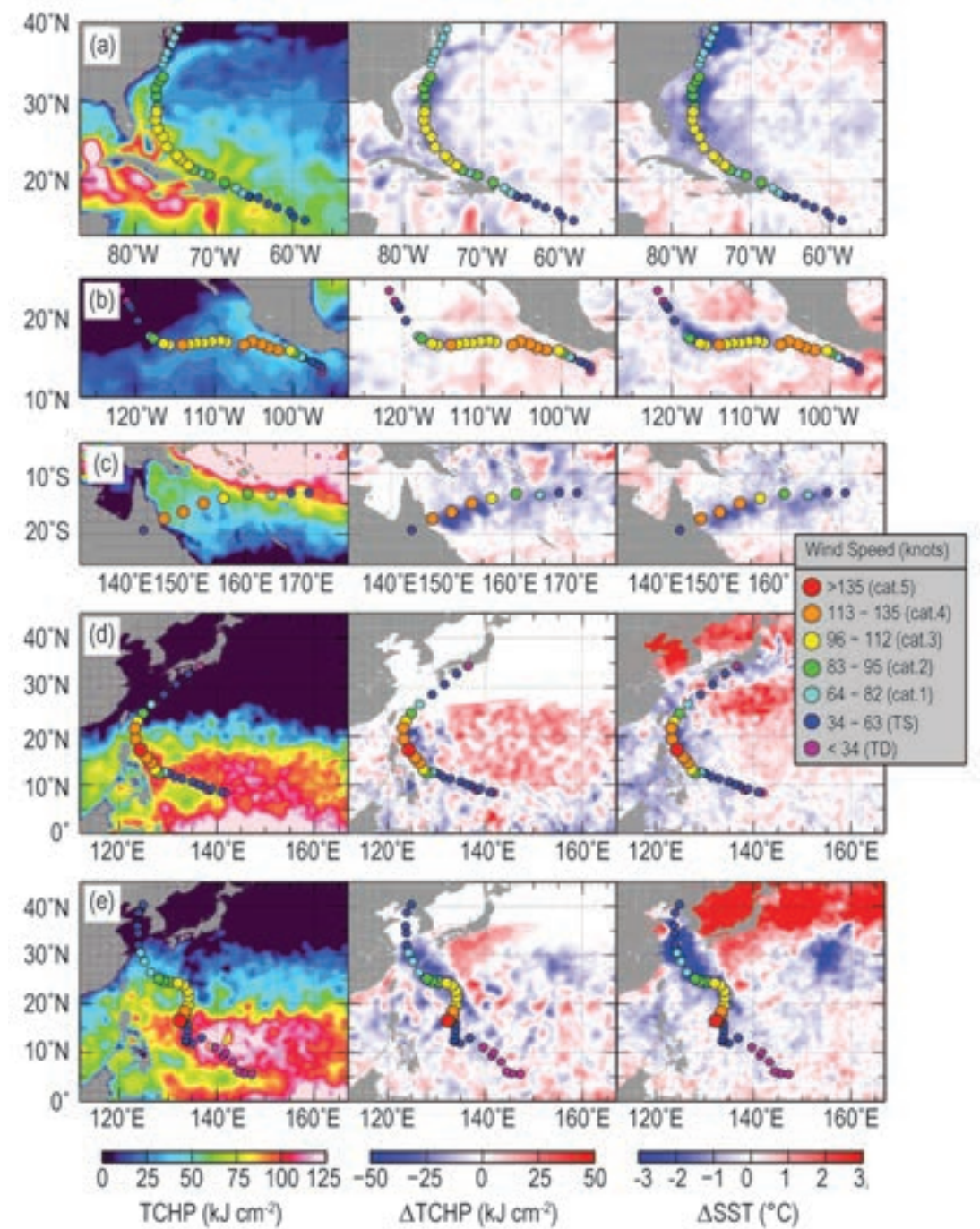

Fig. 4.29. (left) Oceanic TCHP and surface cooling given by the difference between post- and pre-storm values of (center) TCHP and (right) SST for Hurricanes (a) Irene and (b) Hilary, (c) Tropical Cyclone Yasi, and Typhoons (d) Songda and (e) Muifa. The TCHP values correspond to two days before each TC reaches its maximum intensity value.

Five TCs, where the location of their intensification coincided with relatively high values of TCHP along their tracks, are highlighted in Fig. 4.29. These were Irene (Atlantic), Hilary (ENP), Yasi (Southwest Pacific), and Songda and Muifa (WNP). The cooling associated with the wake of major TCs reached values of up to $50 \mathrm{~kJ} \mathrm{~cm}^{-2}$ in TCHP and above $3^{\circ} \mathrm{C}$ in SST. This is important since large cooling could affect the intensification for subsequent TCs in the same region and may also influence the upper ocean thermal structure on regional scales within weeks to months after the passage of the cyclones (Emanuel 2001; Hart et al. 2007; Dare and McBride 2011).

Hurricane Irene, the first hurricane of the Atlantic season, developed during late August, and rapidly be- came a Category 3 major hurricane (Fig. 4.29a), when traveling over waters with TCHP values above 60 $\mathrm{kJ} \mathrm{cm}^{-2}$, and the cooling produced by this TC, even after weakening, reached values larger than $3^{\circ} \mathrm{C}$ in its track.

In the case of ENP Hurricane Hilary, while moving roughly parallel to the Mexican coast and within a very favorable atmospheric environment, Hilary quickly intensified up to $55 \mathrm{kts}\left(28 \mathrm{~m} \mathrm{~s}^{-1}\right)$ on 22 September. While still moving west-northwest within a similarly favorable atmospheric environment, Hilary encountered higher values of TCHP and became a hurricane (Fig. 4.29b). The TCHP increased nearly three-fold from $15 \mathrm{~kJ} \mathrm{~cm}^{-2}$ to values exceeding 40 $\mathrm{kJ} \mathrm{cm}^{-2}$ as the TC began its most rapid period of intensification. In this case, TCHP fields improved operational forecasts that were made by both the Statistical Hurricane Intensity Prediction Scheme (SHIPS; DeMaria et al. 2005) and Rapid Intensity Index (RII; Kaplan et al. 2010). During the next 24 hours, Hilary intensified very rapidly from $55 \mathrm{kts}$ to $125 \mathrm{kts}$ ( 28 $\mathrm{m} \mathrm{s}^{-1}$ to $\left.64 \mathrm{~m} \mathrm{~s}^{-1}\right)$. It is noteworthy that the atmospheric conditions remained nearly constant during this period, illustrating the positive effect that TCHP has on TC development and demonstrating how TCHP information can improve TC intensity forecast model output. With respect to Hurricane Hilary for example, TCHP values remained greater than $30 \mathrm{~kJ}$ $\mathrm{cm}^{-2}$ and this, coupled with favorable atmospheric conditions, persisted for the next 48 hours, allowing Hilary to sustain itself as a major hurricane for more than four days. Eventually, deteriorating ocean and atmospheric conditions caused Hilary to weaken as it continued to move west-northwestward towards the eastern portion of the basin.

The Southwest Pacific basin saw slightly reduced TC activity despite the anomalously elevated TCHP (Fig. 4.27). Nonetheless, three Category 4-5 TCs (Atu, Wilma, and Yasi) occurred in this region. Highlighted 
in Fig. 4.29c, Severe Tropical Cyclone Yasi, which was observed to rapidly intensify over high values of TCHP $\left(>50 \mathrm{~kJ} \mathrm{~cm}^{-2}\right)$ made landfall as a strong Category 4 TC in northern Queensland, Australia (see section $4 \mathrm{~d} 7 i$ ii above).

In the WNP, all of the Category 4 and 5 TCs were observed to intensify over high values of TCHP (typically $>75 \mathrm{~kJ} \mathrm{~cm}^{-2}$ in the western North Pacific) except for Typhoon Roke. Roke was observed intensifying over lower TCHP values $\left(\sim 40 \mathrm{~kJ} \mathrm{~cm}^{-2}-50 \mathrm{~kJ} \mathrm{~cm}^{-2}\right)$. However, this was a relatively fast-moving typhoon, traveling at around $7.5 \mathrm{~m} \mathrm{~s}^{-1}$, as it intensified to its peak at Category 4. As fast-moving TCs induce less storm-induced cooling, they tend to intensify over relatively lower TCHP regions (Lin et al. 2009b). During the WNP typhoon season, 10 typhoons reached Category 1 intensity and $60 \%$ of these reached either Category 4 or 5 status, which is the highest percentage of Category 4-5 typhoon occurrence since $2007^{8}$. Among these, Super Typhoon Songda was first identified on 20 May, and from 24-26 May was over an area of high TCHP $\left(>100 \mathrm{~kJ} \mathrm{~cm}^{-2}\right)$, and rapidly intensified to a Category $5 \mathrm{TC}$, at a rate of $37 \mathrm{kts}^{\mathrm{day}}{ }^{-1}\left(19 \mathrm{~m} \mathrm{~s}^{-1}\right.$ day $^{-1}$; Fig. 4.29d). Between 2005 and 2011, this was the only Category 5 typhoon that occurred during the month of May over the WNP.

The high TCHP of values $>100 \mathrm{~kJ} \mathrm{~cm}^{-2}$ observed in May 2011 suggests that the ocean provided sufficient energy for intensification (Lin et al. 2009a,b), along with other possibly favorable atmospheric conditions. Finally, in the WNP basin, Super Typhoon Muifa (Fig. 4.29e) was first observed on 25 July at latitude $5.6^{\circ} \mathrm{N}$. After 4.5 days of genesis time, Muifa rapidly intensified, from Category 2 ( $85 \mathrm{kts}$ or $44 \mathrm{~m} \mathrm{~s}^{-1}$ ) to Category 5 (140 kts or $72 \mathrm{~m} \mathrm{~s}^{-1}$ ) in only 12 hours on 30 July. This extremely rapid intensification rate, equivalent to $55 \mathrm{kts}\left(28 \mathrm{~m} \mathrm{~s}^{-1}\right)$ in 24 hours is almost double the $30 \mathrm{kts}\left(15 \mathrm{~m} \mathrm{~s}^{-1}\right)$ per day criteria for rapid intensification (Kaplan et al. 2010). It is noteworthy that this rapid intensification took place over an area with high TCHP values that exceeded $120 \mathrm{~kJ} \mathrm{~cm}^{-2}$.

\section{f. Intertropical convergence zones}

\section{I) Pacific-A. B. Mullan}

The intertropical convergence zone (ITCZ) lies approximately parallel to the equator, with a slight

\footnotetext{
${ }^{8}$ It should be noted that while both Songda and Muifa were briefly classified as Category 5 typhoons in the JTWC operational database, they were not officially classified as such by Japan Meteorological Agency, which is the official monitoring World Meteorological Organization center for the WNP.
}

(a)
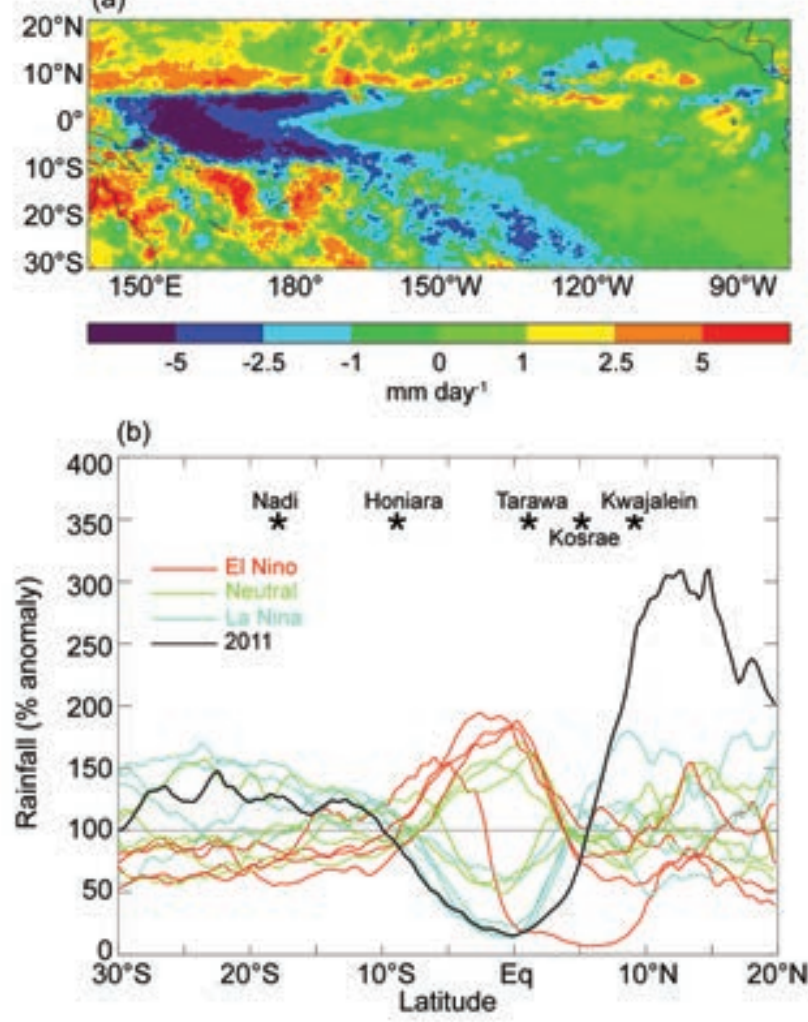

Fig. 4.30. (a) TRMM 3B43 rainfall anomaly for JFM 20 II (mm day ${ }^{-1}$; relative to 1999-2008 mean); (b) Cross sections of JFM rainfall anomalies (\% of 1999-2008 mean) for each year 1998 to $201 \mathrm{I}$, averaged over sector $150^{\circ} \mathrm{E}-180^{\circ}$. Lines are colored according to ENSO status, except for 2011 (black). Stars mark latitude of selected island rainfall sites: $\mathrm{Nadi}\left(\mathrm{Fiji} ; 8^{\circ} \mathrm{S}, 175^{\circ} \mathrm{E}\right)$, Honiara (Solomon Islands; $9^{\circ} \mathrm{S}, 160^{\circ} \mathrm{E}$ ), Tarawa (Kiribati; $1^{\circ} \mathrm{N}, 173^{\circ} \mathrm{E}$ ), Kosrae (Micronesia; $5^{\circ} \mathrm{N}, 163^{\circ} \mathrm{E}$ ), Kwajalein (Marshall Islands; $9^{\circ} \mathrm{N}, 167^{\circ} \mathrm{E}$ ). The anomalous EI Niño year is 1998.

poleward tilt on its eastern end, and varies in position from around $5^{\circ} \mathrm{N}-7^{\circ} \mathrm{N}$ in February-May to $7^{\circ} \mathrm{N}-10^{\circ} \mathrm{N}$ in August-November. The other major convergence zone, the South Pacific convergence zone (SPCZ), extends diagonally from around the Solomon Islands $\left(10^{\circ} \mathrm{S}, 160^{\circ} \mathrm{E}\right)$ to near $30^{\circ} \mathrm{S}, 140 \mathrm{~W}^{\circ}$, and is most active in the November-April half-year.

The Pacific began 2011 in a moderate to strong La Niña, which weakened through the first two quarters of the year to neutral conditions. A weaker La Niña returned in August 2011. Thus, the year was dominated by stronger-than-normal surface easterlies near the date line, cooler sea surface temperatures from the date line eastwards, and the convergence zones being further poleward than usual in both hemispheres, with an enhanced dry zone along the equator. A double ITCZ was present in March and April, with a fairly prominent southern branch 
between $150^{\circ} \mathrm{W}$ and $90^{\circ} \mathrm{W}$, as is typical of La Niña years.

The poleward shift in the convergence zones was most clearly defined in the first quarter of the year (Fig. 4.30). Figure 4.30a shows the January-March rainfall anomalies relative to the Tropical Rainfall Measuring Mission (TRMM) 3B43 1999-2008 climatology. Reduced convection near the equator west of the date line is quite marked and the latitudinal extent of this enhanced dry zone was unusual even for La Niña conditions. Figure 4.30b demonstrates this by presenting transects of TRMM rainfall anomalies from $20^{\circ} \mathrm{N}$ to $30^{\circ} \mathrm{S}$, averaged over the $150^{\circ} \mathrm{E}-180^{\circ}$ sector. Even though the TRMM data cover a fairly short period (starting in 1998), there is a clear separation in the rainfall transects according to the ENSO status, which is determined here from NOAA's Oceanic Niño Index (ONI; http://www. cpc.ncep.noaa.gov/products/analysis_monitoring/ ensostuff/ensoyears.shtml). (For the purpose of Fig. $4.30 \mathrm{~b}$, the quarter was classified as El Niño if two or more months exceeded the $\mathrm{ONI}+0.5^{\circ} \mathrm{C}$ threshold.)

In La Niña years, rainfall in the first quarter tends to be above normal poleward of about $8^{\circ} \mathrm{S}$ and $4^{\circ} \mathrm{N}$, as an average over the $150^{\circ} \mathrm{E}-180^{\circ}$ sector. The dry zone was more extensive in 2011, and the TRMM transects
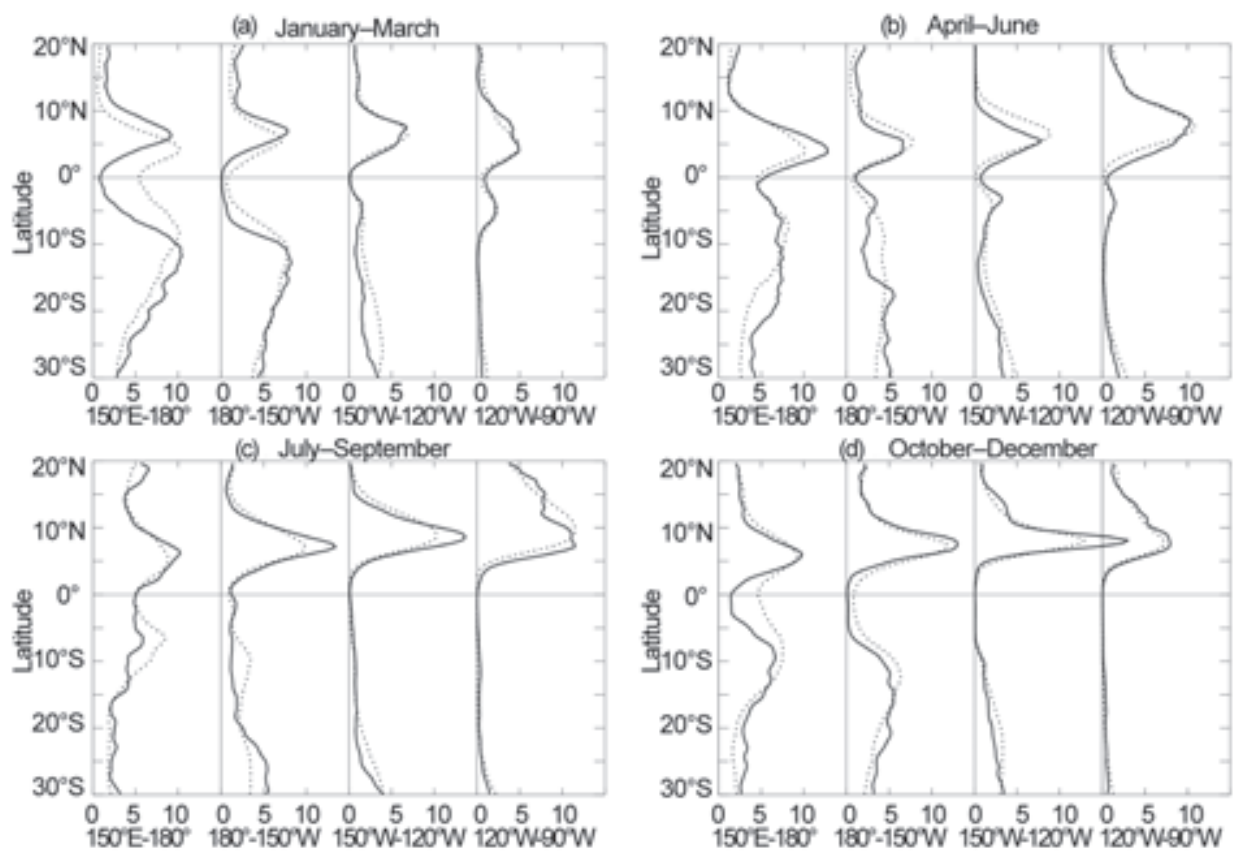

FIG. 4.3I. Rainfall rate ( $\mathrm{mm}$ day $^{-1}$ ) from TRMM analysis for the four quarters (a)-(d) of 20II. The separate panels for each quarter show the $201 \mathrm{I}$ rainfall cross section between $20^{\circ} \mathrm{N}$ and $30^{\circ} \mathrm{S}$ (solid line) and the 1999-2008 climatology (dotted line), separately for four $30^{\circ}$ sectors from $150^{\circ} \mathrm{E}-180^{\circ}$ to $120^{\circ} \mathrm{W}-90^{\circ} \mathrm{W}$. The climatology and 2011 rainfall in the first two quarters are from the TRMM 3B43 data, whereas the 201 I rainfall in the last two quarters are from TRMM $3 A \mid 2$ data. (b) April-June

agree well with island rainfall records. Penrhyn (at $10^{\circ} \mathrm{S}$ ) in the Northern Cook Islands received about $40 \%$ of its long-term seasonal rainfall and Tarawa in the western Kiribati Islands (near the equator) was exceptionally dry, at about $5 \%$ of normal (ICU 2011). North of the equator, Kosrae (at $\left.5^{\circ} \mathrm{N}\right)$ in the Federated States of Micronesia received less than $75 \%$ of normal rainfall for the quarter (http://www. prh.noaa.gov/peac/update.php). Conversely, Fiji at $18^{\circ} \mathrm{S}$ and Kwajalein at $9^{\circ} \mathrm{N}$ were considerably wetter than normal. The rainfall anomaly north of about $8^{\circ} \mathrm{N}$ (Fig. 4.30b) appears exceptionally large, because January-March is normally the dry season in this part of the Pacific.

Figure 4.31 shows Pacific rainfall transects for all four quarters, divided into four longitude sectors. The Pacific transects are derived from the $0.25^{\circ}$-resolution NASA TRMM rainfall data (3B43 product; Huffman et al. 2007), except for July-December 2011 where $0.5^{\circ}$ $3 \mathrm{~A} 12$ data were used due to the current unavailability of 3B43. The 2011 positions of the convergence zones can be compared with the 1999-2008 climatology (see Mullan 2011 for the corresponding figure for 2010). The weak double ITCZ is evident in Fig. 4.31b.

The ITCZ and SPCZ are markedly poleward of their normal positions in January-March (first two panels of Fig. 4.31a). Thereafter, the peak ITCZ rainfall tended to occur near its normal latitude, or even equatorward in the second and third quarters as ENSOneutral conditions prevailed. The SPCZ rainfall was displaced south of its normal latitude for much of the year. The SPCZ could also be described as being farther west than normal in the sense that a coherent convergence zone did not extend much farther east than $150^{\circ} \mathrm{W}$. This is evident in Fig. 4.30a and also in the third panels of Figs. 4.31a-d. Thus, 
(a)
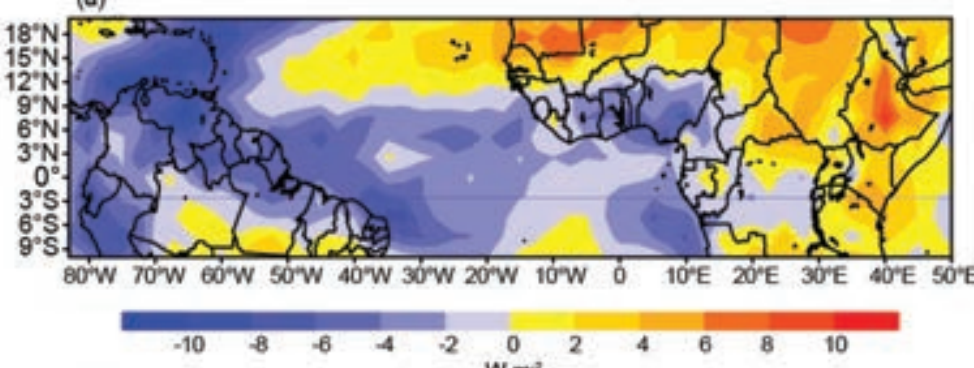

(b)

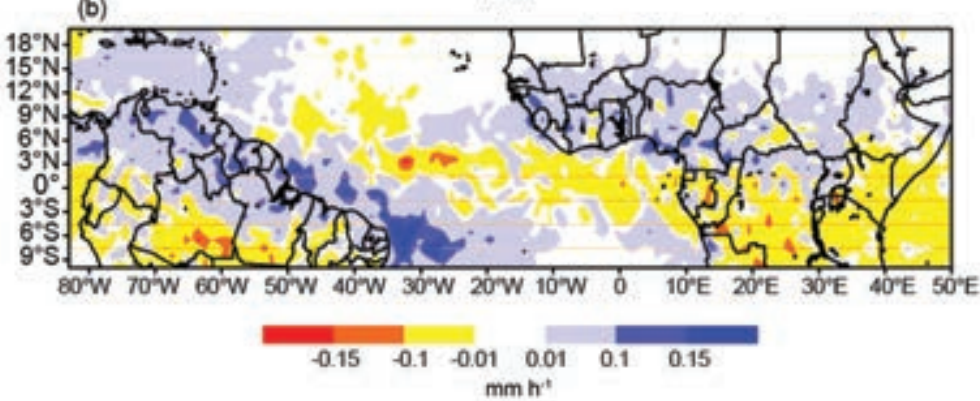

FIg. 4.32. (a) Atlantic NOAA-interpolated OLR (Liebmann and Smith 1996) anomalies ( $\mathrm{W} \mathrm{m}^{-2}$ ) for $201 \mathrm{l}$ and (b) TRMM anomalous precipitation rate $\left(\mathrm{mm} \mathrm{hr}^{-1}\right)$ for Jan-Jun $20 \mathrm{ll}$. The anomalies were calculated based on the climatology for the period (a) 1975-2010 and (b) 1998-2010.

island groups south of the equator in particular tended to experience persistent rainfall anomalies for much of 2011, with an occasional respite during ENSO-neutral months. Tarawa (western Kiribati) and Penrhyn (Northern Cook Islands) had below-normal rainfall for 11 months of the year. Tahiti (French Polynesia), which lies farther to the east $\left(150^{\circ} \mathrm{W}\right)$,

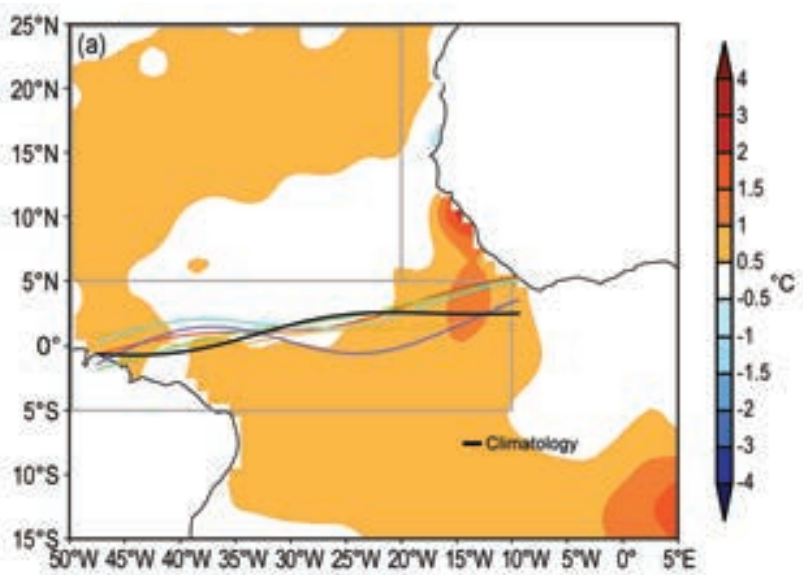

received less than $50 \%$ of its normal rainfall for eight months of the year.

2) AtLANTIC-A. B. Pezza and C. A. S. Coelho

The Atlantic ITCZ is a well-organized convective band that oscillates approximately between $5^{\circ} \mathrm{N}-12^{\circ} \mathrm{N}$ during JulyNovember and $5^{\circ} \mathrm{N}-5^{\circ} \mathrm{S}$ during JanuaryMay (Waliser and Gautier 1993; Nobre and Shukla 1996). Atmospheric equatorial Kelvin waves can modulate the ITCZ interannual variability (Mekonnen et al. 2008; Mounier et al. 2007) and ENSO is also known to influence the ITCZ on the seasonal time scale (Münnich and Neelin 2005). In 2011, the prevailing global scenario was that of a moderateto-strong La Niña from January to April followed by yet another La Niña (weak to moderate) developing from September, with global climate anomalies typical of positive Southern Oscillation index (SOI) persisting in many areas of the globe. The ITCZ responded to this pattern and presented a noticeable enhancement, with negative average annual outgoing longwave radiation (OLR) anomalies in most of the equatorial Atlantic sector surrounding South America (Fig. 4.32a) driven primarily by the anomalous convection observed during the first half of the year (Fig. 4.32b). This pattern contributed to breaking the drought conditions

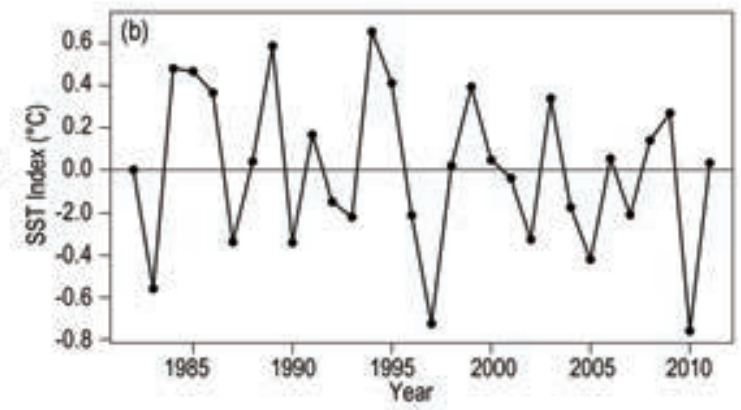

FIG. 4.33. (a) Atlantic ITCZ position inferred from OLR during March 20II. The colored thin lines indicate the approximate position for the six pentads of March 20II. The black thick line indicates the Atlantic ITCZ climatological position. The SST anomalies ( ${ }^{\circ} \mathrm{C}$, Reynolds et al. 2002) for March 2011 based on the $1982-2010$ climatology are shaded. The two boxes indicate the areas used for the calculation of the new Atlantic Index in (b); (b) March SST anomaly time series ( ${ }^{\circ} \mathrm{C}$ ) averaged over the South American sector $\left(5^{\circ} \mathrm{S}-5^{\circ} \mathrm{N}, 10^{\circ} \mathrm{W}-\right.$ $\left.50^{\circ} \mathrm{W}\right)$ minus the SST anomaly time series averaged over the tropical coast of northern Africa $\left(5^{\circ} \mathrm{N}-25^{\circ} \mathrm{N}\right.$, $20^{\circ} \mathrm{W}-50^{\circ} \mathrm{W}$ ) for the period $1982-201$ I forming the Atlantic Index. The positive phase of the index indicates favorable conditions for enhanced Atlantic ITCZ activity. 


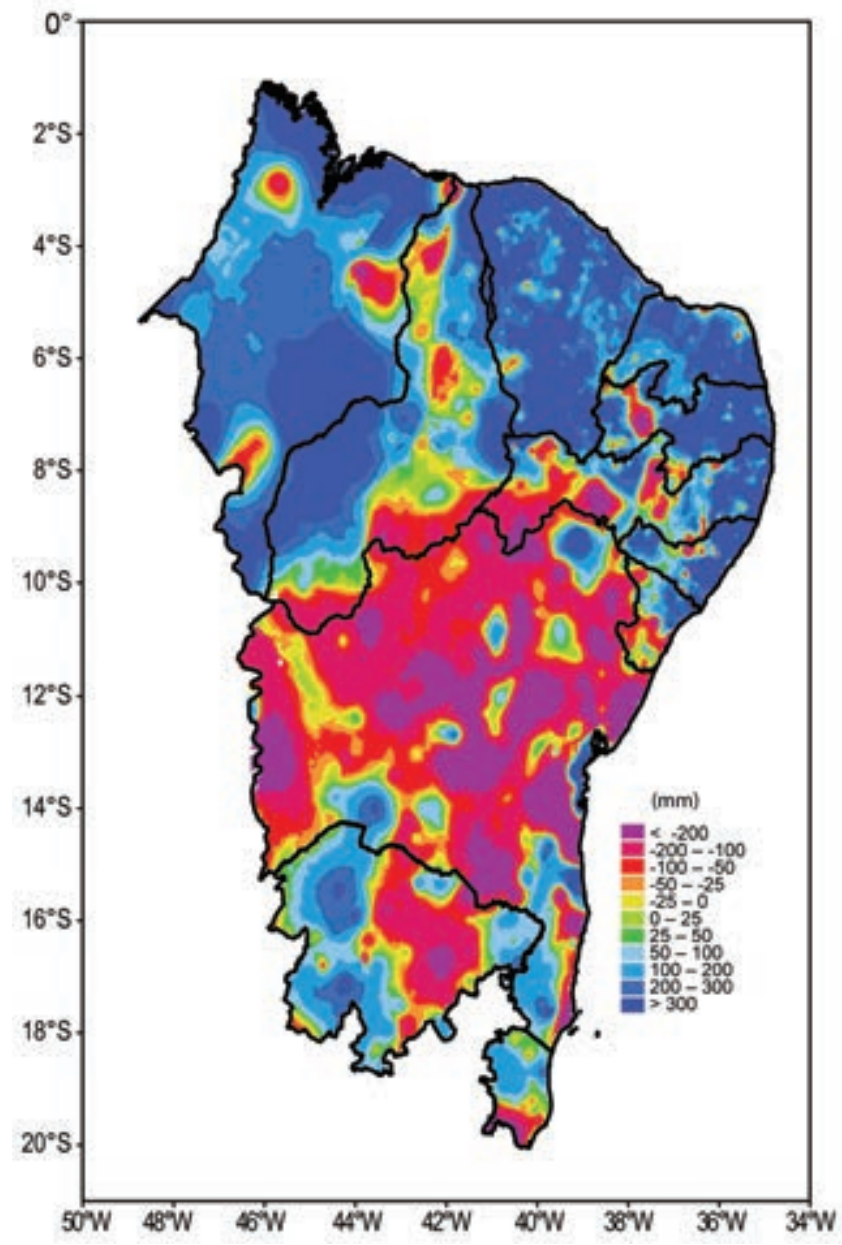

FIG. 4.34. Northeastern Brazil average 201 I precipitation anomaly $(\mathrm{mm})$ with respect to 196 I-90 climatology based on high-resolution station data. (Source: federal and regional networks CMCD/INPE, INMET, SUDENE, ANEEL, FUNCEME/CE, LMRS/PB, EMPARN/RN, LAMEPE/ITEP/PE, CMRH/SE, SEAAB/PI, SRH/BA, CEMIG/SIMGE/MG, and SEAG/ES)

that had previously been established in northeastern Brazil and parts of the Amazon in the previous year.

While the La Niña conditions indirectly helped enhance the ITCZ via Kelvin wave-induced upperlevel divergence in the Atlantic sector, the demise of record-breaking warm SST anomalies observed over the subtropical North Atlantic (Fig. 4.33a) played a fundamental role via a favorable (enhanced) meridional SST gradient, expressed here by the Atlantic Index (see Fig. 4.33b caption for definition). A positive index in 2011, contrasting with the record-breaking negative index of 2010 , implies a return to a more favorable pattern for frequent bursts of organized convection in the southern part of the basin and ultimately an overall enhancement of the ITCZ. Within this scenario, the ITCZ oscillated around its average climatological position for most of the year, with precipitation above average in parts of the eastern Amazon and northeastern Brazil (Fig. 4.34). This effect was due to the explicit dynamical response to upper-level divergence as well as the direct evaporative effect of the onshore trade winds responding to the north-south water temperature gradient, giving a typical La Niña response both in terms of positioning and strength of the ITCZ in 2011.

\section{g. Atlantic multidecadal oscillation-C. Wang}

The Atlantic Multidecadal Oscillation (AMO) is an oscillatory mode defined by the detrended North Atlantic SST anomalies over the region of $0^{\circ}-60^{\circ} \mathrm{N}$ and from the east coast of the Americas to $0^{\circ}$ longitude (Figs. 4.35a,b; Delworth and Mann 2000; Enfield et al. 2001; Wang et al. 2008a). A driving mechanism for the AMO may be the Atlantic meridional overturning circulation (Delworth and Mann 2000; Knight et al. 2005; Dijkstra et al. 2006; R. Zhang et al. 2007; see also section 3 h of this report for detailed information on the meridional overturning circulation). A new study shows that the AMO varies with dust aerosol in the tropical North Atlantic and rain-
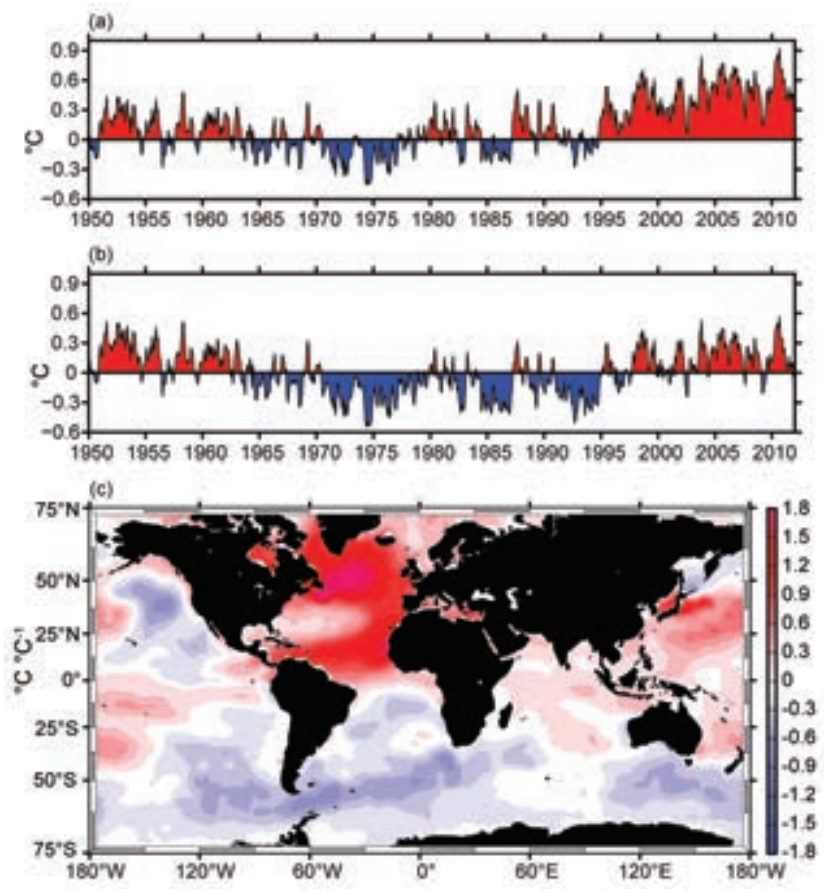

FIg. 4.35. The index of the $A M O$ and its spatial pattern. Shown are (a) SST anomalies $\left({ }^{\circ} \mathrm{C}\right)$ in the North Atlantic of $0^{\circ}-60^{\circ} \mathrm{N}$ and from the east coast of the Americas to $0^{\circ}$ longitude, (b) the AMO index $\left({ }^{\circ} \mathrm{C}\right)$ defined by the detrended (removing the linear trend) North Atlantic SST anomalies, and (c) regression $\left({ }^{\circ} \mathrm{C}\right.$ per $\left.{ }^{\circ} \mathrm{C}\right)$ of global SST anomalies onto the AMO index of (b). The monthly SST anomalies are calculated as departures from the 197|-2000 base period. 
fall in the Sahel, suggesting that a positive feedback exists between North Atlantic SST, dust aerosol, and Sahel rainfall on multidecadal timescales (C. Wang et al. 2012). In addition to multidecadal variability, the AMO also demonstrates high-frequency variability such as an interannual variation via its connection to the tropical North Atlantic and the Atlantic Warm Pool (AWP; a large body of warm water comprising the Gulf of Mexico, Caribbean Sea, and the western tropical North Atlantic), and as such has exhibited a seasonal influence on the behavior of tropical cyclones (TCs) in the Atlantic and Eastern North Pacific (ENP) basins. The extended reconstructed SST (ERSST) data from 1950 to 2011 (Fig. 4.35b) shows that the AMO was in the cold phase from the late 1960 s to the early 1990s and in the warm phase before the late 1960s and again after the early 1990s (Enfield et al. 2001). The AMO is related to SST anomalies over the global oceans as shown in Fig. $4.35 \mathrm{c}$. (a)

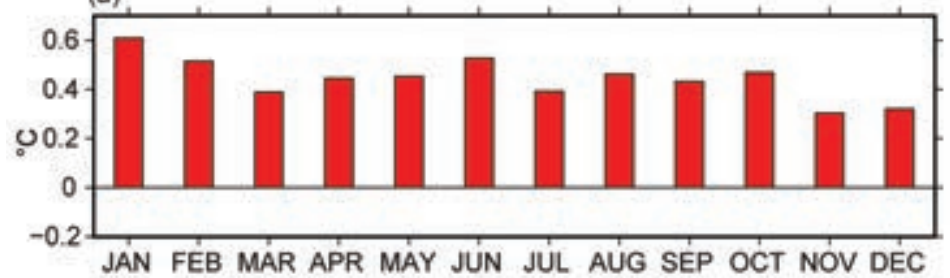

(b) DJF

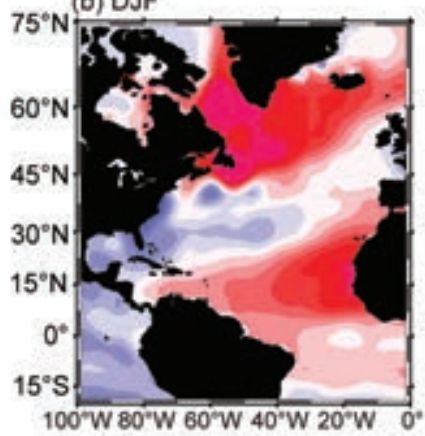

(d) JJA

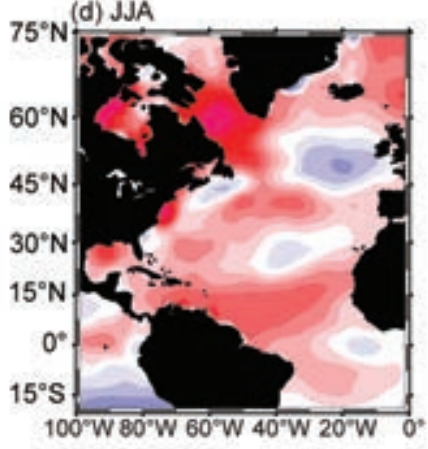

(c) MAM

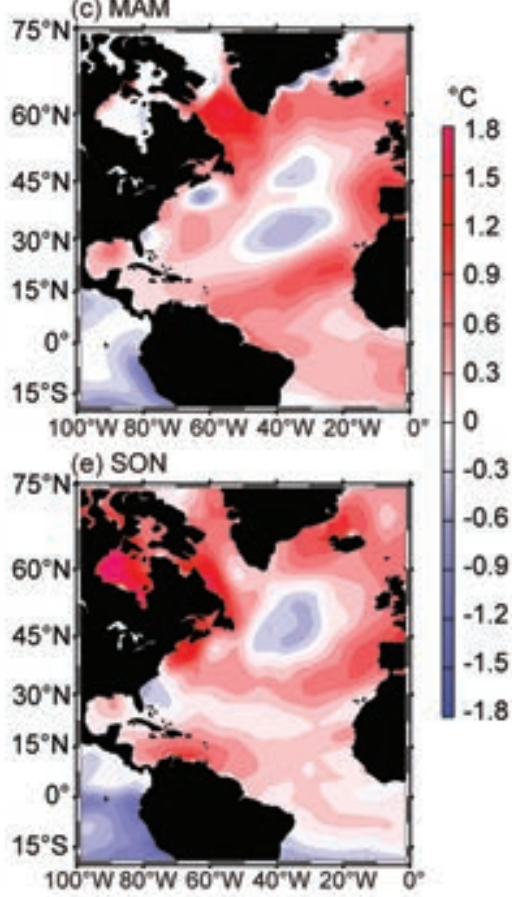

FIG. 4.36. The AMO in 20II. Shown are the (a) monthly North Atlantic SST anomalies $\left({ }^{\circ} \mathrm{C}\right)$, (b) DJF 2010/II SST anomalies $\left({ }^{\circ} \mathrm{C}\right)$, (c) MAM SST anomalies, (d) JJA SST anomalies $\left({ }^{\circ} \mathrm{C}\right)$, and (e) SON SST anomalies $\left({ }^{\circ} \mathrm{C}\right)$. The monthly SST anomalies are calculated as departures from the 197I-2000 base period.
The AMO variability is associated with changes of climate and extreme events, such as drought and flood in North America and Europe, and hurricane activity in the North Atlantic and ENP (Enfield et al. 2001; McCabe et al. 2004; Goldenberg et al. 2001; Bell and Chelliah 2006; Wang et al. 2008a; Wang and Lee 2009). Recent studies show that the relationship of the AMO to TCs is due to its tropical component since the climate response to the North Atlantic SST anomalies is primarily forced at the low latitudes (e.g., Lu and Delworth 2005; Sutton and Hodson 2007). The AMO variability coincides with the multidecadal signal of the AWP and the AWP is in the path of, or a birthplace for, Atlantic TCs (Wang et al. 2008a). Thus, the influence of the AMO on climate and Atlantic TC activity operates through the mechanism of the AWP-induced atmospheric changes by having an effect on vertical wind shear in the hurricane main development region (MDR). A large AWP reduces such shear, while a small AWP enhances it. A large AWP also weakens the southerly Great Plains low-level jet, thus reducing the northward moisture transport from the Gulf of Mexico to the eastern United States and decreasing the boreal summer rainfall over the central US, while a small AWP has the opposite effect (Wang et al. 2006, 2008b). It has also been shown that the AWP variability can produce the observed out-of-phase relationship between TC activity in the tropical North Atlantic and ENP (Wang and Lee 2009).

As of 2011, the AMO has been in its warm phase since 1995. For all months in 2011, the North Atlantic SST anomalies were positive (Fig. 4.36a), with the maximum of the North Atlantic SST anomalies in January $\left(+0.61^{\circ} \mathrm{C}\right)$ and the minimum in November $\left(+0.30^{\circ} \mathrm{C}\right)$. Spatially, the North Atlantic SST anomalies during the boreal winter showed a tripole pattern with the positive SST anomalies in the subpolar North Atlantic and the tropical North Atlantic and the negative SST anomalies in the subtropical North Atlantic (Fig. 4.36b). The SST anomaly pattern divided the AWP into two parts: a colder Gulf of Mexico and a warmer Caribbean Sea/ western tropical North Atlantic. The opposite SST anomaly pattern was consistent with a previous study (Muñoz et al. 2010), which showed that the air-sea fluxes as- 

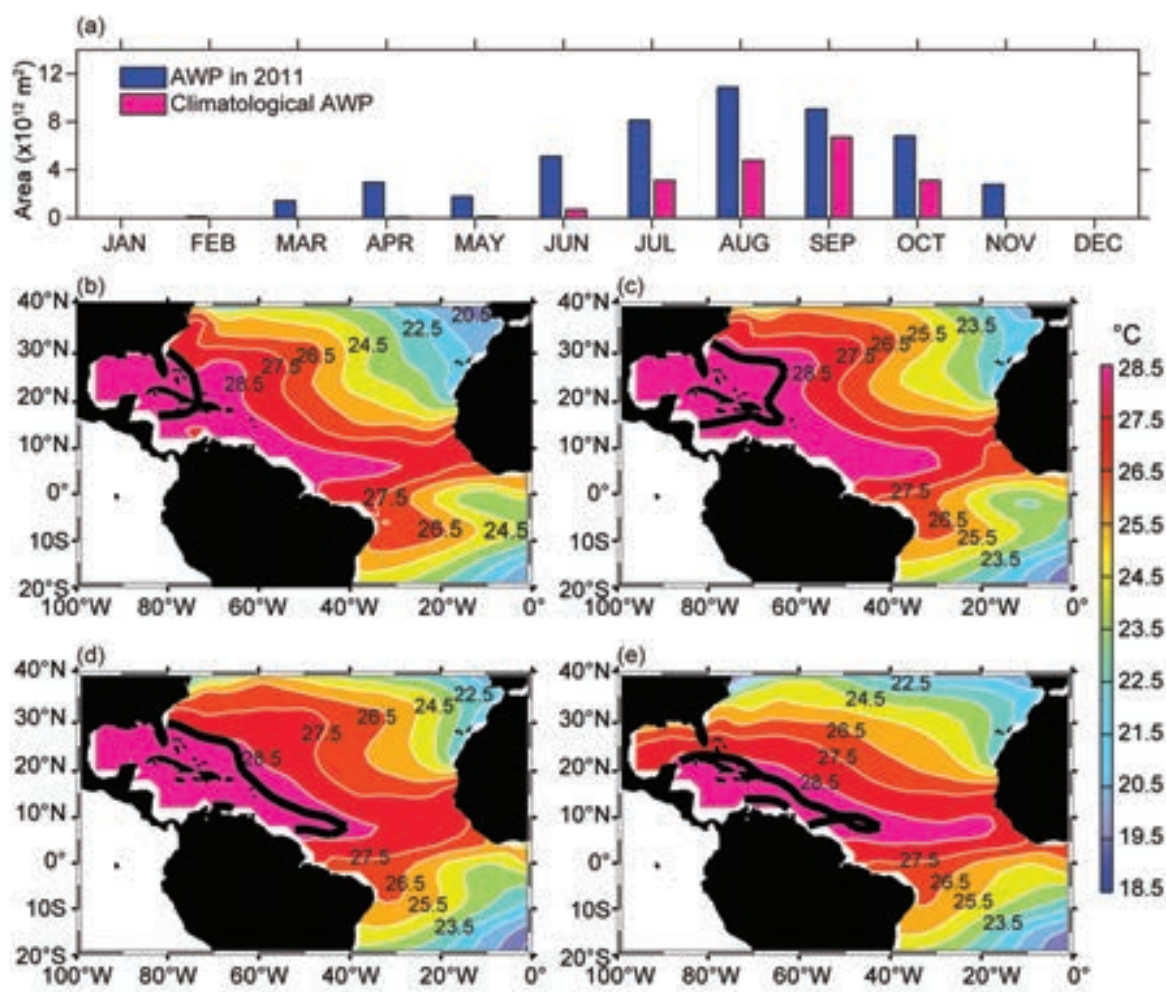

FIg. 4.37. The AWP in 20II. Shown are the (a) monthly AWP area in $2011\left(10^{12} \mathrm{~m}^{2}\right.$; blue) and the climatological AWP area (red), spatial distributions of the 2011 AWP in (b) July, (c) August, (d) September, and (e) October. The AWP is defined by SST larger than $28.5^{\circ} \mathrm{C}$. The black contours in (b)-(e) are the climatological AWP based on the data from 197|-2000.

sociated with ENSO events in the tropical Pacific and local processes were responsible for the SST anomaly distribution. During the boreal spring, summer, and fall of 2011, the cold SST anomalies in the subtropical North Atlantic weakened and the North Atlantic was mostly warm (Figs. 4.36c,d,e).

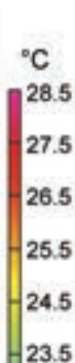

Previous studies have shown that the influence of the AMO on TC activity may operate through the atmospheric changes induced by the AWP or the Atlantic meridional mode (Wang et al. 2008a; Vimont and Kossin 2007). In particular, the AWP can play an important role in the hurricane track (Wang et al. 2011). During the 2011 Atlantic TC season of June to November, the AWP was consistently large (Fig. $4.37 \mathrm{a})$ and the isotherm of $28.5^{\circ} \mathrm{C}$ extended eastward covering almost the entire tropical North Atlantic (Figs. 4.37b,c,d,e). An eastward expansion of the AWP shifted the hurricane genesis location eastward, decreasing the possibility for a hurricane to make landfall in the southeast United States. A large AWP also tended to shrink the North Atlantic subtropical high eastward (C. Wang et al. 2007) and produced a TC steering flow pattern along the Eastern Seaboard of the United States, which steered hurricanes away from the southeastern coast of the US (Wang et al. 2011). The large AWP in 2011 was also associated

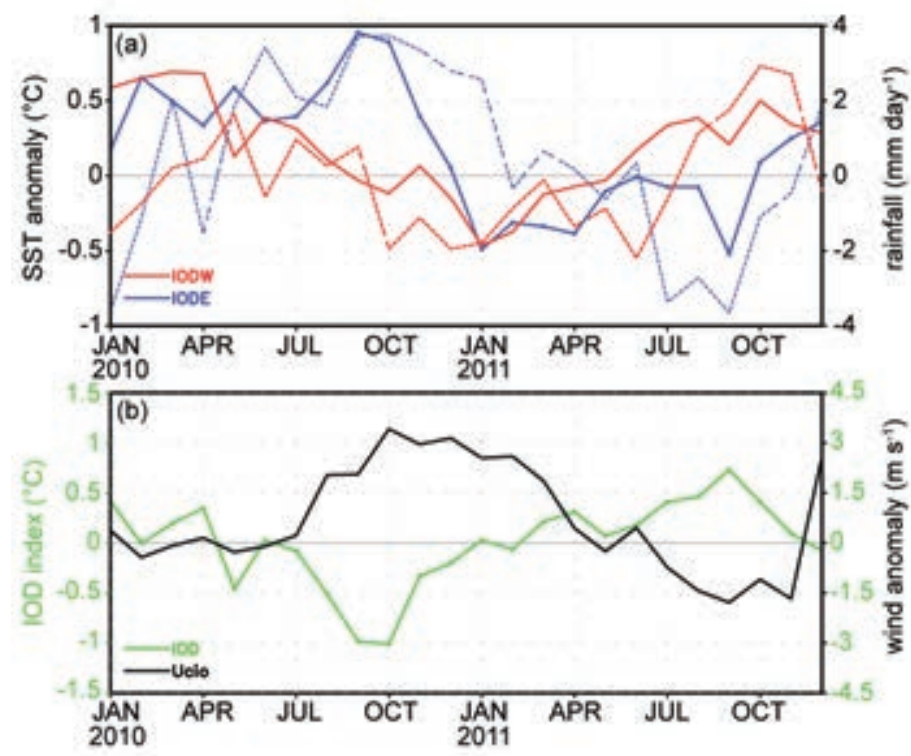

FIG. 4.38. (a) Monthly anomalies of SST $\left({ }^{\circ} \mathrm{C}\right.$, solid lines) and precipitation ( $\mathrm{mm} \mathrm{day}^{-1}$, dashed lines) in the eastern (IODE: $90 \mathrm{E}^{\circ}-110^{\circ} \mathrm{E}, 10^{\circ} \mathrm{S}-0^{\circ}$; blue lines) and western pole (IODW: $50^{\circ} \mathrm{E}-70^{\circ} \mathrm{E}$, $10^{\circ} \mathrm{S}-10^{\circ} \mathrm{N}$; red lines) of IOD. (b) As in (a), but for the IOD index (measured by the SST difference between IODW and IODE, green line) and surface zonal wind anomaly $\left(\mathrm{m} \mathrm{s}^{-1}\right)$ in the central equatorial $1 O$ (Ucio), from $70^{\circ} \mathrm{E}-90^{\circ} \mathrm{E}, 5^{\circ} \mathrm{S}-5^{\circ} \mathrm{N}$, black line. The anomalies were calculated relative to the climatology over the period 19822010. These are based on the NCEP optimum interpolation SST (Reynolds and Chelton 2010), monthly GPCP precipitation analysis (http:// precip.gsfc.nasa.gov/), and JRA-25 atmospheric reanalysis (Onogi et al. 2007). 


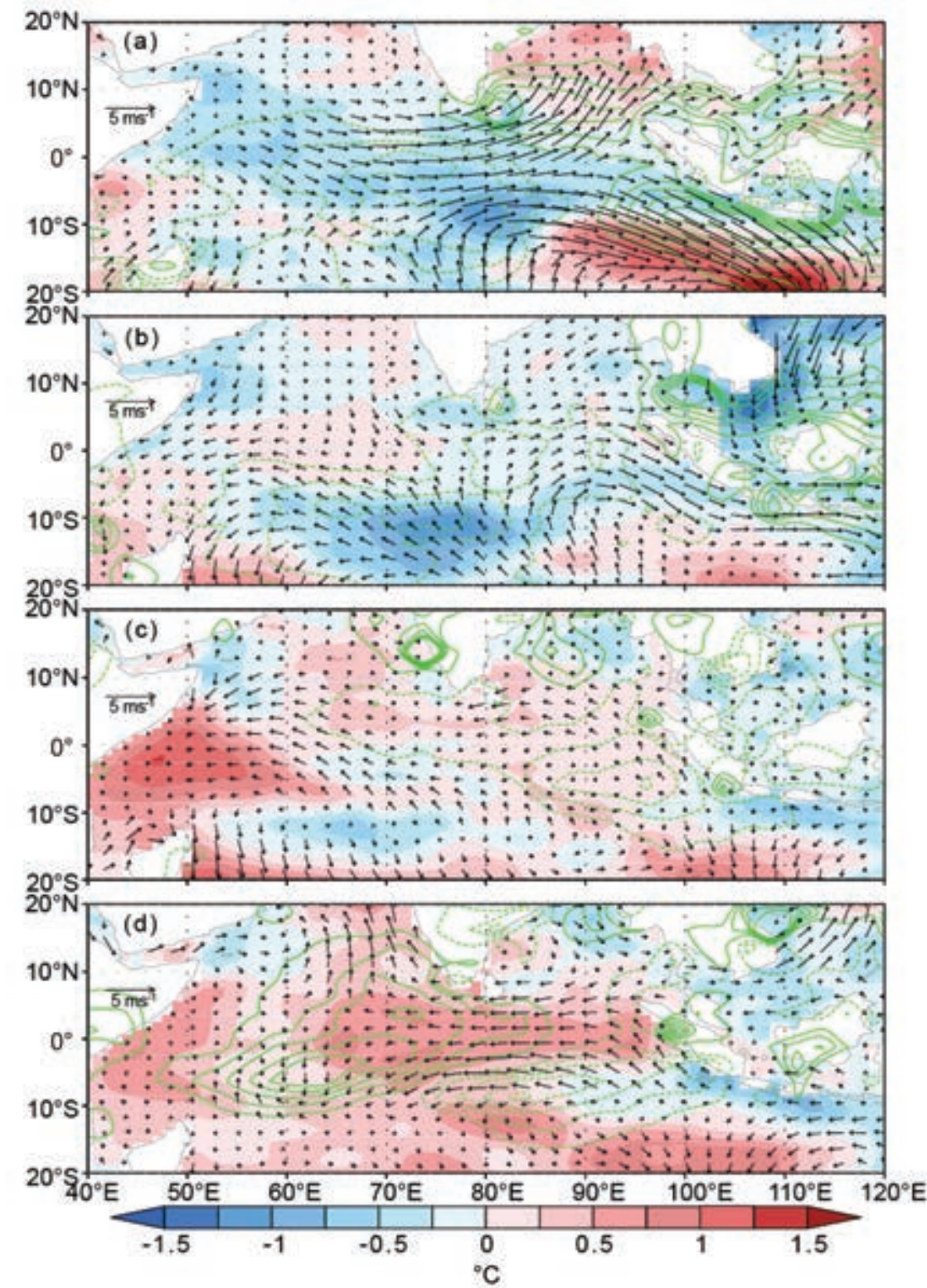

FIG. 4.39. SST ( ${ }^{\circ} \mathrm{C}$, colored scale), precipitation (green contours: $\pm \mathrm{I}, \pm 2, \ldots$, $\pm 5 \mathrm{~mm} \mathrm{day}^{-1}$ ). Solid (dashed) lines denote positive (negative) values, and surface wind anomalies during (a) DJF 2010/II, (b) MAM 20II, (c) JJA 20II, and (d) SON 2011.

with the out-of-phase relationship between TCs in the North Atlantic and the ENP as described previously in this chapter.

\section{h. Indian Ocean dipole-J. J. Luo}

The Indian Ocean dipole (IOD) - a climate mode in the tropical Indian Ocean (IO)-usually starts in boreal summer, peaks in fall, and decays rapidly in early winter. It has been believed that El Niño (La Niña) favors the development of positive (negative) IOD. During 2011, however, a weak positive IOD event occurred in the tropical Indian Ocean (Figs. 4.38 and $4.39 \mathrm{~d}$ ) in spite of the La Niña conditions in the $\mathrm{Pa}$ cific. In particular, the cold SST anomalies in the eastern Indian Ocean were weak, ${ }^{9}$ and the 2011 IOD was not well developed during its peak phase in SON compared to the past three strong positive IODs in 1994, 1997, and 2006. This is similar to what happened in 2007 and 2008 (Luo et al. 2008) and reconfirms the idea that the IOD can sometimes originate from the internal air-sea interactions in the IO (Behera et al. 2006; Luo et al. 2010). The strong La Niña event in 2010 helped to induce excessive surface westerlies in the central equatorial IO by enhancing the Walker cell in the IO. The westerly anomalies tend to cool the SST in the western IO by increasing surface latent heat loss from the ocean but warm the SST in the east by deepening the oceanic thermocline there; this favors the occurrence of a negative IOD in the second half of 2010 (Fig. 4.38). After the collapse of the negative IOD near the end of 2010, the excessive westerlies caused a cool/dry condition in most places of the tropical IO and a warm/ wet condition in the Bay of Bengal and northwest of Australia during early 2011 (Figs. 4.38a, 4.39a). The related anomalous cyclonic winds in the southeastern IO raised the thermocline underneath and induced strong subsurface cooling and cold SST anomalies along $\sim 10^{\circ} \mathrm{S}$. The cold signals propagated westward but disappeared before they reached the western boundary of the IO (Figs. 4.39, 4.40). The drought

\footnotetext{
${ }^{9}$ Like an El Niño or La Niña event, a weak or strong IOD is defined by a threshold value of one standard deviation of the IOD index.
} 
center in the IO gradually moved eastward and reached the eastern IO and Maritime Continent during June-August 2011 (Fig. 4.39c) which is typical of the weakening of the Pacific La Niña condition.

Cold SST anomalies started to develop near the coast of Java, Indonesia, in July 2011; this is closely linked with the southeasterly anomalies along the west coast of Sumatra, which could be partly driven by the north-south air pressure gradient associated with the dry center west of Sumatra and the wet center in the Bay of Bengal. The southeasterly anomalies raised the coastal thermocline and hence, induced the SST cooling. The colder-than-normal SST may, in turn, enhance the north-south pressure gradient and the southeasterly winds. As a result, both the SST cooling and southeasterly winds were enhanced quickly through this air-sea positive feedback. These signals expanded equatorward and westward and peaked in September 2011. There did not appear to be any subsurface cooling propagated from the western IO (Fig. 4.40a), suggesting that the local airsea coupling in the eastern IO must have played a key role in generating the positive IOD event in 2011.

In the western IO, warm SST anomalies started to occur in May 2011 and grew rapidly in June-July 2011 in association with more surface solar radiation heating under less cloud conditions (Figs. 4.38a, 4.39c). The warm SST anomalies caused anomalous easterlies in the western IO during May-July 2011. In August 2011, the anomalous winds in the western IO and the east merged and led to basin-wide easterlies. This caused a pronounced dipole structure of precipitation anomalies, with flooding in the western IO and drought in the east during August-November 2011 (Fig. 4.39d). This dipole structure suddenly collapsed in December 2011 due to the strong westerly anomalies across the equatorial IO basin in association with the influences of both intraseasonal oscillation in the IO and the reenhancement of $\mathrm{La}$ Niña conditions in the Pacific.

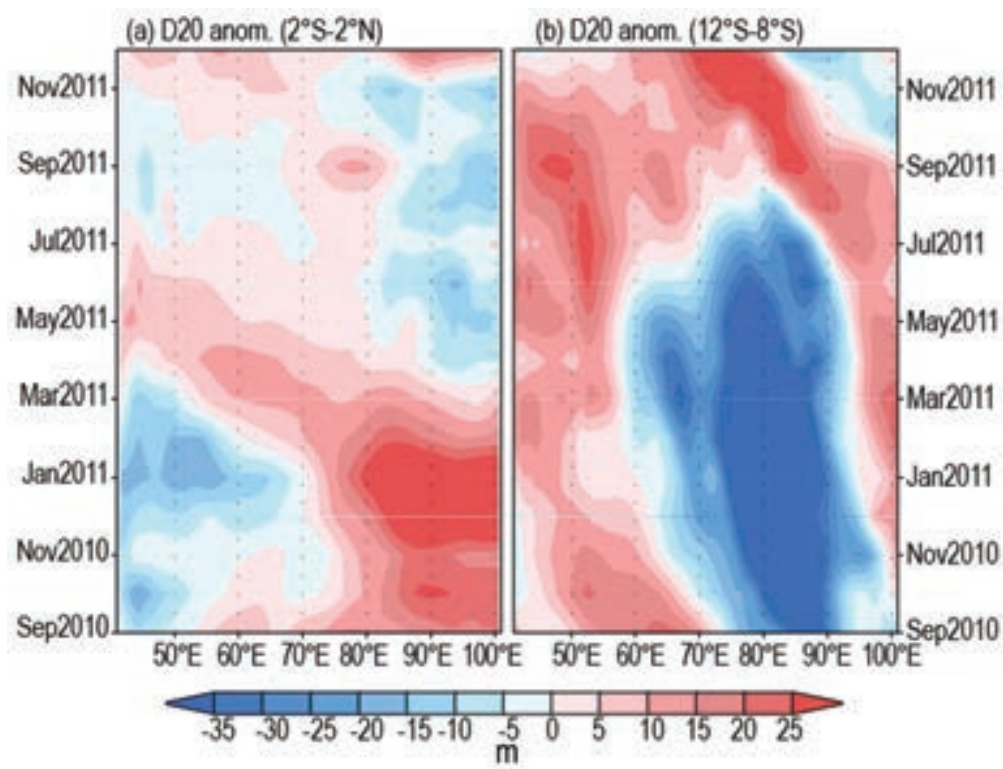

Fig. 4.40. $20^{\circ} \mathrm{C}$ isotherm depth (D20, $\left.\mathrm{m}\right)$ anomalies in (a) the equatorial Indian Ocean $\left(2^{\circ} \mathrm{S}-2^{\circ} \mathrm{N}\right)$ and (b) off-equatorial South Indian Ocean $\left(12^{\circ} \mathrm{S}-8^{\circ} \mathrm{S}\right)$ in 2011 . The data are derived from the NCEP ocean re-

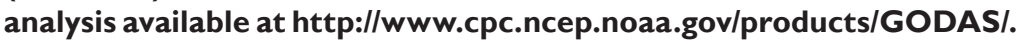




\section{SIDEBAR 4.I: MANAGING CLIMATE RISKS USING POLYNESIAN KNOWLEDGE-P. LEFALE, D. KING, AND A. NGARI}

Long before the advent of numerical weather and climate models, Polynesian communities recognized that changes in biophysical phenomena could be used to forecast changes in local weather and climate conditions (Lefale 2010). Social, cultural, and traditional economic activities were planned and acted upon in response to these changes and revolved around the different seasons. Foremost among these was the capacity to forecast appropriate and inappropriate times for food gathering such as the planting and harvesting of crops and the catching of fish.

While weather and climate patterns have been monitored in the Southwest Pacific using Western scientific techniques since the late 1800s (1890 in Apia, Samoa, for example), little attention has been paid to the atmospheric observations and related expertise developed in-place by Polynesian people. However, recent work aimed at reaffirming Polynesian knowledge of weather and climate phenomena has shown that Maori, Cook Islanders, and Samoans possess their own unique local knowledge systems to forecast the onset of extreme events such as tropical cyclones and storms (Lefale 2003; King et al. 2007).

In Aotearoa/New Zealand, Maori have developed a detailed knowledge of biophysical processes and phenomena, including, among other skills, forecasting adverse weather and climate conditions (King et al. 2005). Ngati Koata, a tribal group from the north of the South Island, knew bad weather was imminent when stones were found in the belly of caught "rawaru" (blue cod). The stones are understood to give the rawaru ballast in the water as bigger waves and swell coincide with stormy conditions. Such indicators were not used in isolation, but rather as parts of a range of indicators that were (and continue to be) observed to confirm, via consensus, the forecast being made.

It is widely recognized in the Cook Islands, especially the southern islands, that a plentiful crop of mangoes typically indicates an active season of cyclones ahead (Fig. SB4.I). Knowledge of this phenomenon is common throughout the South Pacific region, from Vanuatu and Fiji in the west to Samoa and French Polynesia to the east. Migratory birds are also well recognized as indicators of severe weather, especially during summer. The "torea" (Pacific Golden Plover) is known to migrate between the Cook Islands and Alaska in the months of February-March and SeptemberOctober, respectively (see http:// cookislands.bishopmuseum.org/ showarticle.asp?id=4). However, according to Mr. George "Birdman" Mateariki, a bird catcher on the island of Atiu, "The birds on Atiu just disappeared in December [2004], and when those 5 cyclones came in from February 2005 for the Cook Islands, it dawned on me that the torea knew what would happen" (Cook Islands government 20II). 


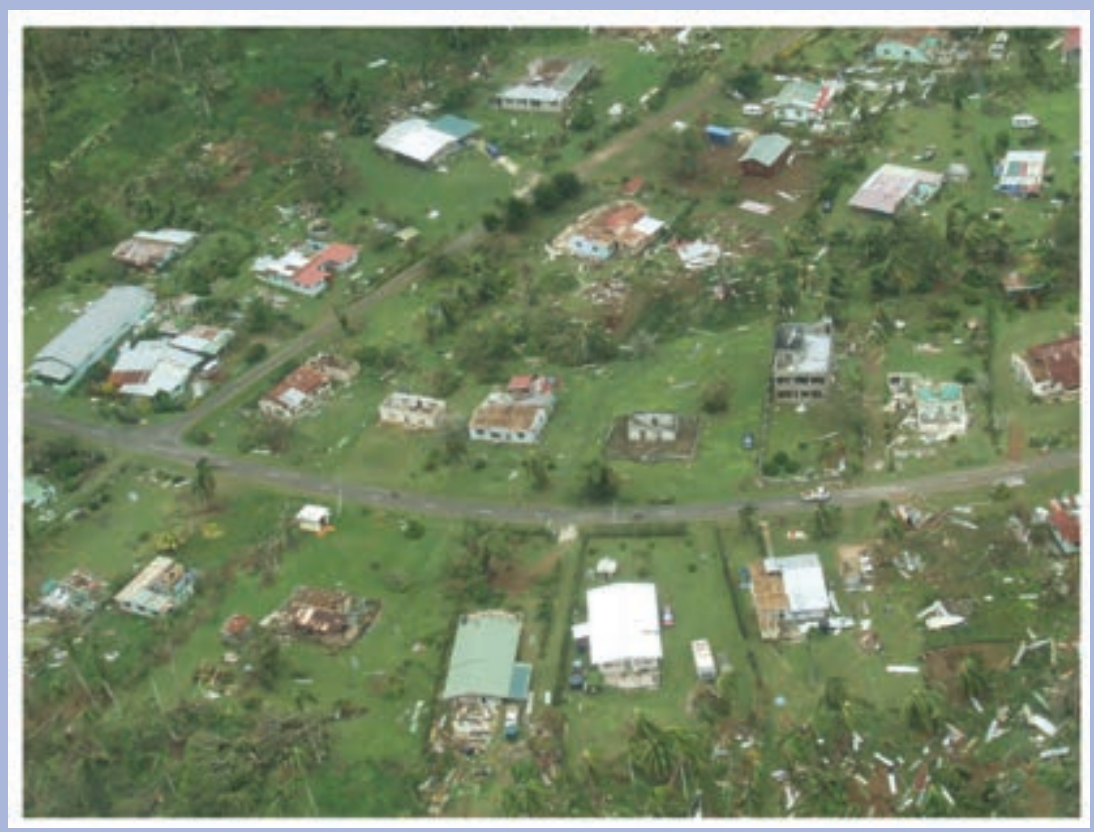

FIG. SB4.2. Widespread damage occurred in the village of Nikaupara on the island of Aitutaki in the Southern Cook Islands caused by Tropical Cyclone Pat in February 2010. (Photo Credit: Mr. Johnny Hosking in liaison with Air Rarotonga)

to cope and adapt to weather and climate variability in the past. It also provides lessons on how to deal with the risks associated with future weather and climate extremes (and related natural hazards), through greater awareness of the natural world and the inherent linkages between atmospheric and biophysical phenomena.

Similar biophysical indicators of change are used in Samoa. For example, the sudden appearance of cockroaches in large numbers in the evening during the cyclone season is understood to portend an approaching cyclone that can bring death and destruction (Fig SB4.2). Further, the appearance of frigate birds during a tropical cyclone signals the eye of the storm has arrived and that the worst of the storm is over. It is important to emphasize that the development and application of such knowledge was (and continues to be) fundamentally about managing climate-related risks linked with daily and seasonal changes in local weather and climate conditions (Cook Islands government 2006).

Reaffirming such knowledge provides an opportunity to understand what has assisted Polynesian people 
5. THE ARCTIC-M. 0. Jeffries and J. Richter-Menge, Eds.

a. Overview-M. 0. Jeffries and J. Richter-Menge

Calendar year 2011 was characterized by continuing change throughout the Arctic environmental system. A key driver of systemwide change is a $\sim 2^{\circ} \mathrm{C}$ increase in annual mean surface air temperature since the mid-1960s, which is $1.5^{\circ} \mathrm{C}$ greater than (more than double) the temperature increases at lower latitudes. This chapter describes some of the systemwide changes in ten categories: Air temperature, atmospheric circulation and clouds; Ozone and UV radiation; Terrestrial snow; Glaciers and ice caps (outside Greenland); Greenland Ice Sheet; Permafrost; Lake ice; Sea ice; Ocean; and Ocean acidification. Some of the key events are summarized below.

Ozone concentrations in the Arctic stratosphere during March 2011 were the lowest ever recorded since 1979, and led to elevated surface UV levels throughout the Arctic and sub-Arctic.

Annually-averaged Arctic temperatures continued to show area-wide positive (warm) anomalies, relative to the end of the 20th century. There were multi-month-long shifts in the dominant wind pattern, responding to changes in the polar vortex, which affected the distribution of surface temperatures and snow and ice conditions. For example, warm air temperature anomalies over the Eurasian Arctic in spring 2011 resulted in a new record low June snow cover extent and spring snow cover duration, and earlier (by 10-30 days) lake ice break-up and shorter (by 14-21 days) ice duration. Conversely, penetration of Arctic air masses into northern and eastern Europe in autumn 2010 and spring 2011 caused earlier freezeup and later break-up, respectively, and thus longer (by 28-42 days) lake ice duration.

On the Greenland ice sheet, below-normal summer snowfall, a decreasing trend in surface albedo, and elevated surface and upper air temperature anomalies resulted in a continued pattern of extreme surface melting and a negative mass balance. To the west, the mass loss from glaciers and ice caps in the Canadian Arctic was the greatest since GRACE (Gravity Recovery and Climate Experiment) satellite measurements began in 2002, continuing a negative trend that dates back to 1987 .

Warm summer temperatures occurred in Alaska; Barrow, on the North Slope, experienced a record 86 consecutive days with minimum temperatures at or above freezing. New record high temperatures occurred at $20 \mathrm{~m}$ below the land surface at all permafrost observatories on the North Slope, where measurements began in the late 1970s.
Sea ice extent in September 2011 was the second lowest on record, while the extent of old ice (four and five years) reached a new record minimum that was only $19 \%$ of the mean for the period 1982-2005. For a second consecutive summer, the northern routes of the Northwest Passage and the Siberian Coast passage of the Northern Sea Route were open, and for a fourth consecutive summer, the southern route of the Northwest Passage was ice-free. An increase and decrease, respectively, in winter and summer cloud cover contributed to surface warming in the Arctic Basin and perhaps the near-record low sea ice extent.

Also responding to the near-record low sea ice extent in nearly all sectors of the Arctic Basin, upper ocean temperatures in summer 2011 were generally warmer than in the previous few summers. The sea surface temperature anomaly averaged over the Beaufort, Chukchi, East Siberian, Laptev, and Kara Seas was $+1.45^{\circ} \mathrm{C}$, the highest since the historical maximum value $\left(+2.8^{\circ} \mathrm{C}\right)$ observed in 2007 .

\section{b. Air temperature, atmospheric circulation, and clouds-}

J. Overland, U. Bhatt, J. Key, Y. Liu, J. Walsh, and M. Wang

The annual mean surface air temperature over Arctic land areas has experienced an overall warming of about $2^{\circ} \mathrm{C}$ since the mid-1960s (Fig. 5.1). In 2011, the annual mean air temperature was slightly warmer than in 2009 and 2010. The cooler temperatures in 2009 and 2010 reflected cold continents in winter, while Eurasia had warmer temperatures in spring 2011. Area-wide positive temperature anomalies (Fig. 5.2), which show systematic changes since the end of

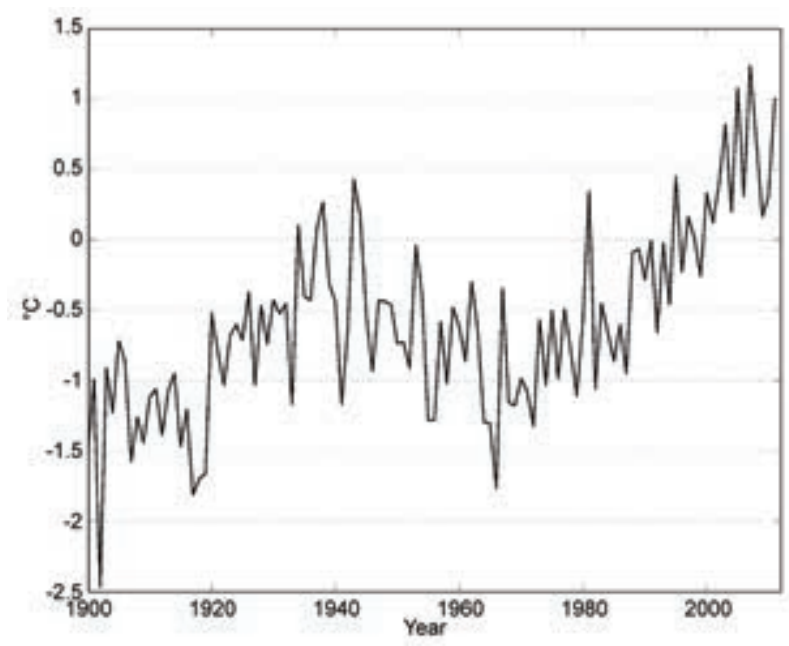

FIG. 5.I. Arctic-wide annual average surface air temperature anomalies relative to the 1961-90 mean, based on land stations north of $60^{\circ} \mathrm{N}$. Data are from the CRUTEM 3v dataset at http://www.cru.uea.ac.uk/cru /data/temperature/. Note this curve does not include marine observations. 
the 20th century, continued in 2011. Note the almost complete absence of negative temperature anomalies in Fig. 5.2. This temperature pattern is a manifestation of "Arctic amplification", which is characterized by temperature increases $1.5^{\circ} \mathrm{C}$ greater than (more than double) the increases at lower latitudes (Overland et al. 2011a).

Spatial distributions of seasonal near-surface temperature anomalies (Fig. 5.3) were influenced by changes in the polar vortex, which is reflected in the sign and magnitude of the Arctic Oscillation index (AO; Table 5.1). A positive index corresponds to strong zonal wind flow, while a negative index corresponds to more meridional and spatially-variable flow. Table 5.1 indicates a large range in the magnitude of the AO in 2011; this has been characteristic of the AO since December 2009. It has been suggested that changes in the polar vortex are increasingly influenced by changes in Arctic surface characteristics, e.g., reduced sea ice and changes in snow cover, but these ideas are still highly controversial (Overland et al. 2011b).

The distinct shifts between large negative and positive phases of the $\mathrm{AO}$ index had a striking effect on the location of major warm and cold regional temperature anomalies in the Arctic and sub-Arctic throughout the year. Early winter 2011 saw a continuation of the negative AO Warm Arctic-Cold Continent pattern (Overland et al. 2011a) of the previous year, with warm temperatures lying north of far eastern Siberia and Alaska, in the vicinity of greater Baffin Bay and far northeastern Canada, and to some extent in the Kara Sea. Beginning in February, there was a major shift to a positive $\mathrm{AO}$ index, with cold temperatures in the Baffin Bay region and warmer anomalies developing in Eurasia due to westerly winds. A new record low June snow cover extent (since satellite observations began in 1966) occurred over Eurasia in 2011 (see section 5d) due to persistent warm spring air temperature anomalies over almost the entire Eurasian sector of the Arctic. In summer, when the AO shifted to a negative state, warm temperature anomalies returned to northern Canada with cool temperature anomalies in the Bering Sea. November and December had a strong positive AO pattern again, with warm anomalies in Eurasia and

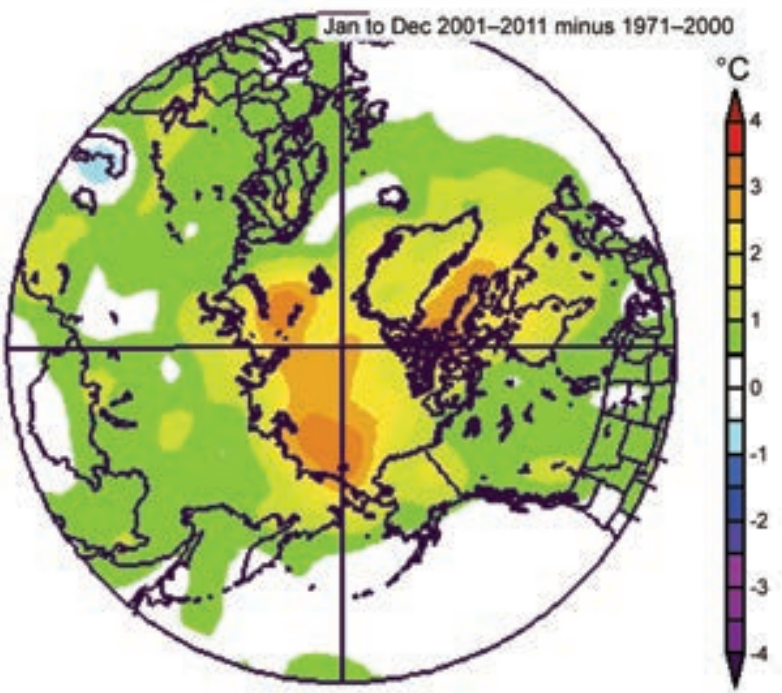

FIG. 5.2. Annual average near-surface $(1000 \mathrm{hPa})$ air temperature anomalies $\left({ }^{\circ} \mathrm{C}\right)$ for $200 \mathrm{I}-\mathrm{II}$ relative to the period 197|-2000. Data are from NOAA/ESRL, http://www.esrl.noaa.gov/psd/. (Source: NCEP/NCAR)
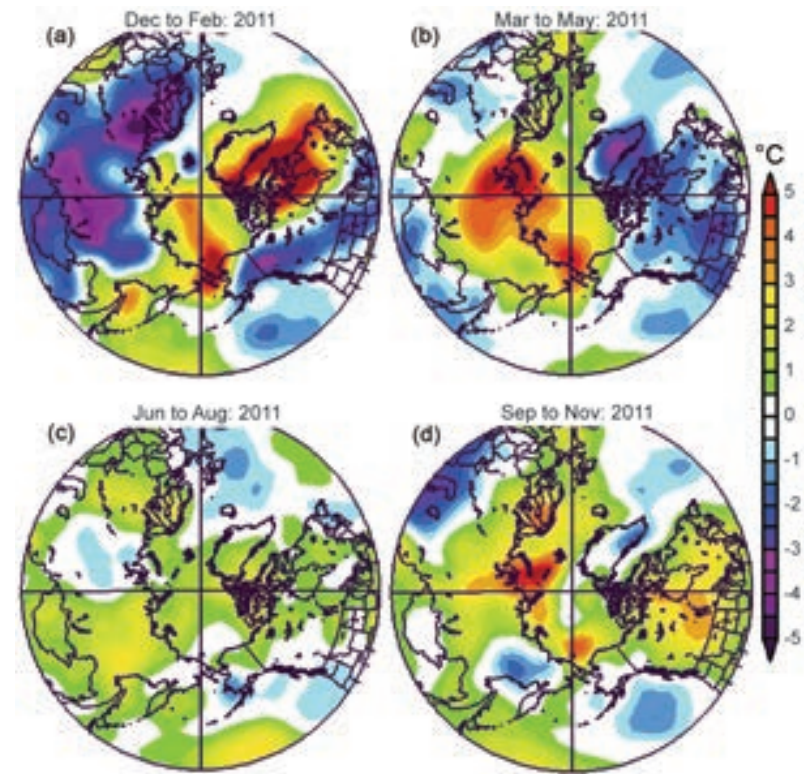

FIG. 5.3. Seasonal, near-surface ( $1000 \mathrm{hPa})$ air temperature anomalies $\left({ }^{\circ} \mathrm{C}\right)$ in $20 \mathrm{II}$ relative to the $198 \mathrm{I}-2010$ baseline period. (a) Dec 2010-Feb 20II, (b) Mar-May 20II, (c) Jun-Aug 20II, and (d) Sep-Nov 20II. (Source: NCEP/NCAR)

TABLE 5.I. Monthly Arctic Oscillation Index for 201 I (from NOAA/CPC). Values are normalized by the stan-
dard deviation of the monthly index.
\begin{tabular}{|c|c|c|c|c|c|c|c|c|c|c|c|}
\hline JAN & FEB & MAR & APR & MAY & JUNE & JULY & AUG & SEP & OCT & NOV & DEC \\
\hline-1.68 & $\mathrm{I} .57$ & $\mathrm{I} .42$ & 2.27 & -0.04 & -0.86 & -0.47 & -1.06 & 0.66 & 0.80 & 1.46 & 2.22 \\
\hline
\end{tabular}


western Canada, and cold anomalies in Greenland and eastern Asia.

The large negative values of the AO during summer 2011, and the associated wind pattern, represent an unusual event. Unlike summer climatology, which has generally weak winds confined to the Arctic, in July 2011 multiple low 850-hPa geopotential height centers formed in southerly locations along the continental rim of the Arctic Basin (Overland et al. 2011b). This provided the unusual warming in west Greenland during summer 2011 (similar to 2010), warm temperatures in Barrow, Alaska, cold temperatures in western Siberia, and kept warm storms from entering the Bering Sea. Barrow had a record (based on over 80 years of observations) 86 consecutive days with minimum temperatures at or above freezing beginning June 30. The previous record was 68 days set in 2009. For the sixth consecutive year, the first freeze of autumn in Fairbanks, Alaska, occurred more than two weeks later than its long-term average. Unlike 2007, when the wind pattern in every summer month contributed toward record sea ice loss in the Pacific Arctic via northward transport of ice and heat toward the North Pole, the near-record sea ice loss in September 2011 occurred despite a more variable wind circulation.

In 2011, Arctic cloud cover was somewhat higher than the average of the last 10 years (2002-11) in winter (January-March) and lower than average in the summer (June-August), particularly over the western Arctic Ocean. Figure 5.4 shows the cloud cover anomalies for representative winter and summer months. In spring and autumn, cloud cover was similar to the 10 -year mean (not shown). The annual average cloud cover in 2011 over the Arctic Ocean was not significantly different from recent years. The 2011 wintertime increase and summertime decrease in cloud cover resulted in greater surface warming, as Arctic clouds generally have a warming effect in the winter and a cooling effect in the summer. This potentially contributed to the near-record low sea ice extent. This contrasts with the general trend over the period 1982-2004, when a decrease in wintertime and increase in springtime cloud cover over parts of the Arctic acted to dampen surface
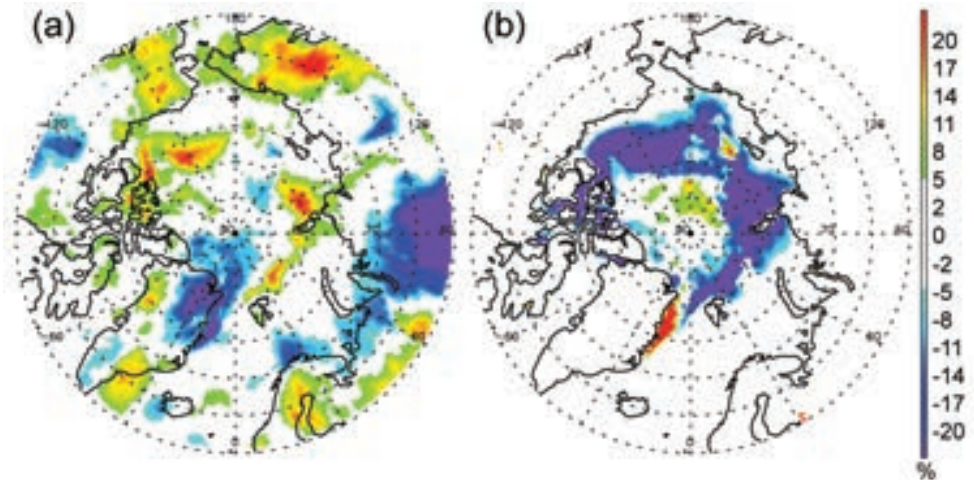

Fig. 5.5. (a) Cloud cover anomalies and (b) sea ice anomalies for September 20II relative to the September mean for the period 2002-II. In both figures, the unit of anomaly is \% above or below normal. Cloud cover is based on Aqua MODIS data. Sea ice concentration is from the Special Sensor Microwave/Imager (SSM/I) using the NASA team algorithm. 


\section{SIDEBAR 5.I: SOURCES OF ATMOSPHERIC CARBON DIOXIDE AND METHANE IN THE ARCTIC-E. J. DLUGOKENCKY AND L. BRUHWILER}

Together, carbon dioxide $\left(\mathrm{CO}_{2}\right)$ and methane $\left(\mathrm{CH}_{4}\right)$ are responsible for $\sim 80 \%$ of direct radiative forcing caused by long-lived greenhouse gases: $2.29 \mathrm{~W} \mathrm{~m}^{-2}$ out of $2.81 \mathrm{~W} \mathrm{~m}^{-2}$ in 2010 (update of Hofmann et al. 2006). Observations of $\mathrm{CO}_{2}$ and $\mathrm{CH}_{4}$ are of particular interest in the Arctic, where there are two potentially large reservoirs of carbon that are vulnerable and where land surface temperatures have been increasing and are projected to increase in the future (McGuire et al. 2009; O'Connor et al. 2010).

The first reservoir, methane-rich clathrate hydrates, occurs in sediments at the bottom of the Arctic Ocean. There is concern that rising ocean water temperatures, especially on the relatively shallow eastern Siberian Arctic continental shelf, will cause the clathrates to destabilize and release massive pulses of methane to the atmosphere (Kennett et al. 2000). However, measurements of $\mathrm{CH}_{4}$ in ice cores (e.g., Severinghaus et al. 1998) do not support the idea that massive pulses of $\mathrm{CH}_{4}$ from clathrates caused rapid climate warming in the past. It remains to be seen whether the climate response to current and future clathrate release will differ from previous records.

The second reservoir, Arctic permafrost, contains $\sim 1000 \mathrm{Pg} \mathrm{C}\left(\mathrm{Pg} \mathrm{C}=10^{15} \mathrm{~g}\right.$ carbon) in the top $3 \mathrm{~m}$ (Tarnocai et al. 2009), significantly more carbon than is currently in the atmosphere $(230 \mathrm{Pg} \mathrm{C})$. As the Arctic warms and permafrost thaws, this ancient carbon can be released as either $\mathrm{CO}_{2}$ or $\mathrm{CH}_{4}$. A recent review of the potential impacts of climate change in the 2 Ist century on northern peatlands, much of it underlain by permafrost, suggests that both $\mathrm{CO}_{2}$ and $\mathrm{CH}_{4}$ emissions from this source will increase significantly in the future (Frolking et al. 20II).

Carbon dioxide and methane abundances from weekly samples collected at seven Arctic and subArctic sites and Mauna Loa, Hawaii, are shown in Fig. SB5.I. High latitude $\mathrm{CO}_{2}$ values are the same as at Mauna Loa, and all sites show a strong seasonal cycle superimposed on the long-term trend to higher values (Fig. SB5.Ia). The seasonal cycle of $\mathrm{CO}_{2}$ at high northern latitudes results from seasonal uptake (photosynthesis) and release (respiration) of carbon by the biosphere. The steep upward trend in $\mathrm{CO}_{2}$ is due to global fossil fuel use.

Like $\mathrm{CO}_{2}$, the $\mathrm{CH}_{4}$ records also have a seasonal cycle superimposed on a long-term trend to higher values (Fig. SB5.Ib). Unlike $\mathrm{CO}_{2}$, the $\mathrm{CH}_{4}$ record shows higher values at the Arctic and sub-Arctic sites than at Mauna Loa. The seasonal cycle at all sites is due to greater photochemical destruction of $\mathrm{CH}_{4}$ in summer than in winter. However, photochemical destruction is slower at high latitudes. This, combined with $\mathrm{CH}_{4}$ transport from lower latitudes and a currently small contribution from high latitude sources, explains the greater $\mathrm{CH}_{4}$ abundance at high latitudes. As the Arctic warms, contributions from local methane sources will likely increase, possibly by a large amount. However, to date, there is no evidence that natural emissions of $\mathrm{CH}_{4}$ in the Arctic have increased significantly in the past decade (Bruhwiler and Dlugokencky 20II).

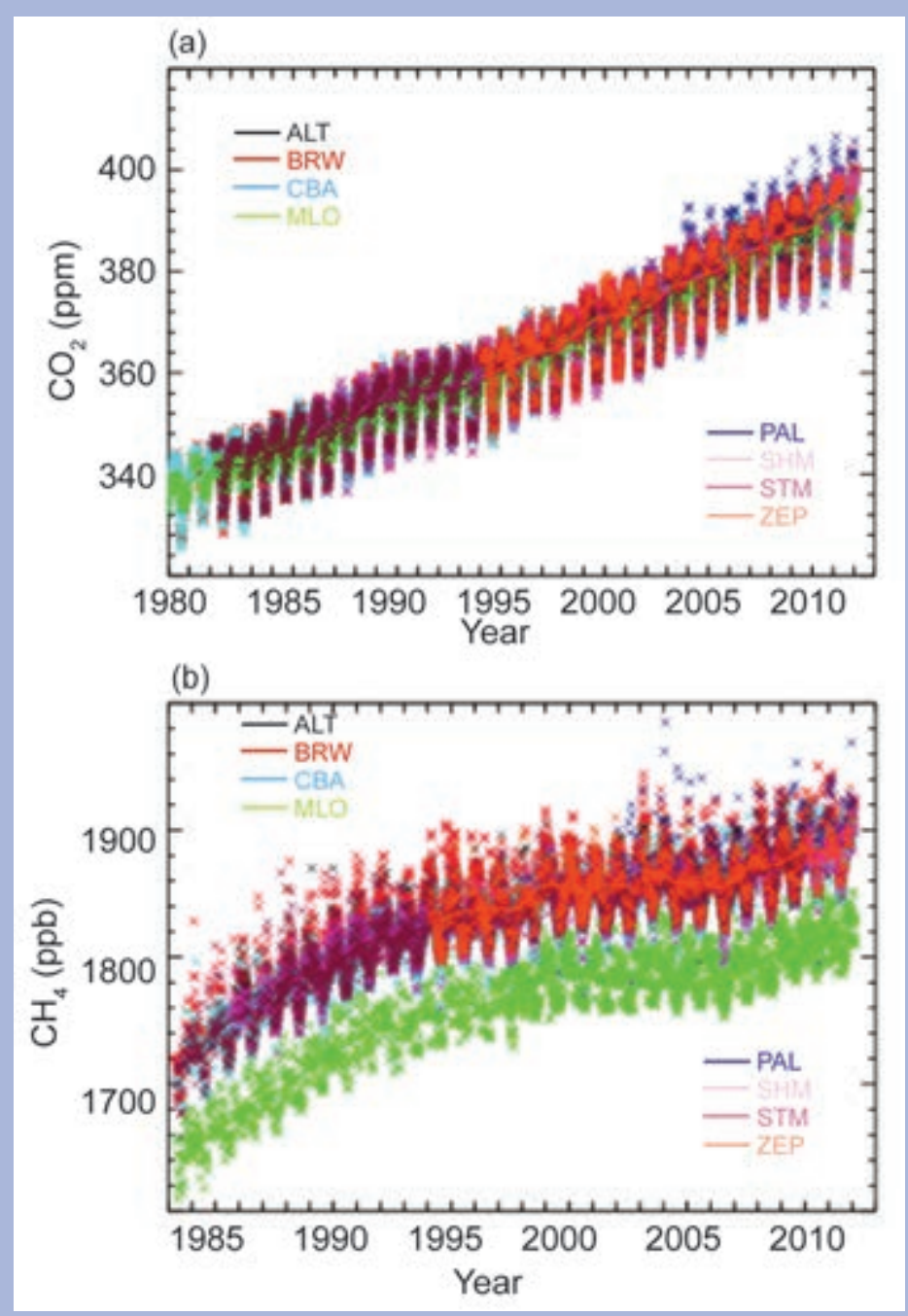

FIG. SB5.I. (a) $\mathrm{CO}_{2}$ and (b) $\mathrm{CH}_{4}$ dry air mole fractions from seven Arctic and sub-Arctic air sampling sites and from Mauna Loa Observatory (MLO), all in the NOAA ESRL air sampling network. The northern sites are Alert, Canada (ALT), Barrow, Alaska (BRW), Cold Bay, Alaska (CBA), Pallas, Finland (PAL), Shemya Island, Alaska (SHM), Summit, Greenland (STM), and Ny Âlesund, Svalbard, Norway (ZEP). Further information about the sites is available at http://www.esrl.noaa.gov/gmd/dv/site/site_table .html\#ccg_surface. 
minimum total ozone column for March 2011, averaged over the "equivalent latitude" (Butchart and Remsberg 1986) band $63^{\circ} \mathrm{N}-90^{\circ} \mathrm{N}$, was $297 \mathrm{DU}$ (Dobson Units). The previous record low, 315 DU, was observed in 2000 (Fig. 5.6). The fraction of the Polar vortex with total ozone below 275 DU is typically near zero for March, but reached nearly $45 \%$ in March 2011. Minimum total ozone in spring 2011 was continuously below $250 \mathrm{DU}$ for about 27 days, and occurred over a maximum area of about 2000000 $\mathrm{km}^{2}$. Record-low values (not illustrated) between 220 DU and 230 DU were reached in small regions of the vortex for about one week in late March 2011.

The ozone loss in spring 2011 was comparable to that observed during the annually-recurring "ozone hole" over the Antarctic. The record loss was mostly caused by chemical destruction of ozone, attributed to the existing stratospheric burden of ozone-depleting halogens and favored by an unusually prolonged cold period in the lower stratosphere in 2011. Low temperatures facilitate the formation of polar stratospheric clouds (PSC), which provide surfaces for heterogeneous reactions that activate stratospheric chlorine. The activated chlorine, in turn, destroys ozone rapidly in catalytic cycles. A good indicator of the potential for chlorine activation and ozone loss is the volume of air within the Polar vortex with temperatures below the PSC occurrence threshold (Rex et al. 2004). Temperatures below the threshold temperature for PSC formation of about $-77^{\circ} \mathrm{C}$ existed between December 2010 and early April 2011. Under these conditions, over $80 \%$ of the ozone present in January, from about $18 \mathrm{~km}$ to $20 \mathrm{~km}$ altitude, had been chemically destroyed by late March (Manney et al. 2011).

The extraordinary situation in 2011 is illustrated in Fig. 5.7, which compares satellite measurements of total ozone column on 3 April 1981 (a year with a longlasting and cold Polar vortex, and relatively low stratospheric chlorine concentrations), 3 April 2002 (long-lasting warm vortex, high total chlorine loading), and 3 April 2011 (long-lasting cold vortex, high chlorine). The figure emphasizes that chemical ozone loss resulting from chlorine activation is most effective in years when there is a longlasting cold vortex, such as 2011.

The low levels of total ozone led to elevated UV levels

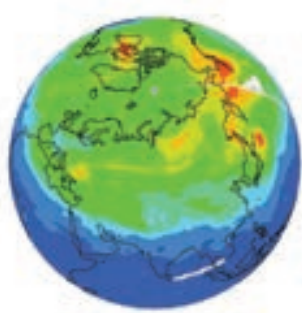

3 April 1981

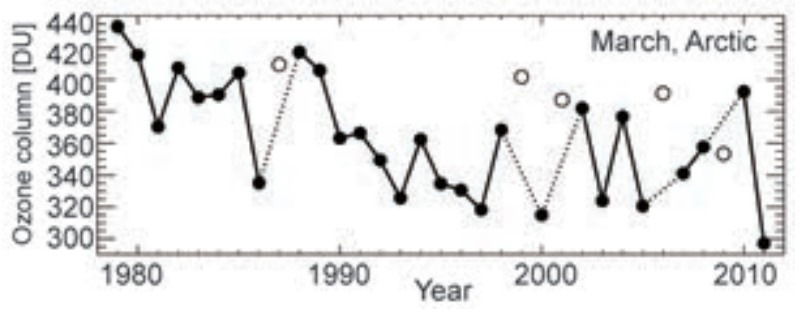

Fig. 5.6. Time series of area-averaged minimum total ozone for March in the Arctic, calculated as the minimum of the daily average column ozone poleward of $63^{\circ} \mathrm{N}$ equivalent latitude. Winters in which the polar vortex broke up before March (1987, 1999, 200I, 2006, and 2009) are shown as open symbols. Ozone in those years was relatively high because of mixing with air from lower latitudes. Figure adapted from Müller et al. (2008), updated using the combined total column ozone database of the New Zealand National Institute of Water and Atmospheric Research (NIWA), Version 2.7, provided by H. Chisholm of NIWA and G. Bodeker of Bodeker Scientific. The area-averaged minimum total ozone quantity is explained in Müller et al. (2008)

throughout the Arctic and sub-Arctic. Figure 5.8 illustrates the UV radiation in terms of the UV index, which is a measure of the ability of UV radiation to cause sunburn in human skin (WHO 2002). Changes in the UV index anti-correlate with changes in total ozone (compare 2011 data in center and bottom panels of Fig. 5.8). Noontime UV indices of March 2011 exceeded historical measurements for this month at all Arctic sites where ground-based UV monitoring systems are located (Bernhard et al. 2011). The maximum enhancement of the UV index relative to the climatological average was $122 \%$ (Fig. 5.8c). While these large relative changes are unprecedented, the absolute increases in UV levels were modest at all Arctic sites (e.g., increase by less than one UV index unit) because the low-ozone event occurred early in spring when the solar elevation was still small. Larger absolute increases of UV indices occurred at lower

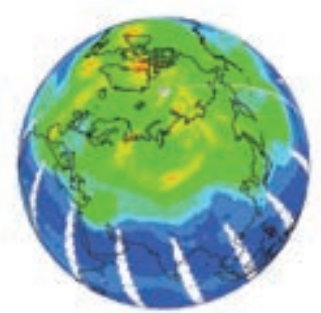

3 April 2002

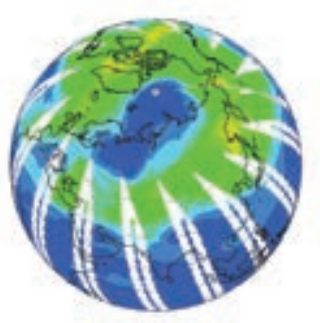

3 April 2011

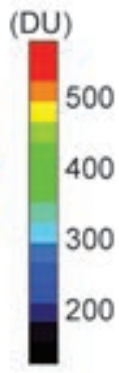

Fig. 5.7. Comparison of total ozone column (DU) measured by satellites on 3 April 198I, 2002, and 20II. Data are from the Total Ozone Mapping Spectrometer (TOMS) onboard the Nimbus-7 (198I) and Earth Probe (2002) satellites, and the Ozone Monitoring Instrument (OMI) onboard the AURA spacecraft (20II). 

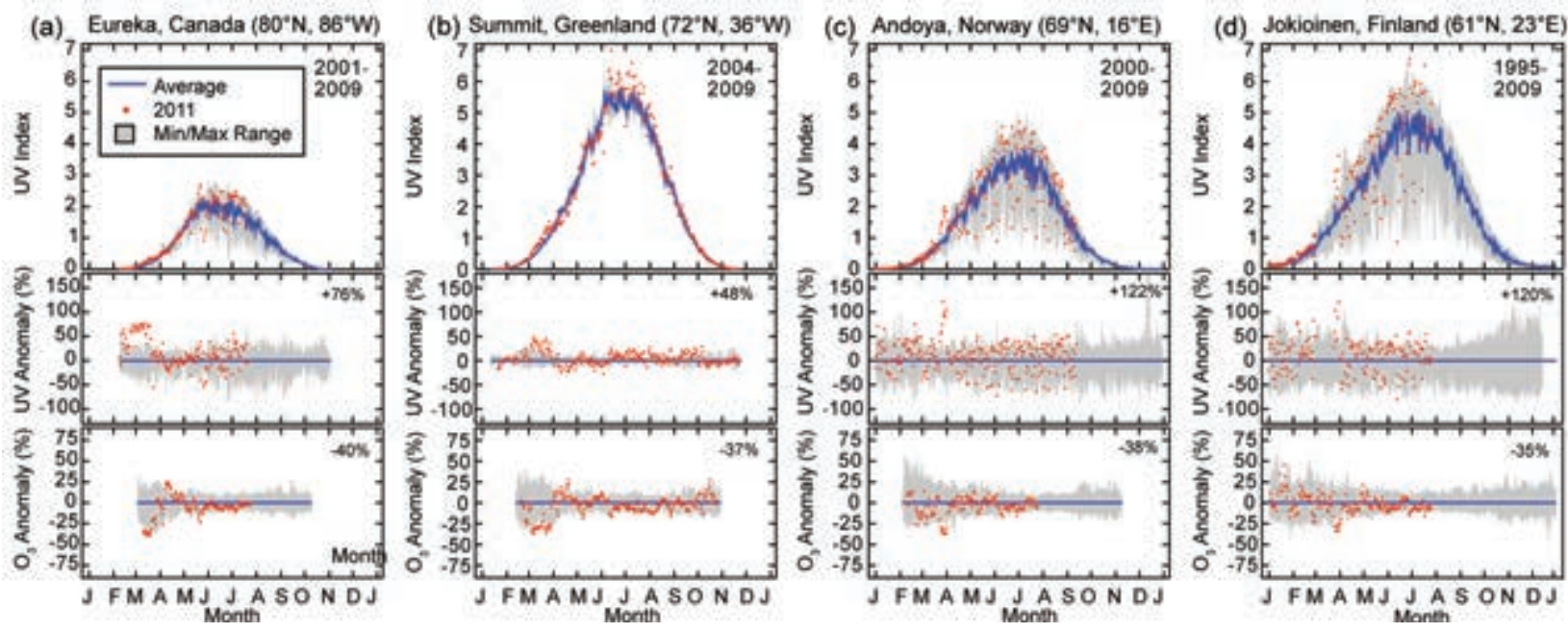

FIG. 5.8. Seasonal variation of the noontime UV Index for four Arctic and sub-Arctic sites measured by groundbased radiometers. The upper panel for each site compares the climatological average (blue line) with the measurements in $201 \mathrm{I}$ (red dots), and historical minima and maxima (shaded range). The latter were calculated from measurements during the periods indicated in the top-right corner of the panel. The center panel shows the anomaly in the UV Index, calculated as the percentage departure from the climatological average. The numbers indicate the maximum anomalies for March and April 20II. The bottom panel shows a similar anomaly analysis for total ozone derived from measurements of the following satellites: TOMS/Nimbus-7 (199I-92), TOMS/Meteor-3 (1993-94), TOMS/EarthProbe (1996-2004), and OMI (2005-II). The shaded range for the ozone dataset is based on data for the years 199I-2009. Ozone data are available at http://toms.gsfc. nasa.gov and http://ozoneaq.gsfc.nasa.gov/.

latitudes during excursions of the Polar vortex in April. For example, on 22 April, the clear-sky UV index over parts of Mongolia $\left(48^{\circ} \mathrm{N}, 98^{\circ} \mathrm{E}\right)$ estimated by TEMIS (Tropospheric Emission Monitoring Internet Service at http://www.temis.nl/uvradiation/UVindex .html) was 8.6 when a lobe of the vortex extended to central Asia. The long-term average for this day at this location is 5.4 with a standard deviation of 0.5 , i.e., the anomaly was more than six standard deviations larger than the climatological mean.

\section{d. Terrestrial snow-C. Derksen and R. Brown}

Time series of satellite-derived Arctic (land area north of $60^{\circ} \mathrm{N}$, excluding Greenland) snow cover extent (SCE), snow cover duration (SCD), and snow water equivalent (SWE) anomalies (relative to a 1988-2007 base period) were calculated to place the 2010/11 snow season in the context of trends and variability during recent decades. Monthly SCE and seasonal SCD (computed separately for the first and second halves of the snow year) anomalies were computed from the weekly NOAA snow chart climate data record (CDR) maintained at Rutgers University and described in Brown and Robinson (2011). The SWE anomalies for 1980-2011 were calculated from an assimilation of surface observations of snow depth and satellite passive microwave measurements (Takala et al. 2011), the Canadian Meteorological Centre (CMC) daily gridded global snow depth analysis (Brasnett 1999), and the ERA-interim atmospheric reanalysis (Dee et al. 2011a).

Air temperatures over the North American Arctic (NA) were below normal in April and early May, coincident with a strongly positive Arctic Oscillation (AO) (see Table 5.1), so SCE was above or near the long-term average during these months (Figs. 5.9a,b). When the AO shifted to a negative phase in May, the surface temperature anomalies became positive. By June, SCE anomalies over the NA sector of the Arctic were the second lowest on record (Fig. 5.9c). Unlike the slow start to the NA melt season, an extensive and persistent warm air temperature anomaly covered the Eurasian Arctic (EUR) through the entire spring season (see Fig. 5.3b), driving below-normal SCE in April and May, with a new record low June SCE over EUR since satellite observations began in 1966 (Fig. 5.9c).

Spatial patterns of seasonal SCD anomalies derived from the NOAA CDR for 2010/11 show an early spring melt anomaly located over the $\mathrm{Ob}$ and Yenisey basins (Fig. 5.9d) contributed to the shortest spring SCD for EUR in the NOAA snow chart record (Fig. 5.9f). A striking feature in the SCD anomaly time series is the seasonal asymmetry of the trends through the data record. The fall start date of snow cover over the Arctic has remained stable during the satellite era (Fig. 5.9e), in contrast to the trend 


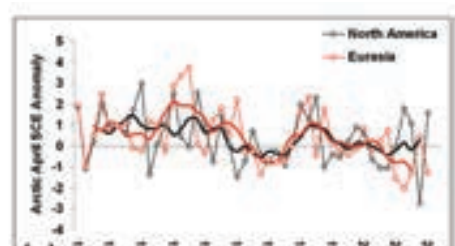

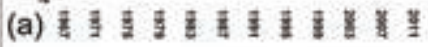

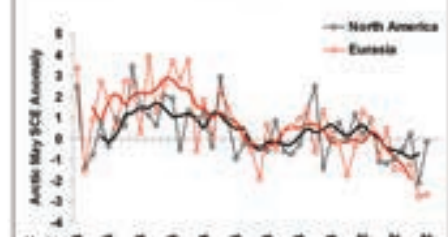

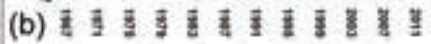

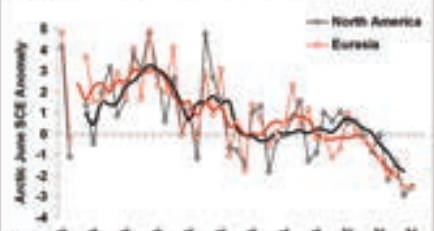

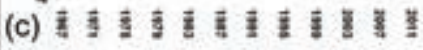

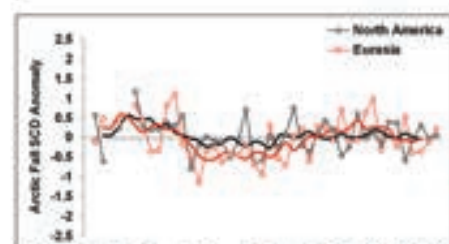

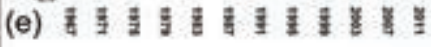
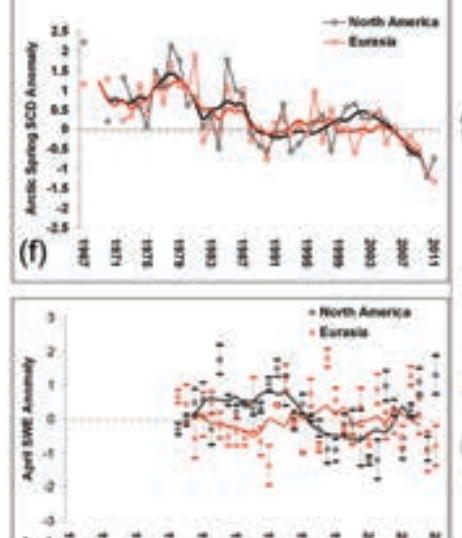

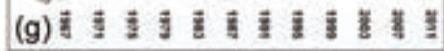
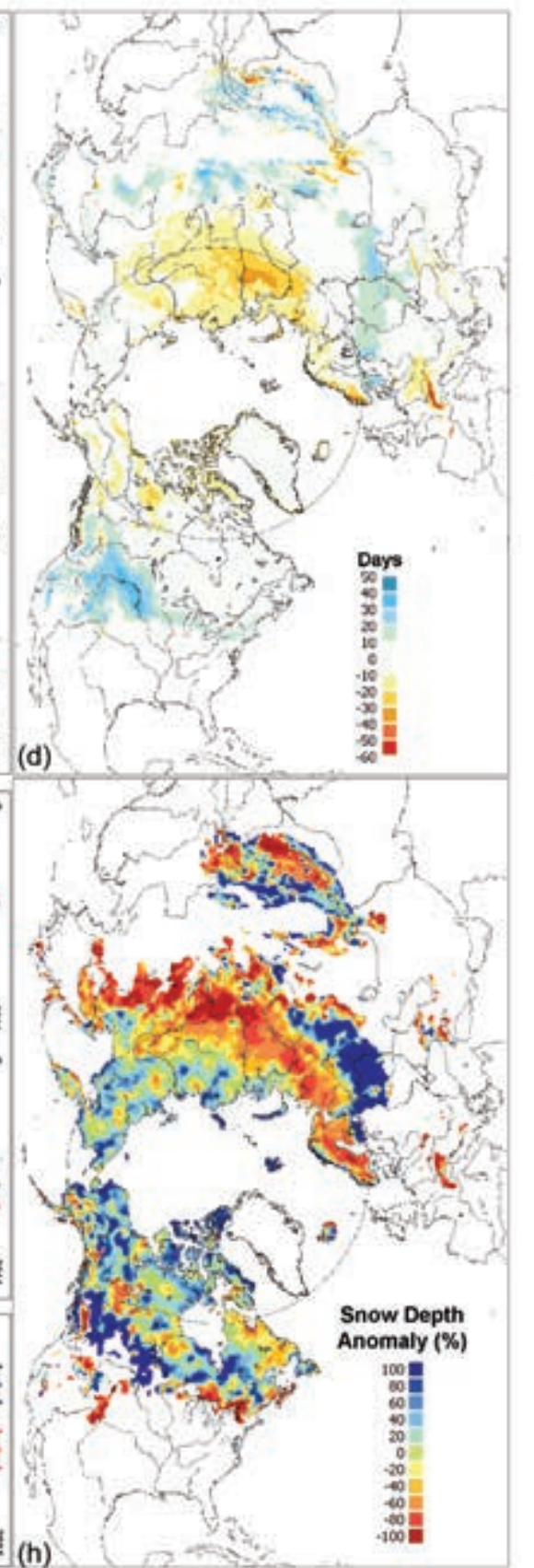

FIG. 5.9. (a)-(c) Monthly Arctic snow cover extent standardized (and thus unitless) anomaly time series (1988-2007 base period) from the NOAA snow chart CDR for (a) April, (b) May, and (c) June 1967-20II (solid lines denote 5-yr moving average). (d) Snow cover duration (SCD) departures (1998-2010 base period) from the NOAA IMS data record for the 2011 spring season. (e)-(f) Arctic seasonal SCD standardized anomaly time series (1988-2007 base period) from the NOAA record for the first (fall) and second (spring) halves of the snow season (solid lines denote 5 -yr moving average). (g) Time series of multidataset average monthly April snow water equivalent standardized anomalies ( \pm the standard error) relative to 1988-2007 base period (solid lines denote 5-yr moving average). (h) April 20II snow depth anomaly (\% of 1999-2010 average) from the CMC snow depth analysis. towards less snow in the spring period (Fig. 5.9f). The below-average Arctic SCE and SCD during 2011 is consistent with a decline in spring snow cover since the 1970s, identified from multiple datasets by Brown et al. (2010); the rate of this reduction has accelerated over the past five years.

The multi-dataset SWE anomaly series for the month of April is characterized by a high degree of interannual variability, with no significant trends (Fig. 5.9g). Across the NA Arctic, 2011 was characterized by the third highest April SWE anomaly in the record. This is also reflected in the mean April snow depth analysis from CMC (Fig. 5.9h), which shows predominantly positive snow depth anomalies over NA. Across EUR, the 2011 April SWE anomaly was near normal.

In summary, although peak SWE was close to average for EUR, and well above average for the NA Arctic, spring SCE and SCD during 2011 were below average across the Arctic because of warm air temperature anomalies during May and June. The observed reductions in spring SCE and SCD are consistent with the poleward amplification of snow cover sensitivity to warming air temperatures (Dery and Brown 2007). In spite of documented positive trends in observed precipitation over high latitudes (X. Zhang et al. 2007; Mekis and Vincent 2011), there is no evidence of pan-Arctic SWE trends when multiple datasets are considered.

e. Glaciers and ice caps (outside Greenland)-M. Sharp and G. Wolken

With an area of over $400000 \mathrm{~km}^{2}$, Arctic glaciers and ice caps are a significant contributor to global sea level change (Meier et al. 2007; Gardner et al. 2011; Jacob et al. 2012). Glaciers and ice caps gain mass by snow accumulation and lose mass by iceberg calving, surface melt, and runoff. The climatic mass balance $\left(B_{\text {clim }}\right.$, the difference between annual snow accumulation and runoff) is an index of how they respond to cli- 
mate change and variability. Note that $\mathrm{B}_{\text {clim }}$ is a new term (Cogley et al. 2011) synonymous with net mass balance $\left(\mathrm{B}_{\mathrm{n}}\right)$ used in previous State of the Climate reports (e.g., Sharp and Wolken 2011a). Consistent with warming surface temperatures, the negative trend in $\mathrm{B}_{\text {clim }}$ of most Arctic glaciers and ice caps continues, albeit with regional variability.

At the time of writing, the only mass balance information available for 2010/11 is an estimate of $-96 \pm 49 \mathrm{Gt}$ (which, in this case, is an estimate of the complete mass balance, $\Delta \mathrm{M}$, which includes mass losses by iceberg calving) for the Canadian Arctic Islands. Derived using GRACE satellite gravimetry, this is the most negative value for this region during the GRACE observation period, 2002-present (B. Wouters 2012, personal communication) and compares with the 2004-09 mean of -63 Gt yr ${ }^{-1}$ (Gardner et al. 2011). The large mass loss is consistent with very warm land surface and upper air $(700 \mathrm{hPa})$ temperature anomalies due to anomalous meridional winds transporting heat into the region from the vicinity of southern Greenland, where anomalously warm sea surface temperatures occurred (Sharp and Wolken 2011b; sections $5 \mathrm{~b}$ and $5 \mathrm{f}$ ). In the previous balance year, 2009/10, the GRACE-derived $\Delta \mathrm{M}$ estimate for this region was $-73 \pm 55 \mathrm{Gt}$ (B. Wouters 2012, personal communication), confirming the growing

importance of glaciers and ice caps in the Canadian Arctic Islands as contributors to global sea level rise (Gardner et al. 2011).

At the time of writing, the most recent in situ measurements of $\mathrm{B}_{\text {clim }}$ for the twenty Arctic glaciers previously reported in the State of the Climate reports (e.g., Sharp and Wolken 2011a) are those for the 2009/10 balance year (World Glacier Monitoring Service 2011). The data (Table 5.2) show that all but one of the twenty glaciers had a negative climatic mass balance. Climatic mass balances of two of the four glaciers in Svalbard, including the one with a positive balance, were all less negative than the previous year. In Iceland, mass balances were all very negative, consistent with high summer air and sea surface temperature anomalies over Iceland and southern Greenland (Sharp and Wolken 2011b). Climatic mass balances of Alaskan glaciers were all negative, with very high mass loss occurring in the eastern Alaska Range (Gulkana). The climatic mass balances of the four glaciers in Arctic Canada were all negative, extending a period of very negative balances in the region that began in 1987 (Sharp et al. 2011).

f. Greenland ice sheet-M. Tedesco, J. E. Box, J. Cappellen, T. Mote, R. S. W. van de Wal, and J. Wahr

The duration of melting in 2011 was above average over much of Greenland, lasting

\section{TABLE 5.2. Annual (2009-10) climatic balances $\left(B_{\text {clim }}\right)$ of 20 glaciers in the Arctic. Source: World Glacier Monitoring Service (20II).}

\begin{tabular}{|c|c|c|c|c|}
\hline Country & Glacier/lce Cap & Latitude $\left({ }^{\circ}\right)$ & Longitude $\left({ }^{\circ}\right)$ & $\begin{array}{l}2009 / 10 \mathrm{~B}_{\text {clim }} \\
\left(\mathrm{Kg} \mathrm{m}^{-2}\right)\end{array}$ \\
\hline \multirow[t]{4}{*}{ Canada } & Devon & $75.42 \mathrm{~N}$ & $83.25 \mathrm{~W}$ & -417 \\
\hline & Meighen & $79.95 \mathrm{~N}$ & $99.13 \mathrm{~W}$ & -387 \\
\hline & Melville South & $75.43 \mathrm{~N}$ & $114.99 \mathrm{~W}$ & -939 \\
\hline & White & $79.45 \mathrm{~N}$ & $90.67 \mathrm{~W}$ & -188 \\
\hline \multirow[t]{9}{*}{ Iceland } & Bruarjökull & $64.67 \mathrm{~N}$ & $16.17 \mathrm{~W}$ & -1570 \\
\hline & Dyngjujökull & $64.67 \mathrm{~N}$ & $17.00 \mathrm{~W}$ & -1540 \\
\hline & Eyjabakkajökull & $64.65 \mathrm{~N}$ & $15.58 \mathrm{~W}$ & -1750 \\
\hline & Hofsjökull E & $64.80 \mathrm{~N}$ & $18.58 \mathrm{~W}$ & -2830 \\
\hline & Hofsjökull N & $64.95 \mathrm{~N}$ & $18.92 \mathrm{~W}$ & -2400 \\
\hline & Hofsjökull SW & $64.72 \mathrm{~N}$ & $19.05 \mathrm{~W}$ & -3490 \\
\hline & Köldukvislarjökull & $64.58 \mathrm{~N}$ & $17.83 \mathrm{~W}$ & -2870 \\
\hline & $\begin{array}{l}\text { Langjökull (South } \\
\text { Dome) }\end{array}$ & $64.62 \mathrm{~N}$ & $20.30 \mathrm{~W}$ & -3800 \\
\hline & Tungnáarjökull & $64.32 \mathrm{~N}$ & $18.07 \mathrm{~W}$ & -3551 \\
\hline \multirow[t]{4}{*}{$\begin{array}{l}\text { Norway } \\
\text { (Svalbard) }\end{array}$} & $\begin{array}{l}\text { Austre } \\
\text { Broggerbreen }\end{array}$ & $78.88 \mathrm{~N}$ & $11.83 \mathrm{E}$ & -440 \\
\hline & Hansbreen & $77.08 \mathrm{~N}$ & $15.67 \mathrm{E}$ & -14 \\
\hline & Kongsvegen & $78.80 \mathrm{~N}$ & $12.98 \mathrm{E}$ & +130 \\
\hline & Midre Lovenbreen & $78.88 \mathrm{~N}$ & 12.07E & -200 \\
\hline \multirow[t]{3}{*}{ USA (Alaska) } & Gulkana & $63.25 \mathrm{~N}$ & $145.42 \mathrm{~W}$ & -1832 \\
\hline & Lemon Creek & $58.38 \mathrm{~N}$ & $134.36 \mathrm{~W}$ & -580 \\
\hline & Wolverine & $60.40 \mathrm{~N}$ & $148.92 \mathrm{~W}$ & -85 \\
\hline
\end{tabular}
up to $\sim 30$ days longer than the 1979-2010 average. Areas along the west and northwest coasts experienced the largest positive anomalies in the number of days when melting occurred (Fig. 5.10). The number of melting days in 2011 estimated from spaceborne passive microwave observations (Tedesco 2007) did not, however, break the previous record set in 2010 (Tedesco et al. 2011); 2011 ranked sixth, after 2010, 2007, 1998, 2002, and 2005.

The area of melt for the period June-August 2011 (Mote 2007) was the third greatest since records began in 1979, behind only 2007 and 2010. Note that the annual ranking is sensitive to the length of the season selected; expanding the season from 15 May to 15 September drops 2011 to the sixth most extensive melt year, following 

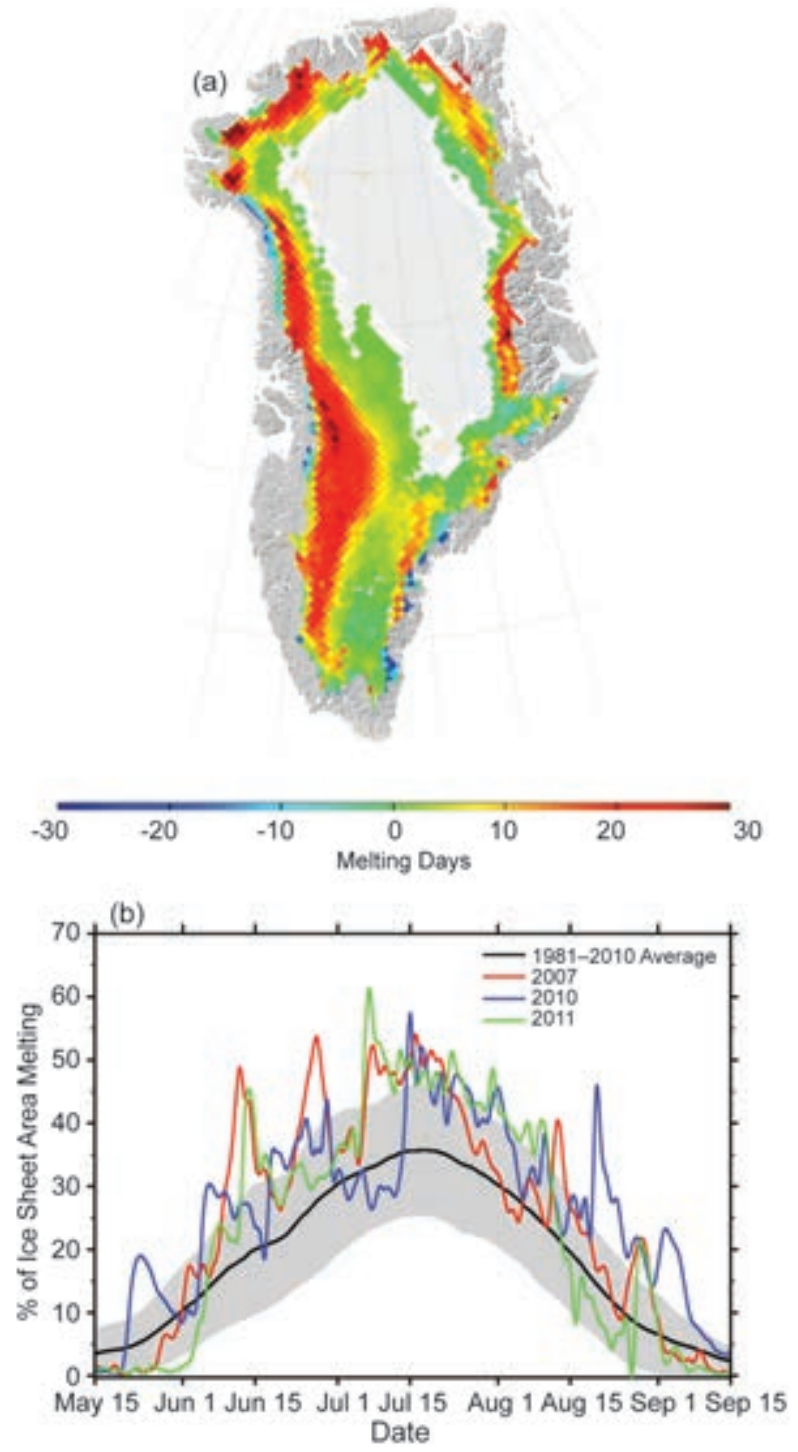

FIG. 5.I0. (a) Map of the $201 \mathrm{I}$ anomaly (relative to a 1979-2010 base period) for the number of melting days and (b) fractional area (\%) of the Greenland ice sheet identified as melting by SSM/I (passive microwave). The standard deviation of the $198 \mid-2010$ base period is shaded.

$2010,2007,2002,1998$, and 2005, in that order. The area subject to melting in summer 2011 was above the average (Fig. 5.10b), with an average value of $31 \%$ of the ice sheet area, compared to $33 \%$ in 2007 and 32\% in 2010 (the $1981-2010$ average is $24.1 \%$ ). No other years since 1979 have had an average $>30 \%$. The linear trend for the area of the ice sheet subject to melting, updated to include 2011, is $16800 \mathrm{~km}^{2} \mathrm{yr}^{-1}\left(\mathrm{R}^{2}=0.58\right)$. This indicates that, on average, in 2011 an area the size of Spain was subject to melting where no melting occurred in 1979.

In situ measurements of surface mass balance, and model estimates (Box et al. 2011), confirm the extreme nature of melting in 2011 on the Greenland ice sheet. The weighted-average mass balance $(-1.9 \mathrm{~m}$ w.e.) measured at the K-transect (in west Greenland near Kangerlussuaq; van de Wal et al. 2005) was the second lowest in 21 years of record and added to the cumulative mass loss that has been characteristic of this location since the late 20th century (Fig. 5.11). According to K-transect measurements, the equilibrium line elevation at the end of summer 2011 is estimated to be $1710 \mathrm{~m}$ above sea level (a.s.l.) compared to a value of $\sim 1500 \mathrm{~m}$ a.s.l. in the early 1990s.

Over the entire Greenland ice sheet, estimates obtained by Gravity Recovery and Climate Experiment (GRACE; Velicogna and Wahr 2006) satellites indicate a cumulative loss of $422 \mathrm{Gt}$ in 2011. This is 80\% larger than the 2003-09 average annual loss rate of $233 \mathrm{Gt} \mathrm{yr}^{-1}$ (Fig. 5.12), the second largest annual loss rate in the GRACE record since observations began in 2003, and close to the 2010 record of $442 \mathrm{Gt}$.

Negative albedo anomalies estimated from the Moderate-Resolution Imaging Spectroradiometer (MODIS, the MOD10A1 product; Klein and Stroeve 2002) are widespread over the ice sheet during the 2011 melt period. MODIS data indicate a statistically significant decrease in the overall albedo of 0.055 during the 12-year period of record (Fig. 5.13a). The albedo anomaly map for summer 2011 (JJA) indicates large negative values, i.e., lower albedo, over west Greenland (Fig. 5.13b), where darker bare ice is exposed following the ablation of the previous winter's snow accumulation.

The extreme melting in 2011 is consistent with relatively warmer temperatures over Greenland (Cappelen et al. 2000, Cappelen 2011). During summer 2011, several ground stations recorded the warmest temperature since the beginning of records, e.g., Upernavik (records dating back to 1873) and Thule Air Force Base (records dating back to 1961; Box et al.

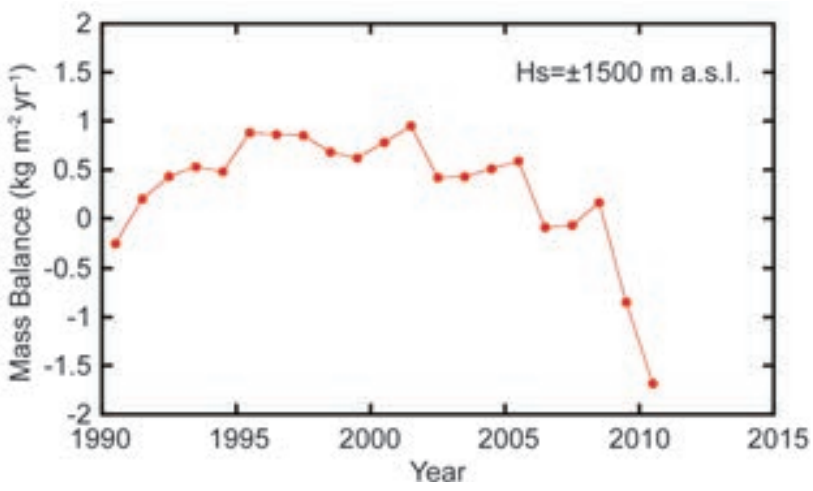

FIG. 5.II. The cumulative mass balance in the vicinity of the equilibrium line altitude $\left(\mathrm{Hs}=\sim 1500 \mathrm{~m}\right.$ a.s.I., $67^{\circ} \mathrm{N}$, $50^{\circ} \mathrm{W}$ ) along the K-Transect of the Greenland ice sheet. 


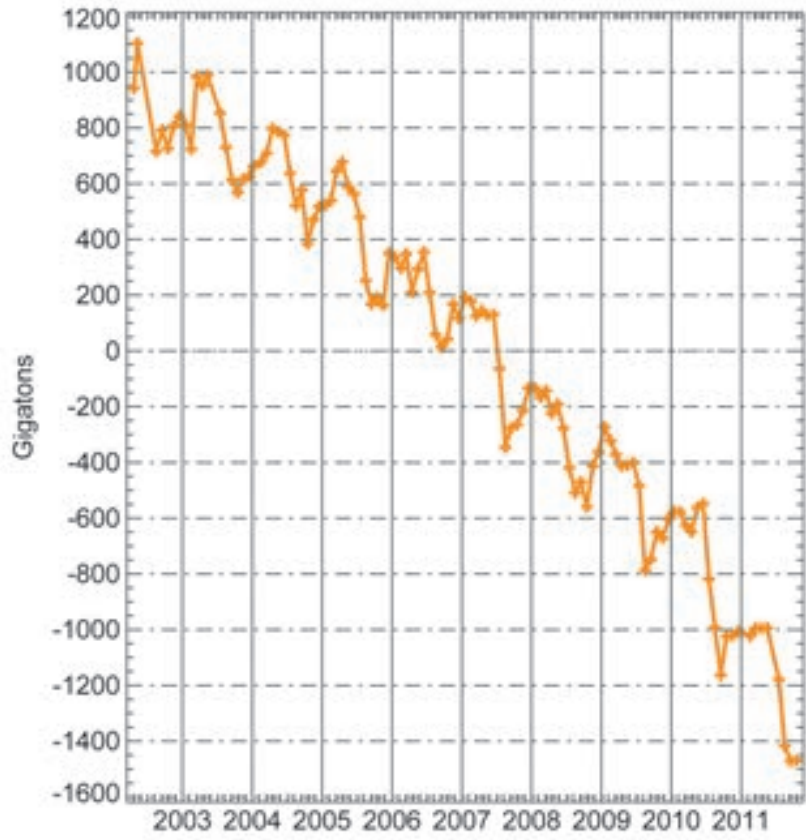

Fig. 5.12. Monthly unsmoothed values (+ symbols) of the total mass (Gigatons) of the Greenland ice sheet from GRACE. On the horizontal axis, each year begins on I January.

2011). Anomalously low temperatures were recorded during spring and autumn 2011. At Kangerlussuaq, April 2011 had the lowest temperature since records began in 1949. Consistent with ground observations, surface temperature estimated under clear sky conditions by MODIS (Wan et al. 2002; Wan 2008) since 2000 indicate an anomalously cold spring and an anomalously warm summer in 2011 (see section $5 b$ for further description of these seasonal air temperature anomalies and the influence of atmospheric circulation).

MODIS data indicate statistically significant ice sheet surface warming in the past decade in both winter $\left(+3.1 \pm 1.9^{\circ} \mathrm{C}\right)$ and summer $\left(+1.8 \pm 0.7^{\circ} \mathrm{C}\right)$. Moreover, seasonally-averaged 2011 upper air temperature data available from twice-daily radiosonde observations (Durre et al. 2006) in the vicinity of Greenland support the ground- and MODIS-based surface temperature observations, indicating anomalous tropospheric warmth in summer and winter and mid-tropospheric cold anomalies in spring. Summer (JJA) 2011 had a persistent negative North Atlantic Oscillation (NAO) index, 2.4 standard deviations below the 1971-2000 summer average. This led to warm air advection from the south along the western coast, causing higher departures from normal summer temperature and drier-than-normal conditions in south Greenland. The Arctic Oscillation (AO)
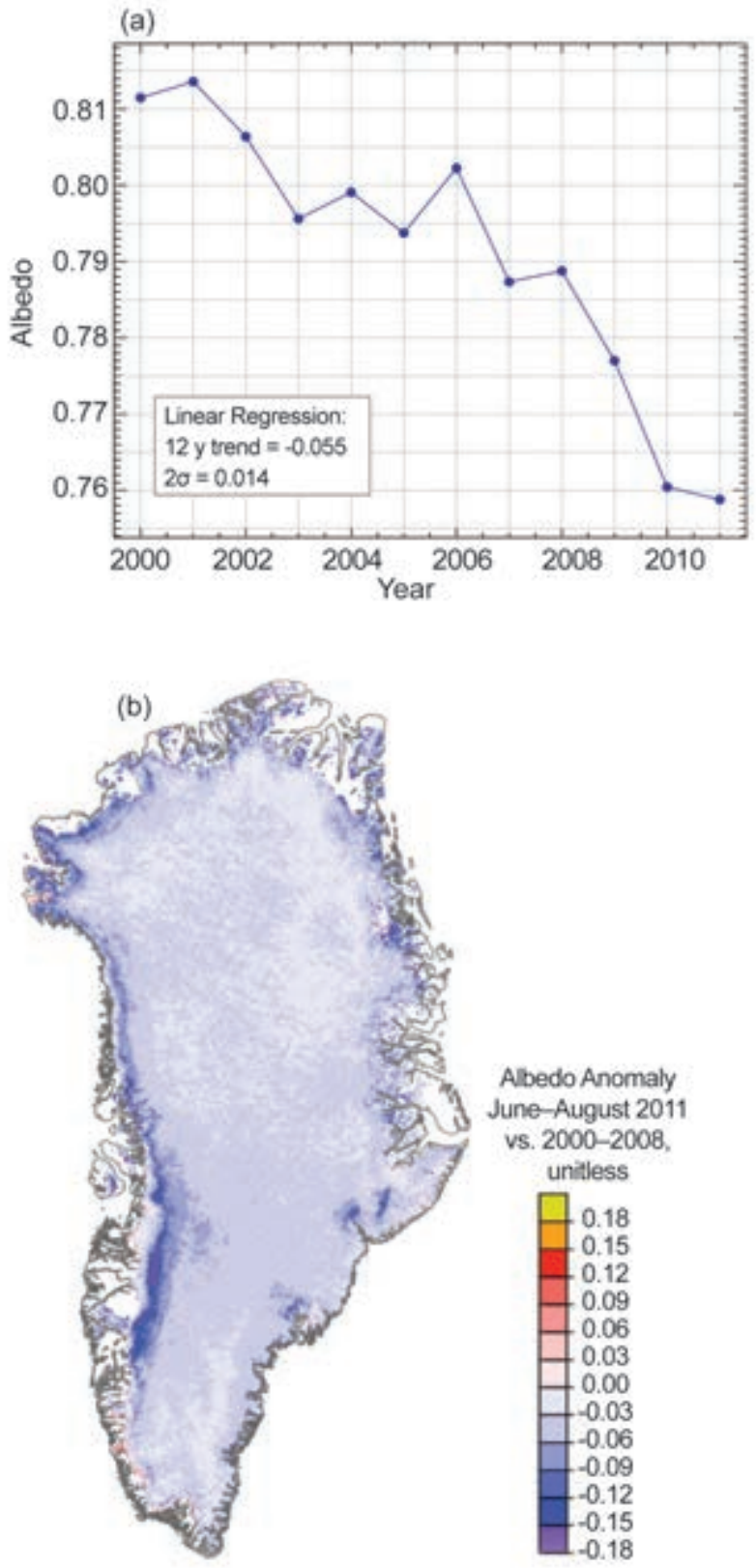

FIG. 5.I3. (a) Greenland ice sheet albedo for the period 2000-II and (b) summer (JJA) albedo anomaly in $201 \mathrm{I}$ relative to the 2000-08 base period. Both (a) and (b) are derived from MODIS.

index was also persistently negative in summer 2011 (see Table 5.1).

A pattern of below-average precipitation for the period September 2010-August 2011 is evident at the west, southwest, and southeast stations of the Danish Meteorological Institute (Cappelen et al. 2000, Cappelen 2011), with the largest anomalies in the south (above one standard deviation). Conversely, in east and northeast Greenland, precipitation was above average (Box et al. 2011). According to measurements at the DMI stations, no annual precipitation 
record was set in 2011. Although the melt season started late in 2011, dry and warm conditions, together with reduced accumulation caused a record bare ice exposure, which, in turn, enhanced the melt. At the south of the ice sheet, lower-than-normal winter accumulation allowed bare ice to appear earlier in the ablation zone.

g. Permafrost - V. E. Romanovsky, S. L. Smith, H. H. Christiansen, N. I. Shiklomanov, D. S. Drozdov, N. G. Oberman, A. L. Kholodov, and S. S. Marchenko

The most direct indicators of permafrost stability and changes in permafrost state are temperature and active layer thickness (ALT). A general increase in permafrost temperatures has been observed during the last several decades in Alaska (Osterkamp 2008; Smith et al. 2010; Romanovsky et al. 2010b), northern Canada (Smith et al. 2010), and Siberia (Romanovsky et al. 2010a).

At most Alaskan permafrost observatories there was substantial warming during the 1980 s and especially in the 1990s (Fig. 5.14). The magnitude and nature of the warming varied spatially, but was typically from $0.5^{\circ} \mathrm{C}$ to $2^{\circ} \mathrm{C}$ at the depth of zero

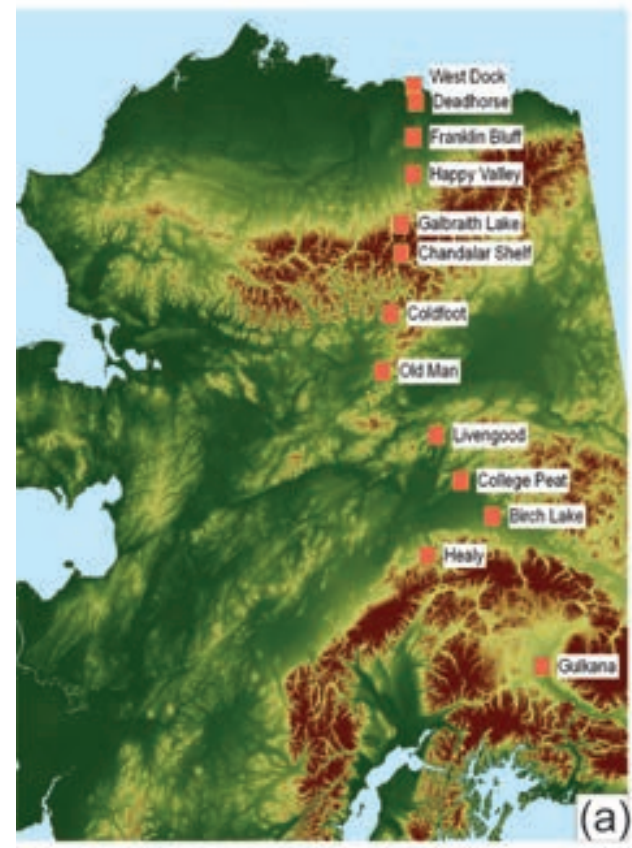

seasonal temperature variation (Osterkamp 2008). However, during 2000-05, permafrost temperature was relatively stable on the North Slope of Alaska (Romanovsky et al. 2011; Smith et al. 2010; Fig. 5.14b), and there was even a slight decrease (ranging from $0.1^{\circ} \mathrm{C}$ to $0.3^{\circ} \mathrm{C}$ ) in Interior Alaska during the last four years (Fig. 5.14c).

The most recent data may indicate that the coastal warming trend has propagated southward towards the northern foothills of the Brooks Range, where a noticeable warming in the upper $20 \mathrm{~m}$ of permafrost has become evident since 2008. In 2011, new recordhigh temperatures at $20 \mathrm{~m}$ depth were measured at all observatories on the North Slope, where measurements began in the late 1970s (Fig. 5.14b). Although these patterns of permafrost warming on the North Slope and a slight cooling in Interior Alaska are in good agreement with air temperature differences between the Arctic and the sub-Arctic, snow distribution variability may also have played a role.

In northwestern Canada, similar increases in cold permafrost temperature have been observed during the last 40 years (Burn and Kokelj 2009). Smaller increases in permafrost temperature have been ob-
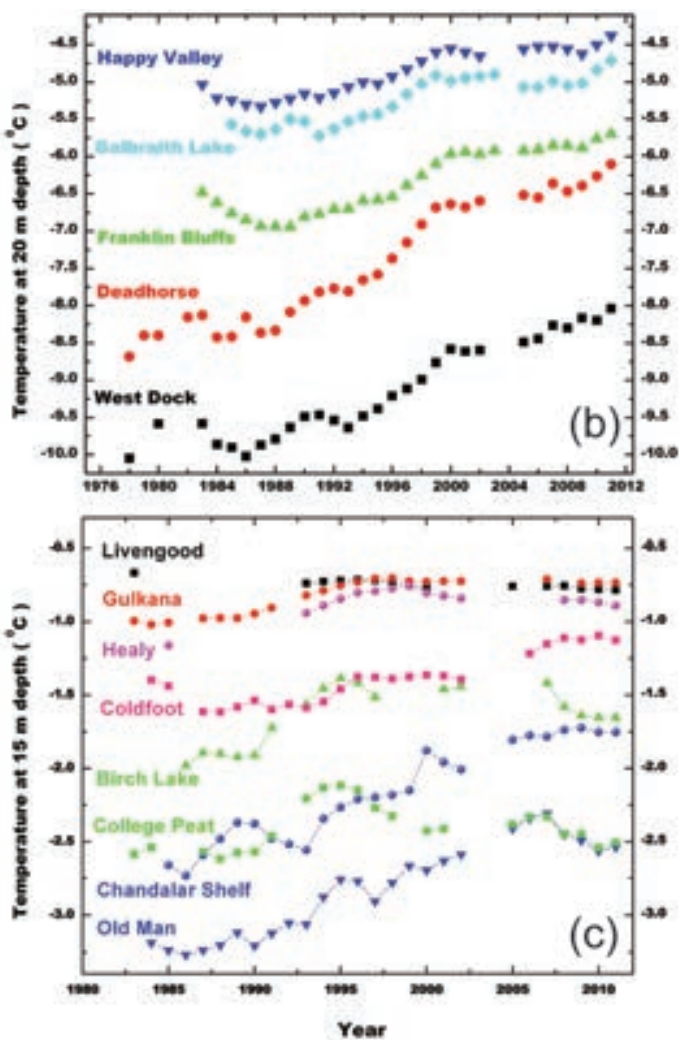

FIG. 5.14. (a) Location of sites where permafrost temperature was measured at (b) $20 \mathrm{~m}$ below the surface at locations from north to south across the North Slope of Alaska in the continuous permafrost zone, and (c) at $15 \mathrm{~m}$ below the surface in the Brooks Range and in interior Alaska. Note the higher permafrost temperatures in (c) interior Alaska than on the (b) North Slope due to the warmer climate of the interior. 
served for warm permafrost in the discontinuous zone, with recent data indicating a negligible change (Romanovsky et al. 2011; Smith et al. 2010). In the high Canadian Arctic, greater warming has been observed, with recent data indicating a continuing steady increase in permafrost temperature since 2000 (Romanovsky et al. 2011; Smith et al. 2010). Permafrost temperature has increased by $1^{\circ} \mathrm{C}-2^{\circ} \mathrm{C}$ in northern Russia during the last 30 to 35 years, but this trend was interrupted by colder conditions in summer 2009 and winter 2009/10 at many locations, especially in the western sector of the Russian Arctic. Long-term permafrost temperature records are limited for the Nordic area, with a few beginning at the end of the 1990s. These, however, show recent decadal warming of $0.04^{\circ} \mathrm{C} \mathrm{yr}^{-1}$ to $0.07^{\circ} \mathrm{C} \mathrm{yr}^{-1}$ in the highlands of southern Norway, northern Sweden, and Svalbard, with the largest warming in Svalbard and northern Scandinavia (Isaksen et al. 2011; Christiansen et al. 2010).

Identification of trends in ALT is difficult, as thaw depth responds to interannual variations in summer air temperature (e.g., Smith et al. 2009; Popova and Shmakin 2009). Decadal trends in ALT vary regionally, with a progressive increase in ALT observed in some Nordic countries, e.g., in the Abisko area of Sweden since the 1970s, with an accelerated rate after 1995, and disappearance of permafrost in several mire landscapes (e.g., Åkerman and Johansson 2008; Callaghan et al. 2010). This increase ceased during 2007-10, coincident with drier summer conditions (Christiansen et al. 2010). ALT has increased since the late 1990s on Svalbard and Greenland, but the rates vary spatially and temporally (Christiansen et al. 2010). In the eastern Canadian Arctic, ALT has increased since the mid-1990s, with the largest increase occurring in bedrock of the discontinuous permafrost zone (Smith et al. 2010). Active-layer thickness on the North Slope of Alaska has been relatively stable, without pronounced trends during the last 15 years (Streletskiy et al. 2008; Shiklomanov et al. 2010).

\section{h. Lake ice-C. R. Duguay, L. Brown, K.-K. Kang, and H. K. Pour}

Lake ice phenology, which encompasses freeze-up (ice-on) and break-up (ice-off) dates, and ice cover duration (ICD), is largely influenced by air temperature changes and is therefore a robust indicator of regional climate (e.g. Duguay et al. 2006; Kouraev et al. 2007; Latifovic and Pouliot 2007). Ground-based observational records have provided evidence of later

\section{SIDEBAR 5.2: CHANGING ARCTIC TUNDRA VEGETATION BIOMASS AND GREENNESS-D. A. WALKER, U. S. BHATT, H. E. EPSTEIN, P. BIENIEK, J. COMISO,}

\section{G. V. FROST, J. PINZON, M. K. RAYNOLDS, AND C. J. TUCKER}

Eighty percent of the non-alpine tundra biome in the Arctic is within $100 \mathrm{~km}$ of the Arctic Ocean and adjacent seas, its distribution largely controlled by cold summer air masses associated with the pack ice. It is expected that if sea ice continues to decline the adjacent tundra areas will warm during the summer (Lawrence et al. 2008), and the higher temperatures will increase tundra primary productivity and biomass (Bhatt et al. 2010; Elmendorf et al. 20II; Callaghan et al. 20II; Epstein et al. 2012).

Recently, Raynolds et al. (2012) established a very strong correlation $\left(r^{2}=0.94, p<0.00\right.$ I) between zonal (climax)aboveground plant biomass at the peak of the growing season at mesic (moist) sites and the annual maximum NDVI (Normalized Difference Vegetation Index). The latter is an index of vegetation greenness derived from Advanced Very High Resolution Radiometer (AVHRR) data. Derived for zonal/climax vegetation along two transects in North America and Eurasia, the Raynolds et al. (20I2) relationship was used by Epstein et al. (20I2) to determine that above-ground tundra biomass at representative sites increased by $19.8 \%$ during the period of the NDVI record (1982-2010). This has major implications for tundra ecosystems, including active layer depth, permafrost temperature and distribution, hydrology, wildlife, and human use of Arctic landscapes.
The biomass-greenness relationship described above offers the promise of easily determining total above-ground tundra biomass from NDVI. However, since the data were limited to vegetation on zonal sites, and it is not known how well the relationship holds for complex landscapes composed of many plant community types, NDVI continues to be used primarily as a measure of greenness and a proxy for total above-ground biomass.

During 30 years of AVHRR observations (1982-20II), areaaveraged MaxNDVI (Fig. SB5.2b) has increased $15.5 \%$ in the North American Arctic, with a particularly sharp increase since 2005, and $8.2 \%$ in the Eurasian Arctic, although values have been nearly constant since 200I (Bhatt et al. 2010, updated to 20II). Summer land temperatures in the tundra regions also show different geographic patterns between 1982 and 20II, with the area-averaged Summer Warmth Index (SWI, the sum of mean monthly temperatures $>0^{\circ} \mathrm{C}$, or thawing degree months) increasing $10.1 \%$ for North America and decreasing $2.6 \%$ for Eurasia (Fig. SB5.2a). Large areas of the Eurasian Arctic are apparently cooling during the summer growing season and contributing to the smaller NDVI response. A decreasing NDVI trend is particularly pronounced in the region adjacent to the northern Barents and Kara Seas (Fig. SB5.2b), where an increase in extent and persistence of the open water sea- 
freeze-up and earlier break-up dates in the Northern Hemisphere, particularly during the second half of the 20th century (e.g., Brown and Duguay 2010). In the last 20 years, however, ground-based lake ice networks have been diminished to the point where they can no longer provide the quality of observations necessary for climate monitoring. Satellite remote sensing is the most logical alternative for Arctic-wide lake ice observing.

Spatial and temporal variability in ice phenology and ICD derived at the pixel level from the NOAA Interactive Multisensor Snow and Ice Mapping System (IMS) 4-km resolution grid daily product (National Ice Center 2008) was analyzed for the 2010/11 ice season and compared to average conditions for the full length of the available satellite historical record (since 2004). The IMS incorporates a wide variety of satellite imagery (AVHRR, GOES, SSMI, etc.) as well as derived mapped products (USAF Snow/Ice Analysis, AMSU, etc.) and surface observations (see Helfrich et al. 2007 for details).

Freeze-up in 2010 was close to the 2004-10 mean throughout much of the Arctic. The major exception was northern and eastern Europe, where freeze-up occurred 20-40 days earlier than mean freeze-up. The most likely explanation for this very early freeze-up is penetration of cold air from the Arctic into Europe in autumn 2011 (see section 5b).

Break-up in 2011 was close to the 2004-10 mean in the North American Arctic. In contrast, a large number of lakes in northernmost Europe and eastern Siberia experienced earlier break-up (10-20 days), while lakes in much of eastern Europe and the southern portion of northern Europe experienced later break-up (10-30 days). The earlier break-up in eastern Siberia is consistent with the record-low June snow cover extent (see section 5d) over Eurasia. The later break-up in eastern Europe and the southern portion of northern Europe is consistent with colder early spring temperatures in this region (see section $5 b$ ).

Compared to the 2004-10 mean, ICD (Fig. 5.15) in 2010/11 was $~ 14$ days shorter in central and eastern Arctic Canada and 14-21 days shorter in eastern Siberia. In contrast, ICD was 14-21 days longer in Baffin Island and western Canada/Alaska and as much as 28-42 days longer in northern and eastern Europe. The combination of earlier freeze-up and later breakup due to colder winter/early spring weather explains the longer ICD over Europe. son in the summer and into the fall could be providing a winter-long source of moisture to these areas, increasing winter snowpack and decreasing winter temperatures (Cohen et al. 20I2).

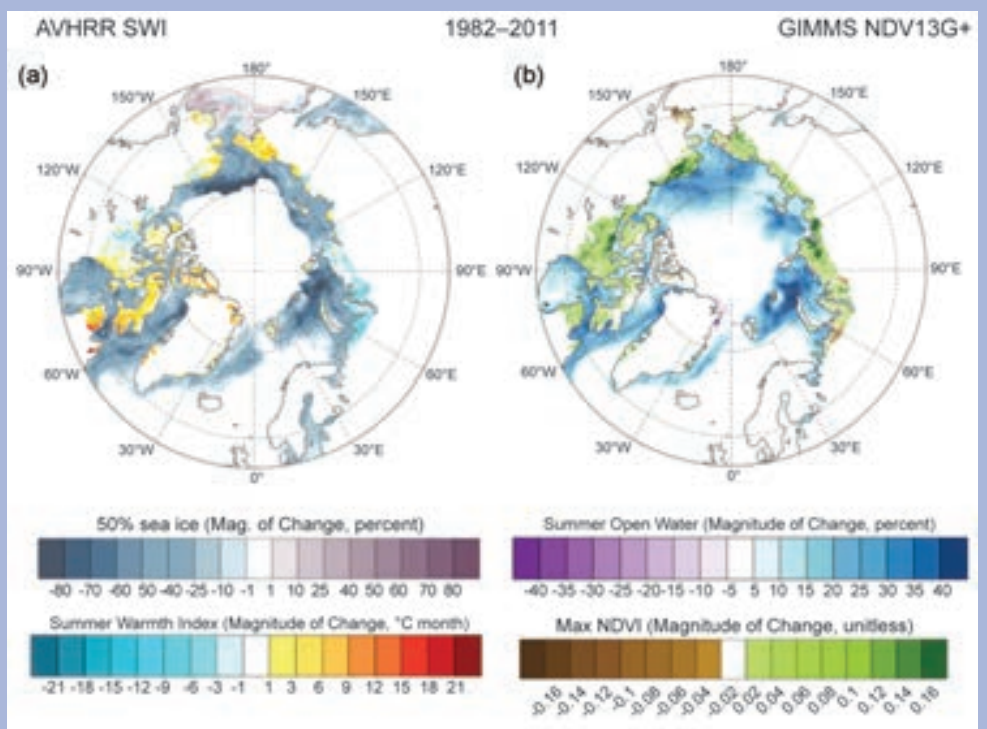

FIG. SB5.2. (a) Magnitude of changes in sea ice break-up (as represented by $50 \%$ sea ice concentration) and Summer Warmth Index for land area. (b) Magnitude of changes in summer (May-Aug) open water and tundra MaxNDVI (annual maximum NDVI, usually reached in early August). Magnitude of change is the slope of the simple linear regression trend line multiplied by the number of years of record (30 years: 1982-20II). The sea ice concentration and open water data were derived from SMMR and SSM/I passive microwave records. Ice concentration time series were assembled using data averaged over a three-week period centered on the week when mean concentrations were $\mathbf{5 0} \%$; the more negative the value on the scale, the earlier $50 \%$ ice concentration, or break-up, occurs. Open water indicates the integrated summer open water amount. All the above information was derived from AVHRR data and the Global Inventory, Modeling and Mapping Studies (GIMMS) dataset. 


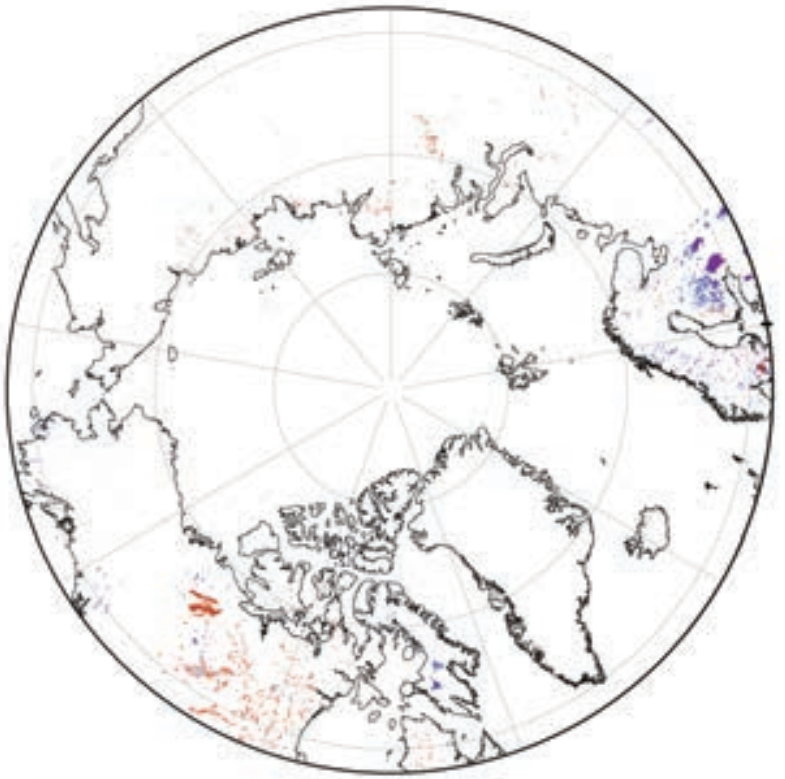

Ice cover duration $2010 / 11$

difference from the mean (days)

longer

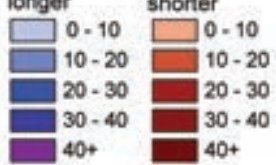

FIG. 5. I5. Ice cover duration anomalies (days) in 2010-II relative to the 2004-10 mean from the NOAA IMS $4-\mathrm{km}$ product. i. Sea ice cover-D. K. Perovich, W. Meier, J. Maslanik, and J. Richter-Menge

Sea ice extent is the primary variable for summarizing the state of the Arctic sea ice cover. Passive microwave instruments on satellites have routinely and accurately monitored the extent since 1979 . There are two months that define the annual cycle and thus are of particular interest: March, at the end of winter, when the ice is at its maximum extent, and September, at the end of summer, when the ice reaches its minimum extent. Maps of ice extent in March 2011 and September 2011 are presented in Fig. 5.16.

As reported by the National Snow and Ice Data Center, on 9 September 2011, sea ice extent reached a minimum for the year of 4.3 million $\mathrm{km}^{2}$. The 2011 minimum is the second lowest, only 0.2 million $\mathrm{km}^{2}$ greater than the 2007 record minimum (http://nsidc .org/arcticseaicenews/) and $31 \%\left(2.1\right.$ million $\left.\mathrm{km}^{2}\right)$ smaller than the 1979-2000 average. The last five summers (2007-2011) have experienced the five lowest minima in the satellite record, and the past decade (2002-11) has experienced nine of the ten lowest minima.

Maximum sea ice extent in 2011 occurred on 7 March and was 14.6 million $\mathrm{km}^{2}$. While the date of maximum extent was about normal compared to the 1979-2000 average, the ice extent itself was $7.7 \%$ less than the 1979-2000 average of 15.9 million $\mathrm{km}^{2}$.
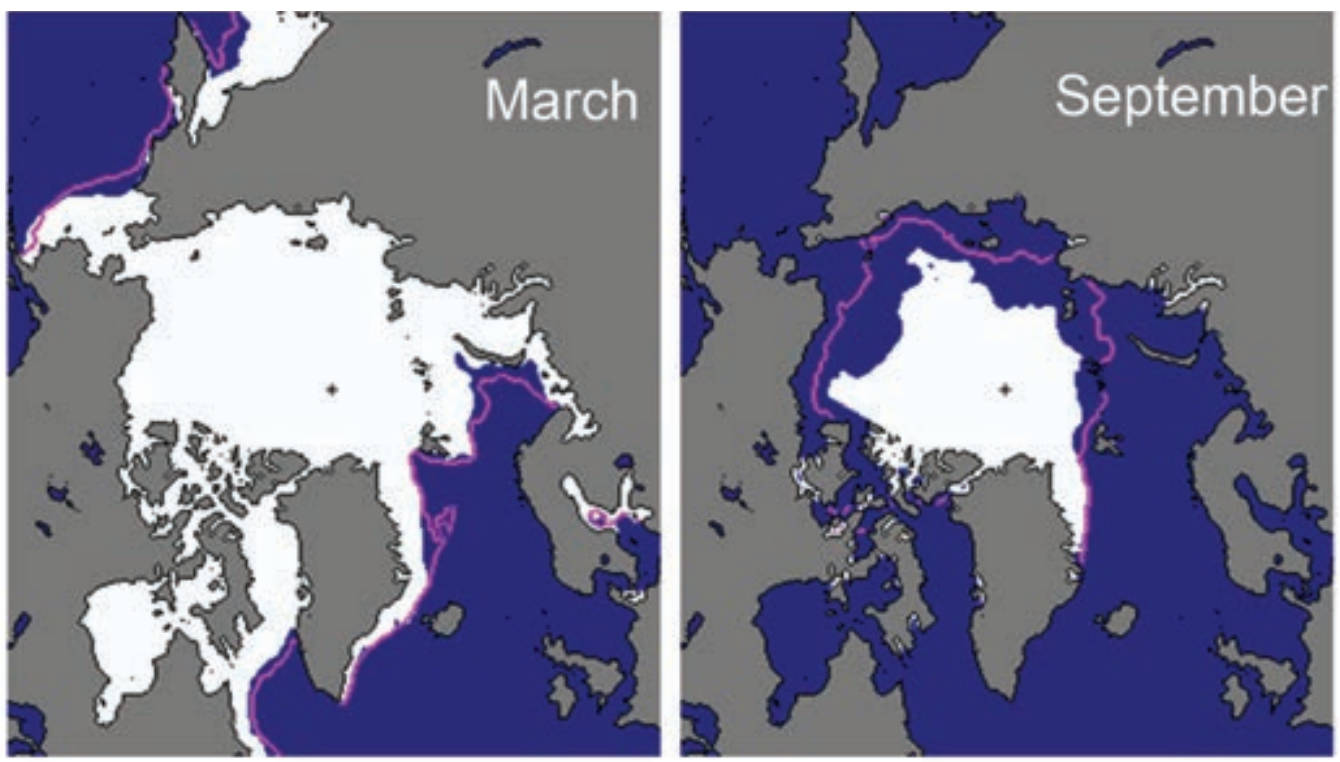

Fig. 5.16. Sea ice extent in March $201 \mathrm{I}$ (left) and September 20II (right), illustrating the respective monthly winter maximum and summer minimum extents. The magenta line indicates the median maximum and minimum ice extents in the given month for the period 19792000. Maps are from the National Snow and Ice Data Center Sea Ice Index, http://nsidc.org /data/seaice_index. 


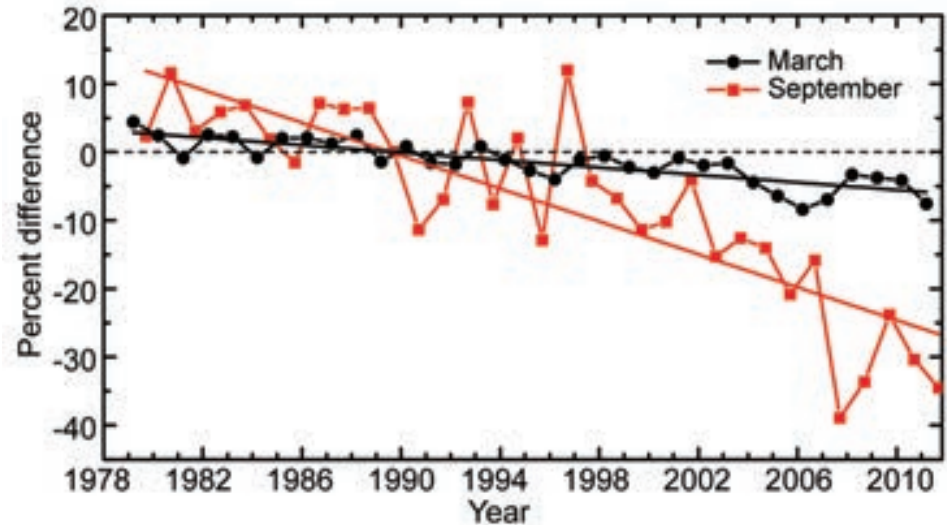

FIG. 5.17. Time series of the percentage difference in ice extent in March (the month of ice extent maximum) and September (the month of ice extent minimum) relative to the 1979-2000 base period. Based on a least squares linear regression (straight sloping red and black lines) for the period 1979-20II, the rate of decrease for the March and September ice extents is $-2.7 \%$ decade $^{-1}$ and $-12.0 \%$ decade $^{-1}$, respectively. Data are from the National Snow and Ice Data Center.

The time series of the anomalies in monthly average sea ice extent in March and September for the period 1979-2011 are shown in Fig. 5.17. The anomalies are computed with respect to the 1979-2000 base period. The large interannual variability in September ice extent is evident. Both winter and summer ice extent exhibit a negative trend, with values of $-2.7 \%$ decade $^{-1}$ for March and $-12.0 \%$ decade $^{-1}$ for September over the period of record.

Monthly ice extents averaged for the periods 1979-2000 and 2001-11 are shown in Fig. 5.18. Ice extents for the 2001-11 average are lower than the 1979-2000 average for all months, and for most months the curves are more than one standard deviation apart. The decline in ice extent is greatest in August, September, and October, and those months also show an increase in interannual variability for the 2001-11 period. The difference in ice extent between these two periods suggests a shift to a new regime of reduced sea ice.

The recent pronounced decrease in the extent of the September sea ice cover has been accompanied by large changes in its spatial distribution compared to 1980 (Fig. 5.16; for more details see figure $\mathrm{SIO} 4$ in Perovich et al. 2011). In 2011, there was a pronounced retreat of ice around the periphery of the Arctic basin and ice loss in the Ca- nadian Arctic Archipelago (CAA), similar to the pattern of ice distribution observed in the past three years. Ice remains in the central Arctic, along northeast Greenland, and adjacent to the northern edge of the CAA. North of Alaska and Siberia, the ice edge forms an arc with lobes of ice extending from both edges. These lobes consist of a mixture of dispersed floes of first-year and multiyear ice amid considerable amounts of open water. This contrasts with many earlier years, including 2007, when the ice edge at the end of summer was compact and most of the remaining ice was a consolidated pack.

Further evidence of the dramatic reduction in the extent of the summer sea ice cover is the conditions in the southern and northern routes of the Northwest Passage and the Siberian Coast passage of the Northern Sea Route. All three routes have been open (i.e., appeared ice-free in the passive microwave imagery) the past two years and the Northwest Passage southern route has been open every year since 2007. Additional information on the routes and on sea ice in the Greenland and Baltic Seas is available from the International Ice Charting Working Group news release (IICWG 2011).

The age of the ice is another key descriptor of the state of the sea ice cover. Older ice tends to be thicker

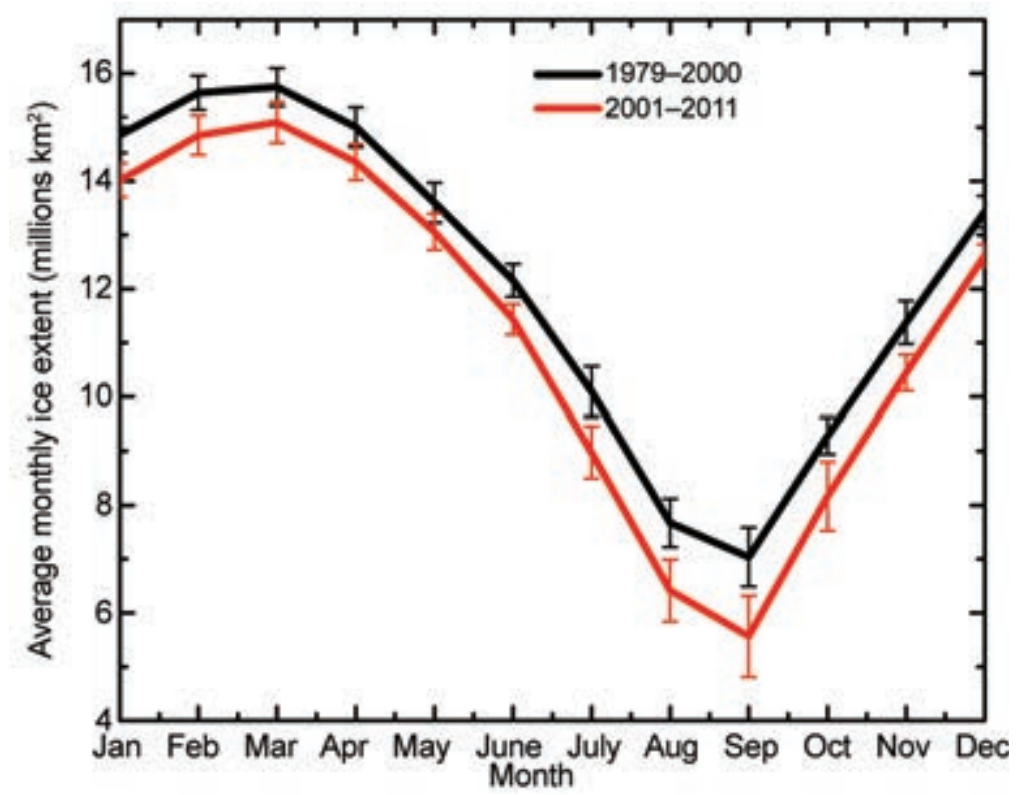

FIG. 5.18. Mean monthly sea ice extent for the periods 1979-2000 (black line) and 200I-II (red line). The vertical bars represent one standard deviation about the mean. 


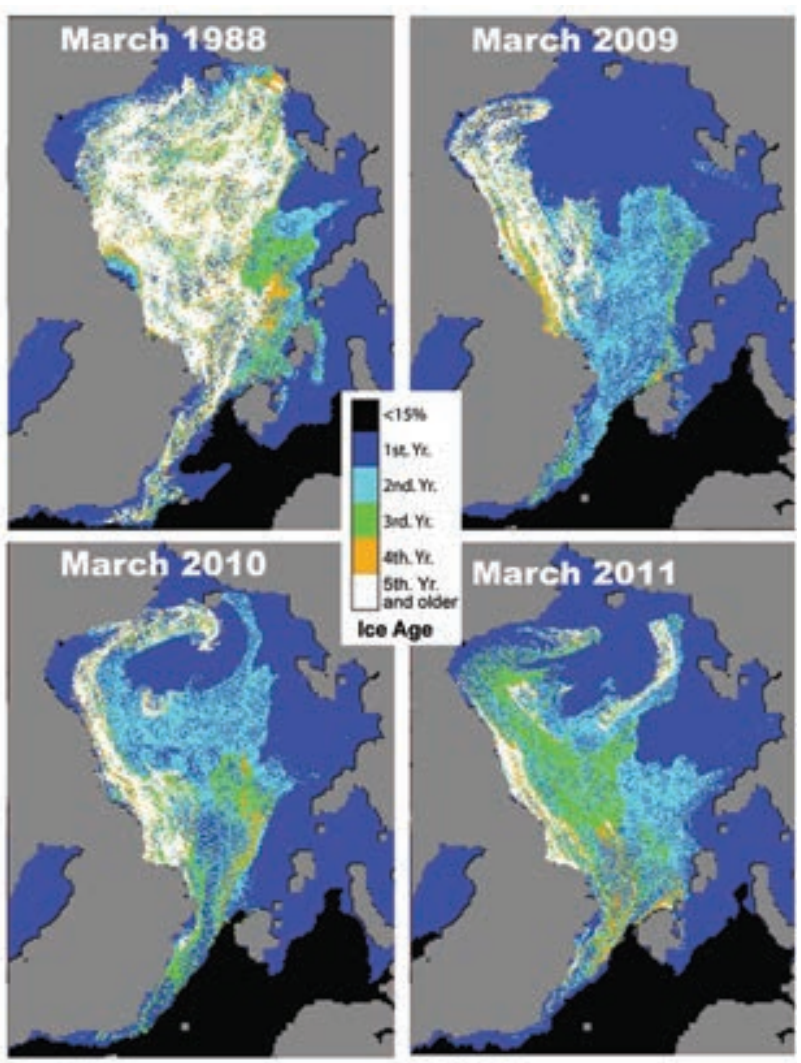

FIG. 5.19. Sea ice age in the first week of March derived from tracking the drift of ice floes in 1988, 2009, 2010, and $20 \mathrm{II}$. Figure courtesy of J. Maslanik and C. Fowler.

and thus more resilient than younger ice. The age of the ice is determined using satellite observations to track ice parcels over several years. This method has been used to provide a record of ice age since the early 1980s. Figure 5.19 shows sea ice age derived from tracking ice parcels from 1979 through 2011. The distribution of ice of different ages illustrates the extensive loss in recent years of the older ice types (Maslanik et al. 2011). Analysis of the time series of areal coverage by age category indicates that the loss of the older (4- and 5-year ice) which began in earnest in 2005 (Maslanik et al. 2011) has continued, reaching a record minimum in summer 2011 of only $19 \%$ of the
1982-2005 mean. There is some recovery of third-year ice coverage from 2010 to 2011 . The net increase in third-year ice from 2010 to 2011 (0.36 million $\left.\mathrm{km}^{2}\right)$ is greater than the decrease in $4+$ year ice $(-0.11$ million $\mathrm{km}^{2}$ ), which suggests a potential gain in ice mass within the multiyear ice cover. However, given that the older ice types tend to be thicker (e.g., Maslanik et al. 2007), this increase might be relatively slight.

j. Ocean-A. Proshutinsky, M.-L. Timmermans, I. Ashik, A. Beszczynska-Moeller, E. Carmack, I. Frolov, R. Ingvaldsen, M. Itoh, T. Kikuchi, R. Krishfield, F. McLaughlin, H. Loeng, S. Nishino, R. Pickart, B. Rabe, B. Rudels, I. Semiletov, U. Schauer, N. Shakhova, K. Shimada, V. Sokolov, M. Steele, J. Toole, T. Weingartner, W. Williams, R. Woodgate, M. Yamamoto-Kawai, and S. Zimmermann

\section{I) WIND-DRIVEN CIRCULATION}

In 2011, the annual wind-driven circulation regime was anticyclonic (clockwise; Fig. 5.20, left panel), with an enlarged and well-organized Beaufort gyre (BG) and strong outflow of sea ice and surface fresh water via Fram Strait to the Greenland Sea. The Transpolar Drift, in its conventional definition, did not exist in 2011. Instead, it split into two branches and sea ice and fresh water in Fram Strait mainly originated from the Kara Sea and partly from the Lincoln Sea. Sea ice and surface waters from the Laptev Sea were largely swept into the BG. Near-surface waters and sea ice from the Chukchi and East Siberian Seas were driven westwards by winds, closing the large-scale circulation cell of the BG in the Canada Basin (Fig. 5.20).
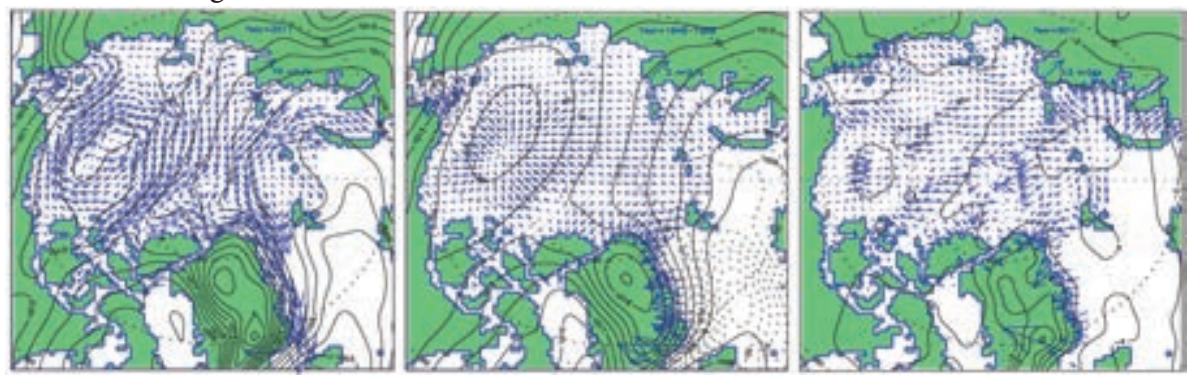

FIG. 5.20. (left) Simulated wind-driven ice motion (arrows) and observed sea level atmospheric pressure ( $\mathrm{hPa}$, black lines) for 20II. Results are from a 2D coupled ice-ocean model (Proshutinsky and Johnson 1997, 20II) forced by wind stresses derived from 20II NCEP/NCAR reanalysis 6-hourly sea level pressure fields. (middle) Ekman transport (vectors, $\mathrm{m}^{2} \mathrm{~s}^{-1}$ ) and sea level pressure (SLP) averaged over 1948-88 showing typical climatic conditions: relatively fresh waters from the entire Arctic Ocean are accumulated in the Beaufort Gyre (BG) region via Ekman transport. (right) 2011 Ekman transport and SLP anomalies relative to 1948-88 climatic conditions. In 20II, SLP over the BG region was somewhat lower than climatology while the accumulation of freshwater increased. The right panel also suggests that the increase of freshwater content in the BG region could originate from local sources. 
A large-scale anticyclonic circulation regime (similar to that shown in Fig. 5.20, left panel) persisted between 1997 and 2011, with only one short-lived reversal to a cyclonic regime in 2009. The anticyclonic regime has dominated for at least 15 years, instead of the typical 5-8 year pattern reported by Proshutinsky and Johnson $(1997,2011)$. It may be that after the anomalous 2007 conditions (a historical minimum September sea ice extent and maximum upper-ocean warming and freshening), the Arctic climate system shifted towards a new pattern characterized by a more persistent anticyclonic regime and with relatively small changes from year to year. On the other hand, a comparison of sea level pressure and Ekman transport shows that the mean fields for 1948-88 (Fig. 5.20, center panel) and 1948-2011 (not shown) are essentially identical, implying that the climate (using a conventional definition of 30-year averaged fields) of ocean dynamics is stable, but that strong interannual and decadal variability exists.

2) OCEAN TeMPERATURE AND SALINITY

(i) Upper ocean temperature

Upper ocean temperatures in summer 2011 (Fig. 5.21) were generally warmer than in the previous few summers, in keeping with stronger sea ice melt, which occurred in nearly all sectors of the Arctic Ocean (see Figs. 5.16, 5.17). The sea surface temperature (SST) anomaly averaged over the Beaufort, Chukchi, East Siberian, Laptev, and Kara Seas was $+1.45^{\circ} \mathrm{C}$, the highest since the historical maximum value $\left(+2.8^{\circ} \mathrm{C}\right)$ observed in 2007 (Steele et al. 2008).

(a)

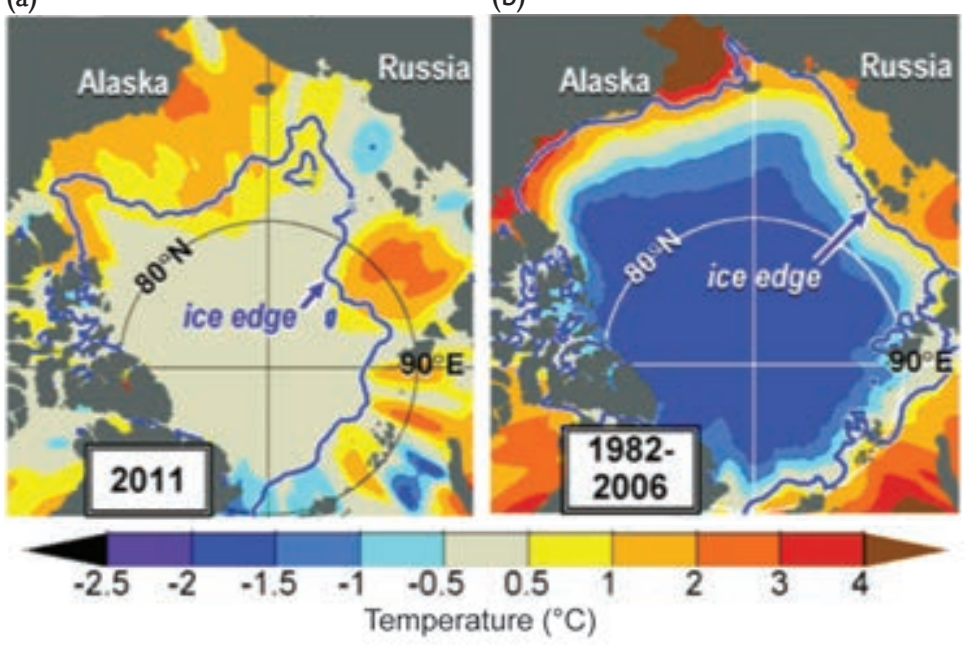

Fig. 5.2I. (a) Summer (Jun-Sep) SST anomalies $\left({ }^{\circ} \mathrm{C}\right.$ ) in $201 \mathrm{I}$ relative to (b) the summer 1982-2006 base period. The anomalies are derived from satellite data according to Reynolds et al. (2002). The September mean ice edge (thick blue line) is also shown.
Partitioning this warming into that found in the western Arctic (Beaufort and Chukchi Seas) versus the eastern Arctic (East Siberian, Laptev, and Kara Seas), the distribution of warming in 2011 was very similar to that in 2007 , i.e., about $60 \%$ western and $40 \%$ eastern. During the intervening cooler years, the partition was more heavily biased toward the western Arctic. Interannual variations in SST anomalies reflect differences in the pace of sea ice retreat, as well as changing advection of warm ocean currents from the south (Steele et al. 2010). In recent years, solar radiation has penetrated more easily into the upper ocean under thinning and retreating ice cover to create warm near-surface temperature maxima (Jackson et al. 2010, 2011).

\section{(ii) Upper-ocean salinity}

Relative to the 1970s Environmental Working Group climatology of the Arctic Ocean (Timokhov and Tanis 1997, 1998), the major upper-ocean salinity differences in 2011 (Fig. 5.22) are saltier central Nansen and Amundsen basins and a fresher Canada Basin, with the maximum freshwater anomaly centered in the BG. Another key feature of the upper ocean salinity, relative to climatology, is that the upper ocean is generally saltier around the southern boundary of the Canada Basin due to intensified upwelling at the basin boundaries associated with the large-scale wind-driven circulation in 2011 (Fig. 5.20, left panel). This circulation pattern shifted the position of the upper-ocean front between saltier waters of the Eurasian Basin and fresher Canada Basin waters. The magnitude of salinity difference from climatology is less than 1 in the Barents Sea, much smaller than in regions of the central Arctic Basin. Upper-ocean salinity in 2011 is fresher than 1970s climatology on the south side of the Barents Sea Opening (BSO) and to the east of Svalbard, while areas of the central Barents Sea and to the north of Svalbard exhibit higher salinity.

In 2011, the magnitude of the freshwater content in the $\mathrm{BG}$ region was comparable to 2008-10 conditions, with the exception that freshwater tended to spread out from the 2007-09 BG center due to some reduction of Ekman pumping. In total, during 2003-11, the BG region accumulated more than $5000 \mathrm{~km}^{3}$ of freshwater; a 
gain of approximately 25\% (update to Proshutinsky et al. 2009) relative to climatology of the 1970s.

\section{(iii) The Atlantic water layer}

Warm water of North Atlantic origin, the Atlantic Water Layer (AWL), resides at depths between approximately $200 \mathrm{~m}$ and $900 \mathrm{~m}$ [less in the vicinity of Fram Strait (FS)] and is characterized by temperatures greater than $0^{\circ} \mathrm{C}$ and salinities greater than 34.5. In 2011, AWL maximum temperature anomalies (relative to 1970s climatology) were generally highest on the Eurasian side of the Lomonosov Ridge, with maximum anomalies greater than $+2^{\circ} \mathrm{C}$ in FS (Fig. 5.22). Warming was less pronounced in the Canada Basin than in the Eurasian Basin. There was little to no temperature anomaly $\left(<0.1^{\circ} \mathrm{C}\right)$ at the southeast boundary of the Canada Basin or in the basin boundary regions adjacent to Greenland and the CAA. Negative (cooling) temperature anomalies were observed in the vicinity of Nares Strait.

The characteristics of the AWL are regulated by the Atlantic water inflow through Fram Strait and via the BSO. After reaching a maximum in 2006 (Fig. 5.23), AWL temperature and salinity in FS have been decreasing and increasing, respectively. In summer 2010, AWL temperature returned to the long-term mean $\left(2.7^{\circ} \mathrm{C}\right)$. The autumn and winter AWL temperatures were slightly lower in 2010/11 than the previous year, while in summer 2011 the mean temperature remained close to that observed in 2010. In summer 2011, an anomalously warm and saline southward flow of AWL was observed in the western FS (not shown). This may indicate that the warm AWL anomaly, which had entered the Arctic Ocean in 2006, has returned to FS after completing a loop in the Eurasian Basin.
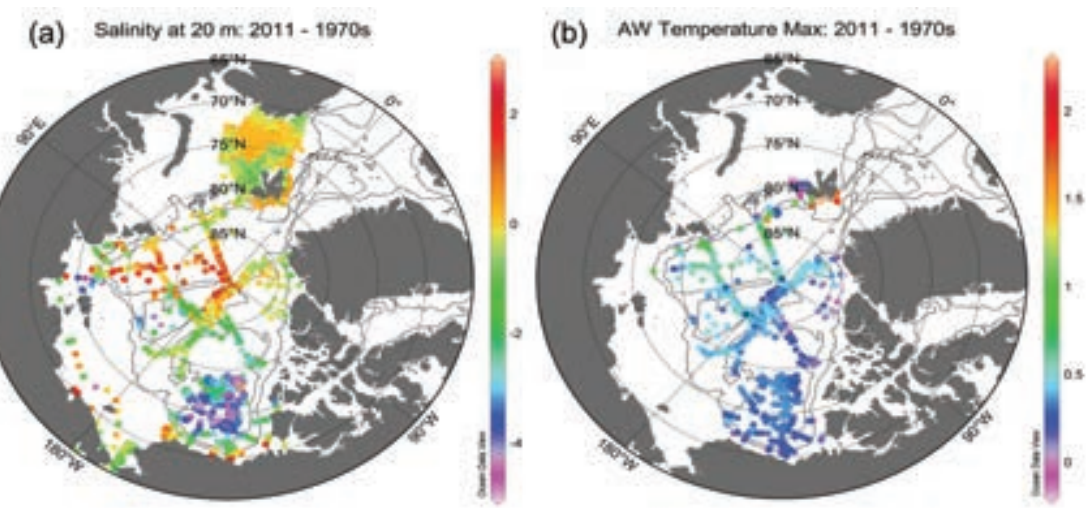

Fig. 5.22. (a) Anomalies of upper-ocean salinity at 20-m depth in 2011 relative to 1970s climatology (see Proshutinsky et al. 20Ilb, figure 0.3). (b) Atlantic Water Layer (AWL) temperature maximum anomalies $\left({ }^{\circ} \mathrm{C}\right)$ in 20 II relative to 1970 s climatology (see Proshutinsky et al. 20I Ib; Fig. 5.6). Contour lines show the $500-\mathrm{m}$ and $2500-\mathrm{m}$ isobaths.
The volume flux via the BSO (Fig. 5.23) was low in 1997-2002 and then relatively high in 2003-06. In 2006, the volume flux was at a maximum in winter and very low during fall. After 2006, the inflow has been relatively low, in particular during spring and summer months. A weak increasing trend in volume transport has been observed since 2009, and the volume flux in 2011 was close to the 1997-2011 mean. The AWL temperature in the BSO (Fig. 5.23) varies asynchronously with water transport, and has been declining since 2006. Thus, since 2009 the temperatures have decreased while the volume flux has increased slightly.

\section{(iv) The Pacific water layer}

The Pacific Water Layer (PWL) is located in the Canada Basin at depths between approximately 50 $\mathrm{m}$ and $150 \mathrm{~m}$ (Steele et al. 2004) and originates from the Bering Strait inflow. The PWL properties and circulation patterns depend significantly on the wind regime (Fig. 5.20) and sea ice conditions (Fig. 5.16). In 2011, winds tended to push Pacific waters northward and westward (Fig. 5.20, left panel) and there were indications of a PWL winter water signal near the Alpha Ridge in 2011, which was not observed in 2007. This is possibly due to the difference in PWL pathways into the Arctic basins in 2007-10, relative to previous years (Proshutinsky et al. 2011a).

The characteristics of the PWL also depend on water transport through the Bering Strait. Subsequent to the high volume transport of 2007 [ 1.0 Sverdrup (Sv), similar to 2004], the 2008 volume transport showed a return to approximately the long-term climatology $(\sim 0.8 \mathrm{~Sv})$, and the data indicate a small increase from that value for 2009 and 2010, with 2010 transports still being below the 2007 maximum. Annual mean temperatures, which showed a step increase of $\sim 1^{\circ} \mathrm{C}$ in 2002 , reverted to colder temperatures in 2008 and 2009, with some indication of a warming recurring in 2010. Annual mean salinities increased from 2003 to 2008 and since then have been in a slight decline, but remain higher than 2003 though still less than in 1991. Combined, these changes suggest 2008 and 2009 had modest heat fluxes which were comparable to 2002-03 and 2005-06, while the 2010 heat flux is somewhat 
(a)

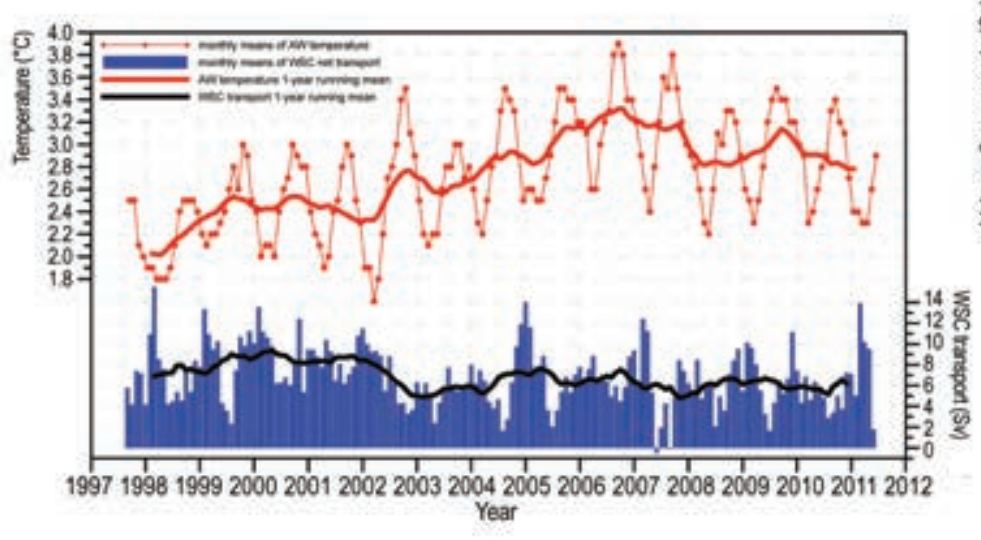

(b)

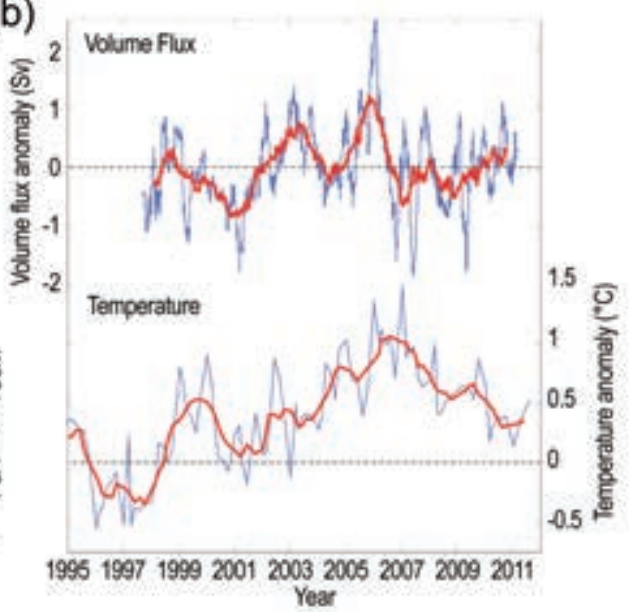

FIG. 5.23. (a) Mean temperature of Atlantic water with a temperature $>I^{\circ} \mathrm{C}$ and the volume inflow in the West Spitsbergen Current, northern Fram Strait, measured by a mooring array at $78^{\circ} 50^{\prime} \mathrm{N}$ maintained since 1997 by the Norwegian Polar Institute and the Alfred Wegener Institute for Polar and Marine Research. (b, upper panel) Volume flux anomalies (Sv) in the Atlantic Water with a temperature $>3^{\circ} \mathrm{C}$ in the Barents Sea Opening. The lines show three-month (blue) and one-year (red) moving averages. Anomalies are calculated based on the 1997-20II mean. (b, lower panel) Temperature anomalies in the AWL. The lines show measured values (blue) and I-year (red) moving average. Anomalies are calculated with respect to the 1997-2006 base period.

higher, similar to 2004 and less than the record high heat flux of 2007. Freshwater flux variability closely resembles volume flux variability, with 2008 and 2009 being less than 2007, and 2010 being closer to the maximum values so far observed in the strait.

\section{3) Sea level}

In 2011, sea level (SL) along the Siberian coast increased relative to previous years. This caused an increase, to $2.66 \pm 0.41 \mathrm{~mm} \mathrm{yr}^{-1}$, in the estimated rate of SL rise since 1954 for the nine stations (after correction for glacial isostatic adjustment; Proshutinsky et al. 2004). Until the late 1990s, SL changes were mostly driven by changes of sea level atmospheric pressure (SLP; more than $30 \%$ of variability, Proshutinsky et al. 2004) due to the inverse barometer effect. In contrast, from 1997 to 2011, mean SL has generally increased while SLP has remained more or less stable. The tendency toward SL rise in this period may be due to steric effects associated with a reduction of sea ice and ocean surface warming (Henry et al. 2012). After 2008, SL decreased to a minimum in 2010 and then increased in 2011. This variable change likely results from a combination of many forcing factors. One important factor is associated with Ekman transport directed toward coastlines (Fig. 5.20, right panel); in 2011, Ekman transport was responsible for positive sea level anomalies along the Siberian coast.

\section{k. Ocean acidification-J. T. Mathis}

Since the Industrial Revolution, rising carbon dioxide $\left(\mathrm{CO}_{2}\right)$ levels in the atmosphere and increased absorption by the oceans have created an ocean acidification (OA) phenomenon (e.g., Caldiera and Wickett 2003) that now threatens a number of marine ecosystems (e.g., Fabry et al. 2009). Nowhere is this problem more pronounced than in the highly productive waters of the Pacific Arctic Region (PAR), i.e., the northern Gulf of Alaska, and the Bering, Chukchi and Beaufort Seas. There, mixing processes and colder temperatures naturally precondition the water column to have lower $\mathrm{pH}$ and carbonate mineral saturation states $(\Omega)$ values compared to more temperate ocean environments.

Data recovered from ocean moorings in 2011 confirm that $p \mathrm{CO}_{2}$ in bottom waters of the PAR can exceed $1500 \mu$ atm for several months each year. This value is well above the threshold for aragonite (a relatively soluble form of calcium carbonate, $\mathrm{CaCo}_{3}$ ) undersaturation $(\Omega<1)$ and greater than model predictions of persistent aragonite undersaturation throughout the PAR this century (Steinacher et al. 2009). These recent data are consistent with previous studies that found seasonal aragonite undersaturation occurring in surface and shallow subsurface waters of the PAR at least a decade faster than models predicted (e.g., Caldiera and Wickett 2005).

The PAR is undergoing extraordinary changes in $\Omega$ brought on by both natural and anthropogenic 
perturbations in an environment that is both sensitive and susceptible to further reductions of $\Omega$ (e.g., Mathis et al. 2011). Remineralization of organic matter exported from surface waters due to primary production (see Sidebar 5.3) rapidly increases bottom water $\mathrm{pCO}_{2}$ over the continental shelves in summer and fall, suppressing $\mathrm{pH}$ and $\Omega$. The removal of $\mathrm{CO}_{2}$ from surface waters by high rates of phytoplankton primary production increases carbonate mineral concentrations between spring and summer, but these increases are partly counteracted by mixing with sea ice melt water and terrestrial runoff that have low carbonate mineral concentrations. While the processes described above play an important role in conditioning marine waters of the PAR to have naturally low $\Omega$, ocean uptake of anthropogenic $\mathrm{CO}_{2}$ has shifted $\Omega$ values for aragonite below the saturation horizon in broad regions of the continental shelf

\section{SIDEBAR 5.3: ARCTIC OCEAN MARINE ECOSYSTEM RESPONSE TO CHANGING SEA ICE AND OCEAN CONDITIONS-K. E. FREY}

\section{AND S. E. MOORE}

Sea ice breakup and melt during spring influence primary production in the Arctic Ocean and its adjacent shelf seas by enhancing light availability as well as increasing stratification and stabilization of the water column. Dramatic declines in sea ice extent, thickness, and annual duration have recently been associated with significant increases in primary production in several sectors of the Arctic Ocean, in addition to significant shifts in the species composition and timing of phytoplankton blooms.

Newly-compiled satellite observations of primary production in the Arctic Ocean over the period 1998-2009 reveal a $\sim 20 \%$ overall increase, resulting primarily from increases in open water extent $(+27 \%)$ and duration of the open water season (+45 days; Arrigo and van Dijken 20II). However, no statistically significant secular trend in net primary production per unit area was found, stressing the overall importance of sea ice decline in driving the observed trends. Of the eight geographic sectors of the Arctic Ocean investigated by Arrigo and van Dijken (20II), four exhibited statistically significant trends in primary production over this 12-year period: Greenland (-13\%), Kara (+70\%), Siberian (+135\%), and Chukchi $(+48 \%)$. Frey et al. (20II) additionally show spatially continuous trends in sea ice cover and primary production across the pan-Arctic (Fig. SB5.3). For the Arctic Ocean as a whole, annual phytoplankton primary production averaged $493 \pm 41.7$ $\mathrm{Tg} \mathrm{C} \mathrm{yr} \mathrm{r}^{-1}$ over the 1998-2009 period (based on direct satellite observations), as opposed to an estimate of $438 \pm 21.5 \mathrm{Tg} \mathrm{C}$ $\mathrm{yr}^{-1}$ over the 1979-1998 period (based on linear relationships with open water extent; Arrigo and van Dijken 20II). However, these overall estimates are likely conservative, as they do not account for potential primary productivity that may occur within or beneath sea ice cover.

The community composition of phytoplankton blooms in the Arctic has also shown measurable trends, with recent observations revealing shifts towards a dominance of smaller sized phytoplankton. With a freshening of the Arctic Ocean and associated reduction in the supply of nutrients, trends towards a dominance of smaller picophytoplankton over larger nanophytoplankton have been observed (Li et al. 2009). Even though the total amount of production may not change, a smaller community size structure of primary producers generally may not allow for large transfers of carbon up the food chain.
New observations of the timing of phytoplankton blooms in the Arctic Ocean also show significant changes. Kahru et al. (2010) report significant trends towards earlier phytoplankton blooms for $11 \%$ of the area of the Arctic Ocean that could be observed with satellite imagery during the period 1997-2009. Areas experiencing earlier blooms in particular include Hudson Bay, Foxe Basin, Baffin Bay, Greenland coasts, Kara Sea, and near Novaya Zemlya; these are also areas roughly coincident with trends towards earlier sea ice breakup during early summer. In some of these regions, peak blooms in phytoplankton production have advanced from September to early July (a shift of up to $\sim 50$ days). Wassmann (20II) also suggests that earlier sea ice retreats cause earlier onsets of the pelagic bloom, thus shortening the growth season of ice algae (which in turn is restricted to occur earlier because of critical limitations of available sunlight). These changes in production were accompanied by biogeochemical shifts in the system, including profound freshening of waters in the Canada Basin and an undersaturation of the surface waters with respect to aragonite, a relatively soluble form of calcium carbonate found in plankton and invertebrates (see section $5 \mathrm{k}$ for further information on ocean acidification).

The timing of phytoplankton and/or sea ice algal production is critical for the quantity and quality of primary production and associated grazers and therefore also the transfer of carbon and energy to higher trophic-level species. Specifically, shifts in primary and secondary production have direct impacts on benthic communities (Grebmeier et al. 2010). Organic carbon supply to the benthos in regions of the northern Bering Sea has declined $\sim 30-50 \%$, as has the infaunal biomass of bivalves that are winter prey for the entire world population of the threatened Spectacled Eider. Recent changes in Arctic benthic biodiversity include shifts in community composition and biomass, which may be related to climate warming. In several cases, switches from longer-lived and slow-growing Arctic species and/or communities to faster-growing temperate species and/or communities reflect increasing water temperatures. Similarly, northern range extensions of several sea floor dwellers likely are tied to the warming habitat. In the Atlantic Arctic, this process is anticipated to result in the "Atlantification" of the benthos, i.e., the replacement of Arctic 
seas around Alaska, with unknown consequences for marine ecosystems.

Because of the numerous natural and anthropogenic forcing mechanisms, the PAR will serve as a bellwether for the impacts of global ocean acidification in the coming decades as the Arctic and sub-Arctic continental shelves rapidly transition to a new state.

communities with those endemic to the North Atlantic. New research on sediment-associated microbes, including bacteria, archaea, viruses, and microscopic fungi, are currently expanding our knowledge of this topic.

These and other changes in the marine ecosystem are impacting higher-trophic species, including seabirds and marine mammals. For example, 7 of 19 of the world's Polar bear sub-populations are declining in number, with trends in two populations linked to reductions in sea ice (Vongraven and Richardson 201I). For the fourth time in the past five years, thousands of walruses hauled out on the northwest coast of Alaska by mid-August 20II, apparently triggered by a lack of sea ice in the Chukchi Sea (Garlich-Miller et al. 20II). The unprecedented haul-outs on land result in pup mortality by crushing and a switch in foraging by walrus from moving sea ice to static shore sites. Conversely, the decline in sea ice provides access to waters north of Bering Strait for feeding by seasonally migrant baleen whales. For example, in August 2010, two bowhead whales (one from Alaska and one from West Greenland, each tagged with satellite transmitters) entered the Northwest Passage from opposite directions and spent approximately 10 days in the same area. This is the first time distributional overlap between the two presumed-isolated populations has been documented. Reduced summertime ice in the Northwest Passage (see section $5 \mathrm{i}$ ) may remove a physical barrier and therefore facilitate genetic exchange between the two populations (Heide-Jørgensen et al. 2012).

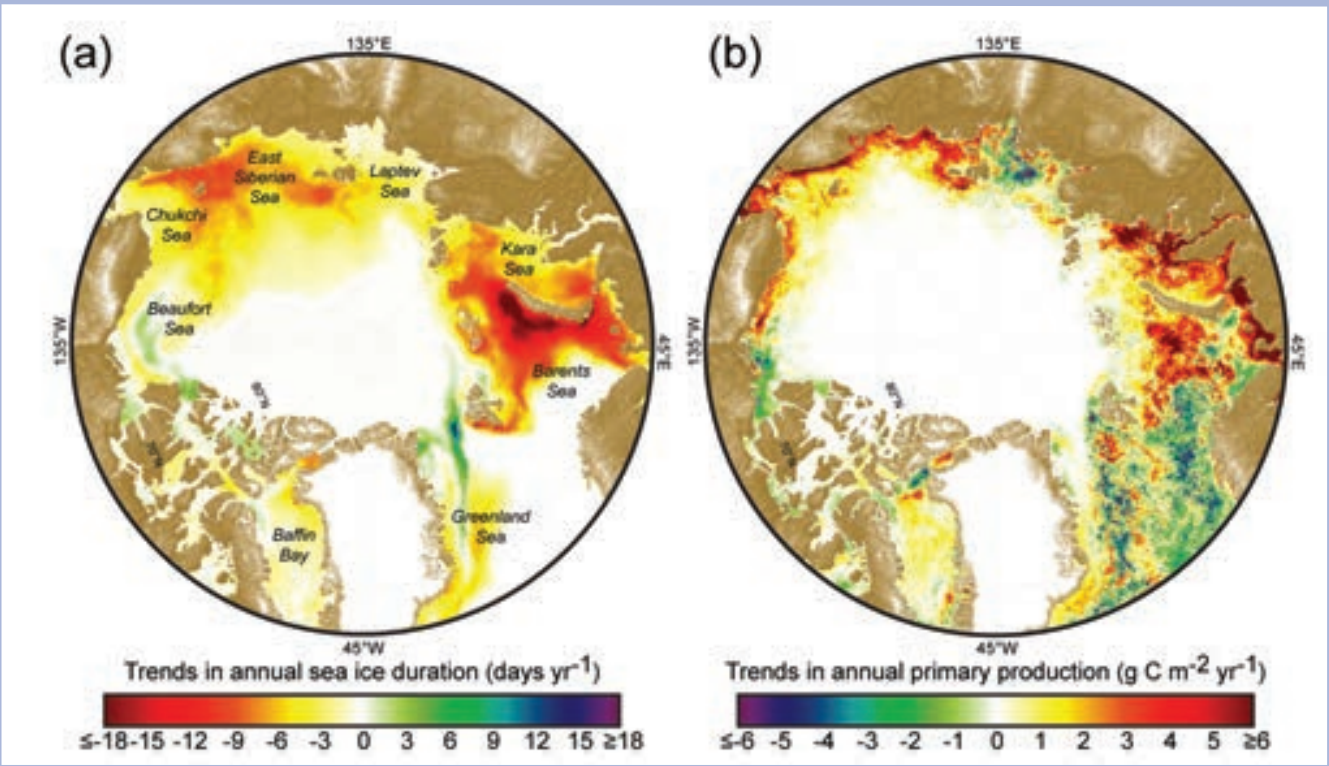

FIG. SB5.3. Trends in annual sea ice duration (days $\left.\mathrm{yr}^{-1}\right)$ and total annual net primary production $\left(\mathrm{g} \mathrm{C} \mathrm{m}^{-2} \mathrm{yr}^{-1}\right)$ across the Arctic Ocean and its adjacent shelf seas from 1998 to 2009 (Frey et al. 20II). Annual sea ice persistence data (based on a I5\% sea ice concentration threshold) are derived from SSM/I passive microwave radiances (Cavalieri et al. 2008) and primary production data are from Arrigo and van Dijken (20II). 
6. ANTARCTICA - R. L. Fogt and T. A. Scambos, Eds.

a. Overview-R. L. Fogt and T. A. Scambos

Antarctica's climate in 2011 appears to have been marked by a quiet start and a relatively intense ending. Annual mean surface pressure anomalies and $2 \mathrm{~m}$ temperature anomalies based on ERA-Interim are displayed in Figs. 6.1a and b, respectively, with the shading denoting how many standard deviations these anomalies were from the 1981-2010 mean. ERAInterim was employed since it is a newer higher resolution (both horizontally and vertically) reanalysis that uses a four-dimensional variational assimilation scheme; further, ERA-Interim has proven to perform better than other reanalyses across Antarctica (Bromwich et al. 2011). Despite Fig. 6.1 indicating above-average surface pressures and temperatures (with the exception of the Weddell Sea) throughout the year over Antarctica, monthly circulation patterns were generally unremarkable until December (actually beginning in the last weeks of November) when more intense low pressures, and in particular a strong low in the Amundsen Sea, led to widespread cooler conditions and resulted in the highest southern annular mode (SAM) index on record for December [+3.53 based on the Marshall (2003) SAM index and +2.573 based on the NOAA CPC SAM index]. The late period was also marked by a strong zonal wavenumber-3 (ZW3) component to the circulation. These patterns occurred during the height of the 2011/12 field season and caused several disruptions and inconveniences, particularly in West Antarctica.

Notable Antarctic climate events during 2011 include:
- Winter and spring temperature anomalies exceeding $+3^{\circ} \mathrm{C}$ over much of the Antarctic continent, more than 2 standard deviations above the long-term mean;

- Below-normal winter temperatures in the northern Antarctic Peninsula, which continued the downward trend there during the last 15 years, effectively stabilizing the temperature trend during the last 30 years;

- A sea ice extent anomaly which increased steadily through much of the year, from a brief record-setting low in April, to well above average in December, the latter trend reflecting the dispersive effects of low pressure systems on sea ice, and generally cool conditions around the Antarctic perimeter;

- Surface melt that was still moderately below normal, but greater than the past two summer seasons (for melt, the 2010/11 austral summer, not the most recent summer, is reviewed since the year's analysis begins at the calendar year end);

- Greater-than-average precipitation along the Dronning Maud Land coast, but generally lower than average along the Bellingshausen Sea coast;

- An extensive, deep, and persistent ozone hole in September, indicating that, while not worsening currently, the recovery to pre-1980 conditions is proceeding very slowly; and

- An all-time record high temperature of $-12.3^{\circ} \mathrm{C}$ observed for South Pole station (on 25 December), exceeding the previous record by more than a full degree.

In October, NASA scientists also
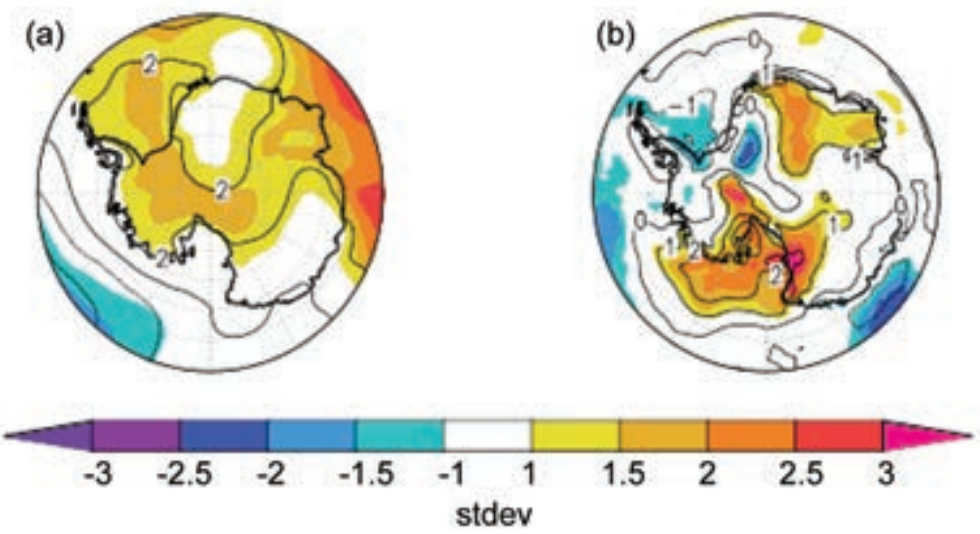

Fig. 6.I. 20II Annual mean (a) surface pressure (hPa) and (b) surface temperature $\left({ }^{\circ} \mathrm{C}\right)$ anomalies based on the ERA-Interim reanalysis. The shading represents how many standard deviations the anomalies are from the 198I-2010 mean (color bar at bottom for scale). Contour interval is $\mathbf{2} \mathrm{hPa}$ for (a) and $\mathrm{I}^{\circ} \mathrm{C}$ for (b). noticed that a major fracture, or rift, appeared in the large Pine Island Glacier Ice Shelf, several kilometers further upstream than previous rifts (as monitored over the past 30 years). The new rifting is likely a result of changing stress conditions due to basal melt of the ice and thinning, and the recent retreat of the grounding line. The glacier, already significantly out of balance (more outflow than incoming snowfall) and accelerating, will probably see a further increase in flow speed as a result.

The climatological averages referenced in this chapter refer to the mean conditions during 1981-2010 period, unless otherwise specified. 
b. Circulation-A. J. Wovrosh, S. Barreira, R. L. Fogt, and T. A. Scambos Antarctic and southern high-latitude circulation features during 2011 were characterized by mild to moderate patterns until late in the year, when an intense Amundsen Sea Low (ASL) and strong zonal wavenumber-3 (ZW3) pattern emerged, although with the ridge and trough locations westward displaced compared to Raphael (2004). Figure 6.2 presents a vertical cross section extending from the troposphere to the stratosphere of geopotential height and temperature anomalies averaged over the polar cap $\left(60^{\circ} \mathrm{S}-90^{\circ} \mathrm{S}\right)$, as well as circumpolar $\left(50^{\circ} \mathrm{S}-70^{\circ} \mathrm{S}\right)$ averaged zonal wind anomalies. The year was then divided into parts for which consistent circulation anomalies were observed, namely January-April, May-June, July-November, and December. For each of these periods, mean surface pressure and surface temperature anomalies are plotted in Fig. 6.3 to highlight the spatial circulation patterns. In all cases, the period 1981-2010 was used to calculate the climatological mean and standard deviation. Similar results are obtained with the NCEP-NCAR reanalysis, although the higher spatial resolution (both horizontal and vertical) of ERA-Interim allows for more features to be distinguished, particularly in the temperature field and throughout the stratosphere. The use of reanalyses or other gridded products is necessary to fill in the gaps between the sparse observational network; 2011 Antarctic climate anomalies from direct observations are discussed in section $6 \mathrm{c}$.

The year began with comparatively weak geopotential height anomalies throughout the troposphere and stratosphere during January-April (Fig. 6.2). February stands out with stronger-thanaverage circumpolar zonal winds in the upper troposphere $(\sim 50 \mathrm{hPa}$ $-200 \mathrm{hPa}$ ), primarily driven by a strong high pressure in the Indian Ocean sector (apparent in the January-April mean in Fig. 6.3a). In the Antarctic interior, surface pressure anomalies were near normal in May-June (Fig. 6.3c), with a few colder-than-average regions in East Antarctica, and warmer-than-average temperatures in the South
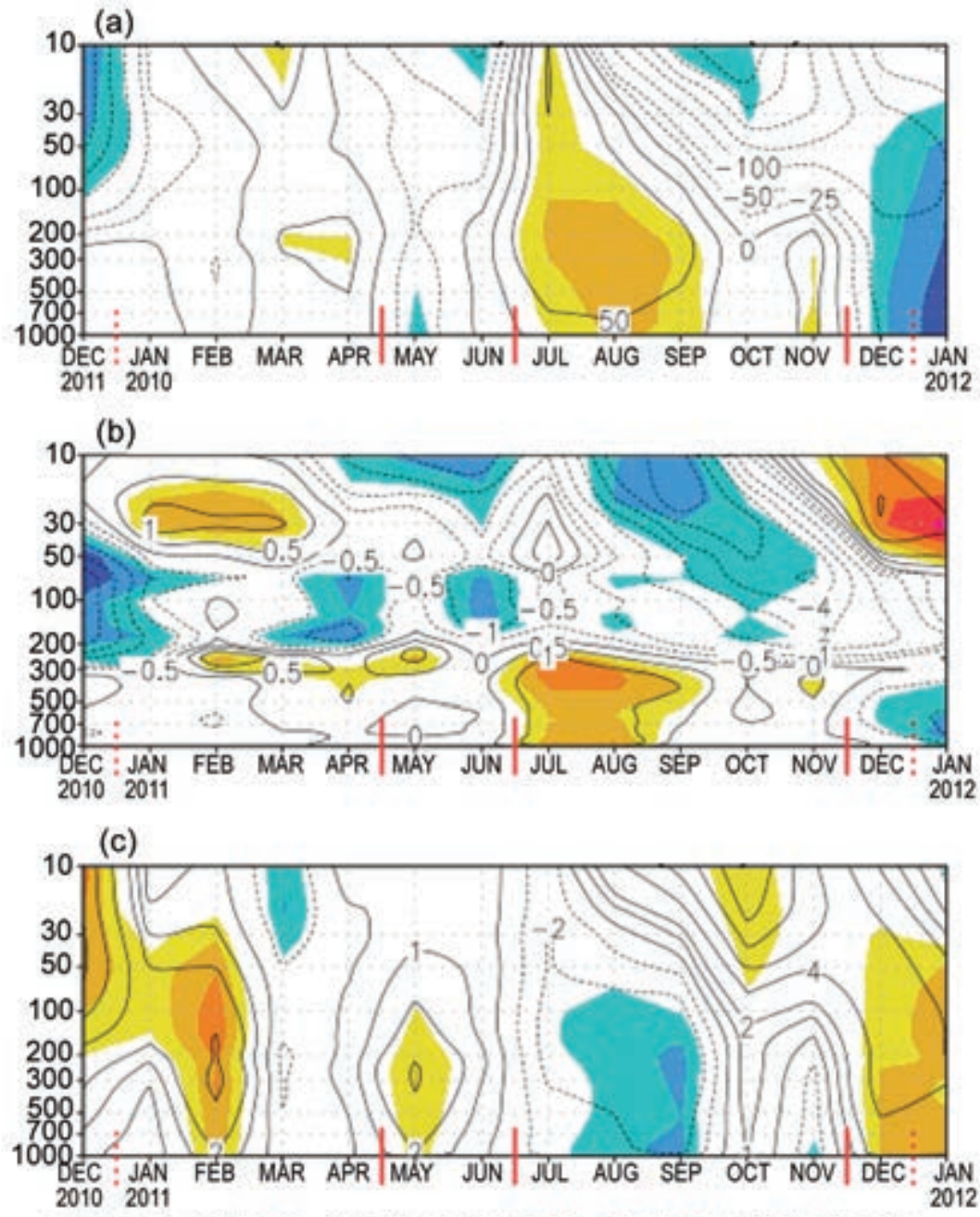

SAM: $\begin{array}{llllllllllll}0.48 & 0.87 & -0.79 & 1.62 & 1.37 & 0.72 & -1.52 & -0.73 & -1.79 & 0.59 & -1.41 & 3.43\end{array}$

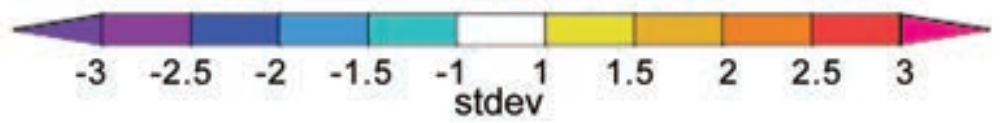

FIG. 6.2. Zonally averaged climate parameter anomalies for the southern polar region in $20 \mathrm{II}$ relative to the $198 \mathrm{I}-2010$ period: (a) polar cap $\left(60^{\circ} \mathrm{S}-\right.$ $90^{\circ} \mathrm{S}$ ) averaged geopotential height anomalies $(\mathrm{m})$; (b) polar cap averaged temperature anomalies $\left({ }^{\circ} \mathrm{C}\right) ;(\mathrm{c})$ circumpolar $\left(50^{\circ} \mathrm{S}-70^{\circ} \mathrm{S}\right)$ averaged zonal wind anomalies $\left(\mathrm{m} \mathrm{s}^{-1}\right)$. The shading represents how many standard deviations the anomalies are from the 1981-2010 mean, as in Fig. 6.I. Red vertical bars indicate the four separate climate periods shown as spatial climate anomalies in Fig. 6.3; the dashed lines near December 2010 and December $201 \mathrm{I}$ indicate circulation patterns wrapping around the calendar year. Primary contour interval is $50 \mathrm{~m}$ in (a), $1^{\circ} \mathrm{C}$ in (b), and $2 \mathrm{~m} \mathrm{~s}^{-1}$ in (c), with additional contours at $\pm 25 \mathrm{~m}, \pm 0.5^{\circ} \mathrm{C}$, and $\pm 1 \mathrm{~m} \mathrm{~s}^{-1}$ in (a), (b), and (c), respectively. Values for the SAM index are shown along the bottom in black and red. (Source: ERA-Interim reanalysis.) 

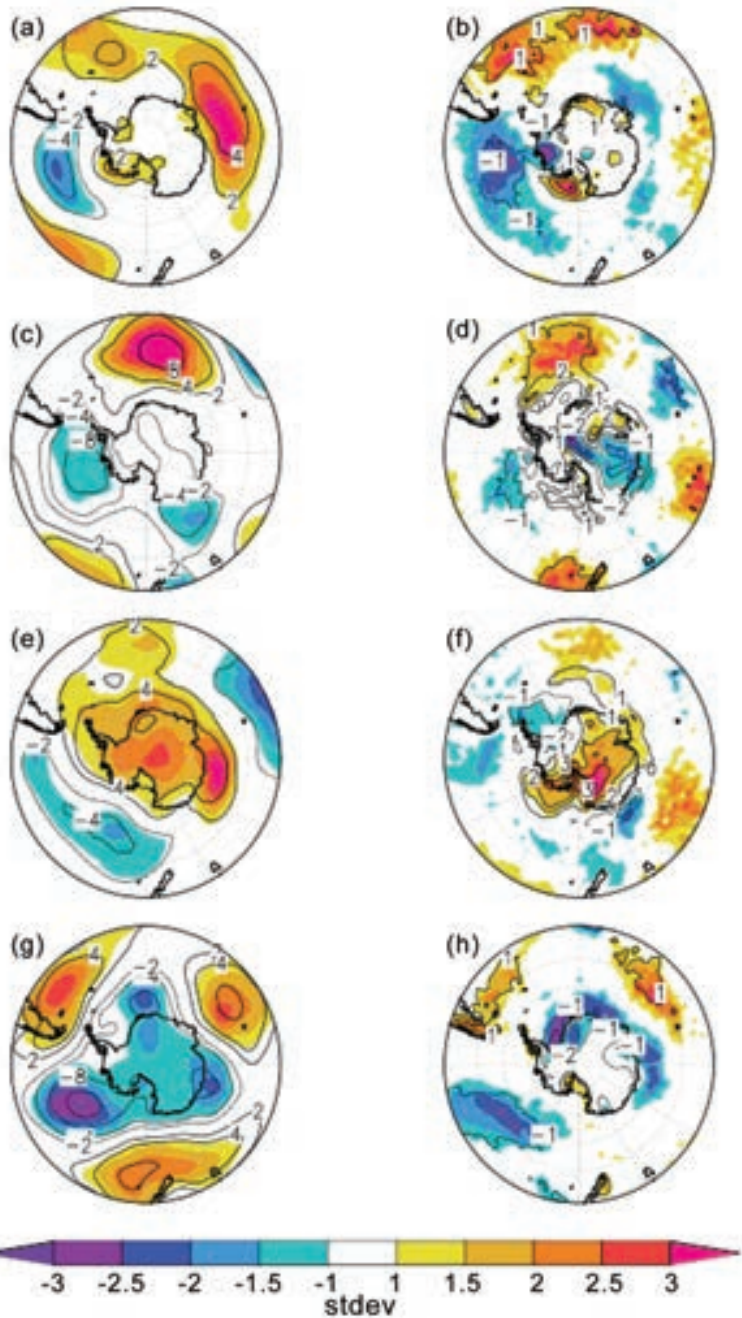

Fig. 6.3 (left) Surface pressure anomaly and (right) $2 \mathrm{~m}$ temperature anomaly contours (every $4 \mathrm{hPa}$ with an additional contour at $\pm 2 \mathrm{hPa}$ and every $I^{\circ} \mathrm{C}$, respectively, zero contours emitted) relative to $198 \mathrm{I}-2010$ climatology for (a) and (b) January-April 20II; (c) and (d) May-June 20II; (e) and (f) July-November 20II; (g) and (h) December 20II. The shaded regions correspond to the number of standard deviations the anomalies are from the 198I-2010 mean, as in Fig. 6.I. (Source: ERA-Interim reanalysis.)

Atlantic (Fig. 6.3d). More distinguishable during this period were the below-average temperatures in the polar stratosphere (Fig. 6.2b), which generally persisted until December.

The austral winter and spring seasons (July-November) were marked by high surface pressure (Fig. $6.3 \mathrm{e})$ and associated above-average geopotential heights throughout the troposphere (Fig. 6.2a). Surface temperatures were also well above normal for all but the Antarctic Peninsula (Fig. 6.3f). These temperature anomalies exceeded $3^{\circ} \mathrm{C}$ for much of the Antarctic continent, and were more than two standard deviations above the 1981-2010 mean. The circumpolar zonal winds were weaker than average during much of this time, although the SAM index was never strongly negative (never $<-2$ ). Examining the monthly circulation anomalies, the pattern was similar to ZW3 throughout much of the winter, especially in August (not shown separately). During this month, strong ridges were observed at $45^{\circ} \mathrm{E}, 150^{\circ} \mathrm{E}$, and $60^{\circ} \mathrm{W}$, and the meridional flow associated with this led to the intrusion of many warm air masses in that month, significantly warming the continental areas to the west of these longitudes.

In December, the circulation pattern switched dramatically. As heights fell over Antarctica (Fig. 6.2a), surface pressures dropped (Fig. 6.3g), and the aboveaverage temperatures diminished to near normal or below average over the continent (Fig. 6.3h). Overall, the circulation pattern was again dominated by ZW3 (Raphael 2004), but the location of the alternating trough and ridge waves were rotated westward. The Amundsen Sea Low (ASL) was very deep and extensive, with central pressures as much as $12 \mathrm{hPa}$ (or > 2.5 standard deviations) below the mean. The ASL center was also shifted significantly northwestward (to $\sim 150^{\circ} \mathrm{W}$, see Fig. $6.3 \mathrm{~g}$ ), leading to a shift in the location of the air temperature anomalies associated with a strong ASL. The intense and shifted pattern of pressure in December (actually beginning in the second half of November) led to severe logistical problems with several major US field research campaigns. At the WAIS Divide camp $\left(79.5^{\circ} \mathrm{S}, 112.1^{\circ} \mathrm{W}\right)$, nine intense storms were recorded between early December and mid-January 2012; at Pine Island camp $\left(75.8^{\circ} \mathrm{S}, 100.3^{\circ} \mathrm{W}\right)$, persistent poor weather resulted in a five-week delay in science activity, and the season had to be abbreviated when weather did not improve in January. Although the SAM index reached a new high record in December, the deep ASL and the alternating wave-train of pressures extending from $\mathrm{New}$ Zealand towards southern South America are more reminiscent of the Pacific South American pattern and the resurgence of La Niña in the autumn of 2011.

\section{c. Surface manned and automatic weather station observations - S. Colwell, L. M. Keller, and M. A. Lazzara}

The Antarctic climate extremes over 2011 are reflected in observations at staffed and automatic weather stations (AWS). A map of key locations described in this section and throughout the chapter is displayed in Fig. 6.4. Climate data from two representative staffed stations (Rothera and Vostok) and 


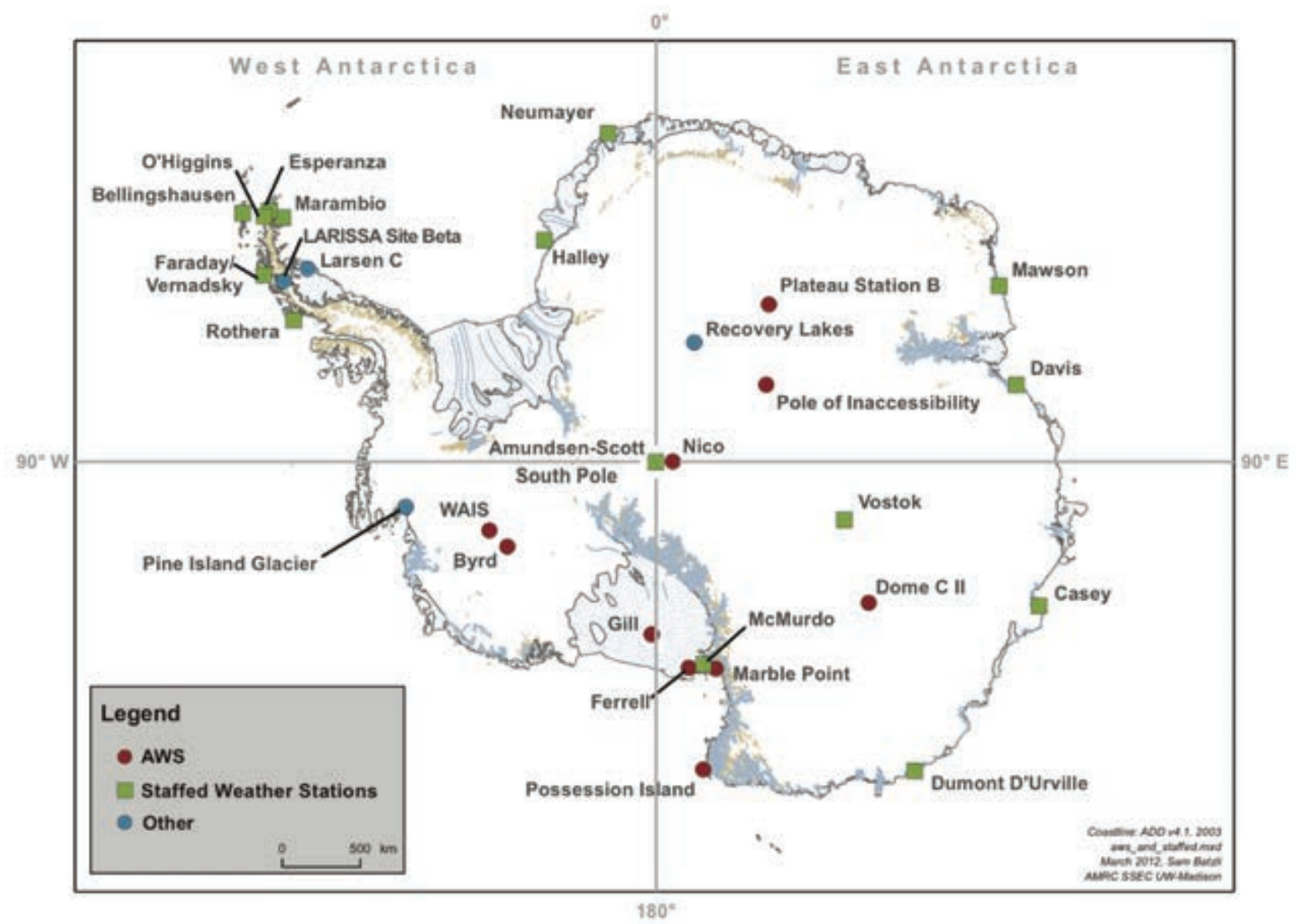

FIG. 6.4. Map identifying locations of automatic and staffed Antarctic weather stations described in chapter 6.

two automatic stations (Byrd and Gill) are displayed in Figs. 6.5a-d. At the staffed stations, wind speeds were near normal throughout the year, reflected in Figs. 6.5a-b.

Monthly mean temperatures on the western side of the Antarctic Peninsula were near average for most of the year. However, temperatures at Marambio station on the eastern side were below average for most months, and many stations on the northern Antarctic Peninsula experienced a cool winter, with temperatures around $4^{\circ} \mathrm{C}-5^{\circ} \mathrm{C}$ below the $1981-2010$ climatology in much of July-September, reflected in Figs. 6.1a and 6.3f. The Antarctic Peninsula region as a whole experienced significantly high pressures during July and August (reflected in Fig. 6.3e), with Rothera station recording a record mean August pressure of $1001.7 \mathrm{hPa}, 14.8 \mathrm{hPa}$ above the long-term mean (Fig. 6.5a).

In the Weddell Sea and Dronning Maud Land region, monthly mean temperatures at Halley and Neumayer stations fluctuated around the long-term mean for most of the year, consistent with the weak annual mean temperature anomalies there (Fig. 6.1b). High monthly mean pressures were recorded at both stations from July to September, with very low pressures ( $>8 \mathrm{hPa}$ below average) in December. Around the Indian Ocean coast of East Antarctica, the monthly mean temperatures at Mawson, Davis, and Casey similarly tended to oscillate around the mean, with temperatures more than $4^{\circ} \mathrm{C}$ above the long-term mean recorded at Davis and Mawson in July, consistent with the warm air advection of the ZW3 influence described in the previous section. In December, all three stations recorded pressures more than $5.5 \mathrm{hPa}$ below the long-term mean, reflecting the dramatic change in circulation at this time.

Reviewing the East Antarctic interior, monthly mean temperatures at Vostok station (Fig. 6.5b) were generally above average, with a new record monthly mean of $-60.6^{\circ} \mathrm{C}$ being set in August, $7.5^{\circ} \mathrm{C}$ above the long-term mean. Overall, 2011 was the second warmest year on record at Vostok with an annual mean temperature of $-53.5^{\circ} \mathrm{C}$. Interestingly, the Dome C II station had a record low monthly mean temperature $\left(-7.6^{\circ} \mathrm{C}\right.$ below normal) for June, but more normal conditions for July and August. At Amundsen-Scott South Pole station, the temperatures varied over the year, sometimes significantly above average and 

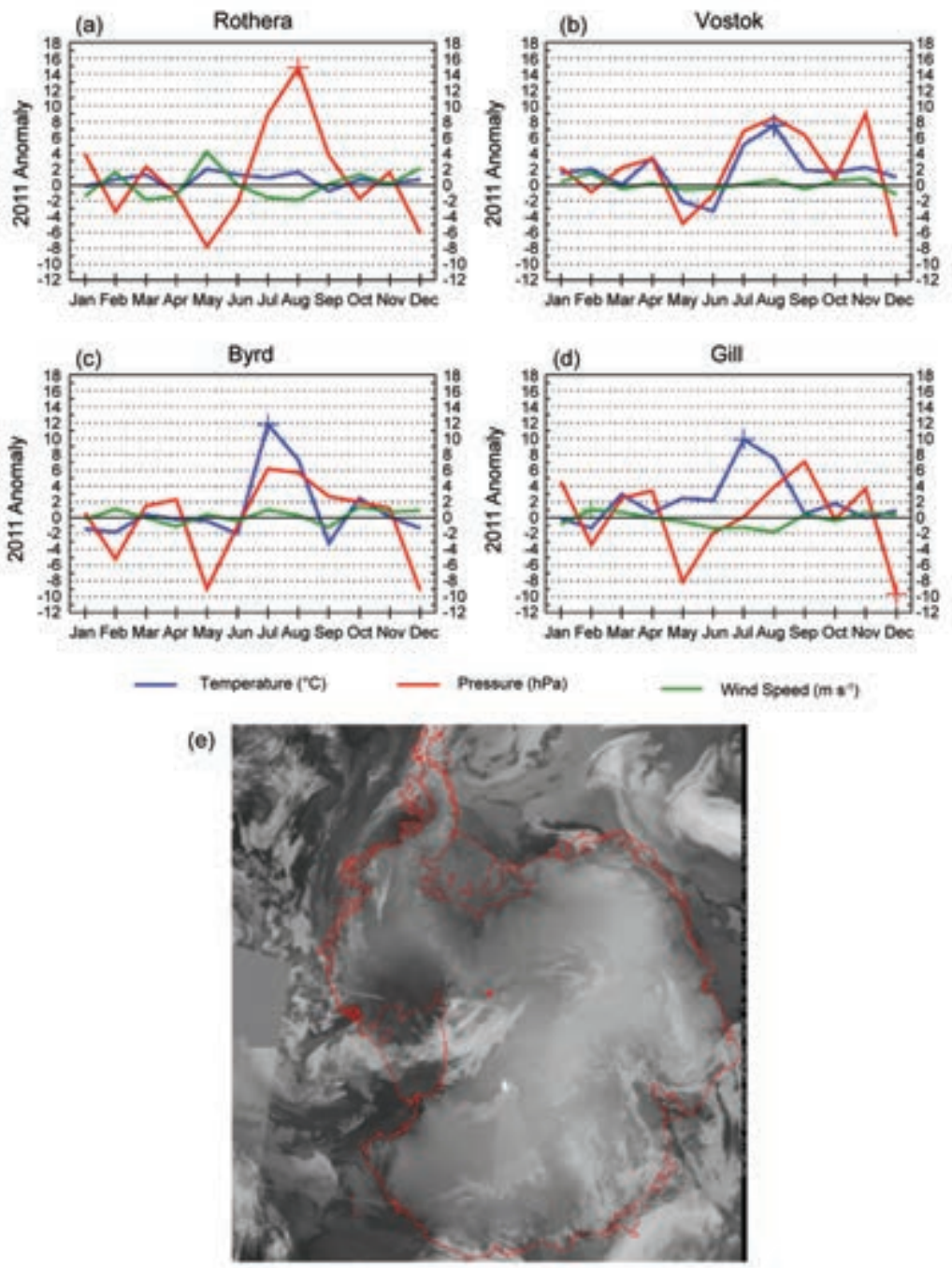

FIG. 6.5. (a)-(d) 20 II Antarctic climate anomalies at four representative stations (two staffed, two automatic). Monthly mean anomalies for temperature $\left({ }^{\circ} \mathrm{C}\right), \mathrm{MSLP}(\mathrm{hPa})$, and wind speed $\left(\mathrm{m} \mathrm{s}^{-1}\right)$ are shown, with plus signs (+) denoting record anomalies for a given month at each station in $201 \mathrm{I}$. Climatological data start in 1976 for Rothera, 1958 for Vostok (with some gaps), 1980 for Byrd, and 1985 for Gill. The base period for calculating anomalies was 198I-2010 for the staffed stations, and the full period of observation for the automatic stations. (e) Satellite mosaic of thermal-band emission on 25 December 201I, date of an all-time record high temperature at South Pole $\left(-12.3^{\circ} \mathrm{C}\right)$. The red dot shows the location of Amundsen-Scott South Pole station.

sometimes below. In May, the mean temperature was $4.8^{\circ} \mathrm{C}$ below average, at $-62.6^{\circ} \mathrm{C}$, the coldest May average ever recorded. In December, the monthly mean temperature was about average but a new record maximum temperature (for any month) of $-12.3^{\circ} \mathrm{C}$ was recorded on 25 December. Multiple AWS records near the South Pole confirmed the record warmth, for example, Nico AWS (100 km grid east of the pole) set a record of $-8.2^{\circ} \mathrm{C}$ for the same day. A satellite thermal infrared image from that day (Fig. 6.5e) shows warm conditions in both the Ross Embayment and the southernmost Ronne Ice Shelf areas, and a series of lows moving inland and southwards across the Ross Ice Shelf.

West Antarctica and the Ross Sea embayment also saw record warmth in July with AWS units Ferrell, Byrd (Fig. 6.5c), Marble Point, Possession Island, and Gill (Fig. 6.5d) all reporting record high monthly temperatures (approximately $-6^{\circ} \mathrm{C}$ along the Ross Sea coast; $-11.8^{\circ} \mathrm{C}$ at Byrd). Possession Island also reported record high monthly mean temperatures for February, June, and August.

The AWS units on the Ross Sea and Ross Ice Shelf had above-normal monthly mean temperatures for most of 2011, reflected in the local maximum temperature anomaly there in Fig. 6.1b. As a result, Ferrell, Gill, Marble Point, and Possession Island all observed their warmest annual mean in 2011. Dome C II also had above-normal temperatures for most of the year, while Byrd was slightly below normal for most of the year. Even though temperatures were quite warm, the wind speeds were close to normal for the year for most of the AWS units. The exceptions occurred in February where Gill tied the record maximum wind speed (Fig. 6.5d) and Dome C II was $0.2 \mathrm{~m}$ $\mathrm{s}^{-1}$ below the record maximum wind speed. All the stations from Byrd across the Ross Ice Shelf to Dome C II had unusually low mean pressure (around $6 \mathrm{hPa}-7 \mathrm{hPa}$ below normal) for May (Fig. 6.5c). Near-record or record low pressure occurred in December at all of the AWS units discussed here, with pressures around $8 \mathrm{hPa}-9 \mathrm{hPa}$ below normal. Gill reported a record low December mean pressure of $973.1 \mathrm{hPa}, 9.6 \mathrm{hPa}$ below normal (Fig. 6.5d). As noted above, coastal stations in East Antarctica also had very low pressures in December, reflecting the regional circulation anomalies that are part of the deep ASL, record positive SAM, and strong ZW3 pattern at this time (Fig. 6.2g). 
d. Net precipitation $(P-E)-D$. H. Bromwich and S.-H. Wang Precipitation minus evaporation (P-E) closely approximates the surface mass balance over Antarctica, except for the steep coastal slopes (e.g., Bromwich et al. 2000; van den Broeke et al. 2006). Precipitation variability dominates $\mathrm{P}-\mathrm{E}$ changes over the Antarctic continent. Precipitation and evaporation/sublimation fields from the Japanese reanalysis (JRA; Onogi et al. 2007) were examined to assess Antarctic net precipitation (P-E) behavior for 2011. The evaporation in JRA was calculated from the surface latent heat flux variable. In comparisons to other long-term global reanalyses (e.g., NCEP1 and NCEP2), JRA has higher model resolution, both horizontally and vertically, greater observational usage, and a more advanced model configuration (Onogi et al. 2007; Bromwich et al. 2007). Nicolas and Bromwich (2011) show that the reliability of JRA P-E is highly ranked in relation to other global reanalyses.

Figures 6.6a-d show the 2011 JRA annual and austral fall (MAM) anomalies of $\mathrm{P}-\mathrm{E}$ and mean sea level pressure (MSLP). In general, the annual anomalies over the high interior of the continent were small (within $\pm 50 \mathrm{~mm} \mathrm{yr}^{-1}$ ), consistent with the low values of snow accumulation in this region. Most coastal regions in 2011 displayed opposite $\mathrm{P}-\mathrm{E}$ anomalies to

\section{SIDEBAR 6.I: RECENT COOLER CONDITIONS ON THE NORTHERN ANTARCTIC PENINSULA-D. MCGRATH AND K. STEFFEN}

Atmospheric warming over the Antarctic Peninsula (AP) during the second half of the 20th century was remarkable, with local trends exceeding $0.5^{\circ} \mathrm{C}$ decade $^{-1}$ (Vaughan et al. 2003; Turner et al. 2005). The complexity of the atmospheric and oceanic circulation around the AP precludes clear attribution of this warming, although modified circulation patterns, largely driven by changes in latitudinal pressure gradients measured by the southern annular mode (SAM) index (Vaughan et al. 200I; Marshall 2003), likely played an important role (Thompson and Solomon 2002; van den Broeke and van Lipzig 2004). There has been increased advection of warm, maritime air towards the AP, and subsequently, an increased upwelling of Circumpolar Deep Water (CDW) onto the continental shelf of the Amundsen-Bellingshausen Sea (ABS; Orr et al. 2008; Jacobs et al. 20II; Martinson 20II). Dramatic reductions in sea ice extent $\left(-6.6 \%\right.$ decade $\left.^{-1}\right)$ in the ABS likely contributed to this warming as well, possibly as a driver and certainly as a positive feedback (Meredith and King 2005; Turner et al. 2009).

This warming has had important glaciological impacts, including widespread glacier front retreat and acceleration along the western margin of the AP and the collapse of the Larsen $A$ and $B$ ice shelves on the eastern edge, the latter being unprecedented during the Holocene (Pritchard and Vaughan 2007; Scambos et al. 2003; Cook and Vaughan 2010; Domack et al. 2005). A key mechanism in the final collapse of these ice shelves has been the propagation of surface meltwater-filled crevasses through the ice shelf, rendering it into a series of narrow, elongated icebergs (Scambos et al. 2003). This process is dependent on having sufficient surface meltwater, and thus is directly tied to the intensity and duration of surface melting on the ice shelf.

Increased surface melting on the Larsen B Ice Shelf, just prior to its collapse, resulted from strong northeasterly and westerly winds, the latter associated with strong föhn flow over the Peninsula, bringing dry, adiabatically warmed air over the ice shelf (van den Broeke 2005). An increase in this phenomenon is attributed to the increased speed of the circumpolar westerlies, associated with the positive polarity of the SAM index. This atmospheric pattern is characterized by more air passing over, rather than being blocked by, the orography of the Peninsula (Orr et al. 2004, 2008; Marshall 2003).

In contrast to the strong warming trends observed during the previous half-century, between 2000 and 20II, AP stations have shown much greater variability, with many stations showing a slight cooling trend (Fig. SB6.Ia; Table SB6.I). The mean annual temperature trend at Marambio station switched from a warming of $+0.65 \pm 0.47^{\circ} \mathrm{C}$ decade $^{-1}$ between 1971 and 2000 to a cooling of $-1.57 \pm 2.4^{\circ} \mathrm{C}_{\text {decade }}{ }^{-1}$ between 2000 and 20II. The cooling has been strongest at other northern AP stations (Bellingshausen, O'Higgins, Esperanza), with a cooling trend of about $-0.7^{\circ} \mathrm{C}$ decade ${ }^{-1}$ over the last 15 years, following a tendency that started with the end of the $1998 \mathrm{EI}$ Niño. However, marked cooling is also evident on the Larsen $\mathrm{C}$ Ice Shelf, the largest remaining ice shelf on the AP. This site
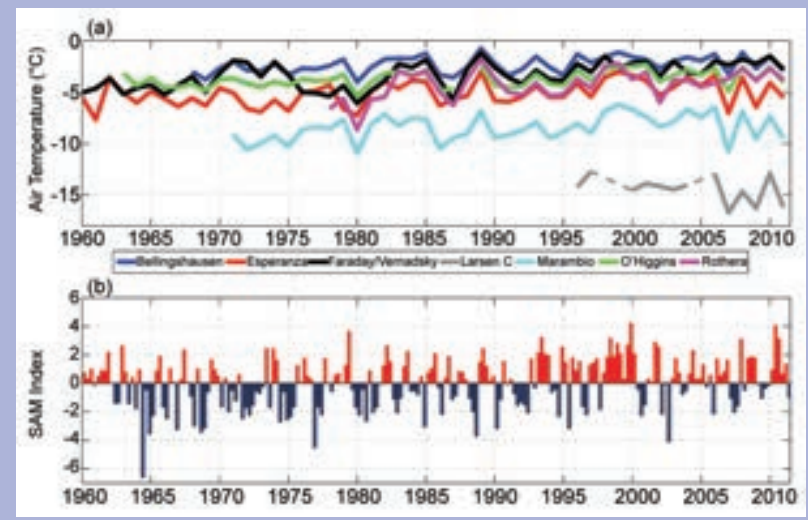

FIG. SB6.I. (a) Mean annual air temperature records $\left({ }^{\circ} \mathrm{C}\right)$ for selected stations on the Antarctic Peninsula. Dashed line for Larsen $C$ indicates incomplete temperature record, precluding calculation of mean annual temperature. (b) Seasonal SAM index calculated from station data (updated from Marshall 2003). 
the previous year, especially over the Ross Ice Shelf (between $150^{\circ} \mathrm{W}$ and $170^{\circ} \mathrm{E}$ ) and Queen Maud Land (between $0^{\circ}$ to $50^{\circ} \mathrm{E}$ ). The two strongest negative annual P-E anomalies for 2011 were observed in Wilkes Land (between $90^{\circ} \mathrm{E}$ and $130^{\circ} \mathrm{E}$ ) and Victoria Land (between $150^{\circ} \mathrm{E}$ and $170^{\circ} \mathrm{E}$ ), extending the $\mathrm{P}-\mathrm{E}$ anomaly observed in those regions in 2010 (Bromwich and Wang 2011). The majority of the Ronne Ice Shelf had lower net precipitation in 2011, in contrast to small negative or positive anomalies during 2010.

These annual P-E anomaly features (Fig. 6.6a) were generally consistent with the mean atmospheric circulation implied by the MSLP anomalies (Fig. 6.1a).
In 2010 (not shown), negative pressure anomaly centers over the Amundsen-Bellingshausen Sea $\left(\sim 105^{\circ} \mathrm{W}\right)$ and the East Antarctic coast $\left(\sim 120^{\circ} \mathrm{E}\right)$ produced stronger offshore flow and less precipitation along these regions. During 2011, there was a similar pair of negative pressure anomalies (Fig. 6.1a), but they were weaker and located farther north away from the coast. The positive pressure anomaly over the South Atlantic Ocean during 2010 was extended into the southern Indian Ocean during 2011. The secondary negative anomalies over the Southern Ocean $\left(\sim 45^{\circ} \mathrm{E}\right)$ and the Weddell Sea $\left(\sim 30^{\circ} \mathrm{W}\right)$ in 2010 were replaced by positive anomalies in 2011. The seasonal P-E has cooled by $-\mathrm{I} . \mathrm{II} \pm 2.4^{\circ} \mathrm{C}$ decade $^{-1}$ between 2000 and $20 \mathrm{II}$, although interannual variability is large. It is important to note that none of the reported trends over the past decade are statistically significant, and cooling of a similar magnitude previously occurred over short time periods earlier in the record (Fig. S6.Ia). However, with the observed variability over the past decade, there is no longer a statistically significant $(p<$ 0.05 ) warming trend for the northern AP over the last 30 years.

The observed warming from 1950 to 2000 , and the more recent temperature variability, cannot be simply and solely attributed to processes associated with the positive trend in the SAM index over this period (Fig. SB6.Ib). These processes certainly influence AP climate, and likely contributed to summertime warming of the eastern AP through increased föhn winds on the lee side of the peninsula (Marshall 2007; Orr et al.
2008). However, a significant portion of the regional warming, especially in winter, can be attributed to warming of the central tropical Pacific Ocean and subsequent atmospheric wave trains directed towards West Antarctica (Ding et al. 20II). This likely contributes to increased upwelling of CDW in the Amundsen Sea sector, driving high basal melt rates for glaciers in this region (Steig et al. 20I2). The strong negative anomaly in sea ice metrics for the $A B S$ region also has a strong influence on the regional climate (Massom et al. 2008; Stammerjohn et al. 2012), although the exact cause of this negative anomaly is challenging to precisely attribute. The multiple forcing mechanisms therefore both highlight the complexity of the profound changes occurring on the AP and attest to the need for continued research to make accurate predictions for the future.

TABLE SB6.I. Mean annual air temperature and trends with $95 \%$ confidence intervals calculated by standard least-squares linear regression over specified time intervals.

\begin{tabular}{|c|c|c|c|c|c|}
\hline $\begin{array}{c}\text { Station } \\
\text { Name }\end{array}$ & $\begin{array}{c}\text { Location } \\
\left({ }^{\circ} \mathbf{S},{ }^{\circ} \mathbf{W}\right)\end{array}$ & $\begin{array}{c}\text { Station } \\
\text { Record }\end{array}$ & $\begin{array}{c}\text { Mean Annual } \\
\text { Temperature } \\
\left({ }^{\circ} \mathbf{C}\right)\end{array}$ & $\begin{array}{c}\text { Trends to } \\
\mathbf{2 0 0 0} \\
\left({ }^{\circ} \mathbf{C ~ d e c a d e}^{-1}\right)\end{array}$ & $\begin{array}{c}\text { Trends } \\
\mathbf{2 0 0 0 - 2 0 I I} \\
\left({ }^{\circ} \mathbf{C ~ d e c a d e}^{-1}\right)\end{array}$ \\
\hline Bellingshausen & $-65.4,-64.4$ & $1968-2011$ & $-2.3 \pm 0.8$ & $+0.35 \pm 0.28$ & $-0.45 \pm 1.3$ \\
\hline Esperanza & $-67.5,-68.1$ & $1945-2011$ & $-5.3 \pm 1.3$ & $-0.40 \pm 0.19$ & $-1.35 \pm 2.2$ \\
\hline Faraday/Vernadsky & $-62.2,-58.9$ & $1950-2011$ & $-3.7 \pm 1.6$ & $+0.59 \pm 0.26$ & $+0.37 \pm 1.2$ \\
\hline Larsen C & $-66.9,-60.9$ & $1995-2011$ & $-14.4 \pm 1.3$ & - & $-1.11 \pm 2.4$ \\
\hline Marambio & $-63.4,-57.0$ & $1971-2011$ & $-8.5 \pm 1.3$ & $+0.65 \pm 0.47$ & $-1.57 \pm 2.4$ \\
\hline O'Higgins & $-63.3,-57.9$ & $1963-2011$ & $-3.7 \pm 0.8$ & $+0.23 \pm 0.21$ & $-0.71 \pm 1.5$ \\
\hline Rothera & $-64.2,-56.7$ & $1978-2011$ & $-4.33 \pm 1.4$ & $+1.15 \pm 0.94$ & $+0.86 \pm 1.6$ \\
\hline
\end{tabular}




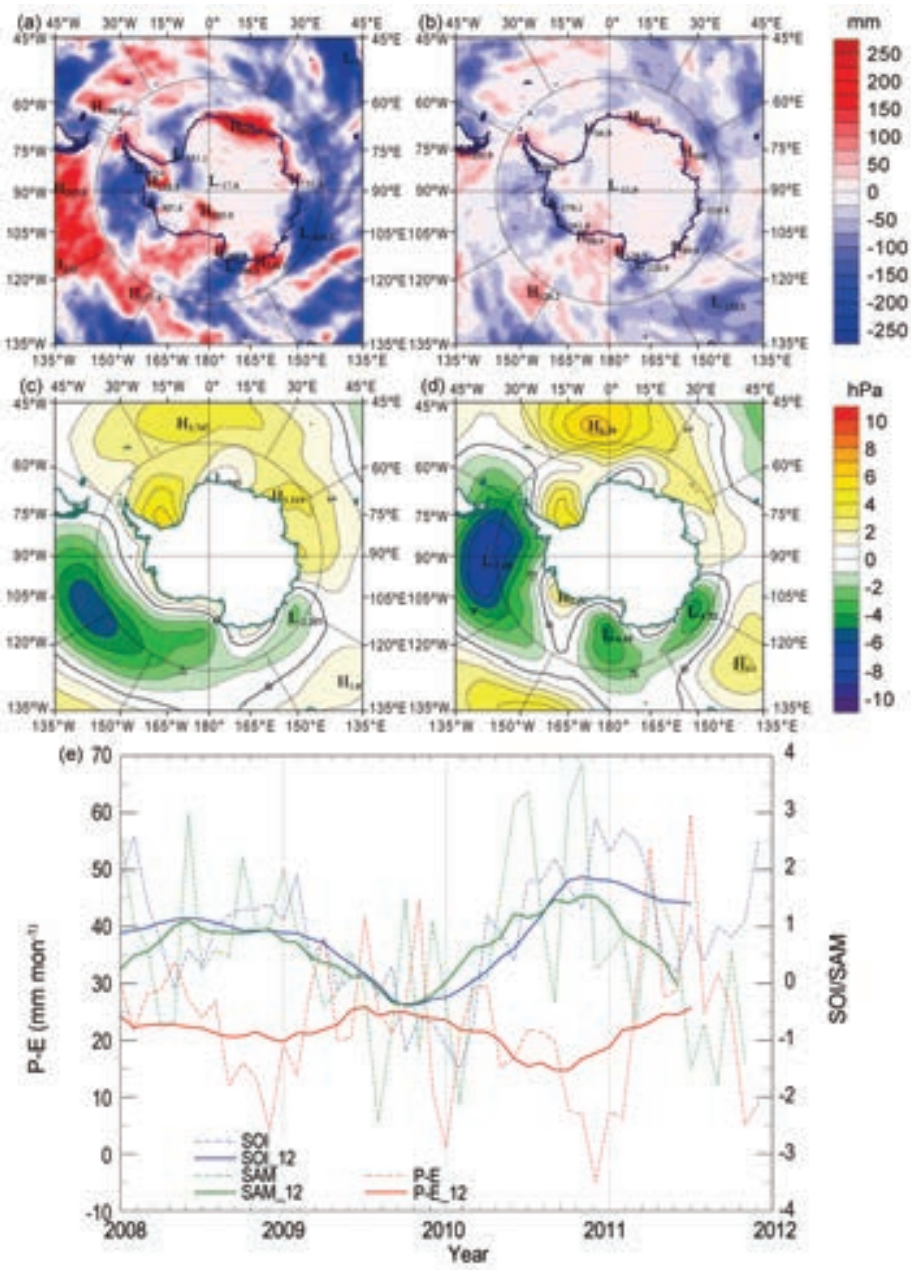

FIG. 6.6. (a)-(d) 20 II annual/seasonal precipitation minus evaporation $(\mathrm{P}-\mathrm{E} ; \mathrm{mm})$ and $\mathrm{MSLP}(\mathrm{hPa})$ anomalies departure from the I98I-2010 means: (a) annual P-E anomalies; (b) austral fall (MAM) P-E anomalies; (c) annual MSLP anomalies; and (d) austral fall (MAM) MSLP anomalies. (e) Monthly total P-E ( $\mathrm{mm}$; red) for the West Antarctic sector bounded by $75^{\circ} \mathrm{S}-90^{\circ} \mathrm{S}$, $120^{\circ} \mathrm{W}-180^{\circ}$, along with the SOI (green, from NOAA's CPC) and SAM (blue, from Marshall 2003) indices since 2008. Centered annual running means are plotted as solid lines.

anomalies can have a large influence on regional annual P-E anomalies. In particular, austral fall values alone contributed more than $50 \%$ of the 2011 annual $\mathrm{P}-\mathrm{E}$ anomalies between the Antarctic Peninsula and the Ross Ice Shelf $\left(60^{\circ} \mathrm{W}\right.$ to $170^{\circ} \mathrm{E}$; Figs. 6.6a-b), and showed good correspondence with austral fall MSLP anomalies (Fig. 6.6d).

The influence of La Niña on P-E also can be observed in Fig. 6.6: from austral fall 2010 to austral winter 2011, negative MSLP anomalies in the Amundsen-Bellingshausen Seas shifted away from the Antarctic coast, ultimately resulting in the large $\mathrm{P}-\mathrm{E}$ anomaly changes west of the Antarctic Peninsula (from positive to negative) and the Marie Byrd
Land-Ross Ice Shelf region (from negative to positive). Earlier studies suggest that those MSLP anomaly features are consistent with simultaneously strong La Niña (Bromwich et al. 2000, 2004) and positive SAM events (Fogt and Bromwich 2006; Fogt et al. 2011). Figure 6.6e shows the time series of average monthly total P-E over the West Antarctica sector $\left(75^{\circ} \mathrm{S}-90^{\circ} \mathrm{S}, 120^{\circ} \mathrm{W}-180^{\circ}\right)$ and monthly SOI and SAM indices (with 12-month running means). It is clear that SOI and SAM are in phase with each other but have opposite behavior to $\mathrm{P}-\mathrm{E}$ in most months from 2008 onward. The correlation coefficients between monthly P-E and index values are SOI: -0.17 $(-0.37$ for annual running mean), and SAM: -0.24 ( -0.71 for annual running mean). There was also some evidence that the SOI and SAM index are becoming out of phase during later months of 2011 .

e. 2010/II Seasonal melt extent and duration-L. Wang and H. Liu

Surface snow melt on the Antarctic Ice Sheet during the 2010/11 austral summer was estimated from satellite data using the Special Sensor Microwave/Imager (SSM/I) instrument by applying a wavelet transformation-based edge-detection method (Liu et al. 2005). This tracks melt onset and end dates from the time series of daily brightness temperatures recorded by the horizontally polarized $19 \mathrm{GHz}$ frequency channel. By accumulating the number of days enclosed by melt onset and end pairs during the austral year in the time series, the total number of melt days is calculated for each image pixel. The first and the last melt day in the year were also recorded as the start day of the melt season and the end day of the melt season. Based on these techniques, maps were generated for melt start day (Fig. 6.7a), melt end day (Fig. 6.7b), and annual melt duration (Fig. 6.7c).

As in most years, seasonal melt during 2010/11 was confined almost entirely to the coastal areas. In extremely warm years (such as 2005) some melt signal was observed well inland, e.g., on the Ross Ice Shelf (Liu et al. 2006). However, the 2011 melt season saw almost no melt events in the interior. The total area that experienced surface melt, or melt extent (Torinesi et al. 2003; Liu et al. 2006), was $1069375 \mathrm{~km}^{2}$. This is greater than the previous season $\left(945000 \mathrm{~km}^{2}\right)$ 
and continues the increasing trend since the 2008/09 season (Wang and Liu 2011). However, the value is still well below the reported average melt extent of the past decades, such as the 26-year (1978-2004) median melt extent $\left(1277500 \mathrm{~km}^{2}\right)$ reported in Liu et al. (2006), and the 20-year mean (1980-99; 1280000 $\mathrm{km}^{2}$ ) reported in Torinesi et al. (2003). The Melt Index (Zwally and Fiegles 1994; Torinesi et al. 2003; Liu et al. 2006) for austral summer 2010/11, calculated as an annual index by accumulating the number of melting days over a certain area (e.g., the entire Antarctica), was 40280625 day. $\mathrm{km}^{2}$, slightly larger than last year's melt index (39 349375 day. km²; Wang and Liu 2011). The melt peak day (Fig. 6.7d) was 29 December 2010, with two smaller peaks in November 2010 and March 2011. The smaller peaks were caused by off-season melt events on the Wilkins Ice Shelf (Figs. 6.7a-b).

Melt area is strongly correlated with latitude; as expected, more melt occurred at lower latitudes than higher ones. Exceptions are the large area of short-period melt on the Ronne-Filchner Ice Shelf, and sporadic melt on Marie Byrd Land (Fig. 6.7c). Extensive melt was seen on the Peninsula, Wilkins, Queen Maud Land, Amery, Shackleton, and Abbot Ice Shelves. Little melt was detected on Ross Ice Shelf,

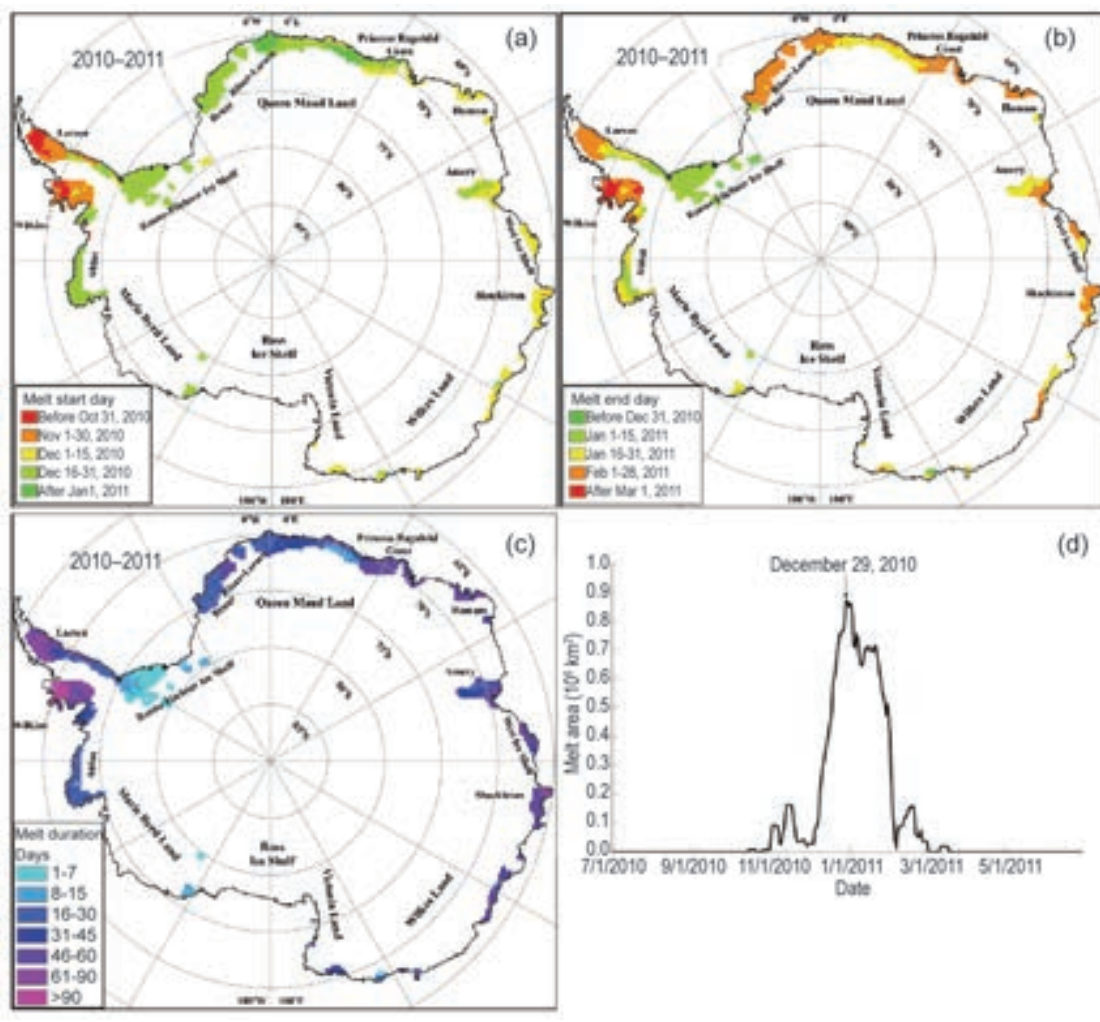

Fig. 6.7. Maps for (a) melt start day, (b) melt end day, and (c) melt duration of Antarctic ice sheet during 2010/II austral summer. Daily melt extent is shown in (d) with melt peak day indicated.
Victoria Land, and Wilkes Land (see Fig. 6.7a for locations). Overall, the melt season of 2010/11 was relatively melt-intensive compared to the past few years in the Antarctic melt record (Tedesco 2009; Tedesco and Monaghan 2009). The magnitude and spatial pattern were similar to those of the previous melt season.

\section{f. Sea ice extent and concentration-R. A. Massom, P. Reid,} S. Stammerjohn, S. Barreira, and T. Scambos

During 2011, zonally-averaged Antarctic sea ice extent was characterized by three broad phases that were closely associated with the changes in largescale patterns of atmospheric circulation described in section $6 \mathrm{~b}$.

From near-average levels at the beginning of the year (compared to the 1981-2010 mean), the zonallyaveraged sea ice extent tracked at 1-2 standard deviations below the long-term mean from mid-January through mid-May (Fig. 6.8a)-including some brief times when it dipped below the 30 -year record. Over this period, negative ice extent anomalies in the (1) eastern Bellingshausen Sea, (2) Weddell Sea (apart from in the southwest), (3) western Amundsen to Ross Seas, and (4) the West Pacific Ocean sector between $75^{\circ} \mathrm{E}$ and $120^{\circ} \mathrm{E}$ outweighed strong positive anomalies over much of the eastern Amundsen Sea and the Indian Ocean sector $\left(10^{\circ} \mathrm{E}-\right.$ $70^{\circ} \mathrm{E}$; Fig. $\left.6.8 \mathrm{~b}\right)$. These positive/ negative ice-edge anomalies are likely to be due to a combination of wind-driven ice advection/compaction and in situ thermodynamic growth, the latter associated with the development of cold pools of SST (in the eastern Ross Sea in particular, e.g., in Fig. 6.8d).

The pattern of the 2010/11 season sea ice retreat and advance during the January-May period (not shown) to a large degree reflects the strong positive SAM/La Niña conditions, with generally negative surface pressure anomalies at higher latitudes, particularly in the Amundsen and Bellingshausen Seas, and below-average sea surface temperatures in 


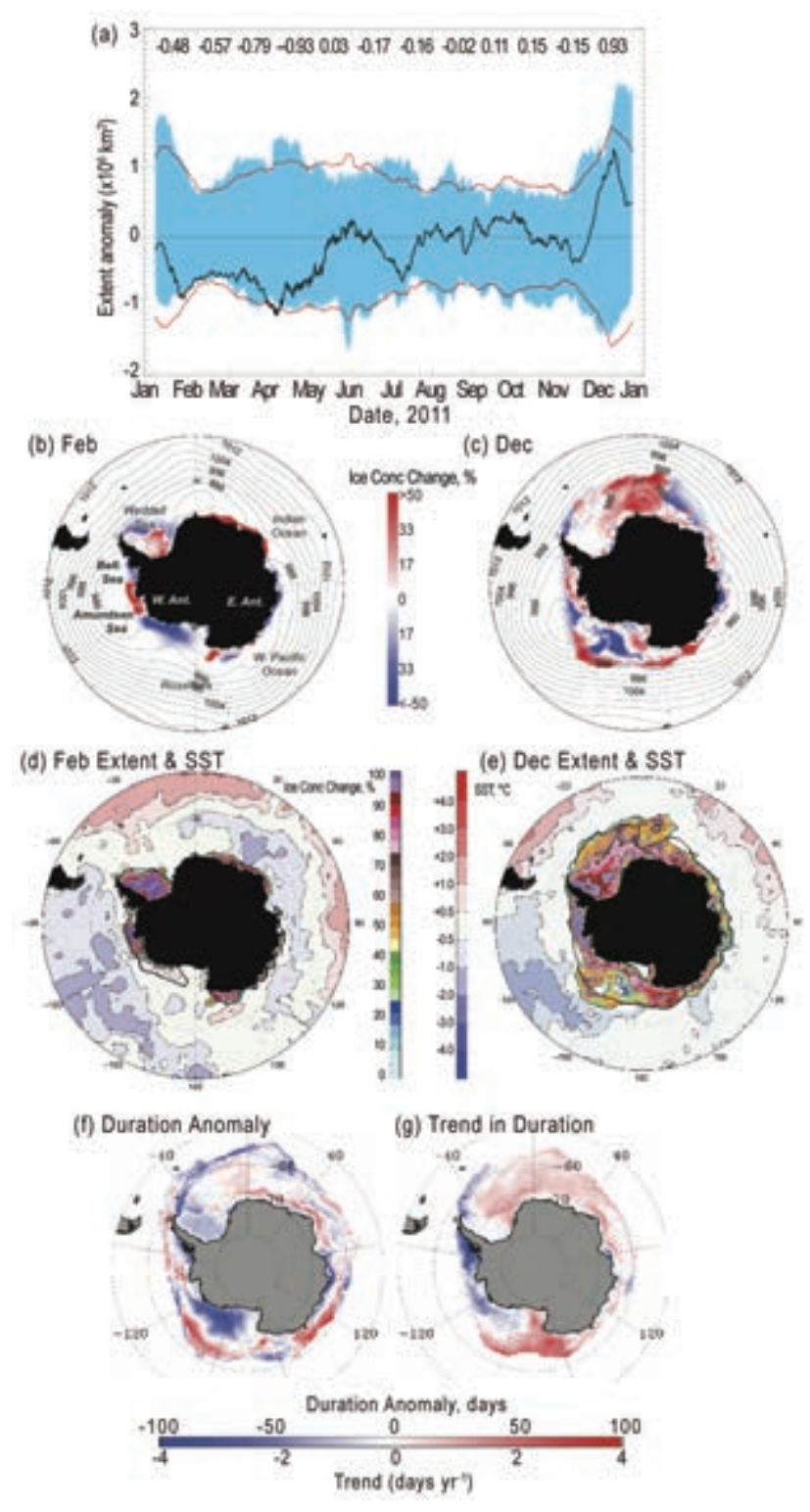

the tropical Pacific. These conditions brought about earlier-than-normal sea ice retreat in the eastern Bellingshausen, western Weddell, and southern Ross Sea regions, contrasting with later-than-normal retreat in the outer eastern Ross Sea, Amundsen Sea, and Indian Ocean regions. For the most part, the sea ice advance anomaly pattern in 2011 mirrored the previous year's retreat pattern (in 2010/11) in that where the 2010/11 sea ice retreat was early, the 2011 sea ice advance was late (in the southern Bellingshausen Sea, western Weddell Sea, eastern Antarctica between $\sim 80^{\circ} \mathrm{E}-120^{\circ} \mathrm{E}$, and southern Ross Sea). Conversely, where the 2010/11 sea ice retreat was late, the advance was early (in the outer Amundsen Sea, outer Ross Sea, Indian Ocean between $\sim 40^{\circ} \mathrm{E}-80^{\circ} \mathrm{E}$, and the West Pacific sector between $\sim 120^{\circ} \mathrm{E}$ and $160^{\circ} \mathrm{E}$ ).
Fig. 6.8. (a) Plot of daily anomaly (black line) from the 198I-2010 climatology of daily Southern Hemisphere sea ice extent for 2011 , based on satellite passive microwave ice concentration data from the GSFC Bootstrap Version 2 dataset (Comiso 1999). Blue banding represents the range of daily values for 198I-2010, while the red line represents \pm 2 standard deviations. Figures at the top are monthly mean extent anomalies $\left(\times 10^{6} \mathrm{~km}^{2}\right)$. (b) and (c) Sea ice concentration anomaly maps for February and December 2011 derived versus the monthly means for $198 \mathrm{I}-2010$, with monthly mean contours of ACCESS MSLP. (Bell is Bellingshausen Sea.) (d) and (e) Maps of monthly mean sea ice concentration for February and December 201I, respectively, with mean ice edge/extent contours for 198I-2010 (black lines) and SST anomaly contours superimposed. The SST anomalies were calculated against the 198I2010 mean and are based on data from the Optimal Interpolation SST version 2 dataset (Reynolds et al. 2002; Smith et al. 2008). (f) Sea ice duration anomaly for 20II/I2, and (g) duration trend (see Stammerjohn et al. 2008). Both the climatology (for computing the anomaly) and trend are based on 198I/82 to 2010/II data (Comiso 1999), while the 20II/12 duration-year data are from the NASA Team Near-Real-Time Sea Ice (NRTSI) dataset (Maslanik and Stroeve 1999).

Of particular interest during April-May was a rapid change from a strongly negative to positive sea ice extent anomaly in the eastern Ross Sea sector. This was a result of a combination of high cyclonic activity, cold air advection, fresh water influx into the mixed layer (precipitation), and cool SSTs.

During the second phase, from mid-May to mid-November, the zonally-averaged extent largely fluctuated about the mean, with the exception of a dip towards two standard deviations below the longterm mean from mid-June to mid-July (Fig. 6.8a). The intervening wintertime dip occurred largely as a result of a southward incursion of the ice edge along a broad front from the tip of the Antarctic Peninsula eastwards across the Indian Ocean sector and in the western Ross Sea, coinciding with a band of anomalously warm SSTs in that region (not shown). This major incursion of the ice edge south of the long-term mean largely persisted through November, but was counterbalanced after mid-July by strong positive ice extent and concentration anomalies elsewhere (e.g., across the southwestern Pacific Ocean sector east of $120^{\circ} \mathrm{E}$, the Ross Sea, and the northwestern Weddell and Bellingshausen Sea-the latter against the long-term negative trend; Comiso 2010; Stammerjohn et al. 2012). During this phase, the general atmospheric circulation reflected a weakening from near-neutral (mid-year) to moderately strong negative 
SAM conditions (during austral spring; Fig. 6.2) and generally positive surface pressure anomalies at higher latitudes (Fig. 6.3e). As a consequence, the sea ice retreat anomaly pattern in 2011/12 was marked by late retreat across the Weddell, West Pacific, and outer Ross Sea regions, more or less opposite to that observed in the 2010/11 season.

The final phase, from mid-November onwards (Fig. 6.8a), entailed a rapid change to a strongly positive zonally-averaged ice extent anomaly and coincided with strong positive SAM/La Niña conditions with a classic ZW3 pattern in atmospheric pressure; low pressure centers in the eastern Weddell Sea, off East Antarctica at $\sim 110^{\circ} \mathrm{E}$, and in the Amundsen Sea (Figs. 6.2e; 6.8c). This resulted in the persistence of above-average ice extents and concentrations in the northeastern Weddell Sea, Ross Sea, and central West Pacific Ocean, plus near-average conditions elsewhere, with the exception of negative regional anomalies in the outer eastern Amundsen Sea, central Ross Sea, and northwestern Weddell Sea (Figs. 6.8c,e). The anomalously extensive sea ice in the Ross Sea also coincided with a region of cooler-than-average SSTs at this time (Fig. 6.8e). Overall Antarctic sea ice extent in December 2011 was the fifth highest since satellite records began in 1979.

The persistence of heavy pack and fast ice conditions along the Indian Ocean coastal sector during December continued to severely affect shipping operations and the resupply of Mawson Station $\left(\sim 62.9^{\circ} \mathrm{E}\right.$, $\left.67.6^{\circ} \mathrm{S}\right)$. Conversely, in February, a strong storm in the McMurdo Sound area removed multiyear fast ice completely, during the early period of lower-thannormal sea ice extent in the southern Ross Sea. This
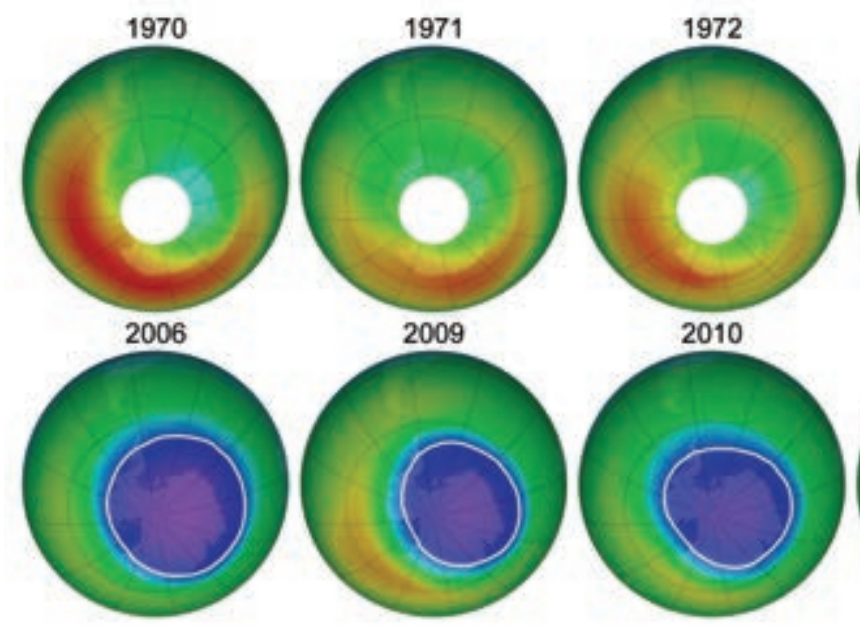

1972

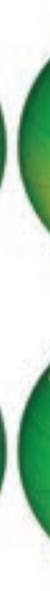

resulted in damage to the ice pier at McMurdo Station, and probably contributed to the calving of two large icebergs from the McMurdo Ice Shelf at the southern end of the sound.

Given the midyear transition in the atmospheric circulation and sea ice anomaly patterns, the resulting sea ice season duration showed generally weak anomalies (Fig. 6.8f) overall (compared to 2010/11, for example). This was due to the fact that sea ice advance and retreat anomalies in most regions largely canceled each other out. In the western Weddell Sea, for example, the annual advance was late but the retreat was also late, so the ice season duration was near normal [relative to the long-term trends (Fig. 6.8g); see also Stammerjohn et al. 2012]. Greatest differences in 2011/12 compared to the long-term trends in annual sea ice season duration occur in the inner eastern Ross Sea (more strongly negative in 2011/12) and the relatively narrow zone in the Indian Ocean sector between $\sim 110^{\circ} \mathrm{E}$ and $150^{\circ} \mathrm{E}$ (more strongly positive). The notable regional "hot-spot" of a long-term trend towards shortening of the sea ice season in the Amundsen-Bellingshausen Sea was less extensive in 2011/12 (Figs. 6.8f,g). Although ice extent and concentration anomalies were negative in this region in the first half of the year (in line with the long-term trend; Comiso 2010), the switch to positive anomalies for the remainder of the year created a near-zero duration anomaly for 2011/12.

g. Ozone depletion-P. A. Newman, E. R. Nash, C. S. Long, M. C. Pitts, B. Johnson, M.L. Santee, J. Burrows, and G. O. Braathen

The Antarctic ozone hole was moderately more severe in 2011 compared to the 1990-2011 period

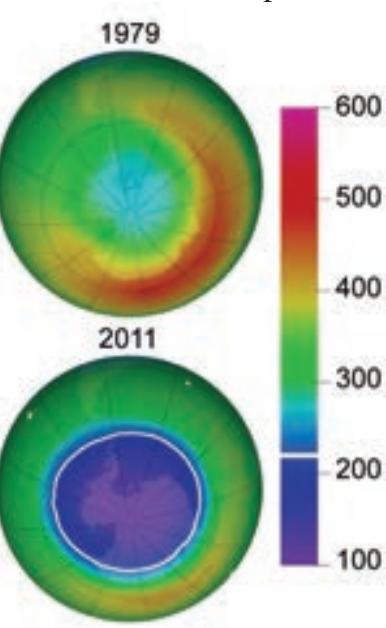

(average taken after the marked depletion in the 1980s). Figure 6.9 displays select October averages of total ozone derived from NASA instruments between 1970 and 2011. Prior to 1980 (top row), severe ozone depletion over Antarctica was not apparent. After 1990, nearly every year has seen a se-

Fig. 6.9. October averages of total column ozone (Dobson Units, DU) derived from vere loss. As is clear the Nimbus-4 BUV (1970-72), Nimbus-7 TOMS (1979), and OMI instruments (2006, 2009-II). The white line denotes the $220 \mathrm{DU}$ (a nominal indicator of ozone depletion). Images courtesy of NASA (see http://ozonewatch.gsfc.nasa.gov). from the bottom right panel (2011), 


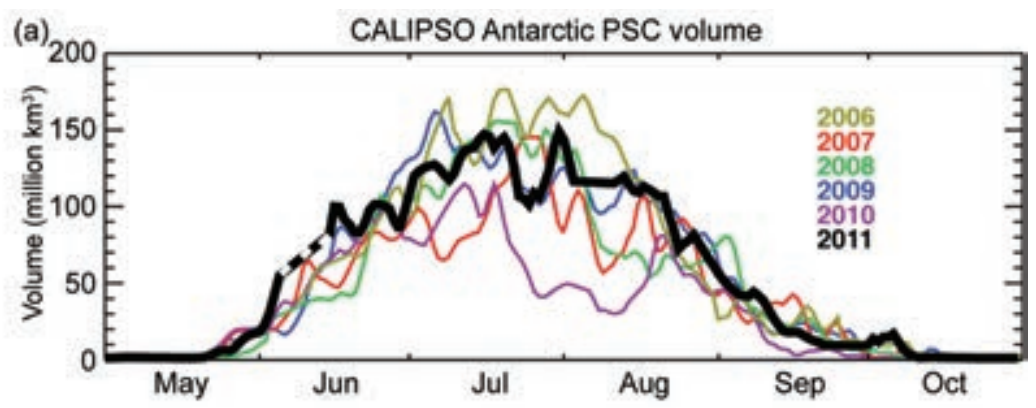

(b)
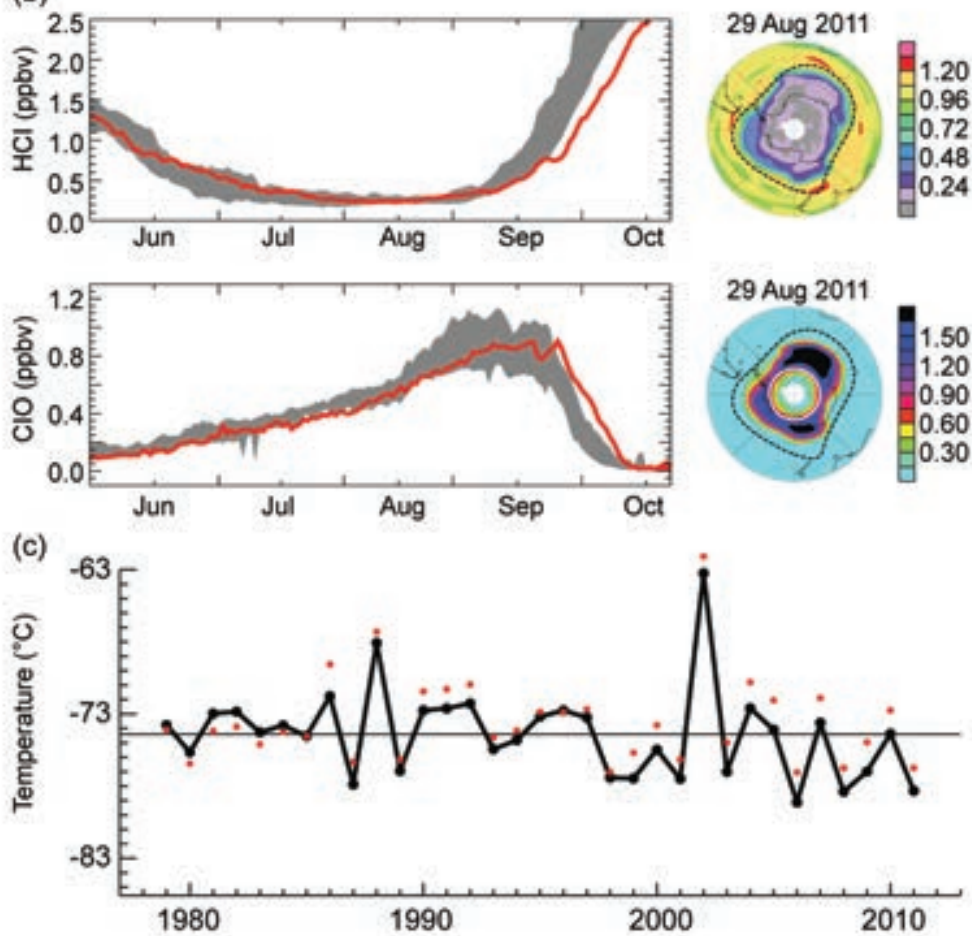

FIG. 6.10. (a) Daily time series of CALIPSO PSC volume for the Antarctic winter season (updated from Pitts et al. 2009). (b) $\mathrm{HCl}$ (top panel) and $\mathrm{CIO}$ (bottom panel) vortex-averaged time series on the $485 \mathrm{~K}(\sim 2 \mathrm{l} \mathrm{km}$, or $40 \mathrm{hPa}$ ) potential temperature surface from the Aura MLS in ppbv. The dashed black contour shown on the maps denotes the vortex edge. Gray shading on left denotes range of Aura MLS measurements during 2005-10, while red lines denote the 2011 values. The white circle on the $\mathrm{ClO}$ map shows the edge of polar night at local noon (updated from Manney et al. 20II). (c) September monthly mean temperature at $50 \mathrm{hPa}, 60^{\circ} \mathrm{S}-90^{\circ} \mathrm{S}$ from MERRA data (black points and line) and NCEP/DOE data (red points). The MERRA data are biased $I^{\circ} \mathrm{C}$ colder than the NCEP/DOE data (Rienecker et al. 20II). In 20II, the average temperature was about $4^{\circ} \mathrm{C}$ below both the MERRA average and the NCEP/DOE average.

the Antarctic ozone loss in this past year was both deep and expansive.

The Antarctic ozone hole's area and depth are typically used as severity metrics. The area usually peaks in mid-September to early October. In 2011, the daily maximum area measured by the Ozone Monitoring Instrument (OMI) peaked at 26.0 million $\mathrm{km}^{2}$ on 12 September. The time-averaged area (7 September to 13 October) was 24.7 million $\mathrm{km}^{2}$. This made the 2011 ozone hole the seventh largest ozone hole over the 1990-2011 period (the 2006 ozone hole was the largest at 26.6 million $\mathrm{km}^{2}$ ). The average depth of the 2011 ozone hole was 106 Dobson Units (DU) - averaged over the period of lowest ozone from 21 September to 16 October (the lowest OMI value was 95 DU on 8 October). The 2011 polar vortex was long lived, keeping the ozone hole near or above daily maximum values from mid-September through mid-November of previous years. Using a 15 September-30 November area average, 2011 was the second largest area in the 1990-2011 period (2006 was the largest for this period). Analyses from the SBUV and GOME-2 satellite instruments provide confirmation of these ozone hole estimates, albeit with slight differences due to instrument and retrieval differences.

Atmospheric profiles of ozone over Antarctica during early October 2011 show $100 \%$ depletion. Ozonesonde measurements on 9 October 2011 from South Pole show $98 \%$ ozone depletion in the $14 \mathrm{~km}-21 \mathrm{~km}$ altitude range. Profile observations from satellites also reveal this severe ozone loss. Aura satellite observations from the Microwave Limb Sounder (MLS) instrument reveal that ozone decreased from above $3 \mathrm{ppmv}$ to approximately $1 \mathrm{ppmv}$ on the $485 \mathrm{~K}$ isentropic surface (about $40 \mathrm{hPa}$ or 21 $\mathrm{km}$ ) between 1 August and 1 October.

The ozone hole is caused by the conversion of chlorine molecules from nonreactive forms into ozone-destroying forms on the surfaces of particles in polar stratospheric clouds, or PSCs (i.e., $\left.\mathrm{HC} 1+\mathrm{ClONO}_{2} \stackrel{P S C}{\rightarrow} \mathrm{Cl}_{2}+\mathrm{HNO}_{3}\right)$. The molecular chlorine photolyzes as the sun rises in spring, and this chlorine (combined with bromine) directly causes catalytic ozone loss. Figure 6.10a shows CALIPSO satellite observations of total PSC volume during the May-October period for six years. The May-October 2011 season showed the third largest average PSC volume (updated from Pitts et al. 2009).

The Aura MLS measures nonreactive $\mathrm{HCl}$ (Fig. 6.10b, top panels) and ozone-destroying $\mathrm{ClO}$ (Fig. 6.10b, bottom 
panels). It is thus able to track the activation and deactivation of chlorine. The June-July $\mathrm{HCl}$ decreases as temperatures cool and PSCs form. As noted in the above equation, $\mathrm{PSC}$ convert $\mathrm{HCl}$ and $\mathrm{ClONO}_{2}$ into reactive chlorine (mainly $\mathrm{ClO}$ and $\mathrm{Cl}_{2} \mathrm{O}_{2}$ ). The resultant June-August $\mathrm{ClO}$ increase occurs because of this conversion. ClO peaks in September from the continued presence of PSCs and the rising sun over Antarctica. In late September, the complete destruction of ozone and evaporation of PSCs causes $\mathrm{ClO}$ (rapid decrease) to be converted back to $\mathrm{HCl}$ (rapid increase). As the right panels of Fig. 6.10b show, lower $\mathrm{HCl}$ and higher $\mathrm{ClO}$ than usual were found inside the 2011 Antarctic polar vortex. The high values of $\mathrm{ClO}$ and low values of $\mathrm{HCl}$ were unusually persistent in 2011 compared to MLS climatology. Time series of SCIAMACHY satellite observations of $\mathrm{OClO}$ and $\mathrm{NO}_{2}$ show persistently high values of $\mathrm{OClO}$ and low $\mathrm{NO}_{2}$ into October 2011, consistent with the higher $\mathrm{MLS} \mathrm{ClO}$. The higher $\mathrm{ClO}$ and $\mathrm{OClO}$, combined with persistently low $\mathrm{NO}_{2}$, enhanced conditions for ozone depletion in 2011, consistent with the relatively large extent of the Antarctic ozone hole during October. Ozone-depleting substances in the 2011 Antarctic ozone hole have only decreased by about $0.2 \mathrm{ppb}$ from peak levels in the 2000-02 period of $4.0 \mathrm{ppb}$.
This amounts to a $12 \%$ drop towards the 1980 level of $2.1 \mathrm{ppb}$.

Temperature variability of the Antarctic stratosphere modulates the year-to-year ozone hole severity. Below-average (above-average) Antarctic temperatures result in large and deep (small and shallow) ozone holes. Figure 6.10c shows Antarctic $\left(60^{\circ} \mathrm{S}-90^{\circ} \mathrm{S}\right)$ September $50 \mathrm{hPa}$ monthly mean temperatures. September 2011 was $4^{\circ} \mathrm{C}$ below average, and therefore consistent with higher levels of PSCs and greater chlorine activation (see also Fig. 6.2b).

The Antarctic stratosphere is warmed by the return of sunlight at the end of the polar winter and by large-scale weather systems (planetary-scale waves) that form in the troposphere and move upward into the stratosphere. The deposition of easterly momentum from these waves decelerates the polar night jet and causes a poleward and downward circulation. This downward circulation adiabatically warms the Antarctic lower stratosphere. During the 2011 Antarctic winter and spring, there were relatively weak wave events. This resulted in a colder-than-normal Antarctic vortex (as shown in Figs. 6.10c and 6.2b) and an unusually persistent Antarctic ozone hole. Low ozone values $(<220 \mathrm{DU})$ were observed until 21 December 2011. 
7. REGIONAL CLIMATES-A. Sánchez-Lugo, J. A. Renwick, W. M. Thiaw, and S. J. Weaver, Eds.

a. Overview-A. Sánchez-Lugo, J. A. Renwick, W. M. Thiaw, and S. J. Weaver

This chapter provides a summary of regional climate conditions-primarily temperature and precipitation-across the globe during 2011, and highlights notable weather events. The chapter is divided into seven main sections: North America, Central America and the Caribbean, South America, Africa, Europe, Asia, and Oceania. Information for a specific region has been provided by local scientists, and the source of the data used is typically the agency affiliated with the authors, unless otherwise noted. Information from 2010 may be included in some instances to accurately cover relevant climate seasons, such as the austral summer and boreal winter seasons.

In summary, North America weather conditions were characterized by strong seasonal and regional variability in precipitation and temperature. Notable events include the United States tornado outbreaks, flooding in Canada, and wildfires in Mexico. Across Central America, two tropical systems caused significant economic losses. In the Caribbean, precipitation patterns were greatly influenced by the La Niña event, resulting in a "very wet" dry season for several islands. Across South America, above-average precipitation was observed across northern parts of the continent throughout the year, with below-average precipitation across the southern regions. Of note were the deadly floods in Brazil-the worst natural disaster in the country's history. Africa was marked by extreme events that triggered humanitarian crises. The drought in East Africa in 2011 was one of the worst in several decades. Across Europe, the European drought was one of the worst events in the century. Russia experienced up to $10^{\circ} \mathrm{C}$ above-average temperatures on several occasions throughout the year, with the most notable warmth in March where some areas were as much as $20^{\circ} \mathrm{C}$ above average. Also of note was the extremely wet two-year period Australia experienced after a decade-long dry period.

For varying reasons, contributions from Egypt, Madagascar, Iraq, and the southwest Pacific were not received this year and thus are not included in this supplement.

\section{b. North America}

I) CANADA-R. Whitewood and D. Phillips

Nationally, 2011 was the eighth warmest year on record since records began in 1948. Winter (DJF

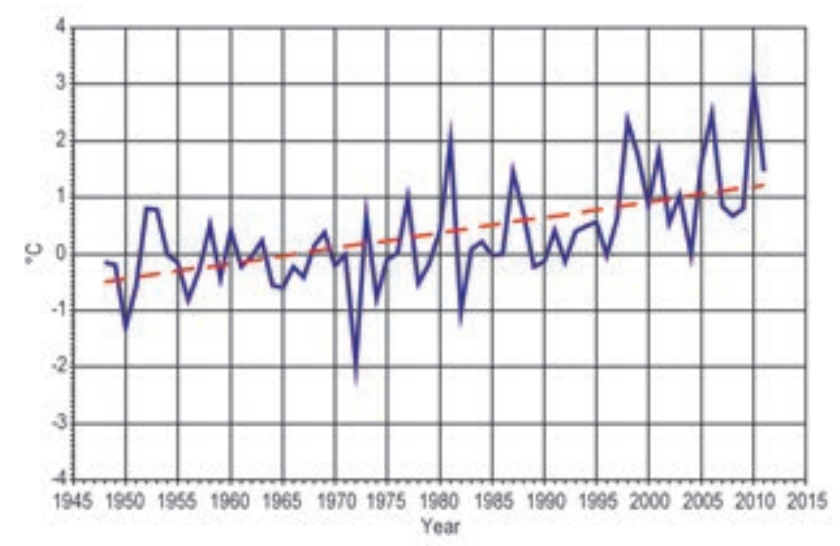

Fig. 7.I. Graph of annual mean temperature anomalies ( $\left.{ }^{\circ} \mathrm{C}\right)$ from 196I-90 normal for Canada 1948-20II.

2010/11), summer, and autumn were warmer than normal, with spring close to normal. Canada experienced its 15th driest year in 2011. Winter, spring, and autumn were all drier than normal, whereas summer was wetter than normal.

\section{(i) Temperature}

The national average temperature for 2011 was $1.5^{\circ} \mathrm{C}$ above the $1961-90$ base period, marking the eighth warmest year since national records began in 1948 (Fig. 7.1). Figure 7.1 also shows that the national annual average temperature has undergone a linear increase of $1.6^{\circ} \mathrm{C}$ over the 64 -year period and that it has been at or above normal since 1993. Much of Canada's warmth was in the north, where temperatures were more than $2^{\circ} \mathrm{C}$ above normal, while southern British Columbia, Alberta, and Saskatchewan had temperatures close to normal in 2011 (Fig 7.2).

The Canadian winter (December 2010-February 2011) was the sixth warmest on record since 1948 with a national average temperature of $2.5^{\circ} \mathrm{C}$ above normal. This was especially noteworthy over the

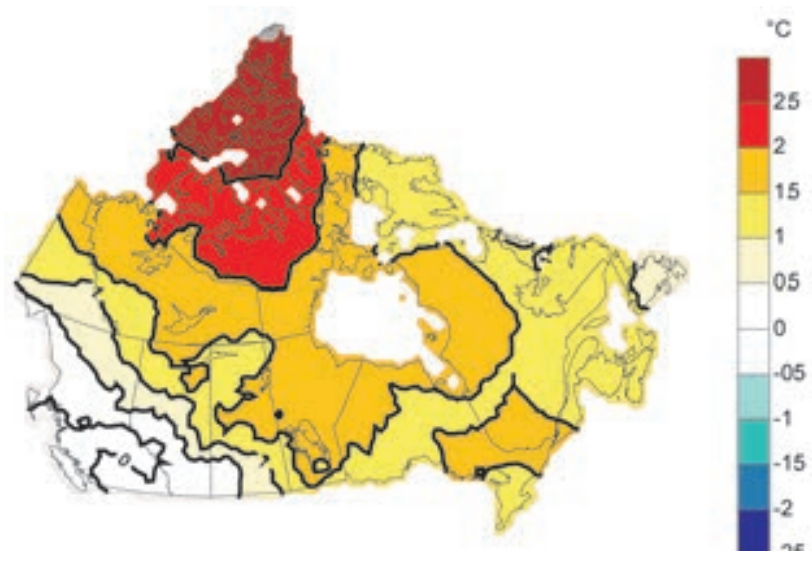

Fig. 7.2. Map of $201 \mathrm{I}$ annual mean temperature anomalies $\left({ }^{\circ} \mathrm{C}\right)$ from 1961-90 normal period for Canada. 
northern portions of Canada as some areas of the Arctic and northern Quebec had temperature anomalies of more than $5^{\circ} \mathrm{C}$ above normal.

Spring 2011 was the only season this year with cooler-than-normal temperatures, although only $0.1^{\circ} \mathrm{C}$ below normal (within the bounds of statistical uncertainty), ranking as the 29th coldest spring since 1948. Most of these negative anomalies occurred from British Columbia, through the Prairies, and into the northern territory of Nunavut. The national average temperature for the summer of 2011 was $1.2^{\circ} \mathrm{C}$ above normal, which makes this the fourth warmest summer since 1948. Autumn 2011 was the third warmest autumn with a na-

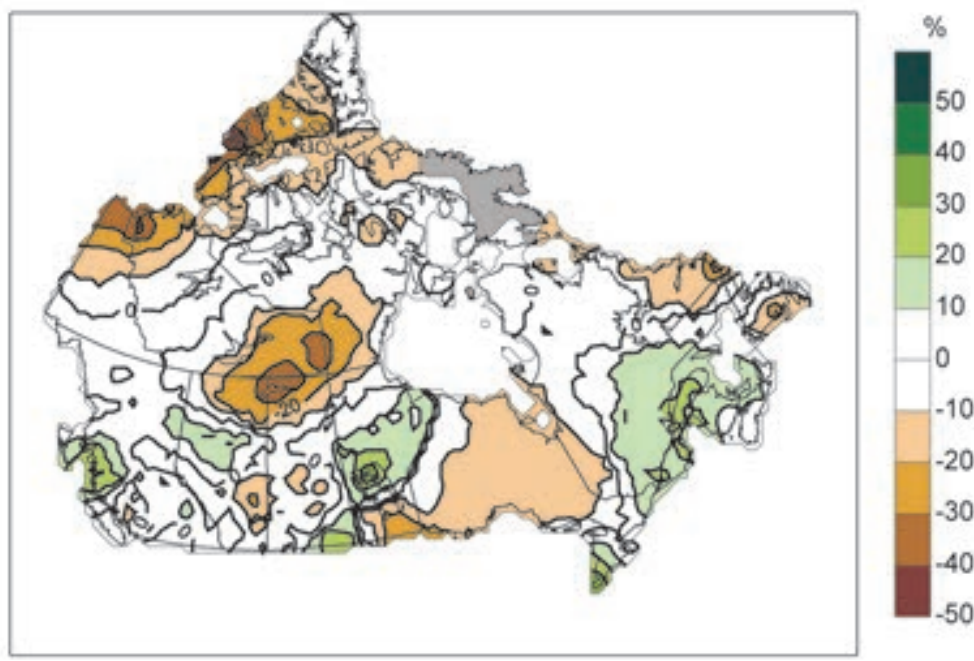

Fig. 7.4. Map of $201 \mathrm{II}$ annual total precipitation percent departure from the 1961-90 normal period.

tional average temperature of $2.2^{\circ} \mathrm{C}$ above normal.

\section{(ii) Precipitation}

Overall, Canada experienced a drier-than-normal year in 2011 ( $5 \%$ below normal), ranking 15th driest in the 64-year period of record. This was also the first year since 1998 with a drier-than-normal national average and was the driest since the persistent wet anomalies which began in 1970 (Fig. 7.3). Most of the drier-than-normal conditions occurred in the northern Yukon, Northwest Territories, and northern Saskatchewan and Alberta, with many regions indicating precipitation that was $80 \%$ of normal (Fig. 7.4). Conversely, the Maritimes, southern Ontario, central Manitoba, and the coastal areas of British Columbia experienced precipitation that was at least $120 \%$ of normal.

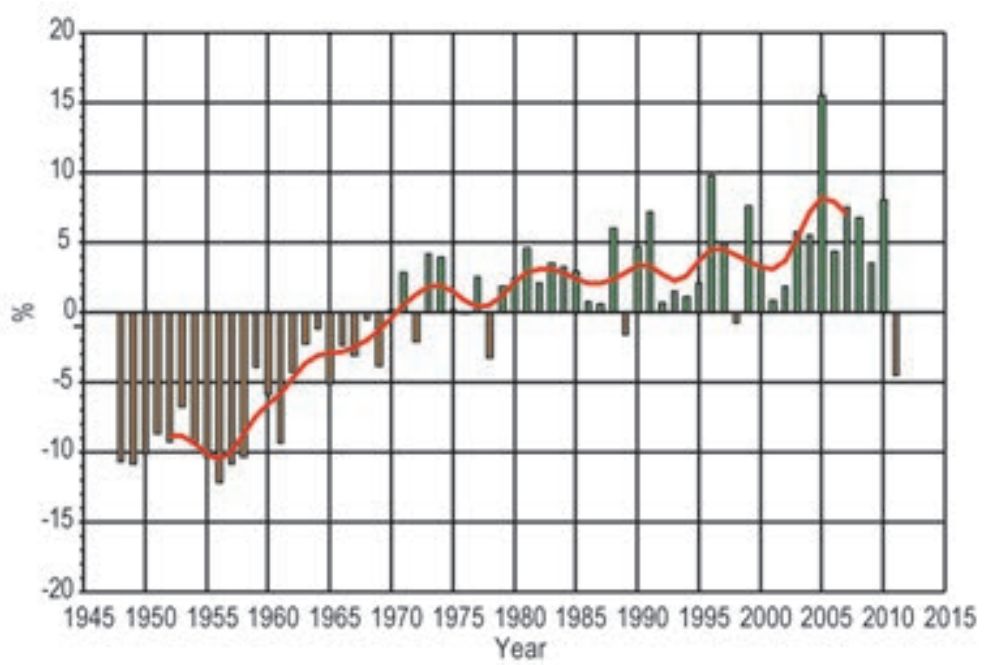

Winter 2010/11 was slightly drier than average, at $97.5 \%$ of normal. Areas of below-normal precipitation include the southern Prairies, Ontario, northern Yukon and Northwest Territories, and southern Nunavut and Northwest Territories, while wetter-thannormal conditions prevailed in northern Nunavut, northern Alberta, and the Maritimes.

Spring 2011 was $87 \%$ of normal (eighth driest), however, with substantial regional variability. From the Prairies northward to the Arctic, conditions were drier than normal, while southern portions of British Columbia, Manitoba, Ontario, Quebec, and New Brunswick were all at least $120 \%$ of normal.

Summer 2012 was the only season with abovenormal precipitation for Canada, (109\% of normal, seventh wettest). The Yukon, Northwest Territories, northern Prairie Provinces, northern Ontario, most of Quebec, and the Maritimes experienced precipitation at least $140 \%$ of normal, while most of Nunavut and southern Manitoba experienced conditions that were less than $60 \%$ of normal.

Autumn saw the return to drier-thannormal conditions for Canada, 90\% of normal, ranking as the 10th driest autumn since national records began in 1948, as the Prairies, northern Yukon, and the Northwest Territories experienced precipitation that was no more than $60 \%$ of normal. Only southern Ontario had above-normal precipitation at $140 \%$.

FIG. 7.3. Graph of 1948-20II annual total precipitation percent departure from 1961-90 normal for Canada. 


\section{(iii) Notable events}

Precipitation this year resulted in a record amount of flooded acreage across central Canada. Officials warned that conditions were ripe for one of the most disastrous spring floods in years, given that several Manitoba lakes and rivers were already near their highest levels ever. Cold temperatures throughout the winter resulted in deep soil-frost penetration, meaning that spring melt water would be prohibited from soaking into the ground. When spring arrived, temperatures remained cold, slowing the inevitable high snowpack melt. Heavy spring rains and snow fell, raising water levels on many of Manitoba's major rivers and lakes. The Red River peaked in Winnipeg on 7 April as the result of an ice jam driving up the water levels. The high stage ranked as the third largest in the last 150 years.

On 9 May the Assiniboine River reached its highest level since 1923 in the city of Brandon, nearly seven meters above average and 20 to 30 times wider in some places. This flooding lasted 120 days and was the largest on record. An estimated 7100 Manitobans were displaced from their homes, with 2700 unable to return by year's end. Flooding swamped three million hectares of farmland and local states of emergency were declared in 70 Manitoba communities. In addition, flood waters forced the closure of 850 roads, including parts of the Trans-Canada Highway.

The spring also brought flooding to southern Quebec, likely the worst for the province since Confederation in 1867. The spring thaw led to swelling rivers that empty into Lake Champlain. Adding to the high water were intense rains, pushing water levels to record highs for 37 days in a row. The overflow moved down the Richelieu River, breaching river banks and flooding hundreds of farms. Losses were estimated at more than $\$ 78$ million (US dollars).

On 21 August, a waterspout came ashore in Goderich, Ontario. Once on land, this tornado caused damage comparable to an EF-3, as measured in the US, causing extensive damage while killing 1 person and injuring 40 others. The Insurance Bureau of Canada estimated that the insured damage exceeded $\$ 100$ million (US dollars).

In western Canada, conditions around the northern Alberta community of Slave Lake were primed for a potentially dangerous fire season in the late spring. A fire broke out on 15 May and spread rapidly due to the $100 \mathrm{~km} \mathrm{hr}^{-1}$ winds. Racing through Slave Lake at $4.2 \mathrm{~km} \mathrm{hr}^{-1}$, the wildfire led to the evacuation of 7000 residents. One-third of the homes and businesses in Slave Lake (about 400 structures) were incinerated in

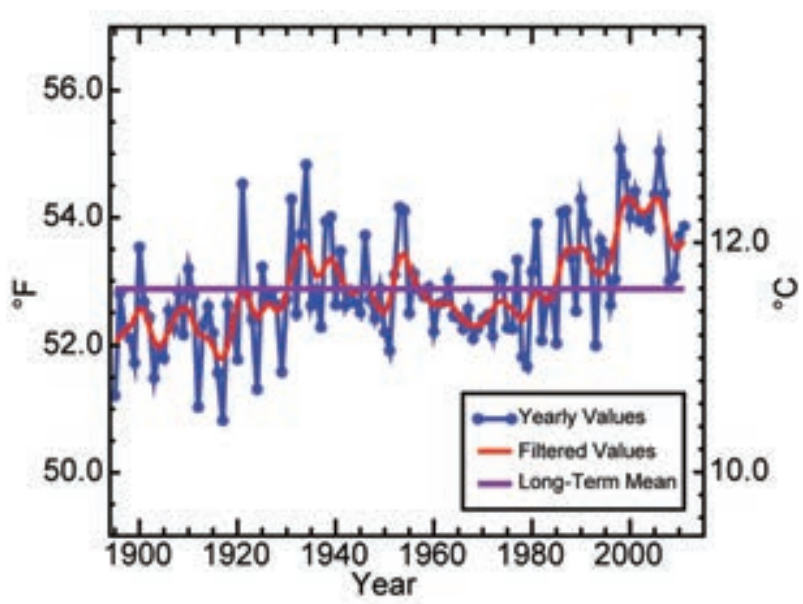

Fig. 7.5. Annual mean temperature $\left({ }^{\circ} \mathrm{C}\right)$ for the contiguous U.S. for the period I895-20II. The filter is a weighted average that is used to smooth the year-toyear changes in the data values that may help identify the presence/absence of trends throughout the data record. (Source: NOAA/NCDC)

the $\sim 1000^{\circ} \mathrm{C}$ heat. The Insurance Bureau of Canada reported the Slave Lake wildfire was the second costliest natural disaster in Canadian history at more than $\$ 700$ million (US dollars), $\$ 400$ million of which were uninsurable losses.

2) United States-J. Crouch, R. R. Heim Jr., and C. Fenimore

Based on preliminary data, the annual average temperature in 2011 for the contiguous United States was $12.2^{\circ} \mathrm{C}$, which is $0.6^{\circ} \mathrm{C}$ above the long-term (1901-2000) average, tying for the 22nd warmest year since records began in 1895 (Fig. 7.5). The nationallyaveraged precipitation during 2011 was slightly below average and ranked as the 51st driest year on record. However, the nationally-averaged value masked regional extremes.

\section{(i) Temperature}

Anomalous warmth dominated much of 2011. As shown in Fig. 7.6a, the 2011 temperature pattern on a statewide level consisted of positive anomalies throughout much of the country. The winter season (December 2010-February 2011) was marked by anomalously cold temperatures across the eastern half of the country. Conversely, the winter season across the western US was near average, with only the West climate region experiencing winter temperatures that were above average. Regional spring (March-May) temperatures were above normal from New Mexico to the Eastern Seaboard. The nationally-averaged summer temperature was the second warmest on record, nearly identical to the summer of 1936 and highlighted by Oklahoma having an average summer 
temperature of $30.5^{\circ} \mathrm{C}$, marking the warmest threemonth period for any state on record. The average autumn (September-November) temperature for the contiguous US was $0.7^{\circ} \mathrm{C}$ above average, ranking as the 16th warmest for the United States.

\section{(ii) Precipitation}

Precipitation for the contiguous US in 2011 was near normal, as the total was only $4.6 \mathrm{~mm}$ below the long-term average of $740 \mathrm{~mm}$. The year was characterized by wetter-than-average conditions across the Ohio Valley and Northeast and drier-than-average conditions across the southern tier of the country. At the state level, it was a record-wet year for Connecticut, Indiana, Kentucky, New Jersey, New York, Ohio, and Pennsylvania. In contrast, Texas had its second driest year on record, at $54 \%$ of normal (Fig. 7.6b). The year began with about $18 \%$ of the country in moderate to extreme drought (based on the US Drought Monitor), mainly stretching from the Southwest through the Central Plains and into the Southeast.

It was the 20th driest winter (December-February) for the contiguous US since national records began in 1895. Consistent with the moderate-to-strong La Niña, most of the southern half of the nation was drier than average, while the Northern Plains were wetter than average. At the end of the 2010/11 winter, much-above-average snowpack was observed for most of the western mountains, in excess of $180 \%$ of normal across the Cascades, Sierra Nevadas, the Great Basin, and the Northern and Central Rockies. Below-normal snowpack was observed across much of the Southern Rockies of Arizona, New Mexico, and southern Colorado. Some areas of New Mexico had end-of-season snowpack totals below their 25th percentile. The winter average snow cover extent for the contiguous US ranked as the fifth largest in the 1966-2011 period of record.

The spring (March-May) precipitation across the United States varied greatly with 10 states record wet across the Northwest, Ohio Valley, and Northeast, while an additional 11 states had spring precipitation totals ranking among their ten wettest. However, the southern US continued to be drier than average during spring.

Summer (June-August) 2011 was the 17th driest for the US, with above-average precipitation across the Northeast, Northern Plains, and California. The southern United States continued to be dry as Texas had its driest summer on record, with just $62.0 \mathrm{~mm}$ of precipitation, compared with the previous driest summer in 1956 of $88.4 \mathrm{~mm}$. The dry conditions,
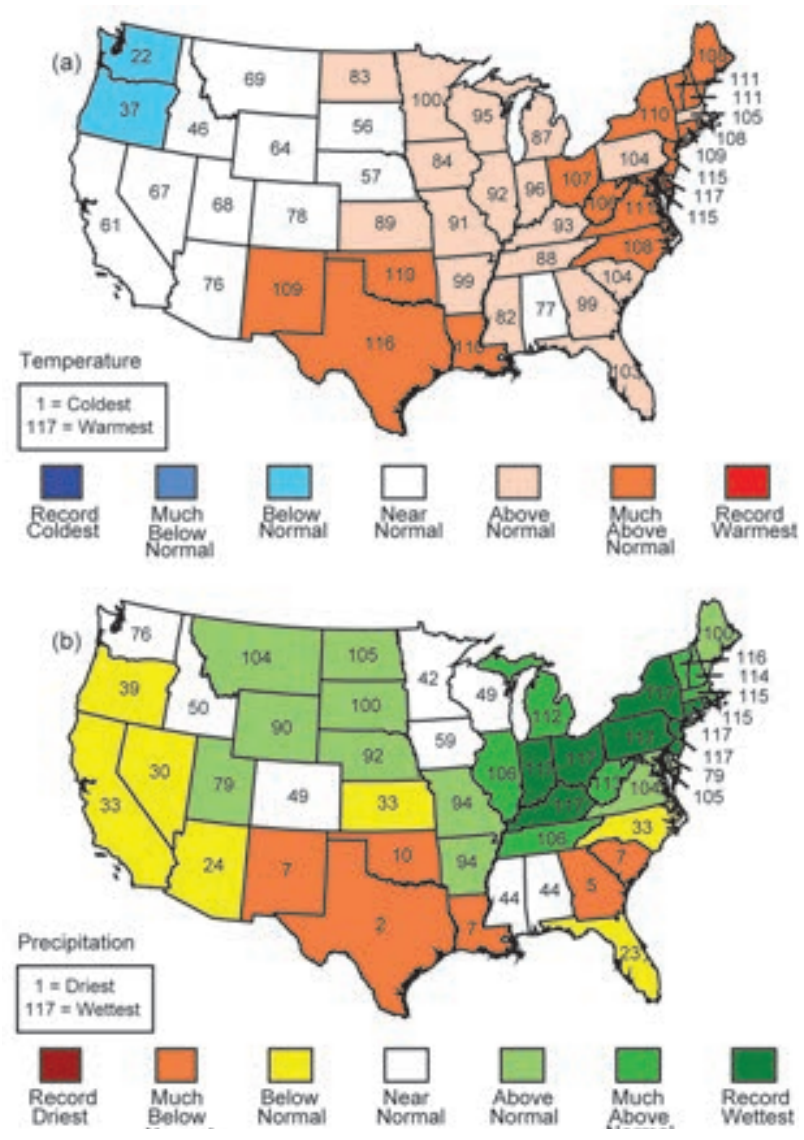

FIG. 7.6. Statewide ranks of annual $201 \mathrm{I}$ (a) temperature and (b) precipitation. A rank of 117 represents the warmest/wettest year since 1895. Much-abovenormal temperature/precipitation is defined as occurring in the top $10 \%$ of recorded years. Above-normal temperature/precipitation is defined as occurring in the warmest/wettest third of recorded years. Muchbelow-normal temperature/precipitation is likewise the bottom $10 \%$ of coolest/driest years since 1895 , and below normal is defined as the coolest/driest third of the distribution. (Source: NOAA/NCDC)

combined with the record heat, caused Texas to experience record potential evapotranspiration (natural water demand). Several climate divisions in Texas, New Mexico, Oklahoma, and Louisiana, as well as the Rio Grande and Texas Gulf Coast river basins, had record low values for the Palmer Hydrological Drought Index in the 117-year record.

Autumn precipitation was near average for the contiguous US. Parts of the Northeast and Ohio Valley had above-average precipitation, with Ohio and Pennsylvania being record wet. A significant portion of the seasonal precipitation came from Hurricane Irene and the remnants of Tropical Storm Lee. Many of the states west of the Mississippi River were near 
average to drier than average. Minnesota had its third driest autumn on record.

\section{(iii) Notable events}

The US tornado season of 2011 was one of the most destructive and deadly on record. During the year, seven individual tornado and severe weather outbreaks caused damage exceeding \$1 billion (US dollars), with total damage exceeding $\$ 28$ billion (US dollars). This represents the most damage from severe weather in a single year since record keeping began in 1980. The 2011 confirmed tornado count stood at 1676, with 33 tornado reports still pending for December. This places 2011 as the second most active year on record for number of tornadoes since the modern record began in 1950 .

The most active tornado period of the year was the spring (March-May), with 1150 confirmed tornadoes across the country, the most on record for any three-month period. The most active month was April, when 758 tornadoes were confirmed. This is the most on record for any month, surpassing the 550 reported in May 2003, and was driven by the two largest tornado outbreaks on record during 14-16 April and 25-28 April. These outbreaks both surpassed the April 1974 Super Outbreak for the most tornadoes during a single outbreak. The 199 tornadoes on 27 April was the most for any single day on record and the 316 fatalities on the same day was the most in the modern period of record for a 24 -hour period. The 22 May Joplin, Missouri, tornado caused damages estimated at $\$ 3$ billion (US dollars) and led to 158 fatalities, surpassing the previous records for both damages and fatalities from a single tornado in the modern tornado record.

During the late spring and early summer, historic flooding impacted much of the central United States. An above-average snowpack across the Northern Rockies, Northern Plains, and Ohio Valley combined with an anomalously wet spring caused significant runoff into the rivers. Some of the worst flooding occurred along the Mississippi, Ohio, Missouri, Souris, and James Rivers. The high water levels put significant stress on the levee systems along these rivers, and several levees were deliberately breached to flood farm lands and protect cities. Record historical crests were set along the Missouri and Mississippi
Rivers, surpassing the floods of the 1920s and 1930s. Total damages approached $\$ 5$ billion (US dollars).

During 2011, approximately 74500 fires burned over 3.5 million hectares across the US. The southern US had the third most active wildfire year with respect to acres burned since records began 2000. Over 1.5 million hectares burned across Texas, the most of any state and $43 \%$ of the national total. The 2011 damages exceeded $\$ 1$ billion (US dollars).

3) Mexico-R. Lobato-Sánchez, R. Pascual-Ramírez, and A. Albanil-Encarnación

After a very wet rainy season in 2010, Mexico experienced its second warmest year since 1971 and thirteenth driest year since 1941. According to preliminary data from the National Meteorological Service of Mexico, the nationally-averaged annual mean temperature was $21.8^{\circ} \mathrm{C}, 1.1^{\circ} \mathrm{C}$ above the normal temperature. Total precipitation was below average, at $89 \%$ of normal.

\section{(i) Temperature}

The national average temperature for 2011 was $21.8^{\circ} \mathrm{C},\left(1.1^{\circ} \mathrm{C}\right.$ above the $1971-2000$ normal $)$ and ranked second only to 2006 as the warmest year since 1971 (Fig. 7.7). The annual average temperature has been above normal since 1993. In 2011, the annual mean temperature was between $1.0^{\circ} \mathrm{C}$ and $1.3^{\circ} \mathrm{C}$ above normal for much of the country. However, some states such as Baja California and the central states of Michoacan, Mexico State, Morelos, Tlaxcala, and Puebla were cooler than normal, while Sonora, Morelos, and Yucatan were near normal (Fig. 7.8a).

Daily mean temperatures for 2011 are shown in Fig. 7.9. Through the year, the average temperature was influenced by three events. The first was an early February winter storm in the northwest that impacted the average national temperature, which dropped nearly two standard deviations below the long-term average. Second, a persistent climatic pattern led to the mean temperature during spring and summer being warmer than average, marking values over the

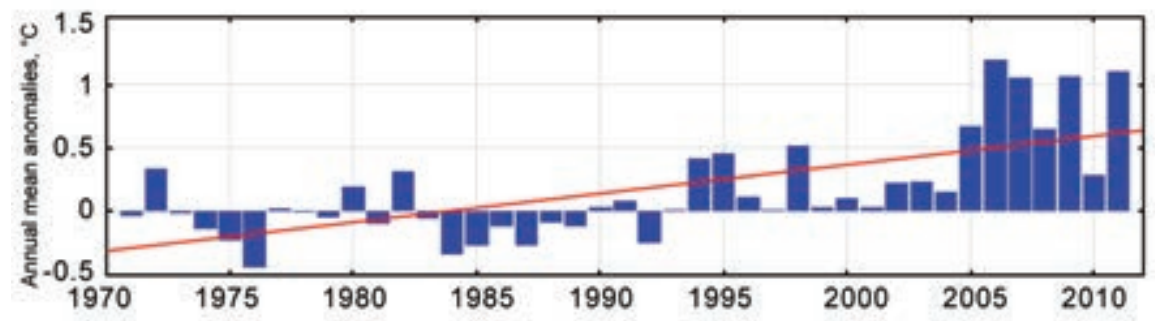

FIG. 7.7. Annual mean temperature anomalies $\left({ }^{\circ} \mathrm{C}\right)$ for Mexico for the period 197I-20 II. The red line represents the trend. (Source: Meteorological Service of Mexico) 
(a)

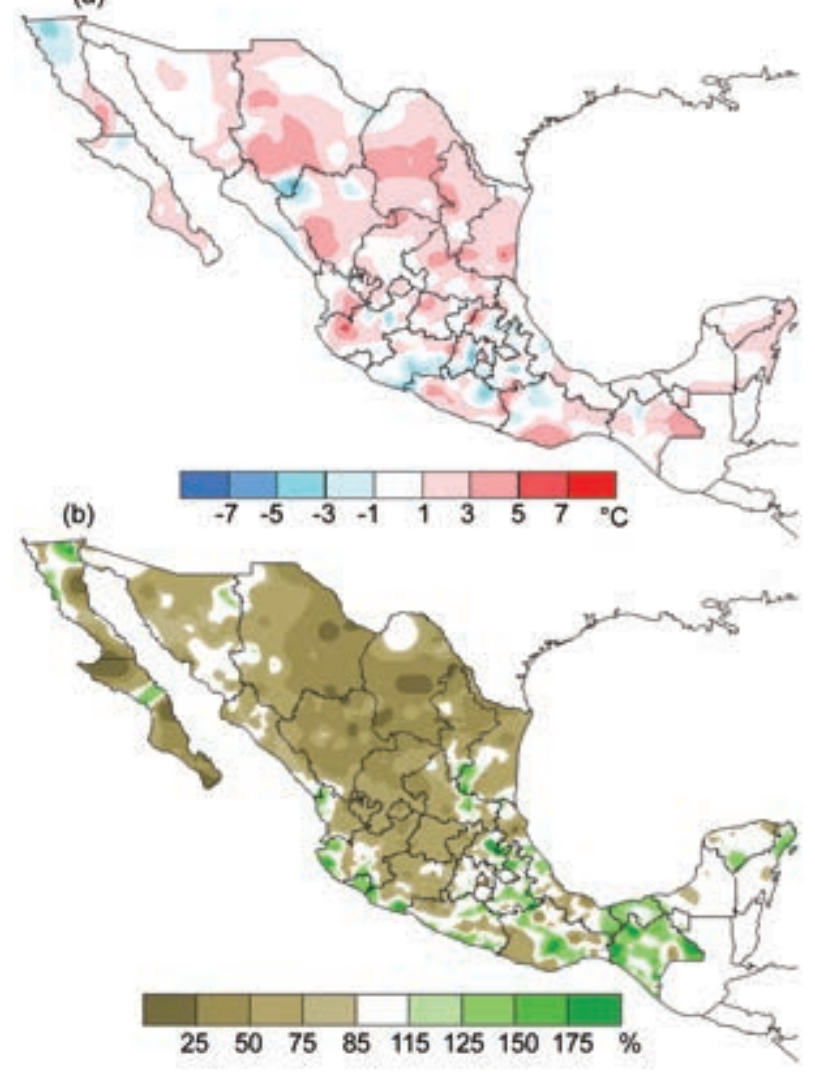

FIG. 7.8. (a) $201 \mathrm{I}$ annual mean temperature anomalies ( ${ }^{\circ}$ C) for Mexico (based on 197I-20 I0 mean) and (b) 201 I annual precipitation anomalies (\% of I94I-20I0 mean). (Source: National Meteorological Service of México)

threshold of two standard deviations. Finally, in late November, a cold front caused the average national temperature to drop below the threshold of two standard deviations.

January was the coldest month of the year with $15.9^{\circ} \mathrm{C}\left(0.6^{\circ} \mathrm{C}\right.$ below normal, $)$ while the period October-December registered a mean of $18.9^{\circ} \mathrm{C}$ that was ranked as normal. June was the warmest month of 2011 averaging $25.9^{\circ} \mathrm{C}\left(2.9^{\circ} \mathrm{C}\right.$ above normal). Through the rainy season (July-September), the mean temperature was $25.5^{\circ} \mathrm{C}\left(2.4^{\circ} \mathrm{C}\right.$ above normal). The

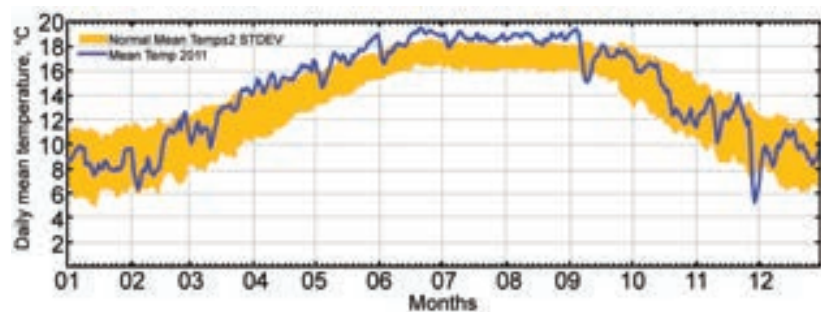

FIG. 7.9. Daily mean temperature in $201 \mathrm{I}$ (solid blue). Shaded area represents the normal threshold of \pm 2 standard deviations derived from 1971-2000. (Source: National Meteorological Service of Mexico) states of Coahuila, Nuevo León, and Zacatecas each had the warmest year over the last 41 years. Temperatures in Chihuahua, Durango, Aguascalientes, Distrito Federal, Tlaxcala, and Campeche ranked as second warmest. Guanajuato, Hidalgo, Quintana Roo, and Tamaulipas each ranked among their top five warmest.

\section{(ii) Precipitation}

Nationally, the year 2011 ranked as the thirteenth driest for Mexico since 1941, averaging $697.2 \mathrm{~mm}$, $\sim 90 \%$ of normal. Rainfall was much below normal during nine months. Only June, July, and November had precipitation near or above normal. The rainfall spatial distribution showed marked differences between the southern and northern regions of the country (Fig. 7.8b). The wettest zones with annual rainfall over $1500 \mathrm{~mm}$ were located southward of $22^{\circ} \mathrm{N}$ covering the zones of Nayarit, Colima, Guerrero, Veracruz, Tabasco, and Chiapas; Colima, Chiapas, and Quintana Roo were the wettest states across the country. In contrast, total rainfall of less than $50 \%$ of normal was observed from central zones to northward regions. Below-normal rainfall was reported in Coahuila, Chihuahua, Durango, and Baja California, all averaging less than $25 \%$ of normal. Durango and Aguascalientes were classified as the driest, with Zacatecas and Guanajuato second driest, Baja California Sur and Coahuila the third driest, and Nuevo Leon and Chihuahua reached the fourth driest year.

\section{(iii) Notable events}

The year 2011 set a new record with the largest area (956 405 hectares) burned by forest fires, exceeding the previous record of 1998 with 843633 hectares; Coahuila was the federal state with the largest area burned, $44 \%$ of the total.

The long-term drought during 2011 was due to a significant reduction in rainfall beginning in late autumn 2010. In June, the drought-affected region expanded to $85 \%$ of the country; this decreased progressively with the onset of the rainy season, reaching $55 \%$ in September, but increased again in October to $61 \%$. By late December, the drought impacts decreased slightly in the north, mainly due to the winter storms described in the previous section; however, it had expanded towards the central region. The area that experienced moderate to exceptional drought covered $54.6 \%$ of the nation, according with the North American Drought Monitor definition, with $9.7 \%$ in the highest category of exceptional drought. 
As of the date of this publication, the impacts of the drought on agriculture, livestock, and human populations have not been completely calculated. Most of the dams located in the northern region had their lowest levels following a poor recharge in the summer 2011. The bean crop dropped by almost half due to the late onset of the rainy season, delaying the sowing. Only $53.4 \%$ of croplands were planted in the main bean-producing states of Chihuahua, Durango, Zacatecas, and San Luis Potosí; in Sinaloa, less than $50 \%$ of agricultural lands were cultivated during the fall-winter 2011/12 season and pastures were not sufficient to feed the livestock. The federal government implemented national and local programs to support the population in order to mitigate the drought impacts, including water delivery for domestic use and temporary employment programs to reinvigorate local economies.

\section{c. Central America and the Caribbean}

I) Central America-J. A. Amador, H. G. Hidalgo, E. J. Alfaro, B. Calderón, N. P. Mora, and I. L. Rivera

For this region, 11 stations were analyzed from 6 countries. The stations located on the Caribbean side are: Phillip Goldson International Airport (MZBZ), Belize; Puerto Barrios, Guatemala; Puerto Lempira, Honduras; Puerto Cabezas, Bluefields, Nicaragua; and Puerto Limón, Costa Rica. The following stations are located on the Pacific side: Tocumen International Airport (MPTO) and David, Panamá; Liberia, Costa Rica; Choluteca, Honduras; and San José, Guatemala.

\section{(i) Temperatures}

On the Caribbean side, the mean temperature for the 2001-10 decade was warmer than the 1971-2000 average, with $0.5^{\circ} \mathrm{C}$ above average at MZBZ, Puerto Lempira, and Puerto Cabezas, and Bluefields. Meanwhile, near-average conditions were present at Puerto Barrios and Puerto Limón. The 2011 mean temperature was near average when compared to the 2001-10 decade, with the exception of Puerto Barrios and Puerto Lempira. During the last decade, the Pacific southernmost stations at MPTO and David, experienced above-average temperatures. In contrast, Liberia had cooler-than-average temperatures, while the northernmost stations of Choluteca and San José had near-average temperatures. A striking feature of 2011 was the higher frequency of near mean temperature conditions and smaller frequency of high mean temperature values in all the Pacific side stations (shown as green line distributions in Fig. 7.10). Since many stations have a large amount of missing data in their daily minimum and maximum temperatures, these two variables were analyzed regionally by taking an average of the five stations on the Pacific slope and the six stations on the Caribbean side. Both minimum and maximum temperatures for the last decade and 2011 were warmer than the 1971-2000 average in the Caribbean and Pacific basins.

\section{(ii) Precipitation}

Across Central America's Pacific side, the stations experienced a near-average rainy season (May-November), with the exception of Choluteca and David, which had a significant early start when compared to the 1971-2000 average. However, when compared to the 2001-10 decade, most stations had a normal start to the rainy season, with the exception of David, which had a late start. Consistent with the La Niña influence and the impact of warmer-than-normal Caribbean sea surface temperatures, the end of the rainy season was later than normal across all stations. With respect to the previous decade, 2011 had a late ending in all stations (but significant in only two stations) with the exception of Choluteca, which showed normal conditions.

\section{(iii) Notable events}

The year 2011 was slightly below average in terms of tropical storm activity in the Caribbean basin $\left(6^{\circ} \mathrm{N}-24^{\circ} \mathrm{N}, 92^{\circ} \mathrm{W}-68^{\circ} \mathrm{W}\right)$, which is unusual considering the development of La Niña and much weaker-than-average $900 \mathrm{hPa}$ winds (inserted arrows in Fig. 7.10) during the period of the prevalence of the Caribbean low-level jet (a characteristic of La Niña events in the region and a condition favorable for tropical cyclone formation; Amador et al. 2006). In the Caribbean basin, Tropical Storm Harvey (19-22 August) and Hurricane Irene (21-28 August), and in the Pacific, Tropical Storm Dora (18-24 July), impacted Central America in different ways, but no human casualties were reported from any of those systems.

The significant 2011 storms that wreaked havoc across Central America were Tropical Depression 12-E (12-13 October) and Hurricane Rina (23-28 October). Rina triggered landslides and floods due to heavy rains in Belize, Guatemala, Honduras, and Nicaragua. A total of 46 fatalities, mostly from Honduras and Nicaragua, were attributed to Rina. Despite the relatively high storm activity in the eastern Pacific, the major regional impact to economic and social welfare was not caused by a hurricane, but by Tropical Depression 12-E (approximate trajectory in red dots in Fig. 7.10). This storm caused significant 


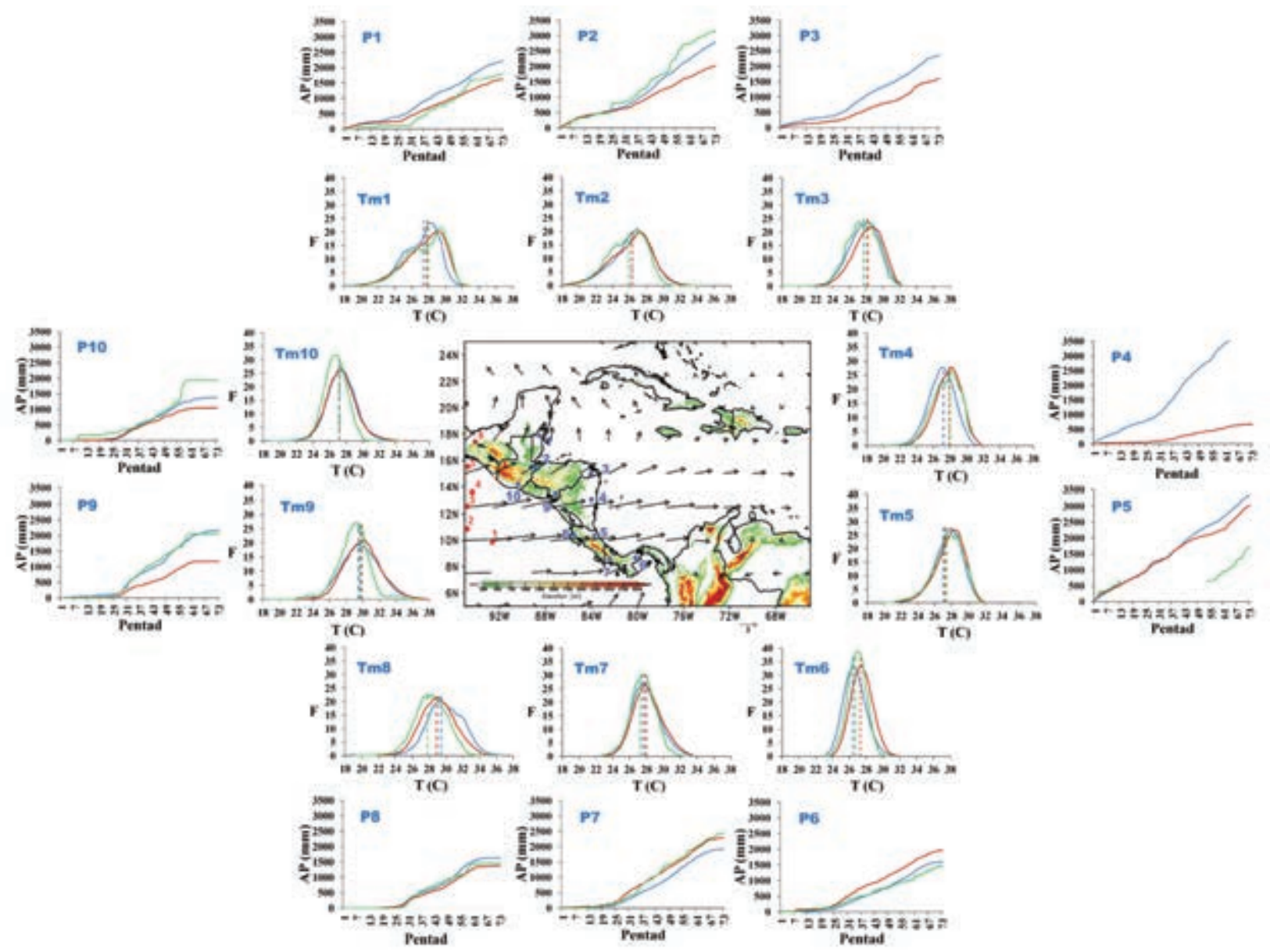

FIG. 7.10. Mean surface temperature frequency $(\mathrm{Tm})$ and accumulated pentad precipitation $(P)$ time series shown for the 10 stations (blue dots depict station location) in Central America: (I) Phillip Goldson International Airport, Belize; (2) Puerto Barrios, Guatemala; (3) Puerto Lempira, Honduras; (4) Puerto Cabezas and Bluefields (showed at their mean geographical position; see text for explanation), Nicaragua; (5) Puerto Limon, Costa Rica; (6) Tocumen International Airport, Panama; (7) David, Panama; (8) Liberia, Costa Rica; (9) Choluteca, Honduras; and (10) San Jose, Guatemala. Blue line represents the I97I-2000 average (base period), red the 200 I-10 decade, and green 20II. Note that stations (3) and (4) do not show 20II precipitation due to a large number of missing data, and station (5) only shows available data for the beginning and ending of the rainy season. The start and end of the rainy season is calculated as follows: the precipitation pentad data were analyzed starting from the beginning of the year. If in any particular pentad at time " $t$ " the precipitation was greater or equal to $25 \mathrm{~mm}$, and the precipitation of day $\mathrm{t}+\mathrm{I}$ was also greater or equal to $25 \mathrm{~mm}$, and the precipitation of $t+2$ was greater than zero, it was considered that the rainy season started at time $t$. A similar procedure was used for computing the end of the rainy season, with the exception that the procedure was applied from the end of the year backwards. Wind anomalies at $925 \mathrm{hPa}$, based on 1958-99 for July. The approximate track for Tropical Depression I2-E is shown for locations I to 6 (red dots) at 7 October 00Z, 7 October I2Z, II October 12Z, 12 October 00Z, 12 October 12Z, and 13 October 00Z, respectively. (Source: NOAA/NCDC)

economic losses in Guatemala, El Salvador, Honduras, Nicaragua, and Costa Rica $(\$ 397, \$ 902, \$ 204, \$ 445$, and $\$ 0.1$ in US million dollars, respectively) with a total of 117 human casualties. A lesson learned from Tropical Depression 12-E is that the relative position and low system motion of a tropical depression with respect to highly vulnerable areas, such as those in Central America, are as important as tropical storm intensity.
2) The Caribbean - M. A. Taylor, T. Stephenson, A. Trotman, J. Spence, 0. Martínez-Sánchez, G. Votaw, I. González-García, R. Pérez-Suárez, B. Lapinel-Pedroso, A. León-Lee, D. BoudetRouco, and N. González-Rodriguez

The climate conditions across the Caribbean during 2011 were largely impacted by the end of the La Niña event in May, the onset of another La Niña in October, and very warm Caribbean sea surface temperatures (SSTs) in the Main Development Region 

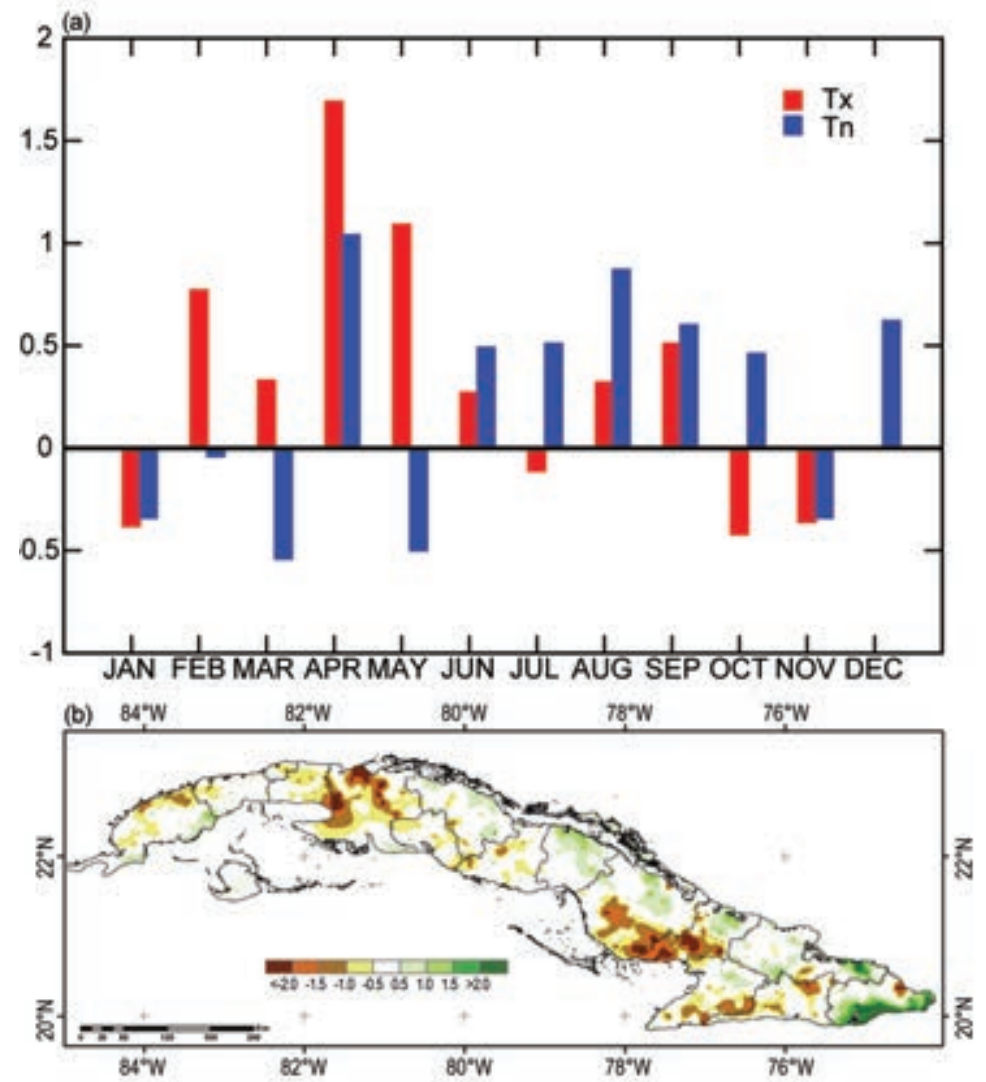

FIG. 7.II. (a) 2011 monthly mean maximum (Tx) and minimum (Tn) temperature anomalies $\left({ }^{\circ} \mathrm{C}\right)$ for Cuba; (b) Annual precipitation anomalies represented as Standardized Precipitation Index (unitless; based on 197/-2000 base period). (Source: Institute of Meteorology of Cuba)

(MDR) for hurricanes $\left(10^{\circ} \mathrm{N}-25^{\circ} \mathrm{N}, 80^{\circ} \mathrm{W}-20^{\circ} \mathrm{W}\right)$ in June and July.

\section{(i) Temperatures}

Parts of the eastern Caribbean experienced belowaverage temperatures for the latter half of the year. Antigua recorded its third coolest July and second coolest August and experienced slightly below-average temperatures in September and December. In Dominica, the 2011 mean temperature at Melville Hall Airport (TDPD) was $26.7^{\circ} \mathrm{C}$, which was the lowest value in the last 30 years.

In Puerto Rico, the 2011 average maximum temperature at the Luis Muñoz Marin International Airport (TJSJ) in San Juan was $0.6^{\circ} \mathrm{C}$ cooler than the $1981-2010$ average of $30.4^{\circ} \mathrm{C}$. The mean temperature at TJSJ was below average for $39 \%$ of the year and above average during $34 \%$ of the year. The
2011 average minimum temperature at TJSJ was $23.6^{\circ} \mathrm{C}$, which is $0.5^{\circ} \mathrm{C}$ cooler than the 1981-2010 average. Across the US Virgin Islands, the mean annual temperature at Henry E. Rohlsen Airport (TISX) in Saint Croix and Cyril E. King Airport (TIST) in Saint Thomas was $0.7^{\circ} \mathrm{C}$ and $0.6^{\circ} \mathrm{C}$ below average, respectively.

In Cuba, monthly minimum and maximum temperatures were near average during 2011 (Fig. 7.11a). However, April and May were significantly warmer than average, with maximum temperature anomalies above $1.0^{\circ} \mathrm{C}$ across all of Cuba. April 2011 was the third warmest April of the last 30 years in Cuba. There were significant positive anomalies of the effective temperature throughout the country, and positive anomalies (as high as $1.4^{\circ} \mathrm{C}$ ) across the western and central regions. In addition, the percentage of days with maximum temperatures above the 90 th percentile was the highest since April 1961.

For Jamaica, extreme temperatures were recorded by several automatic weather stations across the island. The highest maximum air temperature recorded was $37.3^{\circ} \mathrm{C}$, at Barton Isles, St. Elizabeth, in July, while an extreme minimum air temperature of $13.8^{\circ} \mathrm{C}$ was recorded at Bunkers Hills, Trelawny, in February.

\section{(ii) Precipitation}

Precipitation patterns during the Caribbean's dry season (December-April) were impacted by the 2010/11 La Niña event. The impact held true to noted

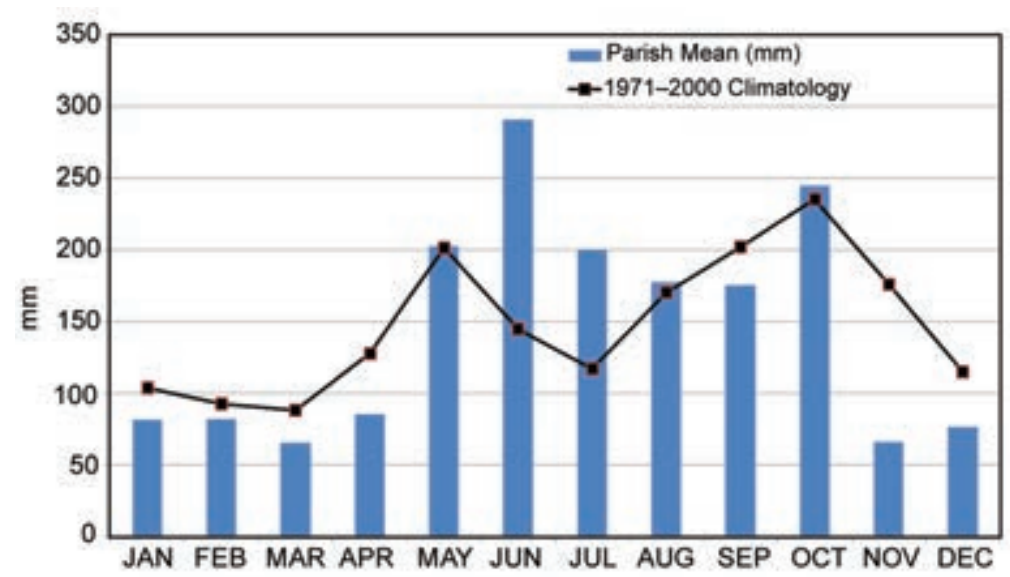

FIG. 7.I2. 20 II mean monthly rainfall $(\mathrm{mm})$ for Jamaica (blue bars) and long-term average 1971-2000. 
tendencies (Stephenson et al. 2007), with the Caribbean being wetter than average in the south and east, but drier than average in the north and northwest.

In Jamaica, rainfall totals were $70-90 \%$ of normal during every month through April, with the largest deficit (67\% of normal) occurring in April (Fig. 7.12). The Dominican Republic reported a similar deficit in rainfall for January-March (SERVIR 2011). In Cuba, $82 \%$ of the country experienced moderate to severe drought conditions during March-May, and in Puerto Rico, only $85 \%$ of the normal precipitation fell through April. St Croix's TISX recorded its driest January on record.

In contrast, the southern and eastern Caribbean experienced much-above-average rainfall. The Barbados Meteorological Service references a "very wet" dry season with cumulative rainfall of $507.2 \mathrm{~mm}$ during January-May, almost twice the 1961-90 average. Rainfall in April was $143.3 \mathrm{~mm}$, or twice the monthly mean, and through May there were approximately five more rain days $(\geq 1 \mathrm{~mm}$ ) per month than the longterm average. The wet "dry season" contributed to an annual rainfall of $1681 \mathrm{~mm}$, the fifth highest since 1942. Similarly, dry season rainfall at both Canefield Airport (TDCF) and Melville Hall Airport (TDPD) in Dominica was $150 \%$ of the $1982-2010$ average, with TDCF recording $2458.5 \mathrm{~mm}$ - the highest since 1982. Monthly rainfall at the E.T. Joshua Airport (TVSV) in St. Vincent and the Grenadines for January-April exceeded each month's long-term average (1979-2011 base period), with April rainfall $(236.7 \mathrm{~mm})$ being more than twice the average of $92.8 \mathrm{~mm}$. In St. Lucia, April was the wettest month for the year, with 407.9 $\mathrm{mm}$, which represented the highest April amount recorded at Hewanorra Airport (TLPL) since 1973.

An abnormally wet "dry season" was also noted for Grenada (above average for January-April) and for Trinidad (see special issue of CAMI Monthly Bulletin, 2012, Vol. 5, No. 1).

By June, with the decline of La Niña and the onset of very warm Caribbean SSTs, most islands experienced average or above-average rainfall, with a few records set between June and August due to the passage of a series of tropical systems, including Tropical Storms Emily and Irene. From as early as April, SSTs in the MDR were $0.5^{\circ} \mathrm{C}$ above average, representing the 14th warmest April SSTs in the last 100 years. The warm surface temperatures persisted through July, with June recording the third largest anomaly since 1950. Rainfall totals in June and July were above average, particularly across the Greater Antilles, significantly offsetting the deficit previously recorded for these northern territories, and, notably occurring during the period referred to as the midsummer drought (July-August). For Jamaica, the July rainfall total $(200 \mathrm{~mm})$ was the seventh highest since records began in 1881 (Fig. 7.12). In Antigua, the July and August rainfall were the second and ninth highest, respectively for those months, since national records began in 1928. St. Croix's TISX had its second wettest June and third wettest July. Martinique had its seventh wettest July and second wettest August on record. In Puerto Rico, a rainfall surplus of $914.4 \mathrm{~mm}$ from late May through September was reported for the San Juan Metro Area with $141 \%$ of the normal precipitation falling across all Puerto Rico. In fact, summer 2011 was the wettest summer on record at TJSJ with a rainfall total of 1098 $\mathrm{mm}$ between June and August. For May-November, most islands reported near-normal rainfall or slightly above-normal activity. The Caribbean Drought and Precipitation Monitoring Network (CIMH 2012) noted that August-October rainfall in the eastern Caribbean islands of Trinidad, Barbados, and St. Lucia was normal, while conditions for Grenada, St. Vincent, Dominica, Antigua, and St. Kitts ranged from moderately to abnormally wet. St. Thomas's TIST had its wettest August and driest October on record. In the north, Jamaica's rainfall was near aver-
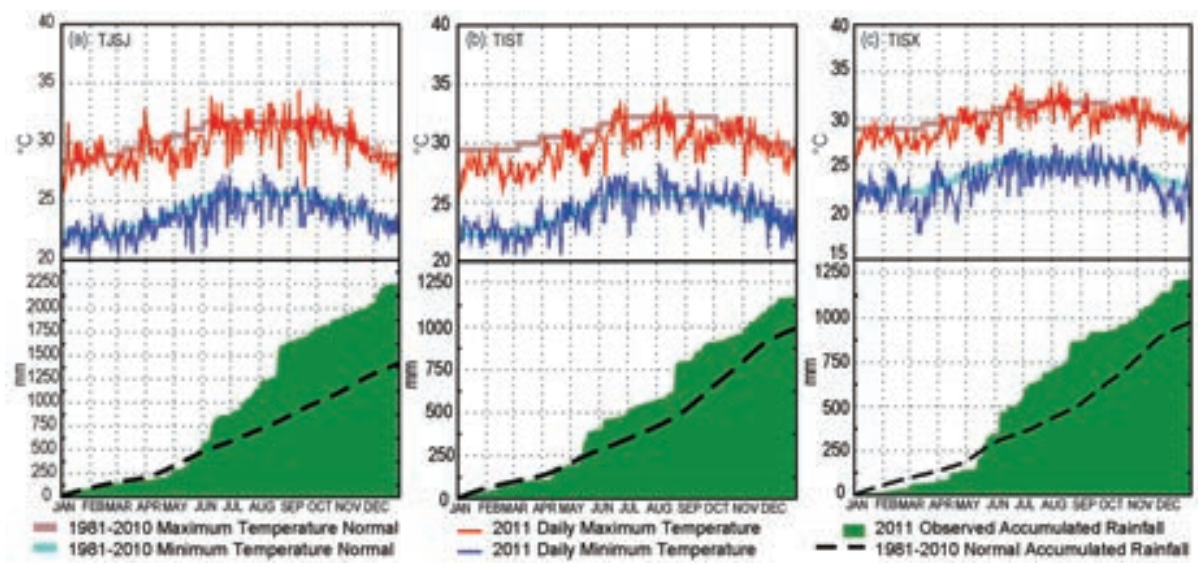

FIG. 7.13. top: 2011 observed daily maximum temperature $\left({ }^{\circ} \mathrm{C}\right.$, red), $1981-2010$ daily maximum temperature normal $\left({ }^{\circ} \mathrm{C}\right.$, brown), $20 \mathrm{II}$ observed daily minimum temperature $\left({ }^{\circ} \mathrm{C}\right.$, blue $), 198 \mathrm{I}-2010$ daily minimum temperature normal $\left({ }^{\circ} \mathrm{C}\right.$, light blue). bottom: $201 \mathrm{I}$ accumulated rainfall $(\mathrm{mm})$ and $198 \mathrm{I}-2010$ mean accumulated rainfall (mm) for (a) TJSJ, (b) TIST, and (c) TISX. (Source: NOAA/NWS) 
age. By December, with the onset of the Caribbean dry season, the La Niña pattern of a dry northwet south appeared to reemerge. Whereas Barbados, Trinidad, and St. Kitts were wetter than average, Jamaica was drier than average.

Overall, in Puerto Rico, 2011 ranked as the second wettest year in nearly 113 years of record keeping in the San Juan Metro Area. An impressive rainfall total of $2239 \mathrm{~mm}$ was reported at TJSJ, which is $807.7 \mathrm{~mm}$ above average (Fig. 7.13a). This total was 34.3 $\mathrm{mm}$ less than 2010, the wettest year on record. According to the Cooperative Weather Observer
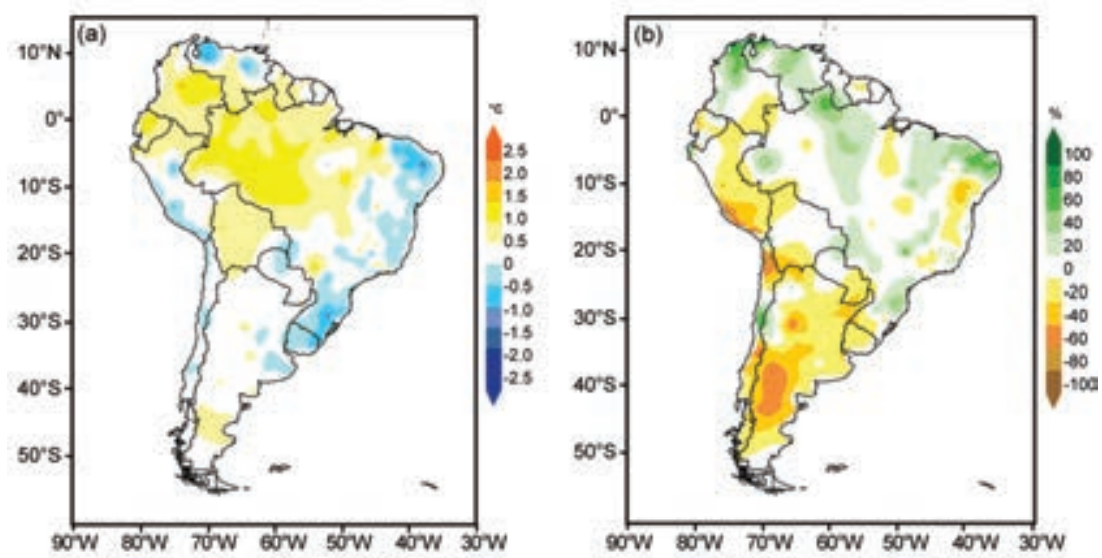

Fig. 7.14. (a) $201 \mathrm{II}$ annual mean temperature anomalies $\left({ }^{\circ} \mathrm{C}\right)$ for South America (197I-2000 base period), and (b) $201 \mathrm{I}$ annual precipitation anomalies (\%) (197I-2000 base period). (Sources: National Meteorological Services of Argentina, Brazil, Bolivia, Chile, Colombia, Ecuador, Paraguay, Peru, Suriname, Uruguay, and Venezuela. The data was compiled and processed by CIIFEN, 20II)

Data, 2011 was a wet year across

the entire forecast area, with $126 \%$ of the normal precipitation falling across all of Puerto Rico and $121 \%$ of normal falling across the US Virgin Islands (USVI). 2011 ranked as the ninth wettest year on record at TIST, as well as TISX, with rainfall totals of $1172 \mathrm{~mm}$ and $1212 \mathrm{~mm}$, respectively (Figs. 7.13b,c).

For Cuba, the annual average rainfall for 2011 was near average. Based on the Standardized Precipitation Index (SPI), $20 \%$ of the country had above-average rainfall accumulation during 2011, with 5\% of the country falling in the moderate to extreme category, while $33 \%$ of the country reflected deficit, with $15 \%$ in the moderate to extreme category (Fig. 7.11b).

\section{(iii) Notable events}

Significant 2011 storms for Caribbean islands include Tropical Storm Emily and Hurricane Irene. Although Emily was a fairly disorganized storm as it tracked into the northeastern Caribbean, it generated strong thunderstorms and gusty winds along its path. Within a 72-hour period on 31 July-3 August, more than $225 \mathrm{~mm}$ of rainfall was recorded at St. Vincent and Grenadine's TVSV. On 2-3 August, Emily tracked south of Puerto Rico and the USVI, leaving rainfall accumulations between $102 \mathrm{~mm}$ and $152 \mathrm{~mm}$, with locally higher amounts of up to $254 \mathrm{~mm}$. The higher rainfall accumulations were observed across the eastern half and portions of southwest Puerto Rico. After tracking over Hispaniola and exiting the northeastern Caribbean on 6 August, its remnants regenerated into a tropical storm, before dissipating the next day. In Puerto Rico, the storm caused at least $\$ 5$ million (US dollars) in infrastructure damage.

Hispaniola was also impacted, where five fatalities were reported in addition to nearly 8000 homes being damaged.

Also notable was Hurricane Irene, which was the first hurricane of the season. Irene originated from a well-defined Atlantic tropical wave east of the Lesser Antilles. On 21 August, Irene made landfall in Puerto Rico at Category 1 hurricane strength, resulting in severe flooding, significant property damage, and one fatality. The 72-hour maximum precipitation totals ranged from $381 \mathrm{~mm}$ to $559 \mathrm{~mm}$. With rainfall from this storm, August 2011 ended as the wettest August on record as well as the wettest month ever across the San Juan Area, with a rainfall total of $471.4 \mathrm{~mm}$. Irene tracked just north of Hispaniola as an intensifying cyclone, causing heavy rainfall and strong winds and killing seven people. After crossing the Turks and Caicos Islands, the hurricane quickly strengthened into a Category 3 major hurricane while passing through The Bahamas. It left behind a trail of extensive structural damage in its wake, primarily on Cat, Mayaguana, Acklins, and Crooked Islands. Government reports noted that upwards of $90 \%$ of all homes and structures on the islands were damaged. Thereafter, Irene curved north and impacted the United States. Total Caribbean economic losses were estimated at nearly $\$ 1.5$ billion (US dollars), with combined insured losses listed around $\$ 1$ billion (US dollars), primarily due to damage in the Bahamas. 


\section{d. South America}

The 2011 annual mean temperature was near normal to above normal in northern South America, the tropical Andes, and western Amazonia. Peru, Chile, and the Atlantic coast of South America were characterized by near-normal to below-normal temperatures (Fig. 7.14a). The annual total precipitation was above normal in northern South America and central Amazonia, but generally below normal in western South America, Argentina, Paraguay, and Uruguay (Fig. 7.14b).

Climate conditions across the region during 2011 were influenced by a La Niña event during the first few months of the year, and the reemergence of $\mathrm{La}$ Niña conditions during the latter part of the year. Typically, La Niña produces above-average precipitation across northern South America, and below-average precipitation across southeastern South America.

I) Northern South America and the tropical ANDES-R. Martínez-Güingla, J. Arévalo, G. Carrasco, E. Jaimes, and $\mathrm{G}$. León

(i) Temperatures

The La Niña influence over the northern parts of South America was evident in the region's temperature. Temperatures during January-March were predominantly cooler than normal across Colombia, Ecuador, and Peru, with temperature anomalies ranging from $0.5^{\circ} \mathrm{C}$ to $2^{\circ} \mathrm{C}$ below the $1971-2000$ average. Coinciding with the decline of La Niña in June, temperatures across the area were warmer than average. In Ecuador, temperature anomalies were between $0.5^{\circ} \mathrm{C}$ and $1.5^{\circ} \mathrm{C}$ above average during July-September. Although minimum temperatures across Peru were near normal during April-June, maximum temperatures were $3^{\circ} \mathrm{C}$ above average. With the reemergence of La Niña in October, temperatures across northern South America were cooler than normal during the final months of the year.

\section{(ii) Precipitation}

In Venezuela, above-normal precipitation was observed during most of 2011, mainly due to the influence of La Niña. The largest precipitation anomaly (166\% of normal) was observed during January-March. July-September was the only time during the year that recorded below-average precipitation, at $94 \%$ of normal. Overall, 2011 was among the top five wettest years for several stations across the country.

Colombia experienced above-average precipitation throughout the year, attributed to La Niña conditions during the first and last few months of the year. North and central regions of Colombia were affected by heavy rainfall during January-March, with anomalies between $150 \%$ and $200 \%$ of normal. In December, precipitation anomalies ranging from $600 \%$ to $900 \%$ of normal were observed over northern Colombia. Overall, the heavy precipitation observed across Colombia throughout the year caused more than 250 deaths and affected two million people.

The coastal region in Ecuador reported anomalies that were $0-80 \%$ of normal during January-March. During April-June, specifically in April, 150-250\% of normal rainfall was observed across the country. July-September was characterized by above-average precipitation over the highlands and the southern coast, with anomalies ranging between $150 \%$ and $800 \%$ of normal (El Oro Province). The highest monthly precipitation anomaly of $840 \%$ of normal was registered in Zaruma (located in southern Ecuador) in July. During October-December, precipitation deficits were observed across the coastal region, with positive anomalies in the Amazonia area.

In Bolivia, above-average precipitation was observed in the eastern Llanos, Altiplano, and valleys during January-March. In January, a maximum daily precipitation of $194 \mathrm{~mm}$ was registered in eastern Llanos, where the monthly normal is $162 \mathrm{~mm}$.

In Peru, precipitation anomalies over the northern region during January-March were 0-40\% of normal, while above-average precipitation was observed across the central and southern regions. During April-June, precipitation anomalies over the northern Amazon jungle and the northern and central highlands reached $400 \%$ of normal. During October-December, northern and central parts of the country experienced above-average precipitation, while the south had below-average precipitation.

\section{(iii) Notable events}

The Libertador Municipality in the Capital District of Venezuela-one of the most densely populated areas in the country-was affected by heavy precipitation that prompted flooding and triggered landslides, leaving over 8900 families homeless. The Orinoco River, the country's largest river, had an above-normal flow level during most of the year. In August, the Apure River flooded, affecting many rural populations.

In Colombia, more than 350 windstorms occurred between June and September in different areas of the country, affecting thousands of families. Strong hailstorms were registered in Bogota, Santander, 
and Cundinamarca in April, July, and October, respectively.

Between January and February, in Cuzco, Peru, a precipitation anomaly over $400 \%$ of normal and stream flow of Paucartambo River of $400 \%$ were registered. This isolated main archeological sites, resulting in economic losses in the tourism sector.

\section{2) Tropical South America east of the Andes-} J. A. Marengo, J. Ronchail, L. M. Alves, and J. Baéz

(i) Temperatures

In January, all of tropical South America experienced warmer than average conditions, about $1^{\circ} \mathrm{C}$ above the 1961-90 average, while near-average temperatures were observed in February and March. In April, warm conditions continued over central and southern Brazil, western Bolivia, and Paraguay, and continued in May and June in northwestern Amazonia and Bolivia. During July-August, warmer-thanaverage conditions persisted across most of the region, with anomalies around $+2^{\circ} \mathrm{C}$ in southeastern Brazil.

However, some regions experienced cooler-thanaverage conditions, nearly $1^{\circ} \mathrm{C}$ below average, during June-August, due to various cold waves that impacted the area. At the beginning of June, a freezing episode in the southern Andes of Peru impacted 13400 people and 4500 head of cattle. At the end of June and beginning of July, cold waves brought cooler-than-average temperatures to the region. Minimum temperatures between $2.8^{\circ} \mathrm{C}$ and $5.3^{\circ} \mathrm{C}$ were observed in São Paulo, where the mean July minimum temperature is $11.7^{\circ} \mathrm{C}$ (1961-90 base period), and the minimum temperature dropped from $20.3^{\circ} \mathrm{C}$ to $12.6^{\circ} \mathrm{C}$, between 1 and 4 July, in Vilhena (Southern Amazon). By mid-July, more than 6000 people and 41000 head of cattle had been affected by temperatures as low as $-26^{\circ} \mathrm{C}$ and 1.6 meters of snow in the Bolivian department of Potosi (southern Altiplano).

In August, five cold surges affected southeastern South America; the two most intense affected Vilhena and southern Brazil. Cold air surges continued during September-November. In the city of São Paulo, the maximum temperature dropped from $33.1^{\circ} \mathrm{C}$ to $17.9^{\circ} \mathrm{C}$ in two days. In December 2011, the lack of rainfall in south central Brazil contributed to warm conditions in the states of Mato Grosso and São Paulo, with temperatures up to $3^{\circ} \mathrm{C}$ above average.

\section{(ii) Precipitation}

During 2011, rainfall was slightly below average (50 mm below the 1961-90 average) across the $5^{\circ} \mathrm{S}-15^{\circ} \mathrm{S}$ latitude band in South America, as well as in southern Bolivia, southern Brazil, and Uruguay. Southern Bolivia, southern Brazil, and Uruguay were impacted by drought, which had begun in August 2010 , affecting crops that resulted in nearly $\$ 60$ million (US dollars) in losses. Meanwhile, rainfall was nearly $150 \mathrm{~mm}$ above average from Colombia to northeastern Brazil, eastern Bolivia, and northern Paraguay.

In January 2011, heavy rains, floods, and mudslides in the Oxapampa region in the central Andes of Peru affected more than 1100 people. In the highlands of the state of Rio de Janeiro, heavy rainfall during January caused the worst flooding and landslides in Brazil in decades. Between 11 and 13 January, nearly 1000 people died and 35000 were left homeless (see Sidebar 7.1). In the city of São Paulo, January 2011 was the wettest since 1943, reaching $491.5 \mathrm{~mm}$, almost twice the month's average.

In February, rainfall in southern Peru, Bolivia, Paraguay, and northern Argentina was about 200 $\mathrm{mm}$ above normal. Above-average rainfall $(50 \mathrm{~mm}-$ $200 \mathrm{~mm}$ ) was observed across northeastern South America and Colombia.

In March, a reversal of rainfall patterns occurred, with below-average rainfall in Bolivia and Paraguay. Above-average rainfall persisted over northern South America and southeastern Brazil (about $150 \mathrm{~mm}$ above average). The January-March sequence resulted in deficit of rainfall (as much as $200 \mathrm{~mm}$ below average) in parts of western and southern Amazonia, just at the peak of the rainy season. In the Peruvian Amazon, however, the water level of the Amazonas River in Iquitos increased very rapidly after the 2010 drought episode, due to very wet local conditions.

In April, rainfall was $200-300 \mathrm{~mm}$ above average in Ecuador and most of western Colombia. In May, rainfall was up to $200 \mathrm{~mm}$ above average from northern South America to northeastern Brazil. In the state of Pernambuco, in northeastern Brazil, intense rainfall left 144000 people homeless. In contrast, rainfall was below average from southern Colombia to southern Brazil.

During June-August, below-average rainfall was detected over northern Brazil, Venezuela, and eastern Colombia ( $200 \mathrm{~mm}$ below average). As a consequence, the level of the Rio Negro in Manaus registered a drop of about $1.24 \mathrm{~m}$ between 13 and 16 September, which is considered the largest reduction in a short time period since 1903 (according to the Serviço Geológico do Brasil). In contrast, intense rainfall continued in western Colombia and northeastern Brazil. Nine people were killed in Pernambuco and 


\section{SIDEBAR 7.I: THE 20 II INTENSE RAINFALL AND FLOODS IN RIO DE JANEIRO-J. A. MARENGO AND L. M. ALVES}

During January 2011, heavy rainfall sparked flash flooding and mudslides across the highlands of the state of Rio de Janeiro in southeastern Brazil, devastating mountain towns. According to Brazilian official sources, the floods and landslides claimed the lives of 916 people and left 35000 people homeless. This was one of the worst natural disasters in Brazil's history.

During the first half of January, rainfall in Brazil was primarily concentrated in a swath from the states of São Paulo, Minas Gerais, Goiás, and southeastward to Rio de Janeiro. While the 196I-90 average rainfall for January in that region is about $230 \mathrm{~mm}$, the rainfall accumulated during January 2011 was approximately $460 \mathrm{~mm}$. According to the Brazilian Meteorological agencies CPTEC INPE (http://www.cptec.inpe.br) and INMET (http://www.inmet.gov.br), the anomalous rainfall was caused by the South

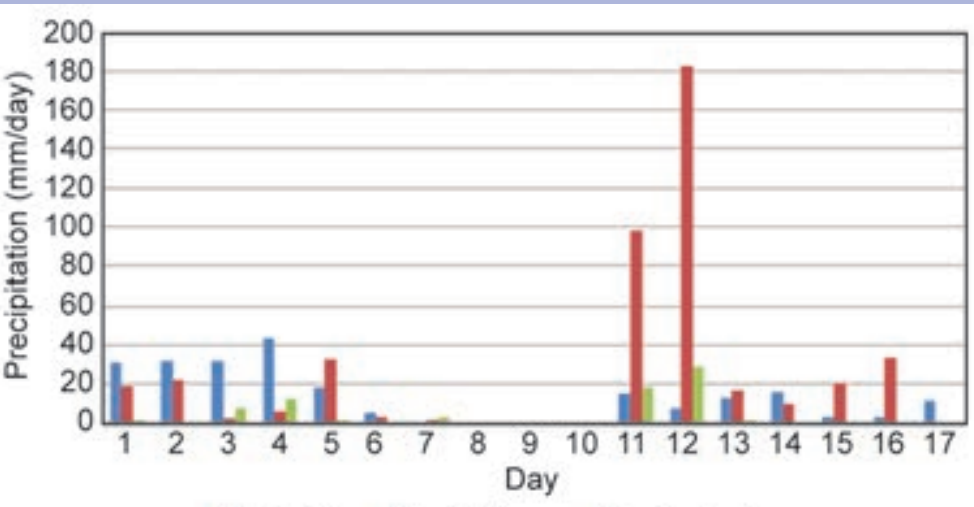

\#Petróbolis = Nova Friburao $=$ Rio de Janeiro

FIG. SB7.2. Daily precipitation $(\mathrm{mm})$ during I-I7 January $201 \mathrm{I}$ in Petrópolis (blue bar), Nova Friburgo (red bar), and Rio de Janeiro (green bar). Monthy January average (196I-90 base period): Nova Friburgo: $232.5 \mathrm{~mm}$; Petrópolis: $201.5 \mathrm{~mm}$; and Rio de Janeiro: 136.4 mm. (Source: INMET) Atlantic convergence zone (SACZ), a typical summer time rainfall-producing mechanism that was fed by moisture transport coming from the Amazon region during that period and by a favorable signal of convection and precipitation by the Madden-Julian oscillation (MJO), that persisted until mid-January. The large-scale pattern was characterized by a weakening of La Niña in the equatorial Pacific Ocean, while over the South Atlantic Ocean, off the coast of southeastern Brazil, sea surface temperatures were $2^{\circ} \mathrm{C}$ above normal. Three episodes of SACZ were detected: I-7 January, II-17 January, and $|8-2|$ January. The two earlier episodes produced intense low-level convergence over southeastern Brazil,

intensified by plenty of moisture coming from the Amazon region. As a consequence, rainfall in the highlands of Rio de Janeiro during $1-7$ January was about $86 \mathrm{~mm}-160$ $\mathrm{mm}$ and about $300 \mathrm{~mm}$ in II-17 January (Fig. SB7.I), well above the January average.

These conditions favored weeks of saturated soil, and together with the intense rainfall from II to I3 January, floods and mudslides were triggered. Numerous houses located in risk areas on the deforested slopes of the mountains were buried, killing hundreds of people. In one of the most affected cities, Nova Friburgo, rainfall on II-I2 January was $182.8 \mathrm{~mm}, 79 \%$ of the monthly
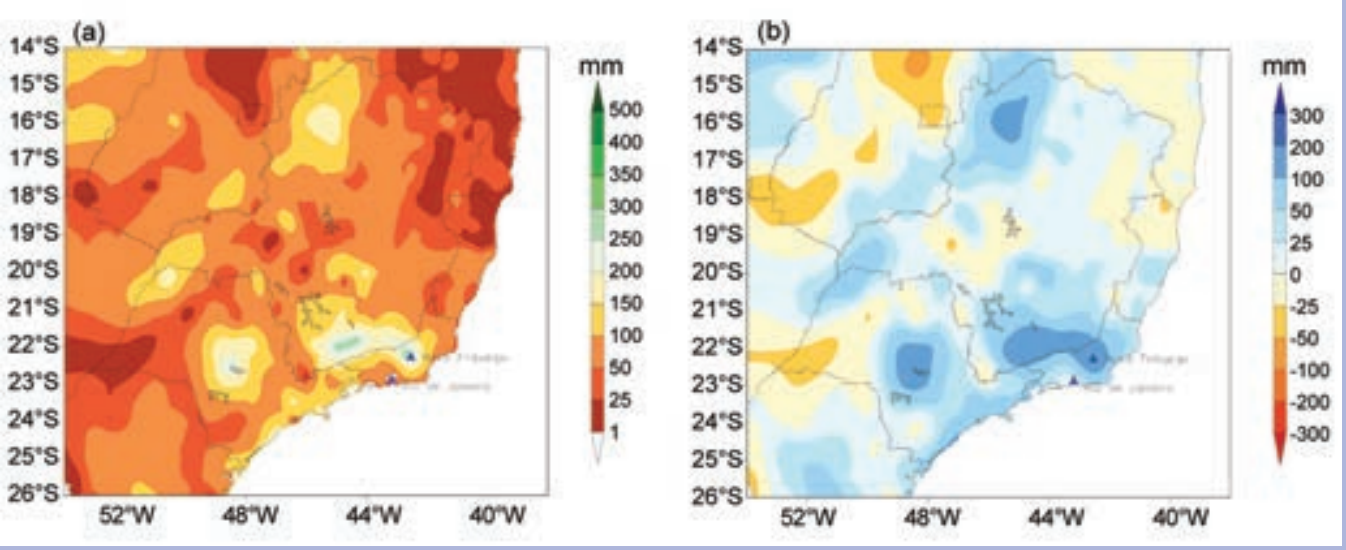
average of 232.5 $\mathrm{mm}$ (Fig. SB7.2). According to the Civil Defense of the state of Rio de Janeiro, 428 people died in this city alone. Croplands were destroyed. Highways, roads, hospitals, and sewage systems all collapsed. The isolation of these cities and the risk of epidemics left the population and local

FIG. SB7.I. (a) Accumulated rainfall ( $\mathrm{mm}) \mathrm{II}-17$ January $201 \mathrm{I}$ in the southeastern Brazil re- governments in a gion and $(b)$ rainfall anomalies $(\mathrm{mm})$ for the same period from the $1961-90$ base period. The permanent state of cities of Rio de Janeiro and Nova Friburgo are marked on the map. (Source: CPTEC-INPE) alert. 
one in Paraiba, and more than 340 families lost their homes in mid-July. By the first week of August, the state of Parana in southern Brazil experienced heavy rainfall and storms, affecting more than 20 cities and 150000 people. The Iguacu River reached a record flow of 12.5 million $\mathrm{L} \mathrm{s}^{-1}$.

In September, drier-than-average conditions persisted in western Amazonia $(100 \mathrm{~mm}-200 \mathrm{~mm}$ below average). During the second week of September, intense rainfall in the state of Santa Catarina in southern Brazil left almost 15000 people homeless, affected more than 900000 people, and destroyed highways.

From November to December, floods and landslides affected hundreds of people and damaged roads and crop fields in the northern and central Andes of Peru. At the beginning of December 2011, heavy rainfall across northern Venezuela caused rivers to overflow, affecting almost 2000 people. On the other hand, most of tropical South America had below-average precipitation (as much as $200 \mathrm{~mm}$ below normal in Amazonia).

3) Southern South America-M. Bidegain, M. Skansi, 0 . Penalba, and J. Quintana

(i) Temperatures

Near- or above-average temperatures were observed over most of southern South America during 2011, with average anomalies up to $+1.0^{\circ} \mathrm{C}$ (Fig. 7.14a). The greatest positive anomaly was observed in Patagonia (south of $40^{\circ} \mathrm{S}$ in Chile and Argentina).

During December 2010-February 2011 (austral summer), warmer-than-average temperatures $\left(+0.5^{\circ} \mathrm{C}\right.$ to $+1.0^{\circ} \mathrm{C}$ ) were observed in Argentina, Uruguay, and central Chile. This behavior was accompanied by positive deviations of the mean maximum and minimum temperatures and below-normal rainfall in the region, during La Niña. From December 2010 through the first days of January 2011, extremely high temperatures (at or above the 90th percentile) affected different regions of Argentina and southern Chile. Over eastern Uruguay the mean monthly temperature anomaly was as high as $3^{\circ} \mathrm{C}$ above the 1961-90 average in January. Between 6 and 11 February, Patagonia experienced above-average temperatures, setting records in several locations. The anomalously warm conditions continued during March-May 2011 (austral autumn) over Argentina and Uruguay.

In contrast, the southern South America winter (June-August) was cooler than average $\left(-0.5^{\circ} \mathrm{C}\right.$ to $-1.0^{\circ} \mathrm{C}$ ) in Chile, central Argentina, and Uruguay. A cold wave between 25 June and 10 July brought coolerthan-average temperatures, $5^{\circ} \mathrm{C}$ to $10^{\circ} \mathrm{C}$ below aver- age, for several days. In Argentina, daily minimum temperatures were as low as $-16.0^{\circ} \mathrm{C}$ in Malargüe (Mendoza Province) on 3 July and $-7.7^{\circ} \mathrm{C}$ in Bolivar (Buenos Aires Province) on 6 July. In central Chile, the minimum temperature was $-3.0^{\circ} \mathrm{C}$ in Santiago on 3 July and $-4.8^{\circ} \mathrm{C}$ in Curico on 4 July. These extreme low temperatures during the Southern Hemisphere core winter claimed the lives of five people in Uruguay. The invasion of cold air also brought heavy snowfall. Snow covered half of Argentina and Chile during 6-8 July, including northern Chile (Atacama Desert) and southern Buenos Aires Province where snowfall is rare. According to the Argentine Weather Service, temperature anomalies of $-1{ }^{\circ} \mathrm{C}$ to $-2^{\circ} \mathrm{C}$ were widespread across Argentina during July 2011. Similar conditions were observed in Chile between Valparaiso and Temuco.

During austral spring (September-November) above-average mean temperature anomalies $\left(+0.5^{\circ} \mathrm{C}\right.$ to $+1.5^{\circ} \mathrm{C}$ ) were observed over the entire region (Uruguay, Argentina, and Chile). In September, several maximum temperature records were set in northwestern Argentina. In Santiago (central Chile), the mean maximum temperature of $23.3^{\circ} \mathrm{C}$ was the highest ever recorded, $4.2^{\circ} \mathrm{C}$ above average. Meanwhile most of southern South America was cooler than average in October 2011. According to the Argentine Weather Service, several locations in Argentina experienced their coolest October in the last five decades. In Chile, this cooling was more moderate, with anomalies around $-1^{\circ} \mathrm{C}$.

\section{(ii) Precipitation}

During 2011, below-average precipitation across southeastern South America was attributed to the La Niña episode, which began during the latter part of 2010 .

In Argentina, the annual rainfall was below the 1961-90 average across much of the region, with eastern Buenos Aires and Cordoba Province being the most affected at $60-80 \%$ of normal. In central Chile, annual precipitation was below normal, resulting in the fourth driest year since 1950. In May 2011, several cities in Argentina and Chile recorded their lowest precipitation totals since 1961, including Iguazú $(4.0 \mathrm{~mm})$, Río Cuarto $(2.0 \mathrm{~mm})$, and Trelew $(0.5 \mathrm{~mm})$. The driest anomalies during June-August 2011 were observed across eastern Brazil, Argentina, northeastern Bolivia, and central and southern parts of Chile. Although isolated heavy rainfall impacted these areas, it wasn't enough to alleviate the dry conditions. 
Heavy rain fell on 15 July across Uruguay and southern Brazil. The maximum 24-hour accumulated rainfall total was $140 \mathrm{~mm}$ observed in Lavalleja and Rocha, both located in Uruguay. In northern Chile's Atacama Desert, a cutoff low pressure system on 3-8 July brought heavy snowfall (up to $20 \mathrm{~cm}$ ) and strong winds (above $20 \mathrm{~m} \mathrm{~s}^{-1}$ ), seriously affecting the mining industry in the high mountains of the Andes and land transportation between Chile, Bolivia, and Argentina.

In Argentina and Uruguay, the drierthan-average conditions were more intense during the second half of the year. However, rainfall in October brought relief to the northern part of the

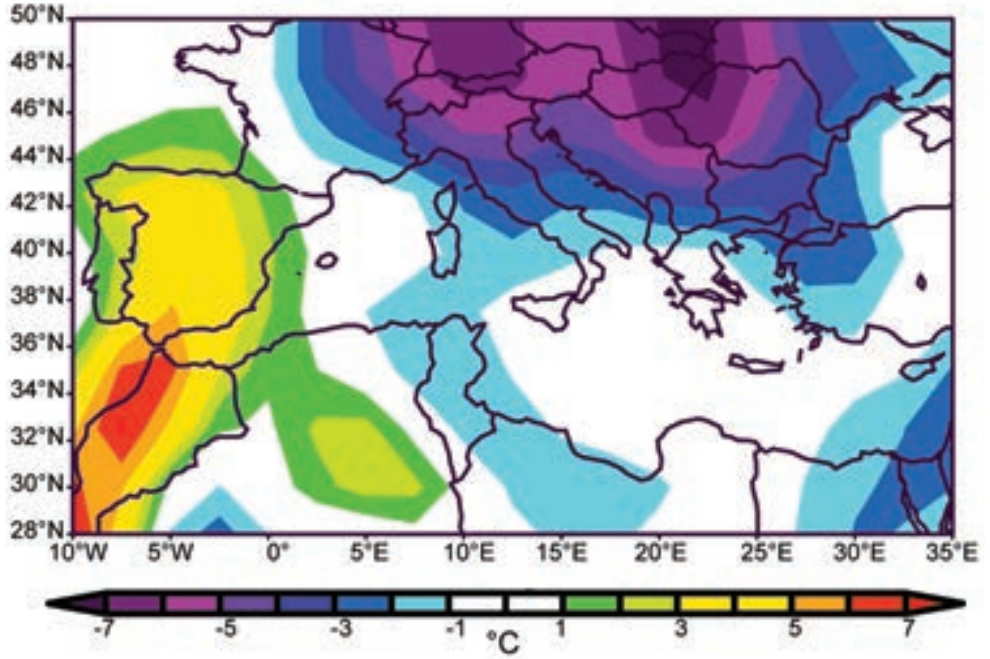

Fig. 7.15. Temperature anomaly $\left({ }^{\circ} \mathrm{C}\right)$ in northern Africa on 2 July 20II. (Source: NOAA/NCEP)

In northern Chile, intense rainfall occurred durregion, and in November to the central and western part of the province of Buenos Aires. In particular, the northern province of Buenos Aires showed deficits in all months during the latter half of the year. Anomalies were the lowest in August, September, and December, reaching values that were $20 \%$ of normal. Nine meteorological stations located in northeastern Argentina recorded their lowest December precipitation totals since 1961. In Chile, the driest months were May-July, October, and December. The central region was the most affected, with deficits of $50-60 \%$. The greatest impacts were in agriculture, freshwater resources, and hydroelectric power.

\section{(iii) Notable events}

Overall, below-average rainfall prevailed throughout much of Argentina in 2011. The excess precipitation occurred locally and some of the events were very intense. Extreme events occurred in February, April, and August. On 23 February, a severe storm brought heavy rain, hail, and strong winds to various neighborhoods around the capital of the province of Mendoza (western Argentina), resulting in floods and fallen trees. On 26 February, another severe storm affected the province of Catamarca, isolating locations due to overflowing rivers and landslides.

Two days of heavy rain caused a state of emergency in Comodoro Rivadavia city (central-east of Patagonia). A total of $120 \mathrm{~mm}$ of rain fell on 12-13 April, almost four times April's monthly average. On 8 August, Iguazú Falls (northeastern Argentina) streamflow increased to eight times its normal flow in only a few hours due to the intense rainfall in southern Brazil. ing 3-8 July and again on 31 July that affected the Atacama Desert region. Daily totals between $20 \mathrm{~mm}$ and $25 \mathrm{~mm}$ were observed, where precipitation is typically near zero or less than $5 \mathrm{~mm}$ during the month.

\section{e. Africa}

I) Northern Africa一 K. Kabidi and A. Sayouri

This region includes Morocco, Algeria, and Tunisia. The 1971-2000 base period has been used to assess anomalies in both temperature and precipitation in 2011.

\section{(i) Temperature}

Generally, both maximum and minimum temperatures were higher than average over the region. The year 2011 was the warmest in the last ten years. The annual maximum temperature averaged between $0.5^{\circ} \mathrm{C}$ and $3.5^{\circ} \mathrm{C}$ above normal with the largest anomaly observed in Taza, in the north-central sector of Morocco, south of the Rif Mountain. The annual maximum temperature anomaly was strongly influenced by extreme warm temperatures during the summer season.

During winter, both positive and negative anomalies were observed. The mean temperature anomaly ranged between $-2.4^{\circ} \mathrm{C}$ at Nador in eastern Morocco to $+1.5^{\circ} \mathrm{C}$ in Sidi Slimane in central Morocco. An exceptional cold wave occurred in January and February. The region experienced significant snowfalls, with temperatures reaching $-7^{\circ} \mathrm{C}$ in Algeria. Positive temperature anomalies returned during the spring season, with anomalies greater than $+1.7^{\circ} \mathrm{C}$. Summer was characterized by exceptional heat waves and ex- 
treme temperatures were recorded. June and July temperature anomalies surpassed $+4.4^{\circ} \mathrm{C}$ in Sidi Slimane (Fig. 7.15), as mean temperatures reached $45.3^{\circ} \mathrm{C}$ and $49^{\circ} \mathrm{C}$ in Sidi Slimane and Ain Saleh, respectively.

\section{(ii) Precipitation}

Overall, the annual precipitation was above average, especially during autumn when rainfall amounts reached $171 \%$ of normal in Rabat in Morocco. Several locations recorded rainfall amounts approaching 100 $\mathrm{mm}$ in a 24 -hour period during this time, resulting in flooding. The winter season was quite active with the development of storms that produced heavy rains approaching $80 \mathrm{~mm}$ in Chefchaouen, Morocco, in a 24-hour period, and over $50 \mathrm{~mm}$ also in 24 -hour period in Tangier, Morocco. In Algeria, a winter storm produced over $60 \mathrm{~mm}$ of rainfall in Echelf and Constantine. More storms that produced over $60 \mathrm{~mm}$ rainfall in less than 24 hours occurred in the northern areas of Algeria and Morocco during the spring, especially in March and May. Rainfall surpluses exceeded $180 \%$ of normal. Summer was dominated by the presence of an anticyclonic system across northern Africa and dry conditions, except for intense heavy rains that fell in northwestern Morocco in early June. During autumn, strong storms produced heavy rains and caused flooding in many locations in Algeria and in Morocco during autumn, especially during October. Records indicated 94.6 $\mathrm{mm}$ at Chefchaouen (northern Morocco), $104 \mathrm{~mm}$ at Bouchegouf (northeastern Algeria), and $78 \mathrm{~mm}$ at $\mathrm{El}$ kala (northern Algeria). Rainfall totals averaged 320\% of normal in Nador (eastern Morocco).

\section{(iii) Notable events}

October and November were marked by a succession of significant heavy rainfall events that led to several floods in Morocco, Algeria, and Tunisia. These events caused important infrastructure damage and loss of human life, especially in Algeria.

Also in Algeria, several forest fires associated with a heat wave and daily temperatures exceeding $49^{\circ} \mathrm{C}$, burned at the end of July and the beginning of August. An estimated 15000 ha of land was affected, according to the Forestry Department of Algeria.

2) Western Africa一 - L. N. Njau and W. M. Thiaw

Western Africa extends from the Guinea coast to Chad and the Central African Republic. All analyses are based on the 1971-2000 base period.

\section{(i) Temperature}

The year 2011 was once again very warm in Western Africa. The monthly temperature remained above average every month and across the region. In January, the temperature was $1.5^{\circ} \mathrm{C}$ above normal and the greatest anomalies $\left(3.5^{\circ} \mathrm{C}\right.$ above the $1971-2000$ base period) were observed in Mauritania, central Niger, and northern Sudan. The positive anomalies increased in February, with temperatures $3.5^{\circ} \mathrm{C}$ above average in Niger, western Chad, and northern Nigeria. In March, temperature decreased, but maintained positive anomalies $\left(>2.5^{\circ} \mathrm{C}\right)$ in Mali, northern Burkina Faso, and western Niger with highest anomalies $\left(>3.5^{\circ} \mathrm{C}\right)$ over central Mali and western Niger. April had a major decline in temperature anomalies, with $(<$ $1.5^{\circ} \mathrm{C}$ ) over northern Mauritania and northwest Mali that persisted in May with the temperature anomalies $\left(<1.5^{\circ} \mathrm{C}\right)$ covering the central part of the Sahel. Unlike the previous year, the June 2011 temperature anomalies $\left(>1.5^{\circ} \mathrm{C}\right)$ intensified spatially over parts of Mauritania, Mali, Burkina Faso, Ghana, Benin, Togo, Niger, and Chad, with an epicenter $\left(>2.5^{\circ} \mathrm{C}\right)$ over northwest Mauritania. In July, temperature anomalies
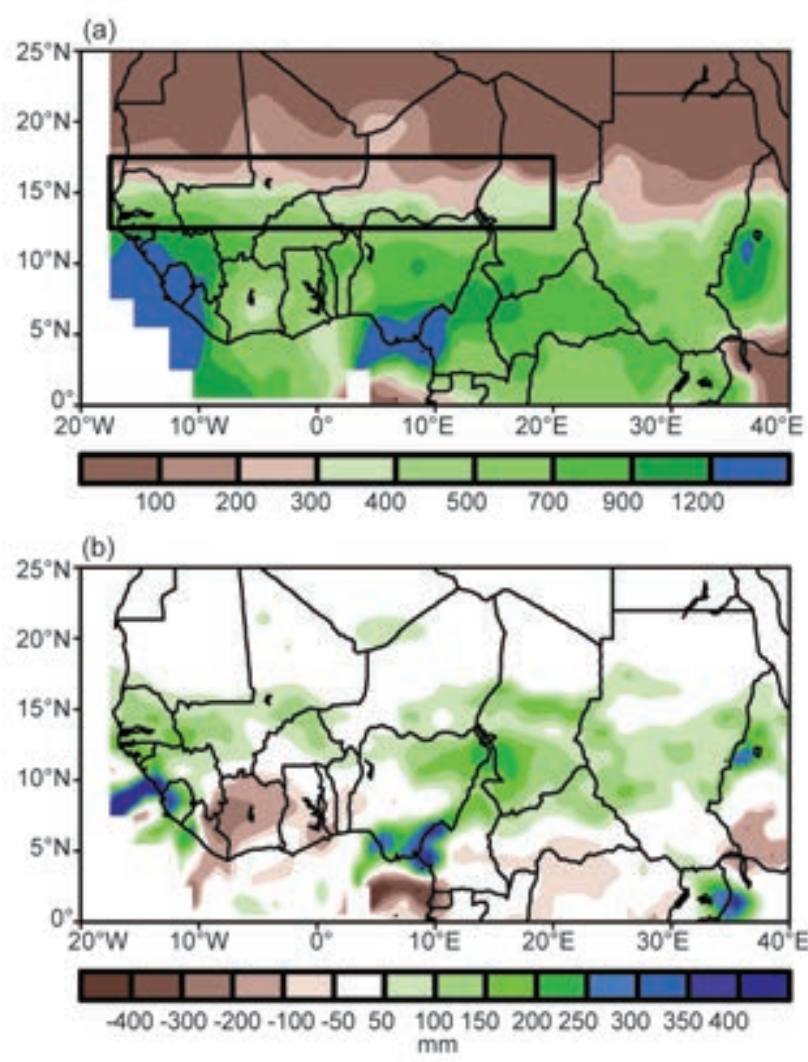

Fig. 7.16. Jun-Sep 20II (a) rainfall $(\mathrm{mm})$ for Western Africa and (b) anomalies (departure from the 197I2000 base period). The boxed region indicates the approximate boundaries of the Sahel region. (Source: NOAA/NCEP) 
$\left(>1.5^{\circ} \mathrm{C}\right)$ were observed over parts of western, central, and eastern Sahel. Temperature anomalies in August ranged between $-1^{\circ} \mathrm{C}$ and $1^{\circ} \mathrm{C}$ over the continent, but peaked in September with anomalies of $+1.5^{\circ} \mathrm{C}$ to $+2^{\circ} \mathrm{C}$ covering parts of Mauritania, Mali, Burkina Faso, Ghana, Benin, Togo, Niger, and northwestern Nigeria, and intensified in October over these parts with an epicenter greater than $2.5^{\circ} \mathrm{C}$, over northwest Mauritania. In November, positive temperature anomalies from $1.5^{\circ} \mathrm{C}$ to $2.0^{\circ} \mathrm{C}$ covered western part of West Africa, with a weak epicenter $>2^{\circ} \mathrm{C}$ over northwestern Guinea. In December, the temperature anomalies were generally normal over West Africa.

\section{(ii) Precipitation}

The year 2011 was characterized by overall nearaverage conditions (compared with the 1971-2000 base period) across most areas in West Africa (NOAA gridded gauge precipitation analysis, PREC/L). Rainfall totals from June to September ranged between $<$ $100 \mathrm{~mm}$ in the northern part of the Sahel to $>1200$ $\mathrm{mm}$ in the western Guinean coast, and along the coastal border of Nigeria and Cameroon (Fig. 7.16a). The rainy season was slightly above average across the Sahel and portions of the Gulf of Guinea. However, rainfall amounts were much less than in 2010, the wettest year in the Sahel in over 50 years. Rainfall was $50 \mathrm{~mm}-100 \mathrm{~mm}$ above average across the Sahel (Fig.7.16b). Surpluses over $200 \mathrm{~mm}$ were observed along the coast of Guinea and along the south border between Cameroon and Nigeria. Rainfall was much below average over most areas in Cote d'Ivoire and portions of western Ghana, with deficits between 100 $\mathrm{mm}$ and $300 \mathrm{~mm}$.

\section{(iii) Notable events}

Overall, the June-September rainy season had a slow start, an early withdrawal, and dry spells, especially in central Sahel. This resulted in poor harvests, food shortages, and scarcity of water availability in affected areas that called for international humanitarian relief assistance. However, in the western end of the Sahel, the West African monsoon system intensified in August, with excessive rains and flooding, especially in Guinea and Mali. Torrential rains during 23-24 August led to floods in the northwestern, central, and northeastern sectors of Guinea, causing significant material damage, and leaving more than 4000 people homeless.

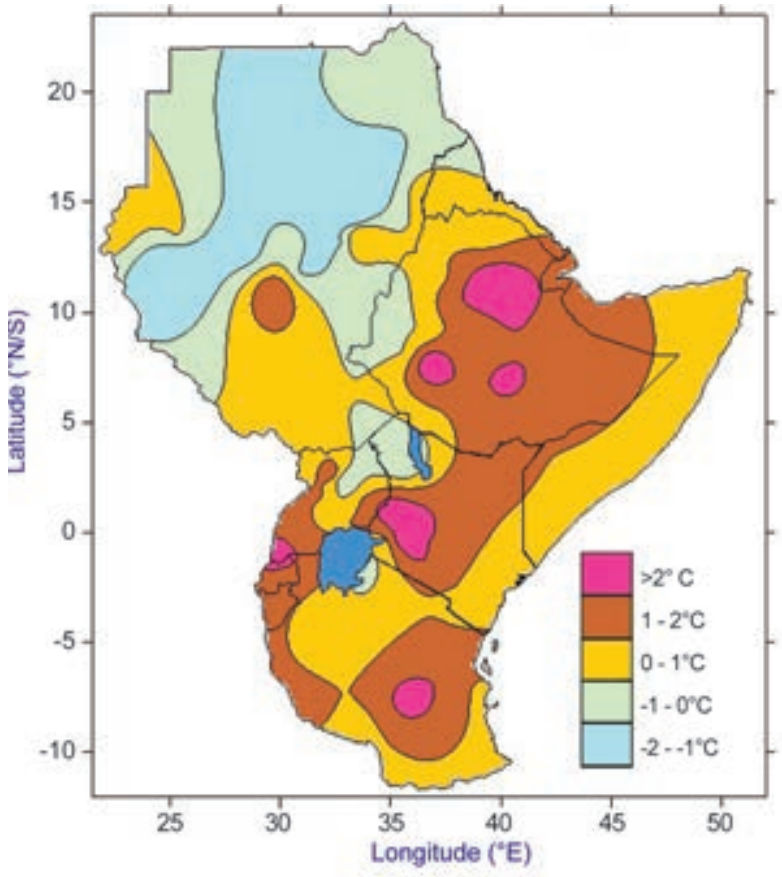

FIG. 7.17. Minimum temperature anomalies for $201 \mathrm{I}$ ( ${ }^{\circ} \mathrm{C}, 1961-90$ base period). (Source: IGAD Climate Prediction and Applications Centre)

3) EAStern Africa一W. Gitau, C. Oludhe, L. Ogallo, Z. Atheru, and P. Ambenje

The Greater Horn of Africa (GHA) can broadly be divided into three sectors. The northern sector encompasses northern and central Somalia, Djibouti, Eritrea, Ethiopia, Sudan, and South Sudan. The equatorial sector covers southern Somalia, Kenya, Uganda, Burundi, Rwanda, and northern Tanzania. The southern sector covers central and southern Tanzania.

March-May marks the main rainfall season or "Long Rains" over the equatorial sector, while a second rainfall season, the "Short Rains" is observed from late September to early December. June to early September marks the rainfall season over the northern sector and the coldest season over the equatorial sector. The western highlands of Kenya also experience significant rainfall during this season. The southern sector receives rainfall from December to February. The base period for this section is 1961-90 unless otherwise stated.

\section{(i) Temperature}

In eastern Africa, noteworthy minimum temperatures, as opposed to mean and maximum temperatures, have been observed recently; hence, these temperatures are discussed in this section. Warmerthan-average minimum temperature anomalies prevailed over much of the GHA, except for northern and central Sudan in the northern sector of the region, and 


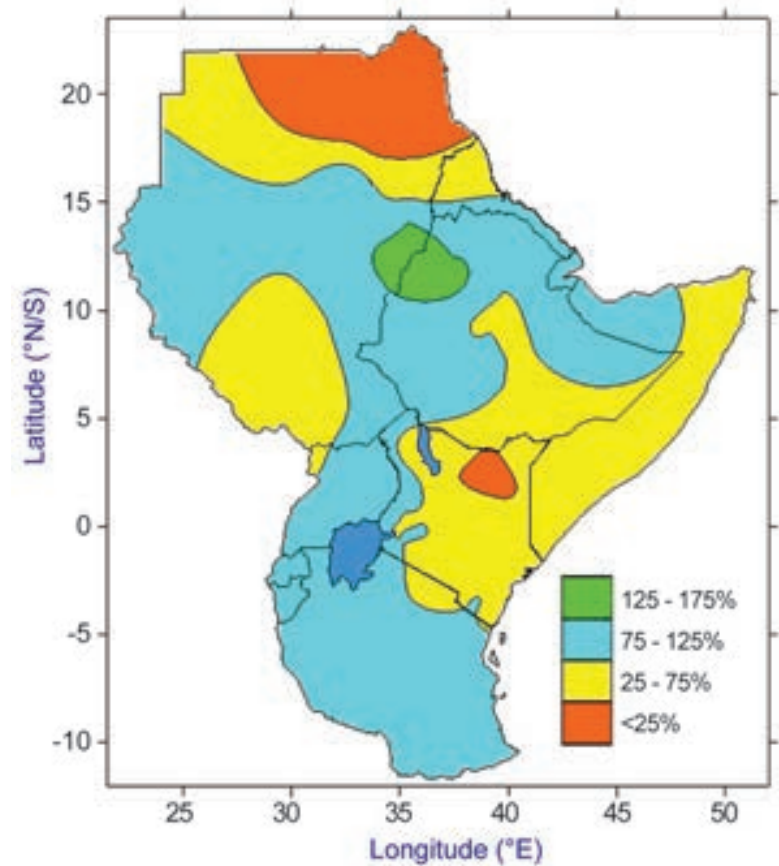

Fıg. 7.18. Rainfall anomalies (\% of normal) for MarchMay 20II (196I-90 base period). (Source: IGAD Climate Prediction and Applications Centre)

portions of northwestern and northeastern Uganda in the equatorial sector of the region. Minimum temperature anomalies exceeded $+2^{\circ} \mathrm{C}$ in central Tanzania, southwestern Kenya, and parts of Ethiopia (Fig. 7.17). Mombasa, Kenya, reported the highest average January minimum temperature in the last 11 years (departure computed based on 2000-10 mean).
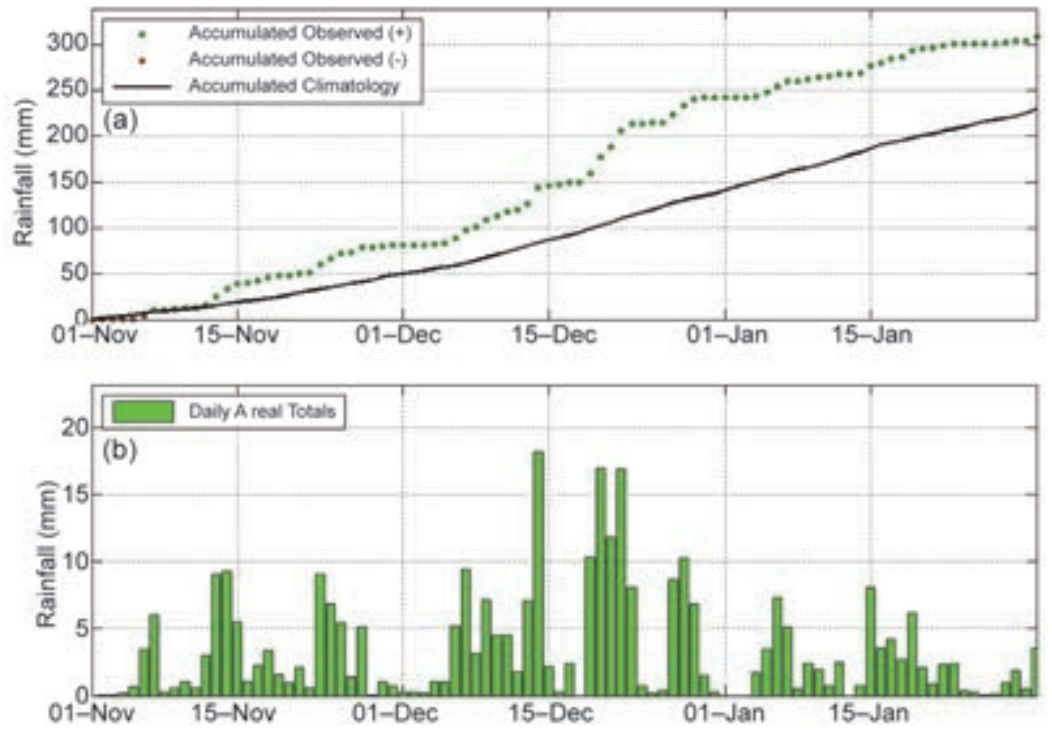

FIG. 7.19. Daily rainfall evolution $(\mathrm{mm})$ over north-central Tanzania derived from satellite and rain gauge measurement for the period Nov 20II-Jan 2012. (a) Solid line indicates cumulative rainfall climatology for the period; dotted line indicates cumulative rainfall from Nov 2011 to Jan 2012. (b) Bars show daily rainfall estimates. (Source NOAA/NCEP)
The minimum temperature also ranked among the highest during most months in 2011 at this location (not shown).

\section{(ii) Precipitation}

From December 2010 to February 2011, parts of western Ethiopia, southern Uganda, western Kenya, and northwestern, western, eastern, and southern Tanzania received between $75 \%$ and $125 \%$ of their long-term average rainfall (1961-90). However, northeastern Kenya, much of Somalia, much of central and eastern Ethiopia, Djibouti, Eritrea, northern and central Sudan, received less than $25 \%$ of the long-term average rainfall. Many stations in this sector recorded rainfall totals below the 40th percentile, based on the 1961-2010 period.

March-May is the main rainfall season over much of the equatorial sector. The eastern parts of this sector received between $25 \%$ and $75 \%$ of their long-term average, while the western equatorial sector and much of the southern sector received between $75 \%$ and $125 \%$ of the long-term average (Fig. 7.18). The low rainfall, which followed the October-December 2010 below-average rainfall season in this sector, resulted in an inadequate supply of water for domestic and industrial use, depleted pasture stocks, increased food insecurity, and conflicts between communities over scarce resources.

June-August (JJA) marks the main rainfall season over the northern sector. The western equatorial sector also receives substantial rainfall during this period. The western, central, and southeastern parts of the northern sector received between $75 \%$ and $125 \%$ of the JJA longterm average rainfall (not shown). Much of the central and western parts of the equatorial sector of the GHA received more than $125 \%$ of the long-term average rainfall.

September-November (SON) marks the second rainfall season known as "Short Rains" over the equatorial sector, while December marks the onset of the rainfall season over the southern sector. During SON 2011, most areas in the Greater Horn of Africa received above-average rainfall, except for Tanzania and the northern areas of Ethiopia and Somalia. However, much of Tanzania, especially the 


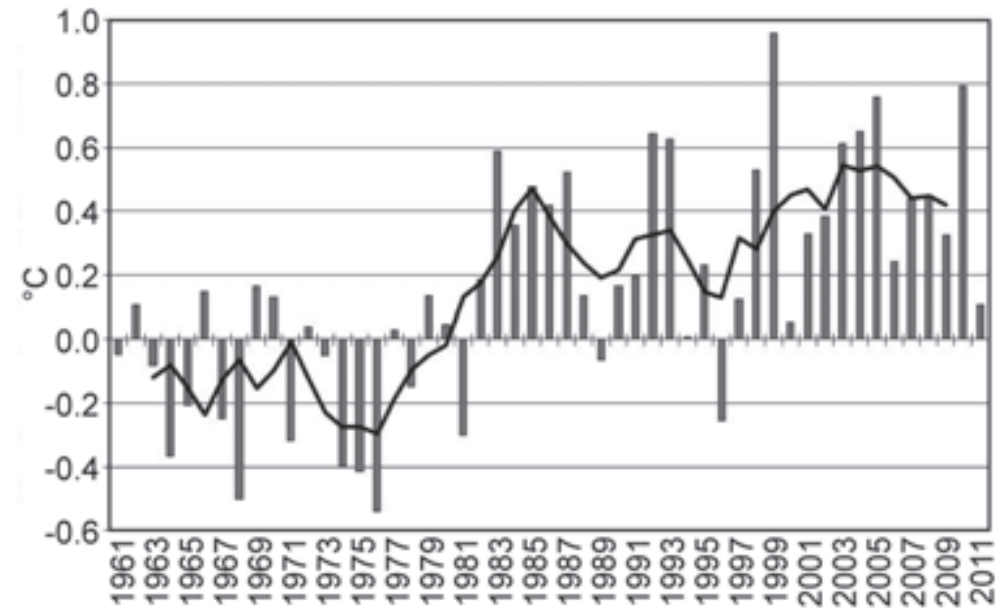

Fig. 7.20. Annual mean temperature anomalies $\left({ }^{\circ} \mathrm{C}, 1961-90\right.$ base period) for 27 climate stations in South Africa, 196I-2011. The bold black line indicates the five-year running mean. (Source: South African Weather Service)

north-central part, received above-average rainfall in December (Fig. 7.19). The enhanced rainfall over the equatorial and southern sectors during the SOND 2011 season resulted in improved availability of water for domestic and industrial use, and high prospects for livestock production due to improved pasture conditions. However, the recurrence of flash floods during the season caused challenges to manage outbreak of water-borne diseases and post-harvest storages. The enhanced rainfall activity was associated with warmer-than-average sea surface temperatures over the western Indian Ocean during the SOND 2011 season, which corresponds to the positive phase of Indian Ocean dipole (see section 4h).

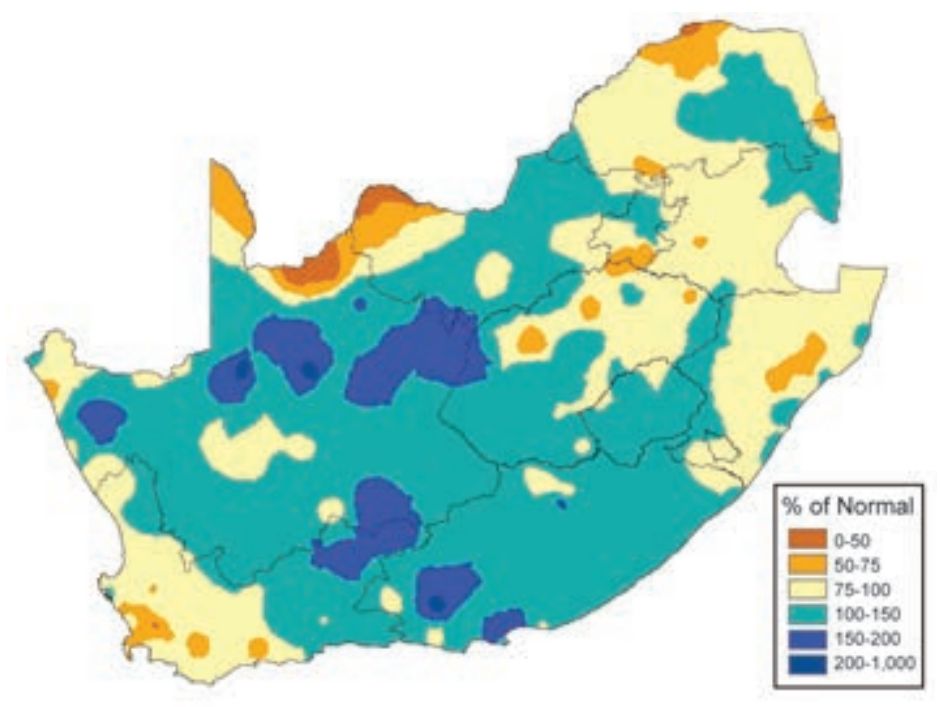

FIG. 7.2I. Rainfall anomalies (\% of normal, 196I-90 base period) for South Africa and Lesotho for 20II. (Source: South African Weather Service)
4) SOUthern Africa一A. Kruger, C. McBride, and W. M. Thiaw

This region includes the countries south of $10^{\circ} \mathrm{S}$ with emphasis on the Republic of South Africa.

\section{(i) Temperature}

For the Republic of South Africa, the annual mean temperature anomalies for 2011, based on the preliminary data of 27 climate stations, was about $0.1^{\circ} \mathrm{C}$ above the 1961-90 base period. Although 2011 was coolest year of the last 11 years, the warming trend indicated by the data of these particular climate stations is still statistically significant at the $5 \%$ level. Figure 7.20 shows that the mean temperatures of the past 15 years were all above normal.

\section{(ii) Precipitation}

The climate of South Africa is very diverse. The complex topography and the different types of rainfall systems influence mean precipitation. Summer rainfall typically occurs from October to April, with a peak in December through March. January-March 2011 precipitation was characterized by above-average rainfall over most of the interior, but was drier than normal over the coastal regions and the northeastern interior. During April-June, almost the whole country received above-average rainfall, except for some isolated regions in the far southwest and northeast. July-September was dry over most of the interior, as well as the west coast. However, above-average rainfall was received over most of the coastal regions, as well as parts of the northeastern interior. Below-average rainfall was seen in October-December over most of the interior, but above-average rainfall prevailed in the western, southeastern, and eastern coastal regions. Above-average rainfall was also received over significant parts of the eastern interior. The annual rainfall anomaly (Fig. 7.21) suggests nearaverage conditions over much of northeastern South Africa, including parts of the Maize Triangle and the Western Cape Province. Rainfall was above average across the interior of South Africa, with rainfall approaching $200 \%$ of the climatological mean in some areas, especially in the Northern Cape Province. 

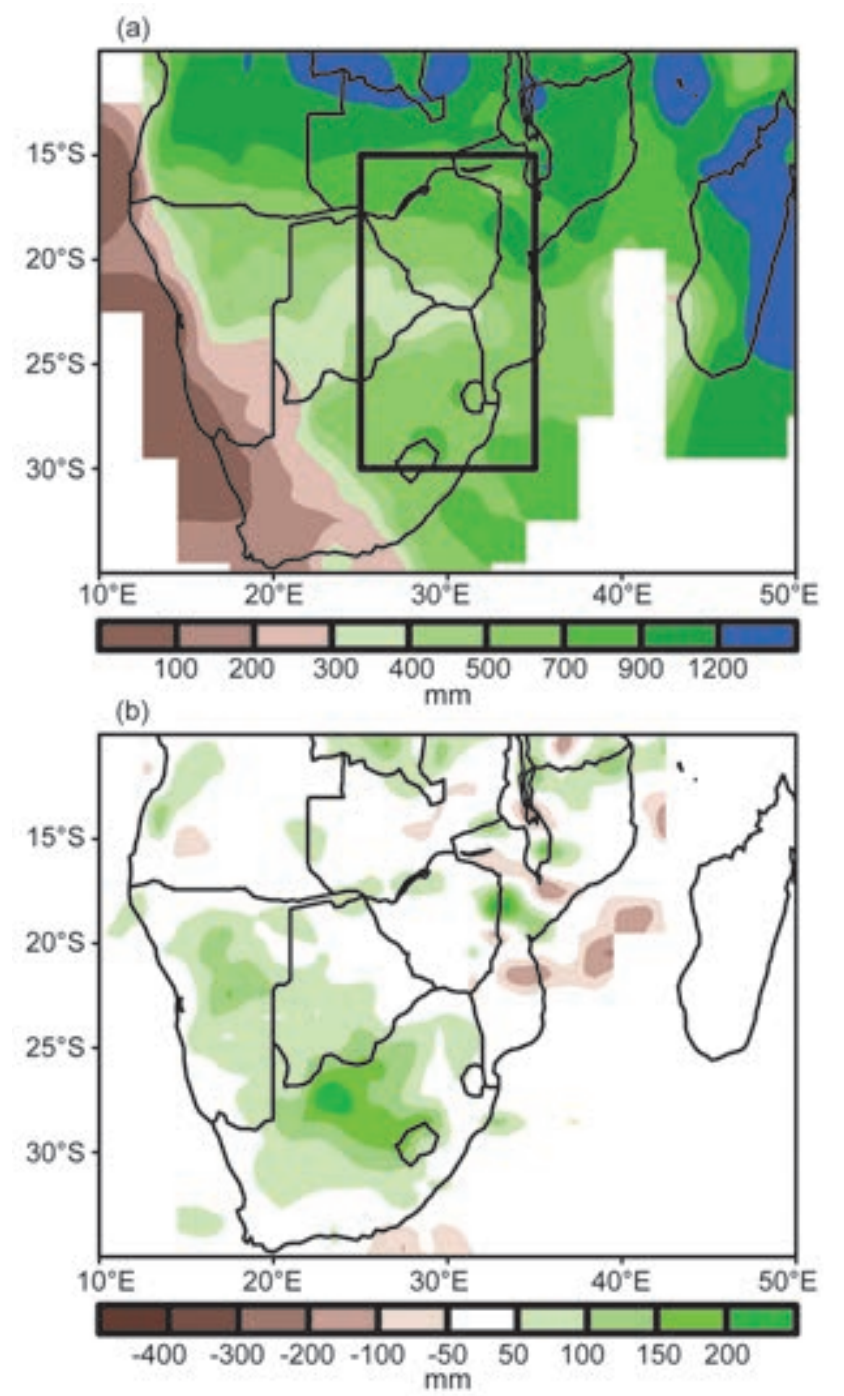

FIG. 7.22. Nov 2010-Apr 20II (a) rainfall (mm) for Southern Africa and (b) rainfall anomalies (departure from the 197|-2000 base period). (Source: NOAA/ NCEP)

For southern Africa, rainfall totals from November 2010 to April 2011 ranged from less than 100 $\mathrm{mm}$ along the west coast of South Africa and coastal Namibia, to more than $1200 \mathrm{~mm}$ along the border between northern Zambia and the Democratic Republic of Congo, and along the northern part and east coast of Madagascar (Fig. 7.22). Southern Africa austral summer features two basic climate zones. The southwestern sector is much drier on average than the remainder of the region. The area of maximum precipitation in the northern part of the region observed rainfall between $700 \mathrm{~mm}$ and $1200 \mathrm{~mm}$. To the south, rainfall in the crop areas of eastern Botswana, Zimbabwe, central Mozambique, and northeastern South Africa received $300 \mathrm{~mm}-800 \mathrm{~mm}$.

\section{(iii) Notable events}

Persistent heavy downpours during January and February 2011 across portions of Zambia, Zimbabwe, and Mozambique elevated water levels along the Zambezi, Pungoe, Buzi, Save, Limpopo, Incomati, and Maputi Rivers in central and southern Mozambique, and caused flooding that displaced local populations and damaged crops. In particular, increased discharges from the Cahora Bassa, Kariba, and the Massingir Dams triggered flooding downstream on the Zambezi River and the Limpopo River, respectively. The flooding in January in South Africa caused extensive damage countrywide, with 33 municipalities in eight provinces declared disaster areas, according to the 2011 update of the South African Weather Service CAELUM database (which also includes other events in South Africa). The worst hit areas were in the Northern Cape, North-West, and KwaZulu-Natal Provinces, where 19 people lost their lives. The flooding affected more than 14400 households and damaged more than 13000 houses. In KwaZulu-Natal alone, damage was estimated at about $\$ 88$ million (US dollars). Damage to roads and bridges was estimated at $\$ 38$ million (US dollars) while damage to infrastructure was estimated at $\$ 18$ million (US dollars). The Vaal, Bloemhof, Gariep, and Vanderkloof Dams, which include the largest dams in South Africa, reached their capacity. The Orange River burst its banks between Upington and Kakamas in the Northern Cape Province. During March, heavy rains caused havoc in Johannesburg and Pretoria. Three people drowned and temporary housing along the Jukskei River, between the two cities, was washed away. Heavy rains also fell in Reivilo, in North-West province, towards the end of April and beginning of May, resulting in damaged roads. Farmers could not transport their animals to auctions and persistent wetness led to various animal diseases. A hailstorm in May damaged or destroyed 53 houses in the Hoyi area of Mpumalanga province, with 341 people affected. In the Eastern Cape province snowfalls led to the closure of the Barkly Pass between Barkly East and Elliot. In addition, roads in the Sneeuberg Mountain area near Nieu-Bethesda were also damaged.

Unseasonably heavy rain fell in June over the Gauteng, KwaZulu-Natal, and Free State provinces, causing localized flooding. In KwaZulu-Natal, 200 people were evacuated from the Powerton informal settlement near Durban after water levels rose in the low-lying areas. Sixteen people were rescued from a farm near Bloemfontein in the Free State province after the Renosterspruit River burst its banks. 
Heavy rain also affected the Western Cape province as well as towns along the Garden Route along the south coast. Roads were submerged, houses flooded, schools closed, and people were evacuated. According to reports, 1895 households and 7300 people were affected. In the Eastern Cape province at least 6 people drowned and 1400 people were displaced following flooding in Port Elizabeth, Uitenhage, Butterworth, and Lusikisiki. Eight people from Palmiet River Primary School, about $30 \mathrm{~km}$ outside Uitenhage, were rescued by helicopter after the bridge between the school and the main road collapsed.

The volcanic ash cloud that originated from the Puyehue-Cordon Caulle volcanic complex in south-central Chile, South

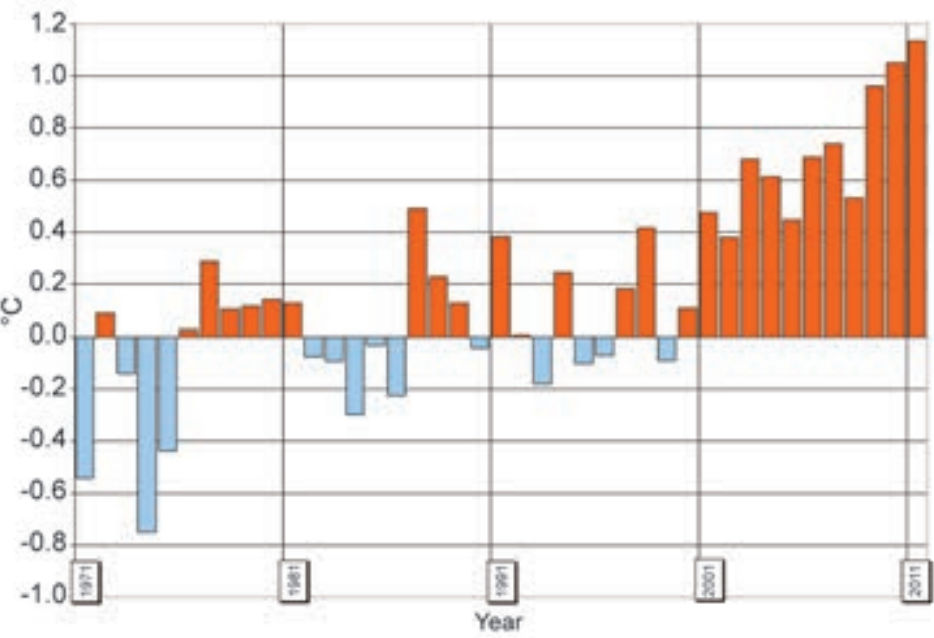

Fig. 7.23. Annual mean temperature anomalies $\left({ }^{\circ} \mathrm{C}\right)$ in Réunion (average of 10 stations) for the period 197I-20II (197I-2000 base period). (Source Météo France, La Réunion)

America, moved over the southern parts of the country on 18-19 June and affected flights to and from Cape Town, Port Elizabeth, and East London.

In Namibia, snow fell on 7 June on the Spreetshoogte Pass between Windhoek and Sossusvlei, which is a very unusual occurrence in this region.

During July a veld fire, driven by strong winds, caused extensive damage to about 8500 ha over at least 17 farms in the district of Ermelo, in Mpumalanga province. Damage was estimated at more than $\$ 1.3$ million (US dollars). Two people died and extensive damage occurred in East London, Eastern Cape, following heavy rain accompanied by hail and strong wind. People were rescued from their houses and vehicles after they were surrounded by flood waters. Gale-force winds also caused extensive damage to property in places in the Western Cape. Heavy snowfalls occurred over the Free State, KwaZulu-Natal, Western and Eastern Cape. Major roads in the four provinces were closed due to the heavy snowfall and ice on the roads. In addition, very cold conditions with rain and snow were reported in most parts of the country. Several towns were snowed in, with schools and businesses closed, power supplies disrupted, and people stranded on roadsides. Some farmers sustained severe stock losses due to the heavy snow and accompanying strong winds.

In August, 13 people were killed when two Albatross airplanes crashed into the Mamotswiri Peak mountains near Tzaneen, Limpopo province, during bad weather conditions. Snowfall caused the closure of Van Reenen's Pass, between the Free State and KwaZulu-Natal provinces. Veld fires fanned by gale-force winds raged out of control in North-West

and the Free State provinces where two people lost their lives.

During October, 1 person died, 166 people were injured, and 2790 were left homeless after a tornado and heavy rain hit the Duduza settlement near Nigel in the Gauteng province. More than 550 homes were destroyed and a disaster area was declared. A tornado also hit the community of Meqheleng in Ficksburg, in eastern Free State, leaving 1 person dead and affecting about 405 people. Heavy rain, hail, and strong winds left several families homeless in the Tsetse village outside Ventersdorp in North-West province. Thirteen people lost their lives in November when heavy rain fell over Paulpietersburg, Pietermaritzburg, and Durban in KwaZulu-Natal. Seven hundred houses were destroyed and thousands of people were displaced.

\section{5) Western Indian Ocean countries-G. Jumaux} and F. Hassane

This region is made of many islands grouped into five countries, including Comoros, Madagascar, Mauritius, Seychelles, and Réunion (France).

\section{(i) Temperature}

For Réunion, 2011 was the warmest year on record since 1971, with an annual mean temperature anomaly of $+1.14^{\circ} \mathrm{C}\left(+0.77^{\circ} \mathrm{C}\right.$ and $+1.51^{\circ} \mathrm{C}$ for annual minimum and maximum temperature, respectively). Réunion also had its warmest June, July, August, and November monthly temperatures since 1971 (Fig. 7.23). For the Union of Comoros, the mean temperature anomaly was once again above its 1971-2000 long-term average. 


\section{SIDEBAR 7.2: AFRICA: THE DROUGHT OF EAST AFRICA IN 2OII-W. M. THIAW}

In 2011, East Africa witnessed one of its most severe droughts in several decades. The drought resulted from two consecutive failed rainy seasons in September-December 2010, (Short Rains season), and in March-May 2011 (Long Rains season), and was considered the worst drought in 60 years according to the UN Food and Agriculture Organization (FAO). Rainfall was much below average across East Africa during the 20II Long Rains (Fig. SB7.3). The season was off to a slow start in February and March. It was also marked by frequent dry spells and an early withdrawal of the rains. Some localities in eastern Africa did not receive rainfall during the entire season. The areas that were most affected by the drought included central and northeastern Kenya, southeastern Ethiopia, and southern Somalia. The lack of rainfall during this season adversely affected crop production and pastures in many sectors in this subregion. River basins such as Juba, Mara, and Shebelle saw their resources depleted, impacting water availability for wild life and pastoral communities. These conditions led to the worst food crisis in this region, which started in May 20II. The UN officially declared famine in localities in Somalia. Millions of people were in immediate need for humanitarian assistance and many people died of diseases related to hunger or malnutrition.

The drought was partially associated with the La Niña episode of 2010/II. While the relationship between La Niña (El Niño) and the Short Rains has clearly been established, and is known to be conducive to below- (above-) average rainfall in eastern Africa (Ropelewski and Halpert 1987), the ENSO teleconnection for the March-May season are not well defined in the scientific literature. This is due in part to the fact that SST anomalies in the tropics are weakest during the spring season. In addition, weather systems during the March-May season are closely tied to the oscillation of the ITCZ over Africa, and topography plays a particularly important role. However, Lyon and DeWitt (2012) found that the rainfall deficit in East Africa during March-May $201 \mathrm{I}$ is part of a long-term precipitation downward trend that can be linked to SST changes in the tropical Pacific. Persistent low-level winds from northeastern Africa and the presence of a midlevel subtropical ridge maintained the ITCZ farther south and contributed to the suppressed rainfall activity.

FIG. SB7.3. Monthly rainfall anomalies $(\mathrm{mm})$ for March, April, May, and June 201 I for eastern Africa (departure from the 197I-2000 base period). (Source: NOAA/NCEP)

\section{(ii) Precipitation}

For Réunion, the annual precipitation amount was about $85 \%$ of the long-term average and was the 15 th driest year since 1971; however, the western part of the island received rainfall that was about $160 \%$ of normal. In contrast, 2011 was the driest year in the historical record in the southern areas of the region, where only $50 \%$ of the long-term average rainfall was recorded. For the Union of Comoros precipitation was about $26 \%$ of long-term average, while the northern part of Grande Comoros was dry during 2011.

\section{(iii) Notable events}

Tropical Cyclone Bingiza made landfall in northeastern Madagascar on 14 February 2011 as an intense storm with maximum sustained wind of $165 \mathrm{~km} \mathrm{hr}^{-1}$. The storm weakened as it crossed northern Madagascar and emerged into the Mozambique Channel 


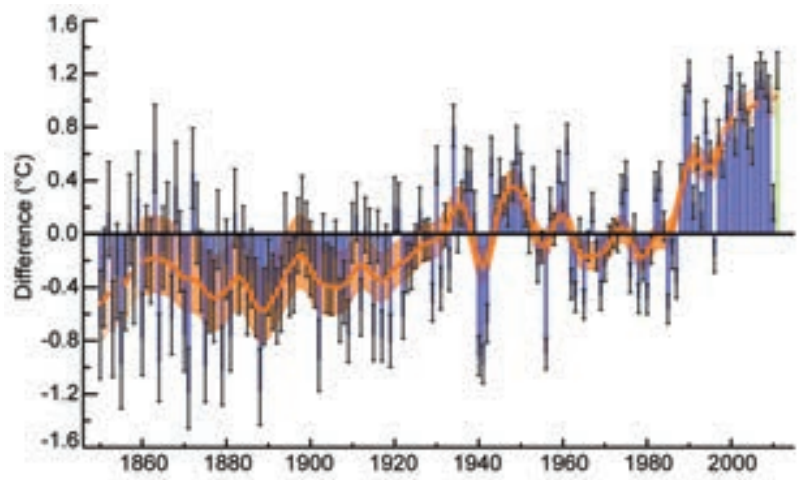

Fig. 7.24. Annual average land surface air temperature anomaly $\left({ }^{\circ} \mathrm{C}\right)$ for Europe $\left(35^{\circ} \mathrm{N}-75^{\circ} \mathrm{N}, 10^{\circ} \mathrm{W}-30^{\circ} \mathrm{E}\right)$ from 1850 to $20 \mathrm{II}$, relative to the $196 \mathrm{I}-90$ base period. The blue bars show the annual average anomaly values and the black error bars indicate the $95 \%$ confidence range of the uncertainties. The green bar is the annual value for $201 \mathrm{I}$. The smooth orange line shows the annual values after smoothing with a 21 -point binomial filter. The dashed portion of the line indicates where the smoothed curve is affected by the choice of endpoint padding and is liable to change in future. The hatched orange area indicates the $95 \%$ confidence range on the smoothed values. Data are from the CRUTEM3 dataset (Brohan et al. 2006).

before turning southward to move across western Madagascar. The storm killed 22 people and injured 13 others.

\section{f. Europe}

I) OVERVIEW - K. Trachte, A. Obregón, P. Bissolli, J. J. Kennedy,

D. E. Parker, R. M. Trigo, and D. Barriopedro

The standard base period used in this section is 1961-90 for temperature and precipitation, unless otherwise specified. Changes in the baseline among European countries conform to different standards applied by the national weather services. All seasons mentioned in this section refer to the Northern Hemisphere.

More detailed information about Europe can be found in the Monthly Bulletin on the Climate in RA VI-Europe and Middle East, provided by the WMO RA VI Pilot Regional Climate Centre on Climate Monitoring (RCCCM, http://www.dwd.de/rcc-cm).

The mean annual air temperature in 2011 for Europe tied with 2007 as the warmest year on record; however, given the observational uncertainties,

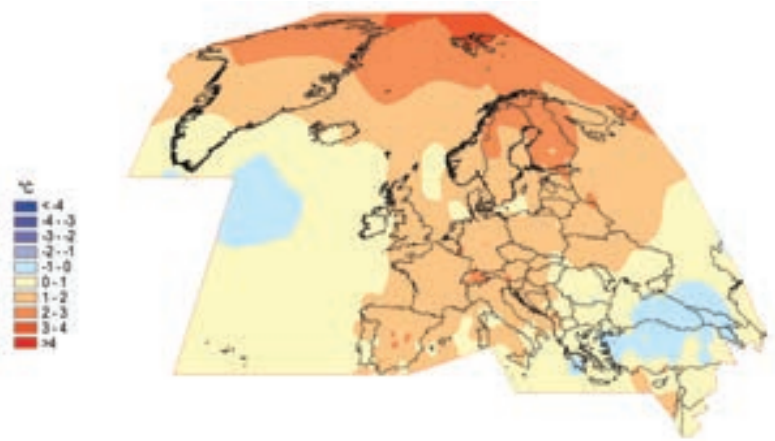

FIG. 7.25. Annual mean temperature anomalies for $201 \mathrm{I}$ in Europe and over the North Atlantic $\left({ }^{\circ} \mathrm{C}\right.$, 196I-90 base period) based on CLIMAT and ship observations. (Source: Deutscher Wetterdienst)

it is not definitively distinguishable from any of the six warmest years since 1850 (Fig. 7.24). According to the CRUTEM3 dataset (Brohan et al. 2006) the land surface air temperature for the European region $\left(35^{\circ} \mathrm{N}-75^{\circ} \mathrm{N}, 10^{\circ} \mathrm{W}-30^{\circ} \mathrm{E}\right)$ was $1.23^{\circ} \mathrm{C} \pm 0.14^{\circ} \mathrm{C}$ above the 1961-90 average. Most of Europe had anomalies of $+1^{\circ} \mathrm{C}$ to $+2^{\circ} \mathrm{C}$ (Fig. 7.25). Only parts of southern Greece, most of Turkey, the eastern Black Sea areas, and the western Caucasus region were below average. All seasons except winter were characterized by above-average temperatures throughout most of Europe. This reflects the continuation of the longterm warming trend in Europe.

Winter season (DJF 2010/11) was anomalously cold in large parts of Europe (Figs. 7.26, 7.27, DJF), mainly due to the very cold December 2010, when
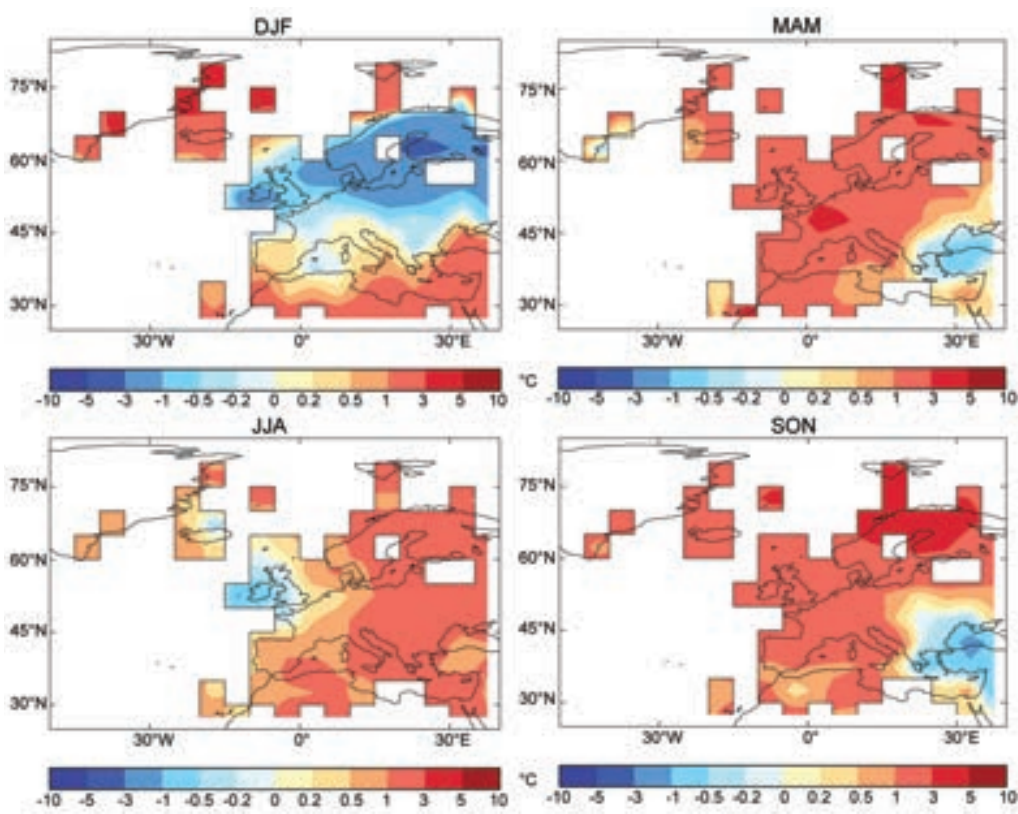

FIG. 7.26. Seasonal anomalies ( ${ }^{\circ} \mathrm{C}, 196 \mathrm{I}-90$ base period) of gridded land surface temperature for Europe. Data from the CRUTEM3 dataset (Brohan et al. 2006). 


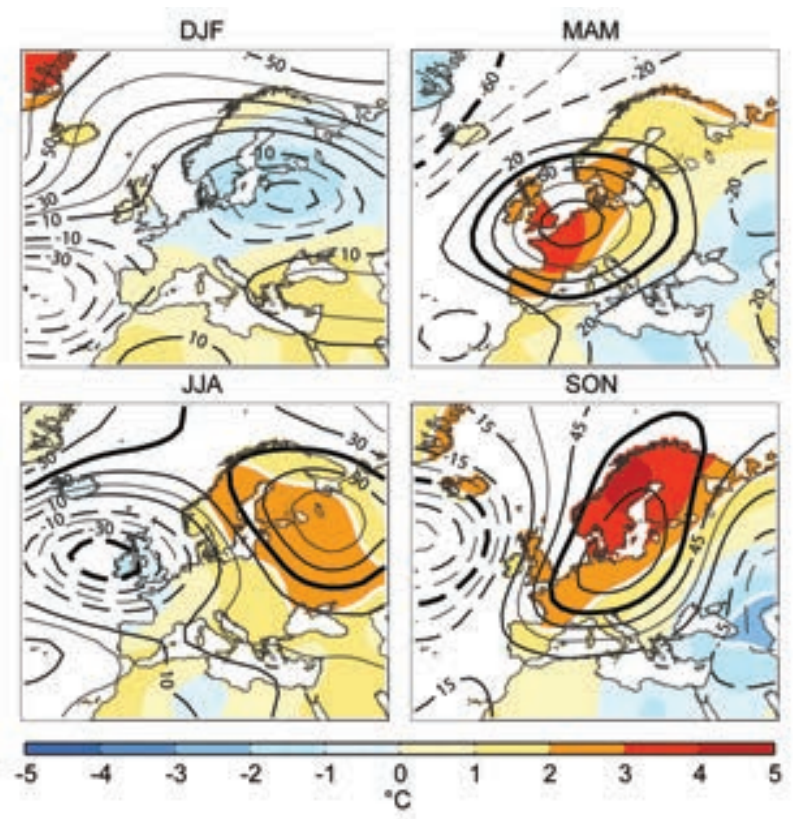

FIG. 7.27. Seasonal anomalies (196I-90 base period) of $500-\mathrm{hPa}$ geopotential height (contour, gpm) and 850 -hPa temperature (shading, ${ }^{\circ} \mathrm{C}$ ) using data from the NCEP/NCAR reanalysis. Winter (DJF), spring (MAM), summer (JJA), and autumn (SON). Black (white) thick lines highlight those geopotential height (temperature) contours with all the encircled grid points having absolute anomalies above their I-sigma level of the base period.

the standardized North Atlantic Oscillation (NAO) index reached strong negative values (-1.85) and the associated weakening of westerly winds reduced warm advection into the north of the continent. Instead, cold air from Russia extended far to the west. In February 2011, a cold trough formed over Russia, leading cold Arctic air to Scandinavia and eastern Europe. Thus, northern and eastern Europe were particularly cooler than average in winter 2010/11, with seasonal anomalies below $-1^{\circ} \mathrm{C}$ over large areas, reaching $-4^{\circ} \mathrm{C}$ in small areas of northwestern Russia. In contrast, Greenland, Iceland, and the Middle East had much-warmer-than-normal air temperatures. Greenland and Iceland were influenced temporarily by a mild Atlantic airflow. Southern Europe had winter temperatures near or slightly-above normal; most of this area (except Iberia) was under prevailing high pressure, particularly the eastern Mediterranean region.

Spring (MAM) was dominated by well-abovenormal air temperatures across most European areas with anomalies exceeding $+3^{\circ} \mathrm{C}$ in the west (Figs. 7.26, 7.27, MAM) due to unusually frequent high pressure systems over continental Europe that also brought record-breaking sunshine. Ireland, the United King-

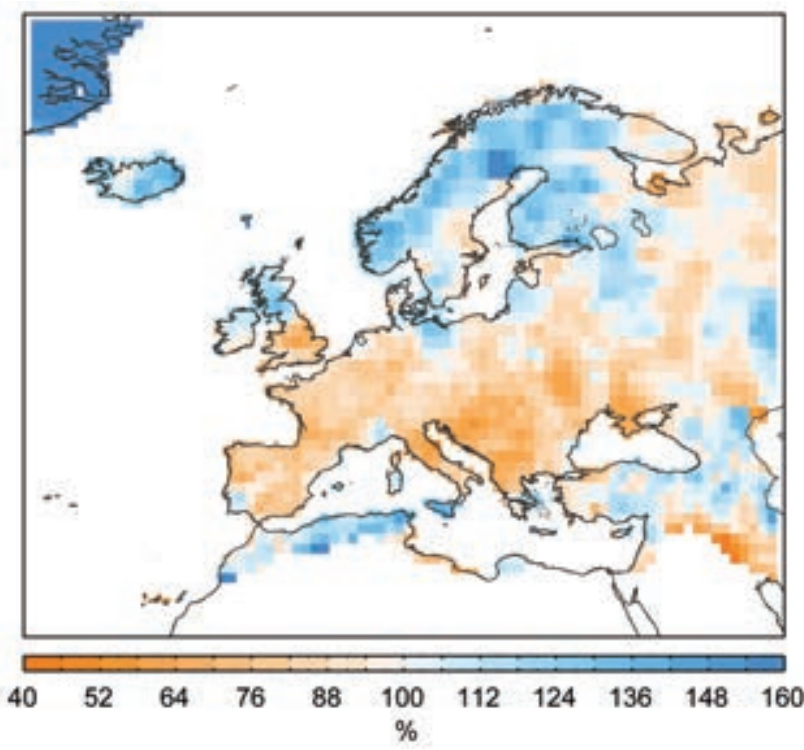

Fig. 7.28. European precipitation totals (\% of normal, 1961-90 base period) for 20II. Only grid points with annual normals above $15 \mathrm{~mm}$ month $^{-1}$ are represented. (Source: Global Precipitation Climatology Centre; Schneider et al. 20II)

dom (UK), Netherlands, Luxembourg, France, Spain, Germany, Switzerland, and Austria experienced a record or near-record warm spring. Only southern Greenland, a larger area around the Black Sea, and the Middle East were outside this high-pressure zone and had below-average temperatures.

Mean air temperatures in summer (JJA) were also above normal in large areas of Europe, particularly over eastern Europe (Figs. 7.26, 7.27, JJA). Only central parts of Iceland, Ireland, the UK, and northwestern France experienced below-average temperatures. This east-west temperature dipole was associated with predominance of lower (higher) than usual geopotential height anomalies over the western (eastern) half of the continent (Figs. 7.26, 7.27, JJA) and some resemblance to the summer NAO pattern, which displayed strong negative values (-1.4). While not as hot as 2010, it was a hot summer in eastern Europe, with seasonal mean anomalies above $+2^{\circ} \mathrm{C}$ over the Baltic countries and of $+3^{\circ} \mathrm{C}$ to $+4^{\circ} \mathrm{C}$ in western Russia; Moscow had its third warmest summer on record (Barriopedro et al. 2011).

Autumn (SON) was warmer than average in most European countries, especially in northern and western Europe, Greenland, the Iberian Peninsula, and the western Mediterranean Sea, where temperature anomalies exceeded +1 to $+2^{\circ} \mathrm{C}$, reaching more than $+3^{\circ} \mathrm{C}$ in northern Scandinavia. Several blocking patterns at high latitudes favored the extremely warm conditions over Scandinavia (Figs. 7.26, 7.27, SON). The blocking was particularly strong in November, 


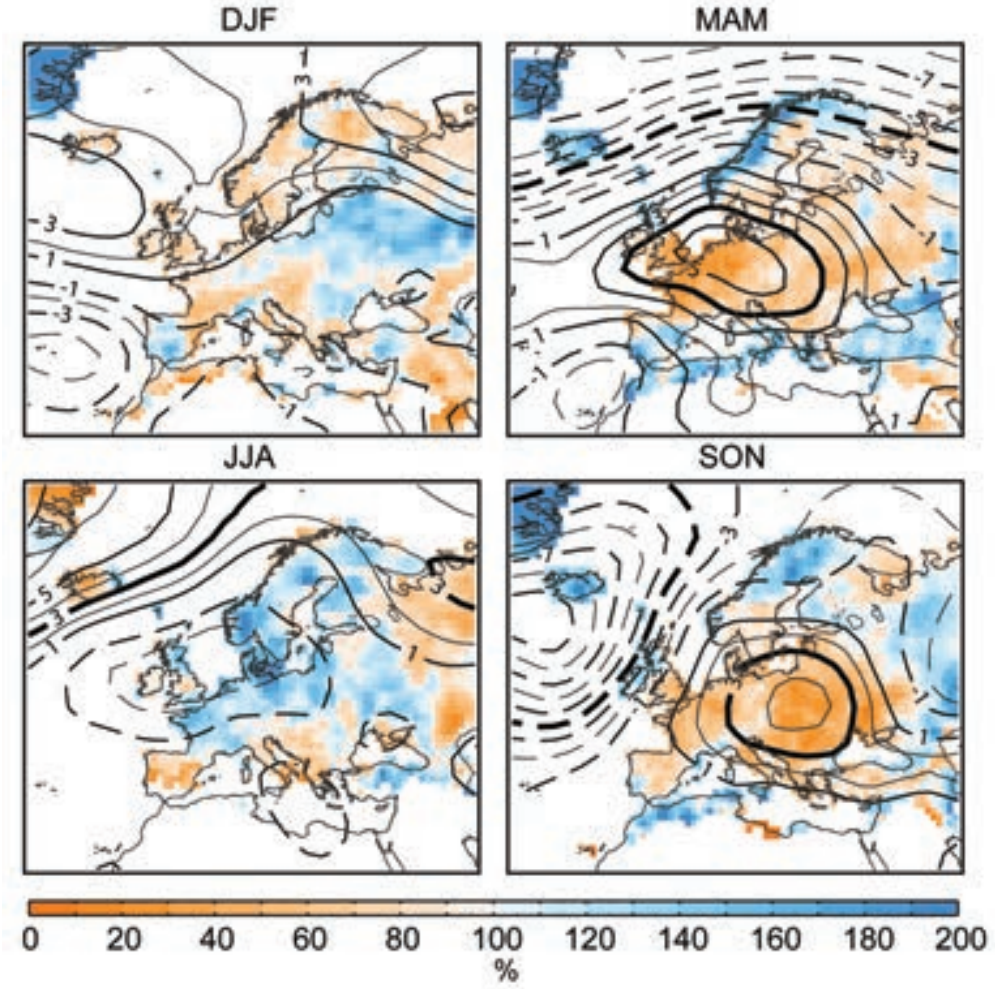

FIG. 7.29. Seasonal anomalies (\%, I96I-90 base period) of sea level pressure ( $\mathrm{hPa}$ ) from NCEP/NCAR reanalysis (contours). Colored shading represents the percentage of seasonal mean precipitation compared with the 196I-90 climatology from the monthly Global Precipitation Climatology Centre (GPCC) precipitation dataset. Only grid points with climatological mean (196I-90 reference period) seasonal precipitation above $15 \mathrm{~mm}$ month ${ }^{-1}$ are represented. Thick black lines highlight those sea level pressure anomalies having absolute anomalies above their I-sigma level of the base period.

which was very warm, relative to normal in northern and western Europe, although it was cooler than average in the Middle East, Turkey $\left(-3.2^{\circ} \mathrm{C}\right.$ anomaly), and the eastern Black Sea regions, and locally on the northern Balkan Peninsula, in relatively good agreement with the extreme positive phase (2.1) of the east Atlantic / western Russia pattern.

In December 2011, the large-scale circulation pattern over Europe changed considerably. The blocking high retreated to Russia, and a mild westerly airflow reached large parts of Europe. The region covered by above-normal temperatures therefore extended to include eastern and northern European regions, with anomalies of more than $+4^{\circ} \mathrm{C}$ (eastern Scandinavia, northern and central European Russia, the Baltic countries, Belarus, and northern Ukraine). December was cooler than normal only in the eastern Mediterranean area, the Middle East, and the northern North Atlantic. It was characterized by strongly positive values of the NAO (2.2).
Precipitation totals in 2011 were above normal over Turkey, Scandinavia, and some other areas of northern Europe (Fig. 7.28). Most of the rest of Europe was frequently affected by anticyclonic systems and, consequently, had below-average annual precipitation totals, particularly the Balkan Peninsula, northern Italy, France, and some other regions of western Europe, where accumulated totals were nearly one-third below their normal. Many areas of the Mediterranean experienced year-round dry conditions, particularly acute in autumn, except the southernmost regions of Europe, which were affected by relatively frequent heavy rainfall episodes.

Most of Europe received near- or below-average precipitation in winter 2010/11 (Fig. 7.29, DJF). Only Greenland, the Iberian Peninsula, and some areas in eastern Europe and Turkey experienced higher-than-normal precipitation totals of $140-180 \%$ over large areas, consistent with the canonical precipitation pattern associated with negative NAO phases.

Spring 2011 was extremely dry in England and Wales, western, central, and eastern Europe, and northern Italy, as well as the Balkan Peninsula, except Greece (Fig. 7.29, MAM), with large areas recording accumulated totals below $50 \%$ of their normal (see Sidebar 7.3). In contrast, northern Europe (especially Greenland, Iceland, Scotland, and the whole Norwegian west coast) and southern Europe (southern and eastern Iberia, southern Italy, Greece, Turkey, the Middle East, and the Caucasus region) received higher-than-normal precipitation totals. This anomalous precipitation configuration is representative of the northward (and southward) shift of Atlantic storm tracks, as a consequence of blocking highs over northern Europe (Trigo et al. 2004).

The pattern was somewhat reversed during summer (Fig. 7.29, JJA). The blocking high over northern and eastern Europe caused Atlantic low pressure systems to cross western and central Europe, but they were then deflected to the north. Heavy rainfall during summer resulted in precipitation totals of up to $180 \%$ of normal in northern and central Europe. Northwestern Russia, the Balkan Peninsula, southern Italy, and Iberia, as well as Greenland and 
Iceland, were all under the influence of positive height anomalies and hence experienced a dry season with summer precipitation totals as low as $50 \%$ of normal in some regions of these areas.

Similar to spring, the weather conditions in most areas of continental Europe were dominated by persistent high pressure systems during autumn (see Sidebar 7.3). These systems were associated with very dry conditions in northern Iberia, central and western Europe, and the Baltic States, as well as Italy, the Balkan Peninsula, and the western part of eastern Europe (Fig.

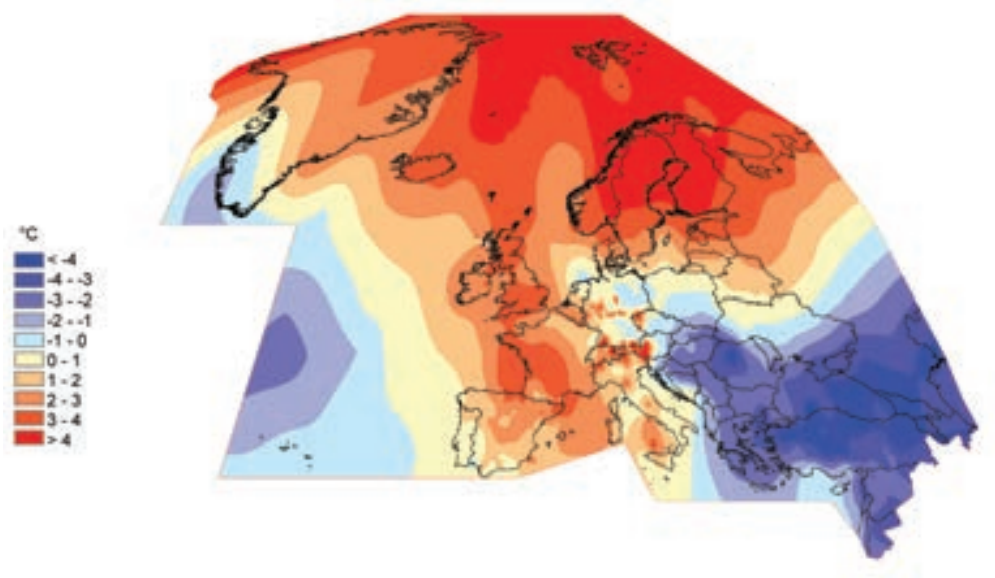
$7.29, \mathrm{SON})$. In November, when high

Fig. 7.31. November 2011 mean temperature anomalies in Europe ( ${ }^{\circ} \mathrm{C}, 196 \mathrm{I}-90$ base period). (Source: Deutscher Wetterdienst) pressure became strongest especially over southern central Europe, less than $10 \mathrm{~mm}$ fell in many places during the month, which corresponds to nearly $10 \%$ of normal in some regions of central Europe. There was $50 \%$ below-normal precipitation in Turkey when $\mathrm{NAO}$ index was positive in November. There is a negative relationship between the NAO index and Turkey's precipitation.

In December, a very strong frontal zone was established over the northern middle latitudes, which separated humid air in the north from drier air in the south. Dryness dominated most of the Mediterranean area, the Iberian Peninsula, and the Middle East, as well as the Caucasus and part of the Balkan Peninsula. Conversely, the western, central, northern, and eastern regions of Europe experienced very wet conditions in December.

Of note, the NAO index was markedly negative in most of the winter and summer seasons. In contrast, it was positive during the dry periods of 2011 (February-April and September-November), indicating that

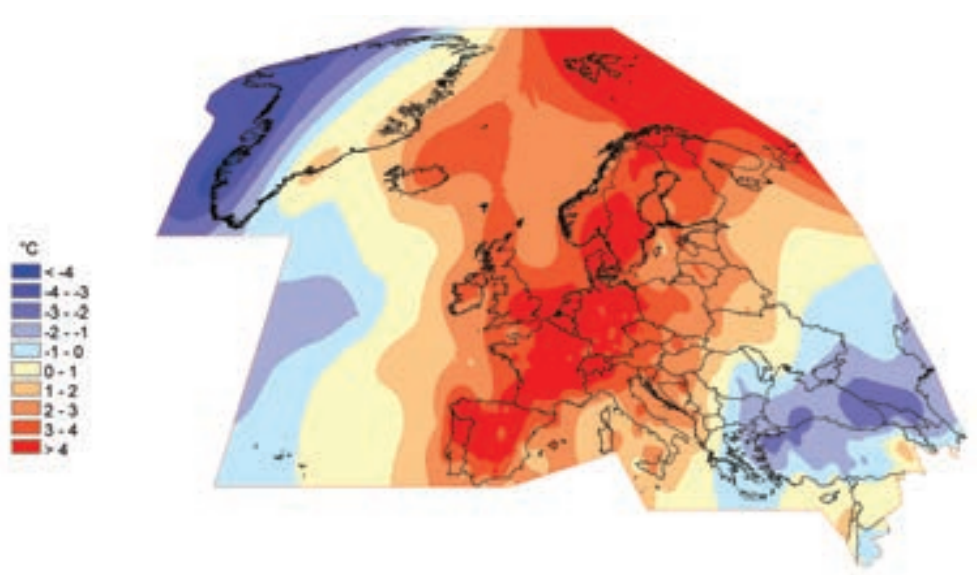

FIG. 7.30. April 2011 mean temperature anomalies in Europe $\left({ }^{\circ} \mathrm{C}\right.$, 1961-90 base period). (Source: Deutscher Wetterdienst) a stronger-than-normal zonal airflow component existed, but did not affect most of the European continent due to highly persistent continental blocking conditions. (see section 2e1).

2) Central and Western Europe-K. Trachte, A. Obregón, P. Bissolli, J. J. Kennedy, D. E. Parker, M. Kendon, and J. Prior

This region includes Ireland, United Kingdom, the Netherlands, Belgium, Luxembourg, France, Germany, Switzerland, Austria, Poland, Czech Republic, Slovakia, and Hungary.

\section{(i) Temperature}

Most of central and western Europe was warmer than average in 2011 (Fig. 7.25), with anomalies around $+1^{\circ} \mathrm{C}$ to $+2^{\circ} \mathrm{C}$. The United Kingdom (UK) had its second warmest year since at least 1910. France saw its warmest year since 1900, Luxembourg since 1947, Switzerland since 1864, and Austria's summits since 1851 when records began.

Winter was near or cooler than normal in all areas of central and western Europe (Figs. 7.26, 7.27, DJF), with December the coldest winter month. Remarkably negative pressure anomalies of $-12 \mathrm{hPa}$ over central North Atlantic during this month led to a highly negative NAO index (-1.85) and more easterlies. Many countries experienced one of their coldest Decembers on record, but the winter as a whole was less cold than winter 2009/10. In early January, when the NAO index switched to positive values, mild air came in from the Atlantic, temperatures rose above normal and 
rivers, swollen by rain and melting snow, flooded in Germany, Austria, and Czech Republic.

Spring 2011 was exceptionally warm (more than $+3^{\circ} \mathrm{C}$ ), especially during April (Fig. 7.30). Periods of high pressure dominated over central and western Europe to an unusual extent. Several western countries reported their warmest spring in at least 100 years (UK, Netherlands, France, Germany, and Switzerland) or second warmest on record (Luxembourg).

In summer, conditions were more anomalously cyclonic and most areas of central and western Europe experienced near-normal to slightly-above-normal temperatures (Figs. 7.26, 7.27, JJA). However, Ireland and the UK mean temperatures dropped below normal, with anomalies down to $-2^{\circ} \mathrm{C}$ in southwest Ireland.

Autumn seasonal average temperatures were above the 1961-90 normal in all areas of western and central Europe which were all located in the western part of the prevailing high pressure zone (Figs. 7.26, 7.27 , SON). November was particularly warm in western Europe, with monthly average records broken in some places. In contrast, southeastern central Europe was colder than average (Fig. 7.31) due to enhanced nocturnal cooling. An autumn mean temperature of $12.2^{\circ} \mathrm{C}$ made 2011 the warmest autumn in over 150 years in Dublin, Ireland. The UK, France, and Switzerland reported their second warmest autumns for at least 100 years, behind only 2006, with anomalies around $+2^{\circ} \mathrm{C}$. December was generally mild, but temperatures in northwestern Europe were near normal.

\section{(ii) Precipitation}

Central and western Europe had near- to belownormal annual precipitation, except in northern parts of both Ireland and the UK and on the German Baltic coast, where the annual totals locally reached $125 \%$ of normal (Fig. 7.28). Scotland experienced its wettest year since at least 1910 and Ireland reported its wettest year since 1986, whereas parts of Slovakia had their driest year since records started in the mid19th century.

Winter was near normal, except for parts of Ireland, the UK, southern France, and the Alpine region, which were often under anomalous high pressure influence and had precipitation totals of $50-80 \%$ of normal (Fig. 7.29, DJF). However, February was wetter than normal in Ireland and most northern parts of the UK due to a more intense and extended area of low pressure $(990 \mathrm{hPa})$ between Southern Greenland and Iceland resulting in increased westerlies.
Spring was dry almost everywhere in the region, except in Scotland (Fig. 7.29, MAM), which was north of the high pressure zone. Germany, the Netherlands, and much of eastern England had their driest spring in more than 100 years, and France experienced its driest in more than 50 years. The dry, warm conditions led to wildfires in early May in the Netherlands, Scotland, Northern Ireland, and parts of England and Wales, and caused significant concern for agriculture and water resources.

In contrast, summer was wetter than normal in most areas due to prevailing cyclonic conditions (Fig. 7.29, JJA). Only Ireland, parts of central England, and southern parts of central Europe had slightly-belownormal precipitation. Ireland reported the driest summer since 2006, while the Netherlands had its wettest since 1906. On 19-22 July thunderstorms with heavy precipitation caused damage in southern and eastern Germany. In Austria, flooding and landslides due to intense thunderstorms on 3-8 August swept four bridges away in Metnitztal, destroyed building roofs in the Innsbruck area, and damaged agricultural crops in Zillertal.

Autumn saw well-below-average precipitation totals (as low as $30 \%$ of normal) in many places due to strong high pressure influence, with the exception of northern parts of Ireland and the UK, which were located at the west flank of that blocking high and where up to $170 \%$ of normal precipitation was observed. Germany, Austria, the Czech Republic, Slovakia, and Hungary all reported their driest November in more than 100 years, and Luxembourg reported its driest since 1947. In December, some strong cyclonic disturbances reached parts of central Europe, bringing a wet end to the year. A storm passed over western and central Europe on 15-16 December, with gusts of more than $100 \mathrm{~km} \mathrm{hr}^{-1}$ over France.

\section{(iii) Notable events}

Low nighttime temperatures caused damages to vineyards during the first week of May as reported by Austria and Germany, resulting in a 15\% drop in income from viticulture.

In Scotland, heavy rain on 11-12 August resulted in floods which disrupted road and rail transport in Glasgow and Edinburgh; this area had experienced persistent wet weather through much of July and early August.

Hurricane Katia moved over the North Atlantic north of Ireland and the UK as a post-tropical storm on 12 September; gusts over $100 \mathrm{~km} \mathrm{hr}^{-1}$ were re- 
corded widely across northern England and southern Scotland.

On 24 October, daily rainfall at the station Dublin Casement Aerodrome in Ireland was $82.2 \mathrm{~mm}$, the greatest daily October rainfall on record at this station since 1954.

On 8 December, a major storm affected Scotland, with winds gusting widely over $130 \mathrm{~km} \mathrm{hr}^{-1}$, and up to $250 \mathrm{~km} \mathrm{hr}^{-1}$ across the mountain summits-the highest gust recorded in the UK since 1996. The storm brought widespread disruption to transport networks and the loss of power to 150000 homes.

Storm Joachim affected southern France, southern Germany, Switzerland, and Austria on 15-16 December with strong gusts at hurricane force, heavy rain and snow. Gusts reached $183 \mathrm{~km} \mathrm{hr}^{-1}$ on Zugspitze Mountain in the Alps (Germany). There were many disruptions of road, rail, and air traffic. Most damage was reported from Austria.

3) The Nordic and Baltic Countries-C. Achberger, K. Trachte, A. Obregón, P. Bissolli, and J. J. Kennedy

This region includes Iceland, Norway, Denmark, Sweden, Finland, Estonia, Latvia, and Lithuania.

\section{(i) Temperature}

The year 2011 was above the 1961-90 long-term mean in the Nordic and Baltic regions, with anomalies ranging between $+1^{\circ} \mathrm{C}$ and $+2.5^{\circ} \mathrm{C}$. The highest anomalies were observed in Finland, northern Sweden, and northern Norway (Fig. 7.25). For places in Finland, Sweden, and Norway, 2011 was one of the warmest three years since national records began in 1900 or earlier, despite a cold winter.

Winter temperatures (DJF 2010/11) were $1^{\circ} \mathrm{C}$ to $2^{\circ} \mathrm{C}$ colder than normal across large parts of the Nordic and Baltic region (Figs. 7.26, 7.27, DJF); down to $4^{\circ} \mathrm{C}$ below normal in southern Norway and Sweden. At the end of a cold February after intense arctic air advection, sea ice extent in the Baltic Seas reached $300000 \mathrm{~km}^{2}$, the largest since 1987 .

Spring temperatures were $0.5^{\circ} \mathrm{C}$ to $3^{\circ} \mathrm{C}$ above normal across the whole region (Figs. 7.26, 7.27, MAM), since northern Europe was much affected by the extended high pressure zone. April was an exceptionally warm month, with monthly mean temperature records set in all Nordic countries.

Temperatures were $1^{\circ} \mathrm{C}$ to $3^{\circ} \mathrm{C}$ above normal across the region in summer (Figs. 7.26, 7.27, JJA). The east European blocking high and warm air advection extended far north to Scandinavia. Finland experienced its fourth warmest summer while Iceland and
Denmark summer temperatures were close to normal. Latvia experienced its warmest June-July period in the past 88 years.

Autumn temperatures continued to be above normal (Figs. 7.26, 7.27, SON), with anomalies of around $+1^{\circ} \mathrm{C}$ in southern Denmark and Lithuania, and exceeding $5^{\circ} \mathrm{C}$ farther north. Again, high pressure influence extended far to the north. Norway and northern parts of Sweden reported their warmest autumn since 1900. December 2011 was much warmer than normal in Finland (by more than $+7^{\circ} \mathrm{C}$ ), Sweden, and the Baltic States, since mild Atlantic air masses often crossed southern parts of northern Europe when moving to the east.

\section{(ii) Precipitation}

Mean annual precipitation conditions were close to normal in most of the Nordic and Baltic regions. However, Norway experienced its wettest year since 1900 , with a national average of $130 \%$ of normal. Similar anomalies were observed locally in Sweden. The Baltic countries and western Iceland were drier, with $60-80 \%$ of normal precipitation totals in some areas (Fig. 7.28).

Winter precipitation was lower than normal in most of the Nordic countries, reflecting prevailing anticyclonic conditions in the north, although there were strong local deviations (Fig. 7.29, DJF). However, in spite of relatively low precipitation totals (Norway received $30-50 \%$ of normal), the snow season started early due to low temperatures and considerable snow depths developed during the winter and early spring. The Baltic States, which were located near the mean center of low geopotential height (Fig. 7.27) had precipitation totals that were $110-130 \%$ of normal; the primary form of precipitation was snow.

Spring was wet, with $130-150 \%$ of normal precipitation in Sweden and Norway (Fig. 7.29, MAM). Low pressure systems were deflected north of the large European high pressure system. The largest anomalies (up to $300 \%$ ) were in central Norway and the west Norwegian coast. Denmark and the Baltic countries were located within the anticyclonic area and had a dry spring (20\% of normal); March and April in particular were very dry (20-40\% of normal).

Summer 2011 was also a wet season in many parts of the region (130-170\% of the normal; Fig. 7.29, JJA). Norway and Denmark, which were especially influenced by cyclonic conditions, experienced their second wettest summer since at least 1900. A large fraction of the summer precipitation came as heavy rainfall events. In contrast, most of Iceland was fre- 
quently under high pressure conditions and had only $30-50 \%$ of normal precipitation.

Autumn precipitation amounts varied considerably, from $130-170 \%$ of normal in southern and northern Norway and northern Sweden, which were north of the high pressure zone, to $30-70 \%$ in Denmark and the Baltic States (Fig. 7.29, SON), which were within. November was a dry month in southern parts, but was followed by a wet December with frequent low pressure systems in most of the region (the wettest on record in Latvia).

\section{(iii) Notable events}

On 24 March, Finland reported heavy snow showers and strong wind gusts that caused a sudden drop in visibility to near zero. Seventy cars were damaged and several dozen people injured.

An unusually wide ranging Saharan Dust transport from Africa to Scandinavia occurred in early April.

Northern and northeastern Iceland were hit by an unseasonal snow storm on 23-24 May.

From 8 to 13 June, flooding occurred in Norway due to torrential rainfall with melting snow. The result was devastating floods that washed away several houses and roads and caused landslides.

On 24 July, thunderstorms brought heavy precipitation across Finland and a daily precipitation total of $121 \mathrm{~mm}$ in Tornio. Flooding in the capital Helsinki on 22 August was caused by a line of thunderstorms from the Gulf of Finland.

On 25 and 26 December, Norway, Sweden, and southern and western parts of Finland were hit by high wind speeds in the severe winter storm Dagmar (up to $113 \mathrm{~km} \mathrm{hr}^{-1}$ in Finland), which was the most damaging winter storm since 2001, causing widespread electricity disruptions. In middle and northern Sweden, trains were halted and roads were temporarily closed. Also in December, the national monthly precipitation record was broken in Kemiönsaari in southern Finland with 190 mm, three times the December monthly average.

4) IBERIA-K. Trachte, A. Obregón, P. Bissolli, R. Trigo, D. Barriopedro, C. Gouveia, and D. E. Parker

This region includes Portugal and Spain.

\section{(i) Temperature}

The Iberian Peninsula was warmer than normal, with annual positive anomalies of $+1^{\circ} \mathrm{C}$ to $+2^{\circ} \mathrm{C}$ in most regions (Fig. 7.25), except in the southwest, where anomalies were $0^{\circ} \mathrm{C}$ to $+1^{\circ} \mathrm{C}$. Spain observed its warmest year since 1961, while Portugal had its annually-averaged maximum temperature among the three warmest since 1931.

The winter season 2010/11 was mostly slightly above normal with $0^{\circ} \mathrm{C}$ to $+1^{\circ} \mathrm{C}$ anomalies (Figs. 7.26, $7.27, \mathrm{DJF})$. Spring was warmer than normal $\left(+2^{\circ} \mathrm{C}\right.$ to $+3^{\circ} \mathrm{C}$ throughout the Iberian Peninsula), except the southern coastal region, which had anomalies of $+1^{\circ} \mathrm{C}$ to $+2^{\circ} \mathrm{C}$ (Figs. 7.26, 7.27, MAM). It was the warmest spring since at least 1951 in Spain and the second warmest in Portugal since 1931. April and May were particularly warm, consistent with the dominance of strong anticyclonic conditions over western Europe (Fig. 7.26); the mean April temperature anomaly in Iberia reached $+3.9^{\circ} \mathrm{C}$, the highest value observed since 1951.

Summer was warmer than normal in southeastern Iberia (related to higher-than-normal geopotential) and near normal in the northwest (Figs. 7.26, 7.27, JJA). June and August were very warm, especially in southern and eastern Spain, with the spatiallyaveraged anomalies reaching $+1.5^{\circ} \mathrm{C}$ and $+1.4^{\circ} \mathrm{C}$, respectively.

Autumn was much warmer than normal due to prevailing anticyclonic conditions in most areas in all three months (Figs. 7.26, 7.27, SON), the third warmest autumn in Portugal and Spain since 1931 and 1960, respectively. Both countries reported a mean anomaly above $+2^{\circ} \mathrm{C}$ in October. December was near normal in the west, but still well above normal in the east.

\section{(ii) Precipitation}

Annual precipitation was below normal throughout the Iberian Peninsula (Fig. 7.28). Average rainfall in Spain was $565 \mathrm{~mm}$ (87\% of the 1971-2000 normal) and $750 \mathrm{~mm}$ in Portugal (85\% of the 1971-2000 normal), mainly due to rainfall deficits during summer and the first part of autumn.

Winter 2010/11 saw far more cyclonic situations than usual and was especially wet in southern parts of Spain, at more than $150 \%$ of normal, whereas eastern areas were very dry. Despite the dry January (50-70\% of normal), Portugal was relatively wet on average (Fig. 7.29, DJF), in agreement with a dominant negative NAO seasonal index (-1.0).

In northern Iberia, spring was dry whereas the rest of the peninsula experienced above-normal precipitation totals (Fig. 7.29, MAM), due to prevailing cyclonic conditions in southern Europe. In Spain, March was wetter than normal (around 150\% of the spatially-averaged normal), while April and May 
were near normal. Southern Portugal experienced $150-200 \%$ of its $1971-2000$ precipitation average in April and May.

Summer was drier than usual throughout the Iberian Peninsula; there was not much cyclonic activity (Fig. 7.29, JJA). Spain had only around 70\% of normal precipitation.

Autumn precipitation in Iberia was slightly below normal (Fig. 7.29, SON), while the first half of autumn was exceptionally dry in Spain with prevailing anticyclonic conditions. September was Spain's driest month for 2011, and its driest September since 1988, with a monthly average of only $15 \mathrm{~mm}$ rainfall-a third of normal. September was also dry in Portugal with $50-75 \%$ of normal, although some areas of Portugal had precipitation totals that were $250 \%$ of normal. The zonal dipole of Fig. 7.27 with negative autumn height anomalies over the eastern Atlantic was more pronounced in November, and all areas in Portugal and most of Spain had above-normal precipitation, at $125-150 \%$ of normal.

In December, the situation reversed. The Azores high became very strong and both Spain and Portugal experienced very dry conditions. Spain recorded precipitation totals $(25 \mathrm{~mm})$ of only $30 \%$ of the spatially-averaged mean $(82 \mathrm{~mm})$. Portugal also received much-below-average rainfall, with as little as $25 \%$ of normal in the south.

\section{(iii) Notable events}

On 16 February, a storm with heavy rainfall, snowfall and wind gusts exceeding $100 \mathrm{~km} \mathrm{hr}^{-1}$ hit the western coast of the Iberian Peninsula, destroying roofs and downing trees.

The warm months of April and May in Portugal were associated with three heat waves, including several tropical nights (i.e., minimum temperature above $20^{\circ} \mathrm{C}$ ). Between the periods of heat waves, heavy rainfall occurred on 29 April and flash floods with heavy sleet and hail affected the region of Lisbon.

The first half of October in Spain was the hottest since at least 1961, with temperature anomalies ranging between $+3^{\circ} \mathrm{C}$ and $+4^{\circ} \mathrm{C}$ and maximum daily temperatures climbing up to $6^{\circ} \mathrm{C}$ above their normal values. Numerous stations in northern, central, and southern Spain exceeded $30^{\circ} \mathrm{C}$ and set new historical daily records for October. This month was also very warm in Portugal, which was affected by two heat waves between the latter part of September and the end of October. The extreme hot weather triggered an unusually high number of fires in October in northwestern Iberia. However, during 23-27 Octo- ber, extreme rainfalls (up to $117.5 \mathrm{~mm}$ in 24 hours) affected northwestern Spain.

5) Mediterranean, Italian, and Balkan Peninsulas —K. Trachte, A. Obregón, P. Bissolli, S. Sensoy, and D. Parker

This region includes Italy, Malta, Slovenia, Croatia, Serbia, Montenegro, Bosnia and Herzegovina, Albania, Macedonia, Greece, Bulgaria, and Turkey.

\section{(i) Temperature}

Mean annual temperatures over the western Mediterranean region and in southeastern Europe were generally above the 1961-90 average. Annual temperature anomalies were mostly $+1^{\circ} \mathrm{C}$ to $+2^{\circ} \mathrm{C}$, although the eastern Balkan Peninsula and the eastern Mediterranean had temperatures near normal (Fig. 7.25), and the northern part of Turkey was slightly cooler than normal.

Temperatures during winter 2010/11 were near normal in most areas but more than $+1^{\circ} \mathrm{C}$ above average over the eastern Mediterranean and Turkey (Figs. 7.26, 7.27, DJF), and more than $+2^{\circ} \mathrm{C}$ in eastern Turkey, due to warm air advection. Parts of the Balkan Peninsula had slightly negative anomalies, particularly eastern parts. February was especially cold over most of the Balkan Peninsula, when cold Arctic air advanced far to the south .

During spring, anomalous warmth affected the western Mediterranean due to extended anticyclonic conditions, with anomalies of up to $+2^{\circ} \mathrm{C}$ to $+3^{\circ} \mathrm{C}$ in northern Italy and Slovenia (Fig. 7.29, MAM); April was especially warm. Conversely, most of Bulgaria, Greece, and Turkey experienced below-average temperatures in spring with anomalies at $0^{\circ} \mathrm{C}$ to $-1^{\circ} \mathrm{C}$ due to cold air advection east of the high pressure zone; localized areas in Turkey observed even cooler anomalies.

Summer temperatures were above normal in most of the area (Fig. 7.29, JJA) due to warm air advection from the southeast. The western Balkan Peninsula experienced particular warmth, with $+1^{\circ} \mathrm{C}$ to $+3^{\circ} \mathrm{C}$ anomalies.

Autumn temperatures were above normal over the western Mediterranean basin due to extended anticyclonic conditions, whereas the eastern region experienced mostly below-average temperatures due to cold air advection from the north (Fig. 7.29, SON). August and September were extremely warm in Italy and on the Balkan Peninsula; October and November were cold in the east. Bulgaria and Turkey reported November monthly anomalies of $-2.7^{\circ} \mathrm{C}$, and $-3.2^{\circ} \mathrm{C}$, respectively, making it the coldest month of 2011 
(Fig. 7.31). In December, most of Italy and the Balkan Peninsula experienced mild air advection with aboveaverage temperatures, especially in northern parts, with anomalies above $+2^{\circ} \mathrm{C}$ in northwestern Croatia and northern Serbia.

\section{(ii) Precipitation}

The year 2011 had less precipitation than normal in northern Italy and most areas of the Balkan Peninsula (Fig. 7.28). Precipitation totals were only $60-80 \%$ of normal and in some areas in Slovenia and eastern Croatia even lower. Much-above-average precipitation occurred only over Sicily, which had more than $125 \%$ of normal.

Winter precipitation totals were $70-90 \%$ of average in Italy and the coastal regions of the Balkan Peninsula (Fig. 7.29, DJF). There was more cyclonic activity in the western Mediterranean basin compared to the east. In northwestern Italy and Sicily, above-normal precipitation amounts were observed. Croatia and Greece reported dry-to-normal conditions, despite the sporadic occurrence of high precipitation events in Greece in January.

With increasing anticyclonicity, the precipitation deficit extended into spring on the Balkan Peninsula and in the northern Mediterranean Sea areas (Fig. 7.29, MAM). However, cyclonic conditions developed over the southern and eastern Mediterranean. Southern Italy and Greece, as well as Turkey (especially its coastal areas) received above-normal precipitation. Sicily reported up to $170 \%$ of normal.

In almost all parts of Italy and the Balkan Peninsula, anticyclonic conditions were prevailing and below-average precipitation totals were reported in summer (Fig. 7.29, JJA) and autumn (Fig. 7.29, SON), despite some heavy thunderstorms, whereas most parts of Turkey had higher-than-normal summer precipitation due to a high convective activity. The Adriatic countries experienced as little as $30-50 \%$ of the normal autumn precipitation. September was the driest month for Bulgaria, especially in the north. Serbia experienced very dry conditions, especially in November with nationally-averaged precipitation totals of less than $25 \%$ of normal. There was $50 \%$ below-normal precipitation in Turkey when NAO index was positive in November. (There is a negative relationship between NAO index and Turkey's precipitation.)

In December, when westerlies reached central and parts of southeastern Europe, the rainfall was normal or higher on the Balkan Peninsula, while Italy and eastern Turkey continued to see deficits.

\section{(iii) Notable events}

On 23 February, a dust storm, which formed west of the Nile delta spread northwards to Crete island (Greece).

In March, a Mediterranean depression brought heavy rainfall, bora (i.e., strong north-to-northeasterly downslope winds at the east coast of the Adriatic Sea), and snowfall to southeastern Europe and Italy. In Greece, a landslide occurred due to heavy rain; and snowfalls on the Peloponnese, in the south, were reported during 8-10 March. In contrast, due to the very dry April, forest fires occurred in Bulgaria on 9 and 30 April.

Dust was transported northward from the North African coast off Egypt and Libya over the Mediterranean Sea on 16 April.

During a hailstorm, which occurred in Ankara on 16 June, the accumulated hail depth reached 20 $\mathrm{cm}$. Some underpass exits were flooded or blocked by hail and traffic was disrupted. Hundreds of cars were damaged by the hail.

On 24-25 August a storm with egg-sized hail caused damage in western and central Bulgaria, and a long dry period from 13 to 30 August caused damage to agriculture.

During 8-17 October, Greece, Bulgaria, and Turkey had extremely heavy rainfall. Turkey reported its highest daily total in October of $300.4 \mathrm{~mm}$ in Antalya. (The record high daily total was $332 \mathrm{~mm}$, set in January 1969.) October rainfall $(395.8 \mathrm{~mm})$ was $483 \%$ of normal ( $82 \mathrm{~mm})$. In Shabla, eastern Bulgaria, due to a vigorous storm during $16-18$ October, $156.5 \mathrm{~mm}$ precipitation within 24 hours was measured, around four times the monthly normal.

Extremely heavy rain on 21 October brought Dubrovnik, Croatia, a daily total of $185.5 \mathrm{~mm}$, nearly twice the monthly normal. During 23-27 October, the Ligurian coast of northern Italy had extreme precipitation totals due to an intense storm system that caused mud and debris slides. Cyclone Rolf hit northwestern Italy during 3-8 November, with high rainfall intensities, producing a 454-mm daily total on 4 November in Vicomorassa, north of Genoa.

In Slovenia on 4 October, record-breaking October maximum temperatures of $29.8^{\circ} \mathrm{C}$ in Bilje and $25.9^{\circ} \mathrm{C}$ in Postojna were observed. 
6) Eastern Europe-K. Trachte, A. Obregón, P. Bissolli, and D. E. Parker

This region includes European Russia, Belarus, Ukraine, Moldova, and Romania.

\section{(i) Temperature}

Eastern Europe was mainly warmer than normal during 2011, especially in the north where the year was $+1^{\circ} \mathrm{C}$ to $+2^{\circ} \mathrm{C}$ above the $1961-90$ average (Fig. 7.25). Ukraine and Romania reported positive anomalies of $+1^{\circ} \mathrm{C}$ and $+0.4^{\circ} \mathrm{C}$, respectively.

The winter season was colder than average, with negative anomalies below $-4^{\circ} \mathrm{C}$ in northwestern Russia (Figs. 7.26, 7.27, DJF). Only southern parts of European Russia were warmer than normal on the seasonal average. February was especially cold throughout eastern Europe, when cold arctic air was advected. In the Ukraine, positive anomalies of $+2^{\circ} \mathrm{C}$ to $+3^{\circ} \mathrm{C}$ in January were followed by anomalies of $-1.5^{\circ} \mathrm{C}$ to $-2.5^{\circ} \mathrm{C}$ in February. The absolute minimum air temperature of 2011 of $-31^{\circ} \mathrm{C}$ in the Ukraine was measured in February in the Luhansk region (not a record). Romania also reported a below-normal anomaly of $-1.2^{\circ} \mathrm{C}$ in February.

During spring (Figs. 7.26, 7.27, MAM), there were positive anomalies in the anticyclonically influenced western part of the Ukraine and Belarus with $+1^{\circ} \mathrm{C}$ to $+2{ }^{\circ} \mathrm{C}$ and in northern European Russia up to $+4^{\circ} \mathrm{C}$, but southeastern areas, which were still under prevailing cold air advection had slightly below-average temperatures.

The summer season brought particularly high positive anomalies over eastern Europe due to an extended blocking high. Western Russia experienced positive anomalies of $+3^{\circ} \mathrm{C}$ to $+4^{\circ} \mathrm{C}$ and Belarus observed $+2^{\circ} \mathrm{C}$ to $+3{ }^{\circ} \mathrm{C}$ (Figs. 7.26, 7.27, JJA). It was the third warmest summer on record in Moscow, but far less extreme than in 2010. July had particularly high anomalies, up to more than $+4^{\circ} \mathrm{C}$, over large parts of western Russia. In the Ukraine, too, July was the warmest summer month with the highest monthly anomalies of summer 2011, and a monthly mean temperature of $19^{\circ} \mathrm{C}-25^{\circ} \mathrm{C}$. Romania reported anomalies of $+2^{\circ} \mathrm{C}$ to $+3^{\circ} \mathrm{C}$ in August for its western and mountain areas.

In the northern part of eastern Europe, the warmth continued into autumn (Figs. 7.26, 7.27, SON). Romania reported an anomaly of $+2.6^{\circ} \mathrm{C}$ in September and more than $+4^{\circ} \mathrm{C}$ in southwestern areas. In southwestern Russia, cold air advection developed and below-average temperature anomalies of $0^{\circ} \mathrm{C}$ to $-1^{\circ} \mathrm{C}$ were observed in the same month. In
December, westerlies crossed Europe to the east, and all areas in eastern Europe experienced well-above normal temperatures, with anomalies of more than $+4^{\circ} \mathrm{C}$ in most of European Russia, the northern Ukraine, and Belarus.

\section{(ii) Precipitation}

Precipitation totals in 2011 were generally around normal in eastern Europe. Only western Ukraine, Moldova, and western Romania had below-normal precipitation totals of $60-80 \%$ (Fig. 7.28). Some areas in western and southern regions of European Russia had totals of more than $125 \%$ of normal.

Winter had near-normal precipitation amounts, except for some areas in western and central European Russia, which had $110-130 \%$ of the long-term mean; southern parts of European Russia were dry (Fig. 7.29 , DJF). There was a notable precipitation deficit during February in most of eastern Europe because of prevailing cold and dry air.

During spring, the Ukraine, Belarus, and parts of Russia were very dry under high pressure influence (Fig. 7.29, MAM). In March, much of the western parts of eastern Europe received only around $40 \%$ of normal precipitation.

During summer, the western areas of eastern Europe were cyclonically influenced and received above-normal precipitation totals while the eastern areas had anticyclonic conditions and below-average values. The Ukraine had its maximum precipitation anomalies in June and July, at $100-150 \%$ of normal. Central and southern regions of the country received persistent heavy rainfalls with $145 \mathrm{~mm}-195 \mathrm{~mm}$ in the last 10 days of June, which is $250-350 \%$ of normal. In Romania, June and July precipitation was $112 \%$ and $129 \%$ of normal, respectively. In contrast, August had long periods of rainless weather in large parts of eastern Europe.

Autumn was dominated by anticyclonic conditions and much-below-average precipitation in the western areas of eastern Europe (Fig. 7.29, SON). The Ukraine, Moldova, and Romania each reported a large precipitation deficit with totals of $30-50 \%$ of the seasonal normal with greatest deficits in September. These deficits partly continued in December; in contrast, European Russia was mostly wet due to frequent low pressure systems, except in the south. 
7) Middle East-A. Hovsepyan, V. Grigoryan, K. Trachte, A. Obregón, P. Bissolli, and D. E. Parker

This region includes Israel, Cyprus, Jordan, Lebanon, Syria, western Kazakhstan, Armenia, Georgia, and Azerbaijan.

\section{(i) Temperature}

The Middle East as a whole in 2011 had a nearnormal annually-averaged temperature, but it was mostly $0.5^{\circ} \mathrm{C}$ to $1^{\circ} \mathrm{C}$ below average in western parts of the South Caucasus (Armenia, Azerbaijan, Georgia; Fig. 7.25).

Winter 2010/11 had mostly anticyclonic conditions and higher-than-average temperatures throughout the region, mostly by more than $1^{\circ} \mathrm{C}$ (Figs. 7.26, 7.27, DJF). The South Caucasus reported seasonal anomalies up to $+5^{\circ} \mathrm{C}$. February temperatures were much below normal in west Kazakhstan $\left(-3^{\circ} \mathrm{C}\right.$ to $-4^{\circ} \mathrm{C}$ anomaly), due to cold air advection from the north, and slightly below normal south of the Caucasus.

In spring, temperatures in west Kazakhstan, Georgia, and eastern Azerbaijan were slightly below average due to cold air advection, but near-to-slightlyabove normal in Armenia, western Azerbaijan, and in southern parts of the Middle East (Figs. 7.26, 7.27, MAM). Warmer-than-average conditions (around $+1^{\circ} \mathrm{C}$ anomaly) dominated throughout the Middle East during the summer season (Figs. 7.26, 7.27, JJA) due to warm air advection from the south. Several countries reported record high maximum daily air temperatures. Armenia experienced an all-time national record of $43.7^{\circ} \mathrm{C}$ on 31 July. Azerbaijan recorded $44.7^{\circ} \mathrm{C}$ (a new local record) on 31 July, and in the last week of July, temperatures reached $44.3^{\circ} \mathrm{C}$ in Israel, $46.5^{\circ} \mathrm{C}$ in Jordan, and $45^{\circ} \mathrm{C}$ in Syria.

Autumn began with above- or near-normal temperatures in September, and ended with a cold November, with anomalies around $-1^{\circ} \mathrm{C}$ in Cyprus and below $-4^{\circ} \mathrm{C}$ in parts of west Kazakhstan and the South Caucasus (Figs. 7.26, 7.27, SON), when cold air was advected east of a strong high over eastern central Europe. Armenia had its coolest November since 1966 , with anomalies reaching as low as $-6^{\circ} \mathrm{C}$; new monthly minimum temperature records were set for certain locations (e.g., $-29^{\circ} \mathrm{C}$ in northern Armenia). December was still slightly cooler than normal or near normal in most areas of the Middle East.

\section{(ii) Precipitation}

Annual precipitation totals were mostly near average in the Middle East (70-130\% of the normal), with some local wet and dry anomalies (Fig. 7.28).
The winter season in the South Caucasus brought particularly high precipitation totals in February, with up to more than $400 \%$ of normal in western Georgia, about 350\% in eastern Georgia, and up to $240-300 \%$ of normal in the Lake Sevan basin in Armenia (Fig. 7.29, DJF), when a broad upper-level trough extended far to the south. Cyprus remained under high pressure influence and reported mainly below-average precipitation totals in winter 2010/11.

The southeastern Middle East was mostly under high pressure influence and experienced a very dry spring in 2011, while other parts of the region were wetter than normal (Fig. 7.29, MAM) due to prevailing cyclonic conditions. Eastern Syria and Jordan had an extremely dry March and May.

Summer was dry over the entire South Caucasus region and West Kazakhstan due to the large blocking high over eastern Europe. Dry conditions, especially in June and July, led to drought in Ararat Valley and Syunik Valley in the south of Armenia (Fig. 7.29, JJA). Autumn had very localized anomalies inland but mostly above-normal precipitation in both the Mediterranean and Black Sea coastal areas and in west Kazakhstan (Fig. 7.29, SON) due to occasional cyclonic activity. In contrast, December was dry in the Middle East and in the South Caucasus region; these areas were influenced by an extended Russian high.

\section{(iii) Notable events}

The year 2011 was remarkable due to the frequent occurrence of weather hazards and climate extremes, particularly for the South Caucasus.

On 23 January, a flood damaged energy systems in western Georgia, and a tornado was recorded in the northeast of Geri area, Cyprus. Strong winds were recorded often during the winter months in the South Caucasus. In particular, in February in Absheron peninsula, Azerbaijan, the wind speed reached $72 \mathrm{~km} \mathrm{hr}^{-1}-100 \mathrm{~km} \mathrm{hr}^{-1}$, with gusts up to 104 $\mathrm{km} \mathrm{hr}^{-1}$. Due to a significant pressure gradient at high altitudes, a strong wind was reported in February in Pushkin pass, with the maximum velocity reaching $115 \mathrm{~km} \mathrm{hr}^{-1}$ and gusts of $165 \mathrm{~km} \mathrm{hr}^{-1}$.

In Armenia, heavy snowfall was recorded in March, and flooding due to heavy precipitation amounts occurred in Kazakhstan during 1-19 April. On 12 April, more heavy snowfall was reported from northern Armenia; on 20 April, "yellow" snowfall (snow with sand/dust from the Arabian deserts) occurred in Gyumri city, Armenia. 


\section{SIDEBAR 7.3: DROUGHT AND PRECIPITATION EXTREMES IN EUROPE—J. J. KENNEDY, M. KENDON, K. TRACHTE, A. OBREGÓN, P. BISSOLLI, R. TRIGO, D. BARRIOPEDRO,}

AND C. GOUVEIA

Spring and autumn 20II exhibited a sharped spatial gradient in precipitation across Europe. While large midlatitude areas of western, central, and even parts of eastern and southern Europe were dominated by a long-lasting dry period in the two transition seasons, the northernmost and southernmost regions of Europe received outstandingly abundant precipitation. Seasonal precipitation totals amounted to $40-80 \%$ of normal (196I-90 base period) in the dry areas and $130-170 \%$ in some of the wet regions (Fig. 7.29). The driest areas were in western Europe in spring, and further east in autumn (Fig. 7.29). In some places, the precipitation anomalies observed during autumn and spring extended into the winter and summer months, respectively, resulting in a similar precipitation pattern for the whole of $201 \mathrm{II}$ (Fig.

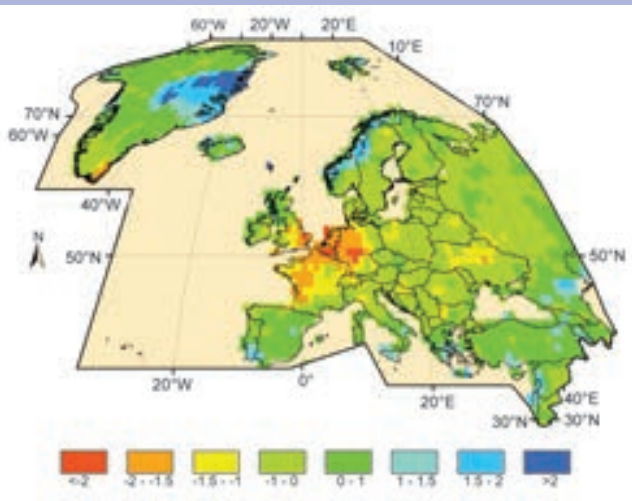

FIG. SB7.4. Standardized Precipitation Index (modified from Pietzsch and Bissolli 2011; deviation from 196I-90 base period) for spring 2011. (Source: Deutscher Wetterdienst) 7.28), though it was less pronounced in central Europe due to a wet summer.

The situation was particularly evident in the UK, where most of southern, central, and eastern England experienced both an exceptionally dry spring and a very dry autumn. As a result, much of central and eastern England received around $75 \%$, or less, of the annual average rainfall for 2011 overall, and less than $65 \%$ in some places. Several counties had their driest year since at least 1910. The dryness may be traced back to December 2009-with 20 out of the 25 months since then seeing below-average rainfall. In contrast, Scotland had its wettest year since national records began in 1910 (it should be noted that some individual station records date back further), with much of southern and central Scotland receiving well over $125 \%$ of average.

Other areas in western and central Europe had a very dry spring and autumn, but with a rainy summer in between the two seasons. Western Germany, the Netherlands, Belgium, Luxembourg, and northern France experienced an extremely dry spring, similar to exceptional droughts in 1976 and the 1990s (Fig. SB7.4). Germany had its driest spring since 1893 and the Netherlands had its driest in at least a century, with an average precipitation total of $49 \mathrm{~mm}$ ( $28 \%$ of normal) and a potential precipitation deficit exceeding the previous record of 1976 until end of May. France recorded its driest spring in 50 years, with precipitation totals that were $46 \%$ of normal. This anomalous situation in spring was accompanied by an unusual recurrence of blocking patterns over the midlatitudes of central Europe, whose centers of action were shifted southward of their usually preferred high-latitude regions (Fig. SB7.5a).

The dryness in England and the wet conditions in Scotland made $201 \mathrm{l}$ a difficult year for agriculture in both areas. There were also wide concerns on water resources in general; drought conditions were declared across parts of eastern England in early summer. The spring drought in central and western Europe created ideal conditions for large wildfires (e.g., those seen in Ireland and coastal parts of the Netherlands). In Germany, Austria, and Hungary, shipping was affected, due to low water levels on the Rhine and Danube Rivers. In May, levels reached their lowest point in a century.

In contrast, the Mediterranean region received well-above-normal precipitation in spring, due to several extreme rainfall events. On I-2 March, a Mediterranean depression with heavy precipitation affected Italy and Slovenia. In Matera, Basiskata (Italy), $129 \mathrm{~mm}$ of rain fell in 24 hours. In Sicily, totals of

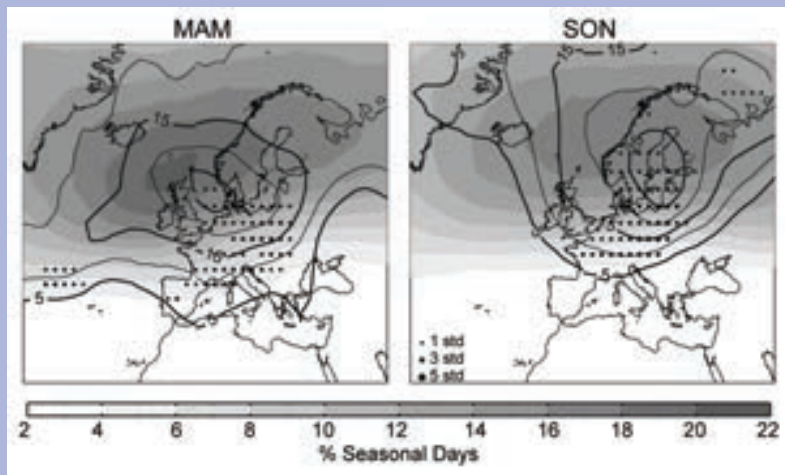

FIG. SB7.5. Seasonal blocking frequency (\% seasonal days, i.e., I\% corresponds to $\sim$ day per season) in (a) MAM and (b) SON. Shaded areas denote the 1948-20I0 mean blocking frequency. Black thick lines indicate the seasonal blocking activity in $201 \mathrm{I}$. Dots highlight those areas where the seasonal frequency of blocking patterns was above the 90th percentile of the 1948-2010 distribution, with the size of the dot being proportional to the exceedance over the climatological mean in standard units (i.e., the standardized anomaly). Blocking patterns are identified following the method described in Barriopedro et al. (2010). (Source: NCEPI NCAR reanalysis) 


\section{cont. SIDEBAR 7.3: DROUGHT AND PRECIPITATION EXTREMES IN}

\section{EUROPE-J. J. KENNEDY, M. KENDON, K. TRACHTE, A. OBREGÓN, P. BISSOLLI, R. TRIGO, D. BARRIOPEDRO,}

AND C. GOUVEIA

$117 \mathrm{~mm}$ in Messina and $109 \mathrm{~mm}$ in Palermo were recorded. On 8-10 March snowfalls in southern Greece and on 9 March heavy snowfalls in Armenia were reported. In southern France, $400 \mathrm{~mm}-500 \mathrm{~mm}$ precipitation totals fell during 12-16 March. In Novi Pazar, in southwest Serbia, torrential rainfall on 23 May caused flooding that damaged about 500 houses.

Autumn 2011 was dominated by unusual warmth and long-lasting dry periods in most countries of Europe, resulting from anomalously high blocking activity over central and northeastern Europe (Fig. SB7.5b). Extremely dry conditions occurred in central, eastern, and southeastern European countries.

November was especially dry (Fig. SB7.6), with record-breaking precipitation deficits in many countries. In Germany and Austria, the lack of precipitation affected shipping on rivers. It was the driest November in Germany since records began in 1881, as well as for the Netherlands and Slovakia. Hungary and Moldova reported only I mm - $3 \mathrm{~mm}$ of precipitation for around $75 \%$ of the country, only $2-7 \%$ of normal. The Czech Republic reported less than $2 \%$ of the normal monthly precipitation across most areas, and Prague had its driest November in its 206-year period of record.

The autumn drought enabled fires in Austria, Romania, and Bulgaria. Damage to forests in Bulgaria was estimated at around \$2.4 million (US dollars). Similarly, the dry and hot autumn months over western lberia also provided optimum conditions for an unusually high number of fires in October. In contrast, heavy precipitation occurred in other places of southern Europe (e.g., more than $400 \mathrm{~mm}$

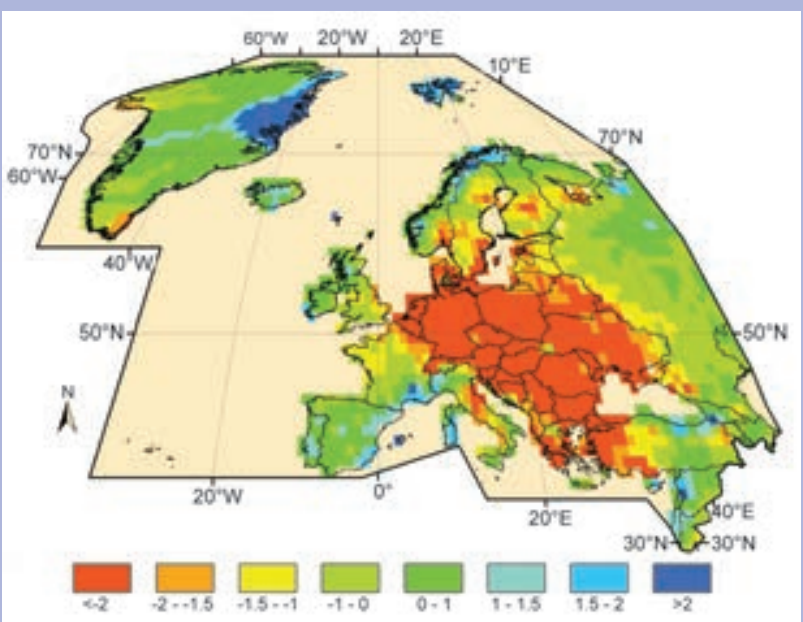

FIG. SB7.6. Standardized Precipitation Index (modified from Pietzsch and Bissolli 20II; departure from 1961-90 base period) for November 20II. (Source: Deutscher Wetterdienst) fell in six hours at the famous Cinque Terre area of the Ligurian coast in northwestern Italy on 25 October). A Mediterranean storm hit coastal areas of southern France on I-9 November with gusts up to $150 \mathrm{~km} \mathrm{hr}^{-1}$ and torrential rain, locally up to $800 \mathrm{~mm}$, over this period (Fig. SB7.7). In Italy, the same storm caused flooding around Genoa when rainfall totals reached $400 \mathrm{~mm}$ in 12 hours on 4 November. The Po River rose by four meters in Turin. This storm was classified as a Mediterranean "tropical storm" by NOAA because of its tropical characteristics, the first ever issued for the Mediterranean.

Persistent high pressure over western and central Europe was responsible for this pronounced climate pattern of dry conditions in these areas and high precipitation north and south of it in both spring and autumn (Figs. 7.29; SB7.7). Despite positive NAO values from February to April and September to December (http://www.cpc. ncep.noaa.gov/products/precip/CWlink/pna/nao.shtml), the blocking high prevented low pressure systems from reaching continental Europe. Instead they were deflected to northern and southern parts of Europe leading to above-normal precipitation totals, following the typical mechanism during these blocking high patterns (Trigo et al. 2004). The surface pressure distribution was similar in spring and autumn, but pressure was highest towards western Europe in spring, whereas in autumn the center was located over eastern central Europe, exceeding 1025 $\mathrm{hPa}$ over the Balkan Peninsula and the western Black Sea area in November. A strongly developed low over Scandinavia at the end of November finally broke the drought situation in central Europe.

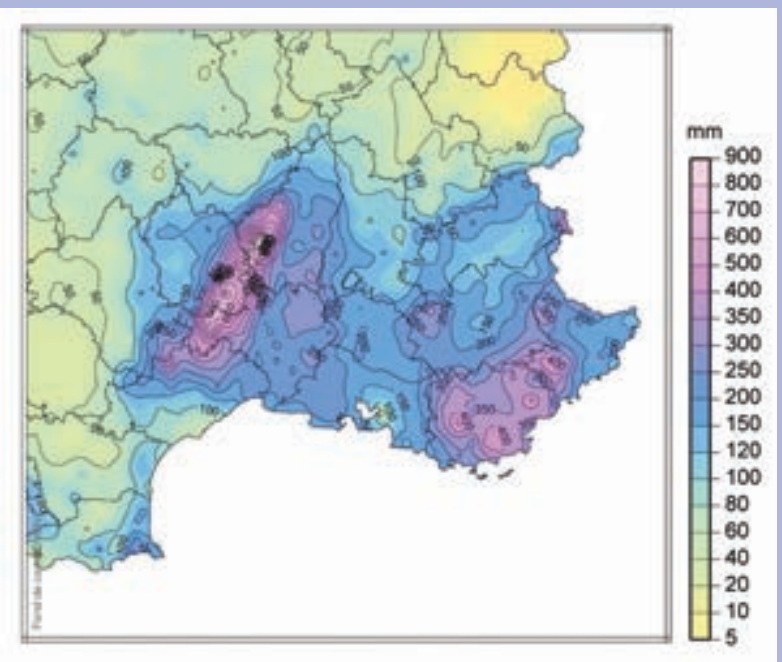

FIG. SB7.7. Accumulated precipitation $(\mathrm{mm})$ for the period I-9 Nov $201 \mathrm{I}$ in southeast France. (Source: Météo France) 


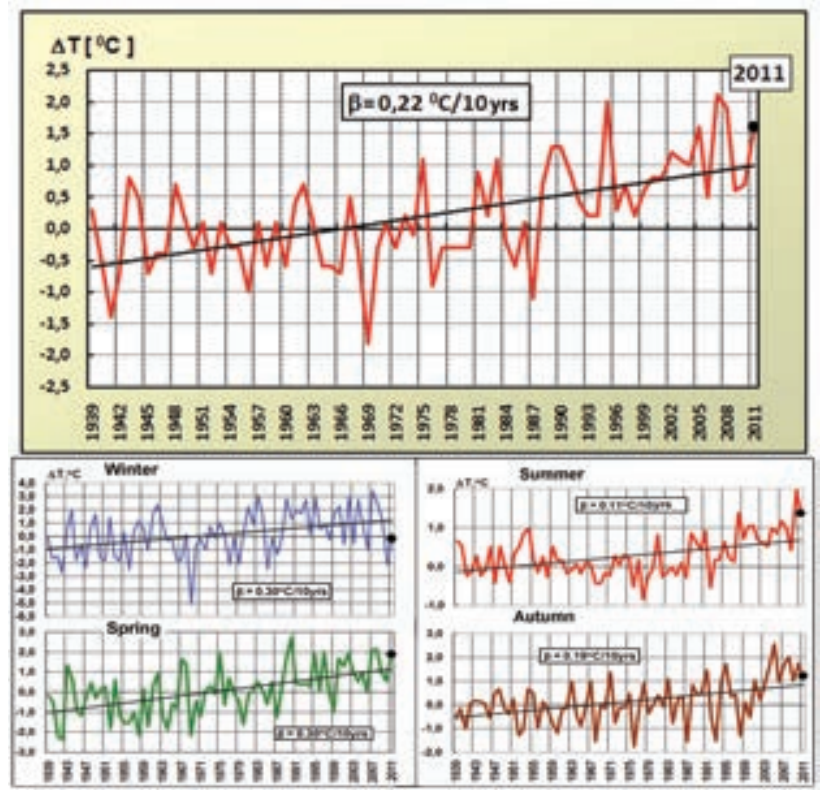

Fig. 7.32. Annual and seasonal mean temperature anomalies $\left({ }^{\circ} \mathrm{C}\right.$ ) averaged over the Russian Federation.

Thunderstorms with severe hail and rainfall were reported from May to August in the South Caucasus. Seventeen days with hail were reported in different locations of Armenia, with hailstones sometimes reaching $25 \mathrm{~mm}$ in diameter. Hail caused loss to agriculture, damaging crops. During 24-27 May, heavy rainfall in the eastern part of Georgia was followed by flash floods that inundated houses. In early June, floods damaged houses and crops in eastern Georgia. From 18 to 19 June, seven people died due to a landslide on Rikoti Pass, which destroyed several buildings. Another heavy rainfall was reported on 7 July in the Vanadzor town in northern Armenia with an intensity of $37 \mathrm{~mm}$ in 40 minutes; on 18 August, in Aparan, Armenia, $51 \mathrm{~mm}$ of rain fell in 40 minutes. And on 3 October, a massive landslide occurred in northern Armenia near the Georgia border after a heavy rainfall: 35 vehicles were buried, seven people were injured, and five people were killed.

On 26 September, a severe hailstorm in the areas of Amiantos and Kiperounta in Cyprus damaged fruit trees, and a tornado on 12 November affected the Cyprian holiday villages of Mazotos and Anafotia.

\section{g. Asia}

I) RussIA-0. N. Bulygina, N. N. Korshunova, and V. N. Razuvaev

(i) Temperature

By and large, 2011 was a warm year in Russia. The mean annual temperature anomaly averaged over the Russian territory was $+1.55^{\circ} \mathrm{C}$ (Fig. 7.32). Along with 2005 , this anomaly ranks as fourth or fifth warmest since 1939. Temperature anomalies averaged over the Russian territory were positive for all seasons, except for winter (DJF) which was close to normal $\left(0.15^{\circ} \mathrm{C}\right.$ below average).

January 2011 was warmer than the long-term average overall. Maximum positive temperature anomalies of $9^{\circ} \mathrm{C}-10^{\circ} \mathrm{C}$, were recorded in northwestern Yakutia. In the south of Western Siberia, however, a large cold island formed, at the center of which mean monthly temperature anomalies reached $-9^{\circ} \mathrm{C}$. In the first ten-day period, air temperatures dropped as low as $-35^{\circ} \mathrm{C}$ to $-44^{\circ} \mathrm{C}$ in the south of the region. The largest negative temperature anomalies were recorded in the Minusinsk basin $\left(-9.4^{\circ} \mathrm{C}\right)$, where the air under winter anticyclone cools significantly at night. In the third ten-day period, minimum temperatures dropped to $-48^{\circ} \mathrm{C}$ in Transbaikalia.

February was the only month during 2011 when mean temperatures were below the long-term average. Northern European Russia experienced the cold island, at the center of which the negative anomalies of monthly mean temperature were greater than $-8^{\circ} \mathrm{C}$. Night temperatures dropped to $-42^{\circ} \mathrm{C}$ to $-46^{\circ} \mathrm{C}$, associated with an intense anticyclone that spread over northern European Russia from the Kara Sea. In the second ten-day period, St. Petersburg experienced record-breaking cold for the entire period. In the latter half of February, cold weather spread to Central Volga and Ural. On the last day of winter, new record-breaking temperature minima were registered in the Volga Region: $-31.6^{\circ} \mathrm{C}$ in Ulyanovsk, $-29.0^{\circ} \mathrm{C}$ in Izhevsk, and $-30.5^{\circ} \mathrm{C}$ in Samara.

Spring over the Russian territory as a whole was much warmer than the long-term average, with a mean seasonal temperature anomaly of $+1.91^{\circ} \mathrm{C}$ (Fig. 7.32). This anomaly is largely connected with very warm March and April temperatures in the north of the country.

Most of Russia was warm during spring. Maximum positive anomalies of mean monthly air temperatures were recorded on the Arctic coast of the Yamalo-Nenets Autonomous District $\left(9^{\circ} \mathrm{C}-12^{\circ} \mathrm{C}\right)$ and Taimyr $\left(8^{\circ} \mathrm{C}-10^{\circ} \mathrm{C}\right)$. During the last days of March, the temperature was more than $20^{\circ} \mathrm{C}$ above normal. Another large warm island formed over northeastern Yakutia and continental areas of the Magadan Region, where mean monthly temperatures were $9^{\circ} \mathrm{C}-10^{\circ} \mathrm{C}$ above normal.

The distribution of mean monthly temperature anomalies in April was similar to March, with temperatures in northern regions considerably higher than those in southern regions. The warm island, 
with temperature anomalies at its center greater than $7^{\circ} \mathrm{C}-8^{\circ} \mathrm{C}$, formed above the eastern YamaloNenets Autonomous District. Warm weather settled unusually early in the south of Western Siberia; new temperature records were established in a number of cities. This was associated with southwesterlies that brought warm air from Central Asia. May was also warmer than the long-term average. The average surface temperature anomaly for summer 2011 was $+1.40^{\circ} \mathrm{C}$ (Fig. 7.32), which ranked third for the period of observation, following the record-breaking year $2010\left(+1.78^{\circ} \mathrm{C}\right)$ and $1998\left(+1.45^{\circ} \mathrm{C}\right)$. The two vast warm areas with anomalies to $+3.9^{\circ} \mathrm{C}$ in central European Russia and to $+2.9^{\circ} \mathrm{C}$ in Yakutia occupied a large part of the Russian area. The area with small negative temperature anomalies (to $-0.5^{\circ} \mathrm{C}$ ) was situated in the Western Siberian Lowland, between the two warm areas.

In June, particularly warm weather was recorded in the Yamal-Nenets Autonomous District, where mean monthly air temperature anomalies reached $5^{\circ} \mathrm{C}-6^{\circ} \mathrm{C}$ in the southeast of the District. Abnormally warm weather persisted throughout the first ten-day period in the Yamal-Nenets Autonomous District and central Krasnoyarsk Territory, with mean daily air temperatures being $10^{\circ} \mathrm{C}-24^{\circ} \mathrm{C}$ above normal in this period. Hot weather in both early and late June was recorded in central European Russia and the Volga Region.

During the first ten-day period of July in midVolga and Lower Volga, daytime temperatures rose to $40^{\circ} \mathrm{C}-43^{\circ} \mathrm{C}$. Southeasterlies brought dry and hot air from the Kazakhstan steppes to mid-Volga. New temperature records were established.

In early August, Dagestan was the warmest area in Europe, as a result of hot air coming from Iran and Turkey. The second ten-day period was hottest in the Volga and Central Chernozem Regions, where temperatures reached $35^{\circ} \mathrm{C}-39^{\circ} \mathrm{C}$. The Upper Volga experienced abnormally warm weather in mid-August, when daytime temperatures rose to $35^{\circ} \mathrm{C}-37^{\circ} \mathrm{C}$. In Western Siberia, with the exception of deep southern regions and the Arctic coast of Yamal, mean monthly temperatures were below normal for two months running (July and August).

Fall temperatures were above normal across Russia, except in Northern Caucasia. September was mostly warmer than the long-term average. The first ten-day period of September was as warm as summer in the Southern Urals. At the end of September, mean daily temperatures in northern Western Siberia were $8^{\circ} \mathrm{C}-10^{\circ} \mathrm{C}$ above normal.
For October, the mean monthly temperature averaged over the whole of Russia ranked third warmest since 1939. In central European Russia, western Siberia, and eastern Siberia the first ten-day period was nearly as warm as summer. Temperature records were broken in many centrally-located cities and Upper Volga. In mid-October, daily temperature maxima were observed in southern European Russia and southern Western Siberia. New daily temperature records were established. On 11 October, a new daily temperature record was established in Krasnodar $\left(30.2^{\circ} \mathrm{C}\right)$, and on 15 October Novosibirsk set a new daily record maximum temperature $\left(20.2^{\circ} \mathrm{C}\right)$.

A positive temperature anomaly averaged over all of Russia was recorded in November. November mean monthly temperatures were above normal over most of the Yamalo-Nenets Autonomous District, Tomsk Region, and Altai Republic. At the Arctic coast of Yamal, the temperature anomaly was more than $+6^{\circ} \mathrm{C}$. Maximum temperature anomalies of $+7^{\circ} \mathrm{C}$ to $+9^{\circ} \mathrm{C}$ were recorded on Taimyr and Arctic islands. In southern European Russia, however, November was much colder than average, with mean monthly air temperature anomalies between $-4^{\circ} \mathrm{C}$ and $-6^{\circ} \mathrm{C}$. Night temperatures dropped to as low as $-15^{\circ} \mathrm{C}$ to $-20^{\circ} \mathrm{C}$, breaking minimum temperature records in a number of cities (e.g., Volgograd, Vladikavkaz, and Makhachkala). Clear nights with anticyclonic conditions contributed to extreme land surface cooling and, as a result, record-breaking low temperatures in central European Russia, with previous records being exceeded by $4^{\circ} \mathrm{C}$ to $5^{\circ} \mathrm{C}$ in many cities.

In December, an intense heat island formed over the Arctic coast and islands in Western Siberia and European Russia, with the highest mean monthly temperature anomalies $\left(+12^{\circ} \mathrm{C}\right.$ to $\left.+14^{\circ} \mathrm{C}\right)$ recorded. At some stations in this region, December 2011 was the warmest such period on record. In Arkhangelsk, the mean monthly air temperature was $-1.1^{\circ} \mathrm{C}, 9.2^{\circ} \mathrm{C}$ above normal (Fig. 7.33). Throughout the month, the daily average temperature was higher than the average maximum temperature (1961-90 base period). On 16 December, a new daily temperature record was established. The last days of December were abnormally warm in northwestern and central European Russia, as well as the Volga Region. Owing to air masses from a warm sector of the deep Atlantic cyclone region, temperature records established in Moscow and St. Petersburg in the 19th century were broken on 27 December. In Moscow, the temperature rose to $5.8^{\circ} \mathrm{C}$ in the evening of 27 December, which is $2.5^{\circ} \mathrm{C}$ higher than the previous record established in 1898 


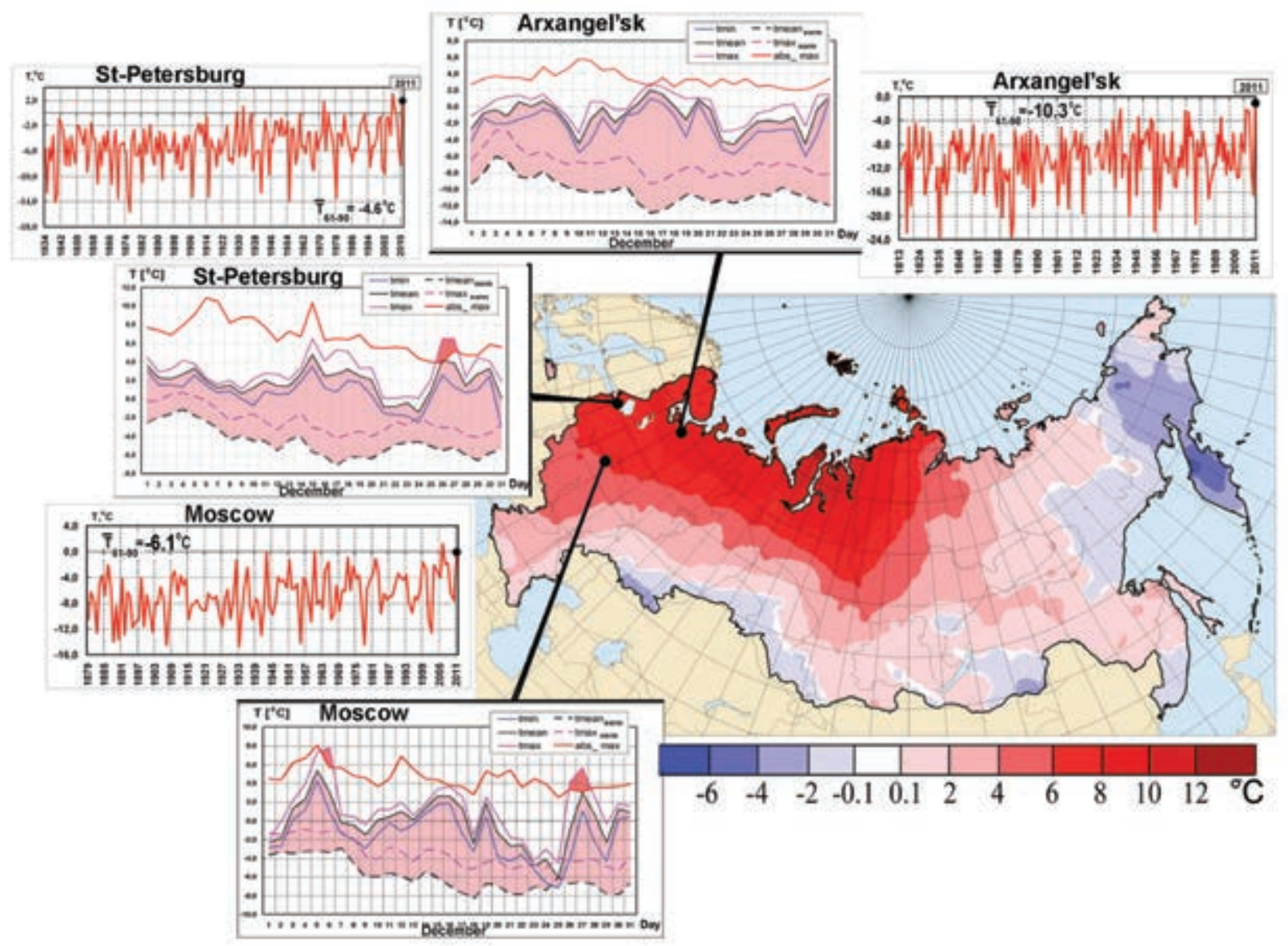

FIG. 7.33. Air temperature anomalies $\left({ }^{\circ} \mathrm{C}\right)$ in December 2011 (196I-90 base period). Insets show the series of mean monthly air temperatures and mean daily air temperatures at meteorological stations Arkhangelsk, St. Petersburg, and Moscow.

$\left(3.3^{\circ} \mathrm{C}\right)$. In St. Petersburg, the maximum temperature was even higher, $7.2^{\circ} \mathrm{C}$, breaking the previous record of $5.2^{\circ} \mathrm{C}$, set in 1881 . New temperature records were also established in Kaliningrad, Pskov, Vologda, Tver, Smolensk, Petrozavodsk, Kostroma, Vladimir, Tula, Oryol, Bryansk, Tambov, Kursk, and Lipetsk.

\section{(ii) Precipitation}

Precipitation over Russia was generally near normal (80-120\%) for the year as a whole. Due to predominantly cyclonic weather over most of European Russia, excessive precipitation was observed in January, from 1.5 to 2 times the monthly normals. The precipitation amount in St. Petersburg was 82.4 $\mathrm{mm}$, or $217 \%$ of normal, which is the highest since records began in 1891. Most of Eastern Siberia received below-normal precipitation and the southern Krasnoyarsk Territory, Tyva, and individual areas in Transbaikalia experienced a precipitation deficit. Cold weather with little snow also prevailed in the Maritime Territory. Owing to cyclones over the Sea of Okhotsk, warm weather with snowfalls settled on Sakhalin. In the north of the Sakhalin region, 17 days with snowfalls were recorded in January. In February, a vast low-precipitation zone in European Russia was associated with a region of cold air, lying from northern regions to the Upper Volga (24-80\% of monthly normal). By contrast, very heavy precipitation fell in the Amur Region and on the western coast of Kamchatka (300-500\% of monthly normal).

In March, northern Siberia and most of the Far East received above-normal precipitation, in places more than three times the monthly normals. Snowfalls during early March in St. Petersburg increased snow supply substantially: on 5 March, the snow depth was $73 \mathrm{~cm}$, the highest amount since records began more than a century ago. The monthly precipitation was above normal in the Upper Volga, mid-Volga, and Ural. In April, heavy precipitation (200-250\% of monthly normal) was recorded over a vast region of northern European Russia and northern Western Siberia, with precipitation totals more than twice the 
monthly normal in places. A precipitation deficit was recorded in Transbaikalia, at $14-41 \%$ of the monthly normal. Heavy rain fell in Northern Caucasia in May. The monthly precipitation normal was exceeded by a factor of two in Chukotka and the Amur Region. In southern Transbaikalia, a precipitation deficit gave rise to extreme fire hazards and forest fires.

In June, a substantial precipitation deficit was recorded in northern European Russia; Altai and Transbaikalia experienced drought conditions that began in the third ten-day period of May. Abovenormal precipitation fell in the Urals, Upper Volga, Yakutia, Kamchatka, and Sakhalin. A precipitation deficit was recorded in July in the Southern Urals, northern Kamchatka, southern Khabarovsk Territory, and Amur Region. Western Siberia received copious precipitation that was produced by frequent cyclones. Monthly precipitation was two to three times higher than normal in northern Eastern Siberia. In August, the precipitation-deficit zone covered central and eastern European Russia. Northern Caucasia, particularly Dagestan, received much above-normal precipitation (300-400\% of monthly normal).

In the first half of September, northwestern European Russia and the Volga Region experienced heavy rains that ended fire hazards in this region. Most of Western Siberia received below-normal precipitation, with the southern part receiving only $11-30 \%$ of normal. Eastern Siberia received below-normal precipitation; only a few individual meteorological stations registered precipitation $20-30 \%$ above monthly normal. The precipitation deficit in southern Eastern Siberia contributed to high to extreme fire hazards.
November contributed to significant precipitation deficits over most of European Russia (20-40\% of monthly normal).

In December, a vast low-precipitation zone spread from Transbaikalia to Chukotka. The coast of the Sea of Okhotsk received only $3-10 \%$ of its monthly precipitation normal.

\section{(iii) Notable events}

- On 9-13 February, 34 avalanches were recorded in Dagestan (Northern Caucasia).

- On 27-28 February, glaze-ice and rime deposition with a maximum diameter of 100 $\mathrm{mm}$ was observed in Kabardino-Balkaria (Northern Caucasia).

- On 16 May, the Republic of Buryatia experienced a severe dust storm, with wind speeds of $25-33 \mathrm{~m} \mathrm{~s}^{-1}$. The storm caused damage to roofs of houses and transmission lines, and toppled trees.

- On 23-27 May, heavy showers caused floods on the rivers in the Krasnodar Territory, with 1312 houses inundated in 16 settlements.

- Floods also occurred in Adygeya (Northern Caucasia). Water rose as much as $6.52 \mathrm{~m}$, which is more than $1 \mathrm{~m}$ higher than the dangerous limit; 558 houses were inundated and 12 houses were completely destroyed.

- In June and July, fires were widespread in Transbaikalia (25 fires over an area of 1059 ha and 18 fires over $1142 \mathrm{ha}$ ) and the Irkutsk Region ( 89 forest fires over the area of 20000 ha).

On 5-7 September, Typhoon Talas brought very heavy and long-lasting rains to the Maritime Territory and the southern Khabarovsk Territory. The largest amount of precipitation was registered at meteorological stations Sosunovo and Rudnaya Pristan in the Maritime Territory, $266 \mathrm{~mm}$ and $249 \mathrm{~mm}$, respectively. In the first half of October, torrential rains occurred in southern European Russia. Settlement Arkhipo-Osipovka, Krasnodar Territory, received 199.1 $\mathrm{mm}$ of precipitation in eight hours on 5 October. A significant precipitation deficit was recorded in southwestern Siberia, while most of Yakutia received above-normal precipitation, 160-280\%. Prevailing anticyclonic conditions in

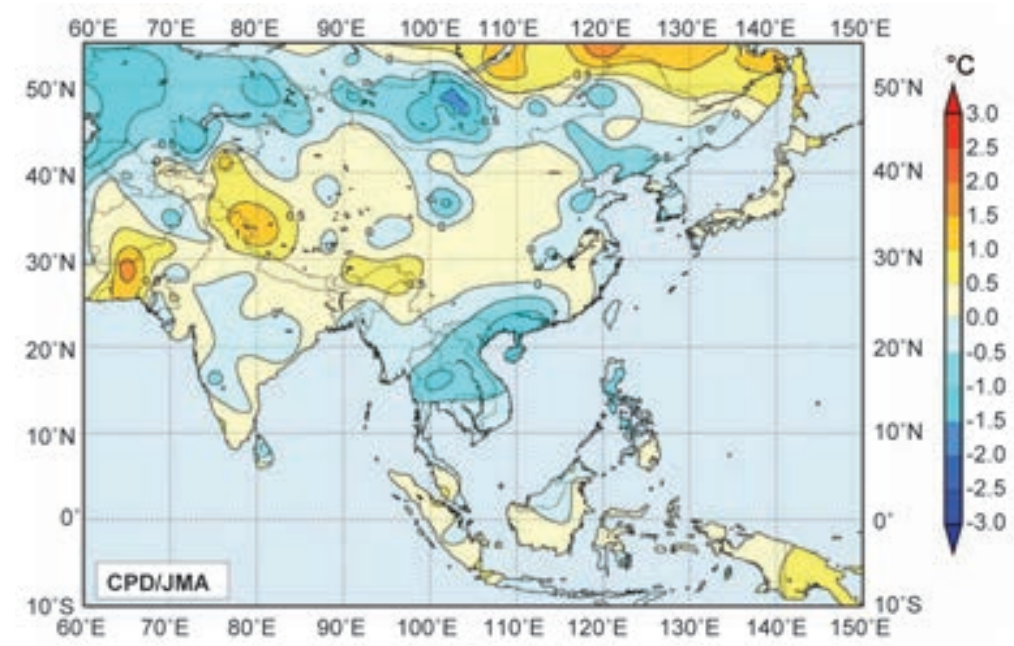

Fıg. 7.34. Annual mean temperature anomalies ( ${ }^{\circ} \mathrm{C}$; $198 \mathrm{I}-2010$ base period) over East Asia and surrounding regions in 2011 (Source: Japan Meteorological Agency). 


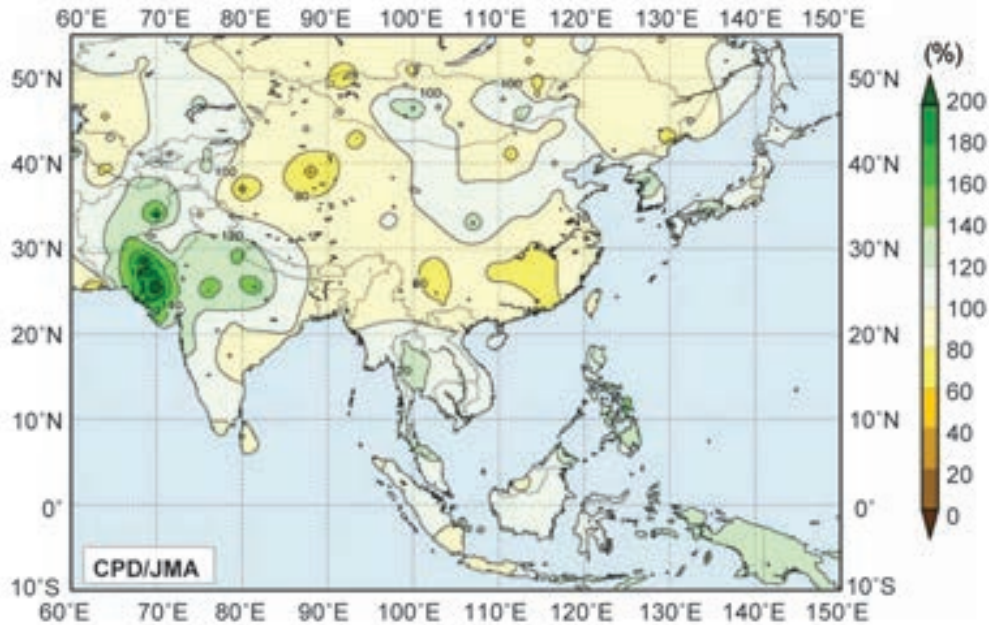

Fig. 7.35. Annual precipitation ratio as percentage of normal (198I2010 base period) over East Asia and surrounding regions in 2011 . (Source: Japan Meteorological Agency)

- On 5 July, heavy rain with hail occurred in Republic of Bashkortostan; $96 \mathrm{~mm}$ of precipitation fell in less than three hours.

- In July, drought in the Altai Territory damaged 1883 ha of winter wheat, 250 ha of sunflowers, and 1500 ha of spring crops.

- On 20 July, heavy rain was recorded in the Nizhniy Novgorod Region (European Russia); $91 \mathrm{~mm}$ of precipitation fell in less than three hours.

- On 31 July, a rare tornado was recorded in Blagoveshchensk; wind speed at the epicenter was about $40 \mathrm{~m} \mathrm{~s}^{-1}$. One person was killed and thirteen were injured. The tornado toppled over trees, tore off roofs, turned cars upsidedown, and damaged transmission lines.

2) EAST AsIA—P. Zhang, Y. Liu, R. Yamada, J. Shin, and L. Oyunjargal

This region includes China, Japan, Korea, and Mongolia.

\section{(i) Overview}

Annual mean temperatures across East Asia showed a nonuniform pattern in 2011 (Fig. 7.34), with positive anomalies over western China and negative anomalies over parts of southern, eastern, and northeast China, the Korean Peninsula, and Mongolia. Annual total precipitation (Fig. 7.35) was near normal in most parts of East Asia. Above-normal precipitation was observed over the Korean Peninsula and parts of Mongolia, while southern and western China received below-normal rainfall.
During January, the East Asian winter monsoon was significantly enhanced due to the pronounced Siberian High and Aleutian Low, leading to extremely low temperatures over wide areas of East Asia. In March, strong cold surges, originating from the Siberian High, occurred over Japan, southern China, and the Indochina Peninsula. In association with the enhanced Asian summer monsoon, the Indochina Peninsula experienced heavy rainfall throughout the monsoon season that caused major floods in Thailand between the 26th and 31st. Forty fatalities were reported and over one million people were affected. In the Surat Thani province, as much as $1270 \mathrm{~mm}$ of rain fell during this period (March average rainfall for the province is $51 \mathrm{~mm}$ ).

\section{(ii) Temperature}

The annual mean temperature over China for 2011 was $9.3^{\circ} \mathrm{C}, 0.5^{\circ} \mathrm{C}$ higher than normal $(1971-2000$ base period) and $0.2^{\circ} \mathrm{C}$ lower than 2010 , ranking as the 15th consecutive warmer-than-average year since 1997. Except in South China, the annual mean temperatures were above normal over most areas of China, as much as $1^{\circ} \mathrm{C}-2^{\circ} \mathrm{C}$ above normal in parts of Xinjiang and Qinghai (in Northwestern China) and Northeast China.

With the exception of winter, average seasonal temperatures were higher than normal in China. The seasonal surface temperature anomalies were $-0.3^{\circ} \mathrm{C}$, $+0.2^{\circ} \mathrm{C},+0.9^{\circ} \mathrm{C}$, and $+0.8^{\circ} \mathrm{C}$ for winter, spring, summer, and autumn, respectively. It was cooler than average in January, with $-2.4^{\circ} \mathrm{C}$ temperature anomalies over the country. However, summer tied with 2007 as the third warmest since 1961. The annual mean hot days (daily maximum temperature $\geq 35^{\circ} \mathrm{C}$ ) across China was 10.6, 3.6 days more than normal, which ranked as the second most since 1961 .

The average surface temperature over Japan (averaged over 17 observatories confirmed as being relatively unaffected by urbanization) in 2011 was $0.15^{\circ} \mathrm{C}$ above the $1981-2010$ average. Interseasonal fluctuations in temperature were large, with belownormal temperatures in spring, and above-normal temperatures in summer and autumn. In particular, seasonal mean temperatures for autumn were significantly above normal in eastern and western Japan, and Okinawa/Amami. 
The average temperature over South Korea for 2011 was $12.4^{\circ} \mathrm{C}$ (averaged over 45 weather stations), which was $0.1^{\circ} \mathrm{C}$ below the $1981-2010$ average. The seasonal surface air temperature anomalies over South Korea were $-1.2^{\circ} \mathrm{C},-0.7^{\circ} \mathrm{C}, 0.4^{\circ} \mathrm{C}$, and $1.2^{\circ} \mathrm{C}$ for winter, spring, summer, and autumn, respectively.

The annual mean temperature averaged across Mongolia was $-1.0^{\circ} \mathrm{C}$, which is $0.6^{\circ} \mathrm{C}$ lower than the 1979-2008 average. Although monthly average temperature for January was significantly below normal, near-normal temperatures were recorded for all other months.

\section{(iii) Precipitation}

In China, the mean annual total precipitation was $556.8 \mathrm{~mm}, 9 \%$ below normal and $18 \%$ less than 2010 , and ranked the driest since 1951 . The total precipitation was below normal consecutively in winter, spring, and summer, but much higher than normal in autumn. The annual rainstorm days were $10.3 \%$ less than normal and ranked as the lowest in the past 30 years. Rainstorms occurred mainly in southern northeast China, eastern north China, the middle and lower reaches of Yellow River and Yangtze River Basin, and south China.

The rain belt of the flood season moved northward earlier than normal in 2011, for the beginning of Mei-Yu (the major summer rainfall period along the middle and lower reaches of the Yangtze River basin that usually occurs from 19 June to 9 July; also known as Bai-Yu in Japan and Changma in Korea) and the rainy season of north China was earlier than normal. Although the beginning of Mei-Yu started early with heavier precipitation and stronger intensity than normal, the mean total precipitation of the Yangtze River basin for 2011 was less than $1000 \mathrm{~mm}$ for the first year since 1979 and the lowest in the past 33 years. The annual total precipitation of the Huaihe and Zhujiang River basins were below normal and the lowest since 2005. The annual precipitation for the Yellow River basin was higher than normal. North China precipitation was slightly above normal, while Beijing was $125 \%$ of normal, marking the first year with annual total precipitation above $700 \mathrm{~mm}$ over the past 13 years. In Huaxi (in Western China), autumn rainfall was the highest in the past 36 years.

In Japan, area-averaged annual precipitation amounts were above normal in northern and western regions. At the end of July, record-breaking rainfall was observed in Niigata and Fukushima Prefectures. During autumn, precipitation amounts were above normal nationwide. In particular, record-breaking rainfall occurred in western Japan due to Typhoons Talas and Roke in September.

In South Korea, the mean annual precipitation was $1622.6 \mathrm{~mm}, 124 \%$ of normal, which ranked as fifth highest since 1973 (highest was 142\% of normal in 2003). Seasonal precipitation was $108 \%, 106 \%, 144 \%$, and $87 \%$ of normal for winter, spring, summer, and fall, respectively. South Korea experienced its wettest summer since 1973 because the continuously hot and humid southwesterly flow along the edge of the North Pacific High collided frequently with dry continental air over the Korean Peninsula, resulting in severe atmospheric instability, which caused heavy rainfall.

In Mongolia, above-average precipitation prevailed throughout much of the country. Average precipitation was $191.5 \mathrm{~mm}, 120 \%$ of the $1979-2008$ long-term average, making 2011 the third wettest year in the past 40 years. Seasonally, winter was the wettest of all seasons; January and February precipitation was between 1.9 and 2.8 times greater than normal in western, central, and Gobi regions, resulting in an extended period of snow cover in those regions. In May, central and eastern regions experienced 110\% of average rainfall and in June, most parts of the country had $230 \%$ of normal rainfall. In October and November, snowfall was 1.4 to 3.1 times higher than average in central and south eastern regions and as a result, snow covered $90 \%$ of the country.

\section{(iv) Notable events}

From late December 2010 to January 2011, the East Asian winter monsoon was significantly enhanced, leading to extremely low temperatures over wide areas of East Asia.

Japan experienced below-normal January temperatures nationwide for the first time since 1986, as well as heavy snowfall on the Sea of Japan side of the country.

In South Korea, a daily minimum temperature of $-12.8^{\circ} \mathrm{C}\left(12.2^{\circ} \mathrm{C}\right.$ below the $1981-2010$ average) was observed on 15 January in Busan, where the weather is usually warmer than other regions of the country in winter. It was the coldest temperature recorded at the station since 1915.

In Mongolia, the monthly mean January temperature was $5.9^{\circ} \mathrm{C}$ below normal, the second lowest in the last 40 years. In particular, days with minimum temperatures below $-45^{\circ} \mathrm{C}$ continued for two to three weeks in the western region.

In Mongolia, dust and snow storms with wind speeds surpassing $100 \mathrm{~km} \mathrm{hr}^{-1}$ occurred frequently during spring. On 28-29 April, a strong dust and 
snow storm with wind speeds of $58 \mathrm{~km} \mathrm{hr}^{-1}-144 \mathrm{~km}$ $\mathrm{hr}^{-1}$ affected much of the country, causing widespread damage.

In South Korea, heavy rainfall occurred in southern and central regions on 9-10 and 26-28 July. During those periods, record high daily and 1-hr maximum precipitations were measured over South Korea. In particular, the total amount of precipitation observed in Seoul during 26-28 July was $587.5 \mathrm{~mm}$, which was the largest amount since record keeping began. On 27 July, the heaviest one-day rainfall since 1907 occurred in Seoul, bringing more than 300 $\mathrm{mm}$ of precipitation. The frequency of heavy rainfall events increased in summer. The number of days with heavy rainfall over $30 \mathrm{~mm} \mathrm{hr}^{-1}$ or $80 \mathrm{~mm}^{\text {day }}{ }^{-1}$ was 2.8 and 2.9 days, which were 1.3 and 1.1 days above normal, respectively. In particular, the number of days with heavy rainfall above $50 \mathrm{~mm}^{\text {day }}{ }^{-1}$ was 0.6 in July, the most in South Korea's record extending back to 1973 .

In South Korea, the average maximum temperature was $25.9^{\circ} \mathrm{C}$ in September, $5^{\circ} \mathrm{C}$ above the 1981-2010 average. The daily maximum temperature reached extreme values in some parts of South Korea. A heat wave warning was issued on 15 September 2011, which was the latest date of the year since heat wave warnings began in South Korea.

In Mongolia, an intense cold front moved through northern region of the country, bringing rain, freezing rain, and snow on mountains on 28 September. During this event, wet snow continued for 11 hours in Darkhan Province and its surroundings, causing $\$ 4$ million (US dollars) in damage to power transmission lines.

In China, regional meteorological hazards were abrupt and frequent. In early 2011, North China, the Yellow River and Huaihe River basin experienced the most serious autumn-winter drought in the past 41 years. The middle and low reaches of Yangtze River basin experienced the most serious winterspring drought in the last 60 years, followed by an abrupt transition from drought to flooding in June. Southwestern China experienced the most serious summer-autumn drought in the past 60 years. The Huaxi region (in midwestern China) and Huanghuai regions (in northern China) experienced regional flooding in September. The southern part of South China experienced a serious rainstorm disaster in October. The heavy rainfall caused water logging and inundation in big cities such as Beijing during the summer and autumn. Persistent heat waves hit Jianghuai and Jiangnan in early May, Northwest

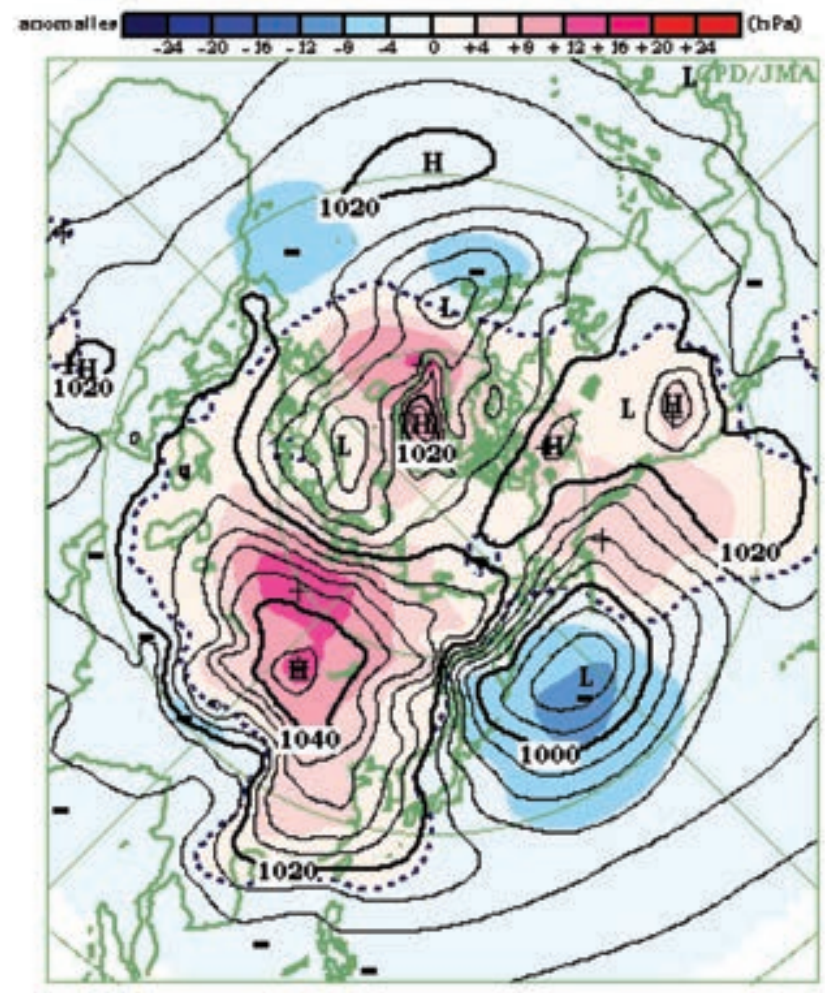

FIG. 7.36. Monthly averaged sea level pressure anomalies (hPa) for January 201 I (1979-2004 base period). The contours show sea level pressure at intervals of $4 \mathrm{hPa}$. The shading indicates sea level pressure anomalies. JRA/JCDAS data were used in the analysis. (Source: Japan Meteorological Agency)

China and the southern part of North China in June, and most parts of South China in August; maximum temperatures in many areas broke historical records.

In Japan, precipitation totalling $851.1 \mathrm{~mm}$ was measured on 19 July over the village of Umaji in Kochi Prefecture due to Typhoon Ma-on, a one-day record for Japan.

Seven tropical cyclones made landfall over China. Direct economic losses of $\$ 3.8$ billion (US dollars) and associated deaths of 28 people were significantly less than the 1990-2010 average.

Japan was also affected by seven tropical cyclones during 2011, three of which made landfall in July and September. The storms brought heavy rain and strong winds to a wide area of the country, and more than 90 people were killed. See section $4 \mathrm{~d} 4$ for more detailed information about the western North Pacific tropical cyclone season.

In spring 2011, China was affected by 8 dust and sand events, many fewer than the 1971-2000 normal (19.2) and the 2001-10 average (12.7). The average number of dust days in northern China was 1.7 (3.9 days less than normal), which ranked the third few- 

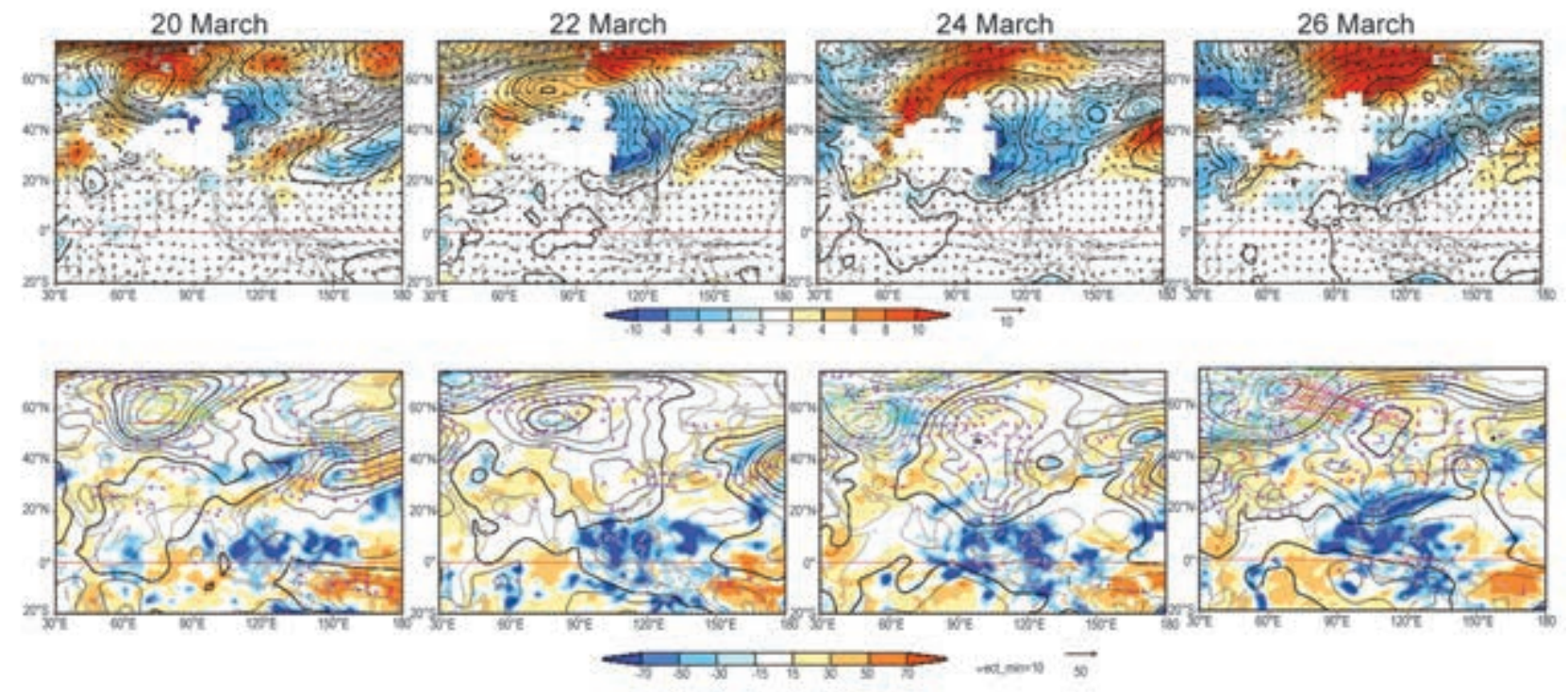

FIG. 7.37. Evolution of cold surges around the South China Sea. The upper panels show anomalies of 10 -m wind vectors $\left(\mathrm{m} \mathrm{s}^{-1}\right)$, sea level pressure at intervals of $4 \mathrm{hPa}$ (contours), and $850-\mathrm{hPa}$ temperature at intervals of $2^{\circ} \mathrm{C}$ (shading); the lower panels indicate $850-\mathrm{hPa}$ wave activity fluxes $\left(\mathrm{m}^{2} \mathrm{~s}^{-2}\right)$, anomalies of $850-\mathrm{hPa}$ stream function at intervals of $2.5 \times 10^{6} \mathrm{~m}^{2} \mathrm{~s}^{-1}$, and OLR $\left(\mathrm{W} \mathrm{m}^{-2}\right)$ (1979-2004 base period). JRA/JCDAS data were used in the analysis. (Source: Japan Meteorological Agency)

est since 1961. And the date of the first event was 12 March, which was the latest since 2001. On 28-30 April, a dust storm affected 11 provinces of China, the most affected by a single storm in 2011.

In Japan, Kosa (yellow sand/aeolian dust) was observed over a large area at the beginning of May. A cumulative total of 194 observations of Kosa were made in May, which was about six times higher than average (32.9) and marked the highest figure for the

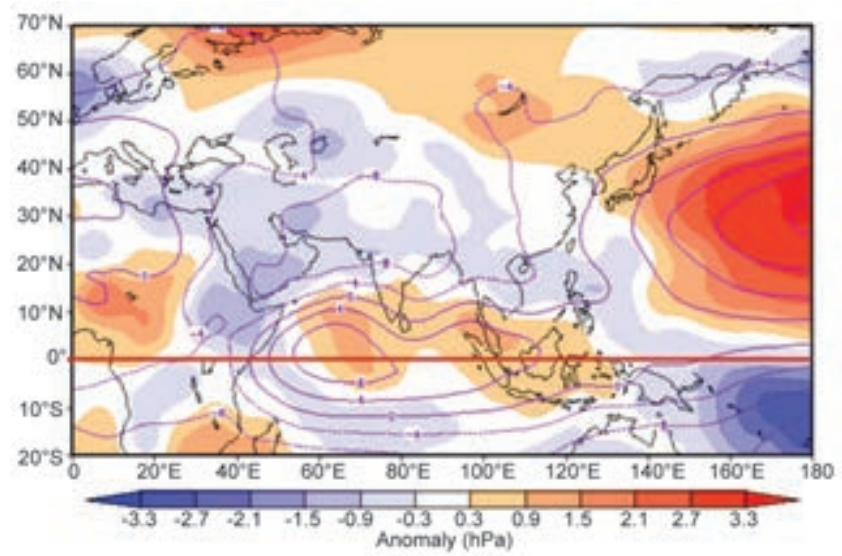

FIG. 7.38. Four-month mean $850-\mathrm{hPa}$ stream function and its anomaly for Jun-Sep 201I. The contours indicate the $850-\mathrm{hPa}$ stream function at intervals of $4 \times 10^{6} \mathrm{~m}^{2} \mathrm{~s}^{-1}$, and the color shading indicates $850-\mathrm{hPa}$ stream function anomalies from the normal. In the Northern (Southern) Hemisphere, warm (cold) shading denotes anticyclonic (cyclonic) circulation anomalies (198I-2010 base period). JRA/JCDAS data were used in the analysis. (Source: Japan Meteorological Agency) month since records began in 1967. While there were 14 days in which any meteorological station in Japan observed Kosa in 2011, which was below the normal number of 24.2 days, a cumulative total of $220 \mathrm{ob}$ servations of Kosa were made in the year, which was near normal (225.3).

\section{(v) Monsoon}

During late December 2010 and January 2011, the East Asian winter monsoon was significantly enhanced, leading to extremely low temperatures over wide areas of East Asia. In the upper troposphere, ridges were seen over the western part of Siberia, and blocking highs developed over the eastern part in January. These conditions were suitable for the enhancement of the Siberian High. The Aleutian Low was enhanced to the east of Japan in January (Fig. 7.36), although it was obscure in December and February. The pronounced Siberian High and Aleutian Low led to a strong winter monsoon over East Asia in January.

The Siberian High was significantly developed in March. High surface pressure southwest of Lake Baikal peaked around 20 March with an extremely cold air mass in the lower troposphere (Fig. 7.37). Thereafter, high-pressure anomalies related to this cold air mass propagated southward along the eastern periphery of the Tibetan Plateau and reached the South China Sea and the Indochina Peninsula late in the month, bringing significant cold surges. 


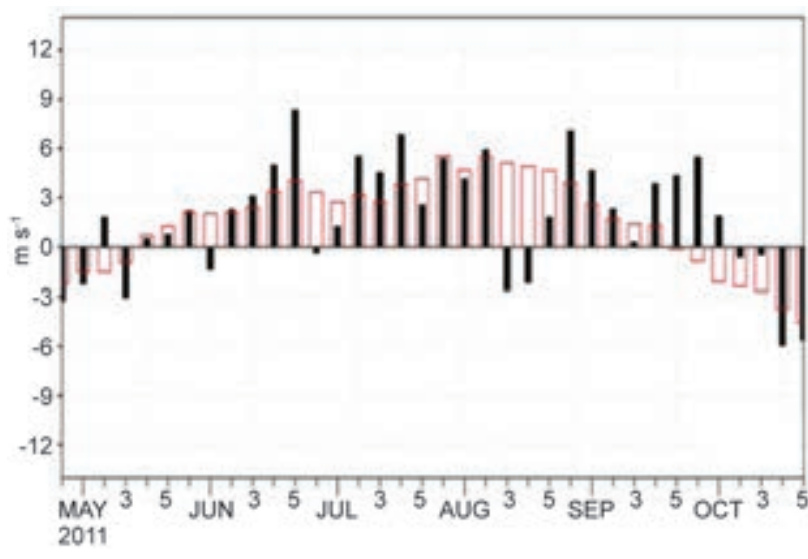

FIG. 7.39. Variation of pentad zonal wind index $\left(\mathrm{m} \mathrm{s}^{-1}\right)$ over the monitoring region $\left(10^{\circ} \mathrm{N}-20^{\circ} \mathrm{N}, 110^{\circ} \mathrm{E}-120^{\circ} \mathrm{E}\right)$. Red open bars represent the climatology. (Source: China Meteorological Administration)

In conjunction with these surges, convective activity was enhanced over the South China Sea and the Indochina Peninsula as well as over the Maritime Continent, where it was strengthened due to La Niña. The intensity of northerly surges around the South China Sea was the strongest for March since 1979.

Convective activity (inferred from outgoing longwave radiation, OLR) for June-September 2011 was enhanced over southern Pakistan, the eastern Arabian Sea, the Bay of Bengal, the Indochina Peninsula, the Philippines and the western Pacific, while it was suppressed over the eastern Indian Ocean and Indonesia. In the upper troposphere, the Tibetan High was pronounced over a broad area. In the lower troposphere, a prominent monsoon trough was observed stretching from northern India to the Philippines, and westerly/southwesterly winds were stronger than normal over a large area from the Arabian Sea to the Philippines (Fig. 7.38). These characteristics of con-

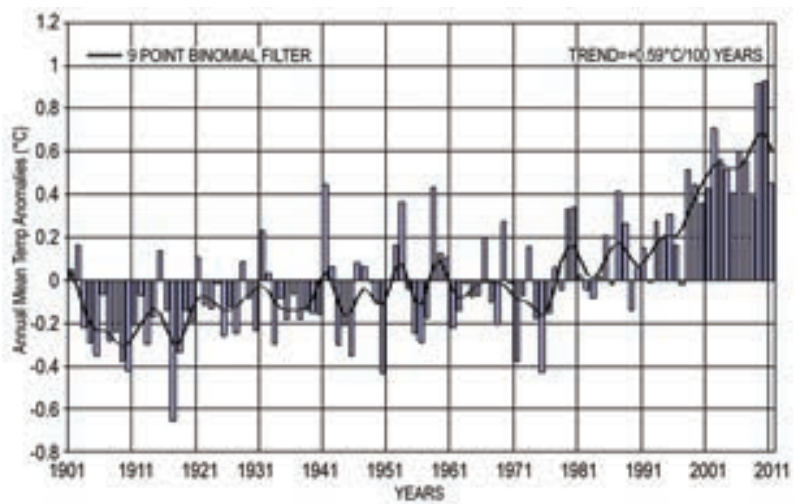

Fig. 7.4I. Annual mean temperature anomalies $\left({ }^{\circ} \mathrm{C}\right.$, 1961-90 base period) averaged over India for the period 190I-20II. The smoothed time series (9-point binomial filter) is shown as a continuous line.

vective activity and atmospheric circulation indicate that the Asian summer monsoon was active.

From May to August, equatorial intraseasonal oscillations were observed propagating eastward with a period of less than 30 days. The areas of active convection originally enhanced by these oscillations were seen to propagate northward around India and east of the Philippines. In October, the active phase of a large-amplitude Madden-Julian oscillation (MJO) propagated eastward from northern South America to the Indian Ocean, and convective activity over the western Pacific, which tends to be enhanced until September, was suppressed.

The South China Sea summer monsoon (SCSSM) in 2011 broke out in the second pentad of May, two pentads earlier than normal, and withdrew in the third pentad of October, three pentads later than normal (sixth pentad of September). The intensity of the SCSSM was -1.34, which was weaker than normal (Fig. 7.39). From the onset monsoon to the first pentad of June, the front of the East Asian sub-

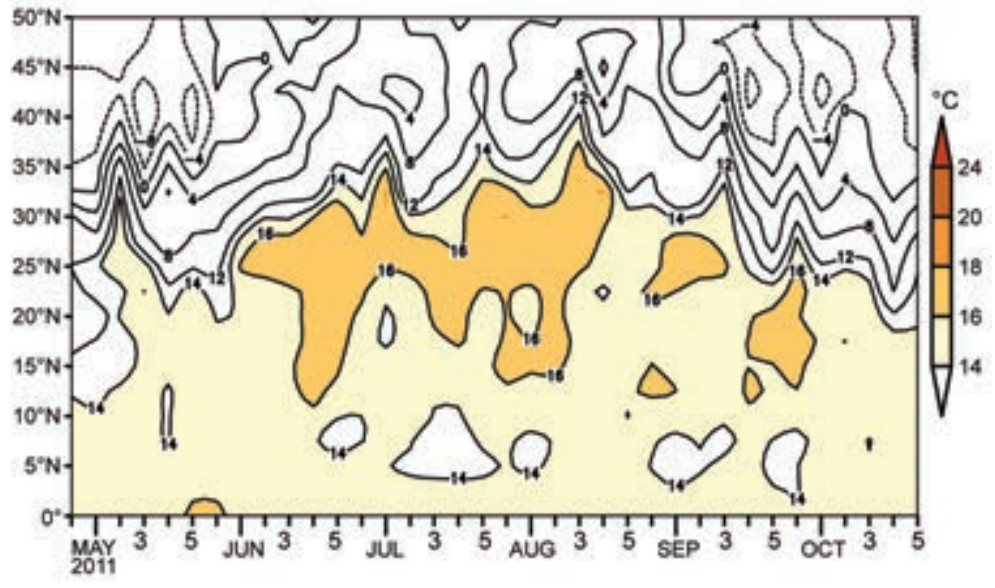

FIG. 7.40. Latitude-time section $\left(110^{\circ} \mathrm{E}-120^{\circ} \mathrm{E}\right)$ of pseudo-equivalent potential temperature $\left({ }^{\circ} \mathrm{C}\right)$. (Source: China Meteorological Administration) tropical summer monsoon (EASSM) maintained over the region from South China to the south of the Yangtze River valley. In the second pentad of June, the front of the EASSM advanced to the Yangtze River valley, and the Mei-yu period started. With the northward moving of the West Pacific Subtropical High (WPSH), the major rain belt correspondingly moved northward. In the sixth pentad of June, the rain belt in eastern China northward advanced to North China and then North China entered rainy season. In the fifth pentad of July, with the ridge of the WPSH retreating southward, the rain belt in 


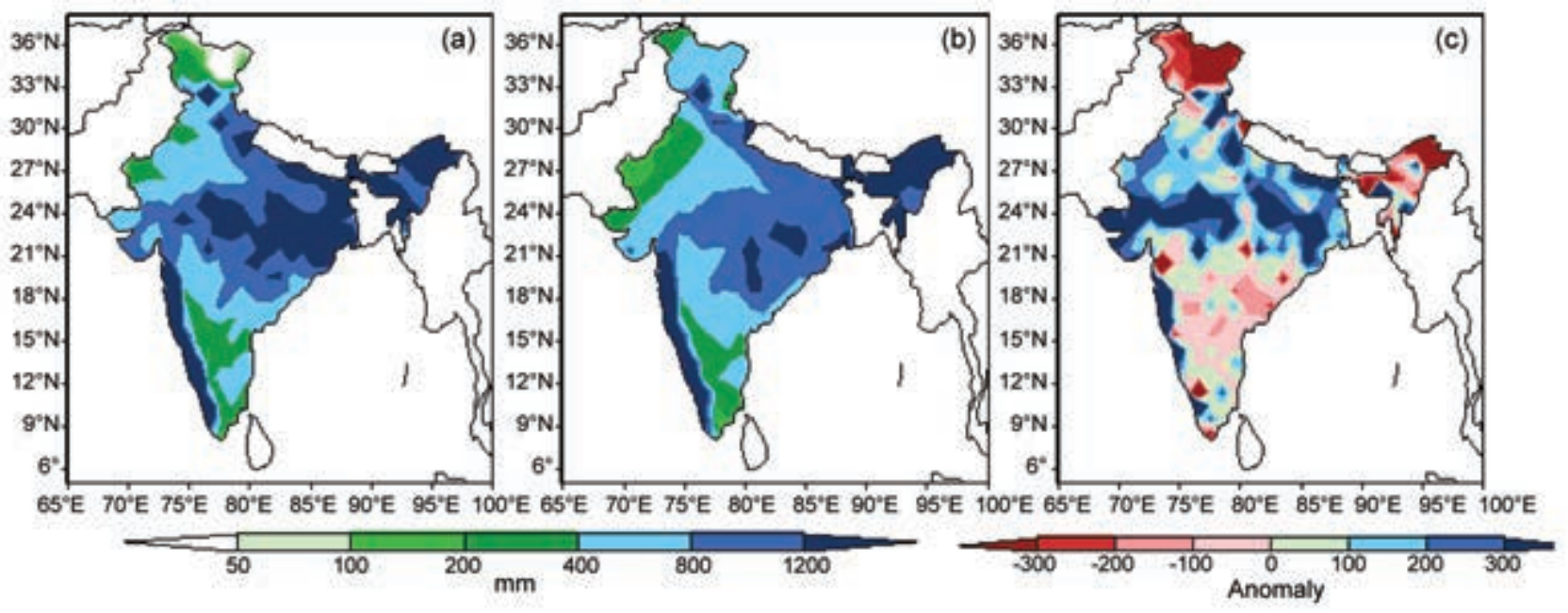

FIG. 7.42. Spatial distribution of monsoon seasonal (Jun-Sep) rainfall ( $\mathrm{mm}$ ) over India in 20II: (a) actual, (b) normal, and (c) anomalies.

eastern China shifted from southward North China. From the second pentad of September, the autumn rain in West China started. Due to tropical cyclone activity during the fifth pentad of September, warm and wet air was maintained over the South China Sea and the tropical western Pacific, which resulted in persistent heavy precipitation over South China. In the third pentad of October, with cold air from the north intruding into the coastal areas and the South China Sea, the thermodynamic property of the air mass changed. The front of the summer monsoon then began to withdraw from the South China Sea and weaken (Fig. 7.40).

3) South AsıA-A. K. Srivastava, M. Rajeevan, L. Zubair, and J. Revadekar

This region includes India, Pakistan, and Sri Lanka.

\section{(i) Temperatures}

South Asia experienced warm temperatures in 2011. While India had relatively few heat wave events, Pakistan experienced several heat waves during the summer months. Severe heat wave events were re-

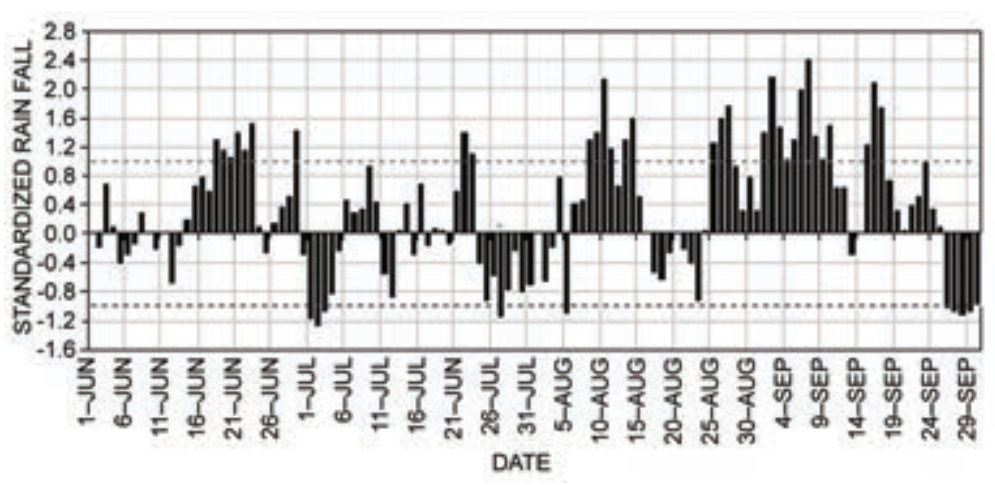

FIG. 7.43. Daily standardized rainfall time series averaged over the monsoon core zone over India (I Jun-30 Sep 20II). ported in different parts of Pakistan in the last week April, the second week of May, and the first week of June. During these events, maximum temperatures were above normal by $6^{\circ} \mathrm{C}$ to $7^{\circ} \mathrm{C}$. Pasni (Balochistan) recorded $50^{\circ} \mathrm{C}$ on 20 May, while the port city of Karachi reported $46^{\circ} \mathrm{C}$ on 21 May, which was the hottest day at Karachi in the past 30 years.

The annual mean temperature anomaly for India in 2011 was $+0.45^{\circ} \mathrm{C}$ above the $1961-90$ average, making it the ninth warmest year on record since national records began in 1901 (Fig. 7.41; 2009 was the warmest at $+0.93^{\circ} \mathrm{C}$ ). Abnormally warm temperatures $\left(+0.85^{\circ} \mathrm{C}\right.$ above average) during the post-monsoon season (October-December) contributed heavily to the positive annual temperature anomaly.

\section{(ii) Precipitation}

The summer monsoon season (June-September) contributes $60-90 \%$ of the annual rainfall over major portions of South Asia. In 2011, the region experienced normal monsoon rainfall activity. However, while India received normal rainfall, Pakistan experienced one of its worst floods during the summer monsoon season.

For India, the long-term average of the summer monsoon rainfall (1941-90 base period) is $890 \mathrm{~mm}$. For 2011, the summer monsoon seasonal rainfall averaged over the country as a whole was $102 \%$ of normal. While the northern plains experienced above-normal rainfall activity, deficient rainfall was reported from northeastern parts and south peninsula (Fig. 7.42). In 2011, the monsoon onset over southern parts of India occurred on 29 May, which 


\begin{tabular}{|c|c|c|c|c|c|}
\hline Station & $\begin{array}{c}\text { 24-hr Rainfall } \\
(\mathrm{mm})\end{array}$ & Date & $\begin{array}{c}\text { Previous } \\
\text { Record } \\
(\mathrm{mm})\end{array}$ & $\begin{array}{l}\text { Date of } \\
\text { Record }\end{array}$ & $\begin{array}{l}\text { Year of } \\
\text { Record }\end{array}$ \\
\hline Kotaap & 122.1 & 29 Jun & 108.9 & 29 Jun & 1977 \\
\hline Guna & 337.2 & 23 Jun & 191.5 & 29 Jun & 1945 \\
\hline Damoh & 275.8 & 22 Jun & 103.6 & 8 Jun & 1971 \\
\hline Sagar & 165.0 & 23 Jun & 158 & 28 Jun & 1945 \\
\hline Vijaywada AP & 115.9 & 7 Jun & 64 & 12 Jun & 1983 \\
\hline Phoolbagh & 149.8 & I Jul & 123.6 & II Jul & 2003 \\
\hline Buldhana & 166.0 & $8 \mathrm{Jul}$ & 122.9 & $25 \mathrm{Jul}$ & 1953 \\
\hline Guwahati AP & 169.4 & 5 Aug & 135.7 & 19 Aug & 2005 \\
\hline Mukteswar & 234.3 & 16 Aug & 203.7 & 24 Aug & 1948 \\
\hline Tehri & 132 & 16 Aug & 110.1 & 13 Aug & 1970 \\
\hline Phoolbagh & 209.4 & 16 Aug & 193.2 & 19 Aug & 2003 \\
\hline Nimach & 258.8 & 9 Aug & 185.9 & I5 Aug & 1957 \\
\hline Chennai City & 156.2 & 25 Aug & 100.3 & 20 Aug & 2008 \\
\hline Gadag & 93 & 20 Aug & 89.6 & 2 Aug & 2002 \\
\hline Kenjorgarh & 193.2 & $23 \mathrm{Sep}$ & 178.4 & $12 \mathrm{Sep}$ & 1963 \\
\hline Jaisalmer & 88.2 & $2 \mathrm{Sep}$ & 81.2 & 9 Sep & 2005 \\
\hline Dwarka & 303.6 & $6 \mathrm{Sep}$ & 135.9 & $4 \mathrm{Sep}$ & 1921 \\
\hline Bhuj AP & 194.9 & $7 \mathrm{Sep}$ & 176.1 & $15 \mathrm{Sep}$ & 1984 \\
\hline Okha & 147.4 & $6 \mathrm{Sep}$ & 88 & $18 \mathrm{Sep}$ & 2005 \\
\hline Rajnandgaon & 107.6 & $7 \mathrm{Sep}$ & 103 & $5 \mathrm{Sep}$ & 1994 \\
\hline
\end{tabular}

was three days earlier than normal. The monsoon steadily advanced until 26 June, covering most parts of the country, except the northwest. After a hiatus of about two weeks, the monsoon covered the whole country on 9 July, about six days earlier than normal. During the season, rainfall over the country was well distributed in time, except in July. Rainfall for the country as a whole in June was $112 \%$ of normal. Rainfall in July was $85 \%$ of normal. However, rainfall activity was above normal both in August (109\% of normal) and September (108\% of normal).

During the monsoon season, 7 of 36 meteorological subdivisions received excess rainfall, 26 received normal rainfall, and 3 received de- ficient rainfall. Of 603 meteorological districts for which data are available, $76 \%$ received excess/ normal rainfall and the remaining $24 \%$ received deficient/scanty rainfall during the season. On the daily time scale, the rainfall distribution over the country was generally above or near normal on most of the days of the season, except for some days in July and September (Fig.7.43). Over the North Indian Ocean, ten low pressure areas were formed during the season, of which four systems intensified into monsoon depressions (one over land). However, two of the monsoon depressions were short-lived. Table 7.1 lists record 24-hr rainfalls that occurred during the 2011 monsoon season. 
During the winter (January-February) season, rainfall over the country was $80 \%$ of normal, while during the premonsoon season (March-May), rainfall was $89 \%$ of normal.

Pakistan, at the western edge of the pluvial region of the South Asian monsoon, receives more than half of its annual rainfall during the summer monsoon season (July-September). The summer monsoon typically sets over northeastern parts of the country around 1 July, with a standard deviation of five days. The 2011 summer monsoon was set on 28 June. The most significant feature of this monsoon season was the record-breaking heavy rainfall over parts of Sindh province. The 2011 monsoon seasonal rainfall averaged over Pakistan was 172\% of normal (1961-90 base period) and ranked as the fifth heaviest monsoon rainfall over the past 52 years. Even though rainfall activity in July was only $83 \%$ of normal, the remaining two months experienced above-normal rainfall activity. Sindh province experienced exceptionally heavy rainfall (347\% of normal) during the season, which was the second heaviest seasonal rainfall since 1961. Most of the rain fell in a four-week period from mid-August to early September. Some stations, including Mithi (1348 mm), Mirpur Khas (866 mm), Nawabshah (650 mm), Chhor (552 $\mathrm{mm})$, and Dadu $(485 \mathrm{~mm})$, recorded very heavy rainfall that exceeded historical seasonal records. Mithi (Sindh) received $300 \mathrm{~mm}$ of rainfall during 1-14 September in four consecutive spells of monsoon rains, which is an all-time record. The heavy rainfall over the Sindh province was attributed to mid-tropospheric cyclones (MTC) that formed over the northeastern Arabian Sea and adjoining northwestern parts of India during late August and early September. The devastating floods affected millions of people, damaged millions of houses, damaged agricultural crops, and claimed at least 250 lives. The 2011 flooding were the worst since the 2010 floods, which devastated the whole country.

Overall, Sri Lanka's total annual rainfall for 2011 was near normal; however, there were large seasonal and regional variations, with sustained regional deficits during March, February, June, July, August, and September. Five episodes of intense rainfall peaking on 6 January, 29 January-4 February, 28 October, 24 November, and 25-30 December compensated for the periods of deficit. The heavy rainfall over the eastern coastal region peaking on 6 January and the impacts of a tropical depression that led to heavy rainfall around 24 November over the southern coast led to loss of life and damage to fisheries and other coastal infrastructure. During 2011, La Niña conditions pre- vailed from January to April and from September to December. Usually during La Niña episodes, rainfall in Sri Lanka is augmented modestly from January to April, there is a slight increase during June to September, and there is a decline from October to December. During 2011, there were significant departures from this pattern, in part due to an unusual pattern of $\mathrm{La}$ Niña influences over the Indian Ocean region and due to heavy rainfall events related to storms and other weather events during January, February, October, November, and December.

The northeast monsoon (NEM) normally sets in over southern peninsular India during October and over Sri Lanka in late November. The NEM contributes $30-50 \%$ of the annual rainfall over southern peninsular India and Sri Lanka as a whole. The 2011 NEM seasonal rainfall over south peninsular India was 96\% of normal. The rainfall over Sri Lanka and northern Maldives during this season was slightly enhanced.

\section{(iii) Notable events}

Severe cold wave conditions prevailed over northern parts of India during the first two weeks of January and also during the second half of December 2011. Maximum temperatures at a number of stations over the northern plains were $5^{\circ} \mathrm{C}-10^{\circ} \mathrm{C}$ below normal on many days during January. The cold wave claimed about 500 lives (approximately 250 alone in the state of Bihar) during January and about 150 lives during December. The cold air that impacted parts of India during the first week of January moved into Bangladesh during the second and third weeks of the month. Night temperatures in Bangladesh were $5^{\circ} \mathrm{C}-10^{\circ} \mathrm{C}$ below normal during the month, which had an adverse impact on agriculture.

In January, heavy snowfall up to $3 \mathrm{~m}$ across the high mountain passes of Rohtang and Kunzam cut off access to portions of far northern India including the Kashmir province.

Dust storms/thunderstorms/lightning accompanied by heavy rains during the premonsoon season claimed over 100 lives in the northern parts of India.

Mumbai city was unusually warm during 12-17 March. Colaba Observatory in Mumbai reported $41.6^{\circ} \mathrm{C}$ on $16 \mathrm{March}$, which was $10.5^{\circ} \mathrm{C}$ above normal and was the all-time highest temperature recorded at that location. Similarly, two other observatories in coastal districts, Ratnagiri (south of Mumbai) and Dahanu (north of Mumbai), also reported record high maximum temperatures, $40.9^{\circ} \mathrm{C}\left(10.1^{\circ} \mathrm{C}\right.$ above normal) and $40.6^{\circ} \mathrm{C}\left(9.4^{\circ} \mathrm{C}\right.$ above normal), respectively, on the same day. 
TABLE 7.2. Seasonal amount of precipitation and temperature over Iran in 2011.

\begin{tabular}{|c|c|c|c|c|c|c|}
\hline \multirow{2}{*}{$\begin{array}{l}\text { Parameter } \\
\text { Precipitation }\end{array}$} & \multicolumn{2}{|r|}{ Season } & Winter & Spring & Summer & Autumn \\
\hline & \multicolumn{2}{|c|}{ Average $(\mathrm{mm})$} & 118 & 42 & 14.5 & 71 \\
\hline & \multirow{2}{*}{$\begin{array}{l}\text { Respect } \\
\text { to (\%) }\end{array}$} & Long term & $8 \%$ & $27 \%$ & $44 \%$ & $14 \%$ \\
\hline & & $\begin{array}{l}\text { previous } \\
\text { year }\end{array}$ & $37 \%$ & $32 \%$ & $200 \%$ & $300 \%$ \\
\hline & \multicolumn{2}{|c|}{ Range from-to (mm) } & 4 to 697 & 0 to 353 & 0 to 772 & 0 to 1293 \\
\hline \multirow[t]{2}{*}{ Temperature } & \multicolumn{2}{|c|}{ Respect to long term } & & & & \\
\hline & \multicolumn{2}{|c|}{ Range from-to $\left({ }^{\circ} \mathrm{C}\right)$} & -6.2 to 22.1 & 8 to 35 & 16 to 39 & 1.7 to 27.2 \\
\hline
\end{tabular}

*red: above long term, blue: below long term, dashed: mixed below and above long term

The death toll due to heavy rains and floods in different parts of India during the southwest monsoon was more than 300 , mostly in the northern and central parts of the country. Heavy rainfall over the south peninsula in November 2011, due to northeast monsoon activity, killed more than 90 people in the state of Tamil Nadu. Very Severe Cyclone Thane (as designated by the India Meteorological Department) formed over the southeast Bay of Bengal on 26 December and crossed the north Tamil Nadu coast (southeast India) on 30 December, claiming at least 50 lives and causing widespread damage.

\section{4) Southwest Asia}

This regional includes Iran and Turkey. Information from Iraq is unavailable this year.

(i) Iran-M. Khoshkam and F. Rahimzadeh

Surface air temperatures were mostly cool across Iran during winter and autumn 2011, while the spring and summer experienced above-normal temperatures over most parts of the country. Mixed patterns including seasons with much-below- and above-normal temperatures have been common in recent decades, accompanied by a long-term increase in temperature. Annual minimum and maximum temperatures in Iran have increased by $0.4^{\circ} \mathrm{C}-0.5^{\circ} \mathrm{C}$ and $0.2^{\circ} \mathrm{C}$ $-0.3^{\circ} \mathrm{C}$ decade $^{-1}$, respectively, over the $1960-2010$ period (ASMERC 2011).

In 2011, Iran experienced wetter-than-normal conditions for winter, summer, and autumn (Table 7.2). These seasons also received more precipitation than they received in 2010. However, the statistics show a decreasing trend of precipitation over the longer term (1960-2010) (ASMERC 2011). Table 7.3 shows the amount of precipitation during August and
November, and for summer and autumn, for several stations where precipitation amounts were higher than normal.

Generally, observed data for 2011 and recent results on longer-term variability (ASMERC 2011) show

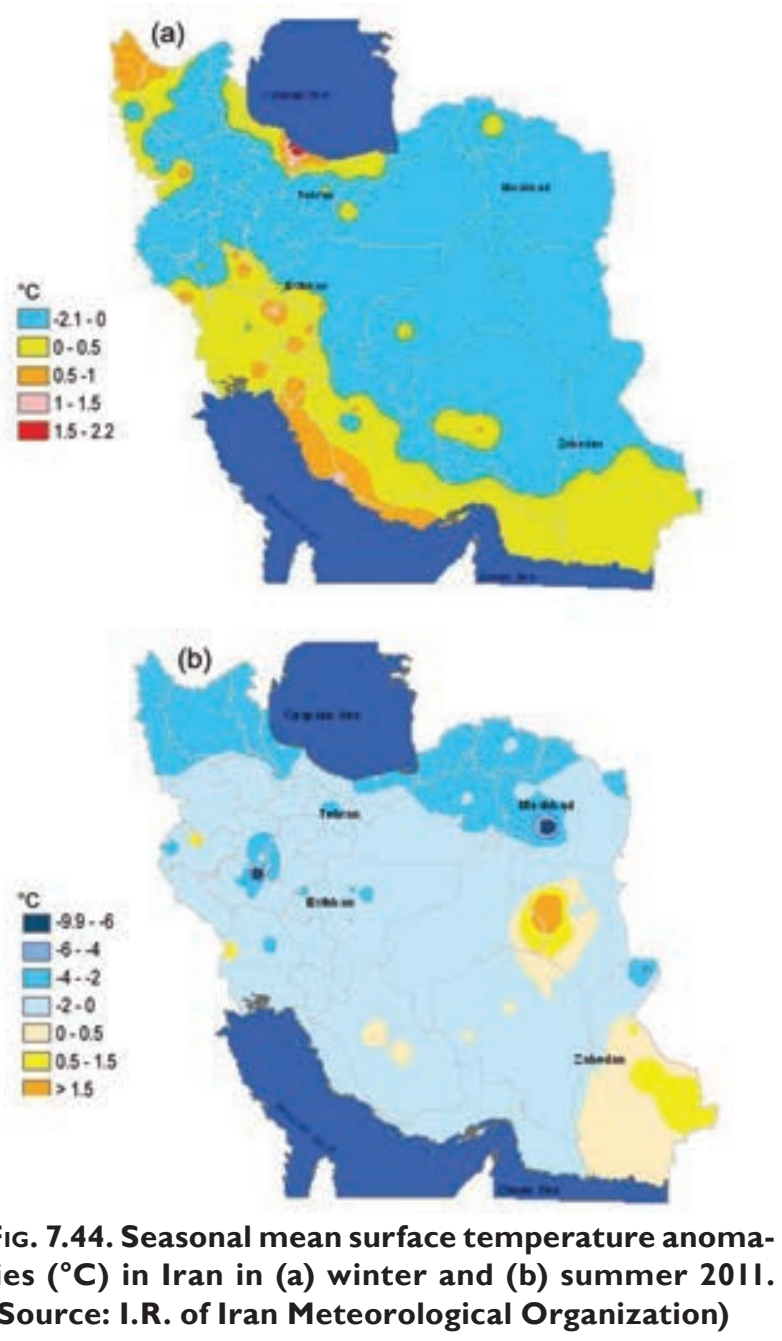




\begin{tabular}{|c|c|c|c|c|c|}
\hline Stations & $\begin{array}{c}\text { August } \\
2011\end{array}$ & $\begin{array}{l}\text { Long-term } \\
\text { average } \\
\text { (Aug) }\end{array}$ & $\begin{array}{c}\text { Summer } \\
2011\end{array}$ & $\begin{array}{l}\text { Long-term } \\
\text { average } \\
\text { (Summer) }\end{array}$ & $\begin{array}{l}\text { Ratio of summer } 201 \mathrm{I} \\
\text { precip against long } \\
\text { term average }\end{array}$ \\
\hline Baft & 43.7 & 3 & 47.1 & 13.3 & $>3$ \\
\hline Zabol & 22 & 0.01 & 22 & 0.08 & $>200$ \\
\hline Kerman & 13.8 & 0.3 & 13.8 & 0.8 & $>17$ \\
\hline Ghazvin & 42.7 & I & 55.6 & 5.3 & $>10$ \\
\hline Karaj & 46.9 & 0.6 & 48.9 & 5.7 & $>8$ \\
\hline Chitgar & 42.5 & 0.5 & 42.9 & 5.7 & $>7$ \\
\hline Tehrann-Mehrabad & 22.3 & 1.1 & 23.11 & 5.4 & $>4$ \\
\hline Abali & 74.1 & 6.8 & 103 & 29 & 3.5 \\
\hline
\end{tabular}

TABLE 7.3b: As in (a) but for November and autumn $201 \mathrm{I}$.

\begin{tabular}{|c|c|c|c|c|c|}
\hline Stations & $\begin{array}{c}\text { November } \\
\mathbf{2 0 I I}\end{array}$ & $\begin{array}{c}\text { Long-term } \\
\text { average } \\
\text { (Nov) }\end{array}$ & $\begin{array}{c}\text { Autumn } \\
\mathbf{2 0 I I}\end{array}$ & $\begin{array}{c}\text { Long-term } \\
\text { average } \\
\text { (Autumn) }\end{array}$ & $\begin{array}{c}\text { Ratio of summer 20II } \\
\text { precip against long } \\
\text { term average }\end{array}$ \\
\hline Esfehan & 77.2 & 9.0 & 93.5 & 26.7 & $>3$ \\
\hline Naien & 31.8 & 7.0 & 59.0 & 19.0 & $>3$ \\
\hline Tehran & 179.0 & 22.5 & 186.0 & 70.0 & $>2.5$ \\
\hline Golpaigan & 196.9 & 25 & 202 & 75 & $>2.5$ \\
\hline Geophysic & 232.8 & 40.5 & 239.5 & 107 & $>2$ \\
\hline Moaelmkleiyep & 158 & 35.5 & 170.4 & 88.0 & $>1.5$ \\
\hline Bijar & 107 & 44.5 & 121 & 89.0 & $>1.5$ \\
\hline Lordgan & 168.5 & 43.5 & 201.8 & 155 & $>1.3$ \\
\hline
\end{tabular}

an increase in interannual and longer term variability of temperature and precipitation over time.

\section{(A) Temperature}

During winter 2010/11 (Table 7.2), the country experienced temperatures mostly $0^{\circ}$ to $2^{\circ} \mathrm{C}$ below average. However, some parts of the coastal area both in the north and south (including the area across the Caspian Sea, the Persian Gulf, and the Oman Sea), and individual small areas in the southwest and southeast recorded anomalies of $+2^{\circ} \mathrm{C}$ (Fig. 7.44a).

Warmer-than-average conditions occurred across most of the country, except in a limited area in the west in spring. The highest values occurred in parts of the east, including Khorasan Rasavi and Semnan Provinces, part of Yazd Province, and Bandarabbas station, with anomalies more than $+2^{\circ} \mathrm{C}$. During summer, average temperatures were $0.5^{\circ} \mathrm{C}-1.5^{\circ} \mathrm{C}$ below average in limited areas distributed over the country, while the rest of the country experienced temperatures $1{ }^{\circ} \mathrm{C}-2^{\circ} \mathrm{C}$ above the long-term average, with anomalies of up to $+3.8^{\circ} \mathrm{C}$ observed at Zabol station in the southeast (Fig. 7.44b). During autumn, a severe cold spell persisted across the country, accompanied by heavy precipitation and high winds, while warmer-than-average conditions of $+1^{\circ} \mathrm{C}$ were limited to a small part in the southeast. Average temperatures were about $2^{\circ} \mathrm{C}-4^{\circ} \mathrm{C}$ below the long-term averge. Broujerd, Kashmar, and Khakhal stations in the northwest recorded $-12^{\circ} \mathrm{C}$, $-8.9^{\circ} \mathrm{C}$, and $-8.3^{\circ} \mathrm{C}$ anomalies, while Saravan, Zahedan, and Iranshahr stations in the southeast recorded anomalies of $+1.1^{\circ} \mathrm{C},+1.1^{\circ} \mathrm{C}$, and $+0.6^{\circ} \mathrm{C}$, respectively. 

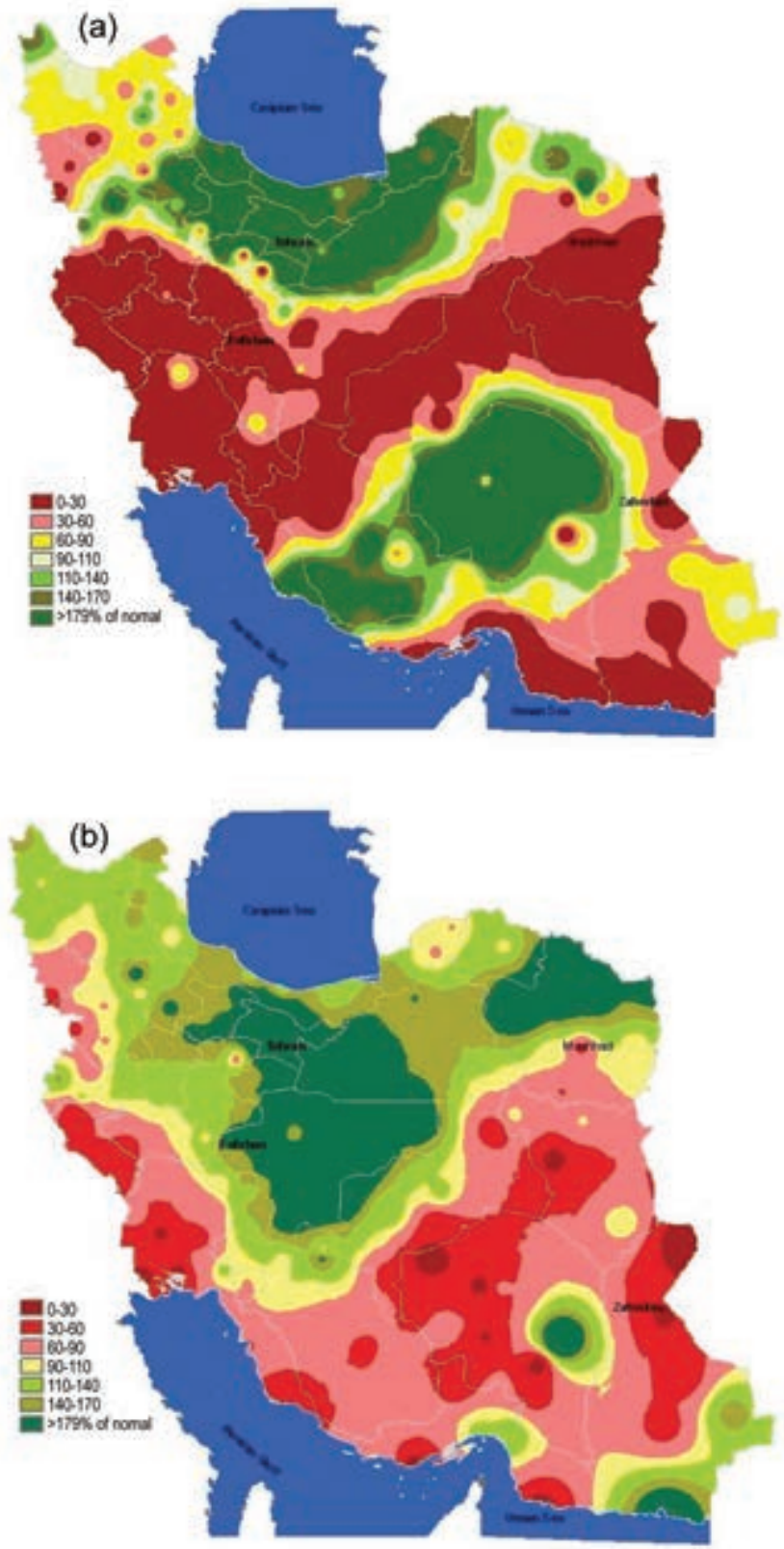

FIG. 7.45. Seasonal precipitation anomalies (\%) in Iran in (a) spring and (b) autumn 20II. (Source: I.R. of Iran Meteorological Organization)

(B) Precipitation

During winter 2010/11 (Table 7.2), areas with average or above-average rainfall (up to $170 \%$ of normal) were confined to the southeast, areas around the Caspian Sea, parts of the northwest, and small parts in the south of the Zagross mountains. A small part of Yazd province received less than $60 \%$ of normal rainfall, while the rest of the country received precipitation amounts between $60 \%$ and $90 \%$ of normal. Similar to 2010, the largest 2011 total rainfall of 697 $\mathrm{mm}$ fell in Bandar Anzali, located in the southwest of the Caspian Sea area, followed by $682 \mathrm{~mm}$ in the southern Zagross mountain area. Through the middle and east of the country, and in localized regions in Sistan and Balochestan Province (across the Oman Sea), winter rainfall was less than $25 \mathrm{~mm}$.

In spring, the amount of precipitation was 30-90\% of normal across most of the country, but up to $170 \%$ of normal in the west and northwest. In contrast to the previous year, the spring of 2011 was the only season of the year where total precipitation was below normal. During spring (Fig. 7.45a), one-third of the country (middle band of Iran) received no measured rainfall, and less than two-thirds received less than $50 \mathrm{~mm}$ precipitation. Only the north, including the area across the Caspian Sea, the Alborz mountain area, and some small limited areas scattered across the country experienced more than $50 \mathrm{~mm}$ precipitation. These areas, in addition to some eastern coastal areas, received above-normal precipitation, while the rest of the country received below-normal precipitation (similar to 2010). The highest recorded precipitation was in Bandar Anzali with $772 \mathrm{~mm}$.

During autumn, the entire country, except the east and southeast, received precipitation between $25 \mathrm{~mm}$ and $250 \mathrm{~mm}$ and even up to $1200 \mathrm{~mm}$ in the Caspian area. Precipitation was less than normal over the southern half of the country, but over $170 \%$ of normal in the north and northeast of the country, as in spring (Fig. 7.45b).

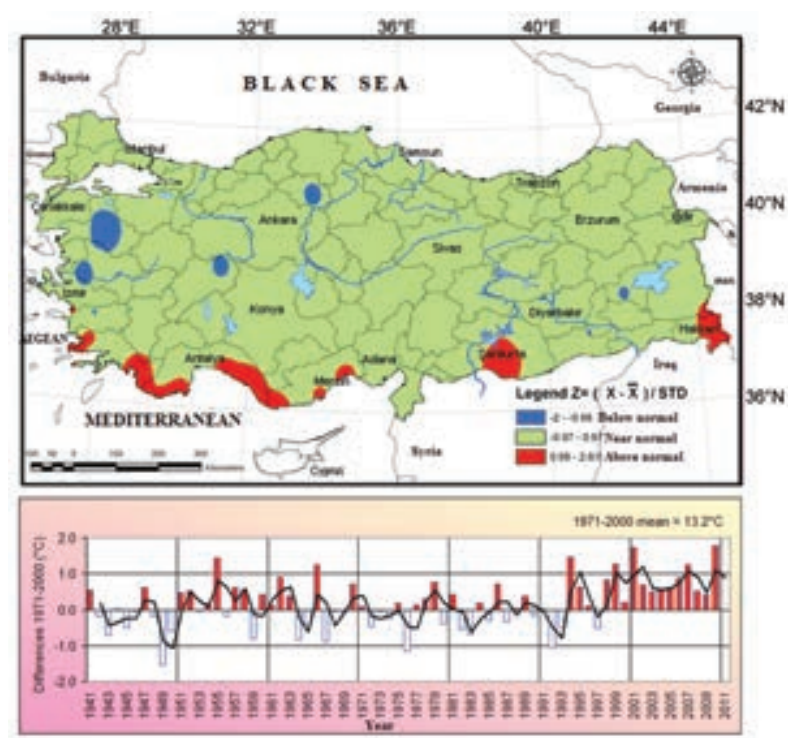

Fig. 7.46. (top) Spatial mean temperature anomalies $\left({ }^{\circ} \mathrm{C}\right)$ in Turkey in 2011 (colors indicate terciles); (bottom) time series of annual mean temperature anomalies in Turkey. 

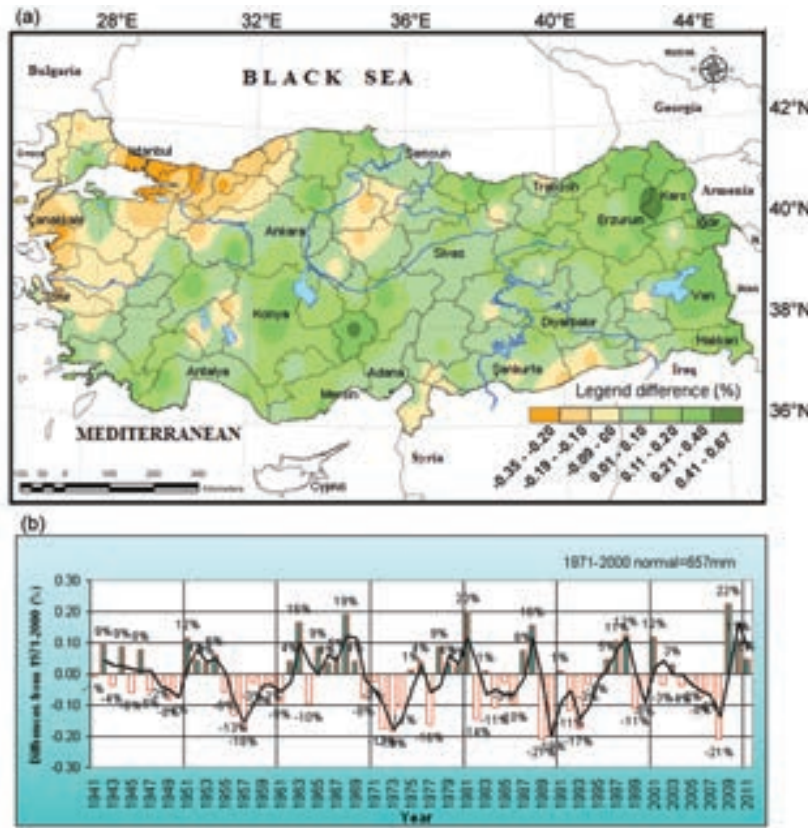

FIG. 7.47. (a) Spatial mean precipitation anomalies in Turkey in 201 I (standard deviations); (b) time series of annual precipitation anomalies in Turkey (\%).

(ii) Turkey-S. Sensoy, Y. Ulupınar, S. Kervankıran, and

M. Demircan

(A) Temperature

Although there were significant temperature anomalies in individual months, Turkey's annual mean temperature in 2011 was near normal (19712000 base period) of $13.2^{\circ} \mathrm{C}$, based on records from 130 stations (Fig. 7.46). Much of the country had nearnormal temperatures overall, although a number of areas in the south had above-normal temperatures while a few regions (Manisa, Balıkesir, Emirdağ, Çankırı Batman, and Bitlis) recorded below-normal annual mean temperatures (Fig. 7.46). Monthly mean

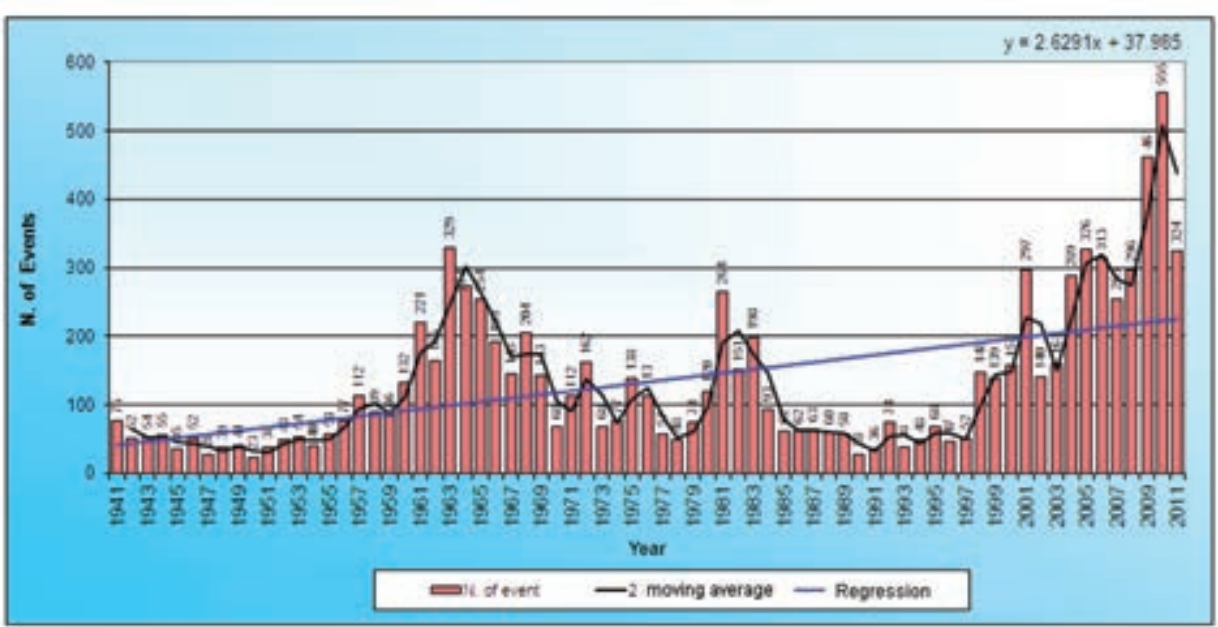

temperatures were above normal in January, February, March, July, August, and September while April, May, October, and November were below normal. June and December temperatures were near normal.

\section{(B) Precipitation}

The rainfall distribution in Turkey is strongly affected by topography. On average, coastal stations and inland stations exhibit large differences in rainfall. Averaged over the country, Turkey received 687 $\mathrm{mm}$ total precipitation for 2011, $30 \mathrm{~mm}$ above normal (1971-2000 base period). Precipitation was also above normal in 2009 and 2010. During 2011, large parts of the country received above- or near-normal precipitation while Marmara, the northwest Aegean and western Black Sea regions, and Antakya, Isparta, Eskişehir, Yozgat, Ceylanpınar, İslahiye, Mardin and Bitlis received below-normal rainfall (Fig. 7.47). Precipitation in Sarıkamış and Niğde's were 167\% and $149 \%$ of normal, respectively. Monthly precipitation was above normal during February, April, May, June, September, and October and below normal during January, March, July, August, November, and December.

\section{(C) Notable eVents}

A total of 324 extreme events were reported in Turkey during 2011, fewer than in 2009 or 2010 (Fig. 7.48). Nearly $36 \%$ (112) of these events were hail, while floods accounted for $28 \%$ of extremes and storms $20 \%$.

Due to flooding in Gaziantep on 11 April, cars and ground floors in many buildings became unusable.

During a hail storm in Ankara on 16 June, up to 20 $\mathrm{cm}$ of hail stones accumulated on the ground. Some underpasses were closed because the hail blocked the exits, and traffic was significantly disrupted.

Fig. 7.48. Annual count of extreme events in Turkey. 


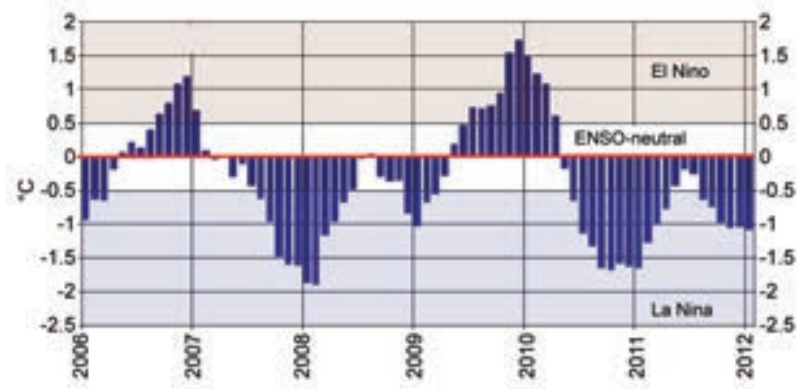

Fıg. 7.49. Time series of the Niño 3.4 SST anomaly $\left({ }^{\circ} \mathrm{C}\right)$ for the period Jan 2006-Jan 2012. La Niña has dominated the climate of the Pacific basin for much of this time period, with 33 months (45\%) having SST in the La Niña category (light blue shaded region). Over the past 30 years, the state of the climate has been in La Niña, EI Niño, and ENSO-neutral 29\%, 26\%, and $44 \%$ of all months respectively. Moderate-to-strong La Niña occurred in late 2007 to early 2008, and again in the latter half of 2010 through early 2011 . A brief period of ENSO-neutral in the boreal summer of 2011 was followed once again by a return to a weak-to-moderate La Niña by the fall of 2011 .

(h) Oceania

[Southwest Pacific section not available in 20II]

I) Northwest Pacific, Micronesia-C. Guard and M. A. Lander

\section{(i) Overview}

This assessment covers the area from the international date line west to $130^{\circ} \mathrm{E}$, between the equator and $20^{\circ} \mathrm{N}$. It includes the US-affiliated islands of Micronesia, but excludes specific discussions concerning the western islands of Kiribati and nearby northeastern islands of Indonesia. In this Pacific region, the climate is strongly influenced by the phase and phase changes of ENSO (section $4 \mathrm{~b}$ ).

The state of the climate of the Pacific basin in 2011 began as a moderate-to-strong La Niña (Fig. 7.49). ENSO-neutral conditions were present by May. ENSO-neutral conditions prevailed through the boreal summer (JJA), and by October 2011, La Niña conditions returned (weak to moderate by the end of the year). Temperature, rainfall, sea level, and tropical cyclone (TC) distribution all roughly corresponded to the behavior that would be expected in a year that experienced the described ENSO conditions. Such years tend to be rather wet, with fairly normal temperatures, but minimal TC activity. Sea levels are generally elevated.

During the first half of 2011, Micronesia experienced relatively strong easterly trade winds and a well-developed

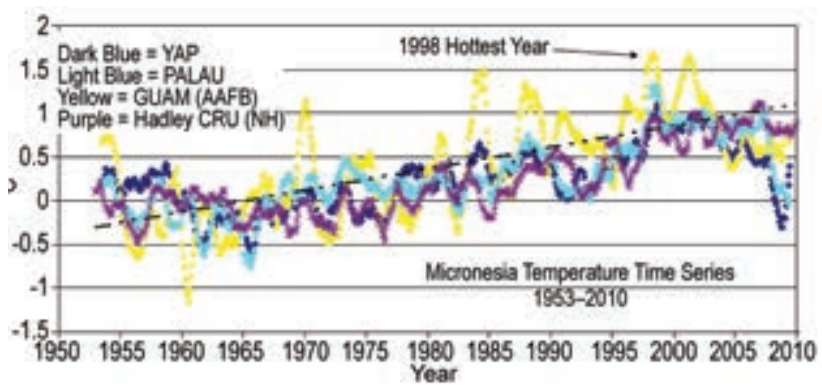

FIG. 7.50. Time series of MaxT anomaly $\left({ }^{\circ} \mathrm{C}\right)$ at AAFB, Koror, Yap, and the Northern Hemisphere. Values are a I2-month moving average of the monthly averages.

near-equatorial convergence zone or intertropical convergence zone (ITCZ) that brought above-normal rainfall to most locations. The midyear transition to ENSO-neutral conditions allowed monsoon activity to render the western half of Micronesia very wet during the boreal summer, while the August-October transition back into La Niña maintained the generally wet pattern, but shifted TC activity west of Micronesia. During the brief period of ENSO-neutral conditions, the western Pacific monsoon reached eastward as far as Guam and the Commonwealth of the Northern Mariana Islands (CNMI), with several episodes of weak to moderate southwesterly surface winds observed during July-September. However, with the return of La Niña later in the year, the monsoon made an early retreat from Guam and the rest of Micronesia. From October through the end of the year, widespread anomalous easterly surface winds returned, TC activity in Micronesia was greatly reduced, and abundant rainfall eased to monthly values at or below normal throughout the region.

\section{(ii) Temperature}

Average monthly maximum temperatures (maxT) and minimum temperatures (minT) across most of

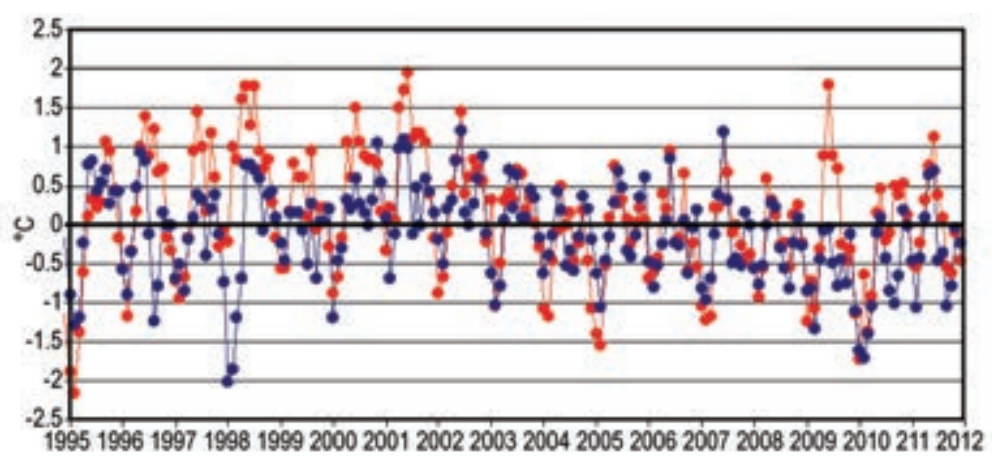

FIG. 7.5I. Time series of anomalies $\left({ }^{\circ} \mathrm{C}\right.$ ) of MaxT (red) and MinT (blue) at AAFB. Anomalies are with respect to the 1981-2010 mean values; thus, the annual cycle is present. 
TABLE 7.4. Maximum and minimum temperature anomalies and rainfall anomalies for selected Micronesian locations for Jan-Jun $201 \mathrm{I}$ and for Jul-Dec 20II. Maximum and minimum temperature anomalies are in ${ }^{\circ} \mathrm{C}$ month $^{-1}$ and rainfall anomalies are in $\mathrm{mm}$. "N" is the normal rainfall taken from the 198I-2010 base period. Locations (latitude and longitude) are approximate. NA indicates that the temperature normals are not available. Kapinga stands for Kapingamarangi Atoll in Pohnpei State, Federated States of Micronesia (FSM).

\begin{tabular}{|c|c|c|c|c|c|c|c|c|c|c|}
\hline \multirow[t]{3}{*}{ Location } & \multicolumn{2}{|c|}{$\begin{array}{l}\text { Max Temp } \\
\text { Min Temp }\end{array}$} & \multicolumn{8}{|c|}{ Rainfall } \\
\hline & $\begin{array}{l}\text { Jan- } \\
\text { Jun }\end{array}$ & $\begin{array}{l}\text { Jul- } \\
\text { Dec }\end{array}$ & $\begin{array}{l}\text { Jan- } \\
\text { Jun }\end{array}$ & $\begin{array}{l}\text { Jan- } \\
\text { Jun }\end{array}$ & $\begin{array}{l}\text { Jan- } \\
\text { Jun }\end{array}$ & $\begin{array}{l}\text { Jul- } \\
\text { Dec }\end{array}$ & $\begin{array}{l}\text { Jul- } \\
\text { Dec }\end{array}$ & $\begin{array}{l}\text { Jul- } \\
\text { Dec }\end{array}$ & $\begin{array}{l}\text { Jul- } \\
\text { Dec }\end{array}$ & $\begin{array}{l}\text { Jan- } \\
\text { Dec }\end{array}$ \\
\hline & ${ }^{\circ} \mathrm{C} \mathrm{mo-1}$ & ${ }^{\circ} \mathrm{C} \mathrm{mo-1}$ & $\mathrm{N} \mathrm{mm}$ & $\begin{array}{l}2011 \\
\mathrm{~mm}\end{array}$ & $\%$ & $\mathrm{~N} \mathrm{~mm}$ & $\begin{array}{l}2011 \\
\mathrm{~mm}\end{array}$ & $\%$ & $\begin{array}{l}2011 \\
\mathrm{~mm}\end{array}$ & $\%$ \\
\hline $\begin{array}{c}\text { Saipan } \\
15^{\circ} \mathrm{N}, 146^{\circ} \mathrm{E}\end{array}$ & $\begin{array}{l}+0.34 \\
+0.30\end{array}$ & $\begin{array}{l}-0.14 \\
+0.07\end{array}$ & 449.1 & 969.0 & 215.8 & 1322.8 & 1240.8 & 93.8 & 2209.8 & 124.7 \\
\hline $\begin{array}{c}\text { Guam } \\
13^{\circ} \mathrm{N}, 145^{\circ} \mathrm{E}\end{array}$ & $\begin{array}{l}+0.66 \\
+0.72\end{array}$ & $\begin{array}{l}+0.03 \\
-0.06\end{array}$ & 691.6 & 932.9 & 134.6 & I788.4 & 2000.0 & 111.8 & 2933.0 & 118.3 \\
\hline $\begin{array}{c}\text { Yap } \\
9^{\circ} \mathrm{N}, 138^{\circ} \mathrm{E}\end{array}$ & $\begin{array}{l}+0.37 \\
-0.06\end{array}$ & $\begin{array}{l}+0.44 \\
-0.12\end{array}$ & 1169.7 & 1642.6 & 140.4 & 1902.0 & 2363.0 & 124.2 & 4005.6 & 130.4 \\
\hline $\begin{array}{c}\text { Palau } \\
7^{\circ} \mathrm{N}, 134^{\circ} \mathrm{E}\end{array}$ & $\begin{array}{l}+0.29 \\
-0.04\end{array}$ & $\begin{array}{l}+0.15 \\
-0.26\end{array}$ & 1717.6 & 2617.2 & 152.4 & 2032.5 & 2612.1 & 128.5 & 5229.4 & 139.4 \\
\hline $\begin{array}{c}\text { Chuuk } \\
7^{\circ} \mathrm{N}, 152^{\circ} \mathrm{E}\end{array}$ & $\begin{array}{l}+0.80 \\
+0.24\end{array}$ & $\begin{array}{l}+0.35 \\
+0.15\end{array}$ & 1584.2 & 1957.3 & 123.6 & 1833.1 & 2204.5 & 120.3 & 4161.8 & 121.8 \\
\hline $\begin{array}{c}\text { Pohnpei } \\
7^{\circ} \mathrm{N}, 158^{\circ} \mathrm{E}\end{array}$ & $\begin{array}{l}+0.15 \\
-0.17\end{array}$ & $\begin{array}{r}-0.43 \\
+0.30\end{array}$ & 2266.4 & 2590.3 & 114.3 & 2336.6 & 2433.6 & 104.2 & 5023.9 & 109.1 \\
\hline $\begin{array}{l}\text { Kapinga } \\
I^{\circ} \mathrm{N}, 155^{\circ} \mathrm{E}\end{array}$ & $\begin{array}{l}\text { NA } \\
\text { NA }\end{array}$ & $\begin{array}{l}\text { NA } \\
\text { NA }\end{array}$ & 1683.8 & 1251.5 & 74.3 & 1454.9 & 1752.9 & 120.5 & 3004.3 & 95.7 \\
\hline $\begin{array}{c}\text { Kosrae } \\
5^{\circ} \mathrm{N}, 163^{\circ} \mathrm{E}\end{array}$ & $\begin{array}{l}+0.27 \\
+0.79\end{array}$ & $\begin{array}{l}-0.64 \\
+0.93\end{array}$ & 2567.9 & 2376.9 & 92.6 & 2342.9 & 2619.8 & III.8 & 4996.7 & 101.8 \\
\hline $\begin{array}{c}\text { Majuro } \\
7^{\circ} \mathrm{N}, 17 I^{\circ} \mathrm{E}\end{array}$ & $\begin{array}{l}+0.23 \\
+0.33\end{array}$ & $\begin{array}{l}-0.31 \\
+0.24\end{array}$ & 1368.3 & 1609.3 & 117.6 & 1868.2 & 2058.7 & 110.2 & 3668.0 & 113.3 \\
\hline $\begin{array}{l}\text { Kwajalein } \\
9^{\circ} \mathrm{N}, 168^{\circ} \mathrm{E}\end{array}$ & $\begin{array}{l}+0.26 \\
+0.02\end{array}$ & $\begin{array}{l}+0.09 \\
-0.21\end{array}$ & 801.4 & 1231.4 & 153.7 & I579.| & I79|.7 & 113.5 & 3023.1 & 127.0 \\
\hline
\end{tabular}

Micronesia have been rising for several decades at a rate that roughly matches the reported rise of global average temperature of $+0.74^{\circ} \mathrm{C}$ in the last century. The temperature time series of Guam's Andersen Air Force Base (AAFB), Koror (Palau, western Micronesia, $7.3^{\circ} \mathrm{N}, 134.5^{\circ} \mathrm{E}$ ), and Yap (Federated States of Micronesia, FSM, $9.5^{\circ} \mathrm{N}, 138.1^{\circ} \mathrm{E}$ ) are coherent (Fig. 7.50), and generally follow the Northern Hemisphere temperature trend noted by the Hadley Climate Research Unit, but with larger interannual variation. Looking more closely at the long-term behavior of the temperature at AAFB (Fig. 7.51), the temperature peaked in the late 1990s, and has fallen slightly since then. The 2011 temperatures across Micronesia were mostly above the 1981-2010 averages, especially in the first half of the year (see Table 7.4), but were below the peak warmth seen in the late 1990s.

In the Pacific tropics, the attribution and causality of month-to-month and seasonal temperature anomalies are more difficult to identify than those for rainfall anomalies. Thus, most of the relatively small six-month temperature anomalies of 2011 as shown in Table 7.4 are not attributable to any discernible cause. The large anomalies seen in 2010 data did not reappear in the 2011 data. Thus, only a few locations and six-month periods are discussed for 2011. 
While most of Micronesia was wetter than normal during the first six-month period (January-June), the warmer-than-normal maxT values at most locations suggest convective-type daytime rain where the temperatures rise rapidly during breaks between the showers. This was especially the case for Guam $\left(+0.66^{\circ} \mathrm{C}\right)$ and for Chuuk (FSM, $\left.7.4^{\circ} \mathrm{N}, 151.8^{\circ} \mathrm{E} ;+0.80^{\circ} \mathrm{C}\right)$. The larger higher-than-normal minT anomaly seen at Kosrae $\left(+0.79^{\circ} \mathrm{C}\right)$ suggests a rather long period of nighttime cloudiness and reduced radiational cooling. Guam's minT of $+0.72^{\circ} \mathrm{C}$ likely reflects the higher daytime maxT.

Temperatures from July to December were closer to normal than those during the first half of the year at most locations. MaxT anomalies for the six-month period (July-December) were generally cooler in the eastern part of the basin (see Table 7.4, Majuro, Kosrae, Pohnpei) and warmer in the western part. Kosrae had the largest reduction of range between the daytime and nighttime temperatures, with a JulyDecemeber maxT of $-0.64^{\circ} \mathrm{C}$ and a $\operatorname{minT}$ of $+0.93^{\circ} \mathrm{C}$. This suggests a rather long and persistent period of daytime and nighttime cloudiness, but limited cloud observations on Kosrae did not allow confirmation of this assumption. Temperature anomalies for the first six-month period and for the last six-month period for selected Micronesian locations are summarized in Table 7.4.

\section{(iii) Precipitation}

Micronesian precipitation during 2011 was fairly typical of a year that begins with a moderate-to-strong La Niña and ends with the reemergence of another La Niña event. The six-month and annual rainfall values for selected locations are summarized in Table 7.4. In the first half of the year, virtually all of Micronesia was considerably wetter than normal. Notable exceptions were the near-equatorial island of Kapinamarangi and its northern neighbor, Kosrae. In more western locations, Palau rainfall for January-June was a recordsetting $152.4 \%$ of normal, while Yap was $140.4 \%$, and the rainfall amounts at Guam and Saipan in the Mariana Islands were $134.6 \%$ and $215.8 \%$ of normal, respectively. Farther east, conditions poleward of $6^{\circ} \mathrm{N}$ were wet and those more equatorward were relatively dry. Thus, Chuuk and Pohnpei had rainfall values of $123.6 \%$ and $114.3 \%$ of normal, respectively, while locations nearer the equator, such as Kapingamarangi and
Kosrae, had values that were $74.3 \%$ and $92.6 \%$ of their respective normal amounts. Finally, at the east end of the region in the Marshall Islands, Majuro had 117.6\% normal rainfall and Kwajalein had $153.7 \%$ of normal.

During the last half of the year, many locations poleward of $6^{\circ} \mathrm{N}$ saw a $10-40 \%$ reduction in rainfall, while others had percentages similar to those in the first half. Locations equatorward of $6^{\circ} \mathrm{N}$ saw a $20-45 \%$ increase in rainfall. From west to east across Micronesia, compared with January-June anomalies, Palau rainfall decreased to $128.5 \%$ of normal, Yap rainfall decreased to $124.2 \%$, Chuuk rainfall decreased only a few percent to $120.3 \%$, and Pohnpei rainfall decreased to $104.2 \%$. Farther east, Majuro rainfall decreased to $110.2 \%(-7.4 \%)$ and that at Kwajalien fell to $113.5 \%$, a very large $40.2 \%$ reduction. Farther north, Guam rainfall decreased to $111.8 \%$ and that at Saipan plunged to $93.8 \%$ of normal.

Farther toward the equator, the rainfall percentage at Kosrae rose to $111.8 \%$ of normal, and at Kapingamarangi, it ascended to $120.5 \%$. The latter location experienced a severe drought in 2010 that continued into 2011. While the January-February 2011 rainfall there was only $11.5 \%$ of normal, rains finally returned in March and continued to be above average thereafter.

For the most part throughout Micronesia, 2011 annual rainfall was wetter than normal. Figure 7.52 shows the annual rainfall amount and percent of normal for the major Micronesian islands. Of the major islands, annual rainfall amounts ranged from a high of $5229.4 \mathrm{~mm}$ at Koror, Palau, (139.4\% of normal) to a low of $2209.8 \mathrm{~mm}$ at Saipan in the CNMI (124.7\% of normal). In addition to Palau at the western edge of the area, Yap was also extremely wet with an annual rainfall of $4005.6 \mathrm{~mm}(130.4 \%)$. At the eastern edge of the area, Majuro was wet with $3668.0 \mathrm{~mm}$ (113.3\% of normal) and Kwajalein had $3023.1 \mathrm{~mm}$ (127.0\%). 
In the central FSM, Chuuk ended the year with $4161.8 \mathrm{~mm}$ (121.8\% of normal), Pohnpei had 5023.9 mm (109.1\%) and Kosrae finished with $4996.7 \mathrm{~mm}$ (101.8\% of normal). The north central island of Guam had $2933.0 \mathrm{~mm}$ (118.3\% of normal) for the year. Only Kapingmarangi ended the year with a slight deficit, measuring $3004.3 \mathrm{~mm}$ or $95.7 \%$ of normal.

\section{(iv) Notable events}

A severe drought occurred at the start of the year at Kapingamarangi. Because La Niña produced cooler-than-normal sea surface temperatures along the equator for several months beginning in the latter part of 2010, the atolls of Pohnpei State located at low latitude (e.g., Kapingamarangi at $1^{\circ} \mathrm{N}$ and Nukuoro at $4^{\circ} \mathrm{N}$ ) had reduced rainfall from July 2010 through early 2011. The low rainfall was most pronounced at Kapingamarangi where the rainfall during September 2010 through February 2011 was $180.9 \mathrm{~mm}$. This level of dryness (only $15 \%$ of normal rainfall during the six-month period) prompted the Weather Forecast Office (WFO) in Guam to issue some eight months of weekly drought advisories for Kapingamarangi. Much needed rainfall finally occurred at the atoll in March 2011, and continued for the remainder of the year. Damage to trees and crops occurred during the long dry spell.

Another notable weather anomaly was high annual precipitation at many islands in Micronesia. Annual rainfall totals in excess of $120 \%$ of normal were experienced at locations in the Republic of Palau, Yap State, Guam, Saipan in the CNMI, and in Chuuk State. The 2011 annual rainfall at the Koror (Palau) Weather Service Office set a new record high. The $5228.8 \mathrm{~mm}$ of rainfall was the highest annual total in a period of record at Koror that extends back to 1948 and also contains a period of climatic record-keeping by the Japanese that covers the years 1932-37. The previous record-high annual total at Koror occurred during 1974 when $4698.7 \mathrm{~mm}$ was observed. The 2011 annual rainfall total was even higher at the Palau International Airport where the $5474.2 \mathrm{~mm}$ was the second-highest 2011 annual total seen in all of Micronesia. It was exceeded only slightly by the 5493.0 $\mathrm{mm}$ recorded at Palikir on Pohnpei Island. The PIA has only a short record that begins in 2004, but it is usually wetter there than at the Koror weather office located only a few miles to the southwest. There were a few rainfall events that caused minor mudslides on the island nation's largest island, Babeldaob.
High sea levels that prevailed in late 2010 continued into 2011 as a result of strong trade winds that increased the easterly wind stress, causing water to mound up in the west of the basin. This caused warm water to mix downward, increasing the oceanic volume and causing sea levels to remain high during the first third of the year. After La Niña peaked in late 2010, sea levels in Micronesia reached their highest values of 2011 in January and February. Average heights ranged from around $+10 \mathrm{~cm}$ above normal at Kwajalein, Yap, Chuuk, and Guam to around $+20 \mathrm{~cm}$ above normal at Majuro, Pohnpei, and Palau. Extreme values ranged from $+50 \mathrm{~cm}$ at Guam to $+115 \mathrm{~cm}$ at Majuro and Palau. Sea levels began to fall in the boreal summer across Micronesia as La Niña waned and gave way to ENSO-neutral conditions. Sea level values almost made it to normal, but the reemergence of $\mathrm{La}$ Niña strengthened the trade winds, and once again, water began to mound up in the western Pacific.

\section{2) Australia-C. Ganter and S. Tobin \\ (i) Overview}

For Australia, back-to-back La Niña events gave a two-year rainfall total for the 2010-11 period of $1408 \mathrm{~mm}$, the wettest such period on record. This surpasses the previous Australian record of $1407 \mathrm{~mm}$, set under sustained La Niña conditions during 1973 and 1974 . The 2011 rainfall total was $51.6 \%$ above average $-705 \mathrm{~mm}$, Australia's second-wettest year since records commenced in 1900 (only 1974 was wetter, with $760 \mathrm{~mm}$ ). As in 2010, 2011 saw numerous significant flood events throughout the year, some resulting in the loss of life.

For the first time since 2001, Australia's annual mean temperature was below the 1961-90 average. With an anomaly of $-0.14^{\circ} \mathrm{C}, 2011$ ranks near the median of observations since 1910. Cooler annual temperatures in Australia are commonly associated with years of widespread, high rainfall. Such a pattern of positive rainfall anomalies across vast areas of continental Australia is typical of La Niña years.

Heavy rainfall at the start and end of the year, and unusual southerly flow in the first half of the year, suppressed maximum temperatures over much of the mainland. Despite 2011's cool anomaly, the 10-year average for 2002-11 was the equal-warmest 10-year period on record for Australia (both 2002-11 and 2001-10 recorded an anomaly of $+0.52^{\circ} \mathrm{C}$ ). 

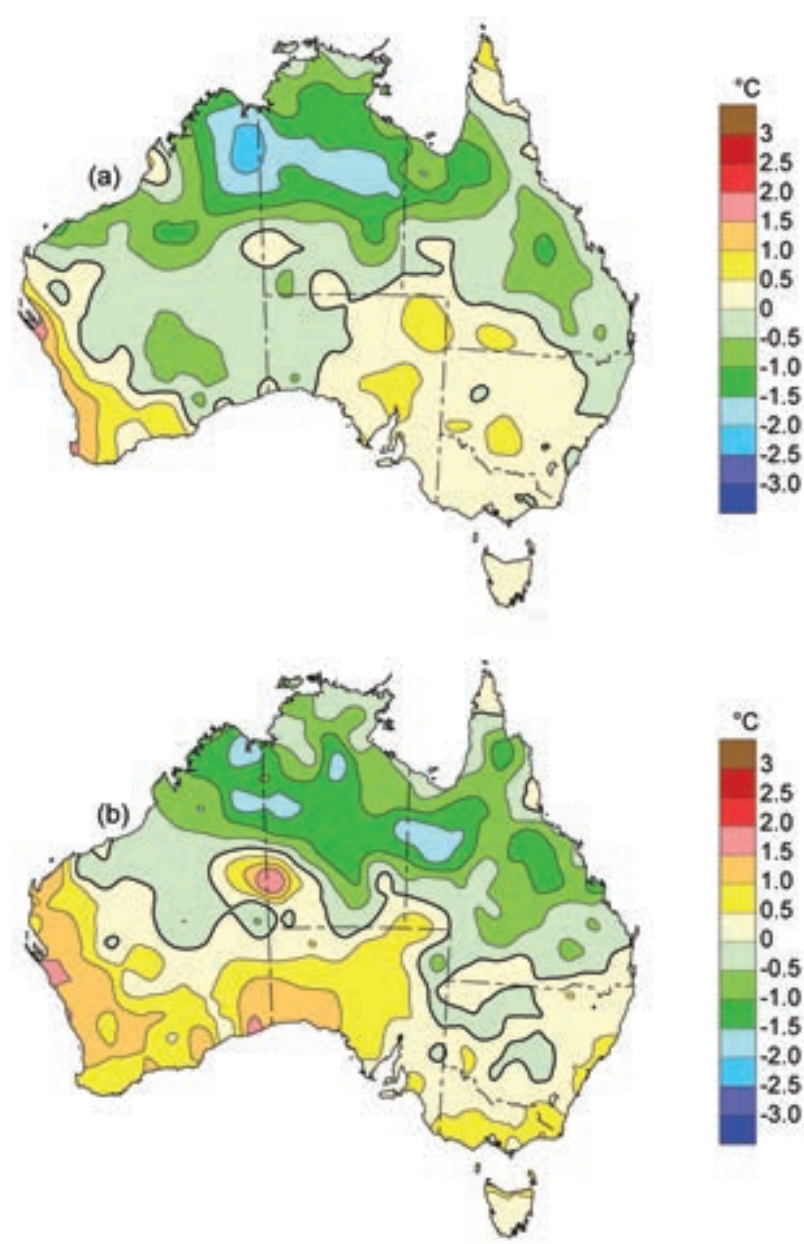

FIG. 7.53. (a) Australian mean annual maximum temperature anomalies ( ${ }^{\circ} \mathrm{C}$; 196I-90 base period) for $201 \mathrm{I}$; (b) Australian mean annual minimum temperature anomalies ( ${ }^{\circ} \mathrm{C}$; 1961-90 base period) for 2011 .

\section{(ii) Temperature}

Even though 2011 was cooler than average nationally, only northern Australia experienced belownormal annual temperatures (both maxima and minima), while across the south, temperatures were above average. Overnight warmth was especially notable in parts of southern Western Australia and South Australia where annual average minimum temperatures were the highest on record. Annual average maxima and mean were also the highest on record along the lower west coast of Western Australia by a large margin. For Australia overall, the maximum temperature anomaly was $-0.25^{\circ} \mathrm{C}$, with minima at $-0.03^{\circ} \mathrm{C}$ (Fig. 7.53 ).

January, July, and August temperatures were well above average for most of Australia, excluding the tropics. Despite being cool over much of Western Australia during February and March, both maxima and minima were highest on record for parts of the western coast in both months. Away from the eastern
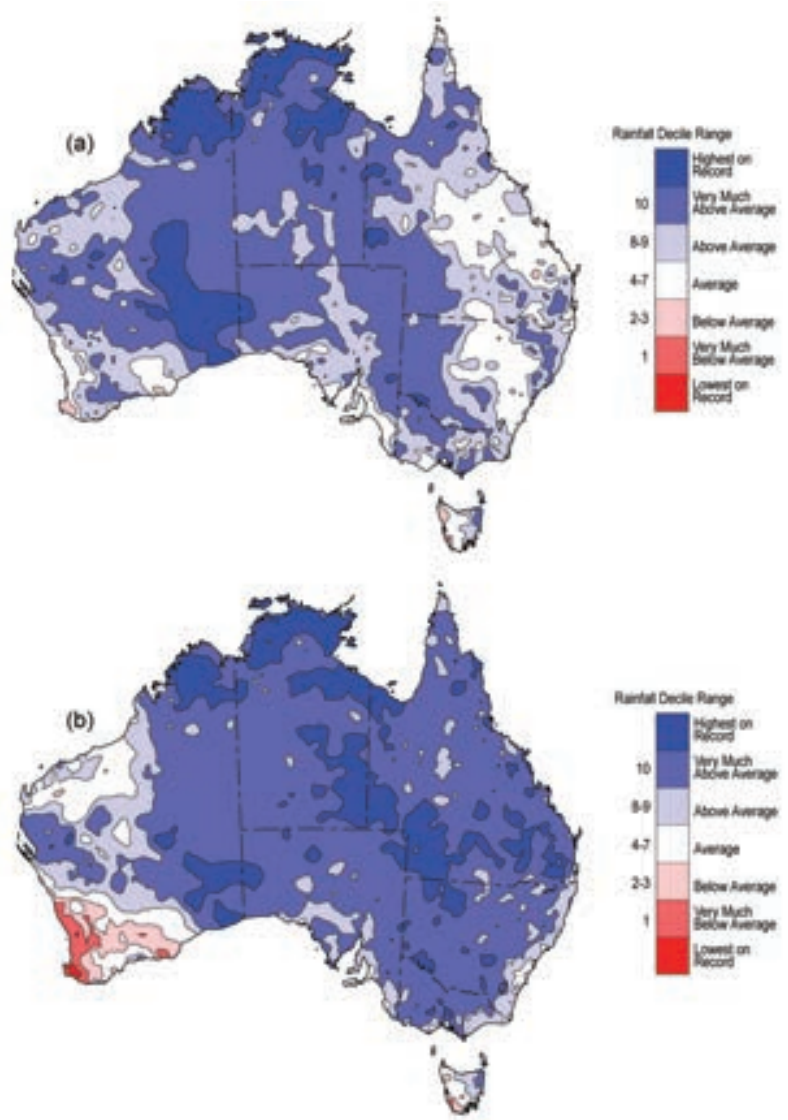

FIG. 7.54. (a) Australian annual rainfall deciles (since 1900) for 20II; (b) Australian annual rainfall deciles (since 1900) for the two-year period 2010-II.

and western coastal strips, March was cooler than average for most of the country, with record-low March maxima and mean temperatures recorded in some regions of northern and southern Australia. Temperatures were very much below average during April, May, and June over northern Australia. June minima were lowest on record (departures of $-4^{\circ} \mathrm{C}$ to $-6^{\circ} \mathrm{C}$ ) for a large area over northern Western Australia and the Northern Territory. July was warm through the southwest, and the most widespread positive anomalies occurred in August, with the majority of Australia south of the Tropic of Capricorn very much above average. For the remainder of the year, conditions were generally cooler than average over the tropics, but warmer than average over the more southern regions.

\section{(iii) Precipitation}

For the year as a whole, the majority of Australia received very-much-above-average rainfall (Fig. 7.54a). Large areas of record-high totals fell in the Kimberley, southeastern Western Australia, and across the north of the Northern Territory. It was the 
wettest year on record for Western Australia and the third wettest for the Northern Territory. Most of the record precipitation fell during the summer months (DJF), and was associated with the Australian monsoon and associated systems across southern parts of the continent. This is consistent with the influence of the 2010/11 La Niña, one of the strongest on record.

Above-average rainfall fell across most of the continent during the first four months of 2011, before the La Niña decayed in autumn (MAM). January brought record-breaking rainfall to the west of both New South Wales and Victoria, and for Victoria, summer was the wettest on record. Rainfall was also above average for much of Western Australia, northern Australia, southeast Queensland, and Tasmania. Very heavy rainfall continued in February and March, though missing the northeast and far southwest in February, and much of Western Australia and parts of the southeastern states in March. As the La Niña decayed, April saw very-much-above-average rainfall in the Kimberley and Top End.

Continuing a trend observed over the past decade, rainfall across southern parts of the continent was below average from May through September in most regions.

La Niña conditions redeveloped during austral spring, with a second, weaker event accompanied by a return to above-average national rainfall. Very warm conditions across the Indian Ocean to the west of the continent were also favorable for increased rainfall over western and southern parts of Australia. October rainfall was very much above average in the north and west, with large areas of highest-on-record totals in southern inland Western Australia. November rainfall was generally very much above average, except for east coast Queensland and December saw above-average rainfall for much of the east and south of Australia.

\section{(iv) Notable events}

In the 2010/11 season, four tropical cyclones made landfall in Australia; Tasha, Anthony, Yasi, and Carlos. All cyclones contributed to flooding, and Yasi and Carlos caused significant wind damage. Carlos contributed to several record-breaking rainfall totals and flooding around Darwin in the Northern Territory, while Yasi was one of the strongest tropical cyclones to hit Queensland in almost a century, causing $\$ 1.3$ billion (US dollars) in damage, according to the Insurance Council of Australia, Catastrophe Disaster Statistics (see http://www.insurancecouncil.com.au/ IndustryStatisticsData/CatastropheDisasterStatistics/
tabid/1572/Default.aspx ). One of the more notable aspects of the 2010/11 cyclone season was the number of tropical depressions. At least 29 systems developed into tropical depressions between November 2010 and April 2011 in the Australian region, the most in a season since at least the mid-1990s (see section 4d7 for more detail).

Exceptionally cool overnight minima were experienced during May and June over northern Australia. Darwin minimum temperatures dropped below $20^{\circ} \mathrm{C}$ every night during June for the first time on record. In total, Darwin had 47 consecutive nights below $20^{\circ} \mathrm{C}$, the fourth longest run in its record.

Between 9 and 11 July, damaging winds and waves were experienced along the west coast of Tasmania, a result of two strong cold fronts passing over the region. The wave-rider buoy at Cape Sorrell measured its highest wave on record, $18.68 \mathrm{~m}$ on the 11th, also the second highest wave ever recorded in the area.

During late January to early February, southern mainland Australia experienced a significant heatwave. Woomera, in South Australia, broke its highest daily temperature record, with $48.1^{\circ} \mathrm{C}$ on 25 January. Sydney experienced its longest hot spell in its 152 year record, with seven consecutive days above $30^{\circ} \mathrm{C}$ (31 January-6 February) and five nights above $24^{\circ} \mathrm{C}$ between 2 and 6 February. August brought unseasonable warmth, with Tasmania recording its warmest August on record. Western Australia's Pilbara region experienced a warm finish to the year. Between 20 and 22 December, numerous sites exceeded $45^{\circ} \mathrm{C}$, with Roebourne Airport recording $49.4^{\circ} \mathrm{C}$ on 21 December, the highest Western Australian December value (and second highest Australia-wide), and the highest temperature anywhere in Australia since 1998.

\section{(v) Significant statistics}

- Mean annual maximum temperature anomaly: $-0.25^{\circ} \mathrm{C}$

- Mean annual minimum temperature anomaly: $-0.03^{\circ} \mathrm{C}$

- Mean annual rainfall anomaly: $+52 \%$ (second highest since records began in 1900)

- Highest annual mean temperature: $28.4^{\circ} \mathrm{C}$, Coconut Island (Queensland)

- Lowest annual mean temperature: $4.2^{\circ} \mathrm{C}$, Thredbo (New South Wales)

- Highest annual total rainfall: $10078 \mathrm{~mm}, \mathrm{Bel}$ lenden Ker Top Station (Queensland) 


\section{SIDEBAR 7.4: AUSTRALIA'S WETTEST TWO-YEAR PERIOD-C. GANTER}

AND S. TOBIN

Australia experienced flooding and heavy rainfall across many regions during 2010 and $201 \mathrm{I}$, an effect of strong La Niña conditions. This exceptionally heavy rainfall resulted in the wettest two-year period on record, with $1408 \mathrm{~mm}$. This was the wettest of any 24-month period, nudging out the calendar years of 1973 and 1974 which had 1407 $\mathrm{mm}$. During 2010-II, most of Australia received rainfall in the highest decile (see Fig. 7.54b).

The spring and summer months from September 2010 to March 2011 were exceptionally wet, associated with a very active monsoon season. Individual months of note include September and December 2010, and March 20II, all record-wettest for their respective months, as well as October 2010 and February 20II, which were second wettest. February and March $201 \mathrm{I}$ recorded the fifth- and third-highest rainfall for any month, respectively.

From September 2010, flooding events were commonplace. Heavy rainfall at the start of $201 \mathrm{I}$ resulted in some of the most significant flooding, in terms of extent, impact, and severity, in Australia's recorded history.

One of the most significant flood events occurred in southeast Queensland and adjacent northern New South Wales. During the second week of January, severe river and flash flooding affected the Brisbane River catchment and Toowoomba/Lockyer Valley, resulting in Brisbane's second highest flood level in 100 years (after January 1974). Farther south, exceptional rain from complex and persistent low pressure systems caused flash flooding across western and central Victoria, and northern Tasmania. Parts of northeast and western New South Wales were also affected. Rainfall of $100 \mathrm{~mm}-300 \mathrm{~mm}$ occurred across much of northern Tasmania and large parts of Victoria.

Victorians were again subject to heavy rainfall and flooding in early February, from thunderstorms associated with ex-Tropical Cyclone Anthony.

March 20II, the wettest month for Australia since January 1984, brought extensive flooding to the eastern Kimberley region in Western Australia resulting from a monsoonal burst. In late March, storm cells brought further flooding to northeast Tasmania (some sites received five times their usual March rainfall), as well as the New South Wales southeast coast and the far east of Victoria.

The high rainfall brought abundant growth to the usually arid center of Australia during 20I0-II. In places, this growth was waist high, and estimates placed the vegetation at levels not seen since 1974. Fires are commonplace during the northern Australian dry season, as grasses dry and cure. The subsequent fire season (August-October) saw the most widespread grass and scrub fires since 1974-mostly the result of lightning strikes-occur over central and northern Australia. In September alone, an area larger than Tasmania (approximately I $500000 \mathrm{ha}$ ) was burnt around Alice Springs in central Australia.
- Highest temperature: $49.4^{\circ} \mathrm{C}$, Roebourne (Western Australia), 21 December-a new December state record

- Lowest temperature: $-16.0^{\circ} \mathrm{C}$, Charlotte Pass (New South Wales), 27 July

- Highest one-day rainfall: $477 \mathrm{~mm}$, Mornington Island (Queensland), 1 March

- Highest wind speed (measured): $206 \mathrm{~km}$ $\mathrm{hr}^{-1}$, Willis Island (Queensland), 2 February (Tropical Cyclone Yasi)

\section{3) New Zealand-G. M. Griffiths (i) Overview}

Annual mean sea-level pressures were much higher than usual well to the east of the North Island in 2011, producing more northeasterly winds than usual over northern and central New Zealand. This circulation anomaly over the New Zealand region is typical of La Niña. The large-scale climate setting was primarily driven by a moderate-to-strong La Niña event at the start of 2011, which eased to neutral in (austral) winter (JJA), but redeveloped to moderate levels during spring (SON). The anomalous northeasterly winds resulted in above-average annual temperatures and well-above-normal annual rainfall, for the northeast North Island and the north of the South Island.

The year 2011 will be remembered as one of extremes for New Zealand. Subtropical lows during January produced record-breaking rainfalls. New Zealand experienced exceptional heat during the first half of February. Winter arrived extremely late-May was the warmest on record, and June was third warmest. In contrast, two significant snowfall events in late July and mid-August affected large areas of New Zealand, with snow lying to unusually low elevations and extremely low air temperatures experienced. Lastly, torrential rainfall in the north of the South Island caused a State of Emergency to be declared on 14 December, following record-breaking rainfall, widespread flooding, and landslides. Takaka recorded $392 \mathrm{~mm}$ of rainfall in 24 hours during this event, the highest 1-day rainfall observed in New Zealand during 2011. 


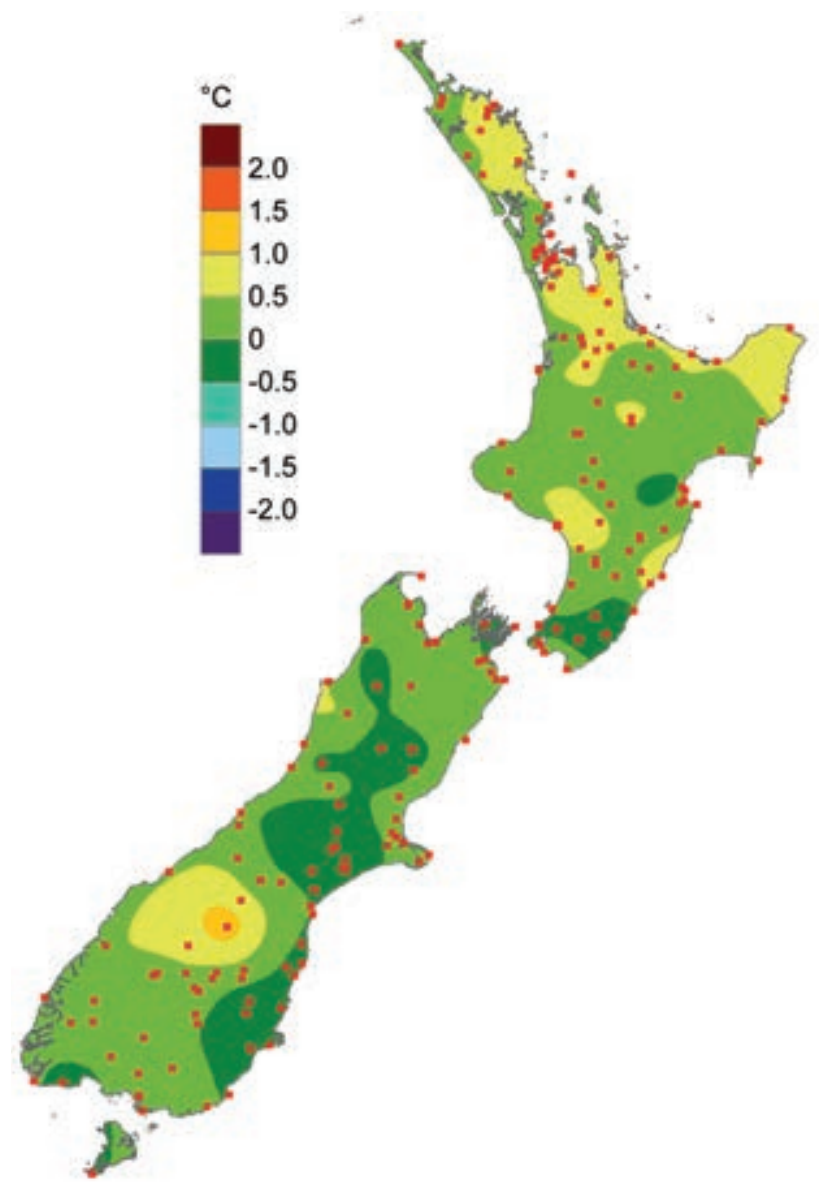

Fig. 7.55. Mean annual temperature anomalies $\left({ }^{\circ} \mathrm{C}\right)$ over New Zealand for 2011.

In the following discussion, the base period is 1971-2000 for all variables. The New Zealand national temperature is based upon a seven-station record (see http://www.niwa.co.nz/our-science/climate/ information-and-resources/nz-temp-record/sevenstation-series-temperature-data).

\section{(ii) Temperature}

Mean annual temperatures (Fig. 7.55) were above the long-term average $\left(+0.5^{\circ} \mathrm{C}\right.$ to $\left.+1.2^{\circ} \mathrm{C}\right)$ in the northeast of the North Island, and over the north of the South Island. Mean annual temperatures were generally near average (within $0.5^{\circ} \mathrm{C}$ of average) elsewhere. It was the warmest year on record at Kerikeri (Northland) and Te Puke (Bay of Plenty).

The nationwide average temperature for 2011 was $12.8^{\circ} \mathrm{C}, 0.3^{\circ} \mathrm{C}$ above the $1971-2000$ annual average, the 17th warmest on record, using NIWA's sevenstation temperature series which begins in 1909. It was notable for six warm months (January, February, May, June, October, and December) and three cold months (April, August, and September).
Record-breaking high temperatures (and humidity) were experienced over much of the North Island on 18 and 19 January, as tropical air was delivered to the country by ex-tropical cyclones Vania and Zelia. The entire country was affected by scorching temperatures between 2 and 7 February, as long-fetch northwest winds became slow-moving over New Zealand. Timaru recorded $41.3^{\circ} \mathrm{C}$ on 6 February, a new all-time record in the area since records began in 1885. Many sites recorded temperatures in excess of $30.0^{\circ} \mathrm{C}$ during 5 and 6 February. Unusually, the heat continued into April and May on occasion, with easterly winds contributing to temperatures of $28.4^{\circ} \mathrm{C}$ at Westport on 26 April, and a heat wave on the West Coast of the South Island and in Nelson on 1 May.

In contrast, the snowfall events 24-26 July and 15-16 August delivered exceptionally cold conditions to New Zealand, with numerous all-time low temperature records broken.

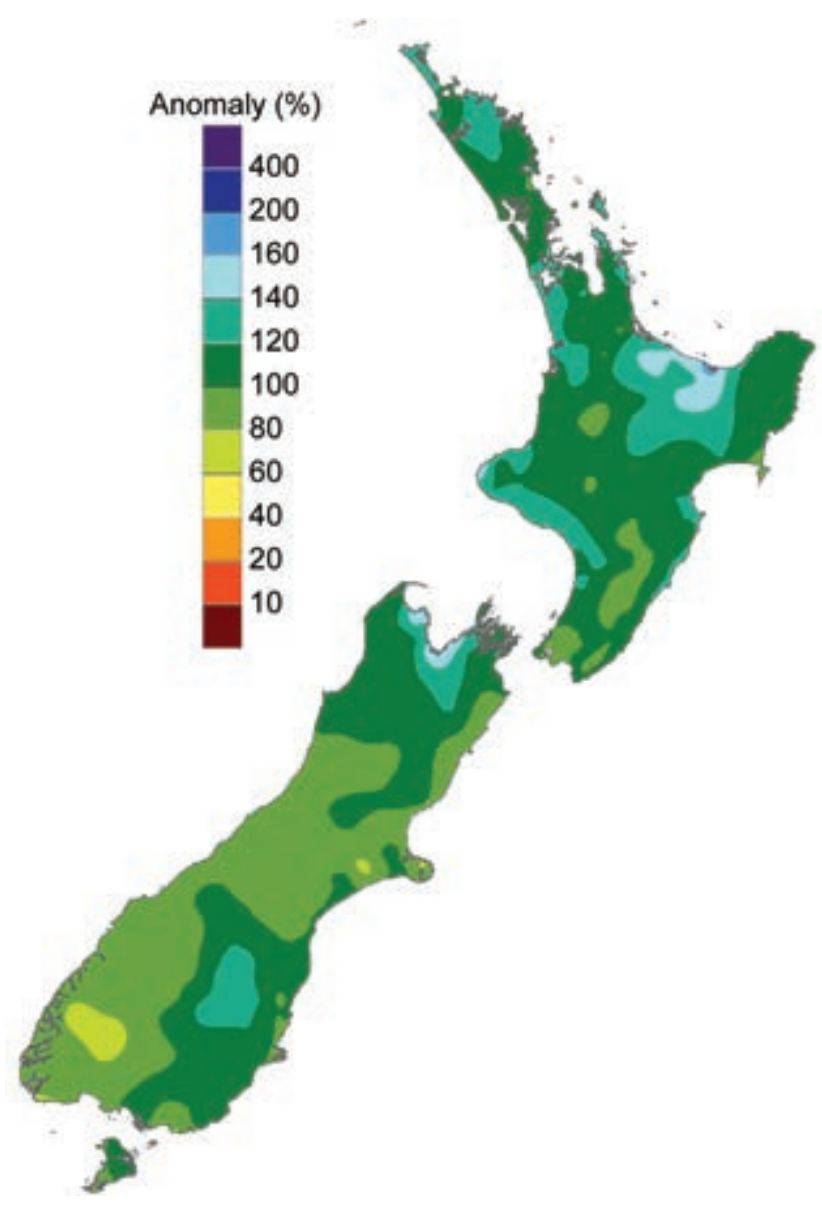

Fig. 7.56. Mean annual precipitation anomalies (\%) over New Zealand for 20II. 


\section{(iii) Precipitation}

In broad terms, six months of the year were wetter than normal and two were drier than normal (August and September). Four months were mixed, with large geographical differences between very wet regions and areas of extreme dryness. Annual rainfall totals for 2011 (Fig. 7.56) were above normal (more than $120 \%$ of normal) in parts of Northland, Auckland, Coromandel, Bay of Plenty, Nelson, and Central Otago, as well as around New Plymouth, Napier, Wanganui, and Palmerston North. In contrast, it was a relatively dry year (with annual rainfall totals $50-79 \%$ of normal) for the Kaikoura Coast and Canterbury, as well as much of Fiordland and Westland. Elsewhere, annual rainfall was in the near-normal range (80-119\% of normal).

The wettest place in 2011 was Cropp River, in the Hokitika River catchment (West Coast) which recorded an annual rainfall total of $9493 \mathrm{~mm}$. The driest of the available reporting locations was Clyde (Central Otago), which recorded $395 \mathrm{~mm}$ of rainfall in 2011.

Soil moisture deficits in 2011 were generally shortlived. At the beginning of 2011, significant soil moisture deficits of more than $110 \mathrm{~mm}$ affected parts of western Northland, Waikato, Bay of Plenty, Gisborne, Manawatu, and Wairarapa, as well as parts of Canterbury and Central Otago. However, the extremely wet January in all North Island regions fully recharged soil moisture levels, and rainfall in March and April replenished all remaining dry soils in the South Island. August and September were relatively dry, and by the end of November, significant soil moisture deficits were observed in regions north of Taupo, as well as Hawkes Bay, Gisborne, Marlborough, and central Otago. Above-normal rainfall totals in December throughout the North Island improved soil moisture levels there, but deficits had become extreme (more than $130 \mathrm{~mm}$ of deficit) in Central Otago and parts of Southland by the end of 2011 .

\section{(iv) Notable events}

Two significant snowfall events occurred in 2011. A polar blast during 24-26 July delivered a bitterly cold air mass over the country. Snowfall was heavy and reached low elevations over Canterbury, the Kaikoura Ranges, the Richmond, Tararua, and Rimutaka Ranges, the Central Plateau, and around Mt. Egmont. Brief dustings of snow were also reported in the ranges of Motueka and Northland. During the event, snow closed major roads, businesses, public transportation services, airports, and schools, and the weight of the snow on power lines caused outages.
During 14-17 August, a second polar outbreak brought heavy snow to unusually low elevations across eastern and alpine areas of the South Island, as well as to suburban Wellington. On 14 August, snow fell to very low elevations across much of the South Island, as well as in central Wellington and the hill suburbs. On 15 August, the southerly winds continued to deliver extremely cold air and snowfalls to the country, and airports and schools remained closed in Christchurch, Queenstown, Invercargill, and Dunedin. On the West Coast, snow fell in Rotomanu, Inchbonnie, Reefton, Greymouth, Blackball, and Ikamatua. Snow fell again to sea level in Wellington, closing schools and Wellington Airport. Both Rotorua and New Plymouth reported snow falling in the central city. Snow fell briefly in Auckland city but did not settle, and was also reported from the Waitakere Ranges, Drury, Waiuku, Clevedon, and the Bombay Hills. The snow reached Northland, with hillside properties around Dargaville reporting snow falling. Taupo Airport was also closed as heavy snow fell around the lake. In the Waikato, snow was seen in central Hamilton (the first time since August 1980), Te Kuiti, and briefly in Raglan. Snow settled in Wanganui, reportedly for the first time since 1974. Between 15 and 17 August, many eastern and alpine South Island roads, as well as lower North Island roads, were affected by snow or ice, and airports, hospitals, mail deliveries, and power lines were impacted in these regions.

On 14 December, heavy rain caused severe landslides and flooding in Nelson and Golden Bay. A State of Emergency was declared. Takaka recorded 392 $\mathrm{mm}$ of rainfall in 24 hours, a new record there, and the highest 1-day rainfall observed in New Zealand in 2011. In Nelson city, the Matai river walkway was closed by flooding, as were many urban and rural roads, isolating communities. More than 100 homes near rising rivers were evacuated. The Coastal Highway was closed at both Appleby Bridge and at Takaka Hill. The community of Collingwood was cut off after the road was washed away, and roads to Pakawau and Puponga were closed. A dam collapsed above Pohara Gully in Golden Bay, and on 15 December, schools in that region were closed after the extreme rainfall closed roads and damaged property. Many landslides threatened properties in the Nelson region, and more homes were evacuated. Many roads in Nelson, Waimea, and Golden Bay remained closed on 16 December, including between Takaka and Collingwood. 
(v) Significant statistics

- The highest recorded temperature was $41.3^{\circ} \mathrm{C}$, observed at Timaru on 6 February (a new alltime high temperature record there).

- The lowest recorded air temperature was $-10.2^{\circ} \mathrm{C}$, recorded at Manapouri on 26 July (a new all-time low temperature record there).

- Of the regularly reporting gauges, Cropp River in the Hokitika River catchment (West Coast) recorded the highest annual rainfall total, with $9493 \mathrm{~mm}$.

- The driest of the available reporting locations was Clyde (Central Otago), which recorded $395 \mathrm{~mm}$ of annual rainfall.

- Takaka experienced the highest 1-day rainfall (392 mm), recorded on 14 December (a new all-time daily rainfall record there).

- Nelson was the sunniest location in New Zealand, recording 2487 hours.

- The highest recorded wind gust was $189 \mathrm{~km}$ $\mathrm{hr}^{-1}$ at Cape Turnagain on 12 July. 


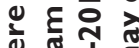

乐 $\frac{1}{\infty}$
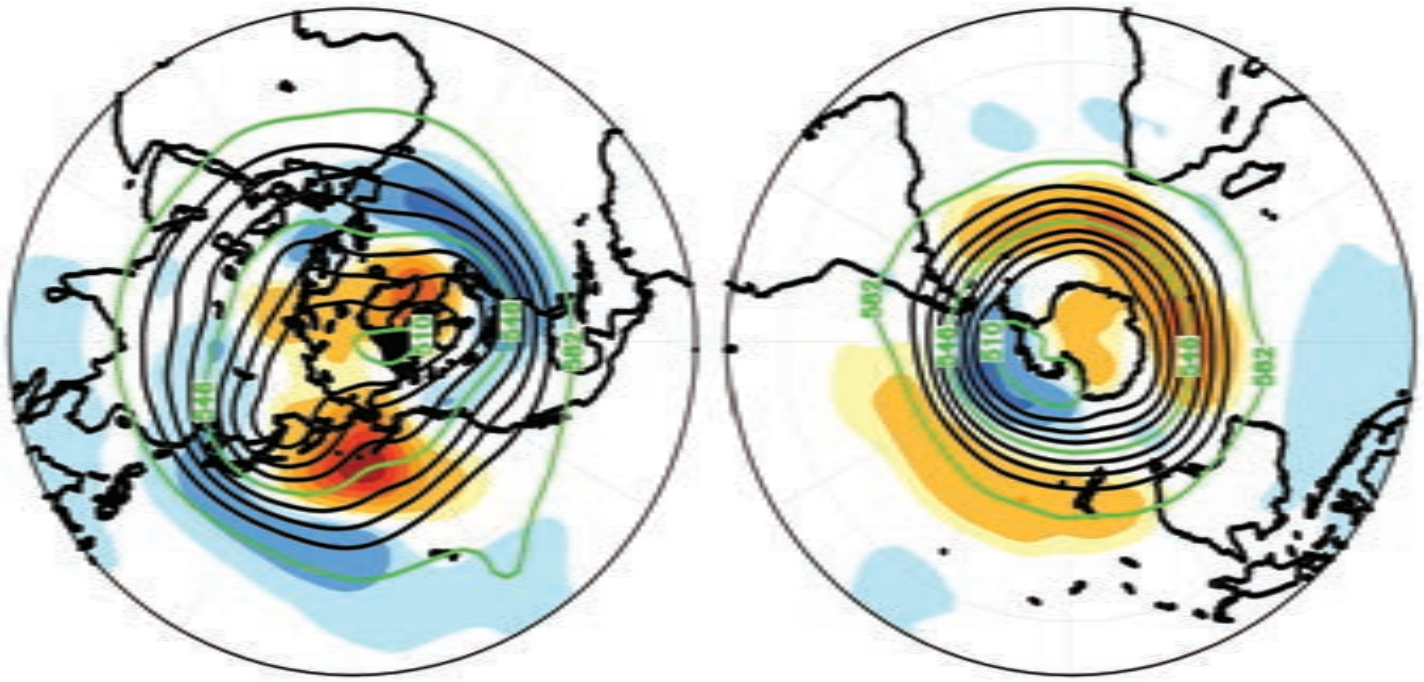

응

है⿴囗十

I

ร ㄷํㅇำ

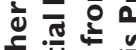

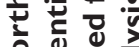

Z $\stackrel{0}{\circ} \cdot \frac{\pi}{\frac{\pi}{c}}$

ลํํㅇำ

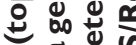

=

ํํㅇ.

ㅇํㅇํ요

ᄂ

응 듬

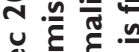

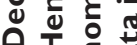

บิ

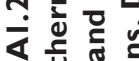

㲅

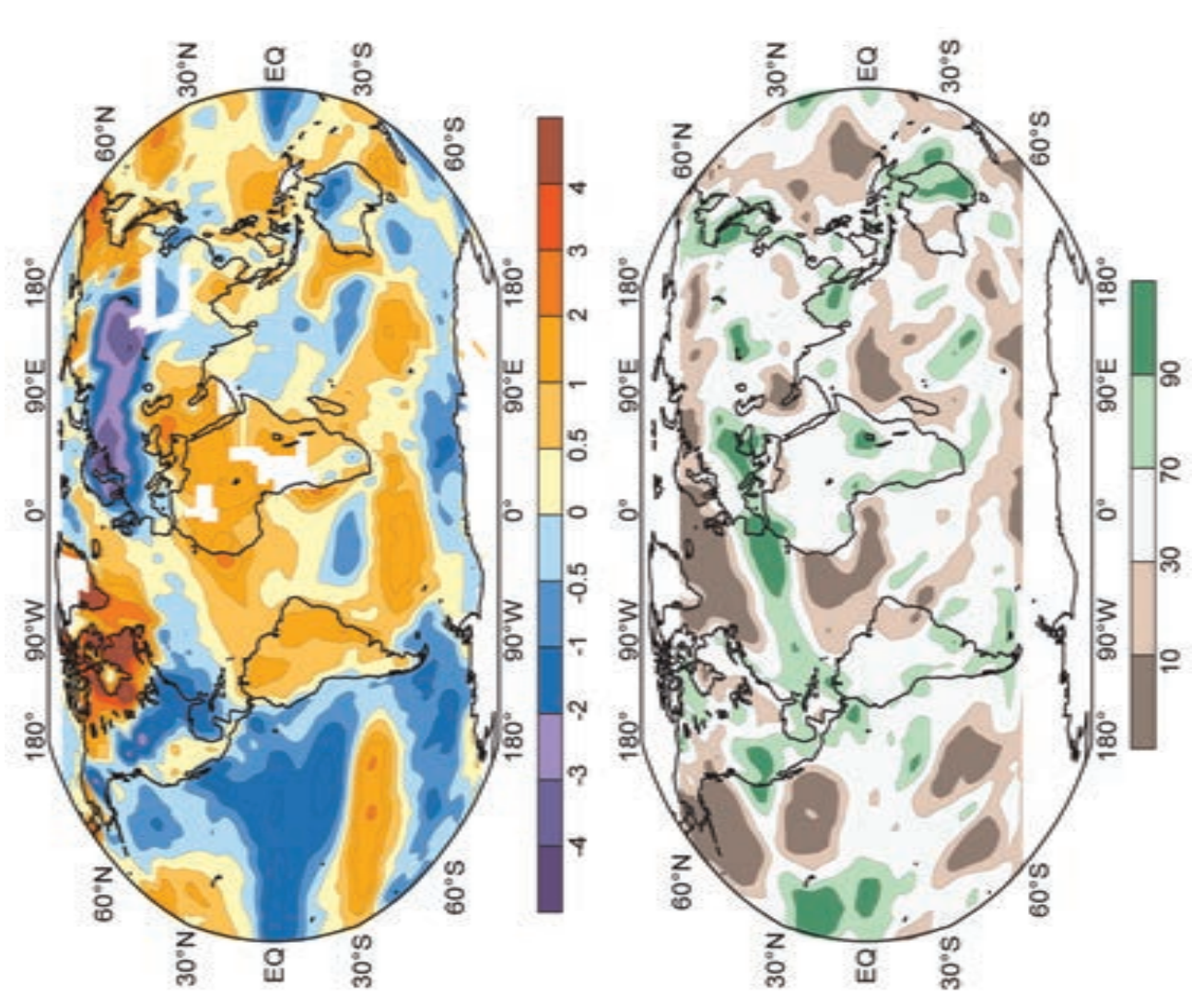

○ิ

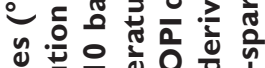

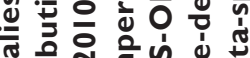

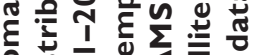

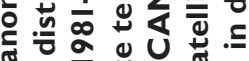

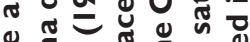

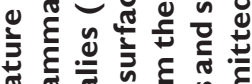

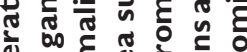

๘

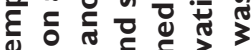

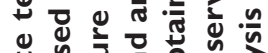

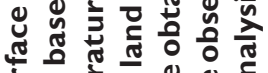

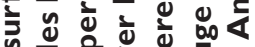

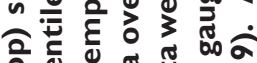

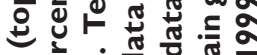

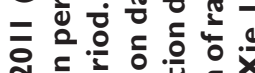

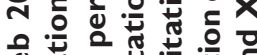

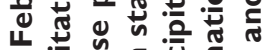

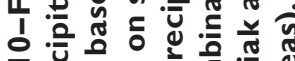

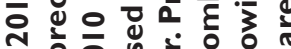

บั้

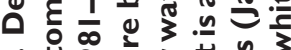

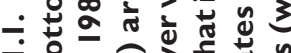

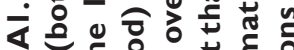

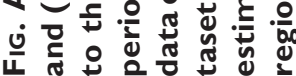



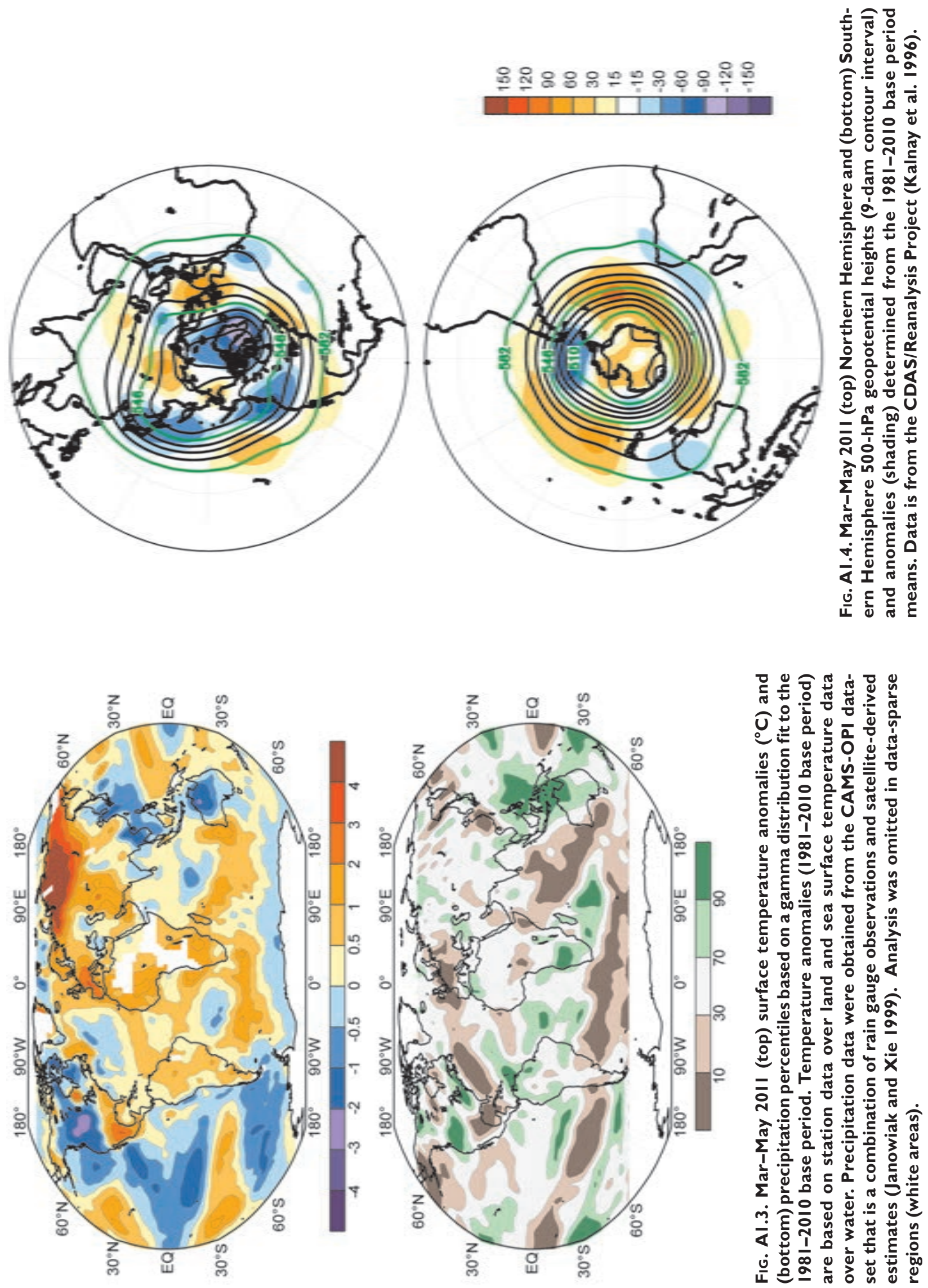

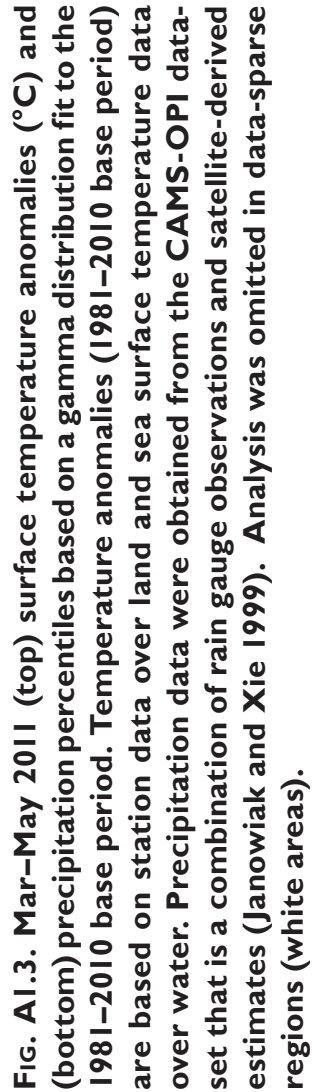




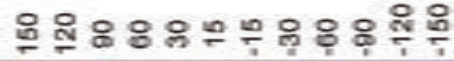
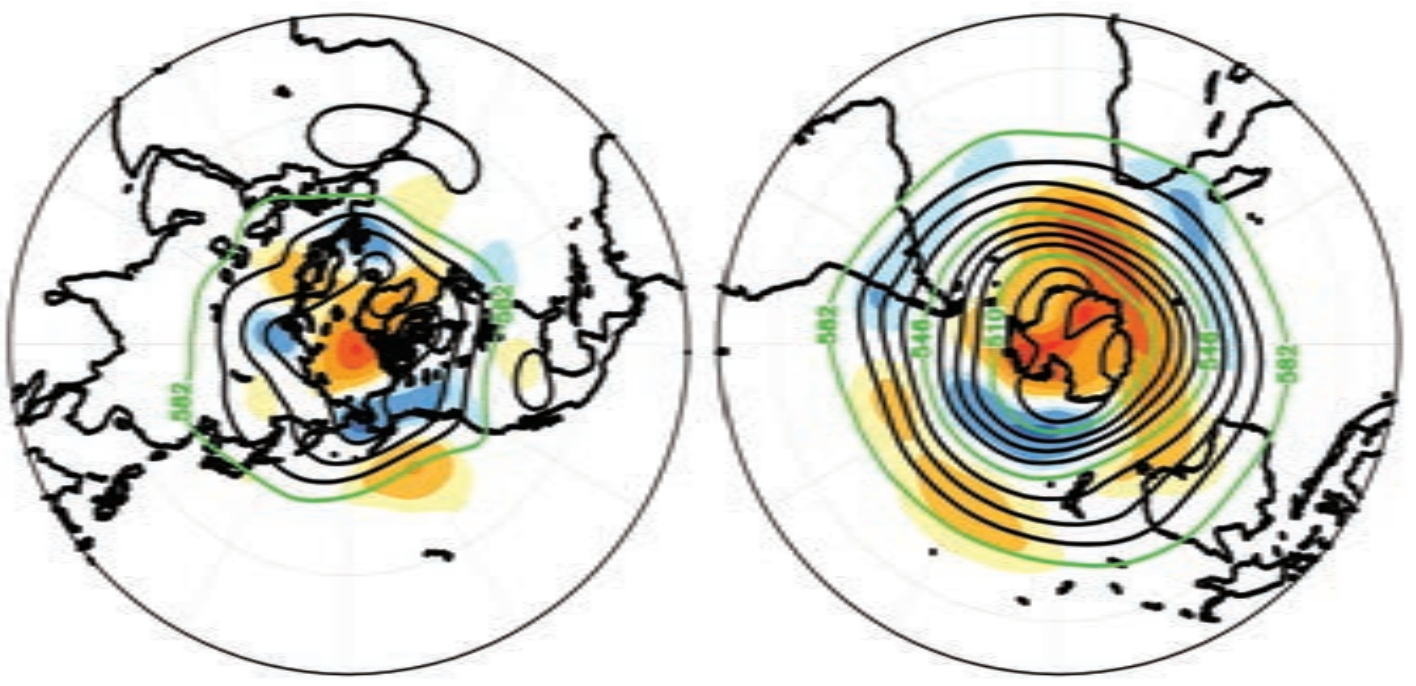

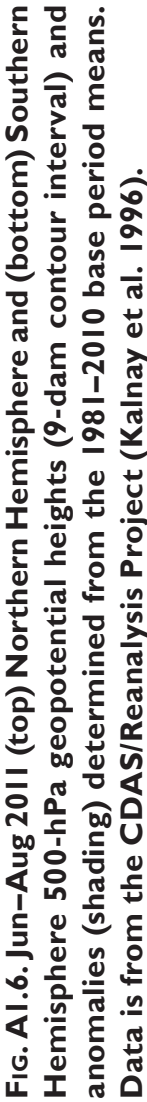
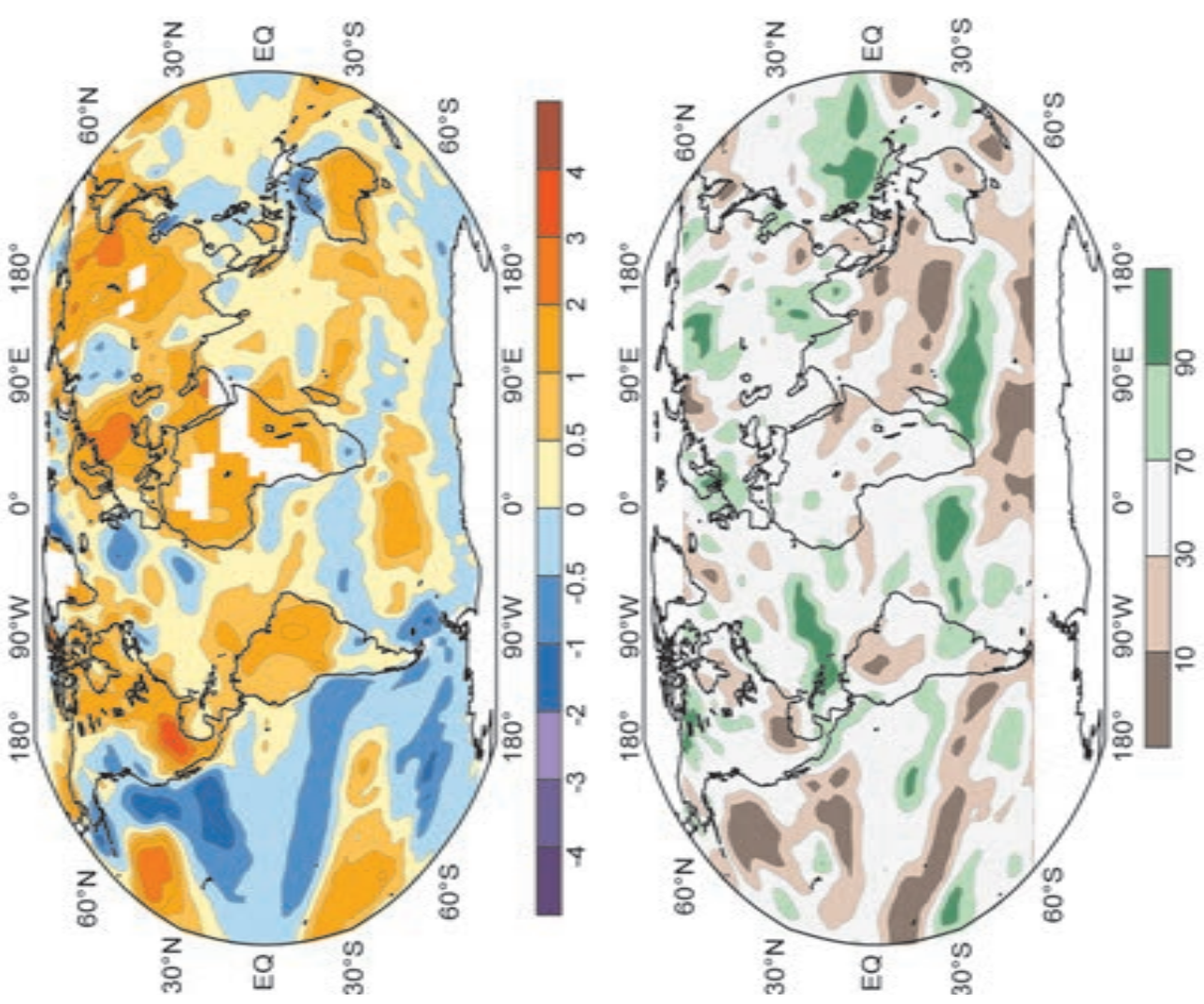

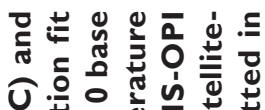

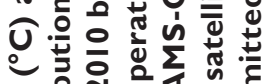
ติ

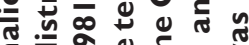

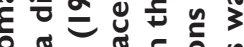

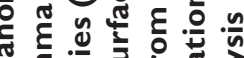

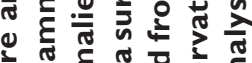

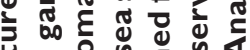

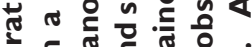
ฮั ฮ

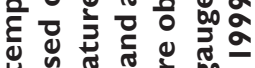
ه ฮ

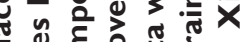

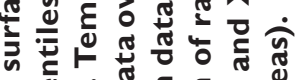

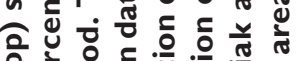

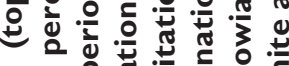

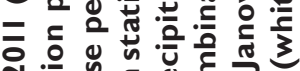
พั้

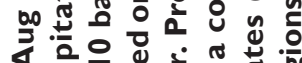

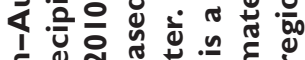

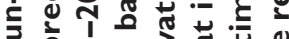

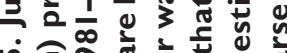

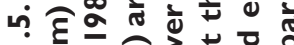

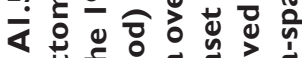

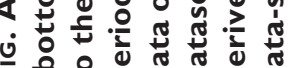
ำ 


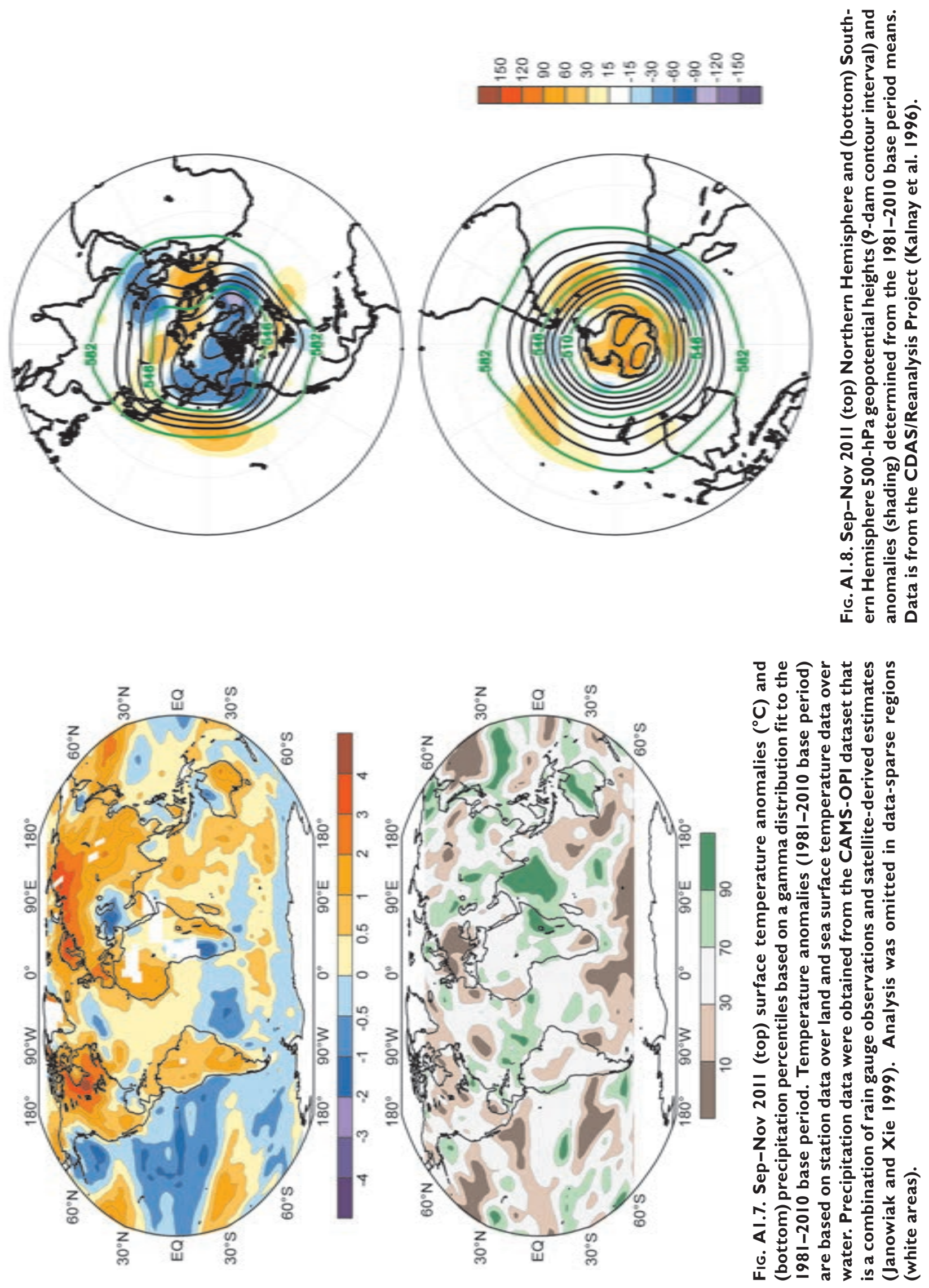


APPENDIX 2: RELEVANT DATASETS AND SOURCES

\begin{tabular}{|c|c|c|c|}
\hline $\begin{array}{l}\text { General Variable } \\
\text { or Phenomenon }\end{array}$ & $\begin{array}{c}\text { Specific Dataset } \\
\text { or Variable }\end{array}$ & Source & Section \\
\hline \multirow[t]{2}{*}{ Aerosols } & $\begin{array}{l}\text { AERONET data } \\
\text { (NASA) }\end{array}$ & http://aeronet.gsfc.nasa.gov/ & $2 g 2$ \\
\hline & Aerosol products & http://www.gmes-atmosphere.eu/data/ & $2 g 2$ \\
\hline Air-sea fluxes & $\begin{array}{l}\text { Woods Hole Oceano- } \\
\text { graphic Institute } \\
\text { (WHOI) OAFlux } \\
\text { Project }\end{array}$ & http://oaflux.whoi.edu & $3 d$ \\
\hline Albedo & MODIS & http://ladsweb.nascom.nasa.gov/ & $2 \mathrm{~h} 2,5 \mathrm{f}$ \\
\hline Biomass Burning & Biomass Burning & http://www.globalfiredata.org/ & $2 \mathrm{~h} 4$ \\
\hline \multirow{6}{*}{ Clouds, Cloudiness } & HIRS & No known public portal & $2 d 4$ \\
\hline & ISCCP D2 & http://isccp.giss.nasa.gov & $2 \mathrm{~d} 4$ \\
\hline & MISR & $\begin{array}{l}\text { http://eosweb.larc.nasa.gov/PRODOCS/misr/level3 } \\
\text { /overview.html }\end{array}$ & $2 \mathrm{~d} 4$ \\
\hline & MODIS Cloud Mask & http://ladsweb.nascom.nasa.gov/ & $2 \mathrm{~d} 4,5 \mathrm{~b}$ \\
\hline & PATMOS- $x$ & http://www.ncdc.noaa.gov/cdr/operationalcdrs.html & $2 \mathrm{~d} 4$ \\
\hline & SOBS & http://www.atmos.washington.edu/ ignatius/CloudMap & $2 \mathrm{~d} 4$ \\
\hline Evaporation & JRA-25 & http://jra.kishou.go.jp & $6 d$ \\
\hline FAPAR & FAPAR & http://fapar.jrc.ec.europa.eu/ & $2 \mathrm{~h} 3$ \\
\hline $\begin{array}{l}\text { Geopotential } \\
\text { Height }\end{array}$ & ERA-Interim & http://www.ecmwf.int/research/era & $6 b$ \\
\hline \multirow{2}{*}{$\begin{array}{l}\text { Glacier Mass or } \\
\text { Volume }\end{array}$} & Glacier Mass Balance & http://www.geo.uzh.ch/microsite/wgms/mbb/suml0.html & $5 e$ \\
\hline & GRACE & http://www.csr.utexas.edu/grace/ & $2 c 3$ \\
\hline \multirow{8}{*}{$\begin{array}{l}\text { Humidity, } \\
\text { [Near] Surface }\end{array}$} & $\begin{array}{l}\text { 20th Century } \\
\text { Reanalysis }\end{array}$ & http://www.esrl.noaa.gov/psd/data/20thC_Rean/ & $2 \mathrm{dl}$ \\
\hline & Dai & by email to adai@ucar.edu & $2 \mathrm{dl}$ \\
\hline & ERA-Interim & http://www.ecmwf.int/research/era & $2 \mathrm{dl}$ \\
\hline & HadCRUH & http://www.metoffice.gov.uk/hadobs/hadcruh & $2 \mathrm{dl}$ \\
\hline & $\begin{array}{l}\text { JRA-25 Atmospheric } \\
\text { Reanalysis }\end{array}$ & http://jra.kishou.go.jp/JRA-25/index_en.html & $2 \mathrm{dl}$ \\
\hline & MERRA & http://gmao.gsfc.nasa.gov/merra/ & $2 \mathrm{dl}$ \\
\hline & NCEP CFSR & http://cfs.ncep.noaa.gov & $2 \mathrm{dl}$ \\
\hline & NOCS 2.0 & http://www.noc.soton.ac.uk/noc_flux/noc2.php & $2 \mathrm{dl}$ \\
\hline Isotherm depth & $\begin{array}{l}\text { NCEP Global Ocean } \\
\text { Data Assimilation } \\
\text { System }\end{array}$ & http://www.cpc.ncep.noaa.gov/products/GODAS & $4 \mathrm{~h}$ \\
\hline Lake Ice & NOAA IMS, 4m Daily & http://nsidc.org/data/g02156.html & $5 \mathrm{~h}$ \\
\hline \multirow{3}{*}{ Lake Levels } & $\begin{array}{l}\text { Altimetric Lake level } \\
\text { Products, USDA }\end{array}$ & $\begin{array}{l}\text { http://www.pecad.fas.usda.gov/cropexplorer } \\
\text { /global_reservoir/index.cfm }\end{array}$ & $2 \mathrm{~d} 8$ \\
\hline & ESA & http://tethys.eaprs.cse.dmu.ac.uk/RiverLake/shared/main & $2 \mathrm{~d} 8$ \\
\hline & LEGOS & http://www.legos.obs-mip.fr/soa/hydrologie/hydroweb/ & $2 \mathrm{~d} 8$ \\
\hline \multirow[t]{2}{*}{ Lake Temperature } & ARCLAKE & $\begin{array}{l}\text { http://hdl.handle.net/I0283/88, http://www.geos.ed.ac.uk } \\
\text { /arclake/ }\end{array}$ & $2 \mathrm{~b} 4$ \\
\hline & IWBP & http://largelakes.jpl.nasa.gov & $2 b 4$ \\
\hline
\end{tabular}




\begin{tabular}{|c|c|c|c|}
\hline \multirow{5}{*}{$\begin{array}{l}\text { Modes of } \\
\text { Variability }\end{array}$} & $\begin{array}{l}\text { Arctic Oscillation } \\
\text { (AO) }\end{array}$ & $\begin{array}{l}\text { http://www.cpc.ncep.noaa.gov/products/precip/CWlink } \\
\text { /daily_ao_index/ao.shtml }\end{array}$ & $2 \mathrm{f3}$ \\
\hline & $\begin{array}{l}\text { Climate Prediction } \\
\text { Center: AAO, AO, } \\
\text { NAO, PNA }\end{array}$ & $\begin{array}{l}\text { http://www.cpc.ncep.noaa.gov/products/precip/CWlink } \\
\text { /daily_ao_index/teleconnections.shtml }\end{array}$ & $3 b, 6 a$ \\
\hline & Oceanic Nino Index & $\begin{array}{l}\text { http://www.cpc.ncep.noaa.gov/products/analysis_monitoring } \\
\text { /ensostuff/ensoyears.shtml }\end{array}$ & $4 a, 4 b$ \\
\hline & $\begin{array}{l}\text { Southern Annular } \\
\text { Mode Index }\end{array}$ & http://www.antarctica.ac.uk/met/gjma/sam.html & $\begin{array}{l}\text { 6a, 6b,6d, } \\
6 f, S B 6.1\end{array}$ \\
\hline & $\begin{array}{l}\text { Southern Oscillation } \\
\text { Index }\end{array}$ & http://www.cpc.ncep.noaa.gov/data/indices/ & $6 \mathrm{~b}, 6 \mathrm{~d}, 6 \mathrm{f}$ \\
\hline \multirow{5}{*}{ Ocean Carbon } & $\begin{array}{l}\text { AOML Monthly Flux } \\
\text { Anomalies }\end{array}$ & $\begin{array}{l}\text { http://cwcgom.aoml.noaa.gov/erddap/griddap } \\
\text { /aomlcarbonfluxes.graph }\end{array}$ & $3 \mathrm{jl}$ \\
\hline & $\begin{array}{l}\text { Hawaii Ocean } \\
\text { Time-series (HOT) }\end{array}$ & http://hahana.soest.hawaii.edu/hot/hot_jgofs.html & $3 \mathrm{j} 3$ \\
\hline & $\begin{array}{l}\text { Surface Ocean } \mathrm{CO}_{2} \\
\text { Atlas (SOCAT) Data } \\
\text { Access System }\end{array}$ & http://www.socat.info & $3 \mathrm{jl}$ \\
\hline & $\begin{array}{l}\text { The U.S. } \mathrm{CO}_{2} / \text { Repeat } \\
\text { Hydrography Program }\end{array}$ & http://ushydro.ucsd.edu & $3 \mathrm{j} 2$ \\
\hline & $\begin{array}{l}\text { Trends in } \\
\text { Atmospheric } \\
\text { Carbon Dioxide: } \\
\text { Mauna Loa, Hawaii }\end{array}$ & http://www.esrl.noaa.gov/gmd/ccgg/trends/ & $3 \mathrm{j} 3$ \\
\hline Ocean Circulation & $\begin{array}{l}\text { Atlantic Meridional } \\
\text { Overturning } \\
\text { Circulation }\end{array}$ & http://www.noc.soton.ac.uk/rapidmoc/ & $3 \mathrm{~h}$ \\
\hline \multirow{2}{*}{ Ocean Color } & $\begin{array}{l}\text { Level } 3 \text { MODIS Aqua } \\
\text { Ocean Color Data }\end{array}$ & http://oceancolor.gsfc.nasa.gov/ & SB5.3 \\
\hline & $\begin{array}{l}\text { Level } 3 \text { SeaWiFS } \\
\text { Ocean Color Data }\end{array}$ & http://oceancolor.gsfc.nasa.gov/ & SB5.3 \\
\hline \multirow{3}{*}{ Ocean Salinity } & $\begin{array}{l}\text { Global Ocean Heat } \\
\text { and Salt Content }\end{array}$ & http://www.nodc.noaa.gov/OC5/3M_HEAT_CONTENT/ & $3 f$ \\
\hline & $\begin{array}{l}\text { World Ocean Atlas } \\
2009\end{array}$ & http://www.nodc.noaa.gov/OC5/WOA09/pr_woa09.html & $3 f$ \\
\hline & $\begin{array}{l}\text { World Ocean } \\
\text { Database } 2009\end{array}$ & http://www.nodc.noaa.gov/OC5/WOD09/pr_wod09.html & $3 f$ \\
\hline $\begin{array}{l}\text { Ocean } \\
\text { Temperature }\end{array}$ & $\begin{array}{l}\text { World Ocean } \\
\text { Database } 2009\end{array}$ & http://www.nodc.noaa.gov/OC5/WOD09/pr_wod09.html & $3 c$ \\
\hline \multirow{2}{*}{$\begin{array}{l}\text { Outgoing } \\
\text { Longwave } \\
\text { Radiation }\end{array}$} & $\begin{array}{l}\text { CERES FLASHFlux } \\
\text { Project }\end{array}$ & http://flashflux.larc.nasa.gov & $3 d$ \\
\hline & $\begin{array}{l}\text { NOAA-interpolated } \\
\text { OLR }\end{array}$ & $\begin{array}{l}\text { http://www.esrl.noaa.gov/psd/data/gridded } \\
\text { /data.interp_OLR.html }\end{array}$ & $4 \mathrm{f} 2$ \\
\hline \multirow{5}{*}{ Permafrost } & Active Layer Thickness & http://www.udel.edu/Geography/calm/data/north.html & $5 g$ \\
\hline & $\begin{array}{l}\text { GTN-P, Alaskan } \\
\text { Repository }\end{array}$ & http://www.permafrostwatch.org & $2 \mathrm{cl}$ \\
\hline & $\begin{array}{l}\text { GTN-P, Norwegian } \\
\text { Repository }\end{array}$ & http://www.ngu.no/kart/permafrost & $2 \mathrm{cl}$ \\
\hline & $\begin{array}{l}\text { Permafrost } \\
\text { Temperature }\end{array}$ & http://permafrost.gi.alaska.edu/sites_map & $5 g$ \\
\hline & Permafrost Data & http://nsidc.org/data/g02190.html & $2 \mathrm{cl}$ \\
\hline
\end{tabular}




\begin{tabular}{|c|c|c|c|}
\hline \multirow[b]{2}{*}{$\begin{array}{l}\text { Phytoplankton, } \\
\text { Ocean Color }\end{array}$} & $\begin{array}{l}\text { MERIS 3rd Data } \\
\text { Reprocessing }\end{array}$ & $\begin{array}{l}\text { http://earth.eo.esa.int/pcs/envisat/meris/documentation } \\
\text { /meris_3rd_reproc/MERIS_3rd_Reprocessing_Changes.pdf }\end{array}$ & $3 \mathrm{j} 4$ \\
\hline & $\begin{array}{l}\text { Ocean Color } \\
\text { Documents: MODIS- } \\
\text { Aqua } \\
\text { Reprocessing } 2010.0 \\
\end{array}$ & $\begin{array}{l}\text { http://oceancolor.gsfc.nasa.gov/WIKI/OCReproc20I00MA. } \\
\text { html }\end{array}$ & $3 j 4$ \\
\hline \multirow{7}{*}{ Precipitation } & CMAP & $\begin{array}{l}\text { http://www.esrl.noaa.gov/psd/data/gridded } \\
\text { /data.ncep.reanalysis.html }\end{array}$ & $2 \mathrm{~d} 3$ \\
\hline & $\mathrm{GHCN}$ & $\begin{array}{l}\text { http://www.ncdc.noaa.gov/temp-and-precip } \\
\text { /ghcn-gridded-products.php }\end{array}$ & $2 \mathrm{~d} 3$ \\
\hline & $\begin{array}{l}\text { Global Precipitation } \\
\text { Climatology } \\
\text { Project (GPCP) }\end{array}$ & http://precip.gsfc.nasa.gov & $2 \mathrm{~d} 3,4 \mathrm{~h}$ \\
\hline & GPCC & http://www.gpcc.dwd.de/ & $2 \mathrm{~d} 3$ \\
\hline & $\begin{array}{l}\text { SSM/I, TMI, and } \\
\text { AMSR-E Data }\end{array}$ & http://www.remss.com & $2 \mathrm{~d} 3$ \\
\hline & TRMM 3AI2 & $\begin{array}{l}\text { http://disc.sci.gsfc.nasa.gov/precipitation/documentation } \\
\text { /TRMM_README/TRMM_3AI2_readme.shtml }\end{array}$ & $4 \mathrm{f} 2$ \\
\hline & TRMM 3B43 Rainfall & $\begin{array}{l}\text { http://disc.sci.gsfc.nasa.gov/precipitation/documentation } \\
\text { /TRMM_README/TRMM_3B43_readme.shtml }\end{array}$ & $4 \mathrm{fl}, 4 \mathrm{f} 2$ \\
\hline Precipitation (net) & $\begin{array}{l}\text { JRA-25 Atmospheric } \\
\text { Reanalysis }\end{array}$ & http://jra.kishou.go.jp/JRA-25/index_en.html & $6 d$ \\
\hline \multirow{6}{*}{$\begin{array}{l}\text { Pressure, Sea Level } \\
\text { or Near-Surface }\end{array}$} & ACCESS & http://www.bom.gov.au/nwp/access/NWPData.shtml & $6 f$ \\
\hline & $\begin{array}{l}\text { AMRC (Antarctic Me- } \\
\text { teorological Research } \\
\text { Center) AWS }\end{array}$ & http://amrc.ssec.wisc.edu/data/ & $6 c, S B 6.1$ \\
\hline & ERA-Interim & http://www.ecmwf.int/research/era & $6 a, 6 b, 6 c$ \\
\hline & HadSLP2r & http://www.metoffice.gov.uk/hadobs & $2 \mathrm{el}$ \\
\hline & $\begin{array}{l}\text { JRA-25 Atmospheric } \\
\text { Reanalysis }\end{array}$ & http://jra.kishou.go.jp/JRA-25/index_en.html & $6 d$ \\
\hline & READER & http://www.antarctica.ac.uk/met/READER/ & $6 c$ \\
\hline \multirow{3}{*}{ River Discharge } & $\begin{array}{l}\text { Arctic-RIMSI River } \\
\text { Discharge }\end{array}$ & http://rims.unh.edu & $2 \mathrm{~d} 5$ \\
\hline & $\begin{array}{l}\text { Dartmouth Flood } \\
\text { Observatory }\end{array}$ & http://floodobservatory.colorado.edu & $2 \mathrm{~d} 5$ \\
\hline & River Discharge & http://waterdata.usgs.gov/nwis - USGS2 & $2 \mathrm{~d} 5$ \\
\hline \multirow{2}{*}{$\begin{array}{c}\text { Sea Ice } \\
\text { Concentration }\end{array}$} & $\begin{array}{l}\text { Nimbus-7 SMMR and } \\
\text { DMSP SSM/I }\end{array}$ & http://nsidc.org/data/nsidc-005I.html & $5 \mathrm{~b}, \mathrm{SB} 5.2$ \\
\hline & $\begin{array}{l}\text { Nimbus-7 SMMR and } \\
\text { DMSP SSM/I } \\
\text { (Bootstrap) }\end{array}$ & $\begin{array}{l}\text { http://nsidc.org/data/docs/daac/nsidc0079_bootstrap_seaice } \\
\text {.gd.html }\end{array}$ & $6 f$ \\
\hline Sea Ice Duration & $\begin{array}{l}\text { Near-Real-Time DMSP } \\
\text { SSM/I-SSMIS Daily } \\
\text { Polar Gridded }\end{array}$ & http://nsidc.org/data/nsidc-008I.html & $6 f$ \\
\hline \multirow[t]{2}{*}{ Sea Ice Extent } & $\begin{array}{l}\text { Nimbus-7 SMMR and } \\
\text { DMSP SSM/I } \\
\text { (Bootstrap) } \\
\end{array}$ & $\begin{array}{l}\text { http://nsidc.org/data/docs/daac } \\
\text { /nsidc0079_bootstrap_seaice.gd.html }\end{array}$ & $6 f$ \\
\hline & NOAA IMS, 4km Daily & http://nsidc.org/data/g02I56.html & $5 i$ \\
\hline Sea Ice Index & $\begin{array}{l}\text { Sea Ice Concentration } \\
\text { from DMSP SSM/I-SS- } \\
\text { MIS Passive Microwave } \\
\text { Data }\end{array}$ & http://nsidc.org/data/seaice_index/archives/index.html & $5 i$ \\
\hline
\end{tabular}




\begin{tabular}{|c|c|c|c|}
\hline \multirow{3}{*}{ Sea Level } & Arctic Sea Level & http://www.whoi.edu/science/PO/arcticsealevel/data.html & $5 j$ \\
\hline & $\begin{array}{l}\text { Ssalto/Duacs } \\
\text { Multimission } \\
\text { Altimeter Products }\end{array}$ & $\begin{array}{l}\text { http://www.aviso.oceanobs.com/en/data } \\
\text { /product-information/duacs/index.html }\end{array}$ & $3 g$ \\
\hline & $\begin{array}{l}\text { University of Hawaii } \\
\text { Sea Level Center }\end{array}$ & http://uhslc.soest.hawaii.edu/ & $3 i$ \\
\hline \multirow{2}{*}{$\begin{array}{l}\text { Sea Surface } \\
\text { Salinity }\end{array}$} & Aquarius & http://aquarius.nasa.gov & SB3.I \\
\hline & $\begin{array}{l}\text { World Ocean Atlas } \\
2009\end{array}$ & http://www.nodc.noaa.gov/OC5/WOA09/pr_woa09.html & $3 e$ \\
\hline \multirow{4}{*}{$\begin{array}{l}\text { Sea Surface } \\
\text { Temperature }\end{array}$} & $\begin{array}{l}\text { Climate Prediction } \\
\text { Center's Monthly } \\
\text { Ocean Briefing }\end{array}$ & http://www.cpc.ncep.noaa.gov/products/GODAS & $3 b$ \\
\hline & ERSST-v3b & $\begin{array}{l}\text { http://www.esrl.noaa.gov/psd/data/gridded/data.noaa.ersst. } \\
\text { html }\end{array}$ & $4 \mathrm{bl}, 4 \mathrm{~d}, 4 \mathrm{~g}$ \\
\hline & HadSST2 & http://www.metoffice.gov.uk/hadobs/hadsst2 & $2 \mathrm{bl}$ \\
\hline & $\begin{array}{l}\text { NOAA Optimum } \\
\text { Interpolation SST } \\
\text { (OISST) v2 }\end{array}$ & $\begin{array}{l}\text { http://www.esrl.noaa.gov/psd/data/gridded } \\
\text { /data.ncep.oisst.v2.html }\end{array}$ & $\begin{array}{l}4 f 2,4 h, \\
5 j 2,6 f\end{array}$ \\
\hline \multirow[t]{2}{*}{ Snow Cover } & $\begin{array}{l}\text { Snow Cover Extent } \\
\text { and Duration }\end{array}$ & http://climate.rutgers.edu/snowcover/ & $2 c 2,5 d$ \\
\hline & SSM/I & http://www.nsidc.org & $6 e$ \\
\hline Snow Depth & $\begin{array}{l}\text { Canadian } \\
\text { Meteorological Centre } \\
\text { Daily } \\
\text { Gridded }\end{array}$ & $\begin{array}{l}\text { http://nsidc.org/data/docs/daac/nsidc0447_CMC_snow_ } \\
\text { depth/index.html }\end{array}$ & $5 d$ \\
\hline \multirow{2}{*}{$\begin{array}{l}\text { Snow Water } \\
\text { Equivalent }\end{array}$} & $\begin{array}{l}\text { ERA-interim } \\
\text { Atmospheric Reanaly- } \\
\text { sis }\end{array}$ & http://www.ecmwf.int/research/era & $5 d$ \\
\hline & $\begin{array}{l}\text { GlobSnow N. } \\
\text { Hemisphere Snow } \\
\text { Water Equivalent }\end{array}$ & http://www.globsnow.info/ & $5 d$ \\
\hline Soil Moisture & GRACE & http://www.esa-soimoisture-cci.org/ & $2 d 6$ \\
\hline Solar Transmission & $\begin{array}{l}\text { Mauna Loa Solar } \\
\text { Transmission }\end{array}$ & http://www.esrl.noaa.gov/gmd/grad/mloapt.html & SB2.3 \\
\hline \multirow{8}{*}{$\begin{array}{l}\text { Stratospheric } \\
\text { Ozone }\end{array}$} & $\begin{array}{l}\text { Calipso (Polar } \\
\text { Stratospheric Clouds) }\end{array}$ & $\begin{array}{l}\text { http://eosweb.larc.nasa.gov/PRODOCS/calipso } \\
\text { /table_calipso.html }\end{array}$ & $6 g$ \\
\hline & $\begin{array}{l}\text { GOME/SCIAMACHY/ } \\
\text { GOME2 Total Ozone } \\
\text { Datasets, GSG Merged } \\
\text { Data }\end{array}$ & http://www.iup.uni-bremen.de/gome/wfdoas & $2 g 3,6 g$ \\
\hline & KNMI OMI & http://ozoneaq.gsfc.nasa.gov & $6 \mathrm{~g}$ \\
\hline & $\begin{array}{l}\text { Multi Sensor } \\
\text { Reanalysis (MSR) of } \\
\text { Total Ozone }\end{array}$ & http://www.temis.nl/protocols/O3global.html & $2 g^{3}$ \\
\hline & $\begin{array}{l}\text { NASA Aura Micro- } \\
\text { wave Limb Sounder }\end{array}$ & http://aura.gsfc.nasa.gov/instruments/mls.html & $6 g$ \\
\hline & $\begin{array}{l}\text { OMI Total Ozone } \\
\left(\mathrm{OMTO}_{3}\right)\end{array}$ & $\begin{array}{l}\text { http://mirador.gsfc.nasa.gov/cgi-bin/mirador } \\
\text { /presentNavigation.pl?tree=project\&project=OMI }\end{array}$ & $2 g^{3}$ \\
\hline & Ozonesonde & http://www.esrl.noaa.gov/gmd/dv/spo_oz/ & $6 \mathrm{~g}$ \\
\hline & $\begin{array}{l}\text { WOUDC } \\
\text { Ground-based Ozone }\end{array}$ & ftp://ftp.tor.ec.gc.ca/Projects-Campaigns/ ZonalMeans/ & $2 g^{3}$ \\
\hline
\end{tabular}




\begin{tabular}{|c|c|c|c|}
\hline \multirow{3}{*}{$\begin{array}{l}\text { Stratospheric } \\
\text { Water Vapor }\end{array}$} & $\begin{array}{l}\text { Boulder Water Vapor } \\
\text { Balloon Data }\end{array}$ & ftp://ftp.cmdl.noaa.gov/ozwv/water_vapor/Boulder_New/ & $2 f 4$ \\
\hline & HALOE Data & http://haloe.gats-inc.com/home/index.php & $2 f 4$ \\
\hline & MLS Data & $\begin{array}{l}\text { http://disc.sci.gsfc.nasa.gov/Aura/data-holdings/MLS/index. } \\
\text { shtml }\end{array}$ & $2 f 4$ \\
\hline \multirow{8}{*}{ Surface Current } & $\begin{array}{l}\text { Long Term Time } \\
\text { Series of Surface Cur- } \\
\text { rents }\end{array}$ & http://www.aoml.noaa.gov/phod/altimetry/cvar & $3 g$ \\
\hline & $\begin{array}{l}\text { Long Term Time } \\
\text { Series of Surface } \\
\text { Currents: Agulhas } \\
\text { Current }\end{array}$ & $\begin{array}{l}\text { http://www.aoml.noaa.gov/phod/altimetry/cvar/agu/index. } \\
\text { php }\end{array}$ & $3 g 2$ \\
\hline & $\begin{array}{l}\text { Long Term Time } \\
\text { Series of Surface Cur- } \\
\text { rents: Brazil-Malvina } \\
\text { Region }\end{array}$ & $\begin{array}{l}\text { http://www.aoml.noaa.gov/phod/altimetry/cvar/mal/BM_ } \\
\text { ts.php }\end{array}$ & $3 g 3$ \\
\hline & $\begin{array}{l}\text { Ocean Surface } \\
\text { Current Analysis - } \\
\text { Real time (OSCAR) }\end{array}$ & http://www.oscar.noaa.gov/ & $3 g$ \\
\hline & $\begin{array}{l}\text { PO.DAAC Physical } \\
\text { Oceanography Distrib- } \\
\text { uted Active Archive } \\
\text { Center }\end{array}$ & http://podaac.jpl.nasa.gov/ & $3 g$ \\
\hline & $\begin{array}{l}\text { Ssalto/Duacs } \\
\text { Multimission } \\
\text { Altimeter Products }\end{array}$ & $\begin{array}{l}\text { http://www.aviso.oceanobs.com/en/data/product-informa- } \\
\text { tion/duacs/index.html }\end{array}$ & $3 i$ \\
\hline & $\begin{array}{l}\text { The Global Drifter } \\
\text { Program, Satellite- } \\
\text { tracked Surface Drift- } \\
\text { ing Buoys }\end{array}$ & http://www.aoml.noaa.gov/phod/dac/gdp.html & $3 g$ \\
\hline & $\begin{array}{l}\text { Tropical Atmosphere } \\
\text { Ocean Project }\end{array}$ & http://www.pmel.noaa.gov/tao/ & $3 g$ \\
\hline \multirow{14}{*}{$\begin{array}{c}\text { Temperature, } \\
\text { [Near] } \\
\text { Surface }\end{array}$} & $\begin{array}{l}\text { AMRC (Antarctic Me- } \\
\text { teorological Research } \\
\text { Center) AWS }\end{array}$ & http://amrc.ssec.wisc.edu/data/ & 6c,SB6.I \\
\hline & $\begin{array}{l}\text { Berkeley Land } \\
\text { Temperature }\end{array}$ & http://berkeleyearth.org/analysis/ & $2 \mathrm{bl}$ \\
\hline & CRUTEM3 & http://www.metoffice.gov.uk/hadobs/crutem3 & $2 b l, 5 b$ \\
\hline & CRUTEM4 & http://www.metoffice.gov.uk/hadobs/crutem4 & $2 \mathrm{bl}$ \\
\hline & ERA-Interim & http://www.ecmwf.int/research/era & $6 \mathrm{a}, 6 \mathrm{~b}, 6 \mathrm{c}$ \\
\hline & $\begin{array}{l}\text { HadCRUT3 Global } \\
\text { Temperature }\end{array}$ & http://www.metoffice.gov.uk/hadobs/hadcrut3 & $2 \mathrm{bl}$ \\
\hline & $\begin{array}{l}\text { JMA Global } \\
\text { Temperature }\end{array}$ & $\begin{array}{l}\text { http://ds.data.jma.go.jp/tcc/tcc/products/gwp/temp/map } \\
\text { /download.html }\end{array}$ & $2 \mathrm{bl}$ \\
\hline & $\begin{array}{l}\text { JRA-25 Atmospheric } \\
\text { Reanalysis }\end{array}$ & http://jra.kishou.go.jp/JRA-25/index_en.html & $2 \mathrm{bl}$ \\
\hline & MERRA & http://gmao.gsfc.nasa.gov/merra/ & $2 \mathrm{bl}, 6 \mathrm{~g}$ \\
\hline & $\begin{array}{l}\text { NASA/GISS Global } \\
\text { Temperature }\end{array}$ & http://data.giss.nasa.gov/gistemp/ & $2 \mathrm{bl}$ \\
\hline & $\begin{array}{l}\text { NCEP/NCAR } \\
\text { Reanalysis }\end{array}$ & $\begin{array}{l}\text { http://www.esrl.noaa.gov/psd/data/gridded/data.ncep } \\
\text {.reanalysis.html }\end{array}$ & $5 b$ \\
\hline & NCEP-CFSR & http://cfs.ncep.noaa.gov & $2 \mathrm{bl}$ \\
\hline & $\begin{array}{l}\text { NOAA/NCDC Global } \\
\text { Temperature }\end{array}$ & http://www.ncdc.noaa.gov/cmb-faq/anomalies.html & $2 \mathrm{bl}$ \\
\hline & READER & http://www.antarctica.ac.uk/met/READER/ & 6c, SB6.I \\
\hline
\end{tabular}




\begin{tabular}{|c|c|c|c|}
\hline \multirow{10}{*}{$\begin{array}{c}\text { Temperature, } \\
\text { Upper } \\
\text { Atmosphere }\end{array}$} & $\begin{array}{l}\text { 20th Century } \\
\text { Reanalysis }\end{array}$ & http://www.esrl.noaa.gov/psd/data/20thC_Rean/ & $2 b 2$ \\
\hline & ERA-Interim & http://www.ecmwf.int/research/era & $\begin{array}{l}2 \mathrm{~b} 2,2 \mathrm{~b} 3, \\
6 \mathrm{~b}\end{array}$ \\
\hline & HadAT2 & http://www.metoffice.gov.uk/hadobs & $2 b 2,2 b 3$ \\
\hline & $\begin{array}{l}\text { JRA-25 Atmospheric } \\
\text { Reanalysis }\end{array}$ & http://jra.kishou.go.jp/JRA-25/index_en.html & $2 b 2$ \\
\hline & MERRA & http://gmao.gsfc.nasa.gov/merra/ & $2 \mathrm{~b} 2,2 \mathrm{~b} 3$ \\
\hline & $\begin{array}{l}\text { NCEP/DOE } \\
\text { Reanalysis } 2\end{array}$ & $\begin{array}{l}\text { http://www.esrl.noaa.gov/psd/data/gridded/data.ncep } \\
\text {.reanalysis2.html }\end{array}$ & $6 g$ \\
\hline & RAOBCORE, RICH & http://imgw.univie.ac.at/en/products & $2 b 2,2 b 3$ \\
\hline & RATPAC & http://www.ncdc.noaa.gov/oa/climate/ratpac & $2 b 2,2 b 3$ \\
\hline & RSS & http://www.remss.com & $2 b 2,2 b 3$ \\
\hline & UAH MSU & http://vortex.nsstc.uah.edu/public/msu/ & $2 b 2,2 b 3$ \\
\hline $\begin{array}{c}\text { TOA Earth } \\
\text { Radiation Budget }\end{array}$ & $\begin{array}{l}\text { CERES EBAF Ed } 2.6 r \\
\text { IDeg }\end{array}$ & http://ceres.larc.nasa.gov/sitemap_ceres.php & $2 f$ \\
\hline $\begin{array}{l}\text { Total Column } \\
\text { Ozone }\end{array}$ & $\begin{array}{l}\text { TOMS and OMI } \\
\text { Sensors }\end{array}$ & http://ozoneaq.gsfc.nasa.gov/ & $5 c, 6 g$ \\
\hline \multirow{5}{*}{$\begin{array}{c}\text { Total Column } \\
\text { Water Vapor } \\
\text { and } \\
\text { Humidity, } \\
\text { Upper Air }\end{array}$} & $\begin{array}{l}\text { COSMIC Land and } \\
\text { Ocean Total Column } \\
\text { Water Vapor }\end{array}$ & http://cosmic-io.cosmic.ucar.edu/cdaac/index.html & $2 \mathrm{~d} 2$ \\
\hline & $\begin{array}{l}\text { GPS Ground-Based } \\
\text { Total Column Water } \\
\text { Vapor }\end{array}$ & http://dss.ucar.edu/datasets/ds72I.I/ & $2 \mathrm{~d} 2$ \\
\hline & $\begin{array}{l}\text { NCEP/NCAR } \\
\text { Reanalysis }\end{array}$ & $\begin{array}{l}\text { http://www.esrl.noaa.gov/psd/data/gridded } \\
\text { /data.ncep.reanalysis.html }\end{array}$ & $4 d 4$ \\
\hline & $\begin{array}{l}\text { SSM/I -AMSR-E Ocean } \\
\text { Total Column Water } \\
\text { Vapor }\end{array}$ & http://www.remss.com & $2 \mathrm{~d} 2$ \\
\hline & TCWV Radiosonde & $\begin{array}{l}\text { Junhong Wang, Earth Observing Laboratory, } \\
\text { NCAR, Boulder, CO. }\end{array}$ & $2 \mathrm{~d} 2$ \\
\hline \multirow{10}{*}{ Trace Gases } & $\begin{array}{l}\text { Atmospheric Green- } \\
\text { house Gas Index } \\
\text { (AGGI) }\end{array}$ & http://www.esrl.noaa.gov/gmd/aggi/ & $2 g I$ \\
\hline & Carbon Dioxide & http://www.esrl.noaa.gov/gmd/dv/iadv/ & $2 \mathrm{gl}, \mathrm{SB} 5 . \mathrm{I}$ \\
\hline & Carbon Monoxide & http://www.esrl.noaa.gov/gmd/dv/iadv/ & $2 g I$ \\
\hline & JPL MLS $(\mathrm{HCl}, \mathrm{ClO})$ & http://mls.jpl.nasa.gov/index.php & $6 g$ \\
\hline & Methane & http://www.esrl.noaa.gov/gmd/dv/iadv/ & $2 \mathrm{gl}, \mathrm{SB} 5 . \mathrm{I}$ \\
\hline & Nitrous Oxide & http://www.esrl.noaa.gov/gmd/hats/combined/N2O.html & $2 \mathrm{gl}$ \\
\hline & ODGI & http://www.esrl.noaa.gov/gmd/odgi/ & $2 \mathrm{gl}$ \\
\hline & Perfluorocarbons & http://agage.eas.gatech.edu/ & $2 \mathrm{gl}$ \\
\hline & Sulphur Hexafluoride & http://www.esrl.noaa.gov/gmd/hats/combined/SF6.html & $2 g I$ \\
\hline & $\begin{array}{l}\text { SCIAMACHY (OCIO, } \\
\left.\mathrm{NO}_{2}\right)\end{array}$ & http://www.sciamachy.org/ & $6 g$ \\
\hline \multirow{2}{*}{$\begin{array}{c}\text { Tropical Cyclone } \\
\text { Data }\end{array}$} & $\begin{array}{l}\text { International Best } \\
\text { Track Archive for } \\
\text { Climate Stewardship } \\
\text { (IBTrACS) }\end{array}$ & http://www.ncdc.noaa.gov/oa/ibtracs/ & $4 d$ \\
\hline & $\begin{array}{l}\text { JTWC Best-track } \\
\text { Dataset } \\
\text { (20II preliminary) }\end{array}$ & $\begin{array}{l}\text { http://www.usno.navy.mil/NOOC/nmfc-ph/RSS/jtwc } \\
\text { /best_tracks/ }\end{array}$ & $4 d 4$ \\
\hline
\end{tabular}




\begin{tabular}{|c|c|c|c|}
\hline $\begin{array}{l}\text { Ultraviolet } \\
\text { Radiation }\end{array}$ & UV Index & http://www.temis.nl/uvradiation/SCIA/stations_uv.html & $5 c$ \\
\hline \multirow{8}{*}{$\begin{array}{l}\text { Wind, [Near] } \\
\text { Surface }\end{array}$} & $\begin{array}{l}\text { 20th Century } \\
\text { Reanalysis }\end{array}$ & http://www.esrl.noaa.gov/psd/data/20thC_Rean/ & $2 \mathrm{e} 2$ \\
\hline & $\begin{array}{l}\text { AMRC (Antarctic Me- } \\
\text { teorological Research } \\
\text { Center) AWS }\end{array}$ & http://amrc.ssec.wisc.edu/data/ & 6c,SB6.I \\
\hline & ERA-Interim & http://www.ecmwf.int/research/era & $2 e 2$ \\
\hline & ISD-Lite wind data & $\begin{array}{l}\text { http://www.ncdc.noaa.gov/oa/climate.isd.index. } \\
\text { php?name=isdlite }\end{array}$ & $2 e 2$ \\
\hline & $\begin{array}{l}\text { JRA-25 Atmospheric } \\
\text { Reanalysis }\end{array}$ & http://jra.kishou.go.jp/JRA-25/index_en.html & $2 \mathrm{e} 2,4 \mathrm{~h}, 6 \mathrm{~b}$ \\
\hline & MERRA & http://gmao.gsfc.nasa.gov/merra/ & $2 \mathrm{e} 2$ \\
\hline & READER & http://www.antarctica.ac.uk/met/READER & $6 c$ \\
\hline & $\begin{array}{l}\text { Satellite } \\
\text { Radiometer Winds } \\
\text { (SSM/I, AMSR-E, } \\
\text { WindSat, SSMIS) }\end{array}$ & http://www.remss.com & $2 \mathrm{e} 2$ \\
\hline \multirow{2}{*}{$\begin{array}{l}\text { Wind, Upper } \\
\text { Atmosphere }\end{array}$} & ERA-Interim & http://www.ecmwf.int/research/era & $6 \mathrm{~b}$ \\
\hline & $\begin{array}{l}\text { NCEP/DOE } \\
\text { Reanalysis } 2\end{array}$ & $\begin{array}{l}\text { http://www.esrl.noaa.gov/psd/data/gridded/data.ncep } \\
\text {.reanalysis2.html }\end{array}$ & $4 \mathrm{~d} 3$ \\
\hline
\end{tabular}




\section{ACKNOWLEDGMENTS}

The editors thank the staff of the Bulletin of the American Meteorological Society for their professionalism and assistance. Specifically, Lesley Williams and Melissa Fernau provided valuable editorial advice and logistical support. As always, the guidance and leadership of Bryan Hanssen and Jeff Rosenfeld was essential. The chapter editors enthusiastically thank their respective internal reviewers, and anonymous external reviewers, for working on very tight timetables to improve the document.

Chapter 2:

- Various reanalysis datasets were provided by Paul Berrisford and Hitoshi Sato (ERA-Interim), Mike Bosilovich (MERRA), Muthuvel Chelliah (NCEP CFSR), Yayoi Harada (JRA-25/JCDAS) and Cathy Smith (20CR).

- Surface humidity data were provided by several of the reanalysis authors above and by Aiguo Dai.

- Kate Willett was supported by the Joint DECC/Defra Met Office Hadley Centre Climate Programme (GA01101).

Chapter 3:

- The editors thank Joel Levy, Oceans chapter editor for the 2005-10 reports, for developing the chapter from its origins and assembling an impressive team of authors.

Chapter 4:

- Charles "Chip" Guard, NOAA/NWS/Guam Weather Forecast Office is thanked for his contributions to and assistance with the section dealing with tropical cyclones in the Western North Pacific basin.

- Bill Ward, NOAA/NWS/Pacific Region Headquarters, Honolulu, Hawaii is thanked for his detailed and very helpful internal review of the chapter.

Chapter 5:

- The NOAA authors note that, with respect to their contributions, "The views, opinions, and findings contained in this report are those of the author(s) and should not be construed as an official National Oceanic and Atmospheric Administration or U.S. Government position, policy, or decision."

- Jim Overland acknowledges the support of the Arctic Research Office of the NOAA Climate Program Office.

- Chris Derksen and Ross Brown thank their data providers: National Snow and Ice Data Centre; European Centre for Midrange Weather Forecasts; NOAA Earth System Research Laboratory; Rutgers University Snow Laboratory; and the Canadian Meteorological Centre.

- $\quad$ Marco Tedesco acknowledges NSF grant ARC 0909388 and the NASA Cryosphere Program, and Roderick van der Wal acknowledges Utrecht University, and several grants from the Dutch National Science Foundation (NWO), including the Spinoza Program and the Netherlands Polar Programme, for support for measurements along the K-transect in west Greenland.

- Vladimir Romanovsky acknowledges NSF grant ARC 0856864 and the Russian Academy of Science for partial support.

- Andrey Proshutinsky acknowledges NOAA support, and data and data analysis made possible by NSF grants ARC 856531, ARC 0856479 and ARC 0806306.

- The ozone and UV essay was supported by NSF grant ARC 0856268 (Ultraviolet Radiation in the Arctic) and European Commission Seventh Framework Programme grant RECONCILE-226365-FP7-ENV-2008-1 (RECONCILE project). Work at the Jet Propulsion Laboratory, California Institute of Technology, was done under contract with the U.S. National Aeronautics and Space Administration.

- $\quad$ Skip Walker and Uma Bhatt acknowledge NSF grant ARC 0902175 and NASA grants NNG6GE00A and NNX09AK56G.

- $\quad$ Karen Frey acknowledges NSF grant ARC 1107645 and NASA grant NNX10AH71G.

Chapter 6:

- Drs. Jan Lieser and Alex Fraser (ACE CRC) are thanked for their comments on the sea ice section.

- Rob Massom acknowledges support from the Australian Government's Cooperative Research Centre programme through the ACE CRC, and contribution to Project CPC18 and AAS Project 4116.

- Ted Scambos was supported under NASA grant NNX09AM78G.

- Sharon Stammerjohn was supported under NSF/OPP 0217282 .

- Matthew Lazzara and the AMRC AWS program acknowledge support from NSF grant number ANT0944018

- Dr. Michiel van den Broeke, Dr. Alberto Setzer, and Dr. Florence Fetterer are all thanked for their internal reviews of the chapter.

Chapter 7:

- The editors acknowledge and thank the numerous $\mathrm{Na}$ tional Hydrological and Hydrometeorological Services for collecting and providing data (and many authors) for this report. 


\section{ACRONYMS AND ABBREVIATIONS}

\section{AAO \\ ACE \\ AGGI \\ ALT \\ $\mathrm{AMO}$}

AMSR-E

AMSU

$\mathrm{AO}$

AOD

AOML

ATSR

AVHRR

AVISO

CAMS

CDR

CERES

CLIVAR

$\mathrm{CPC}$

$\mathrm{CPHC}$

CRU

ECMWF

ECV

$\mathrm{EECl}$

EESC

EOS

ERB

ERBE

ERSST

ESA

ESRL

EU
Antarctic Oscillation

NOAA's Accumulated Cyclone

Energy Index

NOAA’s Annual Greenhouse Gas

Index

Active layer thickness

Atlantic Multidecadal Oscillation

Advanced Microwave Scanning

Radiometer for Earth Observing

System

Advanced Microwave Sounding

Unit

Arctic Oscillation

Aerosol optical depth

Atlantic Oceanographic and

Meteorological Laboratory

Along-Track Scanning Radiometers

Advanced Very High Resolution

Radiometer

Archiving, Validating, and

Interpretation of Satellite

Oceanographic data

Climate Anomaly Monitoring

System

Climate data record

Clouds and the Earth's Radiant

Energy System

Climate Variability and

Predictability

Climate Prediction Center

NOAA's Central Pacific Hurricane

Center

Hadley Centre's Climate Research

Unit

European Centre for Medium-

Range Weather Forecasts

Essential climate variable

Effective equivalent chlorine

Effective equivalent stratospheric

chlorine

Earth Observatory System

Earth radiation budget

Earth Radiation Budget

Experiment

Extended Reconstructed Sea

Surface Temperature

European Space Agency

Earth System Research Laboratory

European Union
FAO

FAPAR

FLASHflux

GCOS

GHCN

GISS

GOME

GPCC

GPCP

GPI

GRACE

GTN-P

HadAT

HadCRUT3

HadGEM1

HadISST

HIRS-W

IBTrACS

ICD

ICPAC

IOD

ISCCP

JGOFS

JMA

JPL

JRA

JTWC

LHF

MDR

MERIS

MISR

MLS
Food and Agriculture Organization

Fraction of Absorbed

Photosynthetically Active

Radiation

Fast Longwave and Shortwave

Radiative Fluxes

Global Climate Observing System

Global Historical Climatology

Network

NASA's Goddard Institute of Space

Studies

Global Ozone Monitoring

Experiment

Global Precipitation Climatology

Centre

Global Precipitation Climatology

Project

Genesis potential index

Gravity Recovery and Climate

Experiment

Global Terrestrial Network on

Permafrost

Hadley Centre's radiosonde

temperature product

Hadley Centre/CRU gridded

monthly temperatures dataset

Hadley Centre global model

Hadley Centre's sea ice and SST

dataset

High Resolution Infrared Sounder

International Best Track Archive

for Climate Stewardship

Ice cover duration

IGAD Climate Prediction and

Applications Centre

Indian Ocean dipole

International Satellite Cloud

Climatology Project

Joint Global Ocean Flux Study

Japanese Meteorological Agency

Jet Propulsion Laboratory

Japanese Reanalysis

U.S. Navy's Joint Typhoon Warning

Center

Latent heat flux

Main Development Region

Medium Resolution Imaging

Spectrometer

Multiangle Imaging

SpectroRadiometer

Microwave Limb Sounder 


\begin{tabular}{|c|c|c|c|}
\hline MOC & Meridional overturning current & RAOBCORE & Radiosonde Observation \\
\hline \multirow[t]{2}{*}{ MOCHA } & Meridional Overturning & & Correction \\
\hline & Circulation Heat Transport Array & RATPAC & Radiosonde Atmospheric \\
\hline \multirow[t]{2}{*}{ MODIS } & Moderate Resolution Imaging & & Temperature Products for \\
\hline & Spectroradiometer & & Assessing Climate \\
\hline MSLP & mean sea level pressure & $\mathrm{RICH}$ & Radiosonde Innovation Composite \\
\hline MSU & Microwave Sounding Unit & & Homogenization \\
\hline $\mathrm{NAO}$ & North Atlantic Oscillation & RSS & Remote Sensing Systems \\
\hline \multirow[t]{2}{*}{ NASA } & National Aeronautics and Space & SAM & Southern annular mode \\
\hline & Administration & SCD & snow covered duration \\
\hline \multirow[t]{2}{*}{ NCAR } & National Center for Atmospheric & SCE & snow cover extent \\
\hline & Research & SCIAMACHY & Scanning Imaging Absorption \\
\hline NCDC & National Climatic Data Center & & Spectrometer for Atmospheric \\
\hline \multirow[t]{2}{*}{ NCEP } & National Centers for & & Chartography \\
\hline & Environmental Prediction & SeaWiFS & Sea-viewing Wide Field of View \\
\hline \multirow[t]{2}{*}{ NDVI } & Normalized Difference Vegetation & SHF & Sensible heat flux \\
\hline & Index & SLP & Sea level pressure \\
\hline \multirow[t]{2}{*}{ NERC } & National Environmental Research & SOI & Southern Oscillation index \\
\hline & Council & SPCZ & South Pacific convergence zone \\
\hline NHC & National Hurricane Center & $\mathrm{SSM} / \mathrm{I}$ & Special Sensor Microwave Imager \\
\hline \multirow[t]{2}{*}{ NOAA } & National Oceanic and Atmospheric & SSH & Sea surface height \\
\hline & Administration & SSS & Sea surface salinity \\
\hline \multirow[t]{2}{*}{ NOMADS } & National Operational Model & SSTA & Sea surface temperature anomaly \\
\hline & Archive and Distribution System & SWE & Snow water equivalent \\
\hline NSIDC & National Snow and Ice Data Center & TCHP & Tropical cyclone heat potential \\
\hline \multirow[t]{2}{*}{ OAFlux } & Objectively Analyzed Air-Sea & TCWV & Total column water vapor \\
\hline & Fluxes & TOA & Top of atmosphere \\
\hline ODGI & Ozone Depleting Gas Index & TOMS & Total Ozone Mapping Spectrometer \\
\hline OHCA & Ocean heat content anomaly & TRITON & Triangle Trans-Ocean Buoy \\
\hline OISST & Optimal Interpolation SST & & Network \\
\hline OLR & Outgoing longwave radiation & TRMM & Tropical Rainfall Measuring \\
\hline OMI & Ozone Monitoring Instrument & & Mission \\
\hline ONI & Oceanic Niño Index & TWC & Terrestrial water storage \\
\hline OPI & OLR precipitation index & WBC & Western boundary current \\
\hline \multirow[t]{2}{*}{ OSCAR } & Ocean Surface Current Analysis- & WBM & Water Balance Model \\
\hline & Real Time & w.e. & water equivalent \\
\hline \multirow[t]{2}{*}{ PATMOS (-x) } & Pathfinder Atmospheres (Extended & WGMS & World Glacier Monitoring Service \\
\hline & Product) & WHOI & Woods Hole Oceanographic \\
\hline $\mathrm{PDO}$ & Pacific decadal oscillation & & Institute \\
\hline \multirow[t]{2}{*}{ PIRATA } & Pilot Research Array in the & WMO & World Meteorological Organization \\
\hline & Tropical Atlantic & WOA & World Ocean Atlas \\
\hline \multirow[t]{2}{*}{ PMEL } & Pacific Marine Environmental & WOCE & World Ocean Circulation \\
\hline & Laboratory & & Experiment \\
\hline PSC & Polar stratospheric clouds & & \\
\hline PSS & Practical salinity scale & & \\
\hline QBO & Quasi-biennial oscillation & & \\
\hline QuikSCAT & Quick Scatterometer & & \\
\hline \multirow[t]{3}{*}{ RAMA } & Research Moored Array for & & \\
\hline & African-Asian-Australian & & \\
\hline & Monsoon Analysis Prediction & & \\
\hline
\end{tabular}




\section{REFERENCES}

Ackerman, S. A., R. E. Holz, R. Frey, E. W. Eloranta, B. C. Maddux, and M. McGill, 2008: Cloud detection with MODIS. Part II: Validation. J. Atmos. Oceanic Technol., 25, 1073-1086.

Adlam, L. S., M. R. Balks, C. A. Seybold, and D. I. Campbell, 2010: Temporal and spatial variation in active layer depth in the McMurdo Sound Region, Antarctica. Antarctic Sci., 22, 45-52.

Adler, R. F., and Coauthors, 2003: The version 2 Global Precipitation Climatology Project (GPCP) monthly precipitation analysis (1979-present). J. Hydrometeor., 4, 1147-1167.

Aiyyer, A., and J. Molinari, 2008: MJO and tropical cyclogenesis in the Gulf of Mexico and eastern Pacific: Case study and idealized numerical modeling. J. Atmos. Sci., 65, 2691-2704.

Åkerman, H. J., and M. Johansson, 2008: Thawing permafrost and thicker active layers in sub-arctic Sweden. Permafrost Periglacial Processes, 19, 279-292.

Allan, R. J., and T. J. Ansell, 2006: A new globally complete monthly historical gridded mean sea level pressure data set (HadSLP2): 1850-2004. J. Climate, 19, 5816-5842.

—, J. A. Lindesay, and D. E. Parker, 1996: El Niño Southern Oscillation and Climatic Variability. CSIRO Publications, 405 pp.

— C. J. C. Reason, J. A. Lindesay, and T. J. Ansell, 2003: 'Protracted' ENSO episodes and their impacts in the Indian Ocean region. Deep-Sea Res. II., 50, 2331-2347.

_, P. Brohan, G. P. Compo, R. Stone, J. Luterbacher, and S. Brönnimann, 2011: The International Atmospheric Circulation Reconstructions over the Earth (ACRE) initiative. Bull. Amer. Meteor. Soc., 92, 1421-1425.

Alley, W. M., R. W. Healy, J. W. LaBaugh, and T. E. Reilly, 2002: Flow and storage in groundwater systems. Science, 296, 1985-1990.

Amador, J. A., E. J. Alfaro, O. G. Lizano, and V. O. Magaña, 2006: Atmospheric forcing of the eastern tropical Pacific: A review. Progr. Oceanogr., 69, 101-142.

Andreae, M. O., and P. Merlet, 2001: Emission of trace gases and aerosols from biomass burning. Global Biogeochem. Cycles, 15, 955-966.

Antoine, D., A. Morel, H. Gordon, V. Banzon, and R. Evans, 2005: Bridging ocean color observations of the 1980's and 2000's in search of long-term trends. J. Geophys. Res., 110, C06009, doi:10.1029/2004JC002620.

Antonov, J. I., and Coauthors, 2010: Salinity. Vol. 2, World Ocean Atlas 2009, NOAA Atlas NESDIS 69, 184 pp.

Arrigo, K. R., and G. L. van Dijken, 2011: Secular trends in Arctic Ocean net primary production. J. Geophys. Res., 116, C09011, doi:10.1029/2011JC007151.
Ashok, K., S. K. Behera, S. A. Rao, H. Weng, and T. Yamagata, 2007: El Niño Modoki and its possible teleconnection. J. Geophys. Res., 112, C11007, doi:10.1029/12006JC003798.

ASMERC, 2011: Assessment of homogeneity of temperature and precipitation time series during 1960-2010 over Iran. ASMERC research report.

Atkinson, G. D., 1971: Forecasters' guide to tropical meteorology. U.S. Air Force Tech. Rep. 240, 360 pp.

Atlas, R., R. N. Hoffman, J. Ardizzone, S. M. Leidner, J. C. Jusem, D. K. Smith, and D. Gombos, 2011: A cross-calibrated, multiplatfom ocean surface wind velocity product for meteorological and oceanographic applications. Bull. Amer. Meteor. Soc., 92, 157-174.

Baccini, A., and Coauthors, 2012: Estimated carbon dioxide emissions from tropical deforestation improved by carbon-density maps. Nature Climate Change, 2, 182-185.

Bajracharya, S. R., S. B. Maharjan, and F. Shrestha, 2011: Glaciers shrinking in Nepal Himalaya. Climate Change: Geophysical Foundations and Ecological Effects, J. Blanco and H. Kheradmand, Eds., InTech, 445-458.

Baldwin, M. P., and Coauthors, 2001: The quasi-biennial oscillation. Rev. Geophys., 39, 179-229.

Baringer, M. O., and J. Larsen, 2001: Sixteen years of Florida current transport at $27^{\circ} \mathrm{N}$. Geophys. Res. Lett., 28, 3179-3182.

— expendable bathythermographs. Part I: Error estimates from model and hydrographic data. Deep-Sea Res. I, 54, 1390-1401.

__ , and Coauthors, 2011: [Global oceans] Meridional overturning circulation observations in the subtropical North Atlantic [in "State of the Climate in 2010"]. Bull. Amer. Meteor. Soc., 92 (6), S95-S98.

Barriopedro, D., E. Fisher, J. Luterbacher, R. M. Trigo, and R. García-Herrera, 2011: The hot summer of 2010: Redrawing the temperature record map of Europe. Science, 322, 220.

Bartalis, Z., W. Wagner, V. Naeimi, S. Hasenauer, K. Scipal, H. Bonekamp, J. Figa, and C. Anderson, 2007: Initial soil moisture retrievals from the METOP-A Advanced Scatterometer (ASCAT). Geophys. Res. Lett., 34, L20401, doi:10.1029/2007GL031088.

Becker, M., B. Meyssignac, W. Llovel, A. Cazenave, and T. Delcroix, 2012: Sea level variations at tropical Pacific islands since 1950. Global Planet. Change, 80-81, 85-98.

Beckley, B. D., N. P. Zelensky, S. A. Holmes, F. G. Lemoine, R. D. Ray, G. T. Mitchum, S. D. Desai, and S. T. Brown, 2010: Assessment of the Jason-2 extension to the TOPEX/ Poseidon, Jason-1 sea-surface height time series for global mean sea level monitoring. Marine Geodesy, 33, 447-471.

Behera, S. K., J.-J. Luo, S. Masson, S. A. Rao, H. Sakuma, and T. Yamagata, 2006: A CGCM study on the interaction between IOD and ENSO. J. Climate, 19, 1688-1705. 
Behrenfeld, M. J., E. Boss, D. A. Siegel, and D. M. Shea, 2005: Carbon-based ocean productivity and phytoplankton physiology from space. Global Biogeochem. Cycles, 19, GB1006, doi:10.1029/2004GB002299.

— and Coauthors, 2006: Climate-driven trends in contemporary ocean productivity. Nature, 444, 752-755.

—, K. Halsey, and A. Milligan, 2008: Evolved physiological responses of phytoplankton to their integrated growth environment. Phil. Trans. Royal Soc. B, 363, 2687-2703.

—, D. A. Siegel, R. T. O'Malley, and S. Maritorena, 2009: Global ocean phytoplankton [in "State of the Climate in 2008”]. Bull. Amer. Meteor. Soc., 90 (8), S68, S70-S73.

Bell, G. D., and M. Chelliah, 2006: Leading tropical modes associated with interannual and multidecadal fluctuations in north Atlantic hurricane activity. J. Climate, 19, 590-612.

— , and Coauthors, 2000: The 1999 North Atlantic and eastern North Pacific hurricane season [in "Climate Assessment for 1999”]. Bull. Amer. Meteor. Soc., 81 (5), S19-S22.

— , and Coauthors, 2007: Tropical cyclones: Atlantic basin [in "State of the Climate in 2006"]. Bull. Amer. Meteor. Soc., 88 (6), S48-S51.

— and Coauthors, 2008: Tropical cyclones: Atlantic basin [in "State of the Climate in 2007"]. Bull. Amer. Meteor. Soc., 89 (7), S68-S71.

— and Coauthors, 2009: Tropical cyclones: Atlantic basin [in "State of the Climate in 2008"]. Bull. Amer. Meteor. Soc., 90 (8), S79-S83.

- and Coauthors, 2010: Tropical cyclones: Atlantic basin [in "State of the Climate in 2009"]. Bull. Amer. Meteor. Soc., 91 (7), S84-S88.

— , and Coauthors, 2011: [ Tropics] Tropical cyclones: Atlantic basin [in "State of the Climate in 2010"]. Bull. Amer. Meteor. Soc., 92 (6), S115-S121.

Bellassen, V., N. Viovy, S. Luyssaert, G. Le Maire, M.-J. Schelhaas, and P. Ciais, 2011: Reconstruction and attribution of the carbon sink of European forests between 1950 and 2000. Global Change Biol., 17, 3274-3292.

Beránger, K., L. Siefridt, B. Barnier, E. Garnier, and H. Roquet, 1999: Evaluation of operational ECMWF surface freshwater fluxes of oceans during 1991-1997. J. Marine Syst., 22, 13-36.

Bernhard, G., and Coauthors, 2011: Ozone and UV radiation. Arctic Report Card, J. Richter-Menge, M. O. Jeffries, and J. E. Overland, Eds., NOAA Rep., 24-33. [Available online at http://www.arctic.noaa.gov/reportcard.]

Berry, D. I., and E. C. Kent, 2011: Air-sea fluxes from ICOADS: The construction of a new gridded dataset with uncertainty estimates. Int. J. Climatol., 31, 987-1001.

Bhambri, R., T. Bolch, R. K. Chaujar, and S. C. Kulshreshtha, 2011: Glacier changes in the Garhwal Himalayas, India,
1968-2006 based on remote sensing. J. Glaciol., 97, 543-556.

Bhatt, U. S., and Coauthors, 2010: Circumpolar Arctic tundra vegetation change is linked to sea-ice decline. Earth Interact., 14 (8), 1-20.

Blake, E., E. J. Gibney, D. P. Brown, M. Mainelli, J. L. Franklin, T. B. Kimberlain, and G. R. Hammer, 2009: Tropical Cyclones of the Eastern North Pacific Basin, 1949-2006. Historical Climatology Series 6-5, NOAA National Climatic Data Center, 162 pp.

—, C. W. Landsea, and E. J. Gibney, 2011: The deadliest, costliest, and most intense United States tropical cyclones from 1851 to 2010. NOAA Tech. Memo. NWS NHC-6, NOAA National Hurricane Center, 47 pp. [Available online at http://www.nhc.noaa.gov/pdf/nws-nhc-6.pdf.]

Bodhaine, B. A., B. G. Mendonca, J. M. Harris, and J. M. Miller, 1981: Seasonal variation in aerosols and atmospheric transmission at Mauna Loa Observatory. J. Geophys. Res., 86 (C8), 7395-7398.

Bolch, T., T. Yao, S. Kang, M. F. Buchroithner, D. Scherer, F. Maussion, E. Huintjes, and C. Schneider, 2010: A glacier inventory for the western Nyainqentanglha Range and the Nam Co Basin, Tibet, and glacier changes 1976-2009. The Cryosphere, 4, 419-433.

—, T. Pieczonka, and D. Benn, 2011: Multi-decadal mass loss of glaciers in the Everest area (Nepal Himalaya) derived from stereo imagery. The Cryosphere, 5, 349-358.

Böning, C. W., A. Dispert, M. Visbeck, S. R. Rintoul, and F. U. Schwarzkopf, 2008: The response of the Antarctic Circumpolar Current to recent climate change. Nature Geosci., 1, 864-869.

Bonjean, F., and G. Lagerloef, 2002: Diagnostic model and analysis of the surface currents in the tropical Pacific Ocean. J. Phys. Oceanogr., 32, 2938-2954.

Bopp, L., C. Le Quéré, M. Heimann, A. C. Manning, and P. Monfray, 2002: Climate-induced oceanic oxygen fluxes: Implications for the contemporary carbon budget. Global Biogeochem. Cycles, 16, 2, doi:10.1029/2001GB001445.

Bousquet, P., and Coauthors, 2011: Source attribution of the changes in atmospheric methane for 2006-2008. Atmos. Chem. Phys., 11, 3689-3700.

Box, J. E., and Coauthors, 2011: Greenland ice sheet. Arctic Report Card, J. Richter-Menge, M. O. Jeffries, and J. E. Overland, Eds., NOAA Rep., 117-138. [Available online at http://www.arctic.noaa.gov/reportcard.]

Boyer, T. P., S. Levitus, J. I. Antonov, R. A. Locarnini, and H. E. Garcia, 2005: Linear trends in salinity for the World Ocean, 1955-1998. Geophys. Res. Lett., 32, L01604, doi:10.1029/2004GL021791

,,,$--- \ldots$, A. Mishonov, H. Garcia, and S. A. Josey, 2007: Changes in freshwater content in the North 
Atlantic Ocean 1955-2006. Geophys. Res. Lett., 34, L16603, doi:10.1029/2007GL030126.

— , and Coauthors, 2009: Introduction. World Ocean Database 2009, NOAA Atlas NESDIS 66, 216 pp.

Brasnett, B., 1999: A global analysis of snow depth for numerical weather prediction. J. App. Meteor., 38, 726-740.

Bretherton, F. P., R. E. Davis, and C. Fandry, 1976: A technique for objective analysis and design of oceanographic instruments applied to MODE-73. Deep-Sea Res., 23, 559-582.

Brocca, L., F. Melone, T. Moramarco, W. Wagner, V. Naeimi, Z. Bartalis, and S. Hasenauer, 2010: Improving runoff prediction through the assimilation of the ASCAT soil moisture product. Hydrol. Earth System Sci., 14, 1881-1893.

Brohan, P., J. J. Kennedy, I. Harris, S. F. B. Tett and P. D. Jones, 2006: Uncertainty estimates in regional and global observed temperature changes: a new dataset from 1850. J. Geophys. Res., 111, D12106, doi:10.1029/2005JD006548.

Bromwich, D. H., and S-H. Wang, 2011: [Antarctica] Net precipitation [in "State of the Climate in 2010"]. Bull. Amer. Meteor. Soc., 92 (6), S164-167.

—, A. N. Rogers, P. Kallberg, R. I. Cullather, J. W. C. White, and K. J. Kreutz, 2000: ECMWF analyses and reanalyses depiction of ENSO signal in Antarctic precipitation. J. Climate, 13, 1406-1420.

_ , A. J. Monaghan, and Z. Guo, 2004: Modeling the ENSO modulation of Antarctic climate in the late 1990s with Polar MM5. J. Climate, 17, 109-132.

—, R. L. Fogt, K. I. Hodges, J. E. Walsh, 2007: A tropospheric assessment of the ERA-40, NCEP, and JRA-25 global reanalyses in the polar regions. J. Geophys. Res., 112, D10111, doi:10.1029/2006JD007859.

_ J. P. Nicolas, and A. J. Monaghan, 2011: An assessment of precipitation changes over Antarctica and the Southern Ocean since 1989 in contemporary global reanalyses. J. Climate, 24, 4189-4209.

Brown, J., O. J. Ferrians, J. A. Heginbottom, and E. S. Melnikov, 1997: Circum-Arctic map of permafrost and ground-ice conditions. National Snow and Ice Data Center, Boulder, CO, digital media. [Available online at http:// nsidc.org/data/ggd318.html.]

Brown, L. C., and C. R. Duguay, 2010: The response and role of ice cover in lake-climate interactions. Progr. Phys. Geog., 34, 671-704.

Brown, R., and D. Robinson, 2011: Northern Hemisphere spring snow cover variability and change over 1922-2010 including an assessment of uncertainty. The Cryosphere, 5, 219-229.

—, C. Derksen, and L. Wang, 2010: A multi-dataset analysis of variability and change in Arctic spring snow cover extent, 1967-2008. J. Geophys. Res., 115, D16111, doi:10.1029/2010JD013975.
Bruhwiler, L., and E. Dlugokencky, 2011: Carbon dioxide $\left(\mathrm{CO}_{2}\right)$ and methane $\left(\mathrm{CH}_{4}\right)$. Arctic Report Card, J. RichterMenge, M. O. Jeffries, and J. E. Overland, Eds., NOAA Rep., 20-23. [Available online at http://www.arctic.noaa. gov/reportcard.]

Burn, C. R., and S. V. Kokelj, 2009: The environment and permafrost of the Mackenzie Delta area. Permafrost Periglacial Processes, 20, 83-105.

Butchart, N., and E. E. Remsberg, 1986: The area of the stratospheric polar vortex as a diagnostic for tracer transport on an isentropic surface. J. Atmos. Sci., 43, 1319-1339.

Caldeira, K., and M. E. Wickett, 2003: Anthropogenic carbon and ocean pH. Nature, 425, 365.

istry changes from carbon dioxide emissions to the atmosphere and ocean. J. Geophys. Res., 110, C09S04, doi:10.1029/2004JC002671.

Callaghan, T. V., F. Bergholm, T. R. Christensen, C. Jonasson, U. Kokfelt, and M. Johansson, 2010: A new climate era in the sub-Arctic: Accelerating climate changes and multiple impacts. Geophys. Res. Lett., 37, L14705, doi:10.1029/2009GL042064.

_ C. E. Tweedie, and P. J. Webber, 2011: Multi-decadal changes in tundra environments and ecosystems: Synthesis of the International Polar Year Back to the Future Project (IPY-BTF). Ambio, 40, 705-716.

Camargo, S. J., K. A. Emanuel, and A. H. Sobel, 2007: Use of a genesis potential index to diagnose ENSO effects on tropical cyclone genesis. J. Climate, 20, 4819-4834.

Campbell, J. W., 1995: The lognormal distribution as a model for bio-optical variability in the sea. J. Geophys. Res., 100 (C7), 13237-13254.

Cappelen, J., Ed., 2011: DMI monthly climate data collection 1768-2010, Denmark, The Faroe Islands and Greenland. DMI Tech. Rep. 11-05, 54 pp. [Available online at http:// www.dmi.dk/dmi/tr11-05.pdf.]

— , B. V. Jørgensen, E. V. Laursen, L. S. Stannius, and R. S. Thomsen, Eds., 2000: The observed climate of Greenland, 1958-99 - with climatological standard normals, 1961-90. DMI Tech. Rep. 00-18, 152 pp. [Available online at http:// www.dmi.dk/dmi/tr00-18.pdf.]

Cavalieri, D., C. Parkinson, P. Gloersen, and H. J. Zwally, 2008: Sea ice concentrations from Nimbus-7 SMMR and DMSP SSM/I passive microwave data. National Snow and Ice Data Center, Boulder, CO, digital media. [Available at http://nsidc.org/data/nsidc-0051.html.]

Cayan, D. R., 1992: Latent and sensible heat flux anomalies over the northern oceans, driving the sea surface temperature. J. Phys. Oceanogr., 22, 859-881.

CEOS, 2012: CEOS Working Group on Climate (WGC) Terms of Reference. Committee on Earth Observation 
Satellites, 2 pp. [Available online at http://www.ceos.org/ images/TERMS_OF_REFERENCE_WGC.pdf.]

Chan, F., J. A. Barth, J. Lubchenco, A. Kirincich, H. Weeks, W. T. Peterson, and B. A. Menge, 2008: Emergence of anoxia in the California current large marine ecosystem. Science, 319, 920.

Chan, J. C. L., 2000: Tropical cyclone activity over the western North Pacific associated with El Niño and La Niña events. J. Climate, 13, 2960-2972.

Cheng, X., L. Wu, F. Hu, and Q.-C. Zeng, 2012: Parameterizations of some important characteristics of turbulent fluctuations and gusty wind disturbances in the atmospheric boundary layer. J. Geophys. Res., 117, D08113, doi:10.1029/2011JD017191.

Chidichimo, M. P., T. Kanzow, S. A. Cunningham, W. E. Johns, and J. Marotzke, 2010: The contribution of easternboundary density variations to the Atlantic meridional overturning circulation at $26.5^{\circ} \mathrm{N}$. Ocean Science, 6 , 475-490.

Chipman, D. W., T. Takahashi, S. Rubin, S. C. Sutherland, and M. H. Koshlyakov, 1997: Carbon dioxide, hydrographic, and chemical data obtained during the $\mathrm{R} / \mathrm{V}$ Akademik Ioffe cruise in the South Pacific Ocean (WOCE Section 4sP, February-April, 1992). TN ORNL/ CDIAC-100, NDP-063, 38 pp. [Available online at http:// cdiac.ornl.gov/oceans/ndp_063/.]

Christiansen, H. H., and Coauthors, 2010: The thermal state of permafrost in the Nordic area during IPY 2007-2009. Permafrost Periglacial Processes, 21, 156-181.

Christy, J. R., R. W. Spencer, and W. B Norris, 2011: The role of remote sensing in monitoring bulk tropospheric temperatures. Int. J. Remote Sens., 32, 1-15.

Church, J. A., and Coauthors, 2011: Revisiting the Earth's sea-level and energy budgets from 1961 to 2008. Geophys. Res. Lett., 38, L18601, doi:10.1029/2011GL048794.

Cogley, J. G., and Coauthors, 2011: Glossary of glacier mass balance and related terms. IHP-VII Tech. Documents in Hydrol. No. 86, IACS Contribution No. 2, 114 pp. [Available online at http://unesdoc.unesco.org/ images/0019/001925/192525e.pdf.]

Cohen, J. L., J. C. Furtado, M. A. Barlow, V. A. Alexeev, and J. E. Cherry, 2012: Arctic warming, increasing snow cover and widespread boreal winter cooling. Environ. Res. Lett., 7, 014007, doi:10.1088/1748-9326/7/1/014007.

Comiso, J., 1999: Bootstrap sea ice concentrations from NIMBUS-7 SMMR and DMSP SSM/I. National Snow and Ice Data Center, Boulder, CO, digital media. [Available online at http://nsidc.org/data/nsidc-0079.html.]

- 2010: Variability and trends of the global sea ice cover. Sea Ice, 2nd ed., D. N. Thomas and G. S. Dieckmann, Eds., Wiley-Blackwell, 205-246.
Compo, G. P., and Coauthors, 2011: The twentieth century reanalysis project. Quart. J. Roy. Meteor. Soc., 137, 1-28.

Cook, A. J., and D. G. Vaughan, 2010: Overview of areal changes of the ice shelves on the Antarctic Peninsula over the past 50 years. The Cryosphere, 4, 77-98.

Cook Islands Government, 2006: Kia vai teateamamao ("Be Prepared"), produced by Cook Islands National Environment Service, DVD.

—, 2011: An interview with Mr. George "Birdman" Mateariki. Signs of Nature for Atiu, produced by Emergency Management Cook Islands and Cook Islands Television, DVD.

Cummins, P. F., G. S. E. Lagerloef, and G. T. Mitchum, 2005: A regional index of northeast Pacific variability based on satellite altimeter data. J. Geophys. Res., 32, L17607, doi:10.1029/2005GL023642.

Cunningham, S. A., and Coauthors, 2007: Temporal variability of the Atlantic Meridional Overturning Circulation at $26.5^{\circ}$ N. Science, 312, 935-938.

— , and Coauthors, 2010: The present and future system for measuring the Atlantic meridional overturning circulation and heat transport. OceanObs'09: Sustained Ocean Observations and Information for Society (Vol. 2), J. Hall et al., Eds., ESA Publication WPP-306, doi:10.5270/ OceanObs09.cwp.21.

Curry, R. G., and M. S. McCartney, 2001: Ocean gyre circulation changes associated with the North Atlantic oscillation. J. Phys. Oceanogr., 31, 3374-3400.

—, R. Dickson, and I. Yashayaev, 2003: A change in the freshwater balance of the Atlantic Ocean over the past four decades. Nature, 426, 826-829.

Dai, A., 2006: Recent climatology, variability, and trends in global surface humidity. J. Climate, 19, 3589-3606.

—, J. Wang, P. W. Thorne, D. E. Parker, L. Haimberger, and X. L. Wang, 2011: A new approach to homogenize daily radiosonde humidity data. J. Climate, 24, 965-991.

Daniel, J. S., and Coauthors, 2011: A focus on information and options for policymakers. Scientific Assessment of Ozone Depletion: 2010, Global Ozone Research and Monitoring Project Rep. 52, World Meteorological Organization, 5.1-5.56.

Dare, R. A., and J. L. McBride, 2011: Sea surface temperature response to tropical cyclones. Mon. Wea. Rev., 139, 3798-3808.

Davidson, E. A., 2009: The contribution of manure and fertilizer nitrogen to atmospheric nitrous oxide since 1860 . Nature Geosci., 2, 659-662.

De Jeu, R. A. M., and M. Owe, 2003: Further validation of a new methodology for surface moisture and vegetation optical depth retrieval. Int. J. Remote Sens., 24, 4559-4578.

—, R. Parinussa, Y. Liu, W. Dorigo, W. Wagner, K. Scipal, H. Dolman, and Z. Su, 2009: Trends and dynamics in 
long term satellite soil moisture data sets. Proc. Earth Observation and Water Cycle Science Symposium, EGU Topical Conf. Series on the hydrological cycle, Frascati, Italy, ESA/ESRIN.

—, W. W. Wagner, W. A Dorigo, and Y. Y. Liu, 2011: [Global climate] Soil moisture [in "State of the Climate 2010"]. Bull. Amer. Meteor. Soc., 92 (6), S52-S53.

Dee, D. P., and Coauthors, 2011a: The ERA-Interim reanalysis: configuration and performance of the data assimilation system. Quart. J. Roy. Meteor. Soc., 137, 553-597.

— - and Coauthors, 2011b: [Global climate] The use of reanalysis data for monitoring the state of the climate [in "State of the Climate 2010"]. Bull. Amer. Meteor. Soc., 92 (6), S34-S35.

Delwart, S., and L. Bourg, 2011: Radiometric calibration of MERIS. Proc. SPIE, 8176, 817613, doi:10.1117/12.895090.

Delworth, T. L., and M. E. Mann, 2000: Observed and simulated multi-decadal variability in the Northern Hemisphere. Climate Dyn., 16, 661-676.

DeMaria, M., M. Mainelli, L. K. Shay, J. A. Knaff, and J. Kaplan, 2005: Further improvement to the Statistical Hurricane Intensity Prediction Scheme (SHIPS).Wea. Forecasting, 20, 531-543.

Denman, K. L., and Coauthors, 2007: Couplings between changes in the climate system and biogeochemistry. Climate Change 2007: The Physical Science Basis, S. Solomon et al., Eds., Cambridge University Press, 499-587.

Dery, S., and R. Brown, 2007: Recent Northern Hemisphere snow cover extent trends and implications for the snow-albedo feedback. J. Geophys. Res., 34, L22504, doi:10.1029/2007GL031474.

Deser, C., and M. L. Blackmon, 1993: Surface climate variations over the North Atlantic Ocean during winter: 1900-1989. J. Climate, 6, 1743-1753.

Deser, M., A. Alexander, S. P. Xie, and A. S. Phillips, 2010: Sea surface temperature variability: Patterns and mechanisms. Ann. Rev. Marine Sci., 2, 115-143.

Dhomse, S., M. Weber, J. P. Burrows, I. Wohltmann, and M. Rex, 2006: On the possible cause of recent increases in NH total ozone from a statistical analysis of satellite data from 1979 to 2003. Atmos. Chem. Phys., 6, 1165-1180.

Di Girolamo, L., A. Menzies, G. Zhao, K. Mueller, C. Moroney, and D. J. Diner, 2010: Multi-angle imaging spectroradiometer level 3 cloud fraction by altitude algorithm theoretical basis document. JPL Publ. D-62358, 23 pp.

Dijkstra, H. A., L. te Raa, M. Schmeits, and J. Gerrits, 2006: On the physics of the Atlantic multidecadal oscillation. Ocean Dyn., 56, 36-50.

Ding, Q., E. Steig, D. Battisti, and M. Kuttel, 2011: Winter warming in West Antarctica caused by central tropical Pacific warming. Nature Geosci., 4, 398-403, doi:10.1038/ NGEO1129.
Dlugokencky, E. J., and Coauthors, 2009: Observational constraints on recent increases in the atmospheric $\mathrm{CH}_{4}$ burden. Geophys. Res. Lett., 36, L18803, doi:10.1029/2009GL039780.

Dohan, K., and N. Maximenko, 2010: Monitoring ocean currents with satellite sensors. Oceanography, 23, 94-103.

Domack, E., and Coauthors, 2005: Stability of the Larsen B ice shelf on the Antarctic Peninsula during the Holocene epoch. Nature, 436, 681-685.

Doney, S., B. Tilbrook, S. Roy, N. Metzl, C. Le Quéré, M. Hood, R. A. Feely, and D. C. E. Bakker, 2009: Surface ocean $\mathrm{CO}_{2}$ variability and vulnerability. Deep-Sea Res. II, 56, 504-511.

Dong, S., S. L. Garzoli, M. O. Baringer, C. S. Meinen, and G. J. Goni, 2009: The Atlantic Meridional Overturning Circulation and its northward heat transport in the South Atlantic. Geophys. Res. Lett., 36, L20606, doi:10.1029/2009GL039356.

Donohue, R. J., M. L. Roderick, and T. R. McVicar, 2007: On the importance of including vegetation dynamics in Budyko's hydrological model. Hydrol. Earth Syst. Sci., 11, 983-995.

Dorigo, W. A., K. Scipal, R. M. Parinussa, Y. Y. Liu, W. Wagner, R. A. M. de Jeu, and V. Naeimi, 2010: Error characterisation of global active and passive microwave soil moisture datasets. Hydrol. Earth Syst. Sci., 14, 2605-2616.

Duguay, C. R., T. D. Prowse, B. R. Bonsal, R. D. Brown, M. P. Lacroix, and P. Ménard, 2006: Recent trends in Canadian lake ice cover. Hydrolog. Processes, 20, 781-801.

Durack, P. J., and S. E. Wijffels, 2010: Fifty-year trends in global ocean salinities and their relationship to broadscale warming. J. Climate, 23, 4342-4362.

Durre, I., R. S. Vose, and D. B. Wuertz, 2006: Overview of the integrated global radiosonde archive. J. Climate, 19, 53-68.

Dutton, E. G., and B. A. Bodhaine, 2001: Solar irradiance anomalies caused by clear-sky transmission variations above Mauna Loa 1957-1999. J. Climate, 14, 3255-3262.

EDGAR, 2009: Emission Database for Global Atmospheric Research (EDGAR), release version 4.0. European Commission, Joint Research Centre (JRC)/Netherlands Environmental Assessment Agency (PBL). [Available online at http://edgar.jrc.ec.europa.eu.]

Elkins, J. W., and G. S. Dutton, 2011: [Global Climate] Atmospheric composition [in "State of the Climate in 2010"]. Bull. Amer. Meteor. Soc., 92 (6), S60 -S61.

Ellis, H. T., and R. E. Pueschel, 1971: Solar radiation: Absence of trends at Mauna Loa. Science, 172, 845-846.

Elmendorf, S. C., and Coauthors, 2011: Global assessment of experimental climate warming on tundra vegetation: heterogeneity over space and time. Ecol. Lett., 15, 164-175. 
Elverhoi, H., 2012: Glacier length change table 1997-2011. Norwegian Water Resources and Energy Directorate. [Available online at http://www.nve.no/Global/Vann\%20 og\%20vassdrag/Hydrologi/Bre/Nedlastinger/Length_ Change_Table_1997-2011.pdf.]

Emanuel, K. A., 1988: The maximum intensity of hurricanes. J. Atmos. Sci., 45, 1143-1155.

- 1995 : Sensitivity of tropical cyclones to surface exchange coefficients and a revised steady-state model incorporating eye dynamics. J. Atmos. Sci., 52, 3969-3976.

- 2001: The contribution of tropical cyclones to the oceans' meridional heat transport. J. Geophys. Res., 106 (D14), 14771-14781.

Enfield, D. B., and D. A. Mayer, 1997: Tropical Atlantic sea surface temperature variability and its relation to El NiñoSouthern Oscillation. J. Geophys. Res., 102 (C1), 929-945.

__ and A. M. Mestas-Nuñez, 1999: Multi-scale variabilities in global sea surface temperatures and their relationships with tropospheric climate patterns. J. Climate, 12, 2719-2733.

,-- , and P. J. Trimble, 2001: The Atlantic Multidecadal Oscillation and its relationship to rainfall and river flows in the continental US. Geophys. Res. Lett., 28, 2077-2080.

England, M. H., and F. Huang, 2005: On the interannual variability of the Indonesian throughflow and its linkage with ENSO. J. Climate, 18, 1435-1444.

Eplee, R. E., Jr., G. Meister, F. S. Patt, B. A. Franz, and C. R. McClain, 2011: Uncertainty assessment of the SeaWiFS on-orbit calibration. Proc. SPIE, 8153, 815310, doi:10.1117/12.892340.

Epstein, H. E., D. A. Walker, M. K. Raynolds, U. S. Bhatt, C. J. Tucker, and J. E. Pinzon, 2012: Dynamics of aboveground phytomass of the circumpolar arctic tundra during the past three decades. Environ. Res. Lett., 7, 015506, doi:10.1088/1748-9326/7/1/015506.

Fabry, V. J., B. A. Seibel, R. A. Feely, and J. C. Orr, 2008: Impacts of ocean acidification on marine fauna and ecosystem processes. ICES J. Marine Sci., 65, 414-432.

— J. B. McClintock, J. T. Mathis, and J. M. Grebmeier, 2009: Ocean acidification at high latitudes: The bellwether. Oceanography, 22, 160-171.

Fairall, C. W., E. F. Bradley, J. E. Hare, A. A. Grachev, and J. B. Edson, 2003: Bulk parameterization on air-sea fluxes: Updates and verification for the COARE algorithm. J. Climate, 16, 571-591.

Falkowski, P. G., 1984: Physiological responses of phytoplankton to natural light regimes. J. Plankton Res., 6, 295-307.

Famiglietti, J. S., and Coauthors, 2011: Satellites measure recent rates of groundwater depletion in California's Central Valley. Geophys. Res. Lett., 38, L03403, doi:10.1029/2010GL046442.
FAO, 2006: Global Forest Resources Assessment 2005. FAO Forestry Paper 147, Food and Agriculture Organization of the United Nations, Rome, 320 pp.

_ 2 2010: Global Forest Resources Assessment 2010. FAO Forestry Paper 163, Food and Agriculture Organization of the United Nations, Rome, 340 pp.

Feely, R. A., C. L. Sabine, J. M. Hernandez-Ayon, D. Ianson, and B. Hales, 2008: Evidence for upwelling of corrosive "acidified" water onto the continental shelf. Science, 320, 1490-1492.

Fekete, B. M., and A. M. MacDonald, 2011: [Global climate] River discharge [in "State of the Climate in 2010"]. Bull. Amer. Meteor. Soc., 92 (6), S46-S48.

— , R. B. Lammers, A. M. MacDonald, L. C. Bowling, and R. Lawford, 2010: [Global climate] River discharge [in "State of the Climate in 2009"]. Bull. Amer. Meteor. Soc., 91 (7), S35.

Fioletov, V. E., and T. G. Shepherd, 2003: Seasonal persistence of midlatitude total ozone anomalies. Geophys. Res. Lett., 30, 1417, doi:10.1029/2002GL016739.

—, G. E. Bodeker, A. J. Miller, R. D. McPeters, and R. Stolarski, 2002: Global and zonal total ozone variations estimated from ground-based and satellite measurements: 1964-2000. J. Geophys. Res., 107, 4647, doi:10.1029/2001JD001350.

_ , and Coauthors, 2008: The performance of the groundbased total ozone network assessed using satellite data. J. Geophys. Res., 113, D14313, doi:10.1029/2008JD009809.

Fischer, A., 2012, Gletscherbericht 2010/2011. Sammelbericht über die Gletschermessungen des Österreichischen Alpenvereins im Jahre 2011. Letzter Bericht: Bergauf 02/2011, Jg. 66 (136).

Fogt, R. L., and D. H. Bromwich, 2006: Decadal variability of the ENSO teleconnection to the high latitude South Pacific governed by coupling with the southern annular mode. J. Climate, 19, 979-997.

,-- _ , and K. M. Hines, 2011: Understanding the SAM influence on the South Pacific ENSO teleconnection. Climate Dyn., 36, 1555-1576.

Folland, C. K., J. Knight, H. W. Linderholm, D. Fereday, S. Ineson, and J. W. Hurrell, 2009: The summer North Atlantic oscillation: Past, present and future. J. Climate, 22, 1082-1103.

Font, J., G. Lagerloef, D. Le Vine, A. Camps, and O. Zanife, 2004: The determination of surface salinity with the European SMOS space mission. IEEE Trans. Geosci. Remote Sens., 42, 2196-2205.

Forster, P., and Coauthors, 2007: Changes in atmospheric constituents and in radiative forcing. Climate Change 2007: The Physical Science Basis, S. Solomon et al., Eds., Cambridge University Press, 129-234. 
Franz, B. A., S. W. Bailey, P. J. Werdell, and C. R. McClain, 2007: Sensor-independent approach to vicarious calibration of satellite ocean color radiometry. Appl. Optics, 46, 5068-5082.

— E. E. Kwiatkowska, G. Meister, and C. McClain, 2008: Moderate resolution imaging spectroradiometer on Terra: Limitations for ocean color applications. J. Appl. Remote Sens., 2, 023525, doi:10.1117/1.2957964.

Free, M., 2011: [Global climate] Lower stratospheric temperatures [in "State of the Climate 2010"]. Bull. Amer. Meteor. Soc., 92 (6), S38-S39.

— , D. J. Seidel, J. K. Angell, J. R. Lanzante, I. Durre, and T. C. Peterson, 2005: Radiosonde Atmospheric Temperature Products for Assessing Climate (RATPAC): A new dataset of large-area anomaly time series. J. Geophys. Res., 110, D22101, doi:10.1029/2005JD006169.

Frey, K. E., K. R. Arrigo, and R. R. Gradinger, 2011: Arctic Ocean primary productivity. Arctic Report Card, J. Richter-Menge, M. O. Jeffries, and J. E. Overland, Eds., NOAA Rep., 69-71. [Available online at http://www.arctic. noaa.gov/reportcard.]

Friedlingstein, P., and Coauthors, 2010: Update on $\mathrm{CO}_{2}$ emissions. Nature Geosci., 3, 811-812.

Frolking, S., J. Talbot, M. C. Jones, C. C. Treat, J. B. Kauffman, E.-S. Tuittila, and N. Roulet, 2011: Peatlands in the Earth's $21^{\text {st }}$ century climate system. Environ. Rev., 19, 371-396.

Ganachaud, A., and C. Wunsch, 2000: The oceanic meridional overturning circulation, mixing, bottom water formation, and heat transport. Nature, 408, 453-457.

Gardner, A. S., and Coauthors, 2011: Sharply increased mass loss from glaciers and ice caps in the Canadian Arctic Archipelago. Nature, 473, 357-360.

Garlich-Miller, J. L., J. G. MacCracken, J. Snyder, R. Meehan, M. Myers, J. M. Wilder, E. Lance, and A. Matz, Eds., 2011: Status review of the Pacific walrus (Odobenus rosmarus divergens). U.S. Fish and Wildlife Service, 155 pp. [Available online at http://alaska.fws.gov/fisheries/mmm/ walrus/pdf/review_2011.pdf.]

Garzoli, S. L., and M. O. Baringer, 2007: Meridional heat transport using expandable bathythermographs. Part II: South Atlantic transport. Deep-Sea Res. I, 54, 1402-1420.

_ S. Speich, A. Piola, and E. Campos, 2010: South Atlantic Meridional Overturning Circulation (SAMOC) Third workshop. CLIVAR Exchanges, 54 (4), 28-29.

GCOS, 2003: The second report on the adequacy of the Global Observing Systems for Climate in support of the UNFCCC. GCOS-82, WMO/TD No. 1143, 74 pp. [Available online at http://www.wmo.int/pages/prog/gcos/ Publications/gcos-82_2AR.pdf.]

_ 2011: Systematic observation requirements for satellitebased data products for climate. GCOS No.154, 127 pp.
[Available online at http://www.wmo.int/pages/prog/gcos/ Publications/gcos-154.pdf.]

Giglio, L., J. T. Randerson, G. R. van der Werf, P. S. Kasibhatla, G. J. Collatz, D. C. Morton, and R. S. DeFries, 2010: Assessing variability and long-term trends in burned area by merging multiple satellite fire products. Biogeosciences, 7, 1171-1186.

Gobron, N., A. S. Belward, B. Pinty, and W. Knorr, 2010: Monitoring biosphere vegetation 1998-2009. Geophys. Res. Lett., 37, L15402, doi:10.1029/2010GL043870.

Goldenberg, S. B., and L. J. Shapiro, 1996: Physical mechanisms for the association of El Niño and West African rainfall with Atlantic major hurricane activity. J. Climate, 9, 1169-1187.

- C. W. Landsea, A. M. Mestas-Nuñez, and W. M. Gray, 2001: The recent increase in Atlantic hurricane activity: Causes and implications. Science, 293, 474-479.

Goni, G. J., and I. Wainer, 2001: Investigation of the Brazil Current front dynamics from altimeter data. J. Geophys. Res., 36 (C12), 31117-31128.

— , and J. A. Trinanes, 2003: Ocean thermal structure monitoring could aid in the intensity forecast of tropical cyclones. Eos, Trans. Amer. Geophys. Union, 84, 573-578.

—_, and Coauthors, 2009: Applications of satellite-derived ocean measurements to tropical cyclone intensity forecasting. Oceanography, 22, 176-183.

_ , F. Bringas, and P. N. Di Nezio, 2011: Observed low frequency variability of the Brazil current front. J. Geophys. Res., 116, C10037, doi:10.1029/2011JC007198.

Gordon, A., and C. F. Giulivi, 2008: Sea surface salinity trends over 50 years within the subtropical North Atlantic. Oceanography, 21, 20-29.

Gottschalck, J. G., and G. D. Bell, 2009: [Tropics] The Madden-Julian oscillation [in "State of the Climate in 2008"]. Bull. Amer. Meteor. Soc., 89 (7), S78-S79.

Grainger, A., 2008: Difficulties in tracking the long-term global trend in tropical forest area. Proc. Natl. Acad. Sci. USA, 105, 818-823.

Grantham, B. A., F. Chan, K. J. Nielsen, D. S. Fox, J. A. Barth, A. Huyer, J. Lubchenco, and B. A. Menge, 2004: Upwelling-driven nearshore hypoxia signals ecosystem and oceanographic changes in the northeast Pacific. Nature, 429, 749-754.

Grebmeier, J. M., S. E. Moore, J. E. Overland, K. E. Frey, and R. R. Gradinger, 2010: Biological response to recent Pacific Arctic sea ice retreats. Eos, Trans. Amer. Geophys. Union, 91, 161-162.

Gruber, N., and Coauthors, 2009: Ocean sources, sinks, and transport of atmospheric $\mathrm{CO}_{2}$. Global Biogeochem. Cycles, 23, GB1005, doi:10.1029/2008GB003349. 
Guglielmin, M., and N. Cannone, 2011: A permafrost warming in a cooling Antarctica? Climatic Change, 111, 177-195.

—, M. R. Balks, L. S. Adlam, and F. Baio, 2011: Permafrost thermal regime from two 30-m deep boreholes in Southern Victoria Land, Antarctica. Permafrost Periglacial Processes, 22, 129-139.

Guinotte, J. M., and V. J. Fabry, 2008: Ocean acidification and its potential effects on marine ecosystems. Year in Ecology and Conservation Biology 2008, R. S. Ostfeld and W. H. Schlesinger, Eds., Ann. New York Acad. Sci., Vol. 1134, 320-342.

Gumbricht, T., P. Wolski, and T. C. McCarthy, 2004: Forecasting the spatial extent of the annual flood in the Okavango Delta, Botswana. J. Hydrol., 190, 178-191.

Haeberli, W., J. Cihlar, and R. Barry, 2000: Glacier monitoring within the Global Climate Observing System. Ann. Glaciol., 31, 241-246.

— ment and challenges of a young research field. J. Glaciol., 56, 1043-1058.

Hahn, C. J., and S. G. Warren, 2007: A gridded climatology of clouds over land (1971-1996) and ocean (1954-1997) from surface observations worldwide. ORNL/CDIAC-153, NDP-026E, 75 pp. [Available online at http://cdiac.ornl. gov/epubs/ndp/ndp026e/ndp026e.html.]

Häkkinen, S., P. B. Rhines, and D. L. Worthen, 2011: Warm and saline events embedded in the meridional circulation of the northern North Atlantic. J. Geophys. Res., 116, C03006, doi:10.1029/2010JC006275.

Hales, B., L. Karp-Boss, A. Perlin, and P. A. Wheeler, 2006: Oxygen production and carbon sequestration in an upwelling coastal margin. Global Biogeochem. Cycles, 20, GB3001, doi:10.1029/2005GB002517.

Hansen, J., R. Ruedy, M. Sato, and K. Lo, 2010: Global surface temperature change. Rev. Geophys., 48, RG4004, doi:10.1029/2010RG000345.

Harnisch, J., and A. Eisenhauer, 1998: Natural $\mathrm{CF}_{4}$ and $\mathrm{SF}_{6}$ on Earth. Geophys. Res. Lett., 25, 2401-2404.

—, R. Borchers, P. Fabian, H. W. Gaggeler, and U. Schotterer, 1996a: Effect of natural tetrafluoromethane. Nature, 384, 32.

$-, \ldots, \ldots$, and M. Maiss, 1996b: Tropospheric trends for $\mathrm{CF}_{4}$ and $\mathrm{C}_{2} \mathrm{~F}_{6}$ since 1982 derived from $\mathrm{SF}_{6}$ dated stratospheric air. Geophys. Res. Lett., 23, 1099-1102.

_-, M. Frische, R. Borchers, A. Eisenhauer, and A. Jordan, 2000: Natural fluorinated organics in fluorite and rocks. Geophys. Res. Lett., 27, 1883-1886.

Hart, R. E., R. N. Maue, and M. C. Watson, 2007: Estimating local memory of tropical cyclones through MPI anomaly evolution. Mon. Wea. Rev., 135, 3990-4005.
Hauri, C., N. Gruber, G.-K. Plattner, S. Alin, R. A. Feely, B. Hales, and P. A. Wheeler, 2009: Ocean acidification in the California current system. Oceanography, 22, 60-71.

Heide-Jørgensen, M. P., K.L. Laidre, L. T. Quakenbush, and J. Citta, 2012:, Northwest Passage opens for bowhead whales. Biol. Lett., 8, 270-273.

Heidinger, A. K., and M. J. Pavolonis, 2009: Gazing at cirrus clouds for 25 years through a split window, part 1: Methodology. J. Appl. Meteor. Climatol., 48, 1100-1116.

Heimbach, P., C. Wunsch, R. M. Ponte, G. Forget, C. Hill, and J. Utke, 2011: Timescales and regions of the sensitivity of the Atlantic meridional volume mean heat transport: Toward observing system design. Deep-Sea Res. II, 58, 1858-1879.

Held, I. M., and B. J. Soden, 2006: Robust response of the hydrological cycle to global warming. J. Climate, 19, 5686-5699.

Helfrich, S. R., D. McNamara, B.H. Ramsay, T. Baldwin, and T. Kasheta, 2007: Enhancements to, and forthcoming developments in the Interactive Multisensor Snow and Ice Mapping System (IMS). Hydrol. Process., 21, 1576-1586.

Helm, K. P., N. L. Bindoff, and J. A. Church, 2010: Changes in the global hydrological-cycle inferred from ocean salinity. Geophys. Res. Lett., 37, L18701, doi:10.1029/2010GL044222.

Hendon, H., C. Zhang, and J. Glick, 1999: Interannual variation of the Madden-Julian Oscillation during Austral Summer. J. Climate, 12, 2538-2550.

Henry, O., P. Prandi, W. Llovel, A. Cazenave, S. Jevrejeva, D. Stammer, B. Meyssignac, and N. Koldunov, 2012: Tidal gauge-based sea level variations since 1950 along the Norwegian and Russian coasts of the Arctic Ocean. J. Geophys. Res., in press, doi:10.1029/2011JC007706.

Hilburn, K. A., and F. J. Wentz, 2008: Intercalibrated passive microwave rain products from the unified microwave ocean retrieval algorithm (UMORA). J. Appl. Meteor. Climatol., 47, 778-794.

Ho, S.-P., Y.-H. Kuo,W. Schreiner, X. Zhou, 2010: [Global climate] Using SI-traceable global positioning system radio occultation measurements for climate monitoring [in "State of the Climate in 2009]. Bull. Amer. Meteor. Sci., 91 (7), S36-S37.

Hofmann, D. J., and S. A. Montzka, 2009: Recovery of the ozone layer. Eos, Trans. Amer. Geophys. Union, 90, 1-2.

_ , J. H. Butler, E. J. Dlugokencky, J. W. Elkins, K. Masarie, S. A. Montzka, and P. Tans, 2006: The role of carbon dioxide in climate forcing from 1979-2004: Introduction of the Annual Greenhouse Gas Index. Tellus, 58B, 614-619. [Updated annually at: http://www.esrl.noaa.gov/gmd/aggi.]

Hosoda, S., T. Suga, N. Shikama, and K. Mizuno, 2009: Global surface layer salinity change detected by Argo and its implication for hydrological cycle intensification. J. Oceanogr., 65, 579-586. 
Hostetler, S. W., 1995: Hydrological and thermal response of lakes to climate: description and modelling. Physics and Chemistry of Lakes, A. Lerman et al., Eds., SpringerVerlag, 63-82.

Hu, Z.-Z., A. Kumar, B. Huang, Y. Xue, W. Wang, and B. Jha, 2011: Persistent atmospheric and oceanic anomalies in the North Atlantic from summer 2009 to summer 2010. J. Climate, 24, 5812-5830.

Huffman, G. J., and Coauthors, 2007: The TRMM multisatellite precipitation analysis: Quasi-global, multi-year, combined-sensor precipitation estimates at fine scale. $J$. Hydrometeor., 8, 38-55.

Hughes, N. A., 1984: Global cloud climatologies: A historical review. J. Clim. Appl. Meteor., 23, 724-751.

Hurrell, J. W., 1995: Decadal trends in the North Atlantic Oscillation: Regional temperatures and precipitation. Science, 269, 676-679.

—, Y. Kushnir, G. Ottersen, and M. Visbeck, 2003: An overview of the North Atlantic oscillation. The North Atlantic Oscillation: Climate Significance and Impact. Geophys. Monogr., Vol. 134, Amer. Geophys. Union, 1-37.

Hurst, D. F., S. J. Oltmans, H. Vömel, K. H. Rosenlof, S. M. Davis, E. A. Ray, E. G. Hall, and A. F. Jordan, 2011: Stratospheric water vapor trends over Boulder, Colorado: Analysis of the 30 year Boulder record. J. Geophys. Res., 116, D02306, doi:10.1029/2010JD015065.

IAI, 2011: Results of the 2010 anode effect survey. International Aluminium Institute, $52 \mathrm{pp}$. [Available online at http://www.world-aluminium.org/cache/fl0000441.pdf.]

IICWG, 2011: News release: National ice services caution that "Open" does not mean ice-free. International Ice Charting Working Group, 21 October 2011. [Available online at http://nsidc.org/noaa/iicwg/docs/IICWG_2011/ IICWG-XII_News_Release.pdf.]

Ingleby, B., and M. Huddleston, 2007: Quality control of ocean temperature and salinity profiles - historical and real-time data. J. Marine Sys., 65, 158-175.

INPE, cited 2012: Prodes project reporting. [Available online at http://www.obt.inpe.br/prodes/prodes_1988_2011. htm.]

Isaksen, K., J. L. Sollid, P. Holmlund, and C. Harris, 2007: Recent warming of mountain permafrost in Svalbard and Scandinavia. J. Geophys. Res., 112, F02S04, doi:10.1029/2006JF000522.

— - and Coauthors, 2011: Degrading mountain permafrost in southern Norway - spatial and temporal variability of mean ground temperatures 1999-2009. Permafrost Periglacial Processes, 22, 361-377.

Ishihara, K., 2006: Calculation of global surface temperature anomalies with COBE-SST. Sokkō-jihō [Weather Service Bulletin], 73 Special Issue, S19-S25, (in Japanese).
Ives, M., cited 2011: Okavango Delta flood update. [Available online at http://www.eyesonafrica.net/updates/ flood-update.htm]

Jackson, J. M., E. C. Carmack, F. A. McLaughlin, S. E. Allen, and R. G. Ingram, 2010: Identification, characterization, and change of the near-surface temperature maximum in the Canada Basin, 1993-2008. J. Geophys. Res., 115, C05021, doi:10.1029/2009JC005265.

— , S. E. Allen, F. A. McLaughlin, R. A. Woodgate, and E. C. Carmack, 2011: Changes in near-surface waters in the Canada Basin, Arctic Ocean, from 1993 to 2009: a basin in transition. J. Geophys. Res., 116, C10008, doi:10.1029/2011JC007069.

Jacob, T., J. Wahr, W. T. Pfeffer, and S. Swenson, 2012: Recent contributions of glaciers and ice caps to sea level rise. Nature, 482, 514-518.

Jacobs, S. S., A. Jenkins, C. F. Giulivi and P. Dutrieux, 2011: Strong ocean circulation and increased melting beneath Pine Island Glacier ice shelf. Nature Geosci., 4, 519-523.

Jacobson, M. Z., and Y. J. Kaufman, 2006: Wind reduction by aerosol particles. Geophys. Res. Lett., 33, L24814, doi:10.1029/22006GL027838.

Janowiak, J. E., and P. Xie, 1999: CAMS-OPI: A global satellite-rain gauge merged product for real-time precipitation monitoring applications. J. Climate, 12, 3335-3342.

Jáuregui, E., 2003: Climatology of landfalling hurricanes and tropical storms in Mexico. Atmósfera, 16, 193-204.

Johnson, D. R., T. P. Boyer, H. E. Garcia, R. A. Locarnini, O. K. Baranova, and M. M. Zweng, 2009: World Ocean Database 2009 documentation. NODC Internal Rep. 20, 175 pp.

Johnson, F., and A. Sharma, 2010: A comparison of Australian open water body evaporation trends for current and future climates estimated from Class A evaporation pans and general circulation models. J. Hydrometeorol., 11, 105-121.

Johnson, G. C., and N. Gruber, 2007: Decadal water mass variations along $20^{\circ} \mathrm{W}$ in the northeastern Atlantic Ocean. Prog. Oceanogr., 73, 277-295.

_ , and S. E. Wijffels, 2011: Ocean density change contributions to sea level rise. Oceanography, 24, 112-121.

Jones, A., and Coauthors, 2009: Evolution of stratospheric ozone and water vapour time series studied with satellite measurements. Atmos. Chem. Phys., 9, 6055-6075.

Jones, P. D., D. H. Lister, T. J. Osborn, C. Harpham, M. Salmon, and C. P. Morice, 2012: Hemispheric and largescale land surface air temperature variations: An extensive revision and an update to 2010. J. Geophys. Res., 117, D05127, doi:10.1029/2011JD017139.

Josey, S. A., E. C. Kent, and P. K. Taylor, 1999: New insights into the ocean heat budget closure problem from analysis of the SOC air-sea flux climatology. J. Climate, 12, 2856-2880. 
Jung, M., and Coauthors, 2010: Recent decline in the global land evapotranspiration trend due to limited moisture supply. Nature, 467, 951-954.

Kahru, M., V. Brotas, M. Manzano-Sarabia, and B. G. Mitchell, 2010: Are phytoplankton blooms occurring earlier in the Arctic? Global Change Biol., 17, 1733-1739, doi: 10.1111/j.1365-2486.2010.02312.x.

Kaiser, J. W., A. Heil, and G. R. van der Werf, 2011: [Global climate] Biomass burning [in "State of the Climate in 2010"]. Bull. Amer. Meteor. Soc., 92 (6), S72-S74.

— timated with a global fire assimilation system based on observed fire radiative power. Biogeosciences, 9, 527-554.

Kalnay, E., and Coauthors, 1996: The NCEP/NCAR 40-year reanalysis project. Bull. Amer. Meteor. Soc., 77, 437-471.

Kanzow, T., U. Send, and M. McCartney, 2008: On the variability of the deep meridional transports in the tropical North Atlantic. Deep-Sea Res. I, 55, 1601-1623.

— , and Coauthors, 2010: Seasonal variability of the Atlantic meridional overturning circulation at $26.5^{\circ} \mathrm{N}$. J. Climate, 23, 5678-5698.

Kaplan, A., 2011: [Global climate] Patterns and indices of climate variability [in: "State of the Climate 2010"]. Bull. Amer. Meteor. Soc., 92 (6), S20-S25.

Kaplan, J., M. DeMaria, and J. A. Knaff, 2010: A revised tropical cyclone rapid intensification index for the Atlantic and east Pacific basins. Wea. Forecasting, 25, 220-241.

Kayano, M., and V. Kousky, 1999: Intraseasonal (30-60 day) variability in the global tropics: Principal modes and their evolution. Tellus, 51A, 373-386.

Kennett, J. P., K. G. Cannariato, I. L. Hendy, and R. J. Behl, 2000: Carbon isotopic evidence for methane hydrate instability during quaternary interstadials. Science, $\mathbf{2 8 8}$, 128-133, doi:10.1126/science.288.5463.128.

Kent, E. C., S. D. Woodruff, and D. I. Berry, 2007: Metadata from WMO Publication No. 47 and an assessment of voluntary observing ship observation heights in ICOADS. J. Atmos. Oceanic Tech., 24, 214-234.

Key, R. M., and Coauthors, 2004: A global ocean carbon climatology: Results from GLODAP. Global Biogeochem. Cycles, 18, GB4031, doi:10.1029/2004GB002247.

Khatiwala, S., F. Primeau, and T. Hall, 2009: Reconstruction of the history of anthropogenic $\mathrm{CO}_{2}$ concentrations in the ocean. Nature, 462, 346-349.

Kiladis, G. N., K. H. Straub, and P. T. Haertel, 2005: Zonal and vertical structure of the Madden-Julian oscillation. J. Atmos. Sci., 62, 2790-2809.

King, D., W. Tawhai, A. Skipper, and W. Iti, 2005: Anticipating local weather and climate outcomes using Māori environmental indicators. NIWA AKL2005-129, 15 pp. [Available online at http://www.niwa.co.nz/sites/default/ files/niwa_report_akl2005-129.pdf.]
—, J. Goff, and A. Skipper, 2007: Maori environmental knowledge and natural hazards in Aotearoa - New Zealand. J. Roy. Soc. New Zealand, 37, 59-73.

Kistler, R., and Coauthors, 2001: The NCEP/NCAR 50-year reanalysis: Monthly means CD-ROM and documentation. Bull. Amer. Meteor. Soc., 82, 247-267.

Klein, A. G., and J. Stroeve, 2002: Development and validation of a snow albedo algorithm for the MODIS instrument. Ann. Glaciol., 34, 45-52.

Klein, S. A., B. J. Soden, and N.-C. Lau, 1999: Remote sea surface temperature variations during ENSO: Evidence for a tropical atmospheric bridge. J. Climate, 12, 917-932.

Knapp, K. R., M. C. Kruk, D. H. Levinson, H. J. Diamond, and C. J. Neumann, 2010: The International Best Track Archive for Climate Stewardship (IBTrACS). Bull. Amer. Meteor. Soc., 91, 363-376.

Knight, J. R., R. J. Allan, C. K. Folland, M. Vellinga, and M. E. Mann, 2005: A signature of persistent natural thermohaline circulation cycles in observed climate. Geophys. Res. Lett., 32, L20708, doi:10.1029/2005GL024233.

Knutti, R., and L. Tomassini, 2008: Constraints on the transient climate response from observed global temperature and ocean heat uptake. Geophys. Res. Lett., 35, L09701, doi:10.1029/2007GL032904.

Kopp, G., and J. L. Lean, 2011: A new, lower value of total solar irradiance: Evidence and climate significance. Geophys. Res. Lett., 38, L01706, doi:10.1029/2010GL045777.

- , G. Lawrence, and G. Rottman, 2005: The Total Irradiance Monitor (TIM): Science results. Solar Physics, 230, 129-139.

Kort, E. A., and Coauthors, 2011: Tropospheric distribution and variability of $\mathrm{N}_{2} \mathrm{O}$ : Evidence for strong tropical emissions. Geophys. Res. Lett., 38, L15806, doi:10.1029/2011GL047612.

Kossin, J. P., and D. J. Vimont, 2007: A more general framework for understanding Atlantic hurricane variability and trends. Bull. Amer. Meteor. Soc., 88, 1767-1781.

—, S. J. Camargo, and M. Sitkowski, 2010: Climate modulation of North Atlantic hurricane tracks. J. Climate, 23, 3057-3076.

Kouraev, A. V., S. V. Semovski, M. N. Shimaraev, N. M. Mognard, B. Légresy, and F. Remy, 2007: Observations of Lake Baikal ice from satellite altimetry and radiometry. Remote Sens. Environ, 108, 240-253.

Kousky, V., and M. Kayano, 1994: Principal modes of outgoing longwave radiation and 250-mb circulation for the South American sector. J. Climate, 7, 1131-1143.

Kratz, D. P., S. K. Gupta, A. C. Wilber, and V. E. Sothcott, 2010: Validation of the CERES edition 2B surface-only flux algorithms. J. Appl. Meteor. Climatol., 49, 164-180.

Kwiatkowska, E. J., B. A. Franz, G. Meister, C. R. McClain, and X. Xiong, 2008: Cross-calibration of ocean color 
bands from Moderate Resolution Imaging Spectroradiometer on Terra platform. Appl. Optics, 47, 6796-6810.

Lagerloef, G., and J. Font, 2010: SMOS and Aquarius/SAC-D missions: The era of space borne salinity measurements is about to begin. Oceanography from Space, V. Barale et al., Eds., Springer.

— Designed to meet the salinity remote sensing challenge. Oceanography, 21, 68-81.

_- R. Schmitt, J. Schanze, and H. Kao, 2010: The ocean and the global water cycle. Oceanography, 23, 82-93.

Lamarque, J. F., and S. Solomon, 2010: Impact of changes in climate and halocarbons on recent lower stratospheric ozone and temperature trends. J. Climate, 23, 2599-2611.

Lander, M. A., 1994: An exploratory analysis of the relationship between tropical storm formation in the western North Pacific and ENSO. Mon. Wea. Rev., 122, 636-651.

Landsea, C. W., and W. M. Gray, 1992: The strong association between Western Sahel monsoon rainfall and intense Atlantic hurricanes. J. Climate, 5, 435-453.

— , G. D. Bell, W. M. Gray, and S. B. Goldenberg, 1998: The extremely active 1995 Atlantic hurricane season: Environmental conditions and verification of seasonal forecasts. Mon. Wea. Rev., 126, 1174-1193.

Latifovic, R., and D. Pouliot, 2007: Analysis of climate change impacts on lake ice phenology in Canada using the historical satellite data record. Remote Sens. Environ., 106, 492-508.

Lawrence, D. M., A. G. Slater, R. A. Tomas, M. M. Holland, and C. Deser, 2008: Accelerated Arctic land warming and permafrost degradation during rapid sea ice loss. Geophys. Res. Lett., 35, L11506, doi:10.1029/2008GL033985.

Le Quéré, C., and Coauthors, 2009: Trends in the sources and sinks of carbon dioxide. Nature Geosci., 2, 831-836.

Le Vine, D. M., G. S. E. Lagerloef, R. Colomb, S. Yueh, and F. Pellerano, 2007: Aquarius: An instrument to monitor sea surface salinity from space. IEEE Trans. Geosci. Remote Sens., 45, 2040-2050.

L'Ecuyer, T. S., N. B. Wood, T. Haladay, G. L. Stephens, and P. W. Stackhouse, 2008: Impact of clouds on atmospheric heating based on the R04 CloudSat fluxes and heating rates data set. J. Geophys. Res., 113, D00A15, doi:10.1029/2008JD009951.

Lee, H., C. K. Shum, K. H. Tseng, J. Y. Guo, amd C. Y. Kuo, 2011: Present-day lake level variation from ENVISAT Altimetry over the northeastern Qinghai-Tibetan Plateau: Links with precipitation and temperature. J. Terrestrial Atmos. Ocean Sci., 22, 169-175.

Lefale, P. F., 2003: Seasons in Samoa. Water Atmos., 11, 10-11. [Available online at http://www.niwa.co.nz/publications/ wa/vol11-no2-june-2003/seasons-in-samoa.]
_- 2010: Ua Afa le Aso Stormy weather today: Traditional ecological knowledge of weather and climate. The Samoa experience. Climatic Change, 100, 317-335.

Lefsky, M. A., 2010: A global forest canopy height map from the Moderate Resolution Imaging Spectroradiometer and the Geoscience Laser Altimeter System. Geophys. Res. Lett., 37, L15401, doi:10.1029/2010GL043622.

Leuliette, E. W., and R. Scharroo, 2010: Integrating Jason-2 into a multiple-altimeter climate data record. Marine Geodesy, 33, 504-517.

- , and J. K. Willis, 2011: Balancing the sea level budget. Oceanography, 24 (2), 122-129.

Levitus, S., J. I. Antonov, T. P. Boyer, R. A. Locarnini, H. E. Garcia, and A. V. Mishonov, 2009: Global ocean heat content 1955-2007 in light of recently revealed instrumentation problems. Geophys. Res. Lett., 36, L07608, doi:10.1029/2008GL037155.

,,--- , J. Reagan, and C. Schmid, 2011 : [Global oceans] Subsurface salinity [in "State of the Climate in 2010”]. Bull. Amer. Meteor. Soc., 92 (6), S88-S92.

L'Heureux, M. L., D. Collins, and Z. Hu, 2012: Linear trends in sea surface temperature of the tropical Pacific Ocean and implications for the El Niño-Southern Oscillation. Climate Dyn., in press, doi:10.1007/s00382-012-1331-2.

Li, W. K. W., F. A. McLaughlin, C. Lovejoy, and E. C. Carmack, 2009: Smallest algae thrive as the Arctic Ocean freshens. Science, 326, 539.

Liebmann, B., and C. A. Smith, 1996: Description of a complete (interpolated) outgoing longwave radiation dataset. Bull. Amer. Meteor. Soc., 77, 1275-1277.

Lin, I.-I., C. C. Wu, I.-F. Pun, and D.-S. Ko, 2008: Upper-ocean thermal structure and the western North Pacific category 5 typhoons. Part I: Ocean features and the category 5 typhoons' intensification. Mon. Wea. Rev., 136, 3288-3306.

—, C.-H. Chen, I.-F. Pun, W. T. Liu, and C.-C. Wu, 2009a: Warm ocean anomaly, air sea fluxes, and the rapid intensification of Tropical Cyclone Nargis. Geophy. Res. Lett., 36, L03817, doi: 10.1029/2008GL035815.

_ , I.-F. Pun, and C.-C. Wu, 2009b: Upper ocean thermal structure and the western North Pacific category-5 typhoons. Part II: Dependence on translation speed. Mon. Wea. Rev., 137, 3744-3757.

Liu, H., L. Wang, and K. Jezek, 2005: Wavelet-based edge detection approach to derivation of snow-melt onset, duration and extent from satellite passive microwave measurements. Int. J. Remote Sens., 26, 4639-4660.

- - — , and — 2006: Spatiotemporal variations of snowmelt in Antarctica derived from satellite SMMR and SSM/I data (1978-2004). J. Geophys. Res., 111, F01003, doi:10.1029/2005JF000318.

Liu, Y., J. R. Key, and X. Wang, 2009: Influence of changes in sea ice concentration and cloud cover on recent Arc- 
tic surface temperature trends. Geophys. Res. Lett., 36, L20710, doi:10.1029/2009GL040708.

—_ _ Z Z. Liu, X. Wang, and S. J. Vavrus, 2012: A cloudier Arctic expected with diminishing sea ice. Geophys. Res. Lett., 39, L05705, doi:10.1029/2012GL051251.

Liu, Y. Y., R. A. M. de Jeu, A. I. J. M. van Dijk, and M. Owe, 2007: TRMM-TMI satellite observed soil moisture and vegetation density (1998-2005) show strong connection with El Nino in eastern Australia. Geophys. Res. Lett., 34, L15401, doi:10.1029/2007GL030311.

—, A. I. J. M. van Dijk, R. A. M. de Jeu, and T. R. H. Holmes, 2009: An analysis of spatiotemporal variations of soil and vegetation moisture from a 29-year satellite-derived data set over mainland Australia. Water Resour. Res., 45, W07405, doi:10.1029/2008wr007187.

_ moisture dataset by blending passive and active microwave satellite-based retrievals. Hydrol. Earth Syst. Sci., 15, 425-436.

Llovel, W., S. Guinehut, and A. Cazenave, 2009: Regional and interannual variability in sea level over 2002-2009 based on satellite altimetry, Argo float data and GRACE ocean mass. Ocean Dyn., 60, 1193-1204.

Loeb, N. G., S. Kato, W. Su, T. Wong, F. Rose, D. R. Doelling, and J. Norris, 2012: Advances in understanding top-of-atmosphere radiation variability from satellite observations. Surv. Geophys., in press, doi:10.1007/s10712-012-9175-1.

Lohmann, U., and J. Feichter, 2005: Global indirect aerosol effects: A review. Atmos. Chem. Phys., 5, 715-737.

Lu, J., and T. L. Delworth, 2005: Oceanic forcing of the late 20th century Sahel drought. Geophys. Res. Lett., 32, L22706, doi:10.1029/2005GL023316.

Lumpkin, R., and S. Garzoli, 2010: Interannual to decadal changes in the southwestern Atlantic's surface circulation. J. Geophys. Res., 116, C01014, doi:10.1029/2010JC006285.

Luo, J.-J., S. Behera, Y. Masumoto, H. Sakuma, and T. Yamagata, 2008: Successful prediction of the consecutive IOD in 2006 and 2007. Geophys. Res. Lett., 35, L14S02, doi:10.1029/2007GL032793.

_-, R. Zhang, S. K. Behera, Y. Masumoto, F.-F. Jin, R. Lukas, and T. Yamagata, 2010: Interaction between El Niño and extreme Indian Ocean dipole. J. Climate, 23, 726-742.

Lyman, J. M., 2011: Estimating global energy flow from the global upper ocean. Surv. Geophys., in press, doi:10.1007/ s10712-011-9167-6.

—_, and G. C. Johnson, 2008: Estimating global upper ocean heat content despite irregular sampling. J. Climate, 21, 5629-5641.

- S. A. Good, V. V. Gouretski, M. Ishii, G. C. Johnson, M. D. Palmer, D. A. Smith, and J. K. Willis, 2010: Robust warming of the global upper ocean. Nature, 465, 334-337.
Lyon, B., and S. J. Camargo, 2009: The seasonally-varying influence of ENSO on rainfall and tropical cyclone activity in the Philippines. Climate Dyn., 32, 125-141.

— and D. G. DeWitt, 2012: A recent abrupt decline in the East Africa Long Rains. Geophys. Res. Lett., 39, L02702, doi:10.1029/2011GL050337.

Ma, Z., and Coauthors, 2012: Regional drought-induced reduction in the biomass carbon sink of Canada's boreal forests. Proc. Natl. Acad. Sci. USA, in press, doi:10.1073/ pnas.1111576109.

MacCallum, S. N., and C. J. Merchant, 2012: Surface water temperature observations of large lakes by optimal estimation. Can. J. Remote Sens., 38, 25-45, doi:10.5589/ m12-010.

Madden, R., and P. Julian, 1971: Detection of a 40-50 day oscillation in the zonal wind in the tropical Pacific. J. Atmos. Sci., 28, 702-708.

— and - 1972: Description of global-scale circulation cells in the tropics with a 40-50 day period. J. Atmos. Sci., 29, 1109-1123.

—, and - 1994: Observations of the 40-50 day tropical oscillation: A review. Mon. Wea. Rev., 122, 814-837.

Mäder, J. A., J. Staehelin, T. Peter, D. Brunner, H. E. Rieder, and W. A. Stahel, 2010: Evidence for the effectiveness of the Montreal Protocol to protect the ozone layer. Atmos. Chem. Phys., 10, 19005-19029.

Maes, C., K. Ando, T. Delcroix, W. S. Kessler, M. J. McPhaden, and D. Roemmich, 2006: Observed correlation of surface salinity, temperature and barrier layer at the eastern edge of the western Pacific warm pool. Geophys. Res. Lett., 33, L06601, doi:10.1029/2005GL024772.

Mainelli, M., M. DeMaria, L. Shay, and G. Goni, 2008: Application of oceanic heat content estimation to operational forecasting of recent Atlantic category 5 hurricanes. Wea. Forecasting, 23, 3-16.

Malhi, Y., and Coauthors, 2002: An international network to monitor the structure, composition and dynamics of Amazonian forests (RAINFOR). J. Vegetation Sci. 13, 439-450.

Maloney, E. D., and D. L. Hartmann, 2001: The Madden-Julian oscillation, barotropic dynamics, and North Pacific tropical cyclone formation. Part I: Observations. J. Atmos. Sci., 58, 2545-2558.

Manney, G. L., and Coauthors, 2011: Unprecedented Arctic ozone loss in 2011. Nature, 478, 469-475.

Mantua, N. J., S. R. Hare, Y. Zhang, J. M. Wallace, and R. C. Francis, 1997: A Pacific interdecadal climate oscillation with impacts on salmon production. Bull. Amer. Meteor. Soc., 78, 1069-1079.

Marshall, G. J., 2003: Trends in the southern annular mode from observations and reanalyses. J. Climate, 16, 4134-4143. 
_ 2007: Short communication: Half-century seasonal relationships etween the Southern Annular Mode and Antarctic temperatures. Int. J. Climatol., 27, 373-383, doi:10.1002/joc.1407.

Martinson, D. G., 2011: Antarctic circumpolar current's role in the Antarctic ice system: An overview. Palaeogeogr., Paleoclimatol., Palaeoecol., 335-336, 71-74, doi:10.1016/j. palaeo.2011.04.007.

Maslanik, J., and J. Stroeve, 1999: Near-real time DMSP SSM/I daily polar gridded sea ice concentrations. National Snow and Ice Data Center, Boulder, CO, digital media. [Available online at http://nsidc.org/data/nsidc-0081. html.]

—, C. Fowler, J. Stroeve, S. Drobot, J. Zwally, D. Yi, and W. Emery, 2007: A younger, thinner Arctic ice cover: Increased potential for rapid, extensive sea-ice loss. Geophys. Res. Lett., 34, L24501, doi:10.1029/2007GL032043.

_ J. Stroeve, C. Fowler, and W. Emery, 2011: Distribution and trends in Arctic sea ice age through spring 2011. Geophys. Res. Lett., 38, L13502, doi:10.1029/2011GL047735.

Massom, R. A., S. E. Stammerjohn, W. Lefebvre, S. A. Harangozo, N. Adams, T. A. Scambos, M. J. Pook, and C. Fowler, 2008: West Antarctic Peninsula sea ice in 2005: Extreme ice compaction and ice edge retreat due to strong anomaly with respect to climate. J. Geophys. Res., 113, C02S20, doi:10.1029/2007JC004239.

Matear, R. J., and A. C. Hirst, 2003: Long-term changes in dissolved oxygen concentrations in the ocean caused by protracted global warming. Global Biogeochem. Cycles, 17, 1125, doi:10.1029/2002GB001997.

Mathis, J. T., J. N. Cross, and N. R. Bates, 2011: Coupling primary production and terrestrial runoff to ocean acidification and carbonate mineral suppression in the eastern Bering Sea. J. Geophys. Res., 116, C02030, doi:10.1029/2010JC006453.

Matsuo, K., and K. Heki, 2010: Time-variable ice loss in Asian high mountains from satellite gravimetry. Earth Planet. Sci. Lett., 290, 30-36.

McCabe, G., M. Palecki, and J. Betancourt, 2004: Pacific and Atlantic Ocean influences on multidecadal drought frequency in the United States. Proc. Natl. Acad. Sci. USA, 101, 4136-4141.

McCarthy, J., and Coauthors, 2004: Patterns in the Okavango Wetland in Botswana, between 1972 and 2000. Ambio, 7, 453-457.

McClain, C. R., 2009: A decade of satellite ocean color observations. Ann. Rev. Marine Sci., 1, 19-42.

—, G. C. Feldman, and S. B. Hooker, 2004: An overview of the SeaWiFS project and strategies for producing a climate research quality global ocean bio-optical time series. Deep-Sea Res. II, 51, 5-42.
McGuire, D. A., and Coauthors, 2009: Sensitivity of the carbon cycle in the Arctic to climate change. Ecol. Monogr., 79, 523-555.

McKinley, G. A., A. R. Fay, T. Takahashi, and N. Metzl, 2011: Convergence of atmospheric and North Atlantic carbon dioxide trends on multidecadal timescales. Nature Geosci., 4, 606-610.

McTaggart-Cowan, R., G. D. Deane, L. F. Bosart, C. A. Davis, and T. J. Galarneau, 2008: Climatology of tropical cyclogenesis in the North Atlantic (1948-2004). Mon. Wea. Rev., 136, 1284-1304.

McVicar, T. R., T. G. Van Niel, L. T. Li, M. L. Roderick, D. P. Rayner, L. Ricciardulli, and R. J. Donohue, 2008: Wind speed climatology and trends for Australia, 1975-2006: Capturing the stilling phenomenon and comparison with near-surface reanalysis output. Geophys. Res. Lett., 35, L20403, doi:10.1029/2008GL035627.

_ , and Coauthors, 2012: Global review and synthesis of trends in observed terrestrial near-surface wind speeds: Implications for evaporation. J. Hydrol., 416/417, 182-205.

Mears, C. A., and F. J. Wentz, 2009: Construction of the RSS V3.2 lower tropospheric temperature records from the MSU and AMSU microwave sounders. J. Atmos. Oceanic Tech., 26, 1492-1509.

Meier, M. F., M. B. Dyurgerov, U. K. Rick, S. O’Neel, W. T. Pfeffer, R. S. Anderson, S. P. Anderson, and A. F. Glazovsky, 2007: Glaciers dominate eustatic sea level rise in the 21st century. Science, 317, 1064-1067.

Meijers, A. J. S., N. L. Bindoff, and S. R. Rintoul, 2011: Frontal movements and property fluxes: Contributions to heat and freshwater trends in the Southern Ocean. J. Geophys. Res., 116, C08024, doi:10.1029/2010JC006832.

Meinen, C. S., M. O. Baringer, and R. F. Garcia, 2010: Florida current transport variability: An analysis of annual and longer-periods. Deep-Sea Res. I, 57, 835-846.

Meister, G., B. A. Franz, E. J. Kwiatkowska, and C. R. McClain, 2012: Corrections to the calibration of MODIS Aqua ocean color bands derived from SeaWiFS data. IEEE Trans. Geosci. Remote Sens., 50, 310-319.

Mekis, E., and L. Vincent, 2011: An overview of the second generation adjusted daily precipitation dataset for trend analysis in Canada. Atmos.-Ocean, 49, 163-177.

Mekonnen, A., C. D. Thorncroft, A. R. Aiyyer, and G. N. Kiladis, 2008: Convectively coupled Kelvin waves over tropical Africa during the boreal summer: Structure and variability. J. Climate, 21, 6649-6667.

Menéndez, M., and P. Woodworth, 2010: Changes in extreme high water levels based on a quasi-global tide-gauge data set. J. Geophys. Res., 115, C10011, doi:10.1029/2009JC005997.

Meredith, M. P., and J. C. King, 2005: Rapid climate change in the ocean west of the Antarctic Peninsula during the 
second half of the 20th century. Geophys. Res. Lett., 32, L19604, doi:10.1029/2005GL024042.

Merrifield, M. A., 2011: A shift in western tropical Pacific sea level trends during the 1990s. J. Climate, 24, 4126-4138.

— , and M. E. Maltrud, 2011: Regional sea level trends due to a Pacific trade wind intensification. Geophys. Res. Lett., 38, L21605, doi:10.1029/2011GL049576.

Miller, B. R., and Coauthors, 2010: HFC-23 ( $\left.\mathrm{CHF}_{3}\right)$ emission trend response to $\mathrm{HCFC}-22\left(\mathrm{CHClF}_{2}\right)$ production and recent HFC-23 emission abatement measures. Atmos. Chem. Phys., 10, 7875-7890.

Mo, K. C., and V. E. Kousky, 1993: Further analysis of the relationship between circulation anomaly anomaly patterns and tropical convection. J. Geophys. Res., 98 (D3), 5103-5113.

Mokhov, I. L., and M. E. Schlesinger, 1994: Analysis of global cloudiness 2. Comparison of ground-based and satellite-based cloud climatologies. J. Geophys. Res., 99 (D8), 17045-17065.

Montzka, S. A., and Coauthors, 2011: Ozone-depleting substances (ODSs) and related chemicals. Scientific Assessment of Ozone Depletion: 2010, Global Ozone Research and Monitoring Project Rep. 52, World Meteorological Organization, 1.1-1.108.

Mooers, C. N. K., C. S. Meinen, M. O. Baringer, I. Bang, R. Rhodes, C. N. Barron, and F. Bub, 2005: Florida current response to cold front passages: Comparison of NOAA cable and Navy model volume transports. Eos, Trans. Amer. Geophys. Union, 86, 269, 272-273.

Mostafaeipour, A., 2010: Feasibility study of harnessing wind energy for turbine installation in province of Yazd in Iran. Renew. Sustain. Energy Rev., 14, 93-111.

Mote, T. L., 2007: Greenland surface melt tends 1973-2007: Evidence of a large increase in 2007. Geophys. Res. Lett., 34, L22507, doi:10.1029/2007GL031976.

Mounier, F., G. N. Kiladis, and S. Janicot, 2007: Analysis of the dominant mode of convectively coupled Kelvin waves in the West African monsoon. J. Climate, 20, 1487-1503.

Mühle, J., and Coauthors, 2010: Perfluorocarbons in the global atmosphere: Tetrafluoromethane, hexafluoroethane, and octafluoropropane. Atmos. Chem. Phys., 10, 5145-5164.

Mullan, A. B., 2011: [Tropics] Intertropical convergence zones [in "State of the Climate in 2010"]. Bull. Amer. Meteor. Soc., 92 (6), S134-S136.

Müller, R., J.-U. Grooß, C. Lemmen, D. Heinze, M. Dameris, and G. Bodeker, 2008: Simple measures of ozone depletion in the polar stratosphere. Atmos. Chem. Phys., 8, 251-264.

Münnich, M., and J. D. Neelin, 2005: Seasonal influence of ENSO on the Atlantic ITCZ and equatorial South America. Geophys. Res. Lett., 32, L21709, doi:10.1029/2005GL023900.
Muñoz, E., C. Wang, and D. Enfield, 2010: The Intra-Americas springtime sea surface temperature anomaly dipole as fingerprint of remote influences. J. Climate, 23, 43-56.

Murata, A., Y. Kumamoto, S. Watanabe, and M. Fukasawa, 2007: Decadal increases of anthropogenic $\mathrm{CO}_{2}$ in the South Pacific subtropical ocean along $32^{\circ} \mathrm{S}$. J. Geophys. Res., 112, C05033, doi:10.1029/2005JC003405.

Murphy, B. F., and B. Timbal, 2008: A review of recent climate variability and climate change in southeastern Australia. Int. J. Climatol., 28, 859-879.

Narama, C., A. Kääb, M. Duishonakunov, and K. Abdrakhmatov, 2010: Spatial variability of recent glacier area changes in the Tien Shan Mountains, Central Asia, using Corona ( 1970), Landsat ( 2000) and ALOS ( 2007) satellite data. Global Planet. Change, 71, 42-54.

National Ice Center, 2008: IMS daily Northern Hemisphere snow and ice analysis at $4 \mathrm{~km}$ and $24 \mathrm{~km}$ resolution. National Snow and Ice Data Center, Boulder, CO, digital media. [Available online at http://nsidc.org/data/g02156. html.]

Nerem, R., D. Chambers, E. Leuliette, G. Mitchum, and B. Giese, 1999: Variations in global mean sea level associated with the 1997-1998 ENSO event: Implications for measuring long-term sea level change. Geophys. Res. Lett., 26, 3005-3008.

$\longrightarrow,-$ C. Choe, and G. Mitchum, 2010: Estimating mean sea level change from the TOPEX and Jason altimeter missions. Marine Geodesy, 33, 435-446.

Neumann, C. J., B. R. Jarvinen, C. J. McAdie, and J. D. Elms, 1993: Tropical Cyclones of the North Atlantic Ocean, 18711992. NOAA National Climatic Data Center, 193 pp.

Newman, P. A., J. S. Daniel, D. W. Waugh, and E. R. Nash, 2007: A new formulation of equivalent effective stratospheric chlorine (EESC). Atmos. Chem. Phys., 7, 4537-4552.

Nicolas, J. P., and D. H. Bromwich, 2011: Precipitation changes in high southern latitudes from global reanalyses: A cautionary tale. Surv. Geophys., 32, 475-494.

Niiler, P. P., R. E. Davis, and H. J. White, 1987: Water-following characteristics of a mixed layer drifter. Deep-Sea Res. A, 34, 1867-1881.

- N. A. Maximenko, G. G. Panteleev, T. Yamagata, and D. B. Olson, 2003: Near-surface dynamical structure of the Kuroshio Extension. J. Geophys. Res., 108, 3193, doi:10.1029/2002JC001461.

NIWA, 2011: NIWA Year in Review 2011. National Institute of Water and Atmosphere Research, 53 pp. [Available online at http://www.niwa.co.nz/about-niwa/annualreports/2011-year-in-review.]

Njoku, E. G., T. J. Jackson, V. Lakshmi, T. K. Chan, and S. V. Nghiem, 2003: Soil moisture retrieval from AMSR-E. IEEE Trans. Geosci. Remote Sens., 41, 215-229. 
NOAA, 2004: The NOAA-NASA Pathfinder Program. University Corporation for Atmospheric Research, $22 \mathrm{pp}$.

Nobre, P., and J. Shukla, 1996: Variations of sea surface temperature, wind stress and rainfall over the tropical Atlantic and South America. J. Climate, 9, 2464-2479.

Novelli, P. C., K. A. Masarie, P. M. Lang, B. D. Hall, R. C. Myers, and J. W. Elkins, 2003: Reanalysis of tropospheric CO trends: Effects of the 1997-1998 wildfires. J. Geophys. Res., 108, 4464, doi:10.1029/2002JD003031.

NRC, 2004: Climate Data Records from Environmental Satellites. National Academies Press, 150 pp.

_- 2011: Assessing Requirements for Sustained Ocean Color Research and Operations. National Academies Press, 100 pp.

O'Connor, F. M., and Coauthors, 2010: Possible role of wetlands, permafrost, and methane hydrates in the methane cycle under future climate change: A review. Rev. Geophys., 48, RG4005, doi:10.1029/2010RG000326.

Oerlemans, J., 1994: Quantifying global warming from the retreat of glaciers. Science, 264, 243-245.

Olsen, A., A. M. Omar, E. Jeansson, L. G. Anderson, and R. G. J. Bellerby, 2010: Nordic seas transit time distributions and anthropogenic $\mathrm{CO}_{2}$. J. Geophys. Res., 115, C05005, doi:10.1029/2009JC005488.

O’Malley, R. T., M. J. Behrenfeld, D. A. Siegel, and S. Maritorena, 2010: [Global oceans] Global ocean phytoplankton [in "State of the Climate in 2009"]. Bull. Amer. Meteor. Soc., 91 (7), S75-S78.

Onogi, K., and Coauthors, 2007: The JRA-25 reanalysis. J. Meteor. Soc. Japan, 85, 369-432.

Orr, A., D. Cresswell, G. J. Marshall, J. C. R. Hunt, J. Sommeria, C-G. Wang, and M. Light, 2004: A 'low-level' explanation for the recent large warming trend over the western Antarctic Peninsula involving blocked winds and changes in zonal circulation. Geophys. Res. Lett., 31, L06204, doi:10.1029/2003GL019160.

_ , G. J. Marshall, J. C. R. Hunt, J. Sommeria, C-G. Wang, N. P. M. van Lipzig, D. Cresswell, and J. C. King, 2008: Characteristics of summer airflow over the Antarctic Peninsula in response to recent strengthening of westerly circumpolar winds. J. Atmos. Sci., 65, 1396-1412.

Orr, J. C., and Coauthors, 2005: Anthropogenic ocean acidification over the twenty-first century and its impact on calcifying organisms. Nature, 437, 681-686.

Osterkamp, T. E., 2008: Thermal state of permafrost in Alaska during the fourth quarter of the twentieth century (plenary paper). Proc. Ninth Int. Conf. on Permafrost, Fairbanks, AK, Vol. 2, D. L. Kane and K. M Hinkel, Eds., Institute of Northern Engineering, University of Alaska, Fairbanks, 1333-1338.

Overland, J. E., U. Bhatt, J. Key, Y. Liu, J. Walsh, and M. Wang, 2011a: Temperature and clouds. Arctic Report Card,
J. Richter-Menge, M. O. Jeffries, and J. E. Overland, Eds., NOAA Rep., 11-19. [Available online at http://www.arctic. noaa.gov/reportcard.]

— K. R. Wood, and M. Wang, 2011b: Warm Arctic-cold continents: Impacts of the newly open Arctic Sea. Polar Res. 30, 15787, doi:10.3402/polar.v30i0.15787.

Owe, M., R. A. M. De Jeu, and T. R. H. Holmes, 2008: Multisensor historical climatology of satellite-derived global land surface moisture. J. Geophys. Res., 113, F01002, doi:10.1029/2007JF000769.

Palmer, M. D., and P. Brohan, 2011: Estimating sampling uncertainty in fixed-depth and fixed-isotherm estimates of ocean warming. Int. J. Climatol., 31, 980-986.

_ , K. Haines, S. F. B. Tett, and T. J. Ansell, 2007: Isolating the signal of ocean global warming. Geophys. Res. Lett., 34, L23610, doi:10.1029/2007GL031712.

Pan, Y., and Coauthors, 2011: A large and persistent carbon sink in the world's forests. Science, 333, 988-993.

Park, G-H., K. Lee, P. Tishchenko, D. Min, M. J. Warner, L. D. Talley, D. Kang, and K. Kim, 2006: Large accumulation of anthropogenic $\mathrm{CO}_{2}$ in the East (Japan) Sea and its significant impact on carbonate chemistry. Global Biogeochem. Cycles, 20, GB4013, doi:10.1029/2005GB002676.

_ - and Coauthors, 2010: Variability of global net sea-air $\mathrm{CO}_{2}$ fluxes over the last three decades using empirical relationships. Tellus, 62B, 352-368.

Pelto, M. S., 2010: Forecasting temperate alpine glacier survival from accumulation zone observations. The Cryosphere, 4, 67-75.

_ 2011: North Cascade Glacier Climate Project 2011 field season report. [Available online at http://glacierchange. wordpress.com/2011/08/28/north-cascade-glacierclimate-project-2011-field-season-report/.]

Peng, C., and Coauthors, 2011: A drought-induced pervasive increase in tree mortality across Canada's boreal forests. Nature Climate Change, 1, 467-471.

PERMOS, 2010: Permafrost in Switzerland 2006/2007 and 2007/2008. Glaciological Report (Permafrost) 8/9, Cryospheric Commission of the Swiss Academy of Sciences, 68 pp. [Available online at http://www.permos.ch/downloads/permos06-08.pdf.]

Perovich, D., W. Meier, J. Maslanik, and J. Richter-Menge, 2011: Sea ice. Arctic Report Card, J. Richter-Menge, M. O. Jeffries, and J. E. Overland, Eds., NOAA Rep., 42-54. [Available online at http://www.arctic.noaa.gov/reportcard.]

Peters, G. P., G. Marland, C. Le Quere, T. Boden, J .G. Canadell, and M. Raupauch, 2012: Rapid growth in $\mathrm{CO}_{2}$ emissions after the 2008-2009 global financial crisis. Nature Climate Change, 2, 2-4. 
Peterson, T. C., and R. S. Vose, 1997: An overview of the Global Historical Climatology Network temperature database. Bull. Amer. Meteor. Soc., 78, 2837-2849.

—, R. Vautard, T. R. McVicar, J.-N. Thépaut, and P. Berrisford, 2011a: [Global climate] Surface winds over land [in "State of Climate 2010"]. Bull. Amer. Meteor. Soc., 92 (6), S57.

—, K. M. Willett, and P. W. Thorne, 2011b: Observed changes in surface atmospheric energy over land. Geophys. Res. Lett., 38, L16707, doi:10.1029/2011GL048442.

_ , P. A. Stott, and S. Herring, Eds., 2012: Explaining extreme events of 2011 from a climate perspective. Bull. Amer. Meteor. Soc., 93, 1041-1067, doi:10.1175/BAMSD-12-00021.1

Phillips, M., E. Zenklusen, M. Kern-Lütschg, and M. Lehning, 2009: Rapid degradation of ground ice in a ventilated talus slope: Flüela Pass, Swiss Alps. Permafrost Periglacial Processes, 20, 1-14.

Pinty, B., I. Andredakis, M. Clerici, T. Kaminski, M. Taberner, M. M. Verstraete, N. Gobron, and J.-L. Widlowski, 2011a: Exploiting the MODIS albedos with the Twostream Inversion Package (JRC-TIP) Part I: Effective leaf area index, vegetation and soil properties. J. Geophys. Res., 116, D09105, doi:10.1029/2010JD015372.

,,,,,,------ , and,$- 2011 \mathrm{~b}$ : Fractions of transmitted and absorbed fluxes in the vegetation and soil layers. J. Geophys. Res., 116, D09106, doi:10.1029/2010JD015373.

Pitts, M. C., L. R. Poole, and L. W. Thomason, 2009: CALIPSO polar stratospheric cloud observations: second-generation detection algorithm and composition discrimination. Atmos. Chem. Phys., 9, 7577-7589, doi:10.5194/acp-9-7577-2009.

Popova, V. V., and A. B. Shmakin, 2009: The influence of seasonal climatic parameters on the permafrost thermal regime, West Siberia, Russia. Permafrost Periglacial Processes, 20, 41-56.

Power, S., T. Casey, C. Folland, A. Colman, and V. Mehta, 1999: Inter-decadal modulation of the impact of ENSO on Australia. Climate Dyn., 15, 319-324.

Prinn, R. G., and Coauthors, 2000: A history of chemically and radiatively important gases in air deduced from ALE/ GAGE/AGAGE. J. Geophys. Res., 105 (D14), 17751-17792, doi:10.1029/2000JD900141.

—_, and Coauthors, 2005: Evidence for variability of atmospheric hydroxyl radicals over the past quarter century. Geophys. Res. Lett., 32, L07809, doi:10.1029/2004GL022228.

Pritchard, H. D., and D. G. Vaughan, 2007: Widespread acceleration of tidewater glaciers on the Antarcitc Peninsula. J. Geophys. Res., 112, F03S29, doi:10.1029/2006JF000597.

Privette, J., J. Bates, T. Karl, B. Barkstrom, D. Markham, and E. Kearns, 2009: NOAA's approach to providing CDRs within a new interagency initiative. Proc. 5th Symp. Future National Operational Environmental Satellite Systems, Phoenix, AZ, Amer. Meteor. Soc., Paper J13.2. [Available online at http://ams.confex.com/ams/pdfpapers/149762. pdf.]

Proshutinsky, A. Y., and M. A. Johnson. 1997: Two circulation regimes of the wind-driven Arctic Ocean. J. Geophys. Res., 102 (C9), 12493-12514.

- , and M. Johnson, 2011: Arctic Ocean Oscillation Index (AOO): interannual and decadal changes of the Arctic climate. Geophysical Research Abstracts, Vol. 13, Abstract EGU2011-7850.

—, I. M. Ashik, E. N. Dvorkin, S. Hakkinen, R. A. Krishfield, and W. R. Peltier, 2004: Secular sea level change in the Russian sector of the Arctic Ocean. J. Geophys. Res., 109, C03042, doi:10.1029/2003JC002007.

—_, and Coauthors, 2009: Beaufort Gyre freshwater reservoir: State and variability from observations. J. Geophys. Res., 114, C00A10, doi:10.1029/2008JC005104.

_- and Coauthors, 2011a: Ocean. Arctic Report Card, J. Richter-Menge, M. O. Jeffries, and J. E. Overland, Eds., NOAA Rep., 42-54. [Available online at http://www. arctic.noaa.gov/reportcard.]

— , and Coauthors, 2011b: [The Arctic] Ocean [in "State of the Climate in 2010"]. Bull. Amer. Meteor. Soc., 92 (6), S145-S148.

Pryor, S. C., and Coauthors, 2009: Wind speed trends over the contiguous United States. J. Geophys. Res., 114, D14105, doi:10.1029/2008JD011416.

Purkey, S. G., and G. C. Johnson, 2010: Warming of global abyssal and deep Southern Ocean waters between the 1990s and 2000s: Contributions to global heat and sea level rise budgets. J. Climate, 23, 6336-6351.

Ramanathan, V., and G. Carmichael, 2008: Global and regional climate changes due to black carbon. Nature Geosci., 1, 221-227.

Randel, W. J., and A. M. Thompson, 2011: Interannual variability and trends in tropical ozone derived from SAGE II satellite data and SHADOZ ozonesondes. J. Geophys. Res., 116, D07303, doi:10.1029/2010JD015195.

Raphael, M. N., 2004: A zonal wave 3 index for the Southern Hemisphere. Geophys. Res. Lett., 31, L23212, doi:10.1029/2004GL020365.

Rast, M., and J.-L. Bezy, 1999: The ESA Medium Resolution Imaging Spectrometer MERIS: A review of the instrument and its mission. Int. J. Remote Sens., 20, 1681-1702.

Ravishankara, A. R., J. S. Daniel, and R. W. Portmann, 2009: Nitrous oxide $\left(\mathrm{N}_{2} \mathrm{O}\right)$ : The dominant ozone-depleting substance emitted in the 21st century. Science, 316, 123-125.

Rayner, D., and Coauthors, 2010: Monitoring the Atlantic meridional overturning circulation. Deep-Sea Res. II, 58, 1744-1753. 
Rayner, N. A., D. E. Parker, E. B. Horton, C. K. Folland, L. V. Alexander, D. P. Rowell, E. C. Kent, and A. Kaplan, 2003: Global analyses of sea surface temperature, sea ice, and night marine air temperature since the late nineteenth century. J. Geophys. Res., 108, 4407, doi:10.1029/2002JD002670.

—, P. Brohan, D. E. Parker, C. K. Folland, J. J. Kennedy, M. Vanicek, T. Ansell, and S. F. B. Tett, 2006: Improved analyses of changes and uncertainties in sea surface temperature measured in situ since the mid-nineteenth century: The HadSST2 data set. J. Climate, 19, 446-469.

Raynolds, M. K., D. A. Walker, H. E. Epstein, J. E. Pinzon, and C. J. Tucker, 2012: A new estimate of tundra-biome phytomass from trans-Arctic field data and AVHRR NDVI. Remote Sens. Lett., 3, 403-411.

Reed, R. J., D. C. Norquist, and E. E. Recker, 1977: The structure and properties of African wave disturbances as observed during Phase III of GATE. Mon. Wea. Rev., 105, 317-333.

Ren, L., and S. Riser, 2010: Observations of decadal-scale salinity changes in the thermocline of the North Pacific Ocean. Deep-Sea Res. II, 57, 1161-1170.

Rex, M., R. J. Salawitch, P. von der Gathen, N. R. P. Harris, M. P. Chipperfield, and B. Naujokat, 2004: Arctic ozone loss and climate change. Geophys. Res. Lett., 31, L04116, doi:10.1029/2003GL018844.

Reynolds, R. W., and D. B. Chelton, 2010: Comparisons of daily sea surface temperature analyses for 2007-08. J. Climate, 23, 3545-3562.

— , N. A. Rayner, T. M. Smith, D. C. Stokes, and W. Wang, 2002: An improved in situ and satellite SST analysis for climate. J. Climate, 15, 1609-1625.

Rienecker, M. M., and Coauthors, 2011: MERRA: NASA's Modern-Era Retrospective Analysis for Research and Applications. J. Climate, 24, 3624-3648.

Rigby, M., and Coauthors, 2008: Renewed growth of atmospheric methane. Geophys. Res. Lett., 35, L22805, doi:10.1029/2008GL036037.

Rintoul, S. R., and Coauthors, 2010: Deep circulation and meridional overturning: Recent progress and a strategy for sustained observations. Proc. OceanObs'09: Sustained Ocean Observations and Information for Society (Vol. 1), Venice, Italy, J. Hall et al. Eds., ESA Publication WPP-306, doi:10.5270/OceanObs09.pp.32.

Rio, M.-H., and F. Hernandez, 2004: A mean dynamic topography computed over the world ocean from altimetry, in situ measurements, and a geoid model. J. Geophys. Res., 109, C12032, doi:10/1029/2003JC002226.

Rodell, M., and J. S. Famiglietti, 2001: An analysis of terrestrial water storage variations in Illinois with implications for the Gravity Recovery and Climate Experiment (GRACE). Water Resour. Res., 37, 1327-1340.
, I. Velicogna, and J. S. Famiglietti, 2009: Satellite-based estimates of groundwater depletion in India. Nature, 460, 999-1002.

—, J. S. Famiglietti, D. P. Chambers, and J. Wahr, 2011: [Global climate] Contributions of GRACE to climate monitoring [in "State of the Climate 2010"]. Bull. Amer. Meteor. Soc., 92 (6), S50-S51.

Roderick, M. L., L. D. Rotstayn, G. D. Farquhar, and M. T. Hobbins, 2007: On the attribution of changing pan evaporation. Geophys. Res. Lett., 34, L17403, doi:10.1029/2007GL031166.

_, M. T. Hobbins, and G. D. Farquhar, 2009: Pan evaporation trends and the terrestrial water balance II. Energy balance and interpretation. Geography Compass, 3, 761-780.

Roemmich, D., and J. Gilson, 2009: The 2004-2008 mean and annual cycle of temperature, salinity, and steric height in the global ocean from the Argo Program. Progr. Oceanogr., 82, 81-100.

— the global oceans with profiling floats. Oceanography, 22, 34-43.

Romanovsky, V. E., and Coauthors, 2010a: Thermal state of permafrost in Russia. Permafrost Periglacial Processs, 21, 136-155.

— S. L. Smith, and H. H. Christiansen, 2010b: Permafrost thermal state in the polar Northern Hemisphere during the International Polar Year 2007-2009: A synthesis. Permafrost Periglacial Processes, 21, 106-116.

,,,--- N. I. Shiklomanov, D. S. Drozdov, N. G. Oberman, A. L. Kholodov, and S. S. Marchenko, 2011: Permafrost. Arctic Report Card, J. Richter-Menge, M. O. Jeffries, and J. E. Overland, Eds., NOAA Rep., 139-147. [Available online at http://www.arctic.noaa.gov/reportcard.]

Ropelewski, C. F., and M. S. Halpert, 1987: Global and regional scale precipitation patterns associated with El Nino/ Southern Oscillation. Mon. Wea. Rev., 115, 1606-1626.

$\longrightarrow$, and — 1989: Precipitation patterns associated with the high index phase of the Southern Oscillation. J. Climate, 2, 268-284.

Roundy, P. E., and G. N. Kiladis, 2006: Observed relationships between oceanic Kelvin waves and atmospheric forcing. J. Climate, 19, 5253-5272.

Rykaczewski, R. R., and J. P. Dunne, 2010: Enhanced nutrient supply to the California current ecosystem with global warming and increased stratification in an earth system model. Geophys. Res. Lett., 37, L21606, doi:10.1029/2010GL045019.

Saatchi, S. S., and Coauthors, 2011: Benchmark map of forest carbon stocks in tropical regions across three continents. Proc. Natl. Acad. Sci. USA, 108, 9899-9904. 
Sabine, C. L., and Coauthors, 2004: The ocean sink for anthropogenic $\mathrm{CO}_{2}$. Science, 305, 367-371.

—, R. A. Feely, F. J. Millero, A. G. Dickson, C. Langdon, S. Mecking, and D. Greeley 2008: Decadal changes in Pacific carbon. J. Geophys. Res., 113, C07021, doi:10.1029/2007JC004577.

Saha, S., and Coauthors, 2010: The NCEP climate forecast system reanalysis. Bull. Amer. Meteor. Soc., 91, 1015-1057.

Saji, N. H., and T. Yamagata, 2003a: Structure of SST and surface wind variability during Indian Ocean dipole mode events: COADS observations. J. Climate, 16, 2735-2751.

$\longrightarrow$, and — 2003b: Possible impacts of Indian Ocean dipole mode events on global climate. Climate Res., 25, 151-169.

— B. N. Goswami, P. N. Vinayachandran, and T. Yamagata, 1999: A dipole mode in the tropical Indian Ocean. Nature, 401, 360-363.

Salby, M., E. Titova, and L. Deschamps, 2011: Rebound of Antarctic ozone. Geophys. Res. Lett., 38, L09702, doi:10.1029/2011GL047266.

Sarmiento, S., and A. Palanisami, 2011: Coherence between atmospheric teleconnections and Mackenzie River Basin lake levels. J. Great Lakes Res., 37, 642-649.

Scambos, T. A., C. Hulbe, and M. Fahnestock, 2003: Climateinduced ice shelf disintegration in the Antarctic Peninsula. Antarctic Peninsula Climate Variability: Historical and Paleoenvironmental Perspectives, E. Domack et al., Eds., Antarctic Research Series, Vol. 79, Amer. Geophys. Union, 79-92.

Schaaf, C. B., and Coauthors, 2002: First operational BRDF, albedo and nadir reflectance products from MODIS. Remote Sens. Environ., 83, 135-148.

Schanze, J. J., R. W. Schmitt, and L. L. Yu, 2010: The global oceanic freshwater cycle: A state-of-the-art quantification. J. Marine Res., 68, 569-595.

Schmitt, R., 2008: Salinity and the global water cycle. Oceanography, 21, 12-19.

Schneider, A., T. Tanhua, A. Körtzinger, and D. W. R. Wallace, 2010: High anthropogenic carbon content in the eastern Mediterranean. J. Geophys. Res., 115, C12050, doi:10.1029/2010JC006171.

Schneider, P., and S. J. Hook, 2010: Space observations of inland water bodies show rapid surface warming since 1985. Geophys. Res. Lett., 37, L22405, doi:10.1029/2010GL045059.

Schneider, U., A. Becker, A. Meyer-Christoffer, M. Ziese, and B. Rudolf, 2011: Global precipitation analysis products of the GPCC. Global Precipitation Climatology Centre (GPCC), Deutscher Wetterdienst. [Available online at http://www.gpcc.dwd.de/.]

Schreck, C. J., J. P. Kossin, and P. A. Hennon, 2012: Global tropical cyclone climatology using IBTrACS. 30th Conf. Hurricanes and Tropical Meteorology, Ponte Vedra Beach,
FL, Amer. Meteor. Soc., 1B.4. [Available on line at http:// ams.confex.com/ams/30Hurricane/webprogram/Paper204685.html.]

Seidel, D. J., N. P. Gillett, J. R. Lanzante, K. P. Shile, and P. W. Thorne, 2011: Stratospheric temperature trends: Our evolving understanding. WIRES: Climate Change, 2, 592-616.

Seiler, W., and P. J. Crutzen, 1980: Estimates of gross and net fluxes of carbon between the biosphere and the atmosphere from biomass burning. Climatic Change, 2, 207-247.

Send, U., M. Lankhorst, and T. Kanzow, 2011: Observation of decadal change in the Atlantic meridional overturning circulation using 10 years of continuous transport data. Geophys. Res. Lett., 38, L24606, doi:10.1029/2011GL049801.

Seneviratne, S. I., T. Corti, E. L. Davin, M. Hirschi, E. B. Jaeger, I. Lehner, B. Orlowsky, and A. J. Teuling, 2010: Investigating soil moisture-climate interactions in a changing climate: A review. Earth-Science Rev., 99, 125-161.

SERVIR, 2011: Severe precipitation deficit in Dominican Republic, Jan - Mar 2011. Accessed 18 May 2012. [Available online at http://servirglobal.net/Global/Articles/tabid/86/ Article/959/Default.aspx.]

Severinghaus, J. P., T. Sowers, E. J. Brook, R. B. Alley, and M. L. Bender, 1998: Timing of abrupt climate change at the end of the Younger Dryas interval from thermally fractionated gases in polar ice. Nature, 391, 141-146.

Shahgedanova, M., G. Nosenko, T. Khromova, and A. Muraveyev, 2010: Glacier shrinkage and climatic change inthe Russian Altai from the mid-20th century: An assessment using remote sensing and PRECIS regional climate model. J. Geophys. Res., 115, D16107, doi:10.1029/2009JD012976.

Sharp, M., and G. Wolken, 2011a: [The Arctic] Glaciers outside Greenland [in "State of the Climate in 2010"]. Bull. Amer. Meteor. Soc., 92 (6), S155-S156.

— land). Arctic Report Card, J. Richter-Menge, M. O. Jeffries, and J. E. Overland, Eds., NOAA Rep., 110-116. [Available online at http://www.arctic.noaa.gov/reportcard.]

—, D. O. Burgess, J. G. Cogley, M. Ecclestone, C. Labine, and G. J. Wolken, 2011: Extreme melt on Canada's Arctic ice caps in the 21st century. Geophys. Res. Lett., 38, L11501, doi:10.1029/2011GL047381.

Shay, L. K., G. J. Goni, and P. G. Black, 2000: Effects of a warm oceanic feature on Hurricane Opal. Mon. Wea. Rev., 128, 1366-1383.

Shiklomanov, N. I., D. A. Streletskiy, F. E. Nelson, R. D. Hollister, V. E. Romanovsky, C. E. Tweedie, J. G. Bockheim, and J. Brown, 2010: Decadal variations of active-layer thickness in moisture-controlled landscapes, Barrow, Alaska. J. Geophys. Res., 115, G00I04, doi:10.1029/2009JG001248. 
Siegel, D. A., and B. A. Franz, 2010: Oceanography: A century of phytoplankton change. Nature, 466, 569-570.

_ , S. Maritorena, N. B. Nelson, and M. J. Behrenfeld, 2005: Independence and interdependencies of global ocean color properties: Reassessing the bio-optical assumption. J. Geophys. Res., 110, C07011, doi:10.1029/2004JC002527.

_ , M. J. Behrenfeld, S. Maritorena, R. T. O’Malley, and E. Fields, 2011: [Global oceans] Global ocean phytoplankton [in "State of the Climate in 2010"]. Bull. Amer. Meteor. Soc., 92 (6), S105-S108.

Simmons, A., 2010: Monitoring atmospheric composition and climate. ECMWF Newsletter, 123, 10-13.

— , K. M. Willett, P. D. Jones, P. W. Thorne, and D. Dee, 2010: Low-frequency variations in surface atmospheric humidity, temperature and precipitation: inferences from reanalyses and monthly gridded observational datasets. J. Geophys. Res., 115, D01110, doi:10.1029/2009JD012442.

Sinclair, M. R., 2002: Extratropical transition of Southwest Pacific tropical cyclones. Part I: Climatology and mean structure changes. Mon. Wea. Rev., 130, 590-609.

Singh, O. P., T. M. Ali Khan, and S. Rahman, 2000: Changes in the frequency of tropical cyclones over the North Indian Ocean. Meteor. Atmos. Phys., 75, 11-20.

Sinnhuber, B. M., G. Stiller, R. Ruhnke, T. von Clarmann, S. Kellmann, and J. Aschmann, 2011: Arctic winter 2010/2011 at the brink of an ozone hole. Geophys. Res. Lett., 38, L24814, doi:10.1029/2011GL049784.

Smith, S. L., S. A. Wolfe, D. W. Riseborough, and F. M. Nixon, 2009: Active-layer characteristics and summer climatic indices, Mackenzie Valley, Northwest Territories, Canada. Permafrost Periglacial Processes, 20, 201-220.

—, V. E. Romanovsky, A. G. Lewkowicz, C. R. Burn, M. Allard, G. D. Clow, K. Yoshikawa, and J. Throop, 2010: Thermal state of permafrost in North America: A contribution to the International Polar Year. Permafrost Periglacial Processes, 21, 117-135.

Smith, T. M., and R. W. Reynolds, 1998: A high-resolution global sea surface temperature climatology for the 196190 base period. J. Climate, 11, 3320-3323.

— temperature reconstruction based on historical observations (1880-1997). J. Climate, 18, 2021-2036.

,$- \ldots$, T. C. Peterson, and J. Lawrimore, 2008: Improvements to NOAA's historical merged land-ocean surface temperature analysis (1880-2006). J. Climate, 21, 2283-2296.

Solomon, S., D. Qin, M. Manning, Z. Chen, M. Marquis, K. B. Averyt, M. Tignor, and H. L. Miller, Eds., 2007: Climate Change 2007: The Physical Science Basis. Cambridge University Press, 996 pp.

—, J. S. Daniel, R. R. Neely III, J. P. Vernier, E. G. Dutton, and L. W. Thomason, 2011: The persistently variable "background" stratospheric aerosol layer and global climate change. Science, 333, 866-870.

SPARC, 2010: SPARC Report on the evaluation of chemistry climate models. SPARC Report No. 5, WCRP-132, WMO/TD-No. 1526, 426 pp. [Available online at http:// www.sparc-climate.org/publications/sparc-reports/sparcreport-no5/.]

Stackhouse, P. W., Jr., D. P. Kratz, G. R. McGarragh, S. K. Gupta, and E. B. Geier, 2006: Fast Longwave and Shortwave Radiative Flux (FLASHFlux) products from CERES and MODIS measurements. Proc. 12th Conf. Atmospheric Radiation. Madison, WI, Amer. Meteor. Soc., P1.10. [Avilable online at http://ams.confex.com/ams/ pdfpapers/113479.pdf.]

Stammerjohn, S. E., D. G. Martinson, R. C. Smith, X. Yuan, and D. Rind, 2008: Trends in Antarctic annual sea ice retreat and advance and their relation to El Niño-Southern Oscillation and southern annular mode variability. J. Geophys. Res., 113, C03S90, doi:10.1029/2007JC004269.

—, R. Massom, D. Rind, and D. Martinson, 2012: Regions of rapid sea ice change: An inter-hemispheric seasonal comparison. Geophys. Res. Lett., 39, L06501, doi:10.1029/2012GL050874.

Steele, M., J. Morison, W. Ermold, I. Rigor, M. Ortmeyer, and K. Shimada, 2004: Circulation of summer Pacific halocline water in the Arctic Ocean. J. Geophys. Res., 109, C02027, doi:10.1029/2003JC002009.

_- W. Ermold, and J. Zhang, 2008: Arctic Ocean surface warming trends over the past 100 years. Geophys. Res. Lett., 35, L02614, doi:10.1029/2007GL031651.

_-, J. Zhang, and W. Ermold, 2010: Mechanisms of summertime upper Arctic Ocean warming and the effect on sea ice melt. J. Geophys. Res., 115, C11004, doi:10.1029/2009JC005849.

Steig, E. J., Q. Ding, D. S. Battisti, and A. Jenkins, 2012: Tropical forcing of circumplolar deep water inflow and outlet glacier thinning in the Amundsen Sea Embayment, West Antarctica. Ann. Glaciol., 53, 19-28, doi:10.3189/2012AoGG0A110.

Steinacher, M., F. Joos, T. L. Frölicker, G.-K. Plattner, and S. C. Doney, 2009: Imminent ocean acidification in the Arctic projected with the NCAR global coupled carbon cycle-climate model. Biogeosciences, 6, 515-533.

Steinbrecht, W., and Coauthors, 2009: Ozone and temperature trends in the upper stratosphere at five stations of the network for the detection of atmospheric composition change. Int. J. Remote Sens., 30, 3875-3886.

— U. Köhler, H. Claude, M. Weber, J. P. Burrows, and R. J. van $\operatorname{der}$ A, 2011: Very high ozone columns at northern mid-latitudes in 2010. Geophys. Res. Lett., 38, L06803, doi:10.1029/2010GL046634. 
Stephenson, T. S., A. A. Chen, and M. A. Taylor, 2007: Toward the development of prediction models for the primary Caribbean Dry Season. Theoret. Appl. Climatol., 92, 87-101.

Stolarski, R. S., and S. Frith, 2006: Search for evidence of trend slow-down in the long-term TOMS/SBUV total ozone data record: the importance of instrument drift uncertainty and fingerprint detection. Atmos. Chem. Phys., 6, 4057-4065.

Stramma, L., G. C. Johnson, J. Sprintall, and V. Mohrholz, 2008: Expanding oxygen-minimum zones in the tropical oceans. Science, 320, 655-658.

Streletskiy, D. A, N. I. Shiklomanov, F. E. Nelson, and A. E. Klene, 2008: 13 Years of observations at Alaskan CALM sites: Long-term active layer and ground surface temperature trends. Proc. Ninth Int. Conf. on Permafrost, Fairbanks, AK, Vol. 2, D. L. Kane and K. M. Hinkel, Eds., Institute of Northern Engineering, University of Alaska Fairbanks, 1727-1732.

Sutton, R. T., and D. L. R. Hodson, 2007: Climate response to basin-scale warming and cooling of the North Atlantic Ocean. J. Climate, 20, 891-907.

Sverdrup, H. U., 1955: The place of physical oceanography in oceanographic research. J. Marine Res., 14, 287-294.

Sweet, W., C. Zervas, and S. Gill, 2009: Elevated east coast sea level anomaly: June - July 2009. NOAA Tech. Rep. NOS CO-OPS 051, 30 pp.

Takahashi, T., and Coauthors, 2009: Climatological mean and decadal change in surface ocean $p \mathrm{CO}_{2}$, and net seaair $\mathrm{CO}_{2}$ flux over the global oceans. Deep-Sea Res. II, 56, 554-577.

—, S. C. Sutherland, and A. Kozyr, 2011: Global ocean surface water partial pressure of $\mathrm{CO}_{2}$ database: Measurements performed during 1957-2010 (Version 2010). ORNL/CDIAC-159, NDP-088(V2010). Carbon Dioxide Information Analysis Center, Oak Ridge, TN, digital media. [Available online at doi:10.3334/CDIAC/otg. ndp088(V2010).]

Takala, M., K. Luojus, J. Pulliainen, C. Derksen, J. Lemmetyinen, J.-P. Kärnä, and J. Koskinen, 2011: Estimating northern hemisphere snow water equivalent for climate research through assimilation of space-borne radiometer data and ground-based measurements. Remote Sens. Environ., 115, 3517-3529.

Tanhua, T., E. P. Jones, E. Jeansson, S. Jutterstrom, W. M. Smethie Jr., D. W. R. Wallace, and L. G. Anderson, 2009: Ventilation of the Arctic Ocean: Mean ages and inventories of anthropogenic $\mathrm{CO}_{2}$ and CFC-11. J. Geophys. Res., 114, C01002, doi:10.1029/2008JC004868.

Tapley, B. D., S. Bettadpur, J. C. Ries, P. F. Thompson, and M. M. Watkins, 2004: GRACE measurements of mass variability in the Earth system. Science, 305, 503-505.
Tarnocai, C., J. G. Canadell, E. A. G. Schuur, P. Kuhry, G. Mazhitova, and S. Zimov, 2009: Soil organic carbon pools in the northern circumpolar permafrost region. Global Biogeochem. Cycles, 23, GB2023, doi:10.1029/2008GB003327.

Taylor, A. H., and J. A. Stephens, 1998: The North Atlantic Oscillation and latitude of the Gulf Stream. Tellus, 40A, 134-142.

Tedesco, M., 2007: Snowmelt detection over the Greenland ice sheet from SSM/I brightness temperature daily variations. Geophys. Res. Lett., 34, L02504, doi:10.1029/2006GL028466.

_ 2009: Assessment and development of snowmelt retrieval algorithms over Antarctica from K-band spaceborne brightness temperature (1979-2008). Remote Sens. Environ., 113, 979-997.

— record through 2009 and its linkages to high-latitude and tropical climate variability. Geophys. Res. Lett., 36, L18502, doi:10.1029/2009GL039186.

—, X. Fettweis, M. R. van den Broeke, R. S. W. van de Wal, C. J. P. P. Smeets, W. J. van de Berg, M. C. Serreze, and J. E. Box, 2011: The role of albedo and accumulation in the 2010 melting record in Greenland. Environ. Res. Lett., 6, 014005, doi:10.1088/1748-9326/6/1/014005.

Thompson, D. W. J., and S. Solomon, 2002: Interpretation of recent Southern Hemisphere climate change. Science, 296, 895-899, doi:10.1126/science.1069270.

Thorne, P. W., and Coauthors, 2005: Revisiting radiosonde upper-air temperatures from 1958 to 2002. J. Geophys. Res., 110, D18105, doi:10.1029/2004JD005753.

_- and Coauthors, 2011: Guiding the creation of a comprehensive surface temperature resource for twentyfirst-century climate science. Bull. Amer. Meteor. Soc., 92, ES40-ES47.

Timokhov, L., and F. Tanis, Eds., 1997: Environmental Working Group Joint U.S.-Russian Atlas of the Arctic Ocean-Winter Period. Environmental Research Institute of Michigan in association with the National Snow and Ice Data Center, Arctic Climatology Project, CD-ROM.

—_, and __ Eds., 1998: Environmental Working Group Joint U.S.-Russian Atlas of the Arctic Ocean-Summer Period. Environmental Research Institute of Michigan in association with the National Snow and Ice Data Center, Arctic Climatology Project, CD-ROM.

Tiwari, V. M., J. Wahr, and S. Swenson, 2009: Dwindling groundwater resources in northern India, from satellite gravity observations. Geophys. Res. Lett., 36, L18401, doi:10.1029/2009GL039401.

Torinesi, O., M. Fily, and C. Genthon, 2003: Variability and trends of the summer melt period of Antarctic ice margins since 1980 from microwave sensors. J. Climate, 16, 1047-1060. 
Trenberth, K. E., J. T. Fasullo, and J. T. Kiehl, 2009: Earth's global energy budget. Bull. Amer. Meteor. Soc., 90, 311-323.

Trigo, R. M., I. M. Trigo, C. C. DaCamara, and T. J. Osborn, 2004: Climate impact of the European winter blocking episodes from the NCEP/NCAR Reanalyses. Climate Dyn., 23, 17-28.

Turner, J., and Coauthors, 2005: Antarctic climate change during the last 50 years. Int. J. Climatol., 25, 279-294.

— , and Coauthors, 2009: Non-annular atmospheric circulation change induced by stratospheric ozone depletion and its role in the recent increase of Antarctic sea ice extent. Geophys. Res. Lett., 36, L08502, doi:10.1029/2009GL037524.

Van de Wal, R. S. W., W. Greuell, M. R. van den Broeke, C. H. Reijmer, and J. Oerlemans, 2005: Surface mass-balance observations and automatic weather station data along a transect near Kangerlussuaq, West Greenland. Ann. Glaciol., 42, 311-316.

Van den Broeke, M., 2005: Strong surface melting preceded collapse of Antarctic Peninsula ice shelf. Geophys. Res. Lett., 32, 12815, doi:10.1029/2005gl023247.

_ , and N. P. M. van Lipzig, 2004: Changes in Antarctic temperature, wind and precipitation in response to the Antarctic Oscillation. Ann. Glaciol., 39, 119-126.

— W. W. van de Berg, E. van Meijgaard, and C. H. Reijmer, 2006: Identification of Antarctic ablation areas using a regional atmospheric climate model. J. Geophys. Res., 111, D18110, doi:10.1029/2006JD007127.

Van der Werf, G. R., and Coauthors, 2010: Global fire emissions and the contribution of deforestation, savanna, forest, agricultural, and peat fires (1997-2009). Atmos. Chem. Phys., 10, 11707-11735.

Vaughan, D. G., G. J. Marshall, W. M. Connolley, J. C. King, and R. Mulvaney, 2001: Devil in the detail. Science, 293, 1777-1779.

— warming on the Antarctic Peninsula. Climatic Change, 60, 243-274.

Vautard, R., J. Cattiaux, P. Yiou, J.-N Thépaut, and P. Ciais, 2010: Northern Hemisphere atmospheric stilling partly attributed to an increase in surface roughness. Nature Geosci., 3, 756-761.

Vavrus, S. J., U. S. Bhatt, and V. A. Alexeev, 2011: Factors influencing simulated changes in future Arctic cloudiness. J. Climate, 24, 4817-4830.

Velicogna, I., and J. Wahr, 2006: Measurements of timevariable gravity show mass loss in Antarctica. Science, 311, 1754-1756.

Vernier, J.-P., and Coauthors, 2011: Major influences of tropical volcanic eruptions on the stratospheric aerosol layer during the last decade. Geophys. Res. Lett. 38, LI12807, doi:10.1029/2011GL047563.

Vieira, G., and Coauthors, 2010: Thermal state of permafrost and active-layer monitoring in the Antarctic: advances during the International Polar Year 2007-09. Permafrost Periglacial Processes, 21, 182-197.

Vimont, D. J., and J. P. Kossin, 2007: The Atlantic Meridional Mode and hurricane activity. Geophys. Res. Lett., 34, L07709, doi:10.1029/2007GL029683.

Visbeck, M. H., J. W. Hurrell, L. Polvani, and H M. Cullen, 2001: The North Atlantic oscillation: Past, present, and future. Proc. Natl. Acad. Sci. USA, 98, 12876-12877.

Viviroli, D., H. H. Durr, B. Messerli, M. Meybeck, and R. Weingartner, 2007: Mountains of the world, water towers for humanity: typology, mapping, and global significance. Water Resour. Res., 43, W07447, doi:10.1029/2006WR005653.

Vongraven, D., and E. Richardson, 2011: Biodiversity - Status and trends of polar bears. Arctic Report Card, J. RichterMenge, M. O. Jeffries, and J. E. Overland, Eds., NOAA Rep., 75-78. [Available online at http://www.arctic.noaa. gov/reportcard.]

Vörösmarty, C. J., C. A. Federer, and A. L. Schloss, 1998: Potential evaporation functions compared on US watersheds: Possible implications for global-scale water balance and terrestrial ecosystem modeling. J. Hydrol., 207, 147-169.

Wagner W., K. Scipal, C. Pathe, D. Gerten, W. Lucht, and B. Rudolf, 2003: Evaluation of the agreement between the first global remotely sensed soil moisture data with model and precipitation data. J. Geophys. Res., 108, 4611, doi:10/1029/2003JD003663.

Waliser, D. E., and C. Gautier, 1993: A satellite-derived climatology of the ITCZ. J. Climate, 6, 2162-2174.

Wan, Z. M., 2008: New refinements and validation of the MODIS land-surface temperature/emissivity products. Remote Sens. Environ., 112, 59-74.

—, Y. L. Zhang, Q. C. Zhang, and Z. L. Li, 2002: Validation of the land-surface temperature products retrieved from Terra Moderate Resolution Imaging Spectroradiometer data. Remote Sens. Environ., 83, 163-180.

Wang, C., and S.-K. Lee, 2009: Co-variability of tropical cyclones in the North Atlantic and the eastern North Pacific. Geophy. Res. Lett., 36, L24702, doi:10.1029/2009GL041469.

_ , D. B. Enfield, S.-K. Lee, and C. W. Landsea, 2006: Influences of the Atlantic warm pool on Western Hemisphere summer rainfall and Atlantic hurricanes. J. Climate, 19, 3011-3028.

—, S.-K. Lee, and D. B. Enfield, 2007: Impact of the Atlantic warm pool on the summer climate of the Western Hemisphere. J. Climate, 20, 5021-5040. 
,$- \ldots$, and —_, 2008a: Atlantic warm pool acting as a link between Atlantic multidecadal oscillation and Atlantic tropical cyclone activity. Geochem. Geophys. Geosyst., 9, Q05V03, doi:10.1029/2007GC001809.

$\_, \ldots$, and _ 2008b: Climate response to anomalously large and small Atlantic warm pools during the summer. J. Climate, 21, 2437-2450.

— S. Dong, and E. Munoz, 2010: Seawater density variations in the North Atlantic and the Atlantic meridional overturning circulation. Climate Dyn., 34, 953-968.

— , H. Liu, S.-K. Lee, and R. Atlas, 2011: Impact of the Atlantic warm pool on United States landfalling hurricanes. Geophys. Res. Lett., 38, L19702, doi:10.1029/2011GL049265.

_ , S. Dong, A. T. Evan, G. R. Foltz, and S.-K. Lee, 2012: Multidecadal co-variability of North Atlantic sea surface temperature, African dust, Sahel rainfall and Atlantic hurricanes. J. Climate, in press., doi:10.1175/JCLID-11-00413.1.

Wang, J., L. Zhang, A. Dai, T. Van Hove, and J. Van Baelen, 2007: A near-global, 8-year, 2-hourly atmospheric precipitable water dataset from ground-based GPS measurements. J. Geophys. Res., 112, D11107, doi:10.1029/2006JD007529.

Wang, L., and H. Liu, 2011: [Antarctica] 2009/10 seasonal melt extent and duration [in "State of the Climate in 2010”]. Bull. Amer. Meteor. Soc., 92 (6), S167.

Wang, L., C.-Z. Zou, and H. Qian, 2012: Construction of stratospheric temperature data records from stratospheric sounding units. J. Climate, 25, 2931-2946.

Wang, X., and J. Key, 2003: Recent trends in Arctic surface, cloud, and radiation properties from space. Science, 299, 1725-1728.

— , and — 2005: Arctic surface, cloud, and radiation properties based on the AVHRR Polar Pathfinder data set. Part II: Recent trends. J. Climate, 18, 2575-2593.

Wanninkhof, R., S. Doney, J. L. Bullister, N. M. Levine, M. J. Warner, and N. Gruber, 2010: Detecting anthropogenic $\mathrm{CO}_{2}$ changes in the interior Atlantic Ocean between 1989 and 2005. J Geophys. Res. 115, C11028, doi:11029/12010JC006251.

Wassmann, P., 2011: Arctic marine ecosystems in an era of rapid climate change. Progr. Oceanogr., 90, 1-17.

Weber, M., L. N. Lamsal, and J. P. Burrows, 2007: Improved SCIAMACHY WFDOAS total ozone retrieval: Steps towards homogenizing long-term total ozone datasets from GOME, SCIAMACHY, and GOME2. Proc. Envisat Symposium 2007, ESA SP-636, Montreux, Switzerland, European Space Agency, 5 pp. [Available online at http://envisat.esa.int/envisatsymposium/proceedings/ posters/3P4/463281we.pdf]

— , S. Dikty, J. P. Burrows, H. Garny, M. Dameris, A. Kubin, J. Abalichin, and U. Langematz, 2011: The Brewer-Dobson circulation and total ozone from seasonal to decadal time scales. Atmos. Chem. Phys., 11, 11221-11235.

Wentz, F. J., 1997:, A well calibrated ocean algorithm for special sensor microwave / imager. J. Geophys. Res., 102 (C4), 8703-8718.

— , L. Ricciardulli, K. A. Hilburn, and C. A. Mears, 2007: How much more rain will global warming bring? Science, 317, 233-235.

WGMS, 2011: Glacier Mass Balance Bulletin No. 11 (20082009). World Glacier Monitoring Service, Zurich, Switzerland, $102 \mathrm{pp}$.

Wheeler, M. C., and G. N. Kiladis, 1999: Convectively coupled equatorial waves: Analysis of clouds and temperature in the wavenumber-frequency domain. J. Atmos. Sci., 56, 374-399.

_- and K. M. Weickmann, 2001: Real-time monitoring and prediction of modes of coherent synoptic to intra-seasonal tropical variability. Mon. Wea. Rev., 129, 2677-2694.

_ , and H. H. Hendon, 2004: An all-season real-time multivariate MJO index: Development of an index for monitoring and prediction. Mon. Wea. Rev., 132, 1917-1932.

WHO, 2002: Global Solar UV Index: A Practical Guide. World Health Organization, 28 pp. [Available online at: http:// www.who.int/uv/publications/en/GlobalUVI.pdf.]

Wielicki, B. A., and Coauthors, 1998: Clouds and the Earth's Radiant Energy System (CERES): Algorithm overview. IEEE Trans. Geosci. Remote Sens., 36, 1127-1141.

Wijffels, S. E, J. Willis, C. M. Domingues, P. Barker, N. J. White, A. Gronell, K. Ridgway, and J. A. Church, 2008: Changing expendable bathythermograph fall-rates and their impact on estimates of thermosteric sea level rise. J. Climate, 21, 5657-5672.

Willett, K. M., P. D. Jones, N. P. Gillett, and P. W. Thorne, 2008: Recent changes in surface humidity: Development of the HadCRUH dataset. J. Climate, 21, 5364-83.

Williams, C. A., G. J. Collatz, J. Masek, and S. N. Goward, 2012: Carbon consequences of forest disturbance and recovery across the conterminous United States. Global Biogeochem. Cycles, 26, GB1005, doi:10.1029/2010GB003947. Willis, J. K., 2010: Can in situ floats and satellite altimeters detect long-term changes in Atlantic Ocean overturning? Geophys. Res. Lett., 37, L06602, doi:10.1029/2010GL042372.

_ face float data to estimate the time-averaged circulation in the upper ocean. J. Geophys. Res., 113, C12017, doi:10.1029/2007JC004690.

— , D. Roemmich, and B. Cornuelle, 2004: Interannual variability in upper ocean heat content, temperature, and thermosteric expansion on global scales. J. Geophys. Res., 109, C12036, doi:10.1029/2003JC002260. 
Wisser, D., B. M. Fekete, C. J. Vörösmarty, and A. H. Schumann, 2010a: Reconstructing 20th century global hydrography: A contribution to the Global Terrestrial Network- Hydrology (GTN-H). Hydrol. Earth Syst. Sci., 14, 1-24.

— , S. E. Frolking, E. M. Douglas, B. M. Fekete, A. H. Schumann, and C. J. Vörösmarty, 2010b: The significance of local water resources captured in small reservoirs for crop production: A global-scale analysis. J. Hydrol., 384, 264-275.

WMO, 2009: Implementation Plan for the Sustained and Coordinated Processing of Environmental Satellite Data for Climate Monitoring (SCOPE-CM), Version 1.3. World Meteorological Organization, 28 pp. [Available online at http://www.wmo.int/pages/prog/sat/documents/SCOPECM_Implementation-Plan.doc.]

_ 2011: Scientific Assessment of Ozone Depletion: 2010. Global Ozone Research and Monitoring Project-Report No. 52, World Meteorological Organization, 516 pp.

Wolski, P., and M. M. Hudson, 2008: Alternative futures of the Okavango Delta simulated by a suite of global climate and hydro-ecological models. Water $S A, 34,605-610$.

Woodruff, S. D., and Coauthors, 2011: ICOADS release 2.5: Extensions and enhancements to the surface marine meteorological archive. Int. J. Climatol., 31, 951-967.

Wooster, M. J., G. Roberts, G. L. W. Perry, and Y. J. Kaufman, 2005: Retrieval of biomass combustion rates and totals from fire radiative power observations: FRP derivation and calibration relationships between biomass consumption and fire radiative energy release. J. Geophys. Res., 110, D24311, doi:10/1029/2005JD006318.

World Glacier Monitoring Service, 2011: Glacier mass balance data 2009/2010. [Available online at http://www.geo. uzh.ch/microsite/wgms/mbb/sum09.html.]

Worton, D. R., and Coauthors, 2007: Atmospheric trends and radiative forcings of $\mathrm{CF}_{4}$ and $\mathrm{C}_{2} \mathrm{~F}_{6}$ inferred from firn air. Environ. Sci. Technol., 41, 2184-2189.

Wunsch, C., and P. Heimbach, 2009: The global zonally integrated ocean circulation, 1992-2006: Seasonal and decadal variability. J. Phys. Oceanogr., 39, 351-368.

Wylie, D. P., D. L. Jackson, W. P. Menzel, and J. J. Bates, 2005: Global cloud cover trends inferred from two decades of HIRS observations. J. Climate, 18, 3021-3031.

Wyrtki, K., 1981: An estimate of equatorial upwelling in the Pacific. J. Phys. Oceanogr., 11, 1205-1214.

Xie, P., and P. A. Arkin, 1997: Global precipitation: A 17-Year monthly analysis based on gauge observations, satellite estimates and numerical model outputs. Bull. Amer. Meteor. Soc., 78, 2539-2558.
Xiong, X., J. Sun, X. Xie, W. L. Barnes, and V. V. Salomonson, 2010: On- orbit calibration and performance of Aqua MODIS reflective solar bands. IEEE Trans. Geosci. Remote Sens., 48, 535-546.

Xue, Y., R. W. Reynolds, V. Banzon, T. Smith, and N. Rayner, 2011: [Global oceans] Sea surface temperature [in "State of the Climate in 2010"]. Bull. Amer. Meteor. Soc., 92 (6), S78-S81.

Yoder, J., C. R. McClain, G. C. Feldman, and W. E. Esaias, 1993: Annual cycles of phytoplankton chlorophyll concentrations in the global ocean: A satellite view. Global Biogeochem. Cycles, 7, 181-193.

Yu, L., 2011: A global relationship between the ocean water cycle and near-surface salinity. J. Geophys. Res., 116, C10025, doi:10.1029/2010JC006937.

_, and R. A. Weller, 2007: Objectively Analyzed air-sea heat Fluxes (OAFlux) for the global ocean. Bull. Amer. Meteor. Soc., 88, 527-539.

_ , J. Xin, and R. A. Weller, 2008: Multidecade global flux datasets from the Objectively Analyzed Air-sea Fluxes (OAFlux) Project: Latent and sensible heat fluxes, ocean evaporation, and related surface meteorological variables. OAFlux Project Tech. Rep. OA-2008-01, 64 pp.

Yueh, S. H., and J. Chaubell, 2012: Sea surface salinity and wind retrieval using combined passive and active L-band microwave observations. IEEE Trans. Geosci. Remote Sens., 50, 1022-1032.

—, S. Dinardo, A. G. Fore, and F. K. Lee, 2010: Passive and active L-band microwave observations and modeling of ocean surface winds. IEEE Trans. Geosci. Remote Sens., 48, 3087-3100.

Zebiak, S. E., 1989: Oceanic heat content variability and El Niño cycles. J. Phys. Oceanogr., 19, 475-486.

Zenklusen Mutter, E., J. Blanchet, and M. Phillips, 2010: Analysis of ground temperature trends in Alpine permafrost using generalized least squares. J. Geophys. Res., 115, F04009, doi:10/1029/2009JF001648.

Zhang, C., 2005: Madden-Julian oscillation. Rev. Geophys., 43, 1-36.

_- and J. Gottschalck, 2002: SST Anomalies of ENSO and the Madden Julian oscillation in the equatorial Pacific. $J$. Climate, 15, 2429-2445.

Zhang, G. J., and M. J. McPhaden, 1995: The relationship between sea surface temperature and latent heat flux in the equatorial Pacific. J. Climate, 8, 589-605.

Zhang, G. Q., J. H. Xie, S. Q. Duan, M. Z. Tian, and D. H. Yi, 2011: Water level variation of Lake Qinghai from satellite and in situ measurements under climate change. J. Appl. Remote Sens., 5, 053532, doi:10.1117/1.3601363. 
Zhang, R., T. L. Delworth, and I. Held, 2007: Can the Atlantic Ocean drive the observed multidecadal variability in Northern Hemisphere mean temperature? Geophys. Res. Lett., 34, L02709, doi:10.1029/2006GL028683.

Zhang, X., F. W. Zwiers, G. C. Hagerl, F. H. Lambert, N. P. Gillet, S. Solomon, P. A. Stott, and T. Nozawa, 2007: Detection of human influences on twentieth-century precipitation trends. Nature, 448, 461-465.
Zhao, L., Q. Wu, S. S. Marchenko, and N. Sharkhuu, 2010: Thermal state of permafrost and active layer in Central Asia during the International Polar Year. Permafrost Periglacial Processes, 21, 198-207.

Zhou, X., M. Geller, and M. Zhang, 2001: Tropical cold point tropopause characteristics derived from ECMWF reanalyses and soundings. J. Climate, 14, 1823-1838.

Zwally, H. J., and S. Fiegles, 1994: Extent and duration of Antarctic surface melting. J. Glaciol., 40, 463-476. 
Libraries: Please file with the Bulletin of the American Meteorological Society, Vol. 93, Issue 7 